Art, History, and

Anachronic Interventions

Since 1990

EVA KERNBAUER

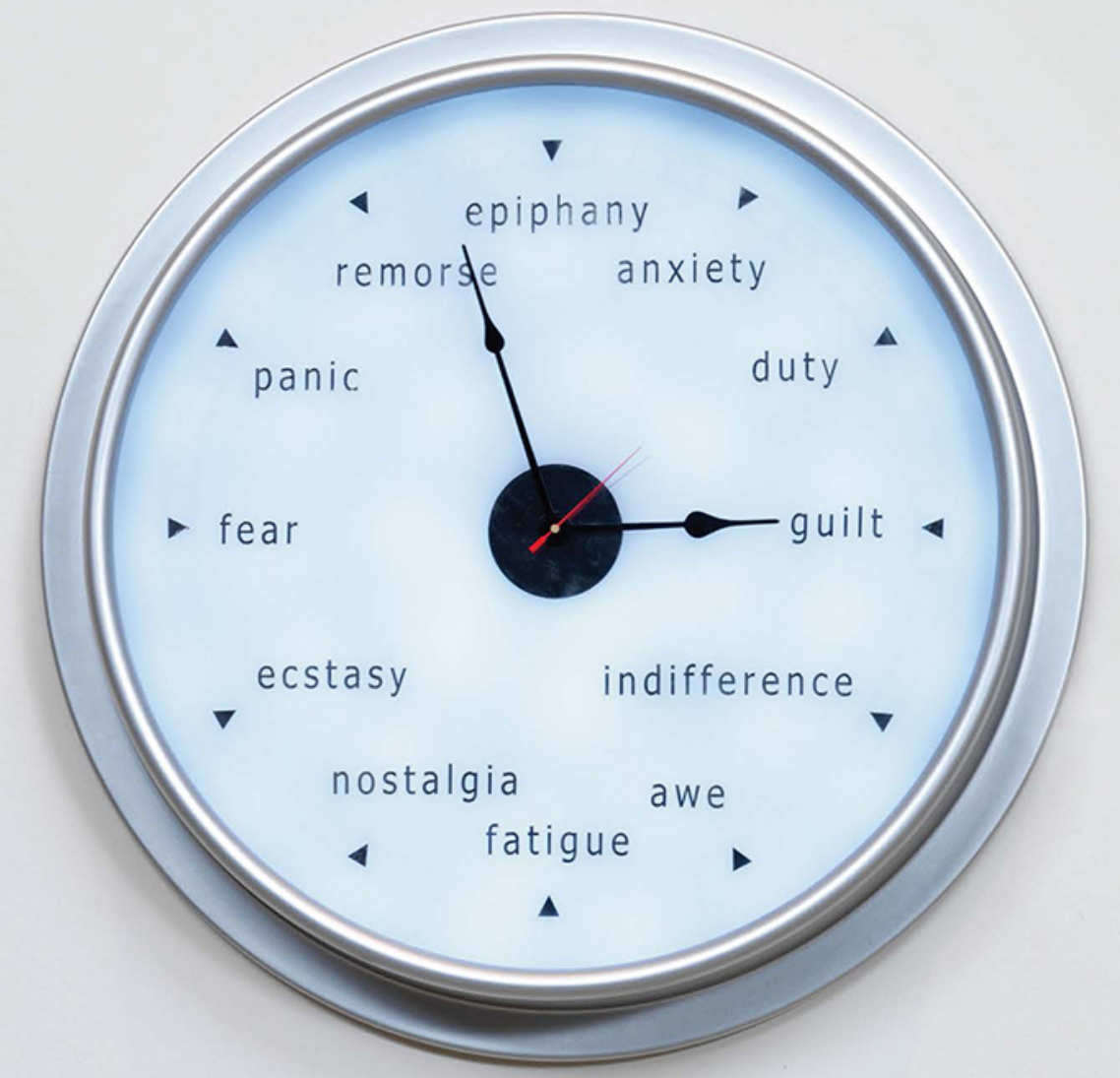




\section{Art, History, and Anachronic Interventions Since 1990}

This book examines contemporary artistic practices since 1990 that engage with, depict, and conceptualise history.

Examining artworks by Kader Attia, Yael Bartana, Zarina Bhimji, Michael Blum, Matthew Buckingham, Tacita Dean, Harun Farocki and Andrei Ujica, Omer Fast, Andrea Geyer, Liam Gillick and Philippe Parreno, Hiwa K, Amar Kanwar, Bouchra Khalili, Deimantas Narkevičius, Wendelien van Oldenborgh, Walid Raad, Dierk Schmidt, Erika Tan, and Apichatpong Weerasethakul, Art, History, and Anachronic Interventions since 1990 undertakes a thorough methodological reexamination of the contribution of art to history writing and to its theoretical foundations. The analytical instrument of anachrony comes to the fore as an experimental method, as will (para)fiction, counterfactual history, testimonies, ghosts and spectres of the past, utopia, and the "juridification" of history. Eva Kernbauer argues that contemporary art-developing its own conceptual approaches to temporality and to historical research-offers fruitful strategies for creating historical consciousness and perspectives for political agency.

The book will be of interest to scholars working in art history, historiography, and contemporary art.

Eva Kernbauer is Chair of Art History at the University of Applied Arts, Vienna.

Cover: Raqs Media Collective, Escapement (detail), 2009. 27 clocks, high gloss aluminium with LED lights, four flat screen monitors, video and audio looped. Courtesy Raqs Media Collective and Frith Street Gallery, London. Photo Alex Delfanne 


\section{Studies in Art Historiography}

Series Editor: Richard Woodfield, University of Birmingham

The aim of this series is to support and promote the study of the history and practice of art historical writing focusing on its institutional and conceptual foundations, from the past to the present day in all areas and all periods. Besides addressing the major innovators of the past it also encourages re-thinking ways in which the subject may be written in the future. It ignores the disciplinary boundaries imposed by the Anglophone expression 'art history' and allows and encourages the full range of enquiry that encompasses the visual arts in its broadest sense as well as topics falling within archaeology, anthropology, ethnography and other specialist disciplines and approaches.

Sculptural Materiality in the Age of Conceptualism

International Experiments in Italy

Marin R. Sullivan

Comparativism in Art History

Edited by Jaś Elsner

Constructing the Viennese Modern Body

Art, Hysteria and the Puppet

Nathan J. Timpano

Messerschmidt's Character Heads

Maddening Sculpture and the Writing of Art History

Michael Yonan

Time in the History of Art

Temporality, Chronology, and Anachrony

Edited by Dan Karlholm and Keith Moxey

New Narratives of Russian and East European Art

Between Traditions and Revolutions

Edited by Galina Mardilovich and Maria Taroutina

Making Art History in Europe after 1945

Edited by Noemi de Haro-García, Patricia Mayayo and Jesús Carrillo

Millard Meiss, American Art History, and Conservation

From Connoisseurship to Iconology and Kulturgeschichte

Jennifer Cooke

New Histories of Art in the Global Postwar Era

Multiple Modernisms

Edited by Flavia Frigeri and Kristian Handberg

Art, History, and Anachronic Interventions Since 1990

Eva Kernbauer

For more information about this series, please visit: https://www.routledge.com/

Studies-in-Art-Historiography/book-series/ASHSER2250 


\section{Art, History, and Anachronic Interventions Since 1990}

Eva Kernbauer 
First published 2022

by Routledge

605 Third Avenue, New York, NY 10158

and by Routledge

2 Park Square, Milton Park, Abingdon, Oxon, OX14 4RN

Routledge is an imprint of the Taylor \& Francis Group, an informa business

(C) 2022 Eva Kernbauer

The right of Eva Kernbauer to be identified as author of this work has been asserted by her in accordance with sections 77 and 78 of the Copyright, Designs and Patents Act 1988.

Open access: Except where otherwise noted, this work is licenced under a Creative Commons Attribution Non-Commercial 4.0 Unported Licence (CC BY-NC 4.0). A PDF of this book can be obtained on https://www.oapen.org.

Trademark notice: Product or corporate names may be trademarks or registered trademarks, and are used only for identification and explanation without intent to infringe.

Library of Congress Cataloging-in-Publication Data

Names: Kernbauer, Eva, author.

Title: Art, history, and anachronic interventions since 1990 / Eva Kernbauer. Description: New York : Routledge, 2022. I Includes bibliographical references and index.

Identifiers: LCCN 2021021873 (print) | LCCN 2021021874 (ebook) |

Subjects: LCSH: Art and history. I History in art. I Art, Modern--20th century-Themes, motives. I Art, Modern--21st century--Themes, motives.

Classification: LCC N72.H58 K47 2022 (print) I LCC N72.H58 (ebook) I DDC 709--dc23

LC record available at https://lccn.loc.gov/2021021873

LC ebook record available at https://lccn.loc.gov/2021021874

ISBN: 978-0-367-76325-1 (hbk)

ISBN: 978-0-367-76326-8 (pbk)

ISBN: 978-1-003-16641-2 (ebk)

DOI: $10.4324 / 9781003166412$

Typeset in Sabon

by SPi Technologies India Pvt Ltd (Straive)

Research results from: Austrian Science Fund (FWF):

P 27877. Published with the support of Austrian Science Fund (FWF): PUB-787 and of University of Applied Arts, Vienna.

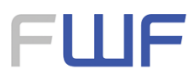

Der Wissenschaftsfonds. 


\section{Contents}

List of Figures vii

Acknowledgements $\quad$ ix

Introduction $\quad 1$

Art and History in a Time out of Joint 4

The Historiographic Turn in Contemporary Art 13

Shared Contemporaneity in the Global Present 17

1 Art As Historiography 27

Depicting History $\quad 28$

Understanding History $\quad 35$

Performing History $\quad 39$

Creating History $\quad 42$

2 Ready for History: The Explosion of the Documentary 50

History, Now: Harun Farocki and Andrei Ujica,

Videograms of a Revolution (1992) 52

3 The Crux of Authorship $\quad 71$

The "I" in History: Tacita Dean $\quad 71$

History by Proxy: Erika Tan and/or Halimah 76

Geography, History, Language: Dialogue and Diglossia

4 Archiving, Recording 90

Nothing to See Here: Walid Raad and the Negative Documents of The Atlas Group $\quad 90$

The Archive in Excess: Matthew Buckingham 95

At the Bottom of History: Dierk Schmidt, SIEV-X-On a Case
of Intensified Refugee Politics (2001-2005) 
vi Contents

5 Showing, Telling, Picturing 111

Gathering Evidence: Amar Kanwar, The Lightning Testimonies (2007) 111

I Will Always Be Here: Zarina Bhimji's Out of Blue (2002)

and Yellow Patch (2011) 124

Trapped in Narration: Omer Fast, Nostalgia (2009) 130

6 Performing 140

History on Stage: Wendelien van Oldenborgh's Maurits Script (2006), Instruction (2009), and Cinema Olanda (2017) 140

The Medium Film: Apichatpong Weerasethakul, Primitive (2009) 148

7 Counterfactual History, Parafiction, and the Critical Ends of Utopia 160

Sensing Possibility, Sensing Probability: Michael Blum's

A Tribute to Safiye Behar (2005) 160

History in Reverse: Yael Bartana's ... And Europe Will Be Stunned (2007-11) 163

$8 \quad$ Testing Truth: Tribunal, Script, Trial 173

History as Trial: Andrea Geyer, Criminal Case 40/61: Reverb (2009) 174

History as Script: Philippe Parreno and Liam Gillick, The Trial of Pol Pot (1998) 178

Truth Distorted in Perspective: Hiwa K, View from Above (2017) 181

9 Anachronism and Anachrony 186

Real and Existing Anachronism: Deimantas Narkevičius's

His-story (1998), Once in the XX Century (2004),

The Head (2007), and Into the Unknown (2009) 186

Kader Attia, The Repair from Occident

to Extra-Occidental Cultures (2012) 194

10 No End of History: Art and History in the Anthropocene 202

$\begin{array}{lr}\text { Bibliography } & 210\end{array}$

$\begin{array}{ll}\text { Index } & 240\end{array}$ 


\section{Figures}

0.1 Danh Võ (left to right), Lot 20. Two Kennedy Administration Cabinet Room Chairs, 2013; Lot 20. Two Kennedy Administration Cabinet Room Chairs, 2013

0.2 Hannes Böck, Five Sculptures from Egyptian Sanctuaries at Museo del Sannio, Benevento: $n$. 252 Crouched Baboon, Diorite; $n .253$ Falcon, Amphibolite; n. 255 Falcon, Gabbro; n. 256 Crouched Baboon, Diorite; n. 280 Apis Bull, Diorite, 2013, still image

1.1 Tomas Schmit, Geschichte, 1979

1.2 Jeremy Deller, The Battle of Orgreave, 2001

2.1 Harun Farocki and Andrei Ujica, Videograms of a Revolution, 1992, still image

2.2 Harun Farocki, Interface, 1995, still image

2.3 Harun Farocki and Andrei Ujica, Videograms of a Revolution, 1992, still image

2.4 Harun Farocki and Andrei Ujica, Videograms of a Revolution, 1992, still image

3.1 Tacita Dean, Pie, 2003, still image

3.2 Tacita Dean, Beautiful Sheffield, from The Russian Ending, 2001

3.3 Erika Tan, APA JIKA, The Mis-Placed Comma, 2017, still image

3.4 Erika Tan, The Weavers Lament. Part I: Performing Pattern / Part II: Mathematical Wefting / Part III: Tensions in the Warp / Part IV: Supplementary Erasure, 2016, installation view

3.5 Unknown artist, Portion of a hand loom exhibited at the Malaya Pavilion, British Empire Exhibition, Wembley, 1924, installation view, Erika Tan, The Weavers Lament, 2016

3.6 Bouchra Khalili, The Archipelago, $2015 \quad 84$

3.7 Bouchra Khalili, Foreign Office, 2015, still image 85

4.1 The Atlas Group/Walid Raad, Missing Lebanese Wars (Notebook Volume 72), p. 132, 1996-2002

4.2 The Atlas Group/Walid Raad, Missing Lebanese Wars (Notebook Volume 72), p. 145, 1996-2002

4.3 Matthew Buckingham, The Truth About Abraham Lincoln, 1992, still image

4.4 Matthew Buckingham, Situation Leading To A Story, 1999, installation view 
4.6 Dierk Schmidt, Xenophobe-Shipwreck Scene, Dedicated to the 353 Drowned Asylum Seekers Died on the Indian Ocean, on the Morning of October 19, 2001, 2001/2002; Untitled, 2001/2002; Freedom, 2001/2002, installation view

4.7 Dierk Schmidt, Untitled, 2001/2002

5.1 Amar Kanwar, The Lightning Testimonies, 2007, installation view (left to right: films 3-5)

5.2 Amar Kanwar, The Lightning Testimonies, 2007, installation view (left to right: films 6-7)

5.3 Amar Kanwar, The Lightning Testimonies, 2007, still image

5.4 Amar Kanwar, The Lightning Testimonies, 2007, still image

5.5 Zarina Bhimji, Out of Blue, 2002, still image

5.6 Zarina Bhimji, Yellow Patch, 2011, still image

5.7 Omer Fast, Nostalgia I, 2009, production photo

5.8 Omer Fast, Nostalgia II, 2009, double video still

5.9 Omer Fast, Nostalgia III, 2009, production photo

6.1 Wendelien van Oldenborgh, Maurits Script, 2006, still image

6.2 Wendelien van Oldenborgh, Instruction, 2009, still image 144

6.3 Wendelien van Oldenborgh, Cinema Olanda, 2017, installation view 146

6.4 Wendelien van Oldenborgh, Footnotes to Cinema Olanda, 2017, installation view

6.5 Apichatpong Weerasethakul, Nabua Song, 2009, still image

6.6 Apichatpong Weerasethakul, An Evening Shoot, 2009, still image

6.7 Apichatpong Weerasethakul, Primitive, 2009, still image

152

6.8 Apichatpong Weerasethakul, Primitive, 2009, installation view

7.1 Michael Blum, A Tribute to Safiye Behar, 2005, installation view 161

7.2 Yael Bartana, Mary Koszmary (Nightmares), 2007, still image

7.3 Yael Bartana, Mur i wieża (Wall and Tower), 2009, still image 165

7.4 Yael Bartana, JRMIP Congress, Hebbel am Ufer Theatre, Berlin, $2012 \quad 166$

8.1 Andrea Geyer, Criminal Case 40/61: Reverb, 2009, six-channel still image

8.2 Liam Gillick and Philippe Parreno, The Trial of Pol Pot, 1998, poster stack

8.3 Liam Gillick and Philippe Parreno, The Trial of Pol Pot, 1998, installation view

8.4 Hiwa K, View From Above, 2017, still image

9.1 Deimantas Narkevičius, His-story, 1998, still image

9.2 Deimantas Narkevičius, The Head, 2007, still image

9.3 Deimantas Narkevičius, Into the Unknown, 2009, still image

9.4 Kader Attia, The Repair from Occident to Extra-Occidental Cultures, 2012

9.5 Kader Attia, The Repair (detail), from The Repair from Occident to Extra-Occidental Cultures, 2012

10.1 Matthew Buckingham, The Six Grandfathers, Paha Sapa, in the Year 502,002 C.E., 2002, installation view 


\section{Acknowledgements}

The cause of as many pleasures as headaches, writing this book has taken up nearly every available hour of numerous personally and politically eventful years. Over their course, its premises, theses, and lines of argumentation have regularly been challenged by new cultural 'turns' and have had to be reconsidered again and again. But the artworks guiding this analysis have continued to function as truly inspiring signposts among the thickets of changing discourses. Indeed, this book has given me the opportunity to come into contact with many wonderful artists. I am greatly indebted to Zarina Bhimji, Michael Blum, Hannes Böck, Harun Farocki, Omer Fast, Andrea Geyer, Liam Gillick, Hiwa K, Deimantas Narkevičius, Wendelien van Oldenborgh, Dierk Schmidt, Erika Tan, and Apichatpong Weerasethakul for their generosity, openness, and willingness to discuss their work; I am equally grateful to all the other artists whom I could not meet personally, as well as to their studio assistants and gallery staff, for their invaluable help.

The first sketch of this research was written in the lively and stimulating working environment of the University of Berne. I am especially grateful to Rachel Mader, Johannes Rössler, and Peter Schneemann for their profound interest in and friendly support of this initial foray. Research began to take shape with the help of an Austrian Academy of Sciences APART scholarship, which was hosted by the Academy of Fine Arts Vienna in the best sense of the word. The largest share of the writing was undertaken at the University of Applied Arts Vienna (Angewandte), where the research was richly nourished by exchanges with my brilliant students and colleagues. I am greatly indebted to this wonderful, open-minded, and creative working environment for invaluable years of professional and moral support, especially to my colleagues Helmut Draxler, Gabriele Jutz, Ines Kleesattel, Eva Maria Stadler, Tanja Widmann, and the students of the seminars Geschichtsbilder and Das gute Alte und das schlechte Neue. Alisa Beck, Lisa Brandl, Kathrin Heinrich, Stefanie Kitzberger, Sarah Lauß, and Aneta Zahradnik assisted at various stages with research and editing. Collaboration with my colleagues from the FWF-funded research project A Matter of Historicity, Kristina Pia Hofer, Marietta Kesting, and Astrid Poyer-who has supported me absolutely indefatigably in many ways for years-is particularly appreciated. Hannes Böck, who acted as artistic advisor on the project, always took time to discuss material and technical aspects of film and video.

Among my colleagues from outside Angewandte, conversations with Sabeth Buchmann and Sven Lütticken were particularly valuable, and I thank them for their critical perusal of several chapters of this book. Karin Harrasser generously gave me several opportunities to discuss excerpts in Braunschweig, Linz, and Vienna. Léa Kuhn's 


\section{x Acknowledgements}

invitation to present parts of the book right before its completion at the Munich Zentralinstitut für Kunstgeschichte was very helpful in finally just letting it walk on its own.

Many research institutions, archives, art institutions, and galleries have supported my research. Of particular importance was a research visit in spring 2016 to the Asia Art Archive, Hong Kong, and the resulting exchange with Chuong-Dai Võ, as well as a visit to the ASEASUK conference at SOAS University of London in autumn 2016. Lena Bühl and Sinae Hyun kindly shared their research findings with me before publication of their respective PhD theses. I am also indebted to the Filmmuseum Vienna for permission to view films from its archival holdings. Iris Hasler and Stephan Knobloch (Städel Museum Frankfurt), Achim Hochdörfer (Brandhorst Collection, Munich), Dean Inkster (Grenoble), Julienne Lorz (Haus der Kunst, Munich), Jeanette Pacher (Secession, Vienna), Simone Sentall (TBA 21, Vienna), and Bettina Steinbrügge (Kunstverein Hamburg) provided valuable material and information, as did Studio Kader Attia, KOW Gallery, and Galerie Barbara Weiss, Berlin; GAK Bremen; Annet Gelink Gallery, Amsterdam; gb agency, Paris; and Kick the Machine Films, Bangkok.

Christine Schöffler and Peter Blakeney (Why Society) contributed substantially to the translation of the first two chapters of the introduction. My sister Barbara saved me whenever words fell into wrong places or my grammar left me. English-language editing was undertaken by the truly amazing Amyrose McCue Gill of TextFormations, who did a great job transforming my writing into correct English while somehow managing to retain my voice. Nick Brock led me through the last steps of copy-editing with impressive accuracy and efficiency.

I am grateful to the Austrian Science Fund (FWF) for its generous funding of this publication, as well as to Angewandte for stepping in with additional support. At Routledge, Isabella Vitti has been an incredibly professional, patient, and supportive partner on the rollercoaster of publishing. I am also indebted to Richard Woodfield for including this book in the series Studies in Art Historiography.

Martin Anton Müller has both intellectually challenged and emotionally sustained me with what I am becoming convinced are inexhaustible resources, and Artur took my mind off writing ever so often at exactly the right moments. This book is dedicated to you both, as it is to my open-minded and generous parents, who have always supported me, no questions asked. 


\section{Introduction}

We require a history that will educate us to discontinuity more than ever before; for discontinuity, disruption, and chaos is our lot. ${ }^{1}$

Hayden V. White, “The Burden of History”

Artworks can represent, narrate, and perform history; relate it to the present; and situate it historically. At the same time, they are part of history; they refer to it; they intervene in it. Art shapes history just as art is shaped by history. This study investigates the different forms, methods, instruments, and interests of what I term "artistic historiography" —art that explores history-with a view to the complex relationship between art and history, propelling the conversation beyond purely content-based or thematic perspectives of artworks.

"Historiography" literally means the writing or drawing of history, referring equally to the academic, artistic, literary, or mythological telling, writing, or representation of history. ${ }^{2}$ This book situates artistic historiography within the context of engagements with history more generally, a politically controversial and heterogeneous field in terms of its actors, subjects, media, institutions, and forms of dissemination. Within this broader context, artistic explorations of history have played an increasingly important role over time, not limiting themselves to illustrating or counteracting existing historical narratives but developing their own forms and instruments of historical research as well as their own historiographical narratives and imaginations. This process has, in turn, led to new concepts of how we experience time-or, more precisely, how past, present, and future relate to one another.

Such an active and involved understanding of historiography requires dismissing two overly simplistic divisions: first, that of events from their representations, which transforms art into a container and history into its contents; second, that of a temporally distant "yesterday" of history from the "now" of contemporary art. Exploring the past means continuously creating it anew. Historical events-when they become the subject of representations-are not "over"; they are instead situated in a historicised "now." Artistic historiography is thus particularly well suited to making visible the experiences of heterochronies and anachronies that are ultimately inherent in every historical experience, narrative, or representation.

Countless exhibitions and publications dedicated to the relationship between art and history in recent years portray an unsettled bond marked by repeated diagnoses of crisis. ${ }^{3}$ This is, at least in part, the legacy of postmodern cultural theory's successive proclamations of the end of narration, the end of art, and the end of history. The resulting evaluation of artistic and popular transformations of history as well as of 


\section{Introduction}

the experience of time has left them stranded in clichés of relativisation, arbitrariness, and disposability. It is my explicit aim to counter this dehistoricisation of experimental conceptions of history and thereby the depotentialisation of artistic historiography. Since postmodernism, notions of art as well as of history have changed fundamentally. The past three decades, which constitute the temporal framework of this book, have seen a realignment of both theory and practice across several phases: since the 1990s, the surpassing of posthistoire concepts and postmodern image theory along with the redefinition of the documentary; since the 2000s, the intense debate over the historicity of contemporary art as a global phenomenon; and, most recently, the performative turn in contemporary art as well as the reevaluation of the relationship between art and politics.

This volume examines works by Harun Farocki and Andrei Ujica (Chapter 2); Tacita Dean, Erika Tan, and Bouchra Khalili (Chapter 3); Walid Raad, Matthew Buckingham, and Dierk Schmidt (Chapter 4); Amar Kanwar, Zarina Bhimji, and Omer Fast (Chapter 5); Wendelien van Oldenborgh and Apichatpong Weerasethakul (Chapter 6); Michael Blum and Yael Bartana (Chapter 7); Andrea Geyer, Philippe Parreno and Liam Gillick (in collaboration), and Hiwa K (Chapter 8); Deimantas Narkevičius and Kader Attia (Chapter 9) to reveal the remarkable diversity in artistic explorations of history. In light of their broad scope, we can observe that not only that artistic engagements with history have increased but also that there is a growing readiness to perceive as historical works that could just as easily be discussed from other perspectives. ${ }^{4}$ Contrary to its apparently clear-cut definition, artistic historiography comprises an astonishingly open and versatile semantic context and has become a paradigmatic arena for investigations into the possibilities of visual representation. ${ }^{5}$ Critical momentum, it is often said, resides in the self-reflective examination of medial communication and visual representation; in narration, authenticity, and realism; and in the political potential of art. However, the writing of history and critical reflection upon history writing cannot be separated cleanly; self-reflection has long become conventional even in much popular culture production. ${ }^{6}$ The specific achievements of artistic historiography thus always have to be discussed in a wider social context.

My second objective, therefore, is to question the cliché that artistic historiography per se promises a better, more critical approach to history, a claim that is often made via the differentiation of artistic from academic and popular histories, the latter of which are generally considered nonreflective approaches. Additional pressure comes from the much-criticised but just as oft-postulated "ethical turn" in art criticism, ${ }^{7}$ with its conflation of aesthetics and morals as well as its expectations of artistic historiography to tell the "right" stories—as if this were so easily determined. ${ }^{8}$ As Tom Holert writes, this amounts to not only a direct appropriation of art for societal issues-and thus a crisis of aesthetic autonomy-but also a crisis of political representation. He therefore recommends taking some distance from the impositions of "urgency ethics" and maintaining the distinction between politics and art in favour of "meta-ethical" evaluation criteria. ${ }^{9}$

This book situates artistic historiography within a larger field of scholarly and pop-cultural engagements with history, considering artistic explorations of history and historiography as equal approaches that critically comment upon, complement, and also contradict these engagements. Artistic practices emerge within the multifaceted and wide-ranging setting of contemporary historiography in an exchange with social, political, and media contexts. Within this diverse and productive field of engagement, I discuss a limited number of works in favour of in-depth analyses. I have selected 
artworks less for their visibility on the international exhibition circuit than for their exemplarity, in the sense of how they reflect certain historiographical problems and theories; their value as artistic contributions to historiography (their "historiographical ethos," so to speak); and their potential to address history in a broader global context.

The discussion opens with an overview of current conceptions of the historicity of contemporary art that is necessary in order to historicise the historiographical ethos itself in contemporary art. The second chapter reviews methodological writings on historiography at an early stage of modernism from about 1815 , when the historical sciences emerged as a discipline. This occurred at a favourable moment when, through the convergence of art, science, and philosophy, history was able to contribute to a greater understanding of the world. ${ }^{10}$ In this chapter, especially, I draw upon the rich body of theory offered by German historiography beginning in the 1800s and moving into the twentieth century. Examining the methodologies of early academic history writing may seem a surprising approach, as contemporary art theory usually recommends distancing from the historical sciences-and from their historicist legacy in particular. ${ }^{11}$ But stepping into the lion's den of historicism (rightly criticised as a prime example of bourgeois politics) provides numerous impulses for researching current artistic historiography. To attain a comprehensive view of the historiographical potential of art, examining the theoretical terrain upon which "history" came to be consolidated as a scholarly discipline is an important starting point. Such an approach offers an opportunity to underline the continuing proximity of artistic and scholarly historiography as well as to draw connections even to protagonists of the critical movement against historicism, namely Walter Benjamin and Siegfried Kracauer. Indeed, historicism itself harbours inspiring concepts—such as, among others, "apodeixis" as elaborated in Gustav Droysen's historiographical theory to encompass representation, research, and reflection, making the term a fruitful one for contemporary artistic approaches to history. A close look also reveals that historicism's theoretical framework did not stop at the well-known postulates of objectivity and linear historical progression for which it is often rejected. Instead, historicism generated extensive material for a critique of these theorems ${ }^{12}$ as well as an array of potential links between "art" and "history"-even if both notions have been considerably transformed since. Finally, the fact that this took place at a time when great efforts were being made to categorise, standardise, and synchronise time ${ }^{13}$ highlights the close connection between historical theory and the experience of time.

Although scholarly and artistic approaches differ from one another regarding their methods, viewpoints, and interests, even as competing procedures they can be productively related to each other. Methods from academic history may be employed artistically and lead to other outcomes. Taking scholarly approaches into account thus enriches our understanding of the capacity of art as an instrument of historiographyeven if the respective fields of artistic and scholarly expertise have shifted considerably since the nineteenth century.

Still, such an approach is inevitably confronted with the charge of perpetuating a concept of history rooted in the Enlightenment-despite fundamental geopolitical, philosophical, and medial transformations since. European historical consciousness did not develop exclusively as the rationally motivated, philosophical-cultural achievement of idealism; it also has roots in experiences of trauma. ${ }^{14}$ Without a doubt, the Enlightenment concept of history became entangled in modernist discourses in a highly problematic way. The idea of history that was born from these contexts-which has since been adapted and reflected in various ways-is thus simultaneously an impulse and a source of friction 
for artistic historiography. In spite of regularly recurring posthistorical and posthumanist conceptions (looming large on our current horizons as well), this much-compromised idea of history-and this is my third thesis-remains a source of orientation and a reference point for action. Just as historiography has been critically scrutinised from its beginnings, it remains vital to review, perpetually, its methods and instruments; to revise and renew them; and, in some cases, to abandon them. Oscar Wilde's well-known quip- “The one duty we owe to history is to rewrite it" ${ }^{15}$ - is insightful especially when applied to history's conceptual and methodological body. Let us therefore first take a look at the complex social context in which historiography is practiced today.

\section{Art and History in a Time out of Joint}

The attractiveness of artistic historiography derives from its double advantage of providing a veritable fund of materials, narratives, and imaginations while at the same time promising socio-political relevance. Historical topics are bestsellers in popular media and provide an array of narrative advantages since they work with recognisable settings and situations. As a US film director in this field has put it, it is easier to develop a character if the audience thinks they already know him or her. ${ }^{16}$

This narrative bonus is capitalised upon more easily using past events than those of the chaotic, unpredictable present. As Matthew Buckingham has noted, the promise of providing meaningful access to (past) reality is, however, primarily fictional: "The fiction of history is to imagine the real. History makes reality desirable. It has the illusion of 'speaking itself' as if it simply happened." ${ }^{17}$ Hence the fictions of history serve both to preserve and to defend the politics and ethics of veracity and authenticity. This is all the more the case in artistic historiography, which, critical of image politics, media politics, and politics proper, is often seen as a diagnostic and therapeutic corrective of the hegemonic representation of historical events in popular media. This view often coincides with the conviction that art serves as a surrogate for the negotiation of history that is lacking within a broader public sphere; that art is able to absorb numerous scattered and homeless individual stories that would otherwise find no place.

Does artistic historiography respond to a crisis of the historical? Dieter Roelstraete has identified a crisis of national historiographies in the age of globalisation, a crisis of globalisation itself, a crisis of public culture, and a crisis of politics and democracy. ${ }^{18}$ The aspiration to renew historiography, in his eyes, is a specific European concern, ${ }^{19}$ which points out the problematic export of Eurocentric concepts of art and history to the global art circuit. But such a conventional notion of history, which evolved as a "sign of the modern" and crystallised in the formation of the modern European nationstates, ${ }^{20}$ has long come under pressure. The erosion of fundamental Enlightenment principles of historiography, culminating in Hegelian thought-belief in progress and linearity; a Eurocentric differentiation between cultures that have history and those who do not-has led to a peak in new models of history that incorporate aspects of perspectivisation and subjectification, the polychronic and synchronic. Among the numerous "ends of history" proclaimed so far, at least one-the expiration of the world order that has shaped Europe since the 1950s through the socio-political upheavals since 1989 that constitute its final moments-is undeniable. If, since the beginning of the new millennium, the course of time has noticeably regained momentum, then too those historiographical narratives focusing on the global North have forfeited their claim to validity. They have been joined by new actors and perspectives, new historical periodisations and categories. 
History is now confronted with profound institutional and technological change. ${ }^{21}$ For some time, the fiction of history as a stable conglomerate of knowledge epitomised in school textbooks; controlled by the combined authority of nation-states, museums, schools, and universities; and unassailable by individual, dissenting experiences has become untenable. In its place, conceptions of history have surfaced that account for the global interdependence (entanglements) of modernity, in which Europe is visible as but one among many actors and history is both continuously written anew and related to a geopolitically expanding present. Historical knowledge today is not conveyed through dusty old tomes of dry prose. It operates and proliferates via mobile, affective image-text clusters that are permanently shared, discussed, revoked, and revisited. Historiographical contents, concepts, and instruments are equally open to discussion. In this "time out of joint," 22 the traditional institutions of historical knowledge have fallen into ideological, communicative, and conceptual crises; the potential for art to pose questions about the past that touch upon urgent global concerns and to develop new historical perspectivisations is growing.

The flourishing of artistic historiography thus has a direct connection with the crisis of "old" history and therefore both impressions-that we are experiencing a crisis or a peak of historiography-are largely owed to the same developments. Time and again, postmodernist theorems linger and break into current debates, indebted, among others, to the pessimist notion of a "pop history" (Fredric Jameson) that abundantly spreads images via the mass media but precludes any authentic engagement with history ${ }^{23}$-an impression that, even today, can be felt in a general mistrust towards images-and, therefore, art-picturing history. Jameson's warning of a transformation of the past into (moving) images also asked for a clear break of art from pop culture. Finally, the entanglement of art and history in postmodern thought is evident in Jameson's double concern that both were fatally threatened by the culture industry: the former by direct contamination, the latter through the loss of authentic historical experience. ${ }^{24}$ Postmodernism's scepticism of the (popular) pictoriality of history arose not least from the realisation that images do not just record or represent history but produce it: directly, simultaneously, in your face. ${ }^{25}$

But from today's point of view, this does not necessarily stand in the way of authentic engagements with history. In contrast to Jameson's and also Jean Baudrillard's pessimistic positions, both of which describe a loss of authenticity and reality, a more complex understanding of the relationship between image and reality now prevails. The role of what used to be called the "recipients" of these much-maligned images is currently perceived as considerably more active and relational in regard to sensory experience. Still, in an age when audio-visual imagery is consistently permeating collective memory, the relationship between imagery and history remains confrontational. To this day, art that deals in history must in some respects oppose images, contextualising them and commenting on them-and thus putting them into perspective. For history is still frequently equated with its representations in media; images of it come to be conflated with reality:

In media societies, it is clear that reality cannot exist without images. Events seem to take place only when they are present in the media. [...] Not just major social and political events but also private, trivial, or suppressed ones today become public realities when images of them "go viral" on social media networks. Thus, a marginal event of the entertainment world can suddenly achieve worldwide notoriety, and cell phone photos of demonstrators can alter the course of an entire country's history. The maker of images is the constructor of reality. ${ }^{26}$ 
The consequences of this continuous potential recycling of images are clearly visible in the knowledge canon of the internet generation: in its online image archive, "readymade" history is always available (at least briefly). Hence artistic interpretations of media images are sometimes presented as discussions of history-as if the agglomeration of images available on the web forms a historical archive that only need to be displayed. Often, such processes, mistaken as "image critique," are performed under the banner of historiography but amount to mere recycling of historical materials or to visually animated press reviews. These phenomena, combined with the unbroken cultural appeal of revivals, retrospectives, and repetitions, allow postmodernist theorems to live on to this day, especially as they concern contemporary historical experience. Hans Ulrich Gumbrecht's description of a "broad present" absorbing past and future reads as if cast in the 1980s: stripped of identity and marked by a historical standstill induced by an "accumulation" of the past in electronic storage and by institutions harbouring collective memory. ${ }^{27}$ Starting from other premises, François Hartog paints a similar picture, warning against an expanding “presentism" — an omnipresence without future or past, characterised by short-term decisions. ${ }^{28}$ Even Jameson has similarly refined his criticism of the loss of history since the 1980s: in our new, timeless, pure present without past or future, the "now" reigns. ${ }^{29}$

Let us not forget the demise of the great historical narratives of European modernism-at least those that aimed to change history. Others have stepped up in their place, but these new narratives neither create nor shape but instead fulfil history: neoliberal capitalism aiming at the global, endless proliferation of ever the same; a financial market that urges direct reproduction as well as the more dystopian posthumanist brands of the Anthropocene. At this point, the affinities to postmodernist, posthistoire pessimism come full circle. With the abandonment of teleology and of belief in progress, which were intrinsic to most emancipatory concepts of history in the twentieth century, devising political blueprints for the future has become considerably more difficult. Ernesto Laclau has formulated the loss associated with this development in his examination of Jacques Derrida's Specters of Marx:

We can do away with the teleological and eschatological dimensions, we can even do away with all the actual contents of the historical messianisms, but what we cannot do away with is the 'promise,' because the latter is inscribed in the structure of all experience. ${ }^{30}$

This "promise" is also the promise of a future, ${ }^{31}$ of a space for political thought and action. ${ }^{32}$

Today, the future is more a category of fear than of hope. This is not only due to the decline of utopian social concepts ${ }^{33}$ but also to the ongoing pandemic-perhaps the most drastic event in a series that have transformed the present into a permanent series of states of exception-and to the ongoing climate catastrophe. The neutralisation of the future as "what radically differs from the present" ${ }^{34}$ is connected to a comprehensive paradigmatic shift that subjects the future to a regime of prognoses, scenarios, and precautions-and that subordinates it to risk management. As a threat to the present, the future must be rendered ineffective. Hardly anything makes Walter Benjamin's catastrophic scenario that things "just go on" more plausible than the permanent dehistoricisation and depotentialisation of the future in the face of looming ecological, economic, and biopolitical catastrophes. ${ }^{35}$ Both concepts, presentism and risk management, point in the same direction: in one case the future cannot, in the other it must not happen. 
Hence, if we wish to reestablish the future as a category of hope, this must be undertaken not so much in opposition to pessimist or catastrophic expectations but rather beyond prognostics as well as beyond neoliberal discourses of a lack of alternatives to existing economic and social orders, of inevitability-all of which precludes any sense of historicity and, with it, any potential for change. ${ }^{36}$

A primary aim of artistic historiography is to let a fresh breeze into this fatalist stagnation. How this is achievable becomes clearer when we take a look at the shape that art dealing with history takes in late capitalism: this is not the calm of still waters. The ongoing reproduction and commodification of history are byproducts of the capitalist transformation of time into a speculative resource. ${ }^{37}$ History is anaesthetised while the rhetoric of teleological progress has shifted to the horizontal, with the aim of endless spatial expansion: "World capitalism in its 'age' after the end of history has not abolished the idea of teleological progress, it has only changed its staging ground: progress is translated into space." ${ }^{38}$ Coupled with the capitalist belief in progress, global space can be mapped, tapped, and valorised; heterochronies are interpreted as "regress"; and migration remains the primary possibility for change for the poor and disenfranchised in capitalism. Activating history in order to reverse this development cannot be accomplished through future-oriented teleology or utopias, but through activating the present: "Historical experience is an experience in and of the present-an experience of the nonidentical temporality that renders the present open to change." 39 Thinking in anachronies, as is frequently practiced in artworks and is pursued in this book, can chart a path away from the stagnant status quo.

While postmodern theorems about the end of history seem like swan songs to the weary late twentieth-century political and economic promises of progress, today modernist paradigms of Western history are questioned by alternative nonsynchronous historiographies. Along with history, the modern time regime is "out of joint," in the political-ethical sense that resonates in Hamlet's "The time is out of joint.” Instead of lamenting the loss of modernist regimes of history-which as ideological conceptions must be historicised-we might, with Jacques Derrida, ask what is to be gained in this situation:

What happens when time itself gets 'out of joint,' dis-jointed, misadjusted, disharmonic, discorded, or unjust? Ana-chronique? [...] Untimely, 'out of joint,' even and especially if it appears to come in due time, the spirit of the revolution is fantastic and anachronistic through and through. ${ }^{40}$

This "ana-chronic" untimely, revolutionary time is a key historiographical concept that Jacques Rancière, following Derrida, elaborated in an early text. ${ }^{41}$ Rancière conceived "anachrony" (the potentiality of events that do not fit into the time categories ascribed to them) in opposition to "anachronism" (the mispositioning of an event within a stable temporal sequence). According to Rancière, describing an event as "anachronistic" aims not only at correcting a wrong chronological dating but at subjecting history to a "regime of probability" that immunises it against that which was not supposed to have been possible. When events are perceived as not appropriate to "their" time, they remain meaningless curiosities or unheard prophecies. This understanding of "anachronism" contrasts with that of "anachrony," the latter being the productive temporal discrepancy of an action, an event, a thought, or a subject with its assigned position in a chronological order. Anachrony makes history (when it is understood as a characteristic of an event) and historiography (when it is understood as a component of historical thought) possible: 
There is no anachronism. But there are modes of connection that in a positive sense we can call anachronies: events, ideas, significations that are contrary to time, that make meaning circulate in a way that escapes any contemporaneity, any identity of time with "itself." An anachrony is a word, an event, or a signifying sequence that has left "its" time, and in this way is given the capacity to define completely original points of orientation, to carry out leaps from one temporal line to another. And it is because of these points of orientation, these jumps and these connections that there exists a power to "make" history. ${ }^{42}$

Anachronic thought, therefore, is not ahistorical but is a prerequisite of historical thinking, as it enables us to perceive the historical potential of ideas, events, and actions.

Other theorists of history have also pointed out the fundamentally anachronic nature of historical scholarship, sometimes under the term anachronism as Rancière's differentiation never became terminologically fixed. Reinhart Koselleck has described the modernist concept of history as a construct dealing with manifold experiences of the "simultaneity of the non-simultaneous," comprising forward- and backwardness as well as linear and circular time concepts. ${ }^{43}$ Hayden White joins Johann Gustav Droysen's Historikand therewith the theoretical foundation of the emerging historical sciences in the nineteenth century - when underlining the anachronic character of historiographical "emplotments": ${ }^{44}$ "Though literally chronological, history is figurally anachronistic." 45 Accordingly, history writing contains indispensable anachron(ist)ic elements. And art history faces the same problem, as art historians also find themselves in the anachronic position of being late in time. Dan Karlholm has recently called for an "after-history" that does justice to this situation, asking not for influences or causes explaining artworks but viewing them as "productive of effects" along the lines of "outfluence" instead of "influence." 46

As Alexander Nagel and Christopher Wood, working with Rancière's concept of anachronism, have demonstrated in detail, temporal mobility (which is a foundation of historiography) is also a specific quality of art. Artworks have a particular capacity to illustrate-and moreover to activate-anachronies. Just as chronological time has yielded its own figurations (clocks, calendars, annals, and timelines), art breeds its own formations of history: repetitions, regressions, distensions, duplications, folds, and bends-and, above all, alongside these formations, the ability to balance incompatible models of temporality. ${ }^{47}$ All of this exemplifies that there is no "natural" course of time and, therefore, of history. In analogy to Hayden White's "emplotment" theory for textbased historiography, it can be seen that every institution, every science, every form of thought possesses its own configurations and narratives on the course of time. This is similar in the different media used in artworks, depending on their respective historicity (in this book, I discuss film, video, photography, painting, drawing, and performance). Especially "time-based" media demonstrate the ability to bend, stretch, and fill time as well as to work explicitly with temporal experience. But while numerous audio-visual works are discussed in the following chapters, the potential to use anachronic figurations and formations in the sense of activating history is independent of the respective media.

Given its more orthodox academic varieties that still dominate teaching practice, it is easy to overlook the potential of art history to challenge chronological representations. Georges Didi-Huberman's writing of art history along the "impurities of time" 48 is a case in point, with its references to Aby Warburg's anachronistic sensitivity to the historicity of artworks. ${ }^{49}$ Nonconformities between formal and historical analyses were also of interest to Walter Benjamin, who, reading Focillon's Vie des formes, noted: 
We have no right to confuse the state of the life of forms with the state of social life. The time that gives support to a work of art does not give definition either to its principle or to its specific form. ${ }^{50}$

The very same point is addressed in Hubert Damisch's abandonment of the notion of time as a container in which the art historian places the artwork, of a "relation conceived of being quite simple, rather like that of a container and what it contains: history and the story unfolding in time, inscribing itself and developing within it." Damisch counters this "euchronic" 51 art-historical ideal:

Whereas it is, quite obviously, the object under study [...] that produces the time, the very duration within which it is inscribed, and within which it must of necessity be known and studied $[, \ldots]$ art $[. .$.$] seems to go about its business quite heedless$ of such questions, as well as of comparable scruples; it takes its materials wherever it finds them (which is not the same as saying haphazardly) and uses them in accordance with its own ends, diverting them, often quite deliberately, from their original contexts. ${ }^{52}$

This disparity between the aesthetic potentiality of artistic objects and their incorporation into historiographical or institutional categories is a recurring theme of artistic discourse. This occurs, for instance, in Danh Võ's series Lots (2013, Figure 0.1), ${ }^{53}$ in which the artist stages the passing of materials and objects through personal, political, aesthetic, religious, and economic categories by acquiring objects of (circumstantial) historical importance and integrating them, through this artistic act, into categories of aesthetic and art-economic valorisation. In If You Were to Climb the Himalayas

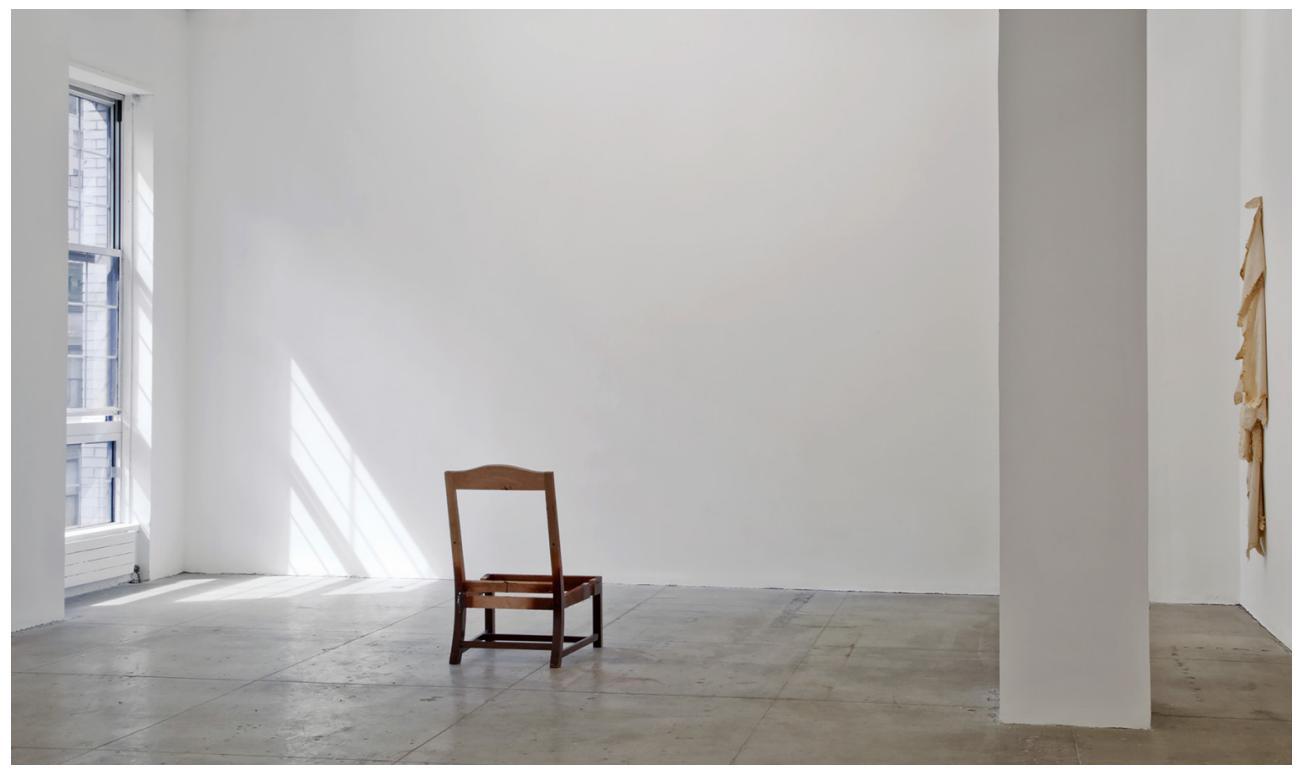

Figure 0.1 Danh Võ (left to right), Lot 20. Two Kennedy Administration Cabinet Room Chairs, 2013. Mahogany, metal, $102.8 \times 66 \times 65.4 \mathrm{~cm}$; Lot 20. Two Kennedy Administration Cabinet Room Chairs, 2013. Muslin, nails, $214.6 \times 40.6 \times 14.6 \mathrm{~cm}$. Courtesy Marian Goodman Gallery, New York (14335). Photo Cathy Carver. (C) Danh Vo 


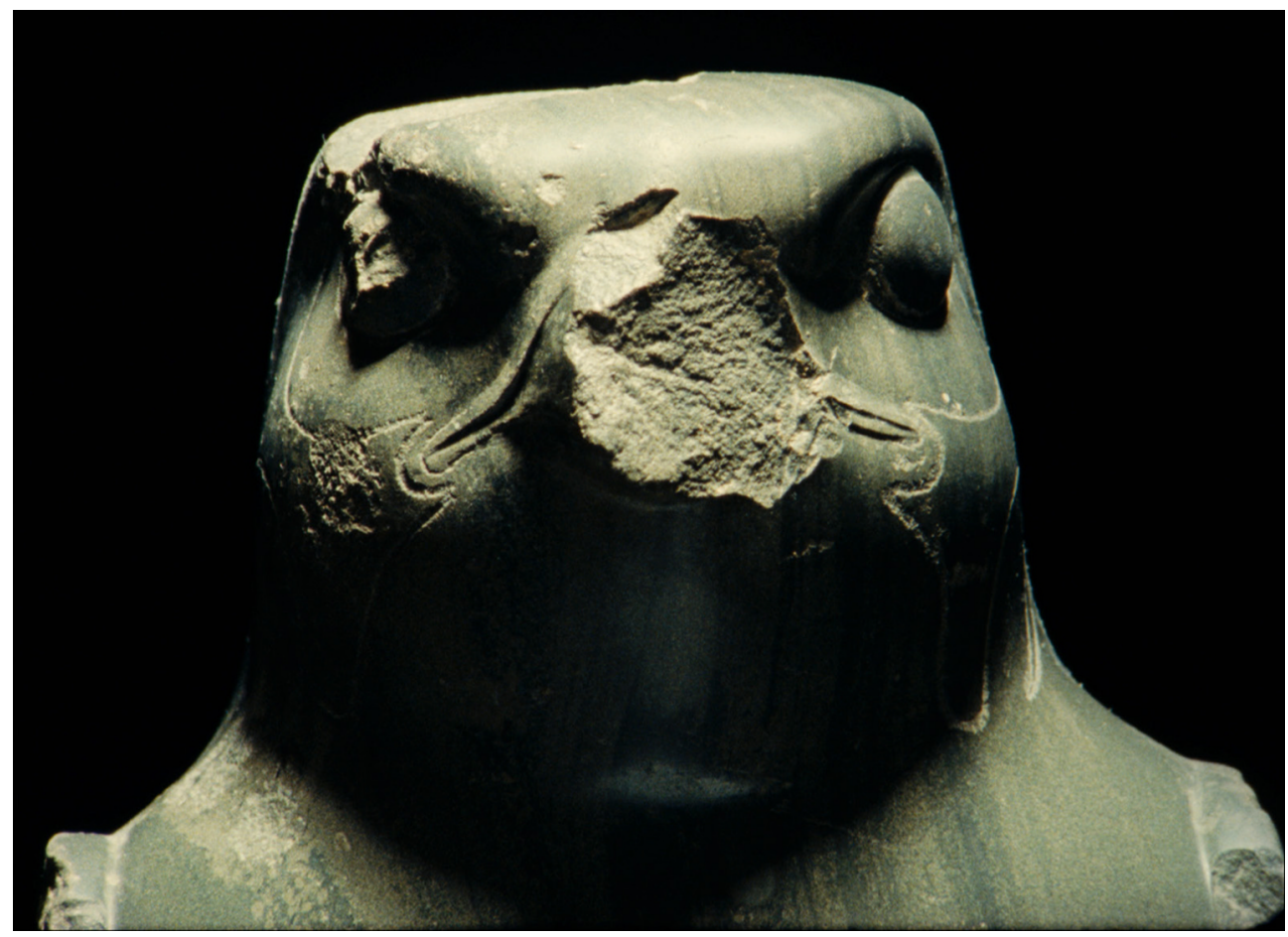

Figure 0.2 Hannes Böck, Five Sculptures from Egyptian Sanctuaries at Museo del Sannio, Benevento: n. 252 Crouched Baboon, Diorite; n. 253 Falcon, Amphibolite; n. 255 Falcon, Gabbro; n. 256 Crouched Baboon, Diorite; n. 280 Apis Bull, Diorite, 2013. Still image, $16 \mathrm{~mm}$ film, colour, silent, 9 mins. Courtesy the artist

Tomorrow (2006) and Oma Totem (2009), history becomes deeply intertwined with the artist's family history to the point of a full biopolitical embrace of his relatives (and their past) in the service of artistic identity and art production.

Like Võ's Lots series, Hannes Böck's 16mm film Five Sculptures from Egyptian Sanctuaries at Museo del Sannio, Benevento: n. 252 Crouched Baboon, Diorite; $n .253$ Falcon, Amphibolite; n. 255 Falcon, Gabbro; $n .256$ Crouched Baboon, Diorite; $n .280$ Apis Bull, Diorite (2013, colour, silent, 9 mins., Figure 0.2) explores how historical and aesthetic values intertwine and how formal and technical dispositifs contribute to generating such categories. This film applies multilayered cinematographic and photographic discourses to antique Roman statues dedicated to the Egyptian cult of Isis, staging them as objects of visual culture and thus shedding light on hybrid forms of history and historiography. ${ }^{54}$

This book introduces a number of other varieties of the anachronic. We will encounter it as a formal device (nonlinear narration, including reversals and entanglements of different temporal layers); as a conceptual strategy for positioning the self within history; and as a phenomenon linked to subjective historical experience. In view of the current structuring of time experience, however, employing anachronies alone does not necessarily entail a critical or political-emancipatory attitude. With digital images expanding, multiplying, and overlapping, what does it even mean to tackle linear or 
chronological concepts of time given that they have become endangered species? My aim, therefore, is to discuss analytically specific methods, forms, and contexts of artistic anachrony (rather than indiscriminately embracing all its uses) in order to argue for specific cases where it indeed works to "make history."

In light of the often fascinating stories told by and represented in artworks dealing with history, formal and conceptual challenges to how time is perceived may seem, at first glance, a modest contribution to social and political debates. But as Giorgio Agamben has emphasised (with recourse to Walter Benjamin), destabilising prevailing perceptions of time bears potent fruit:

Every conception of history is invariably accompanied by a certain experience of time which is implicit in it, conditions it, and thereby has to be elucidated. Similarly, every culture is first and foremost a particular experience of time, and no new culture is possible without an alteration in this experience. The original task of a genuine revolution, therefore, is never merely to "change the world," but also-and above all-to "change time."

If art is supposed to change the world, this means revising not only historical narratives but also conceptions of time and temporal experience-such as the ancient idea that time is just "an empty form of historical events, [...] something objective and natural that contains the things that are 'in' it, like a package." ${ }^{6}$ The rivalry between time and historiography (likewise an ancient concept), which is fuelled by the notion that history should counter the destructive character of time, must also be reconsidered. And finally, we must question the modernist idea of a total integration of human action into standardised, synchronised processes, ${ }^{57}$ which entails a fundamental disengagement from history: "For history is not [...] man's servitude to continuous linear time, but man's liberation from it." 58 In the framework of this historical-philosophical scheme (within which Agamben advocates for a Benjaminian messianic standing still of time), artworks have the potential to transform the experience of time, as illustrated by Deleuze's intertwining of the philosophies of film and time. ${ }^{59}$ The moving images of film and video may explore liberation from time; its bending and folding; and the coalescence of the present and the past, the virtual and actual, the real and the imaginary-heightened all the more through dissemination as digital formats on mobile devices. This destabilisation of linear chronologies is a response to the increasing awareness of the complexity of individual time perception that is catching hold in philosophy, cultural studies, and the natural sciences. ${ }^{60}$ Neuroscience has shown that the human body has a whole series of differently timed "internal clocks" and that the perception of time is primarily a construct of the human brain informed by complex processing, including the combination and suppression of information. Perceptions of duration, simultaneity, pace, and sequence are effects induced by the brain rather than the accurate reflection of an objective reality. Neuroscientist David M. Eagleman therefore compares the brain's construction of time perception with that of visual perception, which has long been proven, with the aid of optical experiments, to be controlled by the brain. Time perception is similarly manipulated and manipulatable. ${ }^{61}$

The traditional perceptuomotor disposition of Western concepts of time, which has established the upright, walking individual as an exemplary analogue for the march of history, is a cultural construct easily confounded in times of political turmoil, as a historical example illustrates. In the autumn of 1815, writer and salonnière Rahel Varnhagen wrote to her husband Karl August von Ense: 
Alas, August, what is happening to our life, to its visual appearance of time! One thought will soon break my head apart: that we are not headed towards the future, that it does not lie ahead of us, but instead streams over our heads from behind. How to defend oneself against this! ${ }^{62}$

When the future flows over your head from behind, your sense of vision-so closely associated with "proper" historical orientation in European thought-is annulled. ${ }^{63}$ It is striking that Varnhagen was primarily concerned about the "visual appearance of time," herself drawing an analogy between time and vision. Her personal existential breaking point was reached when she felt unable to experience the present. The resulting loss of orientation must have been a catastrophic experience for Varnhagen's deeply Enlightenment thinking. If the future was now suddenly "streaming over our heads from behind," had she turned around, turned her back towards time, or was it suddenly coming from the wrong direction? Had time lost its senses in the moment of the catastrophe?

According to the perceptuomotor analogy between our perception of time and interaction with the physical world, we move through time as we move through space: the future is before and the past behind us. This capacity to move in and with time, with open eyes, had been lost to Varnhagen. In some non-European languages and cultures this visuospatial orientation is not mandatory. For example, a study shows that in Malagasy the past is described as "in front of the eyes," because it is already known, while the future is "behind," and "none of us have eyes in the back of our heads." ${ }_{44}$ Another comparative study conducted in Spain has observed similar patterns in the gestures and time conceptions of different Arabic languages. Although linguistic metaphors in which the future is placed in front exist in Arabic, the majority of Moroccan-born interviewees locate the past in front and the future behind, while most Spanish-born interviewees conceptualise time with the future ahead of them. ${ }^{65}$

This phenomenon touches upon one of the upheavals experienced by Varnhagen; a second one remains. In the first study, it was also noted that it is not people but time that moves: ${ }^{66}$ time figuratively catches up with people from behind. Accordingly, in Malagasy, "Happy New Year" is expressed as: "Congratulations for being reached by the year." ${ }^{67}$ This impression of the reversal of standstill and movement is the second aspect of Varnhagen's predicament. Her experience that the future "streams over our heads from behind" while she remains senseless and motionless, without any possibility of defending herself ("How to defend oneself against this!"), evokes a European icon of historical apocalypse: Walter Benjamin's “Angel of History," created in contemplation of Paul Klee's Angelus Novus (1920). ${ }^{68}$ The angel-historian recognises the past as a sequence of catastrophic events but can neither control his own movements nor change the course of history. He is trapped in the storm, Benjamin adds, that "we call progress"-the same storm that propels us into the catastrophe we presently face, in which things "just go on," ever unchanging. Just as Varnhagen witnesses an apocalyptic downfall of her Enlightenment experience of and agency in time, Benjamin depicts a paralysis of the course of time. All this is akin to contemporary conceptions of temporal experience: to our "broad present," to posthistoire, to posthumanist and catastrophic perspectives of inevitability, and to capitalist discourses of a lack of alternatives.

In contrast to fatalist and eschatological theories predicting the end of time and history, many of which have prevailed for decades, ${ }^{69}$ artworks possess considerable potential for tapping manifold diverse forms of temporal experience and opening up historical perspectives. And they do so in conjunction with popular media. Critical art today is free to explore strategies of fictionalisation and dramatisation, subjectivisation 
and reinterpretation even within genres and formats taken from popular media. Among others, Hila Peleg and Erika Balsom have pointedly criticised postmodernism's reductionist approaches to representation, particularly with regard to newer documentary formats. ${ }^{70}$ While postmodern media theory, for example, celebrated the collapse of conventional concepts of representation as inevitable in posthistory, contemporary art requires a more nuanced examination of the relationship between reality and its signs, its forms of representation, and its documents. Hito Steyerl, also among others, has urged for a reexamination of the question of how images and documents contribute today to the reconstruction of reality. ${ }^{71}$ This is all the more important in order to counter the reality effects of mass media "bubbles" and postfactual revisionism, which thrives on the abrogation of all claims to veracity.

Artworks not only stage contemporary polychronic experiences but also actively contribute to their conception and development, operating within the wider context of society, ethics, and politics. As Pamela M. Lee writes, in light of the escalation, acceleration, and expansion of the art world into economic, political, and social realms (in which she also observes a "dilution," since these realms, in turn, increasingly align with the art world), the key question is where and how artworks engender visibilities. ${ }^{72}$ Depicting specific topicseven if indisputably "political," "topical," or "relevant" - is not the only decisive factor for a critical artistic historiography, and neither is the use of anachronic strategies. The question is rather how artworks perform within history's (and their own historically situated) social, ethical, and political entanglements. Artistic historiography is positioned right in the heat of contemporary social and political conflicts, and touches upon core questions of how history is conceived, unlocked, and activated by and for all its potential actors.

\section{The Historiographic Turn in Contemporary Art}

History offers much that is acutely relevant for art, increasingly so as it operates under mounting social, political, and ethical pressures. This is underscored by a growing readiness to perceive artworks from the perspective of historiography-indeed, to speak of a "historiographical turn" (Dieter Roelstraete). Theoretical conceptions of contemporary art ascribe a fundamental role to history and historicity: "The full normative sense of the term contemporary art," Juliane Rebentisch writes, "consists in the fact that it is meant to make our historical present present to us."73 Most theoretical studies of contemporary art stress the importance of its relationship to history-its historicity. Important aesthetic criteria are developed in response to its capacity to advance the theoretically weak designation "contemporary art" both aesthetically and philosophically_to revalue the purely descriptive "contemporary" as "contemporaneity" in the sense of participation in the present. ${ }^{74}$ Along with these developments, the philosophy of history (long a disparaged field) ${ }^{75}$ attains new importance.

But here, too, the ability of art to develop "its own time" 76 is decisive. For in contrast to the "Il faut être de son temps" of modernism, the "contemporaneity" of contemporary art is an anachronic fiction: it does not denote the consonance of art and zeitgeist but instead has a distinctly disjunctive note. According to Giorgio Agamben, contemporaneity means living in and outside one's time simultaneously, which opens up one's own present to the conjunctive: to the potentialities and contingencies of the present as well as to the limits of fully understanding it. ${ }^{77}$ Agamben characterises the paradoxical cognitive capacity of this untimely contemporaneity as one that is not "blinded by the lights" of its own time but instead turns to its "obscure" parts-its untimeliness and "anachronism." 78 


\section{Introduction}

A different approach to the disjunctive nature of the contemporary is offered by postcolonial concepts, which aim at a critical global expansion of conceptions of time. Thinking about contemporaneity thus leads to the core question of how global cultures and identities relate to each other in a time of shared presence: "The world's inhabitants have at last become truly contemporaneous, and yet the world's diversity is recomposed every moment; this is the paradox of our day." ${ }^{79}$ Heterochrony is at the foundation of shared contemporaneity in the global present. Shuddhabrata Sengupta of Raqs Media Collective describes this state as "shared inhabitation of time," a notion that is more directly related to real social conditions than to the abstract term "contemporaneity" that is prevalent in the theoretical discourse of the global North. Sengupta refers to the term "samay," which is used in Sanskrit and other Indian languages to connote "the ability to perceive that someone is standing with you. So in a sense the frame that you are in is already filled with the presence of others and what they bring to life." This entails a sense of the different temporal paces and directions of the global present that encompass conceptual as well as physiological, subjective as well as political dimensions, which in turn must be integrated into everyone's temporal experience:

So much so that even within the body itself, within a single individual, exist different registers and different kinds of velocities. The velocity of waking up in the morning is different from the velocity of being exhausted after a day's labour, and those are two different registers of contemporaneity that even occur within a single individual. ${ }^{80}$

But instead of abandoning history altogether in the face of its obvious disintegration, Peter Osborne has developed a complex philosophical concept for contemporary art that focusses on its temporary disjunctions to strengthen its position. Hence, "con-temporaneity" refers to the geopolitically antagonistic coexistence of diverse social entities and diverse times: "a coming together of different but equally 'present' temporalities or 'times', a temporal unity in disjunction, or a disjunctive unity of present times." 81 It is the socially and politically significant task of art as an agent of contemporaneity to contribute to this speculative unity in disjunction; as Osborne summarises the historical task of contemporary art, along these very lines: "The coming together of different times that constitutes the contemporary, and the movement across social spaces that make up the transnational, are the main axes along which the social meaning of art is to be plotted today." 82

Forging transnationality and transhistoricity, the political significance of art lies in the creation of new social spaces and subjects ("speculative collectives") as its imagined recipients and coproducers. ${ }^{83}$ This significance is closely intertwined with art's historiographical function. Osborne develops a pointed, sometimes polemical rejection of the concept of memory, which for many decades has been a key term in cultural studies. Accompanying the discussion about the impending loss of history, memory, as first developed by Maurice Halbwachs, was soon meant to counterbalance history, and quickly became a guiding metaphor for a wide range of different cultural concepts of different political bents. Subjective recollections, oral histories, and other individual historical sources were combined to form the complex of an interpersonal but individually affective culture of memory that would contribute to the social anchoring of global subjects in an age of acceleration and communication technology. ${ }^{84}$ This concept of memory was decidedly positioned against history, which was rejected as an objective, impersonal institution long alienated from present concerns. The concept of collective memory seemed 
to offer an alternative and better way of linking individuals with their past, especially in view of the demise of the great teleological history of modernism. Compared to history, which Pierre Nora, for one, considered mere "reconstruction," memory was "life," "a perpetually actual phenomenon, a bond tying us to the eternal present." ${ }^{\circ 5}$

Nora's concept was readily absorbed by art theory, seeming well suited to do justice to the subjective, fragmentary, affective character of artistic engagements with the past as well as to the intertwining of memory and identity politics so common since the 1990s. Especially in German-speaking countries, which were still busy struggling with the question of how to approach their fascist past, Jan and Aleida Assmann's writings provided impulses to connect memory and identity, proposing the construction of a cultural (collective) memory as a "connective structure of common knowledge and characteristics-first through adherence to the same laws and values, and second through the memory of a shared past." 86 The socio-political significance of this discourse visibly unfolds within the two possible metaphors expressed, respectively, by the terms "recollection" and "memory": the first describes a repository or storehouse of the past; the other a continuous rewriting of memory on the ever-changing wax tablet of "memoria." ${ }^{87}$ Critical readings were able to merge both aspects. The renewed appreciation of collective memory led to an ethical reevaluation of confrontations with the past, with important connections to writing the history of the Shoah and to new histories driven by postcolonial, feminist, and civil rights movements.

As a tool to oppose generalising universal histories, the concept of memory remains necessary and impactful on current discourse. During an age of global migration, it makes sense to tie the experience of history to dispersed subjects rather than to national or otherwise centralised institutions. Queer theory regularly expresses reservations about historiographical concepts; memory still seems to promise a better space within which to describe individual, nonnormative relationships to the past. ${ }^{88}$

In artworks dealing with history, therefore, the use of memory discourses is still omnipresent as a means of expressing subjective references to the past. But if examined closely, memory has been subjected to fundamental re-readings ${ }^{89}$ and transformations. A random but telling example is a call to "rescue the past" through a "de-privatized, de-nationalized structure of collective memory," jointly written by artist Emily Jacir and scholar Susan Buck-Morss. ${ }^{90}$ This suggests a reinterpretation of "collective" memory along the lines of Walter Benjamin's materialistic history that runs directly contrary to its original meaning. Memory is only politicised if it is put into the context of historical discourse. It seems, then, that the relationship between the two concepts is slowly reversing in terms of their critical potential, as attested by the growing criticism of memory discourse and the growing appreciation of history as a cultural concept in recent years. Criticism has especially been voiced against the culturalisation and anthropologisation of memory as a construct of cultural theory, as this compilation of some of its pitfalls shows:

The reification of bourgeois subjectivity in the name of postmodernism; the revival of primordialism in the name of postcolonialism; the psychoanalytic slide from the hermeneutics of suspicion to therapeutic discourse; the privatization of history as global experiences splinter into isolate chunks of ethnoracial substance; the celebration of a new ritualism under the cover of historical skepticism [... .] Even when advertised as a system of difference, memory gives us a signified whose signifiers appear to be so weighty, so tragic-so monumental-that they will never float free. $^{91}$ 
This critical tirade is directed against reactionary, antirationalist campaigns confronting historical scholarship and is echoed by warnings against the use of memory "as a therapeutic alternative to historical discourse" 92 in art-theoretical debates. And now we have reached a vantage point from which to look at Osborne's radical rejection of memory as a concept for critical art precisely because it is a misinterpretation of historical experience: "A philosophically naive view of memory is one of the main barriers to the production of a critical art." 93

According to Osborne, this naïveté manifests in three main ways: in neglecting the constructed character of artistic representation; in reducing history to the representation of past events; and in perpetuating a set of relationships among individual subjectivity, social subjects, and history that assigns art to reclaiming eroded intersubjective experiences. ${ }^{94}$ In his view, art that seeks to convey the past as individual experience or memory leads directly to political and aesthetic dead ends.

Osborne's criticism urges a comprehensive reconception of artistic historiography, which makes a closer look at his argumentation worthwhile. His first observation is that memory and remembrance are often staged as authentic bits of reality (and identity politics), while aspects of artistic creation and the art-institutional context-the fact, in short, that these are artworks—are downplayed. ${ }^{95}$ In some case, exhibition spaces turn into sites of artificially maintained pieces of subjectivist historical experience, without any reflection on how these retrospections are created in the first place.

Osborne's second critique concerns how memory discourse is, quite counter to its original intentions, directed only towards the past, suggesting, moreover, that it alone can grant access to history: "History is only 'real,' or 'lived,' on this view, as memory." 96 Historical experience is equated with recollection, remembrance, and testimony, when in fact it can only emerge through the interweaving of past, present, and future. To make this point, Osborne refers to Reinhart Koselleck's cognitive concepts of "space of experience" (Erfahrungsraum) and "horizon of expectation" (Erwartungshorizont) as the basis of historiographical thinking-categories that connect each individual uniquely to past, present, and future. ${ }^{97}$ Because of the respective ages (as well as genders, cultures, and social positions) of individuals, their historical perspectives will differ and be "fractioned" in a manner akin to contemporary polychronic experience. ${ }^{98}$ Past and future are intertwined but are not "simple counterconcepts; rather, [they] indicate dissimilar modes of existence, from whose tension something like historical time can be inferred." ${ }^{99}$ This productive tension is fundamental to the epistemology and experience of history. It emerged during the period of upheaval around 1800, which with "history" as a new collective singular opened up the horizon of expectations of a new age, marked by a series of interconnected convictions that the future would bring something new, that this development would accelerate (for the better), and that history could be planned, controlled, "made." 100 Although this set of ideas has since fallen into crisis, the epistemological categories of experience and expectation exist, as do their tensions, indicating "an anthropological condition without which history is neither possible nor conceivable." ${ }^{101}$ Compared to this fractured—but open—polychronic concept, memory culture indeed seems to offer only limited access to historical experience.

Finally, Osborne's third critique is directed against a concept of historical experience that has been crumbling now for some time. He describes memory culture as fostering representations of the past via models of (inter)subjective experience that suggest a coherent network of historically exemplary subjects, communities, and (historical) processes, all of which may be aesthetically experienced and communicated. Along these lines, one may well question the success of the documentary, with its potential to produce 
spectacular moments of authenticity, identity, and affect, and to construct entirely artificial aesthetic entities suggesting a universal global community. According to Osborne, one of the main tasks of critical art should lie precisely in conceiving anew those subjects of history long lost through its ongoing transformations. Art never addresses clearly fixed subjects. Instead, it can create "speculative collectives" corresponding to new geopolitical, technical, and geoeconomic reorganisations as its imagined recipients or producers, who are sorely needed to rethink both art and history. Just as ambitious as the task of bringing today's disjunctive and heterogeneous communities and temporalities together is art's task to create communities, times, and spaces in which it can be experienced. ${ }^{102}$

\section{Shared Contemporaneity in the Global Present}

The intersection of historical, spatial, and temporal perspectives in historiography (superseding Nietzsche's well-known juxtaposition of "world" and "history") has traditionally led to concepts such as the history of mentalities, ${ }^{103}$ before anthropology and ethnography began to make their mark. The European concept of modern history has been decisively shaped by the denial and repression of its geopolitical dimensions. ${ }^{104}$ Dipesh Chakrabarty has trenchantly described how global expansion disrupts this form of historical thought: "Subaltern pasts are signposts of this border [constituted by the practices and discourses that define the modern]. With them we reach the limits of the discourse of history." 105 This touches upon how history is imagined-as a structure and concept of time-and also upon the fundamental question of how to represent the nameless, the dehumanised, the subaltern, the silences in the archive: how and in whose name to write, as it were, the impossible histories of those who have neither voice nor speech. ${ }^{106}$

The disciplines of anthropology and ethnology, which emerged in the late nineteenth century, did little initially to counter Eurocentric perspectives of history. ${ }^{107}$ Instead of disrupting or discriminating Enlightenment history geopolitically—or questioning its premises-both newer disciplines were at first subjected to its logic. In The Savage Mind, Claude Lévi-Strauss neatly fits ethnology into the system of history:

One of them unfurls the range of human societies in time, the other in space. And the difference is even less great than it might seem, since the historian strives to reconstruct the picture of vanished societies as they were at the points which for them corresponded to the present, while the ethnographer does his best to reconstruct the historical stages which temporally preceded their existing form. ${ }^{108}$

This quotation summarises the potential of ethnology as well as its failure. Starting from a critique of this time- and spaceless structuralism, Johannes Fabian has comprehensively analysed the ill-advised chronopolitics of modernity:

The expansive, aggressive, and oppressive societies which we collectively and inaccurately call the West [...] required Time to accommodate the schemes of a oneway history: progress, development, modernity (and their negative mirror images: stagnation, underdevelopment, tradition). In short, geopolitics has its ideological foundations in chronopolitics. ${ }^{109}$

Instead of suspending this world-ordering temporal logic, ethnology established itself as "allochronic" discourse: perpetuating the Hegelian denial of history to non-Western cultures, ethnology placed its object—“othered" peoples—outside history, disputing their 
contemporaneity. Fabian describes the rhetorical strategy of the "ethnographic present" as locating these "others" in a temporality different from that of the ethnographer. ${ }^{110}$

Against the background of such considerations, Osborne's demand for the design of speculative collectivities through art becomes even more urgent: What are the subject formations produced by different concepts of history? As we shall see, several of the artworks discussed in this book attempt to create global contemporaneity by interweaving different media and audiences as well as by evoking diverse concepts of time and history. A purely additive extension of Western history that pluralises historical narratives and integrates minority histories-as is often, and importantly, undertaken in art-does not fundamentally address this problem. Rather, history requires fundamental deconstruction and renewal, possibly through experimental and artistic methods, which Chakrabarty recommends also for academic history writing. As he writes, insight into the limits of Western history has

led to a series of attempts to craft histories differently, to allow for a certain measure of equality between historians' histories and other constructions of the past. Some scholars now perform the limits of history in various ways: by fictionalizing the past, experimenting to see how films and history might intersect in the new discipline of cultural studies, studying memory rather than just history, playing around with forms of writing, and other similar means. ${ }^{111}$

These methods are intended to reconceptualise history outside the normative system anchored in the institutional and epistemological logic of Western modernity, in which art participates. Art can generate experimental ways of recording and conveying history, opening up spaces of imagination and contributing to new ways of structuring and experiencing time and history. It is an instrument ideally suited to developing and testing new synchronic, polychronic, and anachronic concepts. With its aptitude to aesthetically produce its "own times," art may be able to unlock the potentiality of history and historical writing in equal measure.

All these considerations are based on the conviction that, as shown brilliantly by Reinhart Koselleck, history is not a fixed entity but is socially negotiated on the basis of highly diverse concepts and structuring devices. Koselleck's studies on the historicity of time and historical thought are fundamental to this book. They show that history is a flexible and transformable concept, subject to change, and that its current transformations indicate less its final demise than that of the modernist structure that has been essential to history since 1800. Artistic historiography may make its own as well as history's constructed nature visible, as art that deals with history works with devices structuring history: writing, film, painting, photography, performance, sculpture, television, video, and so forth.

History is always situated within and staged by specific media. Newer information and entertainment technologies have had a large share in transforming our contemporary experience of history, and recent audiovisual artworks have repeatedly explored this phenomenon. Sven Lütticken describes the contribution of the "moving images" of film and video to contemporary forms of history writing as an "intervention in the very fabric of the res gestae and the historia rerum gestarum alike-in both the production and reconstruction of history," progressively superseding in importance the hitherto normative connection of writing and history. ${ }^{112}$ The following chapters include discussions of several audiovisual artworks, with a focus on their recent transformation in the course of the increasing integration of performative procedures. For their analysis I have drawn on theoretical approaches by Vivian Sobchack, Kate Mondloch, 
Ursula Frohne, and others. ${ }^{113}$ The importance of the effects of image/sound complexes in contemporary communication and dissemination devices is, however, also explored in other artistic media, as illustrated in Tacita Dean's large-format photogravures The Russian Ending (2001), in Dierk Schmidt's painting series SIEV-X (2001-2005), and in Liam Gillick and Philippe Parreno's installation The Trial of Pol Pot (1998). ${ }^{114}$

This book focuses on the question of how artworks negotiate current transformations in the collective perception and experience of history. I have already stressed that art is not considered, in this study, in opposition to academic history-which is, furthermore, hardly the most powerful actor in the complex socially and politically contested terrain of history today. Nevertheless, artistic and scholarly historiography often intersect and share both a historiographical ethos and an involvement in contemporary truth politics.

That said, explicitly "nonacademic" or "nonscholarly" instances of art exploring history are just as important as those that take more professionalised, scholarly approaches. Art does not require legitimation or contextualisation by academic history. Dieter Roelstraete has developed an analogy of artistic historiography "with a shovel" to describe an "amateur-archaeological" approach focusing on the practical, on craftsmanship, on coincidence, and on a certain readiness to find only broken, incomplete fragments. This image carries with it the specific pathos of stirring up hidden, "buried" truths that must be unearthed to reveal themselves in the enigmatic evidence of material remains. ${ }^{115}$ Archaeological practice is indeed a fruitful analogy for artistic historiography, especially for archivological approaches.

Even if the respective objectives, concepts, and instruments of academic and artistic historiography differ from each other-even if they have often, and productively, been conceived in mutual rejection-theoretically ambitious historical scholarship has been a constant inspiration to contemporary art. I cannot agree with the assertion that "the methods and principles of historical scholarship play hardly any role in the artistic treatment of historical events." 116 Both art and scholarship are connected, to a certain extent, by comparable methodological steps: heuristics, criticism, interpretation, and presentation. The first chapter of this volume examines the historical evolution of this close and fraught entanglement, with a focus on the instruments, premises, and parameters of history as it emerges as a discipline. In particular, the theoretical concept of "apodeixis" may productively be related to contemporary artistic practices. From this starting point, the chapter proceeds to examine the writings of two well-known critics of historicist methods, Walter Benjamin and Siegfried Kracauer, whose experimental approaches to history-leading, in both cases, to anachronic concepts-are important reference points for contemporary art.

The second chapter explores the medial expansion and technical transformation of history, as well as its theoretical repercussions, by means of a study of Andrei Ujica's and Harun Farocki's 1992 film Videograms of a Revolution. Dominating artistic-and other forms - of historical representation over nearly a century, the documentary has been fundamentally transformed by the technological developments of video and the World Wide Web. This has led, as I will argue, to an entirely new relationship between subjects and history that structures artistic and popular approaches today.

The third chapter critically confronts our auctorial protagonist, the artist-historian, in three subchapters. A study of several works by Tacita Dean approaches a question often discussed in the theory of historiography, namely how deeply historians should be ingrained in their own time. Dean's self-creation presents herself as researching, recounting, and performing history-located, like the historical events and materials that inform her work, both within and outside her time. Erika Tan confronts the highly problematic 
but widespread practice of "speaking for others" in her comprehensive art project on historical Malay weaver Halimah binti Abdullah, making transparent the limitations of historical and national classification categories that arise whenever "forgotten" personages are reintroduced into the historical canon. Bouchra Khalili's film Foreign Office, on the other hand, deliberately works with methods of desubjectification developed on the basis of Pier Paolo Pasolini's "free indirect speech" when recounting history. Her historical narrative is not dedicated primarily to conveying voices lost in history but to visibly generating new material. As this chapter shows, artistic histories are vital for a critical examination of the historian's auctorial persona, since they build upon a long-established tradition of authorship criticism in the arts and in ethnography.

The fourth, fifth, and sixth chapters are roughly structured along some basic steps in historiography: "Archiving, Recording," "Showing/Telling/Picturing," and "Performing." Chapter 4 discusses Walid Raad's The Atlas Group Archive as well as several films and texts by Matthew Buckingham in order to address the factual and fictional nature of source material-which is, after all, the foundation of historical research. This chapter considers the archive of history, that is, the what enters into historiography-as-archive and along what categories of knowledge access to it is structured. The ensuing study of Dierk Schmidt's painting series SIEV-X explores the foundation of historical representation, especially if operating without reliable visual source material. Chapter 5 discusses the role of witness testimonies, which, of course, are central to history writing, analysing works by Amar Kanwar, Omer Fast and Zarina Bhimji. Operating from different vantage points, these works shed light on the pitfalls and aporias of representation and narration as well as on how memories migrate temporally and globally-and under which conditions they solidify into seemingly reliable statements. A critical review of several performance and film works by Wendelien van Oldenborgh and Apichatpong Weerasethakul concludes this series of chapters, investigating the question of how history is performed and brought to life. Both artists work, in part, with modified forms of reenactment that enable identification just as well as disidentification with historical stories and personages.

The ensuing three chapters turn from the individual methodological steps of historiography to current uses of several of its instruments: counterfactual historiography; the juridification of history; anachronic and anachronistic concepts of time. Counterfactual historiography - that is, the telling of history through writing and other media that consciously contradicts established courses of history-is an inexhaustible arena for artists working with imagination and utopia. With a comprehensive renewed appreciation for visual imagination, Arjun Appadurai suggests that artworks are of great importance precisely for this reason:

The image, the imagined, the imaginary-these are all terms that direct us to something that is critical and new in global cultural processes-the imagination as a social practice. No longer mere fantasy (opium for the masses whose real work is somewhere else), no longer simple escape (from a world defined principally by more concrete purposes and structures), no longer elite pastime (thus not relevant to the lives of ordinary people), and no longer mere contemplation (irrelevant for new forms of desire and subjectivity), the imagination has become an organized field of social practices, a form of work (in the sense of both labor and culturally organized practice), and a form of negotiation between sites of agency (individual) and globally defined fields of possibility. [...] The imagination is now central to all forms of agency, is itself a social fact, and is the key component of the new global order. $^{117}$ 
Appadurai's conclusion is enlightening: the imaginary is not opposed to reality but can guide action and lead directly, if not into its actual realisation, at least into a social reality. The scenarios of past and future that unfold in artworks engaging with history are part of the social imaginary (Cornelius Castoriadis), especially if, as in Michael Blum's and Yael Bartana's works, fictional characters and movements are inscribed into history and politics until they can hardly be distinguished from reality.

The eighth chapter brings works by Philippe Parreno and Liam Gillick, Andrea Geyer and Hiwa $\mathrm{K}$ into view in order to consider contemporary art and politics under the added weight of their juridification. Contributing to the debate on the truth politics of history as elaborated in Chapter 5, I consider how reality is modified by the specific historiographical, epistemological, bureaucratic, and legal politics of veracity, authenticity, and aesthetics. While anachrony and anachronism are discussed repeatedly in this book-as they are employed in numerous artworks-Chapter 9 reexamines them in depth in an analysis of works by Deimantas Narkevičius and Kader Attia. Both artists explore different forms of anachrony and anachronisms in their works, thereby creating constellations that challenge historical classifications. In view of the extensive thematic complex of history in contemporary art, it is perhaps important to point out the obvious: namely, that no work can be reduced to a particular topic or aspect of historiography, and even if most artworks addressed here are discussed only in terms of specific facets, numerous cross-references and relationships exist and emerge among them.

The final chapter investigates how history has expanded in scale during the Anthropocene, an expansion that calls into question the relevance and tenability of the humanistic, agential concept of history discussed in this book, with its problematic legacies of European Enlightenment thinking and nineteenth-century historiography. By way of conclusion, I return to a discussion of the current waves of posthistoire and posthumanism furthered by the Anthropocene discourse, arguing that the specific potentials and qualities of artistic historiography as presented in this study are needed more urgently than ever. But we begin with a closer look at the historical complex of nineteenth-century historiography and its remarkably unstable position at the intersection of art, science, politics, and philosophy that forms the fundament for exactly these potentials and qualities.

\section{Notes}

1 White, "The Burden of History," 134.

2 In art history discourse, the term "historiography" often describes the history and practice of art-historical writing. In this book, I use the term "artistic historiography"-the "writing" of history undertaken by artworks that study and represent history as well as theoretical reflection upon it-alongside the simple term "history," which is as frequently used to describe the course of past events as it is the practice of writing history. See Bentley, Companion to Historiography; Jordanova, History in Practice. I do not employ the term "historiology," which is occasionally used to denote the "work done by historians" and describes the professional toolkit of history rather than its philosophical foundation, see Boyd, Encyclopedia of Historians, 1:539-43. While the German historiographical tradition offers a rich body of theory, the term Historiographie (historiography) is not clear-cut either: some scholars tend towards a definition limited to academic or professional practice (Muhlack, "Theorie und Praxis der Geschichtsschreibung," 607-20); others argue for a broader understanding, taking into account the term's multifaceted genealogy (Fulda, Wissenschaft aus Kunst).

3 Intensive theoretical debates about the use of the term "contemporary" in history and historiography have appeared in a vast number of exhibitions, conferences, and publications impossible to fully list here. At times, my desk was stacked with book titles including "history" and "posthistory"; "no future" and "futurology"; and so forth. I have especially profited from 
the following titles: Karlholm and Moxey, Time in the History of Art; Lageira, L'art comme histoire; Blocker, Becoming Past; Roelstraete, The Way of the Shovel; Lütticken, History in Motion; Leeb, "Flucht nach nicht ganz vorn"; Godfrey, "The Artist as Historian"; Rifkin, "Face à l'histoire"; Bann, "Face-to-Face with History." Among the many important exhibitions on art and history, Roelstraete's The Way of the Shovel, Museum of Contemporary Art Chicago, 2013, Yilmaz Dziwieor's Whose History?, Kunstverein Hamburg, 2009, Report on Probability, Kunsthalle Basel, 2009, and the four most recent documenta exhibitions, Kassel, 2002, 2007, 2012, 2017, have been especially helpful for my research.

4 My research thus integrates artworks also discussed in the contexts of memory, identity, and the archive; the relationship between the fictional and the documentary; and the performative, ethnographic, and ethical turns in contemporary art.

5 The view that artistic historiography is primarily engaged not with representing history itself but rather with reflecting on historiography's conditions and constraints is often expressed in theoretical writing, for example: "The emphasis that numerous visual artists are now placing on history is part of a long tradition (consider history painting, for instance), but we are also seeing a break with that tradition. These artists are not out to depict historical events or comment on them, but to reflect on the representation of history." See the introduction to Van der Stok, Gierstberg, and Bool, Questioning History, 9. (Emphasis here and in all subsequent quotations is original unless otherwise noted.) I show, instead, that the artworks under consideration here work in much more complex ways to integrate representation and reflection.

6 For an early critical and context-sensitive assessment of self-reflection strategies, see Polan, "A Brechtian Cinema?"

7 Rancière, "The Ethical Turn of Aesthetics and Politics"; Möntmann, Scandalous; Beshty, Ethics.

8 Keith Jenkins has contradicted the idealist notion that a sense of history is indispensable as a foundation for ethical action. In his view, "history" is no more than a construct made up by historians; postmodern theory provides sufficient basis for a new ethical ordering of the present. Jenkins, Why History?

9 Holert, "Für eine meta-ethische Wende."

10 White, "The Burden of History," 125, predicts that history will fade into insignificance if it continues to ignore current scientific and artistic developments.

11 For a thorough criticism of historicist precepts, see Walter Benjamin, "On the Concept of History" (also commonly known as "Theses on the Philosophy of History"): "The historical materialist leaves it to others to be drained by the whore called 'Once upon a time' in historicism's bordello." Benjamin, “On the Concept of History,” 396 (thesis XVI). Benjamin's rejection of academic history writing - its positivisms and its tendencies to naturalise and to frame history in terms of "understanding" and "empathy"-is radical even within the critical debate on historicism in the 1920s and 1930s.

12 Georg G. Iggers, for example, shed light upon the pressure upon the emerging humanities to conform to positivistic principles, especially given their uncertain artistic-philosophical genealogy. See German Conception of History, esp. 124-33.

13 Grafton and Rosenberg, Cartographies of Time.

14 Ankersmit, "Trauma and Suffering." However, as Ankersmit rightly points out, these experiences of trauma have not prevented Western cultures from bringing traumata to large parts of the world in turn.

15 Wilde, The Artist as Critic, 359.

16 See several statements by Ron Howard in press conferences for his film Rush. Jürgen Schmieder, "Fiktion verschmilzt mit Fakten."

17 Buckingham, "Muhheakantuck," 30.

18 Roelstraete, "Wessen 'Ende der Geschichte'?," 78; Roelstraete, "After the Historiographic Turn"; Roelstraete, "2014 remix"; Dziewior, "Keine Atempause."

19 For an enlightening discussion of the connection of artistic historiography to the philosophical ethos of "making history," see Draxler, "Was tun?"

20 Dirks, "History as a Sign."

21 See Gierstberg, "The Big History Quiz." On the wide range of popular history formats and their relationship to academic history writing, see De Groot, Consuming History; Korte and Paletschek, History Goes Pop. 
22 A. Assmann, Is Time out of Joint?

23 "There cannot but be much that is deplorable and reprehensible in a cultural form of image addiction which, by transforming the past into visual mirages, stereotypes, or texts, effectively abolishes any practical sense of the future and of the collective project." Jameson, "The Cultural Logic of Late Capitalism," 28, 46. I do not intend to sweepingly reject Jameson's diagnosis but I do ask for the nuanced application it deserves.

24 However, concern for the contamination of art by the culture industry as exemplified by Fredric Jameson constitutes only one branch of postmodern cultural theory. For a more optimistic assessment gained through a closer examination of 1980s art, see Hutcheon, Politics of Postmodernism. At the same time, important approaches to appropriation and representation emerged in the writings of Craig Owens and Douglas Crimp, breaking ground for the current understanding of artistic practice as part of a larger cultural economy. For a comprehensive discussion of postmodernist art theory, see Lee, New Games.

25 These interpretations survive in a number of exhibitions and texts. See, for example, Poivert, L'événement.

26 Beckmann et al., "Making History," 10.

27 Gumbrecht, Our Broad Present; Gumbrecht, After 1945: Latency as Origin of the Present.

28 Hartog, Regimes of Historicity.

29 Jameson, "The Aesthetics of Singularity."

30 Laclau, "The Time Is out of Joint," 91.

31 For research on the future, see Witzgall and Stakemeier, Die Gegenwart der Zukunft. Among the numerous publications on the end of the future, see Berardi, After the Future; Fisher, Ghosts of My Life.

32 Augé, The Future.

33 Berardi, After the Future.

34 Brauner, Risikolandschaft der Zukunft, 11, cited in Horn, Future of Catastrophe, 6.

35 Horn, Future of Catastrophe, 7, referring to fragment no. 35 from Walter Benjamin's "Central Park," 50: "The concept of progress is to be grounded in the idea of the catastrophe. That things 'just go on' is the catastrophe. It is not that which is approaching but that which is. Strindberg's thought: Hell is not something which lies ahead of us,-but this life here."

36 As illustrated by the "TINA Principle" - short for "There Is No Alternative," attributed to Margaret Thatcher-which, according to David Graeber, is responsible for capitalism's lack of fundamental technical or logistical innovation. See Graeber, "Of Flying Cars."

37 Khatib, "No Future," 648.

38 Ibid., 641. On the fraught relationship between time and space in modernist thought, see Barrows, Time, Literature and Cartography.

39 Ibid., 644.

40 Derrida, Specters of Marx, 25, 140.

41 Rancière, "Le concept d'anachronisme" and Names of History, esp. chapters "The Excess of Words," 24-41, and "The Place of Speech," 61-75. Rancière did not remain terminologically congruent in his differentiation of anachrony and anachronism in later writings (and thus the term "anachrony" did not become fixed, as is shown, for example, by Georges Didi-Huberman's description of similar observations as "anachronism," see n49 below). Conceptually, however, the distinction remained fundamental, as attested by its connections to key lines of thought in Rancière's "La Nuit des prolétaires: Archives du rêve ouvrier" (1981) and "Le Partage du sensible: Esthétique et politique" (2000). Along with the concept, the term "anachrony" has been taken up by Alexander Nagel and Christopher S. Wood in "Interventions" and Anachronic Renaissance, with references to this useful article on the cultural history of anachronism: De Grazia, “Anachronism.” See also Kernbauer, Kunstgeschichtlichkeit.

42 Rancière, "Concept of Anachronism," 47.

43 Koselleck, "Geschichte, Historie"; Koselleck, Futures Past. This approach is set against perceptions of heterochrony as catastrophic, as presented by Ernst Bloch or Karl Mannheim. See Uhl, "Gebrochene Zeit?"

44 White, Metabistory.

45 See Robert Doran's introduction to White, Fiction of Narrative, xxxi. Droysen's concept is even more radical since he attributes the anachronic nature of historiography to aspects not of narration but of research.

46 Karlholm, "Considering Efficient Art History," 16-18. 
47 Nagel and Wood, "Interventions"; Nagel and Wood, Anachronic Renaissance; Kernbauer, "Anachronic Concepts"; Karholm and Moxey, Time in the History of Art; Nowotny, Time; Nowotny, "Life in the Digital Time Machine" (I am indebted to Helga Nowotny for providing me with this unpublished manuscript).

48 Didi-Huberman, Surviving Image; Didi-Huberman, Devant le temps; Didi-Huberman, "Before the Image." Didi-Huberman uses the term "anachronism” to signify "untimeliness," which opens up similarities to Rancière's use of "anachrony."

49 "Tradition, for Warburg, was not a stream on which events and people are born along. Influences are no matter of passive acceptance but demand an effort of adjustment, "eine Auseinandersetzung,' as Warburg put it, which includes that of the present with the past." Bing, “A. M. Warburg," 310.

50 Walter Benjamin cited the original French version. See "On the Theory of Knowledge," in Benjamin, The Arcades Project (N19a,1), 487. Benjamin drew upon Focillon for "On the Concept of History" but did not make note of his concept of the artwork as a rupture in the stream of time, which would have offered various analogies to Benjamin's own concept of "Jetztzeit." Focillon, Vie des formes, 24.

51 Didi-Huberman, Devant le temps, 13.

52 Damisch, The Judgement of Paris, 145-46. On Damisch's model of anachronism, see Mengoni, Anacronie.

53 See the comprehensive analysis by Buchmann, "Putting History to the Test."

54 Ward, "Art in the Age of Visual Culture." See also Kernbauer, "Close Encounters."

55 Agamben, "Time and History," 91.

56 Khatib, Teleologie obne Endzweck, 496.

57 On the standardisation and synchronisation of time in modernity, see Kern, Culture of Time and Space; Ogle, Global Transformation of Time.

58 Agamben, "Time and History," 104.

59 Deleuze, Cinema 2; see Rajchman, "Deleuze's Time, or How the Cinematic Changes our Idea of Art," in Leighton, Art and the Moving Image, 310.

60 For the contribution of phenomenology, see Husserl, Consciousness of Internal Time; Dainton, "Temporality: Philosophical Perspectives."

61 Eagleman, “Temporality: Scientific Perspectives”; Eagleman, "Human Time Perception”; Eagleman and Holcombe, "Causality and the Perception of Time." See also Raqs Media Collective's artistic engagement with recent research in physiology: Gaensheimer, Raqs Media Collective.

62 Rahel Varnhagen to Karl Varnhagen von Ense, dated "Frankfurt am Main, Wednesday, October 11, 1815, half past four in the afternoon," Varnhagen, Briefwechsel mit August Varnhagen von Ense, 355. Varnhagen was upset. The night before, three drunken Russian soldiers had hammered on her door. She was worried about her personal safety, and, as she wrote, reading a poem by Goethe had done the rest.

63 Kernbauer, "With Your Back to the Future."

64 Dahl, "Future Comes from Behind," 198. The Maori also describe the past as "the days in front" and the future as "behind." See Sahlins, Islands of History, 55-56.

65 De la Fuente et al., "Your Past Is in Front of You."

66 However, "passive" constructions also occur in European languages, as illustrated by the French word for future, avenir (that which is to come), even if the Western understanding of time typically is conceived along perceptuomotor lines.

67 Dahl, "Future Comes from Behind," 199. Also, Madagascan thinking tends toward an event-based sense of time focusing on the present: time only passes if something happens.

68 Benjamin, "On the Concept of History," 257-258 (thesis IX).

69 On the history of the concept of posthistoire, see Niethammer, Posthistoire.

70 Balsom and Peleg, Documentary Across Disciplines, 10-19.

71 Steyerl, "Documentarism as Politics of Truth," with references to Didi-Huberman, Images in Spite of All.

72 Lee, Forgetting the Art World, 2.

73 Rebentisch, "Contemporaneity of Contemporary Art," 229.

74 Osborne, Anywhere or Not at All; Rebentisch, Theorien der Gegenwartskunst; Rebentisch, "Contemporaneity of Contemporary Art"; Agamben, "What Is the Contemporary?"; Smith, Enwezor, and Condee, Antinomies of Art and Culture; Rajchman, "The Contemporary: A New Idea?". 
75 Rohbeck, "Rehabilitating the Philosophy of History."

76 I am referring to Helga Nowotny's appropriation of the physical term Eigenzeit, which may be translated as "proper time" or "own time," for cultural theory. See Nowotny, Time.

77 Agamben, "What Is the Contemporary?," 39-54.

78 Agamben, "What Is the Contemporary?," 45-52; see also Ross, Past Is the Present, 14.

79 Augé, Anthropology of Contemporaneous Worlds, 89, cited in Smith, Enwezor, and Condee, Antinomies of Art and Culture, 10. See also Enwezor, "The Postcolonial Constellation."

80 Raqs Media Collective et al., "Has the Moment of the Contemporary Come and Gone?"

81 Osborne, Anywhere or Not at All, 17.

82 Ibid., 163.

83 Ibid., 195.

84 Huyssen, Twilight Memories, 7, 13-36.

85 Nora, "Between Memory and History," 8.

86 J. Assmann, Cultural Memory and Early Civilization, 3; see also A. Assmann, Cultural Memory and Western Civilization; A. Assmann, Shadows of Trauma.

87 A. Assmann, Cultural Memory and Western Civilization, 146-47.

88 Radstone, The Sexual Politics of Time; Love, Feeling Backward; Freeman, Time Binds.

89 "Memory functions less as an instrument with which to explore the past and more as a theatre in which we restage past events here and now. This restaging is based on selecting and sequencing: a process of narration that becomes the site of contestation in the debate around the value of past events." Matthew Buckingham, cited in Allen, "Interview with Matthew Buckingham," 24. Buckingham elaborated more on this subject at the Slade School of Fine Arts in November 2006. See Godfrey, “The Artist as Historian,” 147.

90 Sauerländer, Emily Jacir and Susan Buck-Morss, 27.

91 Klein, "Memory in Historical Discourse," 144.

92 Ibid., 145.

93 Osborne, Anywhere or Not at All, 191, and esp. the chapter "Memory or history?"; Rebentisch, Theorien der Gegenwartskunst, 193-204.

94 Osborne, Anywhere or Not at All, 193.

95 Ibid., 190.

96 Ibid., 192.

97 Koselleck, Futures Past, 255-76. Koselleck has repeatedly opposed the equation of history and the past, referring to Novalis's understanding of history as a "covert inter-linking of the before and after" composed "from hope and memory." Ibid., 258.

98 Ibid., 269, quoting Friedrich Perthes: "Our time has, however, united in three contemporary, existing generations, the completely incommensurable. The monstrous contrasts of the years 1750,1789, and 1815 dispense with all interim and appear in men now living not as a sequence but as coexistence, according to whether they are grandfather, father, or grandson."

99 Ibid., 261; 260: "[T] he presence of the past is distinct from the presence of the future."

100 This leads to Paul Ricœur's examination of Koselleck's writing, which is just as important to Osborne's conception: Ricœur, Narrated Time, 207-16, on Koselleck's "space of experience" and "horizon of expectation."

101 Koselleck, Futures Past, 257; see also Ricœur, Narrated Time, 214.

102 Osborne, Anywhere or Not at All, 195; Rebentisch, Theorien der Gegenwartskunst, 197.

103 As illustrated by Jules Michelet's remark that "history is, first of all, wholly one with geography." Michelet, History of France, 264. On the extension of the historical sciences by ethnology and anthropology, see Lepenies, "History and Anthropology."

104 Osborne, Politics of Time, 16 (with reference to Michelet, among others).

105 Chakrabarty, Provincializing Europe, 110, and esp. the chapter "Minority Histories, Subaltern Pasts."

106 Hartman, "Venus in Two Acts" and Lowe, The Intimacies of Four Continents.

107 Leeb, Die Kunst der Anderen. On more recent fruitful exchanges between history and anthropology, see Goodman, "History and Anthropology."

108 Lévi-Strauss, The Savage Mind, 256. Lévi-Strauss follows this with a qualification: while ethnology is interested in representing the diversity of social forms and necessarily produces discontinuous systems, history tends to suggest continuity and universality.

109 Fabian, Time and the Other, 144. 


\section{Introduction}

110 Ibid., 80 .

111 Chakrabarty, Provincializing Europe, 106, with reference to critical approaches in recent Indian historiography.

112 Lüticken, History in Motion, 8.

113 Sobchack, Persistence of History; Sobchack, "The Scene of the Screen"; Mondloch, Screens; Frohne and Haberer, Kinematographische Räume.

114 In the interests of concision, I have largely refrained from discussing sculpture and monument (despite the ongoing heated debates on public monuments), as they work with a different set of discourses and fields of reference.

115 Roelstraete, "Field Notes."

116 Beckstette, "Das Historienbild im 20. Jahrhundert," 10.

117 Appadurai, Modernity at Large, 31. 


\section{Art as Historiography}

Art that deals with history is frequently accompanied by the appropriation and/or transformation of familiar popular or academic presentation formats: (artists') books, photographs, films, and videos are its predominant media, both in documentary and other approaches. Fictionalisation, reenactment, and counterfactual history, too, are modes employed by scholarly and art works. Mark Godfrey has explored the connections between these in his essay "The Artist as Historian,"1 which uses the well-known phrase "The artist as ..." to illustrate the ever-expanding range of tasks performed by artists. Godfrey's essay is mainly dedicated to artist Matthew Buckingham, who explicitly deals with the theory and methodology of academic history. With references to the research of Hayden White, ${ }^{2}$ Reinhart Koselleck, ${ }^{3}$ Siegfried Kracauer, and Walter Benjamin, Buckingham explores experimental approaches to history that are of lasting influence on contemporary art. In an art-historical review, Godfrey observes that, generally speaking, conceptual art and appropriation art-even when taking up historical topics and materials-were more interested in questions of representation. He locates a shift only in the 1990s, in the works of Steve McQueen, Santu Mofokeng, Fiona Tan, Anri Sala, Jeremy Deller, and Walid Raad, which, while still making use of conceptualist approaches, explicitly formulated an interest in the exploration and representation of history. While I agree to this observation in principle, it should not be used as a strict art-historical timeline. Important works on history, such as Gerhard Richter's painting series 18 October 1977 (1988) and William Kentridge's animated film series Felix in Exile (1989-99), were committed to their own genealogies (namely, a critique of media and the examination of political memory). ${ }^{4}$ Artistic explorations of history emerge at different moments out of distinct contexts, social urgencies, and interests.

Since the beginning of modernism, the relationship between artistic and scholarly history has been characterised by ambivalences: connected by common interests and, often, methods, practitioners still attempted to remain separate whenever seriously tested. For art, turning to history entailed delving into a field of interest established as a scholarly discipline only in the course of the Enlightenment, initially by way of an expansion of philosophy. History was often viewed as closely aligned to the (visual) arts but, in the course of the trend towards its establishment as a science, tried to emancipate itself from these unwanted ties. This chapter will explore how this close but fraught relationship was constantly negotiated and modified during the nineteenth century, and which roles and functions were ascribed to art within the newly emerging practice of history during this transformative period, when it emerged as an academic ("scientific") discipline. 


\section{Depicting History}

"Art" and "history": both concepts were conceived at the threshold of modernism, around 1800. When history was established as a scholarly discipline, debates on its relationship to the neighbouring fields of philosophy, politics, the "exact" sciences, and art played an important role. A frequent point of departure for these considerations was-and still is today-the double meaning of the term "history," which connotes both past events and their representation. ${ }^{5}$ Nineteenth-century scholars developed different approaches to pacify this friction-laden homonymy, ${ }^{6}$, linking the new discipline either to philosophy or to poetics. For connections to the latter, a classical quotation served as a common reference: Quintilian's "Historia est proxima poetis et quodammodo carmen solutum" (history is closest to poetry and is, as it were, a poem in prose). ${ }^{7}$ In nineteenth-century thought, this could simply imply a recommendation that history should be beautifully or well written, but there were more ambitious approaches as well:

In our language the word 'history' combines both objective and subjective aspects and signifies the historiam rerum gestarum as well as the res gestae themselves, the historical narrative as well as the events, deeds, and happenings themselvesaspects that in the strict sense are quite distinct. ${ }^{8}$

In his Lectures on the Philosophy of World History, Hegel deduces from this oft-quoted observation the necessity that historical narrative give meaning to events. In his opinion, this achievement actually surpassed the competencies of history and was, therefore, to be assigned to philosophy. "Writing history" and "making history," therefore, could be merged in meaningful narratives, bestowing a kind of pseudo-sovereignty-at least on the level of its interpretation-to individuals otherwise powerless against the course of history. ${ }^{9}$

Significantly, history thus did not just entail researching, recording, and reconstructing the past but also creating, shaping, and forming it. It is probably not surprising that these processes came to be attributed to history's artistic aspects as well. In his conception of history (which was of lasting influence as it opened up the discipline to aesthetic processes), Schiller depicted the work of the historian as like that of the artist. Wilhelm von Humboldt developed this approach further in a widely disseminated address to the Academy of Sciences in Berlin, 1821, "On the Historian's Task," ${ }^{10}$ locating the kinship of artistic and historical work in the presentation or depiction (Darstellung) of history rather than its narration. "The historian's task," he began, "is to present what actually happened." 11 While retaining the classical analogy to poetry, his concept was apt to include the visual arts as well:

An historical representation, like an artistic one, is an imitation of nature. The basis of both is the recognition of the true form, the discovery of the necessary, the elimination of the accidental. [...] For it is the greatest virtue of a work of art to reveal the inner truth of forms which is hidden in their actual appearance. ${ }^{12}$

Following Schiller, Humboldt's aim was not to align history to either poetry or philosophy by a focus on historical "narrative" (Erzählung) but to draw an analogy between art and historical "depiction" (Darstellung). Even though he often referred to poetry and poets, his notion of depicting history allowed for a theoretical inclusion of the visual arts as well. According to Humboldt, the historian's basic working principles are 
related to those of the artist, even if the former is more committed to imitating nature than the latter, who is inclined to follow creative imagination. Just like the poet-artist, the historian must

work the collected fragments into a whole. [...] The historian worthy of his title must show every event as part of a whole, or, what amounts to the same thing, must reveal the form of history per se in every event described. ${ }^{13}$

Interestingly, while remaining true to some of his classical sources, Humboldt followed less an idealistic than a naturalistic concept of art (and history), which led to a radical reversal of the Aristotelian subordination of history to poetry (which had argued that history was only concerned with the representation of details, not the whole). ${ }^{14}$ Humboldt considered history's potential to be rooted precisely in its relation to tangible, individual reality, arguing that its truthfulness was threatened by philosophical rather than poetic treatment, since subordination to greater causes impaired a clear understanding of individuals and their actions. He admitted that "all history is the realization of an idea [...] realized by mankind in every way and in all shapes in which the finite form may enter into a union with the idea." But "this idea can be recognized only in the events themselves," and the historian "must take great care not to attribute to reality arbitrarily created ideas of his own." 15 A rejection of speculative philosophical history was essential to Humboldt's conception: history's orientation towards art instead of philosophy would guarantee a strong connection to reality. Summing up, he wrote: "In its final, yet simplest solution the historian's task is the presentation of the struggle of an idea to realize itself in actuality." 16

Three and a half decades later, Johann Gustav Droysen quoted this sentence verbatim in an ambitious "Lecture upon the Encyclopedia and Methodology of History," which was later condensed into Historik "Outlines of the Principles of History". ${ }^{17}$ But he explicitly rejected what had meanwhile become a conventional assertion, namely the affinity between art and history:

I do not know what must be further from our minds than viewing the principles of history [...] as the theory of an artistic treatment of history, an investigation into the artistic character of historiography. ${ }^{18}$

At first glance, this appears to be a rejection of any orientation of history towards art. However, Droysen was writing not against Schiller's or Humboldt's concepts but against those of his chosen opponent Leopold von Ranke. ${ }^{19}$ In contrast to Ranke's approach, which Droysen presented as philological and narrow-minded, he calls his own conception of history a Hegelian "master theory." Ranke had built upon Quintilian in his lectures:

History is distinguished from all other sciences in that it is also an art. History is a science in collecting, finding, penetrating; it is an art, because it recreates and portrays that which it has found and recognized. Other sciences are satisfied simply with recording what has been found; history requires the ability to recreate. ${ }^{20}$

In fact, however, after this nod to the conventional relation of history to art, there was little space for any poetical dimension. History only borrowed from aesthetics a "holistic" claim on the universal representation of reality. Its vital criterion of "love of truth" was guaranteed by the historian's impartiality and personal self-effacement. ${ }^{21}$ 
Historians did not need to actively generate meaning at all: they only had to find the already existing structure of meaning in history, faithfully tracing and recording their sources to produce an entirely unartistic "recreation" of history. In a fascinating essay, Frank Ankersmit has described how Ranke shifted the poetic character of history to the past "itself," which for him was "an aesthetic phenomenon of an authentic and sublime beauty"; how he thereby poeticised historical reality instead of assuming a process of poeticisation in historical representation.

The result of this amazing inversion of the domains of reality and of aesthetics was that Ranke thus projected poetry upon the things themselves instead of enclosing poetry and fiction within the domain of language. [...] As a result Ranke could uphold the aesthetic dimension of historiography and at the same time urge the complete, 'objectivist' submission of the historian to the past itself and to scientific method. ${ }^{22}$

Ranke's claim to objectivity was itself shaped by nineteenth-century conventions. ${ }^{23}$ Droysen dismissed it out of hand as a "triviality" 24 that obscured the historian's actual work:

Those, then, who view the historian's supreme task as [...] simply letting facts speak, fail to see that the facts do not speak at all, except through the mouth of one who has perceived and understood them; that the facts do not exist as such, only in remnants in which we recognize them as the causes that bring about events or in the form of memories [...], which to a great extent bring with them those subjective moments that are forbidden to the historian. ${ }^{25}$

This rejection of objectivity (in Ranke's and others' readings) was theoretically grounded as well as politically motivated. This has led to very different assessments of Droysen's work as a historian. Droysen developed his theory and methodology of historiography in a university lecture upon the "Encyclopedia and Methodology of History" held in Jena from 1857 on, which he first published in manuscript, later in printed form as a "Grundriß der Historik" (Outlines of the Principles of History). ${ }^{26}$ Publication was an unusual step to take for methodological lectures; this underlines the import Droysen himself attached to the topic. The text versions known today as Historik comprise fundamental methodological considerations on the "science of history"-a systematic theory of historical methodology that has been regularly rediscovered since the 1960s by a generation of historians who considered their science as urgently in need of theory. ${ }^{27}$ Jörn Rüsen regarded Droysen as an important precursor to theoretically reflective historical scholarship; Hayden White found important impulses for his own study on narrative emplotment in Historik, which actually contains a four-part topology of historical discourse. ${ }^{28}$ Droysen also developed a step-by-step overview of the sequence of historical methodology (heuristics-criticism-interpretation-representation) that proved a stable base for later studies, with representation receiving the most attention since the "poetological turn" instigated by Roland Barthes, Arthur Danto, and Hayden White.

Droysen's historical works, on the other hand, are often received with less enthusiasm. Reinhart Koselleck regarded Droysen's History of Prussian Politics (1855-86) as a “deformed view of the past." ${ }^{29}$ Jörn Rüsen characterised Droysen's work, more favourably, as

politicizing historiography, meaning a relationship between scholarship and political practice that is receiving special attention today. [...] This important feature of Droysen's work is due to his critical demarcation of historical scholarship from 
the idealistic philosophy of history to the politically motivated didactic claim of methodically regulated history within nineteenth-century nationalist aspirations, and to the hermeneutic legitimation of this didactic claim in the face of the scientific postulates of early positivism. ${ }^{30}$

In fact, Droysen's publications are often considered "the epitome of committed, 'patriotic' historiography." ${ }^{31} \mathrm{He}$ was an active member of the Frankfurt National Assembly during the revolution of 1848. In this respect he clearly opposed Ranke's position, whose inaugural lecture in Berlin in 1836, "On the Relation of and Distinction between History and Politics," advocated for the necessity of separating "the offices of history and politics." ${ }^{32}$ By contrast, Droysen polemicised against the recommendation of dispassionate, "eunuch-like objectivity" 33 and equated the competencies of the historian and the politician: "To think historically is to see truth in realities. The statesman is the historian in practice." ${ }^{34}$ In a letter he wrote,

The argument is: the historian is not limited to criticism, as Ranke brings to the fore in his doctrine, but is also an interpreter who must learn and teach to understand. [...] Every historical past must be perceived and felt as a political present. And then I also reverse this claim and demand that the present be understood and treated as an accidental cross-section of the stream of history. ${ }^{35}$

No wonder, then, that Droysen considered Ranke's postulate of objectivity quite absurd. Whether this rejection of objectivity was derived from a critical methodological stance ${ }^{36}$ or due to his advocacy of its political orientation ${ }^{37}$ is a matter of dispute. Droysen opposed the idea of academic freedom and considered the university an "ecclesia militans" in the service of German national unification. His historical self-image was rooted in political ambitions of Hegelian scale, anything but resistant to teleologies and grand narratives. Suggestions that Droysen's "rejection of the postulate of objectivity [...] (at least also) is intended to provide legitimation for a historiography placing itself entirely in the service of politics" are entirely plausible. But it certainly enabled an abandonment of the paradigms of factuality and objectivity that made a radically new conception of historiography possible-as well as still fascinating to read..$^{38}$ Let us look at an excerpt of one of Droysen's lectures in Jena:

The first step towards a correct understanding of history is the insight that it has to do with a presence of materials. [...] While historical narration may recount the course of things from a starting point in imitation of their successive development, research [...] takes the opposite path: it is aware that it deals with material situated in the present, and that from this starting point it goes backwards into the past; or, to be more precise, that in the analysis and interpretation of this point in the present, of what has developed and now exists, research sketches out the idea of a past that is and would remain dead if research did not, as it were, reawaken and examine this point. We may say that the essence of research is to shine a cone of light backwards into the night of oblivion from the point in the present that it captures.

The past is past, insofar as it has not been internalized in this way and thus remained present. Every present immediately disappears, passes away; in our finite way we have only the fleeting moment, but we have it with all that is still there in it, with all the remnants of past presences, with all their internalizations. In order to have more than this moment, more than just this here and now, as humans we 
cannot help but revive these ideational past events-this memory-and make present in them what was; the finite mind - and only it - has the ability, through remembering and hoping, to give the fleeting moment a vastness that is an image of God's eternity; from that moment on we cast these lights of our innermost life-memory and desires-into the darkness before us and behind us; yes, hope is only a reflection of what the past gives us. It is in this shining and radiating backwards-because it creates the imaginings [Gedankenbilder] that fulfil our thought-that humans find their strength and understanding. ${ }^{39}$

This excerpt contains a number of challenges to the understanding of historical scholarship. The first observation rejects analogies between exploring reality and exploring history: the past does not lie before the historian; it is not immediately accessible but is both present (in its remains) and absent (as prior existence). ${ }^{40}$ In a next step, linear, narratological concepts of the "course of things" (Figure 1.1) are abandoned. This insight - that the development of events and the development of historical discourse move in opposite directions-is fundamental: history is retrospective. Reviving the absent past, its hopes and aspirations, is part of the historian's work-it is an achievement of historical writing. Droysen's nonlinear, anachronistic, transhistorical approach does not ignore the fraught relationship between events and their representation, nor does it ignore their noncongruence: history is based just as much on the evidence of lived experience as on its forms of mediation. His ambitious realism can still be useful for current artistic or nonartistic historiography.

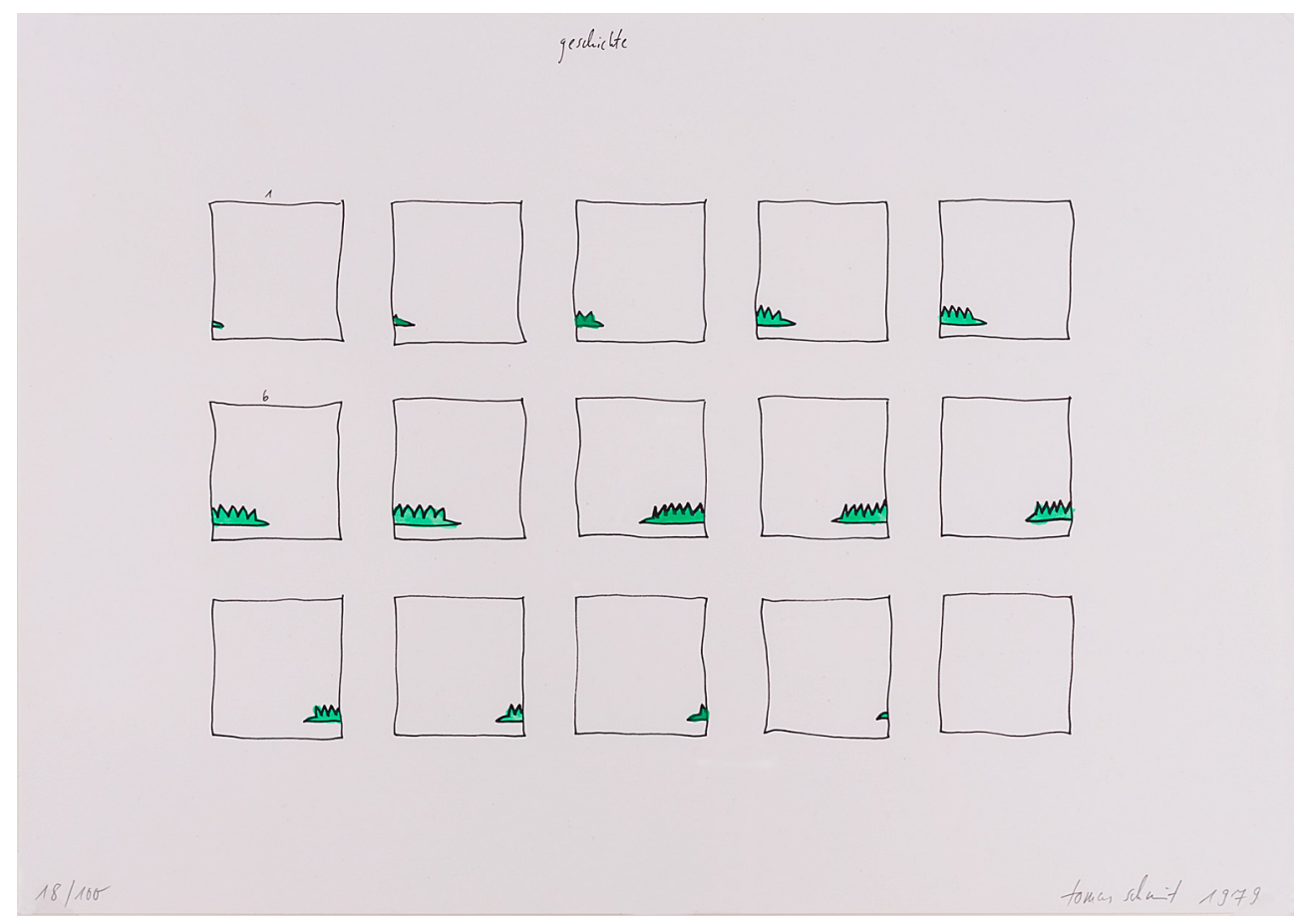

Figure 1.1 Tomas Schmit, Geschichte, 1979. Ed. 18/100. Offset print, hand coloured, $29.8 \times 42$ $\mathrm{cm}$. Museum moderner Kunst Stiftung Ludwig Wien, Vienna (G 413/14). (C) mumok Museum moderner Kunst Stiftung Ludwig Wien 
We, too, have [...] recognized that history is about realities-that is, the relationship between ideas and the material in which they are realized; we, too, will be able to say with Humboldt: in its final yet simplest solution the historian's task is the presentation of the struggle of an idea to realize itself in actuality. But we are far from admitting that this makes historical science belong to the field of fine literature; it would be but a confusion of concepts to say that artistic and aesthetic formations would necessarily need to appear here because we are talking about ideas and representation. One would then have to grasp the concept of art in a breadth that is not, at least, the usual one. ${ }^{41}$

The rejection of artistic aspects articulated in these sentences was intended as a declaration of principles that would irrevocably separate science and art, in the service of the advancement of history to the status of an independent academic discipline. And yet, albeit expressed cautiously and in the subjunctive, there remains the possibility of a proximity to art on the basis of a "concept of art [...] that is [...] not the usual one." What could this mean?

Droysen's own concept of art, as far as we know today, hardly suggests such a "breadth." As coauthor of a comprehensive review of the Berlin Art Exhibition of 1834, for instance, he took rather conventional positions. ${ }^{42}$ But for the purposes of this research, it is not Droysen's understanding of art but rather his concept of representation that is inspiringin a way unimaginable for the author himself, just as it was unthinkable within his conception of art: his understanding was not related to mimesis (which was considered art's representational concept), but to apodeixis. ${ }^{43}$

Nineteenth-century historians interpreted the term historiés apódeixis, which goes back to Herodotus, as explanation, record, or public presentation. ${ }^{44}$ Droysen translated it as "exposition of history" (Darlegung); ${ }^{45}$ his high valuation and interpretation of the term changes across the various versions of Historik. In the 1857 lecture version, apodeixis was described as on a par with other methodological operations (heuristics, criticism, and interpretation). In later editions, the term was elaborated into a separate typology of historical narration (which would become important for Hayden White's research), losing its status as one of the four systematic and methodological steps of historical research. Termed Topik in the last printed version of 1882, representation was reduced to the way history was written: its researching, interpreting character-which initially had been articulated by the term apodeixis-was abandoned. ${ }^{46}$ The earlier lecture version, therefore, is of specific interest for us and deserves special attention: apodeixis is more "than our word representation"; 47 it includes criticism and interpretation. Droysen followed Hegel's distinction "that what we want to grasp, what has happened and done, is quite different from that which we are actually looking for to understand by means of exploration (forschendes Verstehen)." The past "becomes history, but it is not history"; one must first consider events as history and then "transpose them, so to speak." 48 The depiction of history, therefore, was inseparable from its exploration.

Droysen had systematised his historiographical method in the four progressive steps of heuristics, criticism, interpretation, and apodeixis, which are linked by the ongoing progress of historical research and the transformation of historical material. The processes of criticism (the preparation and examination of materials) and interpretation produce "something that is different," namely "precisely our understanding gained through criticism and interpretation, an understanding not only of that material, but from that material, understanding of what is expressed in it." These cognitive processes must find their articulation in historical representation, which, as already quoted, "contains more than our word representation" and comprises, 
after the catharsis of criticism and the analysis of interpretation, the synthesis of their results, the reconstruction of the context in which the researched issue appears both understandable and understood, the didactic form in which we can and should pass it on. ${ }^{49}$

Representation is thus an equivalent to heuristic (the first step); it is retrospective research:

It shows something that does not yet exist in the being-outside-itself of things that is the material as we find it-but that the mind must first synthesize. [...] Research is searching for something; it is not just a matter of coming across something by chance: one must first know what one wants to search for; only then can one find it [...] and $\alpha \pi \circ \delta \varepsilon 1 \xi 1 \varsigma$ [apodeixis] only reveals that for which one is actually looking. ${ }^{50}$

Droysen brings the notion of mystagogy into play at this point, recalling Schlegel's image of the historian as "a prophet looking backward." 51

Apodeixis directly connects research and representation. This is inspiring for critical concepts of artistic historiography today, which have taken Droysen's theories to places far beyond his articulation or even imagination. Apodeixis opens up a broad scope for reflection and creation-for an awareness of the constructed nature of historical depiction-that can be reduced neither to the illustration nor to the authentication of historical research output. While the topology developed in the later versions of Historik has contributed to a recognition of the fundamentally poetological character of history via Hayden White, Droysen's earlier research-based concept of representation offers just as much critical potential for a consideration of how art and history are connected today. This does not necessarily require an attribution of the works of artistic historiography to "artistic research" in the strict, institutionally regulated sense of the term currently prevalent. Instead, it entails an understanding of artistic historiography that does not limit itself to illustrating the results of research created elsewhere. However, as even Droysen himself would separate representation and research in later versions of Historik, his concept of apodeixis found little echo in the theory of historiography. Concepts of art, on the other hand, would be integrated into history again and again over the course of modernism (never again, however, touching upon concepts of representation).

This can be seen in an address to the Naples Academy in 1893 that concludes this overview of nineteenth-century articulations of the relationship between art and history: Benedetto Croce's "History Brought under the General Concept of Art" (La storia ridotta sotto il concetto generale dell'arte). ${ }^{52}$ Following in the footsteps of tradition, Croce's attention was focused on narration. Like Droysen, whom Croce mentioned, at the beginning of his lecture, as a well-known representative of the view of the incompatibility of art and history, he rejected any reduction of the artistic character of history to the question of whether it was well written.

Taking up contemporary artistic developments such as impressionism and symbolism, Croce considered art's function to give shape to research: art is "the (symbolic?) expression of a certain content." But as history, on the other hand, shares with art the function of depicting particular events or persons (Croce was true to Aristotle in this respect), it cannot be a science-and, if that is the case, history must instead be art. ${ }^{53}$

The fact that this rapprochement of art and history occurs at the price of reducing the former to the depiction of reality and of denying the latter its status as a science 
shows how fragile the position of historical scholarship was at the time. The similarity between art and history was furthermore evident, according to Croce, because

there is no reason why historical accounts should be related only by the art of the written word. For even if architecture, or music, or the decorative arts cannot represent historical truth exactly, this is not true of painting and sculpture. Do not, for example, the paintings of Lely-which can be seen in the museums of BethnalGreen or Hampton-Court, and which preserve a very vivid recollection of the ladies, the gentlemen, and the customs of the time-stand on an equal footing with the memories that his contemporaries and Hamilton left us in his Memoirs about life at the court of the Stuart Charles II? Do not Louis David's pictures of Roman history have the same "historiographical" value as Rollin's Roman history? ${ }^{54}$

These ideas are based upon an understanding of history that,

in a purely aesthetic respect-that is, in the representative mode [...]-does not constitute a genre but is a product that enters into various genres, a content that can be expressed by various means. [...] History does not have its own means of expression that assigns it an object. ${ }^{55}$

Art is different from academic history only insofar as the former is "the representation of what is possible" while the latter is "the art of what truly occurred." 56

Croce did not further develop these thoughts, which comprise some of the most prevalent assumptions about the relationship of art and history to date. However, apart from his descientification of history, his concept of artistic representation falls far short of Droysen's, especially from the standpoint of contemporary art. An understanding of art as mimesis cannot answer the challenge of artistic practices of representation that essentially include criticism, interpretation, and research.

These considerations give insight into the discussions about the relationship between historical scholarship and art from a time when the former was still an unfixed entity, though indeed this relationship remains complex to this day. Debates during this earlier period also provide us with impulses to grasp the role of contemporary art within historiography. My aim is not to derive parameters for the evaluation or legitimation of art but to consider its historical ethos, its methods and objectives, and thus the relationship between art and history today. Droysen's concept of apodeixis provides a good working basis for a critical and reflective approach to what the representation of history might entail (both in art and in scholarship)_regardless of his specific politics and of the fact that his naturalistic nineteenth-century understanding of art could not be plausibly associated with this notion.

\section{Understanding History}

Droysen's representational concept was not developed with art-theoretical considerations in mind, but rather as one element within a theory of history understood primarily as hermeneutical. Among the various competencies of the historian, "understanding" had a privileged role. Interconnections between past and present in historical scholarship were most clearly reflected in the core principle of historical research he described as "exploratory understanding" (forschendes Verstehen) ${ }^{57}$ History's protagonist is a powerful character: a politically active historian or a historically trained politician able 
to understand history and thus to connect past and present, lending authority, urgency, and topicality to historiography.

"Understanding" history also altered the task assigned to art in relation to history, as described by Georg Simmel in 1923:

Consider the act in which the historian empathizes with the motives of another person, with the totality and the individual aspects of his nature, even though only fragmentary expressions of both are available to him-the act of placing himself within the total manifold of a tremendous system of forces, each one of which can be understood only if he reproduces it for himself. This act identifies the real import of the demand that the historian is, and must be, an artist. Consider also the usual conception of this demand. The historian functions as an artist only after all the facts of his investigation have been established and only in his activity of representing these facts for the benefit of the reader. This view of the relationship between history and art is completely mistaken. In this sense, it could be said that every creation of the intellect ought to be a work of art. In the case of history, however, art is germane not only to the form in which the results of historical inquiry are presented, but also to the content of these results. ${ }^{58}$

Simmel, too, was apparently looking for a more complex role for art within history than that of simple illustration-one that aimed, instead, at authenticating, unifying, and enlivening historical representation. But an important (socio-)psychological shift had occurred over the decades between Droysen's "exploratory understanding" and Simmel's “empathy." Simmel's artist-historian was to put himself in the position of individuals regarding both their historical and their personal situations-a task for which the modern artist provided a plausible role model. Simmel described a "historical genius" who

represents an inwardly coherent, convincing picture of spiritual processes, links between the thoughts and passions of historical persons, for whose way of thinking there are no longer any examples; his imagination, bringing together the most remote, interpreting the most wondrous, has a material at its disposal that his experience could not have provided him with. ${ }^{59}$

Together with a series of other new concepts in history and the humanities emerging in the first decades of the twentieth century, Simmel's writings mark the beginning of a shift in paradigms. Among its major contributions is Wilhelm Dilthey's The Formation of the Historical World in the Human Sciences (1910), which places the recognition and comprehension of the "productive nexus" (Wirkungszusammenhang) of the world at the centre of the humanities. The "transposition, re-creating, and re-experiencing" of "what is foreign and from the past" is the "fundament of historical science" and is in some respects comparable to an artistic process. It emerges from a "personal genius" that, together with the "development of historical consciousness," works in "exegesis" or "interpretation" (Auslegung), the "understanding of permanently fixed manifestations of life." ${ }^{60}$ Objectivity, therefore, is insufficient: "There is something irrational in all understanding, just as life itself is irrational; it cannot be represented in a logical formula." 61

Dilthey had discussed "interpretation" as part of art in his earlier writings Introduction to the Human Sciences (1883) and The Imagination of the Poet: Elements for a 
Poetics (1887), but only The Formation of the Historical World generates a comprehensive hermeneutic foundation for the human sciences. Numerous cross-references to musical, literary, and visual artworks illustrate a concept of interpretive hermeneutics ${ }^{62}$ that surpasses mere empathy with historical subjects. Historical events should be reexperienced in a manner conscious of their "systematic connections" and structural order. "A truly sympathetic historian can dedicate himself to his subject matter and make himself inwardly into a universe which mirrors the entire spiritual world." 63

The attribution of "understanding" as a proper and adequate category for the human sciences (while "explanation" would belong to the natural sciences ${ }^{64}$ ) was based on an assumed affinity between humans and history: "Individuals can understand history because they themselves are historical beings." Conversely, "human beings recognize themselves in history. We do not grasp human nature through introspection." 65 Since human existence is historically conditioned and realised in history, everything human can only be understood through history, as the examination of history requires the examination of human thought. This formulation provides a scientific foundation for the human sciences on a par with, but different from, that for the natural sciences. The humanities could thus be said to play an important role as a "means of salvation" to rescue the "torn consciousness" of modernity. ${ }^{66}$

Entrelacements among history, human experience, and understanding are explained in even more detail in Dilthey's correspondence with fellow historian Count Paul Yorck von Wartenburg, to whom Dilthey had dedicated his 1883 Introduction to the Human Sciences. In his letters, Yorck pleaded for a psychologising interpretation of understanding:

That the entire psycho-physical reality does not only exist but lives is the germinating seed of historicity. [...] Just like nature, I am history, and in this drastic sense one should understand Goethe's word about having lived at least three thousand years. Conversely, it follows that history as a science can only be the psychology of history. All other historiography, insofar as it is legitimate, is art. ${ }^{67}$

According to this argument, the epistemological foundation of the science of history is a "psychology of history" that connects historical material with the historian's position in the present. If we reconsider, for example, Peter Osborne's criticism of misguided artistic engagements with history, it is quite clear that a direct transfer of such a "psychology" of history to art's function within history would be erroneous (and, as is apparent from the above quotation, not what Yorck had in mind).

However, the primacy of "empathic understanding" was also met with criticism. Among its most direct opponents was Walter Benjamin, who pronounced it wrong both in its assumptions and in its objectives: wrong in assuming a universally ascertainable, continuous identity of all humans past and present; in raising the historian to the level of genius with unlimited potential; and, above all, in approaching history primarily in order to "understand" it, thus naturalising and legitimising the course of history. ${ }^{68}$ Benjamin wrote about comparable errors of literary and art-historical empathy:

This fateful, pathological suggestibility-by virtue of which the historian seeks, through "substitution," to slip into the place of the creator, as though the latter, just because he has made the work, must also be its interpreter-has been given the name "empathy," in which designation mere curiosity ventures forth under the mantle of method. ${ }^{69}$ 
This criticism of literary history was voiced in similar fashion regarding art history: Benjamin explicitly wished to leave behind "an old dogmatic and naive idea of reception" 70 that aimed at reconstructing historical responses to artworks as invariably correct and, ideally, identical with contemporary ones. The transition to history writing was fluid. Andreas Greiert succinctly sums up Benjamin's conviction that: "History as an overarching nexus remains incomprehensible to the human capacity for cognition." 71

Several writings on history focused on the key idea that history is primarily based upon the actualisation of past and present, and thus requires the "presence of mind" (Geistesgegenwart) of the politically committed historian. ${ }^{72}$ Historical materialism is directed against the idea of a transparent, permeable time continuum enabling simple reconstructions of the past:

Historicism presents the eternal image of the past, whereas historical materialism presents a given experience with the past-an experience that is unique. [...] The immense forces bound up in historicism's "Once upon a time" are liberated in this experience. To put to work an experience with history-a history that is originary for every present-is the task of historical materialism. The latter is directed toward a consciousness of the present which explodes the continuum of history. Historical materialism conceives historical understanding as an afterlife of that which has been understood and whose pulse can be felt in the present. ${ }^{73}$

"Consciousness of the present" is required to "blast the epoch out of the reified "continuity of history." 74 In contrast, empathic reconstruction of the past is multiplied, potentiated positivism: it can only be based on what is already known and has been handed down to posterity. Ranke's precept to show things "as they really were" is the "strongest narcotic of the [nineteenth] century" "75 and keeps history inaccessible and inactive.

Benjamin wrote against precisely that form of history writing described by Hannelore and Heinz Schlaffer as "aesthetic historicism": a form of turning history into its hypostasis—of coagulating the past into illustrations-which, to this day, has remained exemplary of those dedynamised, depoliticised, spatial conceptions of history put forward by conservatism, restoration, and neoliberalism. ${ }^{76}$

Historicism turns the temporal relationship of present and past into a spatial one. Burckhardt and Dilthey characterize historical thinking as "contemplation" and "gaze." They compare the form of the presence of the past as it is viewed in the mind with the viewing of pictures. The search for historical meaning finds an answer in aesthetics. ${ }^{77}$

Idealistic philosophies of history teleologically force the past under the logic of progression (i.e., the future) and reconstructive empathy with history under that of the present. Benjamin's philosophy of history attempts to do justice to the inaccessibility of the past, which can only assume connections to the present in rescuing flash-like constellations. The past "attain[s] legibility" only at particular times: "each 'now' is the now of a particular recognizability." 78 The past is the decisive factor in history-potentially, at certain fateful moments, activating the present:

The Copernican revolution in historical perception is as follows. Formerly it was thought that a fixed point had been found in "what has been," and one saw 
the present engaged in tentatively concentrating the forces of knowledge on this ground. Now this relation is to be overturned, and what has been is to become the dialectical reversal-the flash of awakened consciousness. Politics attains primacy over history. The facts become something that just now first happened to us, first struck us; to establish them is the affair of memory. ${ }^{79}$

\section{Performing History}

Regardless of the fact that references to Benjamin's writings are omnipresent in contemporary art and art theory, his scepticism towards understanding history has been given relatively little attention. Among the possible functions of art in history mentioned so far, understanding has remained predominant in artistic practice (as Osborne had observed). Recently, "empathic understanding" has frequently been taken up in the form of an artistic method not discussed by Osborne: reenactment, the physical reperformance of historical events, furthering their visualisation and understanding. ${ }^{80}$ This practice, like so many other artistic strategies discussed here, was initially developed as an instrument of historical science.

Reenactment was first proposed as a scientific method in the 1930s by Robin George Collingwood. ${ }^{81}$ This happened within a conception of historical science founded upon experience-more precisely, the historian's experience: the subject matter of history is that "which can be reenacted in the historian's mind." 82 Since the interpretation of history is based upon the examination of sources and is therefore necessarily constructed, the historian "must reenact the past in his own mind." ${ }^{83}$ This procedure, taking place in his-and we might add her- “constructive imagination," was perfectly suited to countering history's problematic lack of empiricism by conceiving it as a scientific procedure. These reenactments were anchored in the critical examination of historical materials to the point of emancipating the historian from "alleged facts." ${ }^{84}$ Historical sources were only "justified" if in accordance with the "historian's picture of the past." ${ }^{85}$ Historians became, indeed, masters of their materials: "Throughout the course of his work the historian is selecting, constructing, and criticizing; it is only by doing these things that he maintains his thought upon the sichere Gang einer Wissenschaft." ${ }^{86}$ It is striking that Collingwood's historian not only "finds" or "reconstructs" the past but, through the synopsis of those sources critically considered, creates it.

In addition to its scientific foundation, artistic reenactment draws upon the long tradition of identity-shaping popular reenactments in the form of pageants, jubilees, or passion plays-as well as their more commercialised and professionalised offshoots. In these elaborate, often- scripted spectacles, costumed actors reenact victorious battles, tragedies, and other "great moments" in history. Their importance as a point of reference for art was illustrated, for instance, when artist and curator Artur Żmijewski invited Polish reenactment groups to restage the 1945 Battle of Berlin at the seventh Berlin Biennial in 2010 - up to the capitulation of the Reich's capital: a provocative approach in many respects, as reenactments have a long history (and stable presence) in the context of political events and agitation. Among the better-known historical examples is the re-staging of the Storming of the Winter Palace as a socialist mass spectacle choreographed by Russian theatre director Nikolai Evreinov in 1920 in celebration of its third anniversary, which was later used as a historical setting by Sergei Eisenstein for his film October (1927). ${ }^{87}$

Reenactments integrate the documentary and the fictional; they are well suited to restaging historical events either true to historical sources or according to imagined-even 
counterfactual-history. They bring together a whole bundle of instruments that are used in academic history as well as in art. Though inevitably reducing history to a series of well-known actors and events, and thus presenting a simplified understanding of history, reenactments still serve as attractive and didactic participatory instruments for artistic practice. They bring to life past events in all their spectacular physical and affective qualities. But due to their claim to "repeat" the past, reenactments simultaneously risk a hypostasis of historical authenticity and an isolation of past from present, rather than putting forward the actual process of staging and interpreting history. ${ }^{88}$ Ideally, historical reenactments can be used as experimental arrangements in which the past is made to occur again (but differently) and this "repetition" is made visible as a performance in the present. As Maria Muhle writes, a critical application of reenactment enables a dissolution of media-philosophical oppositions between "identification, immersion, affect and fiction on the one hand, and a politically advanced aesthetics of criticism, distance, objectivity and documentarism on the other." ${ }^{99}$ This opposition is often applied to distinguish critical from uncritical, art from popular culture, contemporary from historicist, and lively from dry historical representation. Its dissolution would enable a reconsideration of artworks by examining their relationship to the homonymy of history as event and depiction thereof.

Popular reenactments also thrive in their structural ahistoricity ${ }^{90}$ - that is, in their taking up of historical events and actors as freely available and adaptable items of the past and their offering of a variety of roles and temporary immersion into foreign bodies, lives, and times. These kinds of reenactments are directly related to other popular media attractions that pretend to dissolve the differences between reality and performance, such as reality television or some forms of social media communication. In many popular communication and entertainment formats, ostentatious role play, performative self-exposure, and authenticity effects are deeply interconnected so that even—or especially—in situations of exposed but naturalised artificiality, affective intensities are generated that produce "psychological realism through constructed authenticity effects." ${ }^{91}$ One of the best-known artistic reenactments of recent decades, Jeremy Deller's The Battle of Orgreave (2001, Figure 1.2), has skilfully built upon the potential of this permanent merging of fiction and realism. The Battle of Orgreave has received considerable public attention as a multifaceted project produced and distributed via several media that interweaves past and present, event and reenactment, mediality and authentication with recourse to a number of historiographic formats. Deller staged a reenactment of the extremely violent, politically charged, and much-publicised 1984-85 clashes between police and striking miners in Northern England at their historic site in June 2001. Unlike other popular reenactments, The Battle of Orgreave recalls a traumatic event that had devastating results for the region and is today considered a decisive blow by the Conservative Thatcher government against the formerly powerful miners' union. Deller's staged battle was fought by more than eight hundred tried and tested reenactors and former miners, mostly with newly distributed roles. ${ }^{92}$ While the former were supposed to ensure an orderly, "professional" sequence of events and to ensure the proximity of The Battle of Orgreave to other popular battle reenactments, the latter were meant to generate authenticity, replaying their own past possibly in the roles of former opponents. The exact scenario of the reenactment evolved out of extensive research, including a series of interviews that Deller conducted over an 18-month preparation period in Orgreave. In June 2001, before an audience of hundreds of visitors, two historical scenes that had been scripted and rehearsed in detail were performed, both starting and ending with a sound signal. 


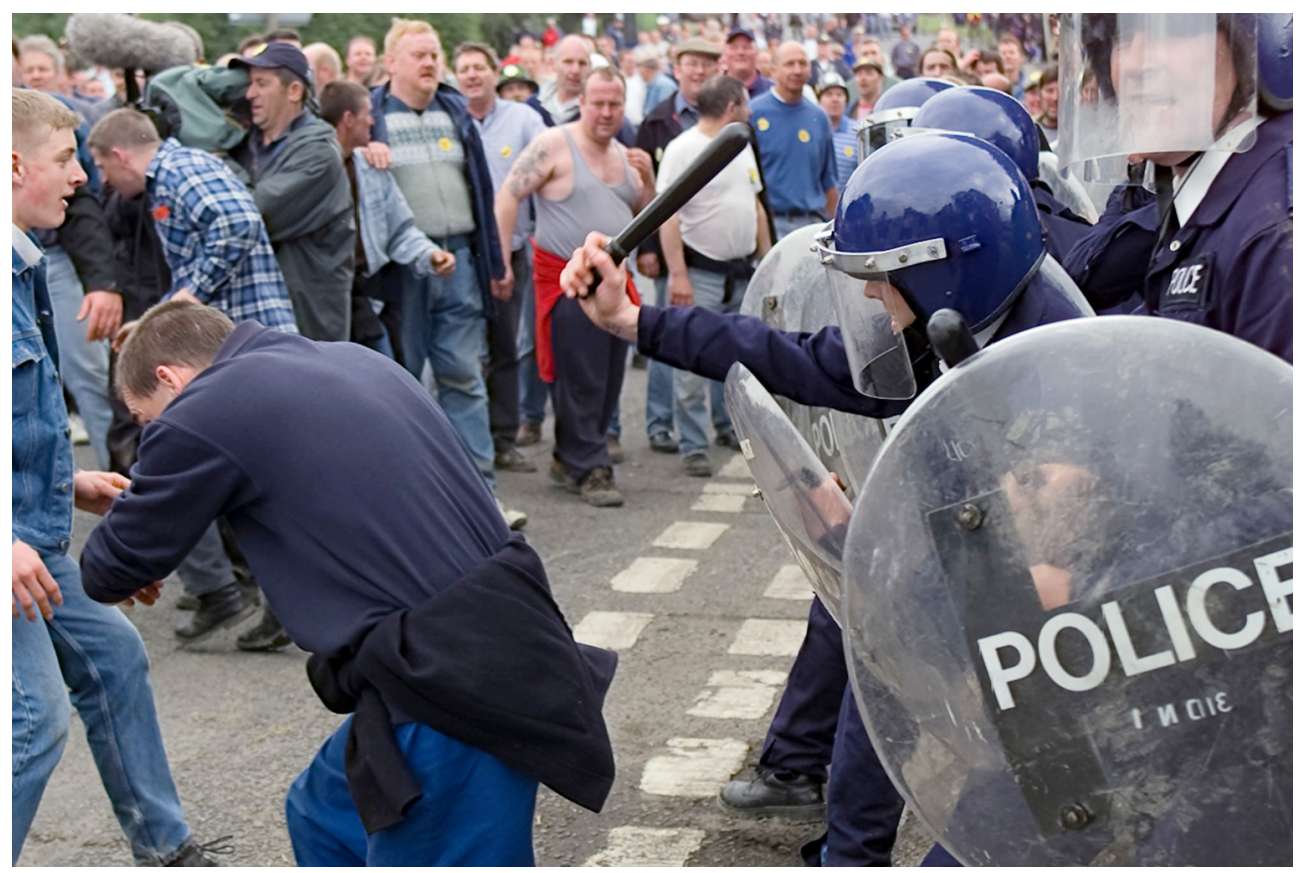

Figure 1.2 Martin Jenkinson, Jeremy Deller's re-enactment of the Battle of Orgreave, June 17, 2001. Film for Channel 4 directed by Mike Figgis and produced by Artangel. (C) Martin Jenkinson Image Library. All rights reserved. DACS/Artimage 2020

The Battle of Orgreave combines several artistic formats: especially in its final phase, which included personal visits and interviews, the preparation period may be considered a participatory art project in its own right. This was followed by the June 2001 public reenactment; the installation The Battle of Orgreave (An Injury to One Is an Injury to All) with numerous relics, historical materials, photo documents, and a timeline of historical events; the publication The English Civil War; ${ }^{93}$ and the film documentary The Battle of Orgreave, directed by Mike Figgis and produced for Channel 4. On the one hand, the film documents the historical events of 1984-85 and critically examines the highly manipulated media reports partly revoked since then; and, on the other hand, portrays the reenactment and its participants in a style similar to a "making of" the art project. ${ }^{94}$

These diverse media and formats, addressed to different publics, facilitated political reevaluations of the Thatcher years both with the help of and beyond the reenactment of a specific event. ${ }^{95}$ The affective impact of the spectacle, the documentation of historical events in the gallery, and their widespread dissemination in public media acted together in a highly effective and provocative combination. As a popular history project, The Battle of Orgreave used historical methods freely and autonomously. As an artwork, it did not aim primarily at better "understanding" of the past but rather at "incorporating" the past, both physically and affectively, with the help of experimental role play. Felix Stalder describes artistic reenactments as a genre characteristic of contemporary digital culture, attesting to the need to let information run "loops through the body"- to experience it physically in order to generate meaning for one's own existence. Referencing curator Inke Arns, Stalder emphasises the importance of artistic reenactments for individual assessments of those "indeterminate images, ambivalent 
documents, and contentious interpretations" that are permanently available for the exploration of the past but that are also in need of actualisation and relation to one's personal situation. An individual's physical insertion into images and situations creates presences of history in the present- "a new reality in the present." 96

Artistic reenactments, repetitions, and reperformances remain as open in their aims and effects as other repertoires used in current artistic practice to bring history into our present. We will encounter related practices repeatedly in this book, especially in the embodiment of and advocation for historical personages in performative, theatrical, or cinematic acts of putting oneself into situations or persons from the past. These acts' contemporary importance, therefore, surpasses that of an artistic genre in a narrow sense and attests to an ongoing transformation of history from means of representation to performative practice, in which the visual arts play an important role.

\section{Creating History}

In his essay “Modernity—an Incomplete Project,” Jürgen Habermas takes up Benjamin's linking of revolutionary politics and temporal experience, which Habermas observes as originating in aesthetic modernity: "We observe the anarchistic intention of blowing up the continuum of history, and we can account for it in terms of the subversive force of this new aesthetic consciousness." Habermas rightly emphasises that "Modernity revolts against the normalizing functions of tradition," that "the time consciousness articulated in [Modernist] avant-garde art is not simply ahistorical; it is directed against what might be called a false normativity in history." This type of "posthistoricist" stance, therefore, is an important contribution to a history renewed and revalued. ${ }^{97}$ The achievement of aesthetic modernity, then, is to overcome aesthetic historicism.

In his essay, Habermas refers in particular to Benjamin's theses in "On the Concept of History," which are among the most-discussed texts on history in contemporary art. Benjamin is often used as an advocate for a sweeping rejection of academic history and for an openness to artistic approaches. In fact, his writings took up some aspects of historicism while rejecting most of its most significant elements: positivism, universalism, the continuum of history, and history written by the victors. His attitude was explicitly directed against conventional and institutionalised historical scholarship. It is true that Benjamin comprehensively rejected academic history as "pure theory" inadequate in terms of its precepts and practices $;{ }^{98}$ as standing firmly on the nationalist, bourgeois "side of victory." It was less necessary, in his view, to rescue the past from oblivion than "from a certain kind of tradition. The way in which [it] is appreciated as 'heritage' is more ominous than its disappearance could be." ${ }^{99}$ Today, with the global rise of nationalisms and of culture wars founded in alleged histories and heritages, his observations are of significance.

Benjamin's interest in history did not begin with "On the Concept of History" but had already germinated in his early writings. ${ }^{100}$ His efforts were mainly directed at developing critical and politically activating forms of historiography. The Arcades Project, which took him years to write and remained unfinished, was intended to represent "the new, the dialectical method of doing history" 101 and to test "the extent to which it is possible to be 'concrete' in the context of the philosophy of history. Nobody will be able to assert that I made things easy for myself." 102

Indeed, Benjamin can hardly be reproached in this respect. The Arcades Project (of which volume $\mathrm{N}$ contains extensive material for the "Theses") was an experiment in figurative, "apodeictic" historiography, ${ }^{103}$ probing various forms: "thought figures, 
dialectical pictures, allegories, tableaus," ${ }^{104}$ maps, cartographies, drafts, dreams, and visions. For Benjamin, the depiction of history included a translation of the image fragments of historical experience into (not only scientific) language. The well-known phrase "history decays into images, not into stories" 105 indicates how historical representation might be achieved without being absorbed by concepts or goals-or by all-encompassing empathy: interweaving art and science, research, criticism, interpretation and depiction, this notion is very different in many respects from but is nevertheless structurally analogous to the concept of apodeixis we have encountered in Droysen's writings. But the word “decays" is significant. The course of history has no transhistorical, final meaning. Each meaning is provisional; each present views history differently. History means taking events out of the stream of time, out of the respective interpretations, categories, and disciplines into which they have been incorporated.

Indeed, art was an important point of reference for Benjamin. That it should be, for anyone delving into history theory, had already been suggested-if in a highly questionable way-in Nietzsche's Untimely Meditations, which Benjamin had read carefully: "Only if history can endure to be transformed into a work of art will it perhaps be able to preserve instincts or even evoke them." ${ }^{106}$ In Benjamin's conception of history, this approach was envisaged through an appropriation of montage. Most conspicuously implemented in film, montage was paradigmatic of avant-garde art practice. As a means of "exploding" 107 artistic genres and traditions, it could also point in the direction of a renewal of history:

The first stage in this undertaking will be to carry over the principle of montage into history. That is, to assemble large-scale constructions out of the smallest and most precisely cut components. Indeed, to discover in the analysis of the small individual moment the crystal of the total event. And, therefore, to break with vulgar historical naturalism. To grasp the construction of history as such. In the structure of commentary. Refuse of History. ${ }^{108}$

The use of montage was intended to thwart subjective interpretation instead of simply modifying earlier historical accounts over and over again. The question of whether the unfinished picture-composite of the Arcades Project was an attempt to implement the principle of montage has been widely discussed. ${ }^{109}$ Doubtlessly, Benjamin struggled for a new literary philosophical style that would allow for the coexistence of diverse narrative perspectives, dimensions, and materials, avoiding a conceptual reduction of history.

The question of possible analogies between art and history also inspired Siegfried Kracauer, who discussed several of Benjamin's texts in his own works. Here, too, we find a concept of representation as both imitation and creation. In his last, unfinished book History: The Last Things Before the Last $(1969,1971)$-an original and innovative examination of traditional as well as contemporary historiography, Kracauer described the historian as following both "realistic" and "formative" tendencies, acting alternately as recipient (collector, recorder) and creator (explicator, interpreter, editor): "So it goes on, spontaneity constantly alternating with receptivity. [...] He [the historian] is both passive and active, a chronicler and a creator." ${ }^{110}$

Kracauer's conception of history was also inspired by new artistic practices, namely photography and film. History: The Last Things Before the Last was dedicated to carving out the joint "anteroom" of historical and photographic reality, aiming at an approach at once utopian and materialistic; unassailed by scientific rationalism; and also sensual-but untainted by an artistic aestheticism detached from life. ${ }^{111}$ Kracauer 
perceived a historical and structural "analogy between historiography and the photographic media." 112 The former due to their nearly simultaneous emergence in the nineteenth century; the latter due to the capacity of photography-as distinct from painting or drawing_of "both recording and penetrating physical reality." ${ }^{113}$ Like Benjamin's introduction of montage, the analogy to photography provided an actualisation of what might be included in the concept of art within historiographical debates besides the mimetic use of drawing, painting, and sculpture. Just as history was not limited to the mere recording and reproduction of reality, neither was photography. The photographer

resembles not so much the expressive artist as the imaginative reader bent on studying and deciphering an elusive text. [...] Owing to the camera's revealing power, he has also traits of an explorer who, filled with curiosity, roams yet unconquered spaces. The genuine photographer summons up his being not to discharge it in autonomous creations, but to dissolve it into the substances of the real-life phenomena before his lens, so that they are both left intact and made transparent. If photography is an art, it is an art with a difference: unlike the traditional arts, it takes pride in not completely consuming its raw material. ${ }^{114}$

Again and again Kracauer evoked the productive tension between creating and recording reality that, in his view, united history and photography methodologically: both had to navigate between the "free development" of their subjects and their obligation to actual life (Lebenswelt). ${ }^{115}$

Kracauer found occasion to discuss his research on the relationship between art and history at several meetings of the high-profile German study group Poetics and Hermeneutics. He had been invited by Romanist scholar Hans Robert Jauß (who concealed his past as a former member of the Waffen-SS not only from Kracauer). Jauß would later describe Kracauer's contributions to the meetings as decisive in "breaking ground regarding social and sociological interests"116_enlivening input the group had urgently been in need of, at least in Kracauer's opinion, who described the one of the meetings as "stuffy." 117 There he presented his ongoing book project History: The Last Things Before the Last with a focus on the significance of art for history. Reacting to a comment by fellow participant Odo Marquard, Kracauer contextualised this significance historically, attributing the revaluation of "the aesthetic as the 'cement' of historiography" to the demise of moral philosophy as the foundation of historiography. ${ }^{118}$ This allocation of a formally consolidating function of art-its status as the "cement" of historiographical research-expresses a surprisingly conventional approach, especially as it seems that Kracauer actually pursued a much more complex concept. As the next chapter on documentary practices demonstrates, his notion of uniting recording and creating in his analogy of history to photography was ideally suited to taking into account history's double nature as event and narrative.

Kracauer's vivid interest in the nonchronological time concepts of anthropology and art history is just as remarkable. He pursued the writings of Claude Lévi-Strauss, George Kubler, and Henri Focillon as impulses for historiography. ${ }^{119}$ This interest was also motivated by his refusal to accept the "living present [...] as the fountainhead and goal of history." 120 "Present-mindedness" was not "the master key which opens all doors to the past"; it should not be confused with a methodological requirement. ${ }^{121}$ Kracauer rather suspected in the presentist approach a problematic inability to detach 
oneself from one's own time. Instead of what he considered an "aggressiveness" of this "present-minded" historian-which "may cause the past to withdraw from him"-he recommended Marcel Proust's attitude of "lean[ing] over backward in an attempt to make [the past] speak; [...] only an 'effort of self-transcendence' in this vein will, perhaps, enable us to arrive at an understanding of our present condition." 122 Kracauer was thus also critical of Nietzsche's On the Uses and Disadvantages of History for Life, which, in Kracauer's view, proposed a "determination [...] to make the past meet the needs of the living." The political reality of how history was suited to these "demands of 'life,"” were clearly before his eyes. ${ }^{123}$

But Kracauer's rejection of a historiography rooted in the present also had more personal aspects. He repeatedly opposed the "belief that people actually 'belong' to their period." The very idea of a homogeneous zeitgeist was, in his view, misleading. Instead, he observed "a precarious conglomerate of tendencies, aspirations, and activities which more often than not manifest themselves independently of one another." In lieu of a heroic, present-minded, politician-historian, he envisaged such a practitioner, no less extraordinarily, as an artist-historian of "chronological extraterritoriality" who does not grow out of time but actively shapes it: "Like great artists or thinkers, great historians are biological freaks: they father the time that has fathered them." Historians' "travels through Time" entangle them and change their identity. They are therefore neither genius-like outsiders nor products of their time. Instead, the historian is "the son of at least two times-his own and the time he is investigating. His mind is in a measure unlocalizable; it perambulates without a fixed abode." 124

As Dagmar Barnouw has shown, Kracauer emphatically claimed such an "unlocalizability" for himself. His escape and exile to the United States-which led to his abandoning his mother tongue, German, as a working and thinking language-contributed to his identification with spatial and temporal "extraterritoriality" to the extent that even references to his date of birth could make him uneasy. ${ }^{125} \mathrm{He}$ had proposed Erasmus of Rotterdam as a model for the historian precisely because of what he perceived as the humanist's distance from Kracauer's own time, which he considered a prerequisite for freedom of thought. This gives us some idea of the high value he placed upon not being "deterministically" absorbed by one's own time. ${ }^{126}$ In this sense, his anachronistic conceptions of subjectivity and history are closely interwoven.

As this chapter recounts, the relationship between art and history was conceived in various ways over the course of shifts from historicist to posthistoricist theories of history: art was to depict history, to perform or to shape it, to help understand it. How these theoretical propositions can be usefully applied to contemporary art depends not only on their respective concepts of art and history but also on how depiction or representation is understood. Droysen's apodeixis provides a brief, unrealised glimpse of an inspiring concept of historical representation that is closer to practices in contemporary art than to those of his own time. Historiography was repeatedly conceived as not purely oriented towards the past, nor always as embedded in continuous, linear time: Droysen favoured a politically committed historian; Benjamin intended history to track down fateful constellations and break up the historical continuum in the process; Kracauer understood "chronological extraterritoriality" as a prerequisite to historiography. These approaches underline the historiographical potential of anachrony as a concept not at all ahistorical but in fact deeply entrenched in history-in both senses of the word, as anachrony is a recurring component of history and historiography. Here, once more, artistic and scholarly historiography meet-contributing, together with other fields, to what defines history today. 


\section{Notes}

1 Godfrey, "The Artist as Historian."

2 White, Content of the Form; White, Metahistory. On the reception of these writings in contemporary art, see Pinto, The Reluctant Narrator.

3 Discussing Koselleck at length are Osborne, Anywhere or Not at All; Ross, Past Is the Present.

4 Some of these projects were presented by Bernhard Jussen in a series of meetings betweenas well as collaborative publications by-scholars and artists, among them Christian Boltanski, Hanne Darboven, Jochen Gerz, Ulrike Grossarth, and Anne and Patrick Poirier. See Jussen, Von der künstlerischen Produktion der Geschichte.

5 See Koselleck and Stempel, Geschichte: Ereignis und Erzählung, particularly Koselleck's essay "Geschichte, Geschichten und formale Zeitstrukturen," 211-22.

6 Michel de Certeau (The Writing of History, xxviii) has described the term history as a "paradox-almost an oxymoron-of a relation established between two antinomic terms, between the real and discourse."

7 In Leopold von Ranke's translation: "History is akin to the poets and is, so to speak, a prose poem." Ranke, "Character of Historical Science," 34.

8 Hegel, Lectures on the Philosophy of World History, 1:115.

9 See Koselleck, "On the Disposability of History," 192-204 and "Geschichte, Historie," 593717. Koselleck ("On the Disposability of History," 196) refers to Schelling's quotation: Man has history "not because he participates in it, but because he produces it." Ricœur (Narrated Time, 212, with further references to Koselleck) considers this development as inseparable from that of the concept of progress and develops this thought further to include the worldmaking power of narration: "Humanity becomes its own subject in talking about itself. Narrative and what is narrated can again coincide, and the two expressions 'making history' and 'doing history' overlap. Making and narrating have become the two sides of one process." On the cultural ethos of "making history," see Draxler, "Was tun? Was lassen?"

10 In his inaugural address (1789), Schiller had emphasised the proximity of history to art, building upon earlier texts such as Schlözer's Presentation of a Universal History (1779), which had compared the combining of historical findings with the designing of a mosaic. See Rüsen, "Historische Methode," 63. On Schiller's concept of history, see Rüsen, Konfigurationen des Historismus, 139-56. On Schiller's own historical writing, see Dann, Oellers, and Osterkamp, Schiller als Historiker; Fulda, Wissenschaft aus Kunst; Hofmann, Rüsen, and Springer, Schiller und die Geschichte.

11 Humboldt, "On the Historian's Task," 57.

12 Ibid., 61.

13 Ibid., 58, 61.

14 Aristotle, Poetics, 28 (Chapter 9, 1451 b): "For this reason poetry is more philosophical and more serious than history; poetry utters universal truths, history particular statements."

15 Humboldt, On the Historian's Task, 70-71.

16 Ibid., 70.

17 "Historik" (historics) was meant to provide a similar foundation to history as poetics had to literature. The term was first used in Grundzüge der Historik, an 1837 publication by historian G. C. Gervinus.

18 Droysen, Historik, 1:217. All translations into English are my own unless otherwise noted.

19 As Nippel ("Zum Kontext von Droysens Geschichtstheorie," 353) explains, Droysen shared this opposition to Ranke with other historians such as Häusser, Sybel, Treitschke, and Mommsen.

20 Ranke, "On the Character of Historical Science," 33.

21 Ranke, "Fragment einer Vorlesungseinleitung von 1840."

22 Ankersmit, "Truth in Literature and History" (unpublished English version of Ankersmit, "Wahrheit in Literatur und Geschichte"). I am indebted to Frank Ankersmit for providing me with his English manuscript.

23 On the history of objectivity, see Daston and Galison, “The Image of Objectivity." Ranke's narrative history was comprehensively rejected by the Annales School as a covert philosophy of history (White, "Narrative in Contemporary Historical Theory," 32). In Roland Barthes' view, the ideological separation between the res gestae and the historia rerum gestarum produces a falsified performative discourse in which the speaker/historian appears as if he 
or she were outside of the discourse, while he or she actually generated it. Roland Barthes, "The Discourse of History," 138.

24 Droysen, Historik, 1:219.

25 Ibid., 218.

26 Historik is a condensed handbook based upon the lectures with short, doctrinal paragraphs. It was first published in a manuscript edition in 1857 and was reprinted in 1868 and 1882, with an English translation published in 1897. I am mostly quoting from the lecture transcripts, not from the published handbook.

27 Koselleck, "Über die Theoriebedürftigkeit der Geschichtswissenschaften.”

28 Rüsen, Historische Vernunft, 7-19, passim., and esp. 10-11, with numerous references to Droysen. Rüsen (ibid., 15) considers Droysen's Historik as a "form of reflection of historical thought, which is necessary as a 'theory' to present and substantiate history as a discipline." See also White, "Narrative in Contemporary Historical Theory," 61. White was particularly interested in Droysen's differentiation among distinct forms of historical narration (interrogative, recitative, didactic, discussive), an obvious model for White's own research. Droysen, Historik, 1:217-83; Outlines of the Principles of History, 49-57. See White, "Review of History, by Johann Gustav Droysen."

29 Koselleck, "Erfahrungswandel und Methodenwechsel," 67; Nippel, "Das forschende Verstehen," 344.

30 See Jörn Rüsen's introduction to Droysen, Texte zur Geschichtstheorie, 6.

31 Rebenich and Wiemer, Johann Gustav Droysen, 9.

32 Ranke, "On the Relation of and Distinction between History and Politics," 75-82.

33 Droysen, Historik, 1:236. The term "eunuch" directly cites a similar castigation of objectivity in Nietzsche, "On the Uses and Disadvantages of History for Life," 84, 86.

34 Droysen, Historik, 1:399.

35 Johann Gustav Droysen to Wilhelm Arendt, 29 July 1856, cited in Nippel, Johann Gustav Droysen, 221.

36 Baumgartner and Rüsen, Historische Objektivität, 71.

37 Nippel, Johann Gustav Droysen, 85, 192, 219-38, and passim.

38 Nippel, "Das forschende Verstehen," 377.

39 Droysen, Historik, 1:9-10.

40 White, The Content of Form, 94.

41 Droysen, Historik, 1:217.

42 Droysen, "Berliner Kunst-Ausstellung (1834)," 47-79.

43 See Pandel, Mimesis und Apodeixis, 62, 66-68. On the use of artistic concepts of representation for scientific history, see Ankersmit, "Historical Representation."

44 Pandel, Mimesis und Apodeixisis, 11; Saupe, Der Historiker als Detektiv, 129-30, esp. $130 \mathrm{n} 18$.

45 Droysen, Outlines of the Principles of History, 49-50.

46 On the semantic shifts of representation in the various versions of Historik, see Rüsen, "Historische Methode," esp. 64-65.

47 Droysen, Historik, 1:157.

48 Ibid., 1:69. See also Pandel, Mimesis and Apodeixis, 21.

49 Droysen, Historik, 1:57.

50 Ibid., 1:58.

51 Ibid., 1:57.

52 Croce, La storia ridotta sotto il concetto generale dell'arte.

53 Ibid., 17, 31. Croce only treats history as comprising the depiction of events, not their actual course.

54 Ibid., 32-33. In the related footnote (n47) Croce refers to the dictum of Italian Renaissance historian Paolo Giovio: "Historians write great things for scholars, and painters paint them on the walls for the people."

55 Ibid., 37.

56 Ibid., 50.

57 Droysen, Historik, 1:69. In a similar passage in Outlines of the Principles of History, 12, "forschendes Verstehen" is translated as "understanding by means of investigation."

58 Simmel, Problems of the Philosophy of History, 91.

59 Ibid., 86. 
60 Dilthey, Selected Works, 3:237; Makkreel, Dilthey.

61 Dilthey, Selected Works, 3:239.

62 Ibid., esp. 3:241-47.

63 Ibid., 1:140.

64 On Dilthey's opposition of "explanation" and "understanding" as concepts appropriate to the natural sciences and the humanities, respectively, see Riedel, Verstehen oder Erklären?

65 Dilthey, Selected Works, 3:173, 269.

66 Riedel's introduction to Dilthey, Der Aufbau der geschichtlichen Welt, 16-17, explains the philosophical limits and political contexts of the foundation of the humanities.

67 Letter from Graf Paul Yorck von Wartenburg to Wilhelm Dilthey, 4 January 1888, in Dilthey, Briefwechsel, 177. Among others, Martin Heidegger (Being and Time, 363-69) and Giorgio Agamben (Infancy and History) have worked on this correspondence. See Gadamer, "Diltheys Verstrickung in die Aporien des Historismus."

68 Greiert, Erlösung der Geschichte vom Darstellenden, 515; see Benjamin's early text fragment "The Philosophy of History of the Late Romantics and the Historical School." Siegfried Kracauer later contradicted Benjamin's view that empathy would inevitably lead to identification with rulers' perspectives. See Baumann, "'Here goes B. wrong."

69 Benjamin, Origin of the German Tranerspiel, esp. the "Epistemo-critical foreword," 35.

70 Benjamin, "Eduard Fuchs, Collector and Historian," 262.

71 Greiert, Erlösung der Geschichte vom Darstellenden, 370.

72 In this respect, Benjamin was delighted to quote Turgot's conviction that politics must "foresee" the present: "Presence of mind as a political category comes magnificently to life in these words of Turgot: 'Before we have learned to deal with things in a given position, they have already changed several times. Thus, we always perceive events too late, and politics always needs to foresee, so to speak, the present." Benjamin, The Arcades Project, 477-78 (N 12a,1).

73 Benjamin, "Eduard Fuchs, Collector and Historian," 262; see the related passages in "On the Concept of History" (esp. theses XV-XVII) and in convolute "N" of The Arcades Project, esp. 462-63, 475.

74 Benjamin, The Arcades Project, 474 (N9a, 6).

75 Ibid., 463 (N3, 4).

76 Schlaffer and Schlaffer, Studien zum ästhetischen Historismus. On the hypostasis of history in the Romantic period, see Bann, Romanticism and the Rise of History. Bann $(1995,14)$ quotes Louise von Broglie's remark that history is the "muse of our time," which neatly illustrates historicism's aestheticisation of history. Rüsen, Ästhetik und Geschichte, 72, 80.

77 Schlaffer and Schlaffer, Studien zum ästhetischen Historismus, 13.

78 Benjamin, The Arcades Project, 462-63 (N3,1).

79 Ibid., 388-89 (K I, 2).

80 Even a cursory overview of exhibitions on reenactment practices in recent art appears inexhaustible. See esp. A Little Bit of History Repeated, Kunst-Werke Berlin, 2001; Life, Once More: Forms of Reenactment in Contemporary Art, Witte de With Center for Contemporary Art, Rotterdam, 2005; Experience, Memory, Reenactment, Piet Zwart Institute, Willem de Kooning Academy, Amsterdam, 2005; Once More ... with Feeling. Reenactment in Contemporary Art and Culture, Reg Vardy Gallery, Sunderland, 2006; Abistoric Occasion: Artists Making History, Mass MOCA, North Adams, 2006; Now Again the Post: Rewind, Replay, Resound, Carnegie Art Center, Buffalo, 2006; History Will Repeat Itself, Hartware MedienKunstVerein Düsseldorf and Kunst-Werke Berlin, 2008. Useful publications on the topic are, among others, Vanessa Agnew, "Introduction: What is Reenactment?"; Lütticken, Life, Once More; Leeb, "Flucht nach nicht ganz vorn"; Muhle, "History Will Repeat Itself."

81 Dilthey had recommended "re-experiencing" the past by "transfer of one's self" into history, in order to transform it "back into life." Dilthey, Selected Works, 3:234.

82 Collingwood, The Idea of History, 302; Dray, History as Reenactment. For a critical review of Collingwood's idea of overcoming distance to the past with a conception based on identity, see Ricœur, Narrated Time, 144-47.

83 Collingwood, The Idea of History, 302.

84 Ibid., 244.

85 Ibid., 245.

86 Ibid., 236; "sichere Gang einer Wissenschaft" is a quotation of Immanuel Kant.

87 Arns, Cubarov, Sasse, Nikolaj Evreinov \& andere. 
88 See Leeb, "Flucht nicht ganz nach vorn."

89 Muhle, "History Will Repeat Itself." Regarding this opposition, Muhle refers to Voss, "Fiktionale Immersion zwischen Ästhetik und Anästhetisierung."

90 Agnew, "Introduction: What is Reenactment," 327.

91 Knaller, introduction to Realitätskonstruktionen in der zeitgenössischen Kultur, 9-21.

92 Among Deller's many collaborators was reenactment expert Howard Giles.

93 Deller, English Civil War Part II.

94 The project was produced by Artangel. Deller had submitted his project in answer to an open call to artists that Artangel had organised together with The Times and the English lotteries. See Lingwood, Morris, and Noord, Off Limits, 91.

95 Claire Bishop's analysis of the project emphasises the importance of the use of different media and levels of visuality. Bishop, Artificial Hells, 30-37.

96 Stalder, The Digital Condition, n.p.

97 Habermas, “Modernity: An Incomplete Project," 5.

98 Greiert, Erlösung der Geschichte vom Darstellenden, 508.

99 Unpublished text fragment in Benjamin, Gesammelte Schriften, 1:pt. 3, 1242; see also Benjamin, The Arcades Project, 473 (N9,4).

100 Greiert, Erlösung der Geschichte vom Darstellenden.

101 Benjamin, The Arcades Project, $838\left(\mathrm{~F}^{\circ}, 6\right)$. The project came to a halt in 1929 precisely because of Benjamin's difficulties bringing his research into communicable form. In a letter to Theodor W. Adorno, Benjamin describes problems with the "rhapsodic character" of the work and, according to Tiedemann, found its "illicit poetic' formulation irreconcilable with a study that had 'our generation's decisive historical interests as its object.'” Tiedemann, "Dialectics at a Standstill, 937.

102 Benjamin to Scholem, Berlin, April 23, 1928, in Scholem and Adorno, Correspondence of Walter Benjamin, 333; Tiedemann, "Dialectics at a Standstill," 932.

103 Bolle, "Geschichte," 400; Greiert, Erlösung der Geschichte vom Darstellenden, 503.

104 Bolle, "Geschichte," 403.

105 Benjamin, The Arcades Project, 476 (N11,4).

106 Nietzsche, "On the Uses and Disadvantages of History for Life," 95-96.

107 "The montage explodes the framework of the novel, bursts its limits both stylistically and structurally, and clears the way for new, epic possibilities." Benjamin, "The Crisis of the Novel," 301.

108 Benjamin, The Arcades Project, 461 (N2,6).

109 Tiedemann, "Dialectics at a Standstill," 931-32.

110 Kracauer, History, 47.

111 Mattl, "Foto, Film, Geschichte," 119.

112 Kracauer, History, 57.

113 Ibid., 54.

114 Ibid., 55; quoting, in the same paragraph, photographer Paul Strand.

115 Ibid., 55, 58.

116 Jauß, “Epilog,” 529. On Kracauer's effect on the study group, see Wagner, “Anfangen”; Baumann, Im Vorraum der Geschichte.

117 Wagner, “Anfangen," 57n9.

118 See the discussion notes on the group's third meeting, "Das Ästhetische als Grenzerscheinung der Historie,", in: Jauß, Die nicht mehr schönen Künste, 570.

119 The extent to which the historical sciences drew back upon art historiography as a role model remained a topic within the research group. See Jauß, "Geschichte der Kunst und Historie."

120 Kracauer, History, 63.

121 Ibid., 76.

122 Ibid., 78-79; similarly, "to frighten the past back into the past," ibid., 69.

123 Ibid., 74.

124 Ibid., 66, 68, 69, 93, 103.

125 Barnouw, Critical Realism, 14. In a letter to Hans Kohn, February 4, 1964, Kracauer wrote, in German: "My kind of existence depends on the preservation of a state of extraterritoriality with regard to chronological time" (translated by Dagmar Barnouw). See Mülder-Bach, "Mancherlei Fremde"; Jay, "The Extraterritorial Life of Siegfried Kracauer."

126 Kracauer, History, 28. 


\section{Ready for History \\ The Explosion of the Documentary}

Among the theoretical positions on historiography mentioned so far, Siegfried Kracauer's double conceptual structure of history as both recording and shaping reality most closely corresponds to documentary film and photography, which have been a foundation of both artistic and academic historiography for decades. The documentary incorporated artistic aspects, both conceptual and technical, from its very beginnings, which has led to contradictions and paradoxes that regularly inform art-theoretical discussions to date: "Documentary' is often taken as the antonym to 'artistic,' yet it stems primarily from the artistic field-beyond art, yet very much a part of it." ${ }^{1}$ Analyses of the history and concept of the documentary illustrate its ambiguous relationship to art; this has, more often than not, led to a rejection of any potential kinship. ${ }^{2}$ Close associations of art with the documentary were often, from a defensive stance similar to that of historical methodology, perceived as a threat to its realism and its scientific, exact nature. This alone suggests that, among all artistic genres and methods, the documentary is closest to history. Its paradoxes are thus best answered by pointing out history's double nature: recording and shaping reality are not opposite procedures, but correspond exactly to both the course of events and the depiction thereof.

Documentary practices are situated in the midst of a constantly changing constellation of art, science, bureaucracy, journalism, justice, and truth politics. As an artistic genre, it has been criticized frequently because it shares procedures with ethnography, the police apparatus, and information technology, partaking in their identification procedures and normative-and often-restrictive-logics. Important impulses for furthering and critiquing uses of the documentary in art were put forward by documenta $X$ (1997) curated by Catherine David with a focus on conceptualist methods in contemporary art-and by documenta 11 (2002)-under the direction of Okwui Enwezor-which situated the documentary as the lingua franca of political art in the age of globalization at the centre of contemporary art while initiating a thorough critique and reassessment of its practices that continues to this day. ${ }^{3}$ This critique focuses on the documentary's often-ostentatious factism and its inherent paradoxical promise of direct representation and control of reality, which brings together the two irreconcilable poles of "factishness" (the fetishization of facts): ${ }^{4}$ to "find" and "fabricate" at the same time.

Documenta 11, in particular, presented numerous artworks exploring the possibilities and aporias of the documentary. ${ }^{5}$ This inspired an intensive examination of the documentary's artistic roots, with new and experimental practices critiquing the fetishization of historical material. At the same time, a comprehensive examination of the metaphorology of memory and temporal experience emerged; this became particularly significant in the context of the "historical media" photography and film. ${ }^{6}$ Wang Bing's West of the Tracks (2003), a film project dedicated to the two "eroding"

DOI: $10.4324 / 9781003166412-3$ 
classical subjects of the documentary- "the workers" and "the factory"-impressively illustrates the fundamental revisions that resulted from a century of artistic practice of and debate around the documentary. ${ }^{7}$

The documentary cannot be defined by specific formal or stylistic conventions; its characteristics are shifting constantly. ${ }^{8}$ The specific pictorial rhetorics of a documentary film from the 1920s or 1950s are recognizably different from contemporary examples, as are those of documentary art practices from the 1970s or 1990s. Certainly, as an instrument of historiography, the documentary is subject to era-specific forms of "emplotment." As this book focuses on documentary film and video, it will become apparent how procedures of representation and fabrication intertwine on multiple levels and contribute to the drama of authentication, inquiry, confirmation, and questioning that is inherent in artistic and scholarly history in equal measure. As Jacques Rancière has elucidated, documentary film is not "the polar opposite" but a different mode of cinematographic fiction (given, in his view, even more freedom, since it is not subject to the conventions of fiction- "the imaginary production of verisimilitude, of effects of the real"). ${ }^{9}$ Harun Farocki has described how this interplay of different modes or image rhetoric may work:

Even if it is perhaps impossible to say what constitutes the documentary or non-documentary approach, there are films that absolutely want to be one or the other. We call that the documentary gesture. On the one hand there are feature films that assert "we are a highly organised construction" and, through a particular way of handling the camera, choreography comes into being as a way of dealing with space, and a quite extraordinary position, which casts the only conceivable gaze upon an event. This slightly boastful stance, this tongue-in-cheek bragging with prior knowledge of what is about to happen, is an old topos in feature films. [...] The converse example would be a feature film that says "I am rather documentary" and the camera can't keep pace with events; in other words, the profilmic event is so autonomous that the camera is unable to seize the best image at every moment. A documentary film may equally assert "I'm incredibly genuine, I don't know anything in advance and so I'm not always quite in focus and the lighting's a bit clumsy" or, for a moment, it may not have the relevant object in the frame at all. Or indeed, in the fourth and last case, it may claim "I'm entirely in control of the circumstances and am actually a feature film.” That means that if you're lucky, for a moment, the audience might take a documentary film for a feature film, or vice-versa. ${ }^{10}$

In order to grasp this "gesture" in its context-bound and open nature, stylistic or methodological definitions are not sufficient. Bill Nichols suggests another approach by assigning the documentary to a discourse of "sobriety," 11 defined not by an adherence to specific formal criteria but to specific social institutions that promise a direct, comprehensible, and transparent relationship to reality and derive their authority from it. Among them are science, economics, politics, education, and law: "These systems assume they have instrumental power; they can and should alter the world itself, they can effect action and entail consequences." ${ }^{12}$ As already mentioned, the authority and power of these institutions is eroding rapidly today. Instead, propelled by its ongoing critical examination of history and reality via the documentary, art has consolidated its significance in the forum of truth politics all the more strongly. As Tom Holert has observed, "the critique of documentary realism has played a decisive role in the dissemination of documentary culture," 13 and this critique must also include its recurring use in artistic practice. 


\section{Ready for History}

Art's ongoing and productive confrontation with the documentary shows not only how the latter keeps reemerging as an attractive, critical tool but also, in a wider context, how image criticism serves to reestablish the belief in images to convey information, meaning, and truth. Tom Holert historically situates this critical "meta-discourse"14 in a tradition of reciprocal legitimation of media critique and documentary culture. Referencing Michael Renov, Holert emphasizes how much the proliferation of the documentary was accompanied by

a normalising spread of uncertainty about the status of images, their connection to reality, their authenticity. [...] In the process, this very authenticity is constantly both asserted and disputed, the desire for true images both awakened and methodically disappointed. ${ }^{15}$

This paradoxical and productive interplay is a main theme of Harun Farocki's and Andrei Ujica's joint 1992 film project Videograms of a Revolution. Taking an impetus from Farocki's description of the "documentary gesture," the following pages ask which artistic and technological media are actually capable of this gesture. Does a documentary film necessarily need to know in advance where it leads? Do simultaneous recordings of events that are happening right now therefore fundamentally violate the rules of historiography?

\section{History, Now: Harun Farocki and Andrei Ujica, Videograms of a Revolution (1992)}

One of the rules of correct handling of historical sources is the accurate separation of the actual, inaccessible events and material traces of them. When approaching the former, the circumstances of this approach must be made visible and comprehensible, in accordance with the truth claims of academic as well as of artistic history writing. However, the distinction between history as event and as representation becomes difficult on closer examination, as Harun Farocki and Andrei Ujica's documentary film Videograms of a Revolution (1992, video transferred to $16 \mathrm{~mm}$, colour, sound, 106 mins.) demonstrates. ${ }^{16}$ The film follows the spectacular overthrow of the Romanian Ceauşescu regime in December $1989^{17}$ as well as the profound critical debate triggered by the events and their representation in public and private media. The work can thus also be viewed as a case in point of the reciprocal questioning and confirmation of media critique and artistic documentary described by Tom Holert. The film raises questions about the relationship between reality and its representation in media technology that, in many respects, introduced a paradigm shift in how history and historiography are created and perceived even to this day.

Videograms of a Revolution consists exclusively of found-footage video clips, some from private sources, others from Romanian state television. As the centre of its national telecommunications, the Bucharest TV station was at the strategic core of the revolution: history was made precisely at the spot of its own recording. The neologism "videograms," which merges drawing and writing and suggests a kind of autopoietic historiography via the mechanical recording of images, attests to a similar epistemological shift. The directors present themselves as mere "monteurs" of the filmic narrative, while the actual "authors"-i.e., the professional and private creators of the assembled images-are listed in detail in the film credits. 
Videograms of a Revolution was conceived in the context of an intensive theoretical discussion concerning media impacts on the perception of historical events and the formation of political memory. The Romanian Revolution was the spectacular final act in the series of collapsing communist regimes in Central and Eastern Europe in 1989. While most of these collapses allowed for an imagery that remained within the realm of the symbolic-the "Velvet Revolution" in Czechoslovakia, the "fall" of the Berlin Wall marking the beginning of the German "Wende" (turn)—the situation in Romania was perceived as exceptional. It provided the full classical revolutionary scenario: ${ }^{18}$ a country oppressed by a despotic tyrant; protests; violent suppression; riots verging on civil war; then the revolution's victory and the dictator's flight, arrest, trial, and execution. All this happened within seven days, five of which were broadcast live on television when the state TV station hitherto restricted to the political representation of the regime morphed into the centre of insurgent communications and control. To observers in Romania and abroad, this appeared to be not only a "real" but a "real time" European revolution: history, as an iconically condensed live televisual event, had become literally (a)live.

Ironically, however, this overfulfilment of the revolutionary script soon raised doubts about the actual course of events. Their continuous transmission via the "a-historical" ${ }^{19}$ medium of TV seemed obscene and led to a suspicion that behind the flood of media images inexplicable and unresolved events and actors were lurking. These doubts were soon to be confirmed. First, the number of victims fighting against the regime in Timişoara on December 17, 1989 had to be revised several times-from estimates of about 60,000 dead, as related in the first days of the revolution, to a few thousand, according to international observers, and finally to around $700 .{ }^{20}$ In January 1990, on German television, Romanian doctors confirmed that widely broadcast images of alleged victims of the rebellion actually showed autopsied corpses from a nearby hospital and thus people who had died under completely different circumstances. This had happened in Timişoara as well, where indeed, as Andrei Ujica put it, the revolution had started as a "mass psychotic reaction of a city that could not find its dead." ${ }^{21}$ And when, in April 1990 after some copyright haggles, the first complete documentation of the trial and execution of Nicolae and Elena Ceauşescu was broadcast on public TV in France, a French forensic doctor expressed doubts about the authenticity of even these images. In his opinion, the execution of the Ceauşescus had already taken place shortly after the sentence was pronounced and had been repeated hours later for TV. ${ }^{22}$

Thus, rather than as the brilliant conclusion to a year of revolutions and of the bicentennial commemoration of the 1789 French Revolution-as both dramatic model and political benchmark - the revolution in Romania was inserted as a historical farce into the omnipresent posthistoire concepts of the 1990s. Western reactions to the unmasking of the "fake" images were indignant, lamenting not only politically motivated deception but also media corruption as a quasi-moral offence. For the newspaper Le monde diplomatique, the images from Timişoara became the worst fraud in the history of television; ${ }^{23}$ Giorgio Agamben perceived the shameless display of exhumed corpses as a new culmination of Debordian spectacle, as a "sometimes quite obvious" forgery authenticated by a media apparatus making true and false indistinguishable and communicating "solely through the spectacle." ${ }^{24}$ In a more sober reaction, Serge Daney stated that people in Romania, "used to [the practice of] lying for bad or wrong causes," might not have believed "that on the one day their cause would be a just one, they could be blamed for a slight manipulation of information." 25 
A series of conferences and publications followed, with contributions by well-known film and media theorists, among them Jean Baudrillard, Serge Daney, Vilém Flusser, Friedrich Kittler, Margaret Morse, Paul Virilio, and Peter Weibel. Many authors viewed the manipulated and manipulative images of the Romanian Revolution as symbols of the collapse of the critical, enlightening potential of media. The possibility of private, unprofessional video images finding their way into live television was perceived as a double rupture with the established rules of public information culture: a social rupture in that the conventional institutions of information (public radio and television, established print media, etc.) were suddenly replaced by an unmanageable number of private, anonymous, obscure actors; a medial rupture that was entailed in the threat of live transmission. The spectacular circulation of images-precursor of a phenomenon well known to us today ${ }^{26}$ - threatened the cultural-critical maxims of political argumentation: critical distance and objectivity, ideally framed in writing. The sheer quantity of available visual material is paradigmatic of that "flood" of mass media images (Bilderflut) that constitutes a key term in postmodernist media theory (which nevertheless mostly ignores the specific socio-technological dynamics and political contexts of images).

Jean Baudrillard, one of the most prominent spokespersons of media critique at the time, received the "Timişoara syndrome" with somewhat cynical fascination. A new low in the virtualization of death, he saw it as contributing to a demystification of both communication and revolution:

For, if the media image has put an end to the credibility of the event, the event will, in its turn, have put an end to the credibility of the image. Never again shall we be able to look at a television picture in good faith, and this is the finest collective demystification we have ever known. ${ }^{27}$

Although the fake images that circulated during the course of the Romanian Revolution worked with conceivably simple technical and political means of manipulation, they ignited an extensive discussion in culture and media critique that soon surpassed the issue of manipulated images to address the fundamental question of whether images in general, and, with them, events, could be trusted:

It is all an effect of the infernal cycle of credibility. The actors and the media sensed obscurely that the events in Eastern Europe had to be given credibility, that the revolution had to be lent credibility by an extra dose of dead bodies. And the media themselves had to be lent credibility by the reference to the people. Leading to a vicious circle of credibility, the result of which is the decredibilizing of the revolution and the events themselves. ${ }^{28}$

The fact that dramatic credibility (vraisemblance) was given priority over authenticity and that images of "fake" executions and "fake" victims were circulated was perceived as the pictorial-ethical downfall of the Romanian Revolution. It had failed to generate images capable of successfully partaking in the medial image cycle-the "industry of the visible." ${ }^{29}$ Thus, it had also become implausible as an event. The Romanian Revolution provided a show aimed at the "spectacle of the real," ${ }^{30}$ promising "laying hold of things almost before they have taken place." ${ }^{31}$ In order to develop "from document to documentary," the images provided lacked not only technical and pictorial lucidity and recognizability but also context and historical perspectivation. ${ }^{32}$ History as event and representation farcically coincided. 
The ongoing discovery of image manipulations ironically continued to raise expectations, therefore, of the "actual" and "authentic" images-because, if these were "fake" images, where were the "true" ones?-celebrating the myth of transparent, reliable images as a democratic ideal unattainable by Romania, whose corrupt image politics could comfortably be condemned. From Western European viewpoints, the spectacle of the Romanian Revolution was nothing more than a caricature of the French Revolution (which had, however, hardly worked more nobly in regard to its own image politics), rather evoking the highly dubious legacy of the 1917 Russian Revolution, which had tried to compensate for its lack of pictorial evidence with manipulation, more manipulation, and the aforementioned theatrical reenactments directed by Nikolai Evreinov. ${ }^{33}$ The Romanian Revolution of 1989 was accused of a similar (and similarly outdated) manipulation of images.

Benjamin Young has rightly pointed out that, ultimately, the images of the Romanian Revolution were ill suited as subjects of the media-theoretical discussion described above, and would have lent themselves rather better to an analysis of how images are inscribed into political agency. ${ }^{34}$ If they were discernible at all as signs of democratization (as teledemocracy), it was because-according to Claude Lefort's political-theoretical model-a multitude of private and professional images allowed a multiperspectival presentation when, after the fall of the dictator and the TV station, the centre of power had been made void. In Videograms of a Revolution, Andrei Ujica and Harun Farocki took up precisely this interpretation.

\section{Film as Seminar}

Videograms of a Revolution was initially created as a cinematic contribution to the aforementioned debate in French and German media theory triggered by the Romanian revolution. Andrei Ujica, a German resident since 1981, had already coedited a publication on the events in Romania, ${ }^{35}$ which had caught the attention of Harun Farocki, who was then still known primarily as a filmmaker, author, and activist. Even though both directors were deeply involved in the critical debate that was then underway, ${ }^{36}$ their film led to a radical revision of its main arguments. While it is a striking media-critical analysis of how visuality and politics intersect, the film directly reverses interpretations of a mere "telerevolution" — as the Romanian Revolution would come to be called-and concludes by defending reality just as much "against" the images as "through" them.

As a documentary, Videograms of a Revolution explores the suitability of video recordings for the documentation of historical events. Are the images they generate documents at all, even if they primarily convey direct, simultaneous "liveness?" Shown in chronological order, 106 mins. of visual material created during the revolution in Timişoara and Bucharest are organized into 19 chapters via text inserts and voiceover comments. ${ }^{37}$ The majority had not previously been broadcast on television: "The Revolution was Videotaped, not Televised." ${ }^{38}$ In order to facilitate the viewer's understanding of the course of events, the directors mark those images that were actually shown on Romanian TV in December 1989 with inserts. After the first interrupted broadcast on Televiziunea Română, the improvised insert Televiziunea Română Libera (Free Romanian Television) appears, demonstrating that the revolution had taken control of the channel. (This label was later replaced by a more professional logo.) The quality of the images is often poor, as indeed these are often spontaneously and furtively created eyewitness documents. In many cases, they are not capable of showing or illustrating clearly recognizable events. Their "apparition", therefore, is one not 
of legibility or visibility, but of an almost myopic presence at the confusing events, reinforced by the aesthetic texture of blurred, shaky video images. ${ }^{39}$ This aesthetics suggests that, by visualizing the conditions of the origins of images-their "unconscious historiography" ${ }^{40}$ - the truth they reveal can be approached. Hito Steyerl has elaborated this belief with reference to the "live" broadcast of the US invasion of Iraq on $\mathrm{CNN}$ in 2003:

On the level of form, the truth of these images is contained in the fact that the form of their construction presents a real imprint of their condition of production. Their content can correspond to reality, but it doesn't have to; doubt will never be cast aside fully. The way in which reality presses into its form is mimetic and unavoidable; it cannot be circumvented. ${ }^{41}$

I will come back to this positivistic shift of evidence from substance to structurewhich, in my opinion, remains a highly doubtful construction of truth politics. Indeed, the images of the Romanian Revolution do not so much make visible the events themselves as their connection to television. Providing a hysterical spectacle of the intersection of media and reality, these "documents" seemed to destroy all (critical) distance between both, making them not only indistinguishable but apparently identical. This visual material offers examples of a "penetration of history, politics and visuality" 42 that would later be exploited far more skilfully in the terrorist attacks of 11 September 2001.

Videograms of a Revolution exposes the numerous paradoxes of this intersection. The images document, first of all, the omnipresence of the media apparatus: repeatedly, cameras film cameras, as if the frenzy of communication and documentation alone was worth being recorded as the best proof of the significance of events. People crowd to pose for and appeal to cameras, but it is unclear whether they are involved in the events in any further way. One video shows dead bodies in an open vehicle, probably to convey that these are victims of the regime or of the revolution. They are first presented to the camera and then to a crowd, whose members are asked to kneel down before the dead. Most people remain in this pose long after the vehicle has passed by-they stay for the camera. This sequence is immediately followed by images of a group addressing several cameras to demand the death of the dictator, (01:25:42-01:28:35, Figure 2.1). This shocking, "obscene" display, not only of an awareness of the presence of the cameras but also of an orientation of all actions towards the laws of the telegenic, is typical of most images of Romanians in the film, regardless of whether the person behind the camera was a professional or not. Prime Minister Constantin Dăscălescu was likely led to repeating the dissolution of his government on December 22, 1989 by motivations similar to those that had led to the reenactment of the Ceauşescus' execution for television: one of his staff appealed to the excited crowd with the words: "Help TV do its job" (00:46:16-00:47:00). Stelian Pintilie, a former general of the Securitate (secret police) who was acting as deputy minister for telecommunications in December 1989, would later look back on the television media's presence with undiminished pride as the "first live broadcast of a revolution." 43 Obviously, the idea of a "telerevolution" did not originate from Western media philosophy, as illustrated by a statement by the first director of Televiziunea Română Libera, Aurel-Dragos Munteanu: “Television has made the revolution; television is the revolution." ${ }^{44}$ From the point of view of revolutionary politics, the staging of events for TV was not a covert action but was integral to the revolution. 


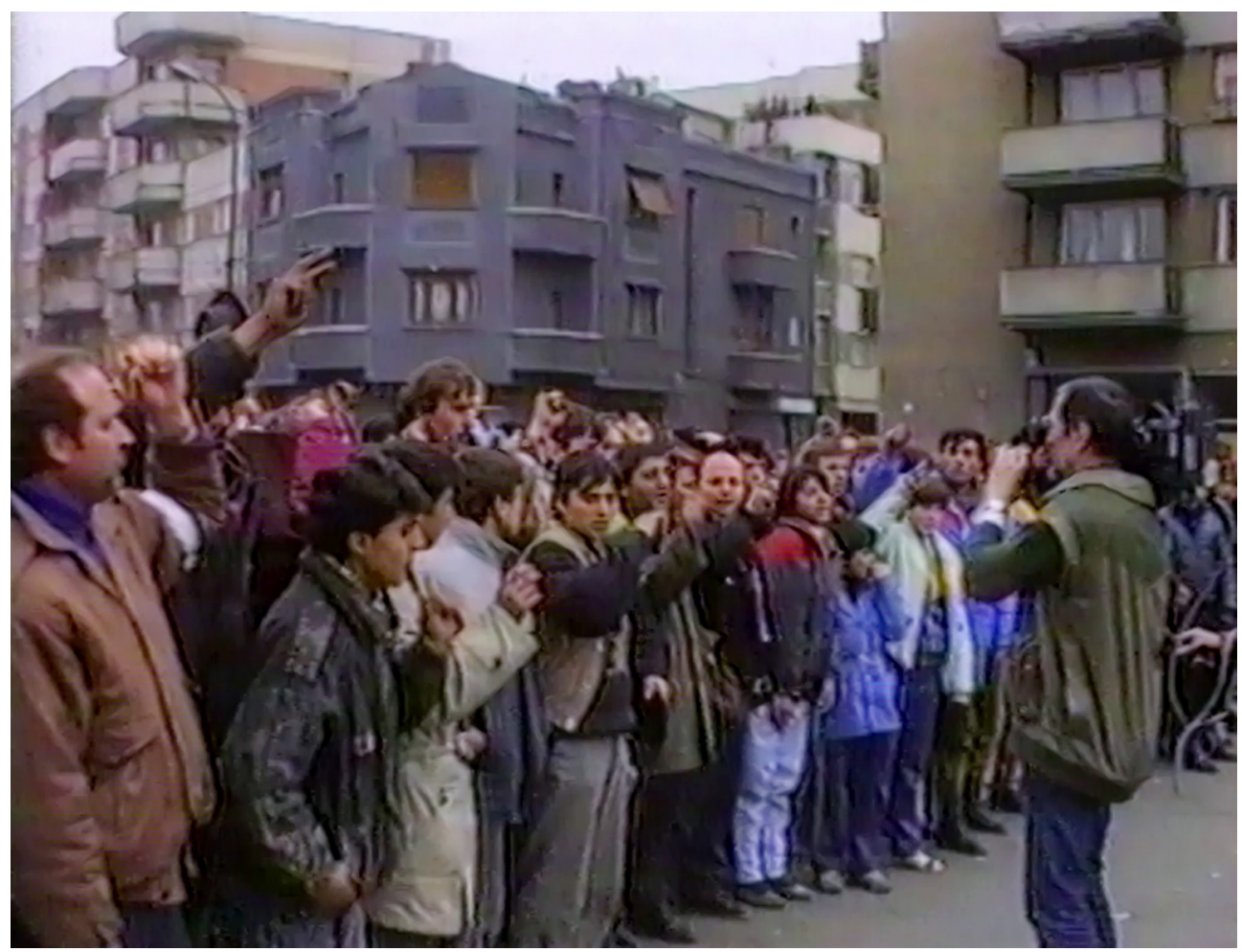

Figure 2.1 Harun Farocki and Andrei Ujica, Videograms of a Revolution, 1992. Still image, video transferred to $16 \mathrm{~mm}$, colour, sound, 106 mins. Photo (C) Harun Farocki/Andrei Ujica 1992

Who, however, was the intended addressee of all these appeals to cameras? The Romanian people? Revolutionary insurgents in neighbouring countries? An international, Western audience? Many of the video recordings were only ever watched because they were included in Ujica and Farocki's film, which was how most images of the revolution were made accessible to a larger audience for the first time. To some extent, the television media apparatus itself-in an abstract, immaterial sense-was the imagined recipient. This was a logical consequence of the role of state TV under the dictatorship: it had been reserved to the Ceauşescus and had broadcast only state propaganda for decades. Hijacking image production and eventually the TV station itself were acts with high symbolic significance and that directly made the new power relations visible.

The first video images shown in Videograms of a Revolution were shot on December 20, 1989 in Timişoara, where the revolution originated..$^{45}$ That afternoon, Ceauşescu had returned from a hastily organized state visit to Tehran in the belief that he had bypassed the political crisis, which he presented as orchestrated by Western intelligence services. The next day, after some hesitation, he decided to counteract the protests erupting in Timişoara with a state-organized rally as a demonstration of loyalty to himself. The event was to be broadcast live on TV-a fatal mistake. Only a few minutes into his speech, the dictator was interrupted by a commotion in the crowd and loud screams. The origin of the disruption has never been determined with certainty, ${ }^{46}$ but Ceauşescu stopped speaking and his face froze in an irritated expression that was clearly visible on TV. Whatever the cause, the dictator's own televisual collapse and the 
interruption of the transmission that directly followed it would become a turning point of the revolution. Television found itself in a state of political and technical emergency: the time continuum of the live televisual flow was suddenly interrupted by the revolution actually going "live". ${ }^{47}$

Videograms of a Revolution illustrates this state of emergency by juxtaposing the actual recordings of the TV camera-which, shortly afterwards, panned to the sky, a move that often occurred in the case of "unrepresentable" events, we learn from the voice-over-with what was broadcast nationwide-ironically, an insert with the text panel "transmisiune direct" (live broadcast). When the commotion had subsided, the broadcast continued, the dictator still struggling to retain the crowd's attention. Some contemporary witnesses perceived this disruption of the visual propaganda stream as a wake-up call, returning a sense of reality so long eclipsed:

We had found ourselves in a space completely emptied of historical time, in a vacuum, with a thick slab from a special, more or less frozen time, dictatorship time, pressing on our heads. Television had also belonged to this time slab; it had become a dull image. [... But] because of this interference, Romanian television suddenly found itself in harmony with social time, as articulated by the crowd on the street. ${ }^{48}$

The dream of experiencing the political end of the dictatorship via television was fed not least by decades of live broadcasts from the Ceauşescu palace that propagated a direct connection between dictator and people. Disrupting this connection broke through "dictatorship time" and opened "real time."

For the revolution, this unplanned TV moment was extremely valuable, at least regarding its ability to communicate via images: they show the collapse and failure of a dictatorial media apparatus. Their effect is highly authentic; they demonstrate what Boris Groys has described in detail: disturbances and interruptions of the media apparatus confirm the ontological suspicion that media images may not be identical with what they represent (their "submedial space" ${ }^{49}$ ). But this does not result in critical knowledge of how they may be freely fabricated, rather in the impression that finally it may be possible to get a glimpse of what lies "below" them—of what is "really" happening. All justified doubts about media mechanisms, then, are immediately replaced by an authenticity effect owing to the affective experience of how "true" images are being unmasked. Thus disturbances and interruptions are key moments in the (re)authentication of media images; indeed, critical awareness of the mechanism is based on the premise of the potential authenticity of images, which is refuted and created anew in a continuous loop. ${ }^{50}$ Against the odds, we believe in images. Because we do not see what is happening, because the camera is averted, because the transmission is interrupted, media images assert their veracity. Our contemporary reception of media is deeply rooted within this drama of authenticity and simulation. ${ }^{51}$

As Serge Daney put it, every media theory is based on a belief in images, but it is a belief that has become "malevolent." ${ }^{2}$ Tom Holert has pointed out the paradoxical consequences:

It is enough to drive one crazy: the more strictly you frame the documentary image and its production criteria-through media-critical commentaries, by questioning the objectivity and veracity of specious showmanship and so on-the more plausible it seems to use such images to ascertain the truth. [...]

The more often media-critical newsreaders urge the viewer to distrust the images shown, the better people can look at those images without continuing to expect an answer to questions about the potential "veracity" of the images. The critical 
insight into the rhetorical character of the images has been replaced by the affirmative acceptance of that given..$^{53}$

Routinely forwarded image scepticism is completely integrated into the media apparatus as we know it. Many analyses of Videograms of a Revolution describe the film as a search for Groys" "submedial space." 54 This assumption corresponds not only to a repertoire of artistic media critique prevalent at the time, but also to Farocki's own affirmation that "it is not a matter of what it is in the picture, but rather, of what lies behind it." 55 This suggests, again and explicitly, that behind the images, a political standpoint, an intention, or an interpretation of what is being documented is waiting to be revealed. On several occasions, however, Farocki expressed a deep mistrust of images. The legacies of Roland Barthes's semiology and Jean-Luc Godard's cinematic deconstructions of visuality resound in the filmmaker's rich body of writings and statements:

You have to mistrust pictures just as much as you mistrust words. [...] There is no literature or linguistic criticism without an author who criticizes the existing language. It's the same with films. You don't have to search for new, never-before-seen images, but you have to take the images at hand and work on them in such a way that they become new. There are various ways to do this. My way is to look for submerged meaning, clearing away the detritus on the images. ${ }^{56}$

Whether this "detritus" lies on the pictures or is part of them-whether "clearing away" allows us to look at pictures or behind them-may seem a trivial semantic point. However, Farocki's cinematic image analysis clearly goes far beyond attempts to reveal a submedial space. He uses comparative film montage as an analytical instrument to arrange and rearrange film and video images, highlighting their formal, institutional, and medial references and contexts to produce new interconnections and readings. This method allows us to scratch the surface of the images but also, and more importantly, to have their respective surfaces comment upon each other. ${ }^{57}$ Farocki demonstrates this procedure in his short film Schnittstelle (Interface, video-BetaSp, 23 mins., 1995, Figure 2.2), his "self-portrait" at the editing table, ${ }^{58}$ with explicit reference to Videograms of a Revolution. This "soft montage" describes a method aimed not primarily at isolating fixed pictorial meanings but at proposing diverse possibilities for connecting them and for presenting them as dependent on specific constellations. ${ }^{59}$ As Christa Blümlinger points out, interestingly, analogue film editing is not Farocki's foremost frame of reference, although his short film shows a $16 \mathrm{~mm}$ editing table next to the video-editing suite. Instead, he describes his workplace as equipped with digital methods of investigation and image processing-informed both by their function in communications cycles and by their (analogue or digital) display-and himself as a filmmaker fully integrated into the image-media apparatus in terms of craftsmanship, technology, and research.

Today, research is widely accepted as integral to artistic practice. In the early 1990s, media-critical theorems typically found artistic equivalents in the self-reflexive, antinarrative, deconstructive attitude of the new documentary film. Linda Williams has succinctly summarized its pictorial ethos: "It has become an axiom of the new documentary that films cannot reveal the truth of events, but only the ideologies and consciousness that construct competing truths." ${ }^{60}$ In the context of the critical debate out of which Videograms of a Revolution emerged, it seemed natural to perceive the film primarily as an example of the new documentary. Williams describes a shift of truth from the level of reference to that of analysis, which entails a shift in argument from correspondence to coherence. ${ }^{61}$ In a certain 


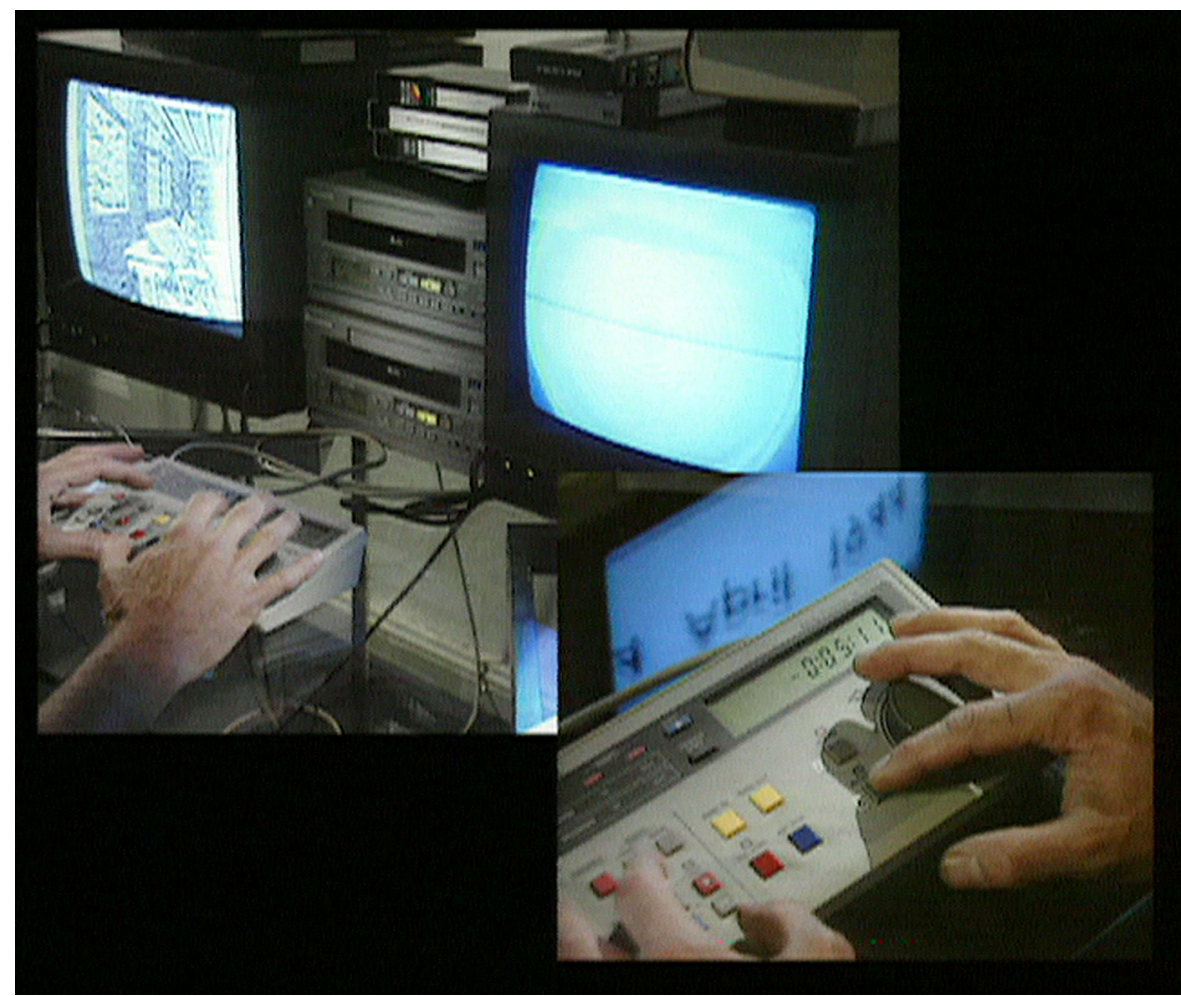

Figure 2.2 Harun Farocki, Interface, 1995. Still image, video-BetaSp, 23 mins. Photo @ Harun Farocki, 1995

respect, the conviction (also expressed in the quotation from Hito Steyerl above) that the form and style of images mirror their conditions of production corresponds to coherence theory: even fake and misleading material can yield truth and veracity. And, as also noted above, the conviction that the truth of a given document is not revealed in what it presents but in the conditions of its representation only shifts the promise of "truthful" pictorial evidence from one aspect to another. While the analysis of visual documents is fundamentally necessary in terms of its techniques, conventions, and formats, it is deceptive to assume that formal evidence is somehow "truer" or more easily accessible than that of content. It is important to deconstruct not only images but also those "image-text amalgams" 62 that structure artworks as well as media communications. The critical analysis of images, furthermore, is not the exclusive competency of art but can and should be supported by scholarship on the contexts in which they are embedded, such as media and politics.

Videograms of a Revolution had initially been conceived along the lines of one of the most prevalent assumptions of contemporary media theory, namely as a deconstruction of the revolutionary "scenario" that had already been exposed as a media-political fiction. As Farocki later explained, the filmmakers had planned an theoretical analysis through film of the video recordings of the Romanian Revolution-“a film like a seminar," providing lessons through the presentation of corrupt images.

So we drove to Bucharest to collect material addressing the question whether the cameras had "reproduced" images of the revolution or "produced" them-(in Vilém Flusser's terms, whether the imagination was “old” or "new”). We had envisaged a 
discussion, but soon came to realize that the material required a filmic narrative. A narrative which by its fractured nature included the discussion. ${ }^{63}$

Viewing the images led to a remarkable overthrow of the initial concept. The dubious, fragmented recordings were not asking to be perceived simply as a didactic piece-they were not just compromised material for theoretical discussions but required a different approach.

After we had again and again seen images showing tens or even hundreds of thousands of people coming together in order to achieve the overthrow of the old regime it seemed absurd to call this a television revolution. We dismissed our initial idea of a filmed analysis and decided to reconstruct the five days of a revolution, from 21 to 25 December 1989, from various sources of material, as comprehensively as possible. ${ }^{64}$

This was an astonishing change of course-all the more so because the directors ended up mounting the found footage chronologically, alongside the much-criticized revolutionary "scenario," choosing the reconstruction of events as their narrative. The film begins with the first riots and demonstrations, continues with the interruption of Ceauşescu's public and televised speech, follows the crowd to the TV station, and closes with Nicolae and Elena Ceauşescu's failed escape, arrest, and execution. It was "as if history itself created its own shape," Farocki wrote. ${ }^{65}$

The emerging procedure was directly opposed to the prevalent theoretical premise at the time-that of a "telerevolution", a revolution culminating merely in a media event. Watching the film is like watching the revolution, but in order to achieve this historicizing effect, the images needed to be critically reviewed, contextualized, and expanded via the corrective of a detailed commentary; the addition of information and references; and finally - and, in my view, necessarily - the transfer of these fragmented, tainted, and obscure video recordings of uncertain provenance into the more reliable, credible, and authoritative format of a film. ${ }^{66}$ Only then could such a montage of clips be considered a "reconstruction" of events. Transferring the present-oriented video recordings into a filmic documentary made it possible to experience them, if not as history, then at least as media history.

\section{Ready for History: Film, Video, Television}

The term "videograms" suggests an interweaving of image and writing, evoking a kind of automated historiography created exclusively via moving images. And really, though the actual image creators are meticulously identified in the film's credits, their recordings are presented as if they were purely mechanical fabrications: "The camera is endangered" (voice-over at 00:04:53-00:04:56). "A camera explores the situation" (text panel at 00:15:14). "By getting a glimpse of the commotion, it [the camera] was the first to change sides, more out of curiosity than intentionally" (voice-over at $00: 23: 27-00: 23: 35)$. The cameras are presented as political actors so that history is recorded via something like technological autopoiesis. History's course may be erratic and often interrupted, phenomena that only enhance the impression that we are not viewing a product of historiography but witnessing history-not only as it is being made but as it "makes itself."

Both directors, who had participated seriously in the critical debate instigated by the revolution, decided to present its highly problematic, tainted visual output in the form of a documentary narrative that "included the discussion." This discussion was not 
identical with the one prevalent in France and Germany around 1990, but ranged from an analysis of the political and technological conditions of historiography to a defence of history against the relativity of images and against those variants of media criticism contributing to the relativization of truth and meaning.

The sheer quantity of video material alone is astonishing in view of the repressions of the Ceauşescu regime. While every typewriter had to be registered, video cameras proliferated completely uncontrolled. Farocki explains this as a "fixation" on the written word characteristic of communist repression, and indeed video was initially primarily reserved for private use. News of the political upheaval spread via radio, telephone, and word of mouth. ${ }^{67}$ As Farocki emphasizes, this made it even more difficult to "read" the found footage. In one instance, the filmmakers received recordings of the escape of the Ceauşescu couple from two different sources, one from a probable sympathizer of the revolution, the other from a probable Securitate agent, but the clips hardly differed in style. "It seems to be more difficult to impart pictures with spirit than words; and it seems more difficult to read that with which the pictures were imbued." ${ }^{68}$ Videograms of a Revolution repeatedly addresses the problem of how the found recordings lack evidence. As they hardly provide any political "proof" of a specific reading of events, the voice-overs are engaged less in "deciphering" them than in commenting on their ambiguity or in suggesting interpretations. The use of video cameras as instruments of history thus led to a revision of what the documentary entails.

A case in point: a long shot at the beginning of the film (from 00:03:39) is taken from a camera located on the top floor of an apartment building, aimed at a park and the street behind it. We see a demonstration passing by - that is, we see and hear some of it, and the voice-over tells us that it is there. The actual event itself is hardly discernible on video. Farocki suggests an interpretation:

With his picture, the man behind the camera proves that he did not just look away. In addition, his film looks forward to times in which one can show such pictures; it serves to summon up the dawn of such an era. ${ }^{69}$

Many of these unreadable images are generated by the belief that an event is somehow "documented" by the mere fact that a camera is pointed at it. The voice-over commentary helps to contextualize the clips but cannot make them "speak." Often the cameras seem utterly useless in documenting what has happened in fact. An informed eye (in this case represented by the directors' commentary) is necessary to reconstruct-or at least guess at - the actual events depicted. In order to be able to generate visibility, the video documents must first be inscribed into the cultural and technical processes of producing evidence. ${ }^{70}$

Videograms of a Revolution thus impressively explores the problem of documentary's "discourse of evidence," seeking to "externalize evidence-to place it referentially outside the domain of the discourse itself, which then gestures to its location there, beyond and before interpretation." ${ }^{\prime 1}$ Put differently, documentary evidence is an effect of discourse and interpretation that covers the traces of its own fabrication. The images in Videograms of a Revolution have little to show and less to tell; content, messages, and meanings have yet to be ascribed to them. Although the film sets out in search of visual evidence, characterized by Peter Geimer as "being in the picture on the one hand, and requiring additional activation on the other," 72 it focusses on this additional activation, located in the technical, authoritative, and paratextual instances of visual presentation, and pointing to a fundamental break between the production of images and meaning. Serge Daney has succinctly described this phenomenon in a sober reply to invocations of the power of images stemming from the "image flood" variety: 
There was never so much talk about the "power of the image" until it ceased having any. The overwhelming majority of "images" which have free reign on television today are less images with any intrinsic force, than images which represent power, and which "work" for power just like "brand images" work for corporations. ${ }^{73}$

Looking at the found footage from the Romanian Revolution, it is useful to recall Daney's distinction between "images" and the "visual." 74 The video clips are not "images" in the sense of a humanistic "stubborn resistance" to the endless loop of pure signals, nor do they fit completely into the stream of the "visual" - not because they are valuable or true but precisely because they are largely (technically as well as creatively) unprofessional: bad, mute, "blind," unreliable witnesses.

Again and again cameras are more likely to be carried away by events than to document and clarify them visually. They seem fascinated with participating in the revolution, seeking to create history by sheer mediality. The visual state of emergency-that is, the convergence of events and representation-was achieved in the first TV moment of the revolution, in the public broadcast of Ceaussescu's interrupted speech, with the gap in transmission corresponding to a gap in political representation. But this did not happen again, even with hundreds of cameras on the streets. While the hysterical search for images continued, these came more and more slowly, more and more belatedly, until the dictator's and his wife's execution was broadcast hours late, undermining the politics of representation of the revolution and, especially, its authenticity. Significantly, Farocki would later describe the images of Ceauşescu's trial and execution as the "worst [...] of the entire revolution." 75 Their sheer unprofessionalism, their blurred and frayed quality, their indifference in regard to what they were actually supposed to testify to, their utter reliance on the video apparatus to generate intention, meaning, and evidence-all this was reminiscent of terrorist action and certainly failed to attest to the legal validity of the new power relations. As Daney wrote, the Ceauşescus' execution, repeated again and again on television, became a "grim simulation of a symbolic [act] that had become unable to achieve." 76

But instead of exploring the expectations and notions disappointed by these images, let us turn to their truth-claims as uncovered and defended by Farocki and Ujica. They do so, most effectively, in the film's prologue and epilogue, which stand out with respect to the rest of the filmic narrative and are presented without the detached voice-over commentary accompanying the other images.

In a cold opening, a wounded woman is shown lying in a hospital bed in Timişoara, weeping incoherently (Figure 2.3). She is surrounded by friends, family, and a group of cameramen. Noting the cameras around her, she asks to be recorded, collects herself, and addresses the Romanian people via television. She introduces herself as Rodica Marcau, recounts her attempt to defend a cooperative in Timişoara against the Securitate, and asks for support for the revolution. Baudrillard's “Timişoara syndrome" is thus contrasted right at the beginning of the film with a moving testimony from Timişoara. At the end of the film, after the long credits documenting the found footage sources, comes another direct appeal. People have gathered in a private living room. A man emerges from the group and condemns the fallen regime. Remembering the suffering and deaths the revolution cost his family and friends, he bursts into tears and concludes his speech: "I wish you a merry Christmas. Long live free Romania." By means of their direct address and their personal views of the revolution, these two Romanian voices from December 1989 surpass and "purify," as it were, all the other clips of doubtful intention and content. The images are thus finally allowed to reach 


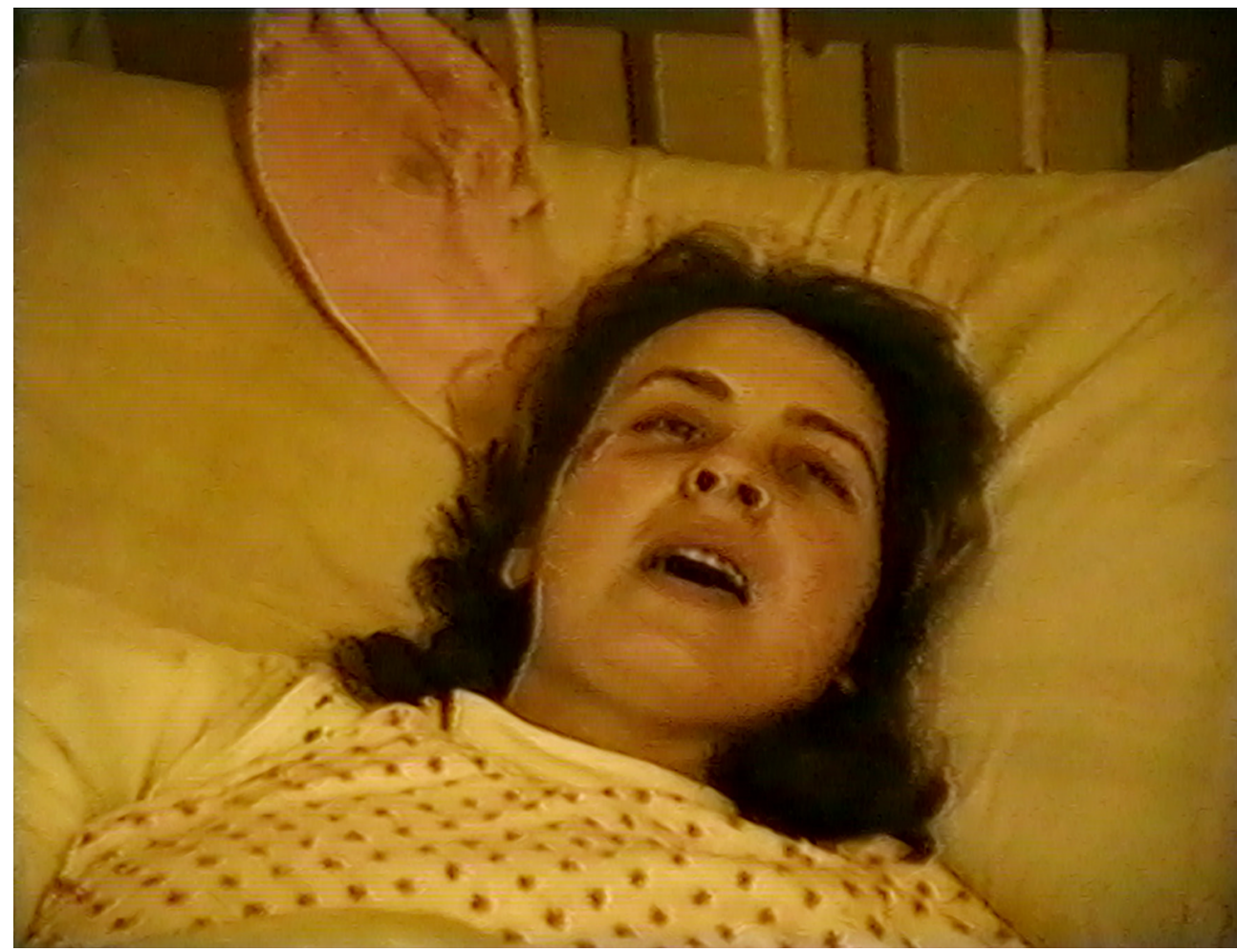

Figure 2.3 Harun Farocki and Andrei Ujica, Videograms of a Revolution, 1992. Still image, video transferred to 16mm, colour, sound, 106 mins. Photo (C) Harun Farocki/Andrei Ujica 1992

the destination for which they were intended: communicating actual events; attesting to violence, chaos, and emotion. It thereby becomes clear how the Romanian Revolution merged two conflicting visual conventions: private recordings intended for family and friends, and public documenting of the political events "outside," both made with the same cameras-which (not only in Romania) were still considered more suitable for recording Christmas parties than for broadcasting world news.

Videograms of a Revolution describes a profound change in communication technology and media that is still ongoing today, and it does so with the aim of salvaging the truth claims of the documentary for a newly emerging apparatus of image politics: film turned to video, public to private, documentation to simultaneous recording, mobile cameras fusing with moving bodies. If the fundamental elements of the documentary are completely transformed, Videograms of a Revolution suggests, it is all the more important to preserve and defend its ethos, and thus that of history. The significance of this shift to digital media for a reevaluation of history is manifest in the fact that its double nature as event and its representation has been merged in simultaneous recording.

The use of video cameras is associated with an organization of temporality that is geared not towards event-oriented perception of time but towards duration, ${ }^{77}$ leading to a completely different understanding of history. Video does not primarily represent the world. Instead, it records the progression of the continuous flow of time, closely interweaving camera and body-in-motion. This is all the more true for the visual material of the Romanian Revolution, as its intended (if rarely reached) addressee was 
television-which, due to its permanent "nowness" (a feature that transforms even prerecorded material into actuality and immediacy), is associated with the destruction of history rather than with its preservation, especially if compared with photography and film. ${ }^{78}$ Television is an apparently exemplary media-technological medium of "presentism" and the "end of history." Videograms of a Revolution thus documents the emergence of a highly improbable actor of democratic political communication-television, the epitome of one-way communication, infotainment, and mass consumption-by means of another highly improbable means of documentation-the video camera. Okwui Enwezor has associated the simultaneity of image and history generated in Videograms of a Revolution with a permanent state of emergency similar to carnival:

Intercutting professional footage, television studio broadcasts, and raw data recorded by amateurs camped out on the streets, Farocki and Ujica use the archive to rework the relationship between power and popular forms of representation in a mode that moves beyond spectacle and instead utilizes the expressive instruments of Mikhail Bakhtin's notion of the carnivalesque, elaborating forms of theatrical heteroglossia, the grotesque, critical dialogism. ${ }^{79}$

Enwezor has observed that the power of the television apparatus (which invites passive consumption) in this instance became bound together with an altogether different technological medium, as the video recordings of the Romanian Revolution attest to an active, participatory mode of image production. ${ }^{80}$ After decades of living under a "time slab," television finally achieved its long-imagined dream: to transmit real life from the street "live" into private homes. ${ }^{81}$

Activity instead of passivity, participation instead of one-way communication, politics instead of entertainment, all in a long overdue gesture of politically emancipating the much-maligned, private, feminized mass media: ${ }^{22}$ this is the potential political scope of image production the Romanian Revolution evokes; these are the hopes periodically awakened and disappointed in the digital age. To this day, video and television-as well as their contemporary successors, the internet and social media-permanently set us in active mode. ${ }^{83}$ "Liveness" has been replaced by "online" connection, as an apparatus of constant mutual affirmation of presence and contact. ${ }^{84}$

Instead of proclaiming the end of history and authenticity, Videograms of a Revolution describes a new cultural image practice. Let us look at the final sequence before the "Christmas scene" described above. Again we are in a private apartment; a group of people has gathered to view the dictator's trial and execution on TV. This politically significant moment - which is, actually, the joint televisual witnessing of a politically significant moment-is recorded on several cameras (Figure 2.4). A detailed voice-over commentary analysing this media-technical overload concludes with the words: "Film was possible, because there was history. We look on, and have to think, if film is possible, then history, too, is possible." This conclusion is found in similar form in a short description of the film written by Ujica: "Only the videocamera, with its heightened possibilities in terms of recording time and mobility, can bring the process of filming history to completion. Provided, of course, that there is history." ${ }^{85}$ Apparently, the filmmakers did not trust the found images sufficiently to allow them to be regarded as history without commentary and montage, without "filming." But they did respect the "readiness for history" ${ }^{86}$ attested by these images, the historical consciousness of their diverse creators in the sense of an agential, medial inscription into history as a permanent present, preserved by the endless recording and monitoring of the flow of time, which might turn into history at any moment. 


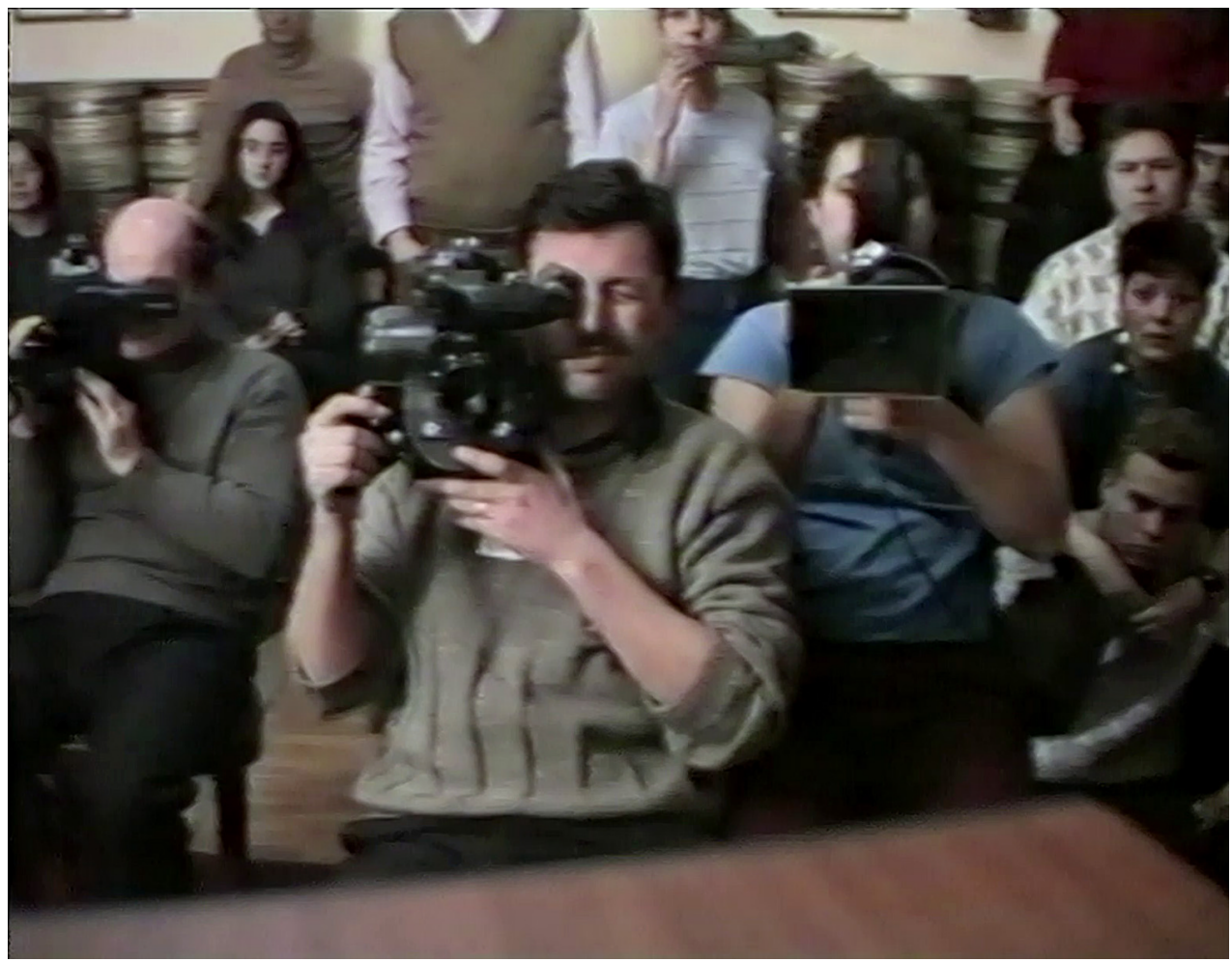

Figure 2.4 Harun Farocki and Andrei Ujica, Videograms of a Revolution, 1992. Still image, video transferred to $16 \mathrm{~mm}$, colour, sound, 106 mins. Photo $($ ) Harun Farocki/Andrei Ujica 1992

Videograms of a Revolution thus not only confronted the media-theoretical position of denying any veracity or truth to the found footage of the Romanian Revolution but also suggested new conceptions of the documentary. These new imaginings of what may become admissible media for and formats of the documentary reflect the technological and sociopolitical changes that had only begun to emerge on the horizon in 1989 but have since dominated global communication and the depiction of history. Today we experience the enormous extent of this transformation: electronic media have changed not only our perception of reality and our ways of communicating, but also our ways of organizing ourselves within time and space. Media technologies have long been used as extensions of human perception and communication. The way we relate to time and space, therefore, no longer primarily follows the traditional perceptuomotor disposition but is experienced interactively and synchronously. ${ }^{87}$ The abundance of endlessly produced new (image) data easily surpasses any human capacity to appreciate it even in minuscule part, while each of us contributes to the proliferation of new flows of time (and duration) in a parallel digital universe by means of video and mobile phone cameras.

The temporal structure generated by digital media, with its constant distribution of images ${ }^{88}$ is fundamentally different from previous types. We experience new kinds of time perception in a world shaped by global capitalism, after the "cinematographic time" ${ }^{89}$ of modernity. As Farocki and Ujica recognized early on, we need to acknowledge those synchronous and digital forms of documenting and preserving time that 
demonstrated, over the course of the Romanian Revolution, a "readiness for history" open to new conceptions of history that challenge the principles of the artistic documentary to the point of breaking it into new, presentist, digital constellations.

\section{Notes}

1 Lugon, "Documentary: Authority and Ambiguities," 35.

2 Wöhrer ("Die Kunst des Dokumentierens," 54) cites John Grierson, who first used the term programmatically: "Documentary was from the beginning [...] an anti-aesthetic movement. [...] What confuses the history is that we always had the good sense to use the aesthetes. [...] It was, paradoxically, with the first-rate aesthetic help of people like Flaherty and Cavalcanti that we mastered the techniques necessary for our quite unaesthetic purpose."

3 Within the extensive discussion of the documentary in art, these contributions are especially helpful: Balsom and Peleg, Documentary Across Disciplines; Lind and Steyerl, The Greenroom; Steyerl, Die Farbe der Wahrheit; Enwezor, Archive Fever.

4 Latour, On the Modern Cult of the Factish Gods.

5 See, among others, Zarina Bhimji's Out of Blue and Walid Raad's The Atlas Group, discussed in chapters 4 and 5.

6 See Stan Douglas's film installation Ouverture (1986), which combines historical footage of a train journey by the Edison Film Company in 1899 and 1901 with a text track from Marcel Proust's $\grave{A}$ la recherche $d u$ temps perdu, thus paralleling film and memory. See also Jean-Luc Godard's large-scale series Histoire (s) du cinéma (1988), which links film and history. On photography as a medium for depicting the past, see Barthes, Camera Lucida. On film as a historical medium, see Ferguson, Art and Film since 1945; Hohenberger and Keilbach, Die Gegenwart der Vergangenheit.

7 Ramos-Martínez, "Oxidation of the Documentary."

8 Nichols, Representing Reality; Nichols, Blurred Boundaries, esp. 92-106.

9 Rancière, "Documentary Fiction," 158.

10 "Control and Contingency. Excerpts from a conversation between Antje Ehmann, Harun Farocki and Volker Pantenburg." In Peleg, New Practices Across Disciplines, 12.

11 Nichols, Representing Reality, 3-4.

12 Ibid., 3.

13 Holert, Regieren im Bildraum, 192; see Hito Steyerl's concept "documentality" as the "permeation of a specific documentary politics of truth with superordinated political, social and epistemological formations. Documentality is the pivotal point, where forms of documentary truth production turn into government—or vice versa." Steyerl, "Documentarism as Politics of Truth."

14 Holert, Regieren im Bildraum, 191.

15 Ibid., 192-93.

16 Chapter 2 of the present volume is a revised version of Kernbauer, "Establishing Belief: Harun Farocki and Andrei Ujica, Videograms of a Revolution."

17 On the controversial question of interpreting the events in Romania as a "revolution," see Siani-Davies, The Romanian Revolution, esp. 3-4; Preuße, Umbruch von unten, 586-96.

18 Amelunxen and Ujica, Television/Revolution, 96.

19 Doane, "Information, Crisis, Catastrophe," 227.

20 On international estimates of the number of December 1989 victims, see Siani-Davies, The Romanian Revolution, 280-81. According to later estimates, in the days before the Ceauşescus' flight on 22 December, about 150 people died in Timişoara, 169 nationwide. A far higher number of victims, almost 1000 people, died in street fights during the first days after the change of power. Siani-Davies, The Romanian Revolution, 97, and Gabanyi, "Die rumänische Revolution von 1989," 256.

21 Amelunxen and Ujica, Television/Revolution, 88.

22 Amelunxen and Ujica, "Eine Chronologie der Ereignisse," 24; Schneider, "Das Gericht im Off. Der Prozeß gegen die Ceauşescus," 139.

23 Amelunxen and Ujica, "Eine Chronologie der Ereignisse," 23.

24 Agamben, "Marginal Notes," 81-82. Agamben went so far as to claim that even Nazi image policy had not dared to do the same. 
25 Daney, "Nicolae und Elena," 87. First published in Libération, 26 April 1990.

26 Rothöhler, Das verteilte Bild.

27 Baudrillard, "The Timişoara Massacre," 60; See also Young, "On Media and Democratic Politics," 245-60.

28 Baudrillard, “The Timişoara Massacre," 57-58.

29 Holert, Imagineering, 29.

30 Cowie, "The Spectacle of Actuality," 19.

31 Baudrillard, "Pataphysics of the Year 2000," 9.

32 Peleg and Balsom's introduction to Documentary Across Disciplines, 12, referencing Rosen, "Document and Documentary," esp. 240.

33 Arns and Horn, History Will Repeat Itself, 100; Arns, Cubarov, and Sasse, Nikolaj Evreinov.

34 Young, "On Media and Democratic Politics."

35 Amelunxen and Ujica, Television/Revolution.

36 The two filmmakers discussed their material in a men-only discussion with Andrei Plesu, Peter M. Spangenberg, Manfred Schneider, and Friedrich Kittler for their film Kamera und Wirklichkeit, shown on German TV in 1992.

37 The film blends both directors' styles. Ujica's more narrative film projects differ from Farocki's analytical style, as illustrated by Out of the Present (1996) and The Autobiography of Nicolae Ceaușescu (2010). The latter, a documentary of the Ceaușescu era, is a compilation of more than 1000 hours of propaganda material from Romanian archives.

38 Hall, Archive of the Romanian Revolution.

39 Holert, "The Apparition of the Documentary," 152.

40 Adorno, Aesthetic Theory, 240.

41 Steyerl, “The Uncertainty of Documentarism.” Steyerl (Die Farbe der Wabrheit, 15) similarly asserts that "its form will inevitably tell the truth about the context of the image itself, its production and its conditions." Other texts find him taking a more relativizing position between "realists" and "constructivists." See Steyerl, "Documentary Uncertainty."

42 Holert, Regieren im Bildraum, 13, 14. See also Geimer, "Wer regiert den Autor?"

43 Pintilie had ensured that Romanian radio and television broadcasts between 19 and 31 December 1989 could also be received abroad. See Gabanyi, Die unvollendete Revolution, 10.

44 Ibid., 9.

45 On the chronology of events, see Gabanyi, Die unvollendete Revolution, 11-19; Siani-Davies, The Romanian Revolution of 1989, 53-143 and 252-56; Amelunxen and Ujica, Television/ Revolution, 11-24.

46 On speculations regarding the origins of the commotion disrupting Ceauşescu's speech, see Siani-Davies, The Romanian Revolution, 84-85; Gabanyi, Die unvollendete Revolution, 94-95.

47 Doane, Information, Crisis, Catastrophe. On the ideology of "real-time" television, see Feuer, "The Concept of Live Television." See also John T. Caldwell's concept of the aesthetics of televisual "image effects" and "image performances" in Caldwell, Televisuality; Caldwell, "Live Slippages."

48 Ciocârlie, in Amelunxen and Ujica, Television/Revolution, 41-42.

49 Groys, Under Suspicion, 17-31.

50 This belief is necessary, as we rely on images to structure our everyday experience: "If there is a consensus emerging among the newest generation of documentary scholars, it may just be that representations of the real have more rather than less power to shape our world than heretofore, that the production and control of the flow of historically based images is increasingly the arena of social power that matters most. It's just that the sites and situations of documentary culture have exploded exponentially-on cable TV twenty-four hours a day, on urban billboards and big-screen displays, in museums and on the Internet." Renov, "Documentary Horizons," 324. See also Demos, The Migrant Image, xvii, 256n10.

51 Groys, Under Suspicion, esp. 19-22. Mary Ann Doane (Information, Crisis, Catastrophe) also points out the importance of the moment of media "catastrophe" to reactivate its promise of referentiality.

52 Daney, "Montage Obligatory."

53 Holert, "The Apparition of the Documentary,"160-61.

54 See Wenzel, E., “'Hinter der sichtbaren Oberfläche der Bilder,"” 275: "The authors try to get behind the visible surface, so to speak, of an image production in December 1989 in Romania that not only showed the social upheaval, but televisually authenticated and authorized it." 
55 Farocki in Etwas wird sichtbar (1982), cited in Elsaesser, "Harun Farocki," 12.

56 Farocki on Images of the World and Inscription of War (1988), cited in Pantenburg, "Visibilities," 26; see Pantenburg, Farocki/Godard.

57 Pantenburg, Farocki/Godard; Blümlinger, Kino aus zweiter Hand, 234-37; Didi-Huberman, "How to Open Your Eyes"; see Farocki's later lectures and texts on the topic: Farocki, Bilderschatz; Ernst and Farocki, "Towards an Archive for Visual Concepts."

58 Blümlinger, Kino aus zweiter Hand, 237-43.

59 Pantenburg, Farocki/Godard, 111-12.

60 Williams, "Mirrors without Memories," 13.

61 On the distinction between correspondence and coherence theory (and other philosophical theories of truth), see Kirkham, Theories of Truth.

62 Holert (Regieren im Bildraum, 15-16) underlines that images are seldom used independently in contemporary media, instead appearing as "hybrid image-text amalgams" or as "audiovisual affect clusters" that generate meaning.

63 Farocki, "Substandard," 260.

64 Farocki, "Written Trailers," 228.

65 Farocki, "Substandard," 265.

66 Videograms of a Revolution was produced for the cinema. It was Farocki's last such feature-length film before he turned to showing his work in exhibitions on a regular basis. See Farocki, "Written Trailers," 229.

67 Farocki, "Substandard," 255.

68 Ibid., 260.

69 Ibid., 255.

70 Holert, "The Apparition of the Documentary," 159.

71 Nichols, "The Question of Evidence," 99.

72 Geimer, Ordnungen der Sichtbarkeit, 7.

73 Daney, "Montage Obligatory."

74 Ibid.: "The visual would be the optical verification of a purely technical operation. The visual is without reverse shot, it lacks nothing, it is closed, looped, a little like the image of pornographic spectacle, which is only the ecstatic verification of the working of organs (and nothing more). As for the image-this image we loved in cinema to the point of obscenity-the situation would be rather the contrary. The image always takes place at the border of two force fields, it is meant to bear witness to a certain otherness; and although it always has a hard core, it always lacks something. The image is always more and less than itself."

75 Farocki, "Substandard," 259.

76 Daney, "Nicolae und Elena," 89.

77 "But with television, there is no longer representation, because television is itself a direct image of time. Video is time. Cinema is but one symptom of this new dimension. Cinema is an adventure of perception, whereas television is an adventure of time. [...] It is therefore useless to search exclusively for representation-images in video, because for images it is necessary to make things, to construct situations, events, forms of life. Insisting on the visibility (or better the nonvisibility) of video images is a false issue that brings us back to cinema." Lazzarato, Videophilosophy, 219-20.

78 Doane, Information, Crisis, Catastrophe, 227.

79 Enwezor, “Archive Fever," 39.

80 Lazzarato, Videophilosophy, 220.

81 "People now look upon scenes never before within their range; they see politics as practiced, sports as played, drama as enacted, news as it happens, history as it is made"-an idealistic projection on TV's potential, all of it in passive mode. Orrin E. Dunlap (1947), cited in Auslander, Liveness, 15.

82 Douglas, The Feminization of American Culture; Spigel, "Television in the Family Circle"; Huyssen, "Mass Culture as Woman."

83 Bourdon, "Live Television Is Still Alive." For an early, clairvoyant analysis of the entanglement of "old" and "new" media, which already includes a reference to the increased possibility of surveillance and manipulation of consumers, see Caldwell, "New Media/Old Augmentations."

84 Couldry, "Liveness."

85 Ujica, "Short text on Videograms of a Revolution." 
70 Ready for History

86 See Vivian Sobchack's introduction to The Persistence of History, 5.

87 Sobchack, "Scene of the Screen."

88 Rothöhler, Das verteilte Bild.

89 Doane, Emergence of Cinematic Time. 


\section{The Crux of Authorship}

The theoretical contributions to modern historiography discussed in Chapter 1 differ in many respects yet are united in their attribution of specific roles to the historian. Assumed to be male in most of the texts discussed herein, he is envisioned as a mastermind of universalization and synthetization; an impartial guarantor of objectivity; a practical politician anchored in the present; an emphatic interpreter able to incarnate historical subjects; and a distant, anachronic observer of his contemporaries. Each of these assigned roles represents a distinct methodical approach to and practice of history. But despite this performative foregrounding of the historian's role, historical scholarship in and of itself has produced surprisingly little authorship criticism. Artistic historiography, on the other hand, comes with a rich—albeit ambivalent—art-theoretical legacy that places immense weight on the role of the artist. Art that deals with history thus provides abundant material for reflection on authorial (self-)conceptions and on how various (artistic) subjectivities might handle the "raw material" of history-its documents, persons, and stories. Examining the works of three female artists working in the field of history, this chapter illustrates how artistic, auctorial subjectivity and the author's task of representing absent voices can be negotiated, especially when encountering other historical subjects.

\section{The "I" in History: Tacita Dean}

Tacita Dean's short film Pie (2003, 16mm, colour, optical sound, 7 mins., Figure 3.1) records a view out of the window of the artist's studio in Berlin-Mitte. A flock of magpies gathers on a wintry tree, their cackle mixing with the surrounding traffic noise. Attentive observers will notice that, especially around the lower right edge of the frame, the image is blurred-a phenomenon resulting from the exchange between warm and cold air moving through the open window. This barely visible effect results, it seems, from natural causes rather than from an intentional artistic gesture, and yet it serves to remind us of the location of the studio and thus ultimately of the artist's presence.

In comparison to other, more narrative works by Dean, who often turns to historical events-in works such as The Story of Beard (1992), Girl Stowaway (1994), Disappearance at Sea (1996), Disappearance at Sea II (1997), and Teignmouth Electron (2000)-this scene is unspectacular. But it makes all the more apparent a striking aspect of her work. The actual event depicted in Pie is itself caused by the way the artist has "prepared" the world to be recorded on film. The materiality of analogue film is brought to the fore, thus addressing a topic important to the artist, who has been pursuing its replacement with digital techniques in her work for years. ${ }^{1}$ The $16 \mathrm{~mm}$ film material leaves its blurred mark, as the artist has placed 


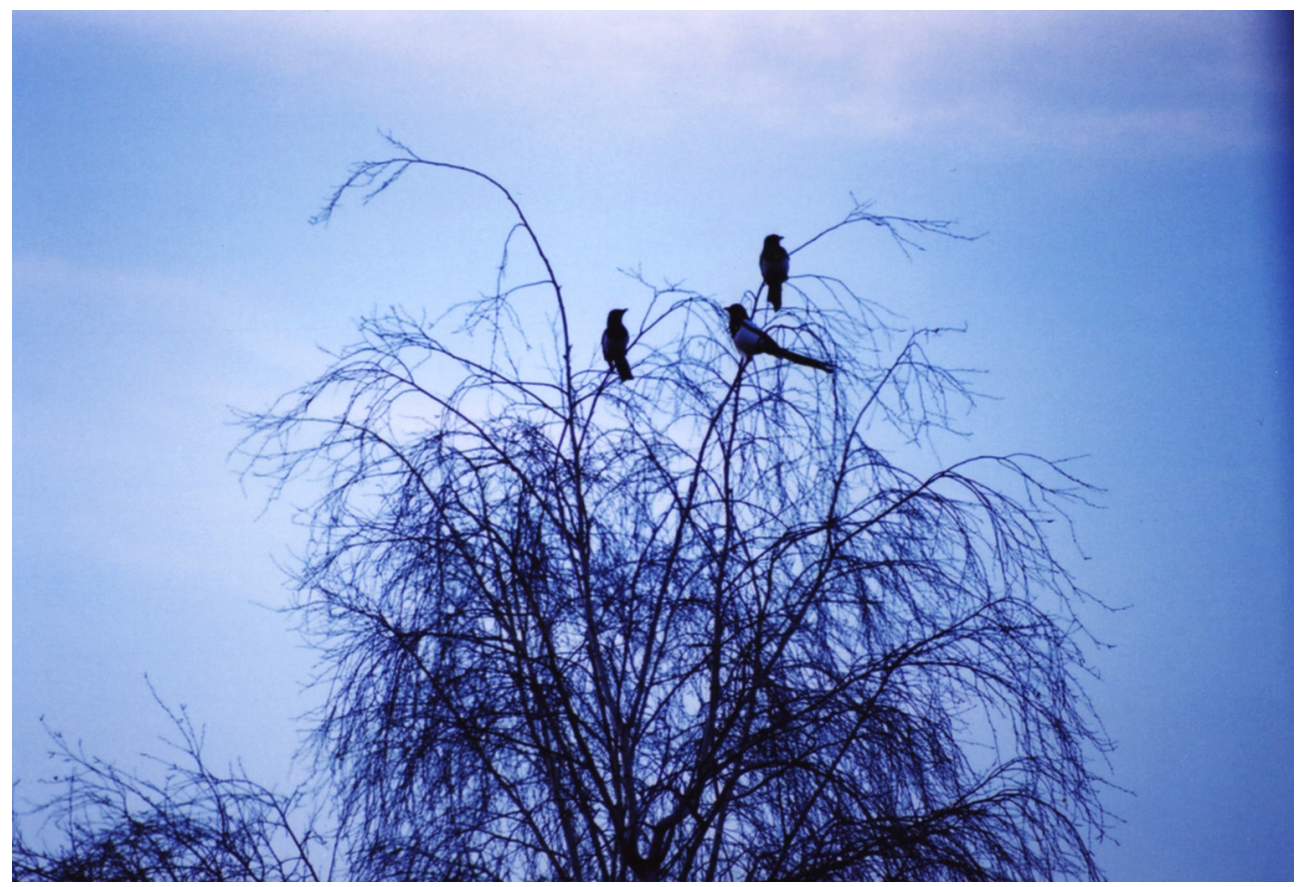

Figure 3.1 Tacita Dean, Pie, 2003. Still image, 16mm, colour, optical sound, 7 mins. Courtesy the artist; Frith Street Gallery, London; and Marian Goodman Gallery, Paris and New York. (C) the artist

the camera at the open window. In a short text, Dean brings together historical and personal associations with magpies, ending with a hint of the transience of the captured scene:

Now it's dark outside and I can hear some of them at last settled in my tree. I am afraid they may leave soon, as they only gather together for a short while in the spring to resolve territorial conflicts and establish their social standing. Their numbers are already depleting, and I miss them. ${ }^{2}$

This inscription of personal, often-melancholic associations into a found setting that the artist literally takes possession of ("my tree") is characteristic of Dean's work. A series of photoengravings entitled The Russian Ending (2002) also deals with mourning, albeit with a distinctly joyful, comic note. In this series, the artist tested different narrative modes (similar to Hayden White's "emplotments")—an idea that emerged after a conversation with printmaking expert Niels Borch Jensen about the early Danish film industry. At the beginning of the twentieth century, this industry briefly switched to producing films with two alternative endings for the international market-happy endings for the US audience, tragic ones for the Russian audience-leaving open which ending the rest of the world and the Danish audience preferred. Dean collected old postcards with views of catastrophes, disasters, wars, and the like, transferred them to photoengraving, and enlarged them several times. She published the resulting 20 scenes, scribbled over with handwritten notes and comments in a portfolio printed by Borch Jensen. The resulting cinematic storyboards overwrite the images and reinterpret them. Dean's handwritten notes perceive the photographs as freely available starting points for filmic narratives that can be assigned to specific genres, such as "A disaster movie" or "A cheaper Moby Dick" or a "B movie." 
“The Sinking of the SS Plympton" shows a stranded, sideways-tilted hull; the handwritten note commenting on the tragic loss of human life- "hands lost / all crew lost / all lost / LOST AT SEA"-is written below the shipwreck in the centre of the picture, while above it a "ZOOM IN" is recommended. The drama, therefore, is not necessarily the actual shipwreck ${ }^{3}$ but its cinematic staging as suggested by instructions to the camera. The found images are nothing but material for fictionalization, free to be transferred into "emplotments." Tragedy and comedy are proximate: the notes on Beautiful Sheffield (Figure 3.2), a black-and-white photogravure of a dystopian industrial landscape, propose a nostalgic musical about environmental pollution intended to overwhelm the audience with light and sound effects. Ultimately, The Russian Ending is also an ironic commentary on the growing attribution of truth value to analogue film and photography in the digital age. ${ }^{4}$

In his essay "An Archival Impulse" (2004), Hal Foster has emphasized the importance of idiosyncrasies in Dean's works, pointing out a tendency to identify the artist's practice with lost stories and individuals. ${ }^{5}$ Indeed, Dean's works are deeply personal and are directed against objectifiable archival structures: they revolve around her curiosity, which alone structures the manifold materials that she collects, processes, and arranges into displays and narratives. Chance is a guiding principle, but it is not of the playful or casual variety used in Dadaist or conceptualist settings; rather, this is a fateful, meaningful chance. ${ }^{6}$ Dean's practice is driven by the dynamics of searching, observing, and empathizing with historical characters, materials, and documents that subtly become enmeshed with the artist's curiosity and intuitions, her daily routines, interests, and observations (and vice versa). Historical research becomes a treasure hunt, as it leads to the discovery of enigmatic characters and captivating stories-and to artworks that allow viewers to witness the artist's fascinating expeditions into the past. But this is

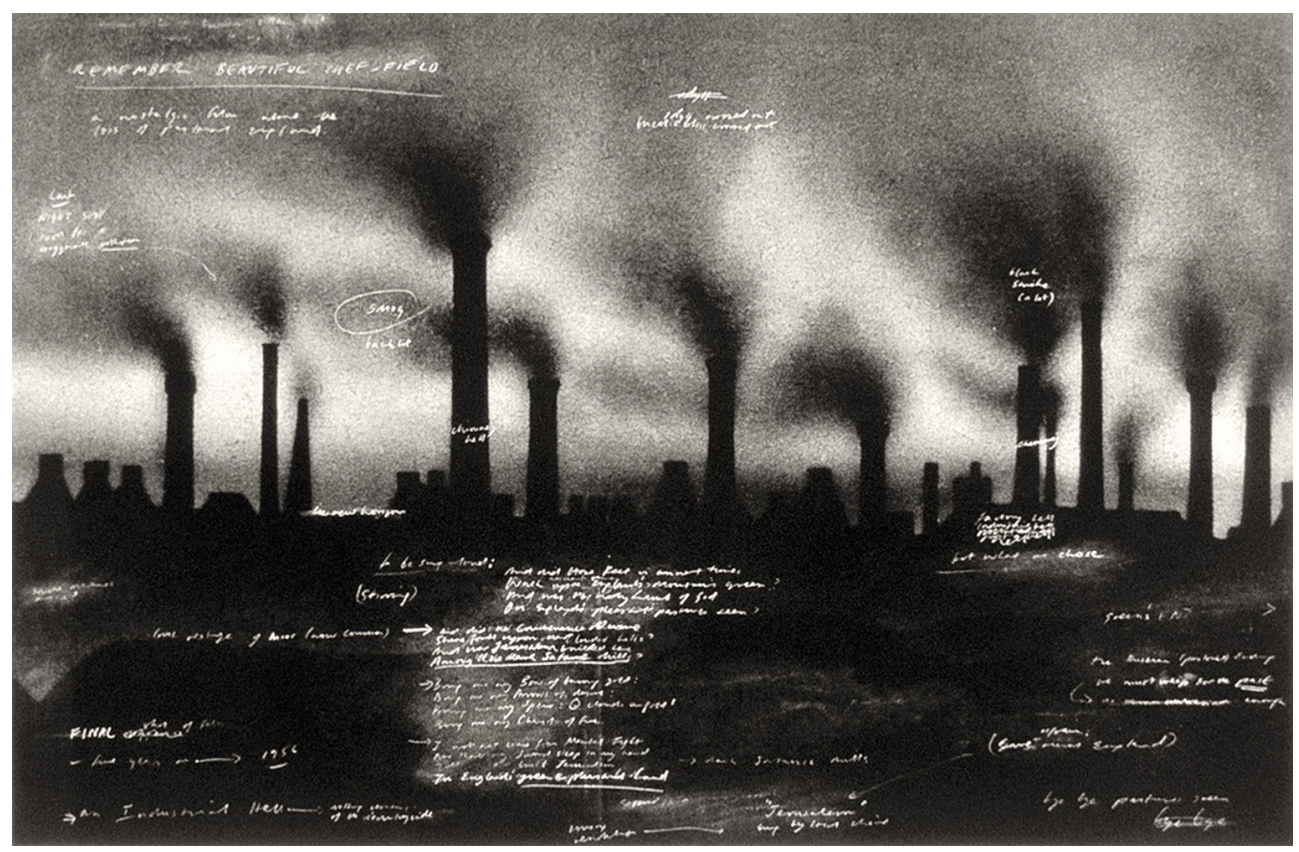

Figure 3.2 Tacita Dean, Beautiful Sheffield, 2001. From The Russian Ending series. Portfolio of 20 etchings in photogravure, each $54 \times 79.4 \mathrm{~cm}$. Courtesy the artist; Frith Street Gallery, London; and Marian Goodman Gallery, New York and Paris 
not a narcissistic gesture; rather, it reveals the pull of history that absorbs all aspects of Dean's life, resulting in a heightened perception of not only the numerous untold stories out there but also her own involvement in them.

A characteristic example of this approach is the early installation Girl Stowaway (1994), which includes a film (16mm, b/w, 8 mins.) and 12 photographs, drawings, prints, and small-format objects. Dean's point of departure was the discovery of a photograph of a young Australian woman who made a crossing to Falmouth, England in the 1920s disguised as a man. As in many of her subsequent works, Dean here used ships, shipwrecks, and the sea as motifs, ${ }^{7}$ which can be viewed both as a reference to an outmoded form of mobility and as a romantic symbol of destiny. Girl Stowaway consists of the $16 \mathrm{~mm}$ short film reconstructing the visually undocumented journey of young Jean Jeinnie in black and white as well as of the other photographs, texts, and objects that document a completely different journey: that of the artist as she researched the young Australian woman. In the process, Dean comes across a series of chance findings that she uses to create a surprising and exciting poetic fabric, including a newspaper clipping reporting Jean Jeinnie's voyage; a postcard of the ship (the Herzogin Cecilie); and an album cover of David Bowie's Jean Genie (a homophone of the young woman's name), which itself is a tribute to Jean Genet, whose name in turn refers to a shrub (the broom) that is often found on the English coast where the ship was wrecked in the 1930s.

These are just some of the steps in a narrative that also takes dramatic turns, as Dean relates in a conversation with Jeffrey Eugenides:

How that whole story began was I found a photograph of this girl stowaway in a second-hand book at a flea market, The Last of the Wind Ships. She stowed away in 1928 on a ship called the Herzogin Cecilie, which was sailing from Australia to Falmouth in England, Cornwall. I was instantly attracted to this image of her so I bought the book. It was actually my first relevant flea-market purchase. Then I took it with me on a trip to Glasgow, Scotland, and in Heathrow Airport I put my bag, which had the book in it, through the hand-luggage $\mathrm{x}$-ray machine, walked through the security arch, and then went to collect it, and the bag had just disappeared. It was extraordinary. Then quite mysteriously and strangely, a week later I got a phone call, while I was still in Glasgow, saying that my bag had been found going around and around the Aer Lingus luggage belt in Dublin Airport.

[...] I picked it up at the airport on my way back to London, and at first I was trying to get some press attention on how unsafe it can be to put all your best belongings into that $\mathrm{X}$-ray machine. But then I decided to write the newspaper article myself, telling the story of how my stolen bag containing the stowaway's picture had made its way to Dublin by this strange circuitous route. I made and printed it in the style of the British newspaper the Guardian. At the same time I wanted to make a parallel article in the style of the period that I imagined she had stowed away in. I had studied at Falmouth School of Art, so I already had a relationship to that town. I rang up the Falmouth Packet, the local newspaper, and told them I wanted to fabricate an article about the stowaway, and they actually had a record of her arriving in Falmouth on the Herzogin Cecilie in 1928; her name was Jean Jeinnie and she stowed away from Port Lincoln in Australia. [...]

After that, I decided to take it even further and I fabricated a film with a windup Kodak camera of her, I mean of somebody who looked a bit like her, aboard my version of the Herzogin Cecilie. She'd stowed away in 1928, and I found out the 
ship had wrecked in 1936. At that point I decided to go on a sort of pilgrimage to find the place where the real Herzogin Cecilie sank, off Bolt Head in Devon, the county up from Cornwall. [...]

I went to Starehole Bay with a friend and camped above the wreck (which you can still see) which you're technically not supposed to do. We filmed the wreck of the Herzogin Cecilie the next morning on this beautiful July day, and then left. Then a day or two later, we saw that on the very day we were there, hours or even minutes after we left, a young woman had been raped and murdered in daylight. The whole thing became sort of uncanny and unpleasant because we became the last people who- the friend I was with in fact turned out to be the last person who had seen her alive and he also saw her murderer. [...] I was questioned in Brixton police station, my friend was questioned down in Cornwall. We had to make maps of where we were, and of course our maps just didn't match at all.

[...] The most extraordinary thing is that suddenly in the Guardian, there was a photograph of Starehole Bay showing the wreck of Herzogin Cecilie. And within my own narrative, you know, the whole thing began with me fabricating the Guardian article. ${ }^{8}$

Jean Jeannie's actual story ultimately remains unknown, even after Dean discovered these few individual clues about the girl's passage. The artist's journey in Jeannie's footsteps gradually becomes the centre of the narration, although Dean's report as quoted above is not presented in the gallery. Nevertheless, the installation unfolds along Dean's seeking of clues to an ultimately unsolvable mystery, leading to numerous turns and coincidences for which Dean borrows the Surrealist term "objective chance": a fateful chain of events arising out of an unexplainable necessity. ${ }^{9}$ The artist's report of her research as determined by found documents and materials that attract further narratives, inseparably interweaving researcher and history, recalls her use of the term "analogue": "haptic," "localizable," “auratic" (in Benjamin's sense). ${ }^{10}$ Historical things are determined by their materiality, physicality, and presence; they must have aged, changed, or been lost, as the traces of time are imprinted on them. History, in this sense, requires "analogue" artistic practice. Analogue forms of collecting-itself belonging to a perishing culture ${ }^{11}$ — come closest to such an accumulative understanding of history, with accidental finding of objects and stories that are remnants of their time. The artistic techniques associated with this approach to history are those frequently used by Dean: analogue film, writing, drawing, ${ }^{12}$ and other graphic media that allow the visible inscribing of time and materiality.

When Dean was asked to contribute to a discussion on obsolete materials and technologies-which, following Benjamin, lends itself to a critique of technological and capitalist rhetorics of progress-she wrote:

For me, obsolescence is a state of normality. Everything that excites me no longer functions in its own time. The one thing I have noticed is that so often I am attracted to things conceived in the decade of my birth. I court anachronism-things that were once futuristic but are now out of date-and I wonder if the objects and buildings I seek were ever, in fact, content in their own time, as if obsolescence was invited at their conception.

So obsolescence is about time in the way film is about time: historical time; allegorical time; analog time. I cannot be seduced by the seamlessness of digital time; like digital silence, it has a deadness. I like the time you can hear passing: the 
prickled silence of mute magnetic tape or the static on a record. So obsolescence has an aura: the aura of redundancy and failure; the aura around what has been improved upon.

And yet obsolescence hounds my working life. Laboratories close down. Shops no longer stock spools. Brown magnetic tape is unavailable and the musician in the Fernsehturm updates his keyboard. And so obsolescence ends in an underworld of people dealing from dark rooms and flea-market stalls, until enough time passes, so that whatever it was that was obsolete, has now become rare. And rare no longer holds my attention. ${ }^{13}$

Dean's understanding of obsolescence not only implies being "outmoded" or "late" in a linear understanding of time but rather protests against a continuous progression of history entailing permanent erasures of practices, materials, epistemologies. Her practice springs from an anachronistic way of thinking and includes phenomena that were never at home in any time: futuristic innovations, designed past their time and now smiled at as relics of an era that was never theirs. This chronological homelessness is in part shared by the artist in an anachronic attitude that comes close to Siegfried Kracauer's extraterritoriality. As she clearly states, this attitude is not one of nostalgia but rather aims at capturing phenomena as they are in the process of evanescence-a unique, potentially essential experience of (dis)appearing. ${ }^{14}$ This last glow is similar to the legendary "green ray," an optical phenomenon of the setting sun, traced in yet another of Dean's films (The Green Ray, 2001). Her curiosity is aimed at objects and techniques that belong to this specific form of transience, in its material, auratic, personal, handwritten, "analogue" form. Her artistic historiographies interweave the time of the artist-historian and the time of the researched objects with the ever-renewing times at which her works are viewed and viewed again. Quite in contrast to any objective denial of subjectivity, Dean places her own curiosities, interests, and personal perspectives at the centre of her works. She presents herself as simultaneously entangled within and outside of history. As a paradigmatically anachronic artist-historian, she transfers her chronological wanderlust to her audience, presenting herself as part of the histories she has excavated.

\section{History by Proxy: Erika Tan and/or Halimah}

In an extensive project presented in different media since 2013, Erika Tan has been working with a historical personage, Malayan weaver Halimah binti Abdullah. ${ }^{15}$ "Halimah," as she is referred to in Tan's project, was brought to London during the British Empire Exhibition at Wembley in 1924-25. This exhibition was, at the time, the largest ever staged worldwide, dedicated to showcasing the global influence of the British Empire and presenting its colonial territories and dominions. Raw materials, along with agricultural and industrial products from more than 50 countries under British rule, were exhibited, as were the latest technological and agricultural developments from Britain itself. Surrounded by a purpose-built, "never-stop" railway line that connected the various parts of the vast area at Wembley Park, the exhibition included several country pavilions as well as spectacular attractions, including a purpose-built mine, a power plant, and a life-size replica of Tutankhamun's tomb discovered in Luxor just two years before. ${ }^{16}$ The exhibition's aim was to demonstrate the political and economic power and unity of the British Empire with a life-size spectacle, despite the ongoing struggles of its dominions and territories for independence. The exhibition guide 
describes the event as a "Family Party" intended "to strengthen the bonds that bind the Mother Country to her Sister States and Daughter Nations". ${ }^{17}$ Indeed, as sometimes happens with family celebrations, this exhibition staged a unity that had long since ceased to be a reality.

Together with 19 other people who lived and worked beside her in the Malayan Pavilion, Halimah binti Abdullah demonstrated and sold "native" crafts. ${ }^{18}$ In front of visitors, the group performed embroidery, weaving, and sewing as well as weapon and tin production. ${ }^{19}$ This display of people from non-European cultures was familiar to the public from fairs; from the 1860s onwards, world and colonial exhibitions across Europe had also introduced ethnographic attractions. ${ }^{20}$ In Great Britain, the Colonial and Indian Exhibition of 1886 had 34 "Indian craftsmen" demonstrate traditional manufacturing techniques. Several of these "genuine artisans, such as may be seen at work within the precincts of the palaces of many of the Indian Princes," 21 were former inmates of the central prison in Agra, who had learned their crafting skills in the colonial penal system and were supervised in London by the prison warden. ${ }^{22}$ Visitors could learn their names, their respective origins, and the diverse crafts they performed from the booklet accompanying the exhibition..$^{23}$ It is significant that it was forced, colonial labour that was to demonstrate the indispensability of manual labour in the industrial age. While British workers experienced the convergence of humans and machines on a daily basis as part of the ongoing mechanisation of production, manual laboursupported only by most basic, traditional devices-was exploited as a form of mass production in the colonies and, at the same time, presented as a fascinating curiosity at world and colonial exhibitions. ${ }^{24}$

The Malayan Pavilion at Wembley was not the only one showcasing non-European humans. The British Empire Exhibition included several "races in residence" in their respective national pavilions: "representatives of [...] local inhabitants at work in local conditions." 25 More than 270 men, women, and children were presented in what was suggested were their respective "typical" environments. The Hong Kong Pavilion recreated a life-size "native street" of shops, cafés, and restaurants operated by Chinese shop assistants, craftsmen, cooks, and waiters. A reproduction of a West African village showed how several families "live and move and have their being." A native theatre group performed several times a day in the Burmese pavilion. ${ }^{26}$ Little is known about the backgrounds of and motivations for these people to travel to Europe and be publicly presented in this way. At the Colonial and Indian Exhibition, their presence was, in many cases, forced, but the craftsmen and women in the Malay Pavilion at Wembley were designated as "staff." Their primary task was to represent their country. The question of who should present British Malaya, or be presented as a country representative, was given considerable attention: "From the very first it was the Committee's ambition that Malaya should be represented by Malays." ${ }^{27}$ A striking insistence on the primacy of self-representation was at the basis of the inclusion of Malay craftsmen and women into the British Empire Exhibition.

Irrespective of how the public may have perceived them, the Malay artisans may not have understood themselves as "ethnological exhibits." Halimah binti Abdullah, who was about 60 years old, performed as an "expert weaver": a representative both of a culture and a craft. Presenting her premodern craftmanship entailed embodying the "allochronic" timelessness—and thus lack of history—of the colony. ${ }^{28}$ The "races in residence" at Wembley were not considered spectacular savages like those human exhibits presented in countless other contemporary fairs and shows but, even so, they had very little presence outside the exhibition. Within the Malaya Pavilion, the staff 
were accommodated in poorly heated converted army barracks. ${ }^{29}$ And so, Halimah binti Abdullah's fate turned out to be similar to that experienced by other "living exhibits" transported to London: just a few weeks after she arrived in London she died of pneumonia. She was buried in the Muslim part of Surrey's Brookwood Cemetery. ${ }^{30}$ Several of the weavings created in the Malayan Pavilion were subsequently incorporated into the collection of the Victoria \& Albert Museum, either via purchases or as gifts, to provide evidence of the excellent craftsmanship in the colonies-the foundation of the British Empire's wealth.

This is the sparse information that Erika Tan was able to gather on Halimah binti Abdullah: "A minor figure in the exhibition history of Malaya, Halimah exists as a series of footnotes, gaining historical attention only for the act of premature or untimely death from pneumonia, in London and away from home." ${ }^{31}$ The examination of this historically documented personage, whose circumstances are largely unknown, has become the subject of the project series The Forgotten Weaver by the Singapore-born British artist. Tan started with the premise of considering the possibility of Halimah binti Abdullah's "repatriation." This aimed less at a physical transfer of her remains than at a figurative reintegration of her artistic and cultural heritage into contemporary Singapore. Tan developed this question in a series of projects in the context of SG50, the 50th anniversary of the city-state in 2015, which was celebrated, among other events, with the creation and opening of the National Gallery Singapore (NGS) and, with it, the establishment and presentation of a collection that would represent Singapore's longstanding, rich, and diverse cultural tradition. From the outset, Tan addressed issues of representation critically within her project, especially the political and ethical aspects of embodying, representing, and speaking for (absent) others. If Halimah binti Abdullah was on view in 1924 for a few months as a representative of a culture and a craft, what does it mean, then, to make her, almost 100 years later, the subject and material of an artwork that would feed her anew into the globalized exhibition circuit, albeit foregrounding critical aspects of representation? This question also extends to a nuanced discussion of Tan's own position: her engagement with Halimah binti Abdullah highlights Tan's own professional issues with an identity politics that repeatedly defines her only in relation to her country of origin.

The concept of representation encompasses aesthetic, epistemological, and political aspects, the latter particularly acutely in the depiction of-or acting by proxy for-persons who are absent, not able, or not authorized to act directly. ${ }^{32}$ Artworks aimed at portraying particular persons, stories, scenes, etc. are situated in the epicentre of the fundamental problem of how to represent this absent outside( $\mathrm{r}$ ), the "subaltern," ${ }^{33}$ such that it is (they are) recognizable without being stereotyped, advocated for without being patronized, acted for by proxy without being denied their own position as a speaker. These pitfalls are already inherent in artistic documentary, as they are indeed in every artistic or nonartistic act of showing, naming, and defining. ${ }^{34}$ They moreover inform artistic historiographies dedicated to rendering forgotten or marginalized histories visible and audible, especially those representing the cultural "other." As Hal Foster has outlined, the desire of artists and their audiences to gain access-via these hitherto unheard voices-to "truer" and "more real" foundations of history may outweigh any awareness or reflection on their own position as speakers or listeners within the institution of art. This problematic "siting of political truth in a projected alterity" 35 is also applicable to artistic history if it promises access to historical truth via the presentation of "other" voices (or those imagined as such). There remains to the historian, as Foster notes with reference to Benjamin, only an "impossible place": that "of a benefactor, of an ideological patron." 36 
In Wembley, Halimah binti Abdullah was exhibited as a representative of a colonial craft. Expanding the exhibition into real space (by the replication of entire neighbourhoods, the mine, the railway, and so forth) and showcasing "real life" as a spectacle was a gesture that upstaged not only the traditional exhibition (a means of displaying objects, texts, and images) but also reality itself. The British Empire Exhibition certainly did not reflect reality. Rather, it produced the spectacle of imperial unity and portrayed the economically beneficial (to the empire) continuation if not active expansion of manual work (in the colonies).

In her artistic exploration of the British Empire Exhibition, Tan directly engages with the instrument of animation so impressively used in Wembley: "Halimah" first appeared in the 20-minute video A Presentation by Proxy (2013) at a video conference in which she (Halimah) digitally represented the absent Erika Tan, who had been invited to speak at a book presentation. ${ }^{37}$ The life breathed into "Halimah" consisted of a digitally animated "Malay" voice. ${ }^{38}$ "Halimah" introduced herself as speaking in place of the artist-who, conversely, had adopted her story. From the beginning, then, their relationship was one of reciprocal transformation and representation: "Halimah" spoke through Erika, Erika through "Halimah." "Halimah's" ensuing presentation pointedly addressed issues of identity: she began by stating her biographical and cultural background, arguing that this is often required when someone represents someone else. She introduced herself as a performance artist and participant in the largest exhibition ever in London, having acted-with her coperformers-as "social animators," housed in a "residency" at the exhibition venue. "Halimah," therefore, appeared simultaneously as subject and object of history, in a double role that she described by quoting Alain Resnais's Les statues meurent aussi (1953): “When men die, they enter into history. When statues die, they enter into art." This opened the question of whether the dead Halimah binti Abdullah had become "history" or had, by becoming part of Tan's work, entered the realm of art.

When A Presentation by Proxy was shown at NUS Singapore in 2013, preparations for SG50 were in full swing. The question of which artists, which art histories, and which cultures would become part of the Singapore Galleries at the newly opened National Gallery, was fiercely debated. This is reflected in Tan's notes:

For example, while as of 2014 the Malay demographic made up 13.3\% of Singapore, in the recent list of " 50 Singaporean Artists You Should Know for SG50" published by an international news site, only 4 of the 50 mentioned were Malay, the rest being Chinese or Eurasian. This equals only $8 \%$ of the total and all 4 were male. ${ }^{39}$

The question of whether Halimah binti Abdullah, as a Malay weaver (hence, as a craftswoman), would ever make the transition into Singaporean art history, was discussed in a structured live debate within the framework of the exhibition EX PARTE (2015) at London's Brick Lane Gallery during the SG50 celebrations. Four theorists and curators contributed arguments for and against the idea of Halimah binti Abdullah's "repatriation" and her role as a cultural ambassador. Tan brought both projects together in a new performance, which she developed for the Centre for Contemporary Art Singapore (NTU CCA Singapore) that same year. In Halimah-The-Empire-Exhibition-Weaver-who-Died-WhilstDemonstrating-Her-Craft, several performers appeared as "Halimah," directly debating her representativity and exemplarity. "Halimah's" identity was expanded across different roles, the performative mode allowing the testing of different narratives and forms of representation so as to probe into the historical character and her legacy. 
This discussion is further complicated by the fact that Halimah binti Abdullah had actually originated not from what is today Singaporean territory but from the neighbouring Sultanate of Johor (now Malaysia), which had also been under British administration as part of Malaya. In the context of Tan's project, this entailed a slow shift from questions of repatriation to those of reappropriation and to the historical reference points of Singapore's contemporary production of cultural identity. As a logical next step, Tan moved the debate directly onto the premises of the National Gallery Singapore, shortly before its opening. APA JIKA, The Mis-Placed Comma (2017, 9 mins. 54 secs., Figure 3.3) combined, within a two-channel video work, a live debate among a group of young (predominantly Chinese) women, dance performances by Som Said (chosen for her acknowledged status as a Cultural Medallion holder for Malay Dance and for her similarity in age to Halimah binti Abdullah), an all-female film crew (predominantly Chinese), and the background activities of male (mostly migrant) construction and technical staff. ${ }^{40}$ The question of deputy representation was thus addressed in the symbolic centre of Singapore's national self-location. Here, too, the problem of advocacy in the context of cultural, linguistic, and economic power asymmetries was made clearly visible: just as this problem characterizes the relationship between Erika Tan and Halimah binti Abdullah, it is also evident in the confrontation of the young, eloquent "Halimah" performers-from the

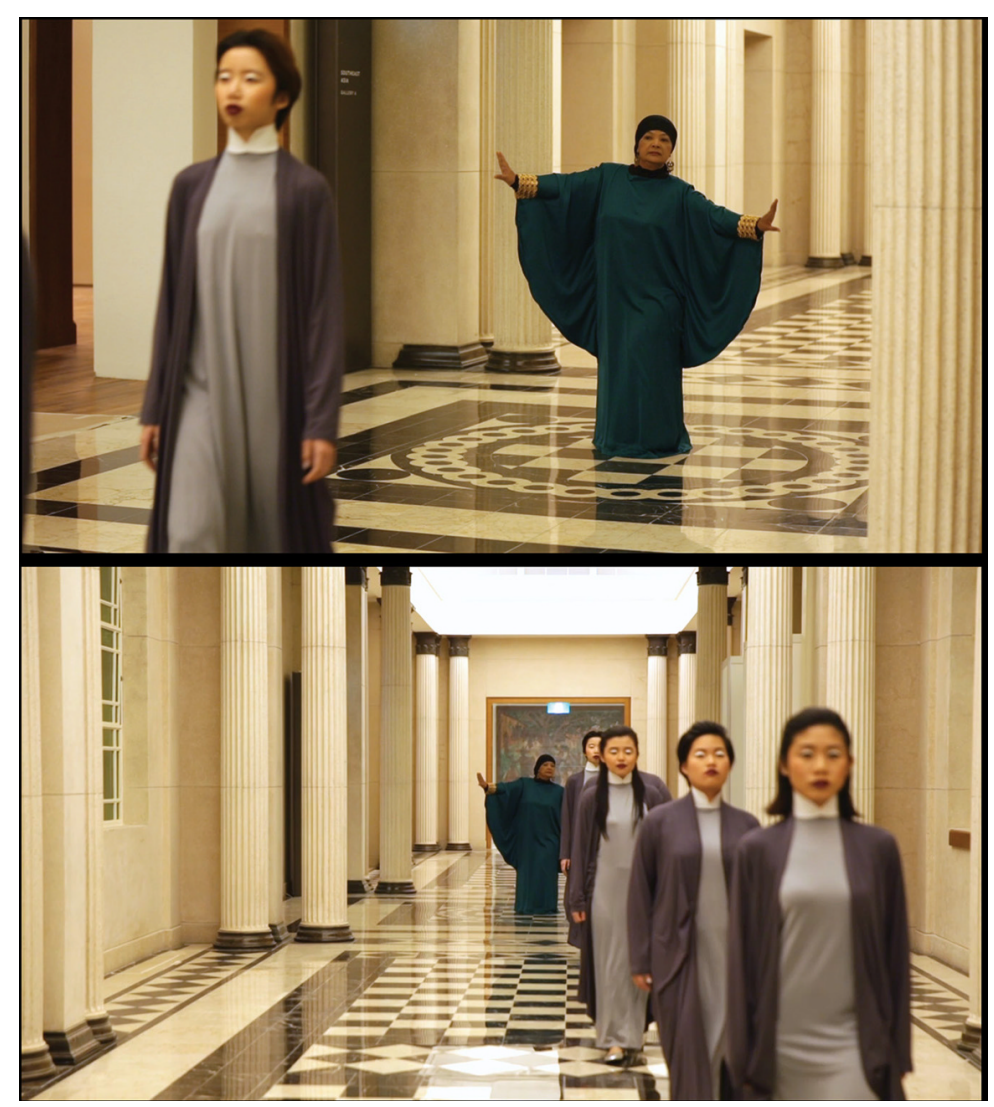

Figure 3.3 Erika Tan, APA JIKA, The Mis-Placed Comma, 2017. Still image, synchronized two-channel video, 9 mins. 54 secs. Commissioned by The National Gallery Singapore Image () Erika Tan 2017 
educated and tendentially dominant Chinese-descended population-acting somewhat as jurors within this national space and culture with the older Malay dancer, who primarily addresses the audience through the means of traditional dance and a voice-over inhabiting the space. All the questions hitherto central to the project-questions of representation, of acting and speaking for by proxy, of history as a site of cultural projection-were brought under examination within the symbolic centre of Singapore's national culture.

As the artwork unfolds, the film crew observe, document, and reflexively reconstruct the staging of this "piece of history." Within the video, weaving as craft is represented in the voice-over spoken by Som Said, both during her performance itself and through the weaving together of these disparate strands and elements. The craft is also more directly referenced in the presence (on screen and within the National Gallery spaces) of an incomplete wooden loom loaned to the artist from a museum that had previously employed a weaver from the region to visit Singapore and demonstrate her craft. On completion of this activity, the weaver returned home, leaving the loom and an incomplete textile behind. The story of the incomplete loom and textile connects this work to The Weavers Lament, an installation Tan produced for the exhibition Artists and Empire (Singapore and London, 2016/17, Figure 3.4). This installation was conceived to include the "return" to Singapore of an historical artefact from the British Empire Exhibition: ${ }^{41}$ the original Malayan Pavilion loom, used by the weavers, with incomplete textile, which had been housed in the stores of the Victoria \& Albert Museum in London (Figure 3.5). Theoretically, this was a remnant of Halimah binti Abdullah's work; more importantly, it constituted a direct testimony of the work produced at the exhibition. The Weavers

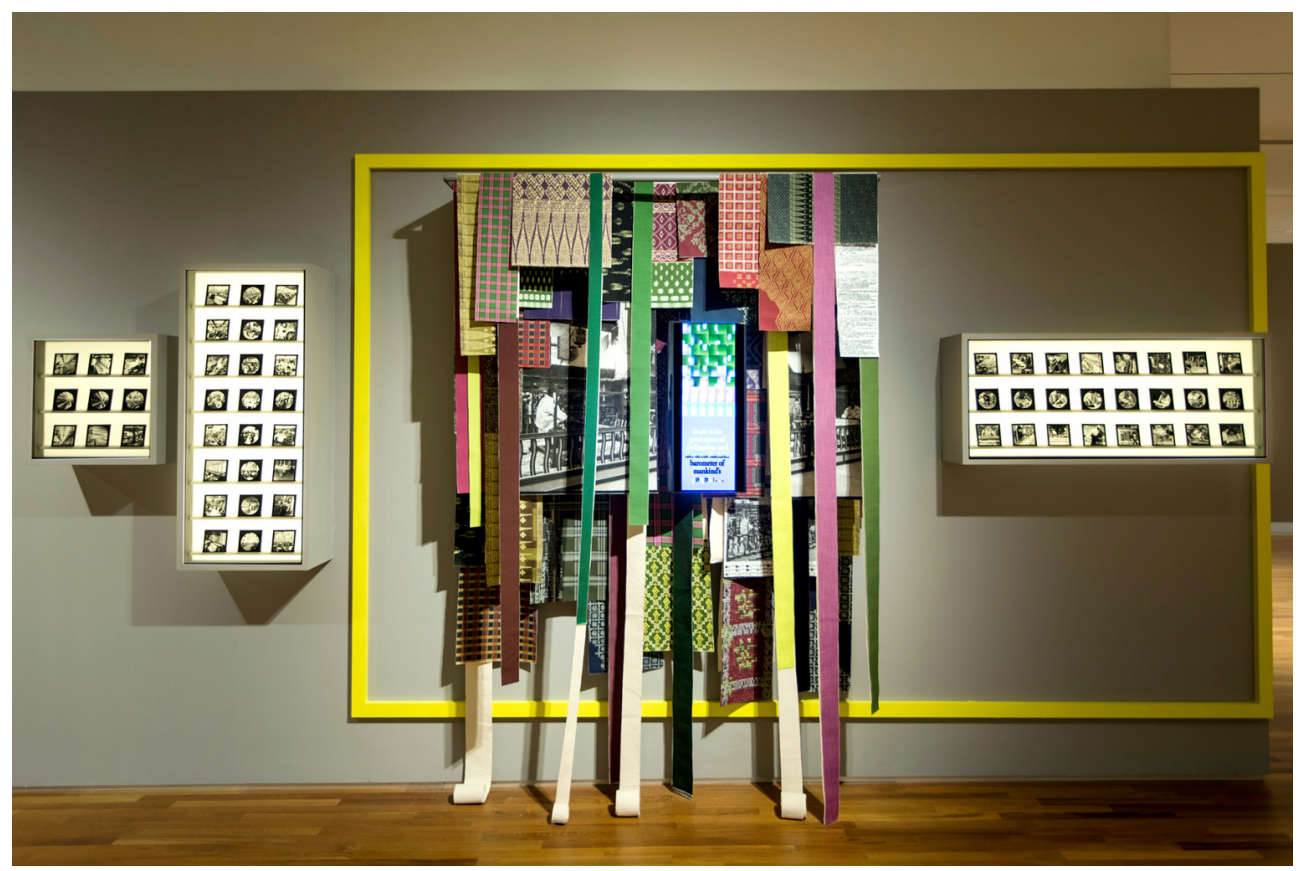

Figure 3.4 Erika Tan, The Weavers Lament. Part I: Performing Pattern / Part II: Mathematical Wefting / Part III: Tensions in the Warp / Part IV: Supplementary Erasure, 2016. Magic lantern glass slides, digital textile prints on canvas, HD video. Exhibited in Artist and Empire: (En)countering Colonial Legacies, National Gallery Singapore. Collection of the artist. Image courtesy National Gallery Singapore 


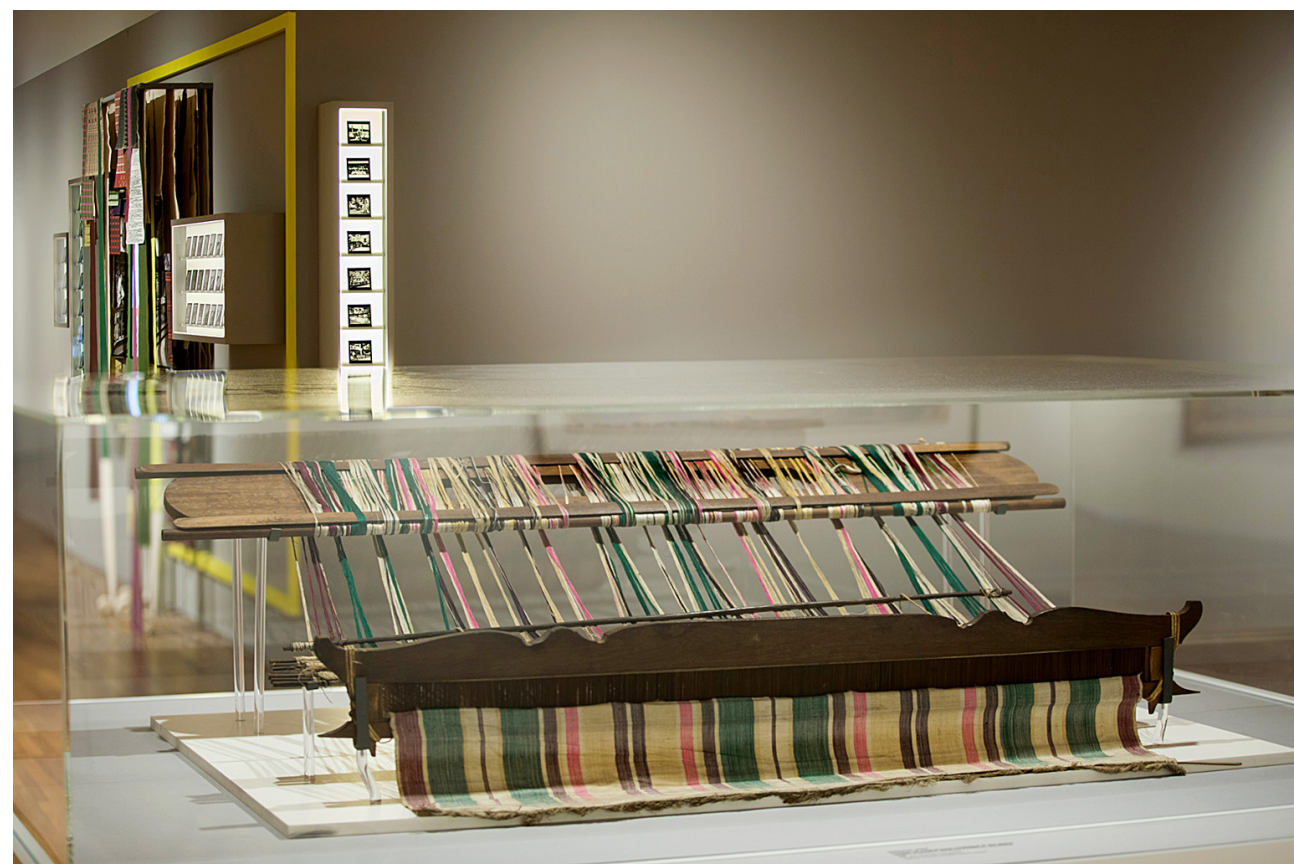

Figure 3.5 Unknown artist, Portion of a hand loom exhibited at the Malaya Pavilion, British Empire Exhibition, Wembley, 1924. Teak, cane, silk threads, cord, bamboo, $188 \times 130$ $\mathrm{cm}$. Victoria and Albert Museum, London. Installation view, Erika Tan, The Weavers Lament, 2016. Exhibited in Artist and Empire: (En)countering Colonial Legacies, National Gallery Singapore. Image courtesy National Gallery Singapore

Lament also included digital fabric prints on canvas depicting other historical textiles from the Malayan Pavilion also in the Victoria \& Albert Museum collections: a display of magic lantern glass slides documenting other regional female handloom weavers; European women and children working mechanical mills; and more recent industrial scale textile production in Asia, again all performed by women. A looped video was shown alongside the textiles that detailed the economic and political context of the emergence of the textile industry up to its current mechanisation and digitisation.

In the literal sense of the word, the installation interwove historical information and images into a complex social history that provided the exhibited textiles with context while posing the question of whether an adequate engagement with their creators had taken place. If Malay textiles were now becoming musealized-and thus artworksthis was directly linked to the downfall of the British textile industry in the first decades of the twentieth century. "Halimah" had now-via several intricate paths that foregrounded the musealization of her craft more than her having become the subject of an artwork-entered art history as an artist: "her" loom had arrived at the museum.

"Halimah" takes up a similar position in The "Forgotten" Weaver (2017), the penultimate work in the project series produced for the Diaspora Pavilion at the 57th Venice Biennale (2017). Here, a loom-like apparatus served as a projection space for two videos from the project series: APA JIKA, The Mis-Placed Comma and Balik Kampung: Return by Proxy. On a narrow screen made from packaging strapping, the films were only partially visible, providing less detailed information than in previous versions. Instead, the artwork staged the historical context of weaving, as installation, performative, and 
audio-visual components were condensed into woven fabric. Ironically, "Halimah" had thus entered the framework of the Venice Biennale-Europe's preeminent art exhibition-which, with its national pavilions, continues to harbour the spirit of the World Fairs. But she could only do so in the Diaspora Pavilion, which alone could provide a platform for her craft and for her status as the citizen of a country no longer in existence.

Tan's project points out not only one representative historical fate and its echo in the present but also the pitfalls of appropriating, reappropriating, and activating historical personages in contemporary art and cultural politics. Her series leaves us with more than just the memory of a formerly forgotten footnote in history. It presents a critical and reflective examination of the practice of representing absent, sometimes subaltern, subjects, against which academic and artistic history should equally be measured as they are always speaking for absent voices.

\section{Geography, History, Language: Dialogue and Diglossia in Bouchra Khalili’s Foreign Office (2015)}

Bouchra Khalili's installation Foreign Office (2015) consists of a 22-minute digital film of the same name, shot in an 6:7 image ratio; a screen print entitled The Archipelago, featuring an abstract political cartography of the city of Algiers; and 15 large-format colour photographs of historical sites in the Algerian capital. ${ }^{42}$ The film treats a phase from the first decade of Algeria's independence, 1962-72, when the city was considered a "Mecca for revolutionaries." The silkscreen shows a cartography of more than a dozen "foreign offices" of liberation movements based worldwide, their acronyms marked in white on a light blue background (Figure 3.6): ANC (African National Congress), FRELIMO (Mozambique Liberation Front), MPLA (Popular Movement for the Liberation of Angola), several Palestinian liberation organizations, BPP (Black Panther Party), FLE (Eritrean Liberation Front), and ZAPU (Zimbabwe African People's Union). Working with Edouard Glissant's concept of “One-World” (Tout-Monde), The Archipelago depicts the former offices of these organizations in Algiers as seemingly solitary units that, connected to each other underground, are spread out across the entire urban space. The 15 colour photographs show their former office buildings, now largely abandoned or converted (only one of the Palestinian liberation organizations still has a seat in the city), and former hotels that used to house well-known artists and activists such as Stokely Carmichael and Miriam Makeba. One photograph shows the site of the former Hotel Victoria, where Karl Marx-like Eldridge and Kathleen Cleaver of the Black Panther Party decades later-stayed in the spring of 1882. Three others show sites important to Berber writer and activist Kateb Yacine, a protagonist of the Algerian liberation struggle.

The film begins within a strikingly scenographic setting introducing the set-up within which the historiography will unfold. A frontal camera shot shows an empty table in front of two empty stools. Several rows of photographic documents and a technical drawing of a camera are mounted on the back wall. This provides the setting in which two young protagonists discuss the history of Algiers (Figure 3.7). Khalili's introduction to the past begins with a demonstration of how to approach it via historical documents. The next shot shows a poster of the 1969 Pan-African Festival that was held in Algiers, accompanied by a stirring acoustic prelude: a piece by jazz musician Archie Shepp that opens: "Nous sommes revenus! We have come back! [...] Jazz is an African music!" Then an insert shows the film's title, followed by that of the first and shortest chapter, "The Geography." Here, the archipelagic cartography of Algiers from the silkscreen is being created. Using black pencil, a young woman and a young man take turns marking locations of numerous revolutionary "foreign offices" located in Algiers, reciting the names and acronyms of the organizations in their respective original languages. 


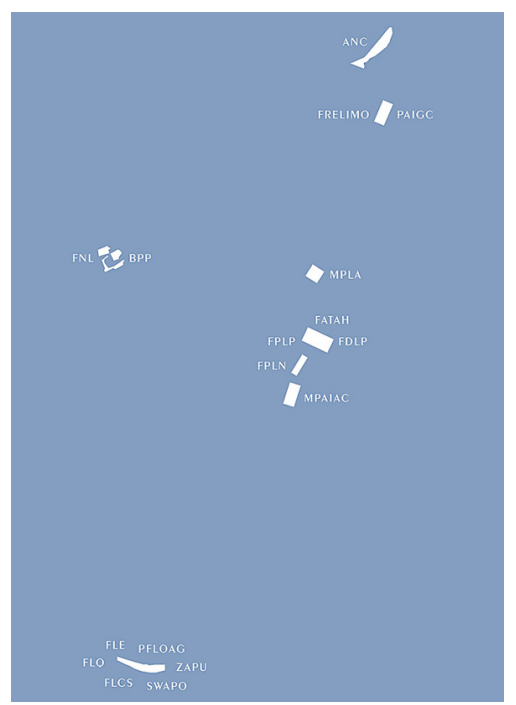

Figure 3.6 Bouchra Khalili, The Archipelago, 2015. Silkscreen print, $70 \times 50 \mathrm{~cm}$. Courtesy the artist and mor Charpentier

In the second and longest chapter, "The History," the set-up from the first shot comes into view again: A dialogue arises between the two protagonists, who describe and discuss the different actors and political groupings depicted by the photographic documents mounted on the back wall. Each speaks a different language used in Algeria: the young woman speaks Algerian Arabic; the young man, Kabyle. Additionally, they alternate between English and French. All this helps to illustrate the confusion of languages at the Algiers Pan-African Festival of 1969, where debates arose around what the "right" language should be for political struggle. In Algiers, the practice of using the transnational language of the colonizers, as had been done at the first Festival mondial des arts nègres in Dakar in 1966, was rejected; although French remained the common tongue for many prominent activists, English and Arabic were used for the concluding cultural manifesto. ${ }^{43}$ In Khalili's film, the different languages illustrate different political projects and identities so that the two speakers alternately perform different (historical and contemporary) roles: Algerian Arabic; the ancient Berber language Kabyle, suppressed now for generations; French as the official language; and English as the contemporary global lingua franca. What is formally presented as dialogue, therefore, actually turns out to be a juxtaposition of historical and contemporary identities-even more so as the text spoken by the interlocutors mostly consists of quotations. As in Erika Tan's "Halimah" project, the two speakers do not speak "from within" or "for themselves" but present a polyphonic montage of different, even dissonant, historical moments and positions.

The chapter opens with a historical narrative:

It begins with a night that lasted for centuries. A colonial night that spread everywhere. [...] We wake up from a nightmare that lasted 132 years. Others were already awake, others are awaking with us, others will follow. 


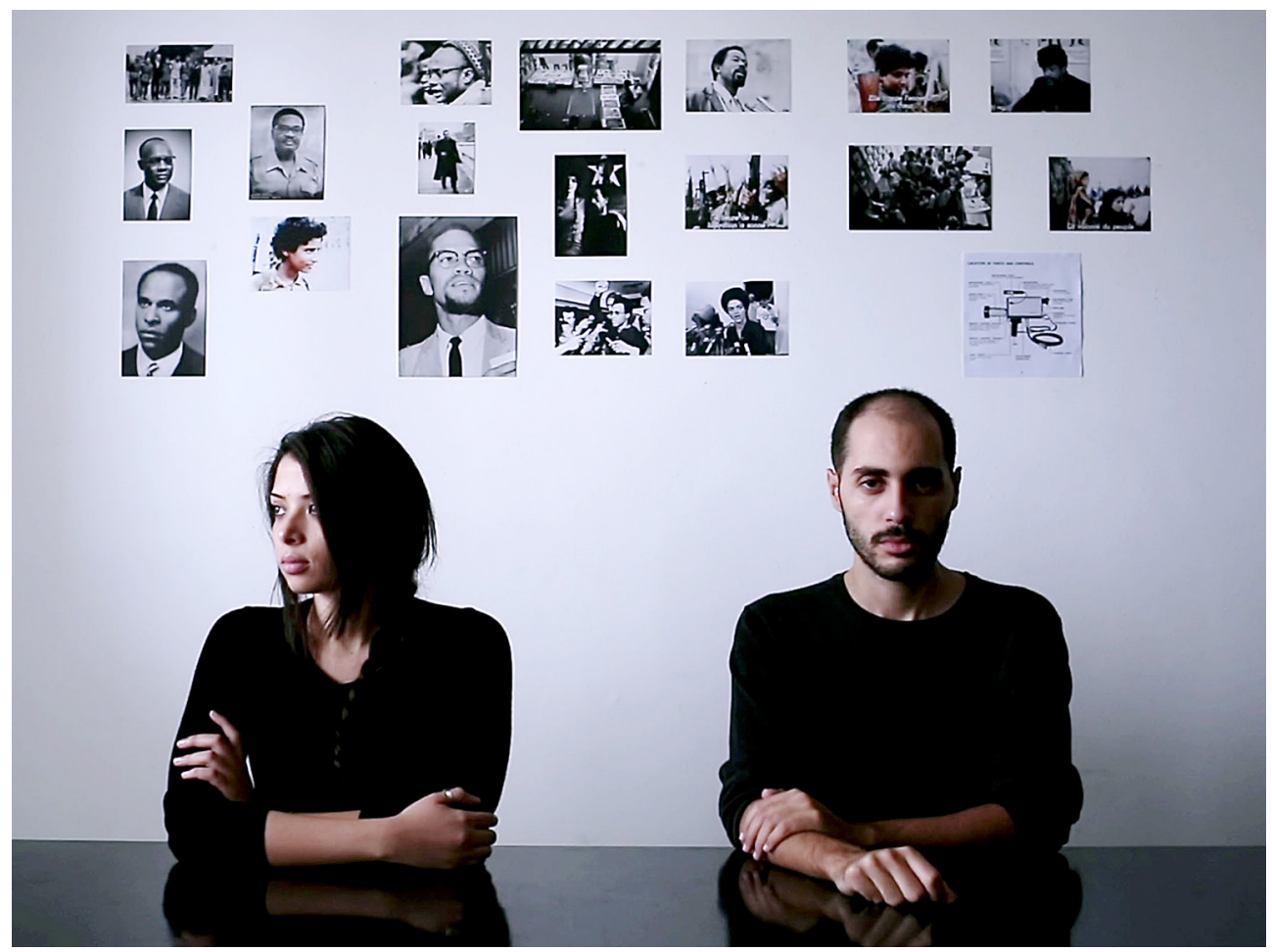

Figure 3.7 Bouchra Khalili, Foreign Office, 2015. Still image, digital film, colour, sound, 22 mins. Courtesy the artist and mor Charpentier

These sentences echo the emancipatory literature of the young republic with borrowings from Ferhat Abbas's La nuit coloniale (1962). The speakers then proceed to analyse the visual documents presented on the back wall: Who is shown and how? Which types of encounter are documented? Out of what connections did they emerge? The photographs show activists from Algiers: Amílcar Cabral, Mario Pinto de Andrade, Agostinho Neto, Eldridge Cleaver, and Frantz Fanon. There are also other, less wellknown activists such as an Omani freedom fighter with the nom de guerre Peninsular Moon. The two young people discuss the activists portrayed; trace their biographies; recite statements and quotations from their writings and from related historical sources; express doubts about some of the identifications in the pictorial documents, which are indeed at times contradictory; and comment upon the way the activists are presented. Amílcar Cabral, for example, looks different in two photographs taken ten years apart and in different places, portrayed once as an agronomist and once as a revolutionary. Which of these Amílcars wrote texts such as "The Weapon of Theory," "Practical Problems and Tactics" and "National Liberation and Culture," from which the interlocutors quote?

Time and again, the montage illustrates individual historical moments and encounters. Eldridge Cleaver, for example, who made Frantz Fanon's The Wretched of the Earth mandatory reading for all Black Panthers (as the "Black Bible"), appears as a globally connected figure. His film about the young Republic of the Congo-Congo Oyé, We Have Come Back, believed lost for decades-is mentioned, and the woman 
informs us that it was edited by Chris Marker over the phone. ${ }^{44}$ This is where the technical drawing comes into play, showing a Sony Portapak camera (one of the earliest video cameras) as if it, too, were a historical actor. The next section addresses the history of the organization Popular Front for the Liberation of Oman and the Arab Gulf, which leads to mention of still other lesser-known revolutionaries. Using a newspaper clipping from 1972 in addition to two colour photographs from the Ottoman liberation struggle (including the photograph of Peninsular Moon), the mundane daily routine of an activist's communications and preparations is described. All this historical material is accessible exclusively through the two protagonists, who appear in the role of historians. Their hands demonstrate, mark, make connections; they present the photographs not as evidence of specific interpretations but as material on a par with the text passages performed in their dialogue. History does not exist outside of or independently from its discussion in the present.

At the end of "The History," the young woman looks at the assembled photographic documents and asks: "And how does this story end?" One after another, the activists' portraits are taken down from the white presentation wall and their careers are described. Some died prematurely or were murdered; some gave up or dropped out; some failed; some became dictators; some were victorious.

The third chapter, "The Language," discusses how the passing of history from generation to generation can be disrupted and how communicating in different languages can lead to different narratives. Despite these attempts at appropriation, the resulting narratives remain alien to the two protagonists. Why do these events seem so unreal, the woman asks, as if they had never happened or had taken place on another planet? Talking about them makes them more real, the man answers, even if the historical sites and actors themselves have disappeared. The image of the archipelago, a reference to sunken, lost history, comes to mind; the memory of Algeria's revolutionaries is submerged by other narratives. Constructing a new identity out of its reconstruction is closely connected to the excavation of other submerged cultures and identities. The interlocutors discuss Kateb Yacine's statement that the French language remains in the country as "spoils of war"; it can be used to fight against foreign domination in a postcolonial context. Similarly, we hear in the film, memory can be liberated with the help of narratives that now seem foreign, even if direct contact with history has been lost:

These stories, they are there, all around us. And if we collect a small loot, then it must be shared. Sharing images and stories, narrating them, and translating for others. [...] This reading is the translation of a translation. Because we will never read the original text.

Earlier projects by Bouchra Khalili, such as Mapping Journey (2008-11), in which migrants trace their year-long migration routes into and throughout Europe, had worked with personal narratives. Compared to such an approach, the explicitly "impersonal" speech acts in Foreign Office are striking. They do not express personal memories, individual positions, or specific political identities. Khalili repeatedly emphasizes the "nonarchival" character of her technique of montage, describing instead a "fabrique historiographique non-archivique" (nonarchival historiographical factory) that avoids fetishization as well as the effects of authentification and authority that the artist associates with historical documents. In contrast, Khalili foregrounds historiographical writing as a gesture of creation that can only be complete in its contemporary actuality. ${ }^{45}$ Explicitly referring to Michel de Certeau's writings, she describes historiography as an intervention into history analogous 
to her understanding of filmic montage. The artist-historian moves a world that has been immobilized as history: "This world no longer moves itself. We set in in motion." ${ }^{46}$ In accordance with this active understanding of historiography (foregrounded so often in the theory of history), Khalili does not consider Foreign Office a documentary film in the sense of prioritizing representation over construction. Rather, the work demonstrates the examination of historical materials via reconstructing apparatuses and devices.

The setting at the beginning of the film, then, is akin to a film editing suite. Khalili reveals the technical and medial arrangement through which history becomes a narrative and film becomes a "history factory"-she grants us a look at the interweaving of film and history, which she undertakes in reference to Godard's Histoire(s) $d u$ cinema. ${ }^{47}$ The title of her exhibition Blackboard (Paris, Jeu de Paume, 2018) reinforces this connection, as it takes up the concept of film as display board that Jean-Luc Godard and Jean-Pierre Gorin had presented as members of the Dziga Vertov Group at Yale University in $1970.4^{48}$ The film functions as a dispositif that presents regimes of display, visibility, and emplotment.

By assembling quotations from various sources, settings, and moments, Khalili creates a "collective" and polyphonic discourse. This engages with Pasolini's concept of "free indirect discourse" that arises from authors speaking through the language of their protagonists, resulting in performative speech acts intended to represent collective discourse..$^{49}$ Thus, the artist's "original" authorship is as much thwarted as has been that of her protagonists. Her role is that of an "organiser of a mechanism that allows a multiplicity of voices to speak." ${ }^{50}$ This, again, avoids the ethnographic pitfalls of "speaking for others" since it avoids expressive, subjective forms of authentication. "Free indirect discourse" is performed without synthesis or empathy. Its polyphony is the product of montage. This directly refers to Khalili's reading of Michel de Certeau: "[The historian] reveals himself on the other's stage. He speaks in that spoken word come from elsewhere, and the question of to which of the two it belongs is no longer an issue." ${ }^{51}$ On the stage of history, the historian collects foreign voices, merging his or her identity with theirs. This results in spatial and temporal "displacements" that characterize historical speech as well as artistic representation. These are not potentially bridgeable limitations that need to be overcome as we speak "for" or "about" others. Instead, these displacements form a basis for avowing our distance to history and avoiding the illusions of direct appropriation and representation. As Pasolini writes,

In the case where, in order to reanimate the thoughts of his character, an author is compelled to reanimate his words, it means that the words of the author and those of the character are not the same: the character lives, then, in another linguistic or psychological, or cultural, or historical world. He belongs to another social class. And the author therefore knows the world of that social class only through the character and his language..$^{52}$

Foreign Office thus performs an examination of history in full awareness of the artist-historian's distance to it. This is demonstrated not only by the filmic montage of history and present but also by the other artworks in the installation. The Archipelago provides a diagrammatic model to represent a specific geopolitical moment; the photographs testify to a contemporary exploration of the presence of the past. Every tapping of history generates new materials; every new (historiographical) speech generates new voices. Khalili assembles ever-growing dialogical layers of materials from the past so that history does not emerge out of an "excavating," archaeological operation but as 
a cycle of production that, while it is happening, immediately piles up new materials elsewhere, before our eyes, in the present. The work of the historian thus is not limited to narrating or conveying existing information. It yields ever new translations, new perspectives. Sometimes this allows a dialogue with the past; sometimes a (spatial or temporal) diglossia of diverse languages and voices that stand side by side.

\section{Notes}

1 See, in particular, Dean's film installations The Green Ray (2001), Kodak (2006), and Film (2011). Dean views the disappearance of analogue film, which has become obsolete within the period of a single century, as the loss of a unique visual experience. Erika Balsom, who is critical of the fetishistic marketing of film on the art market, appreciates Dean's works as an examination of the specific viewing habits, sociabilities, and historicities of film. See Balsom, "A Cinema in the Gallery."

2 Dean, "Pie."

3 Wikipedia, s.v., "List of shipwrecks of the Isles of Scilly."

4 Gunning, "Moving Away from the Index."

5 Foster, "An Archival Impulse."

6 On the role of chance in Dean's works, see Fer, "A Natural History of Chance."

7 Dean's exploration of the sea and seafaring also includes How to Put a Boat in a Bottle (1995), Delft Hydraulics (1996), Disappearance at Sea (1996), Disappearance at Sea II (1997), Teignmouth Electron (2000), and Amadeus (2008).

8 Eugenides, "Tacita Dean."

9 Breton, L'amour fou, 127. With this term, borrowed from quantum mechanics, Breton described inexplainable, irreducible phenomena and events that follow the artist's unconscious wishes.

10 Dean, “Analogue,” 8; Baker, “Artist Questionnaire," 26.

11 Armstrong, Scenes in a Library, 16.

12 Dean, "Analogue," 8-9.

13 Baker, "Artist Questionnaire," 26.

14 Pichler, "Horizon and Line of Fate."

15 The series comprises several performances, installations, and video works created since 2013. See Erika Tan's personal website, https://www.erikatan.net, as well as The Forgotten Weaver project website http://theforgottenweaver.blogspot.com, containing historical documents.

16 The exhibition took place from April to November 1924 and from May to October 1925. For general information, see British Empire Exhibition 1924 and Lawrence, Official Guide.

17 Lawrence, Official Guide, 13.

18 The most informative source-apart from the colourful exhibition guide available in the Pavilion that, however, offers general information on Malaya instead of on the display on view-is the government report on the exhibition, which details the names of the staff, informs of Halimah's death, lists costs as well as revenues, and collects criticism and suggestions for improvement for future presentations: Caldecott, Report on the Malaya Pavilion.

19 Lawrence, Official Guide, 85.

20 Qureshi, Peoples on Parade. The Paris World Exhibition of 1867 was the first to introduce the presentation of humans as "tableaux vivants" (Greenhalgh, Ephemeral Vistas, 85). Sometimes European cultures were also exoticized in this way: the Glasgow Empire Exposition of 1938 included a "Highland Village" (An Clachan) showcasing Scottish textile and basket weavers. Stanard, "Interwar Pro-Empire Propaganda."

21 Cundall, Reminiscences of the Colonial and Indian Exhibition, 28.

22 Mathur, "Living Ethnological Exhibits."

23 Cundall, Reminiscences of the Colonial and Indian Exhibition, 29-30. As was reported in the daily press, Queen Victoria invited some of the artisans to a meeting at Windsor Castle and had portraits of them made individually. See Alison Smith, entry on Rudolf Swoboda's portraits of Bakshiram, Ramial, and Muhammad Hussain, in Smith, Blayney Brown, and Jacobi, Artist and Empire, 72-73. The Austrian painter Swoboda, a nephew of the Orientalist Leopold Carl Müller (“Orient-Müller”), continued to be supported by Queen Victoria. See Mathur, An Indian Encounter. 
24 Clendinning, "On the British Empire Exhibition."

25 Lawrence, Official Guide, 126.

26 Ibid., 74, 76, 93. See Clendinning, "On the British Empire Exhibition.”

27 Caldecott, Report on the Malaya Pavilion, 20.

28 Fabian, Time and the Other, 32 and passim.

29 The inadequate paraffin stoves were replaced in 1925 by central heating; electric light was also introduced. The Malayans were housed apart from the other "races in residence" in "their" pavilion at their own request; their living quarters were to conform, as far as possible, to the comfort they were used to in Malaya. Caldecott, Report on the Malaya Pavilion, 20.

30 Ibid., 21.

31 Tan, The Forgotten Weaver, project website, http://theforgottenweaver.blogspot.com.

32 Schaffer, Ambivalenzen der Sichtbarkeit, 83-85 (with reference to Tredell, "Stephen Heath," 12-20, esp. 19).

33 Spivak, "Can the Subaltern Speak?"

34 Rosler, "In, Around, and Afterthoughts."

35 Foster, "The Artist as Ethnographer," 204.

36 Benjamin, "The Author as Producer," 773.

37 This video was shown at the book presentation for Come Cannibalise Us, Why Don't You? Sila Mengakanibalkan Kami, Mabu Tak? at the National University of Singapore Museum.

38 The artist decided to use an Indonesian voice, as a Malayan one was unavailable. Erika Tan, conversation with the author, July 9, 2018.

39 Tan, "Notes on the London Debate." Here, Tan is referencing Sonia Kolesnikov-Jessop's article, "50 Singapore Artists You Should Know for SG50," Blouin Art Info, December 30, 2014. There was also discussion between the artist and curators of Siapa Nama Kamu? about the lack of Malay female artists within the National Gallery collections during the commissioning of APA JIKA, The Mis-Placed Comma, however, the data is unverified and remains word of mouth.

40 "Apa Jika" is Malay for "what if." This work was commissioned for Unrealised, a special program to mark the inauguration of the National Gallery Singapore. Initially conceived as a physical exhibition of works that responded to this historic moment, the commissions were moved online, to be accessed within the galleries.

41 Over the course of the exhibition, the textiles were sold; after it ended, more textiles were added to London collections through purchases and donations.

42 The following explanations are based on visits to the exhibitions Bouchra Khalili at the Vienna Secession and Bouchra Khalili: Blackboard at the Jeu de Paume, Paris, in June and July 2018, respectively. In Vienna, Foreign Office was shown with only 3 of the 15 photographs on display in Paris.

43 “Pan-African Cultural Manifesto.” See Hadouchi, “African culture,” 121.

44 Chris Marker and Eldridge Cleaver were connected through William Klein, who worked on Marker's Loin de Vietnam and whose film about the Pan-African Festival in Algiers was made at the same time as Eldridge Cleaver Black Panther.

45 Vincent, "An Interview with Bouchra Khalili."

46 "Ce monde ne se remue plus. On le remue.” De Certeau, "Histoire et Structure," 168. Cited in Vincent, "An Interview with Bouchra Khalili."

47 Lax, "A Conversation between Bouchra Khalili and Thomas J. Lax," 73.

48 Khalili, "Blackboard."

49 Pasolini, "Comments on Free Indirect Discourse."

50 Gili, “A Populated Opacity," 165.

51 De Certeau, The Mystic Fable, 233. See Vincent, "An Interview with Bouchra Khalili."

52 Pasolini, "Comments on Free Indirect Discourse," 87. 


\section{Archiving, Recording}

The technical, mass media-driven explosion of the documentary since the 1990s has led to an expansion of its instruments, procedures, and genres: fictionalisation, staging, reenactment, preenactment; docudrama and mockumentary approaches; essay film and vérité modes ${ }^{1}$; performance, repetition, and appropriation-all are common artistic practices deployed in order to engage with history. The interweaving of documentary and fiction is not limited to the presentation, narration, or communication of historical content; it already permeates the research and processing of sources, data, and discourses: the work on the archive of history. The term "archive" and the "general and interdisciplinary science" of archivology comprise various scholarly and artistic interests, agendas, and approaches to working with the past. ${ }^{2}$ In its Foucauldian sense, further developed by Derrida, the archive is that epistemological and discursive construct that designates documents as such. It is a place of production (rather than representation) of knowledge, of structures of selection and ordering, designating a material- and process-oriented instead of a representation-oriented approach to history.

\section{Nothing to See Here: Walid Raad and the Negative Documents of The Atlas Group}

The archive as a site of production and discourse is at the centre of a well-known project by Lebanese-US artist Walid Raad that was first prominently shown at documenta 11 in 2002. According to Raad, The Atlas Group was a project undertaken "between 1989 and 2004 to research and document the contemporary history of Lebanon, with particular emphasis on the Lebanese wars of 1975 to 1990." Its "archive" combined made and found film footage, photographs, prints, and collages presented by Raad as documents of Lebanese history.

The historiographical—and, with it, political—claim of this archive is expressed in the collective "we" designating a "group" as the author of what was actually Raad's art project. Fictionalisation thus not only characterised the archived "documents", but also this gesture of anonymising and collectivising authorship in order to conceive the project as global and transnational. ${ }^{4}$

One of the earliest works to be found in the archive of The Atlas Group exemplarily questions scientific historiography and functions as the artistic foundation of the archival structure. It is described as a prime example of speculative historiography in Peter Osborne's exploration of artistic historiography. ${ }^{5}$ Missing Lebanese Wars. Notebook Volume 72 (Figures 4.1-4.2) was first published as a contribution to the journal Public Culture. This work consists of pages from a notebook from the supposed estate of "Dr. Fadl Fakhouri," described as "the foremost historian of the civil war in

DOI: 10.4324/9781003166412-5 


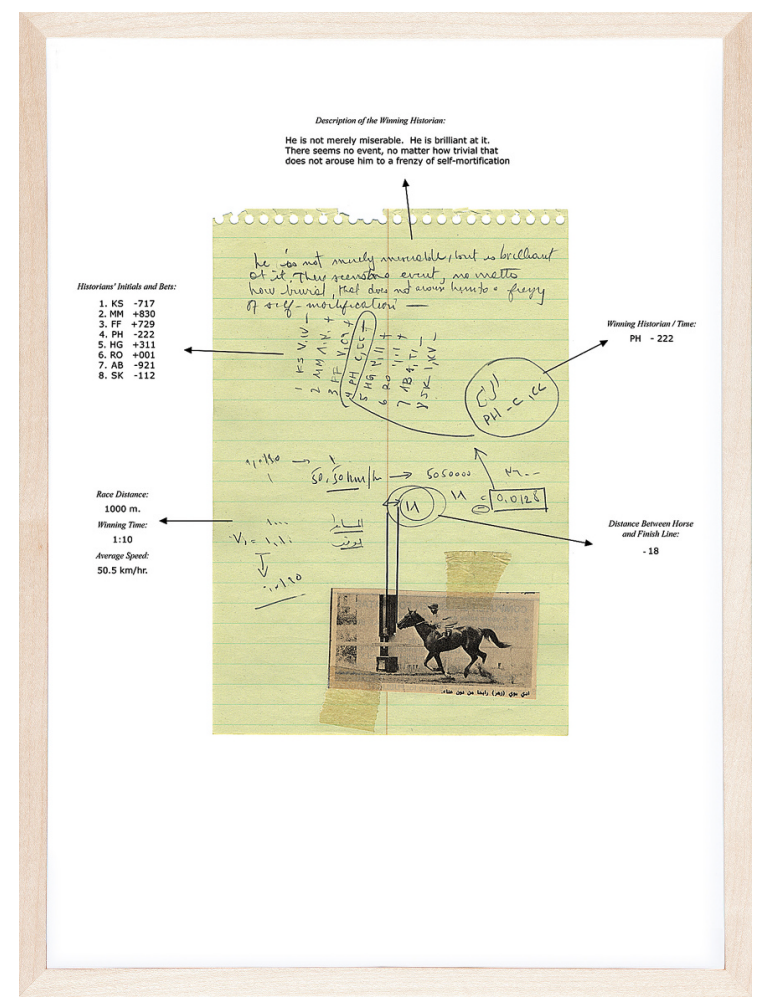

Figure 4.1 The Atlas Group/Walid Raad, Missing Lebanese Wars (Notebook Volume 72), p. 132, 1996-2002, Inkjet print on paper, 33.2 x $24.2 \mathrm{~cm}$. Courtesy the artist and Archivo Fotográfico Museo Nacional Centro de Arte Reina Sofía. (C) the artist

Lebanon.” These were illustrated in the journal version as black-and-white reproductions introduced by the following text:

It is a little known fact that the major historians of the Lebanese civil war were avid gamblers. It is said that they met every Sunday at the race track-Marxists and Islamists bet on races one through seven; Maronite nationalists and socialists on races eight through fifteen.

Race after race, the historians stood behind the track photographer, whose job was to image the winning horse as it crossed the finish line, to record the photo-finish. It is also said that they convinced (some say bribed) the photographer to snap only one picture as the winning horse arrived. Each historian wagered on precisely when-how many fractions of a second before or after the horse crossed the finish line-the photographer would expose his frame.

The following pages have been reproduced from the notebooks of Dr. Fadl Fakhouri. Until his death in 1993, Dr. Fakhouri was the foremost historian of the civil war in Lebanon. Each page includes a photograph clipped from the post-race-day issue of the newspaper, Al-Nahar; notations on the race's distance and duration; the winning time of the winning horse; Dr. Fakhouri's calculations of averages; the historians' initials with their respective bets; and the time discrepancy predicted by the winning historian. Written on each page is also a brief paragraph in English. Dr. Fakhouri's widow, Zainab Fakhouri, has referred these to her husband's habit of including short descriptions of the winning historians in his notebooks. ${ }^{6}$ 


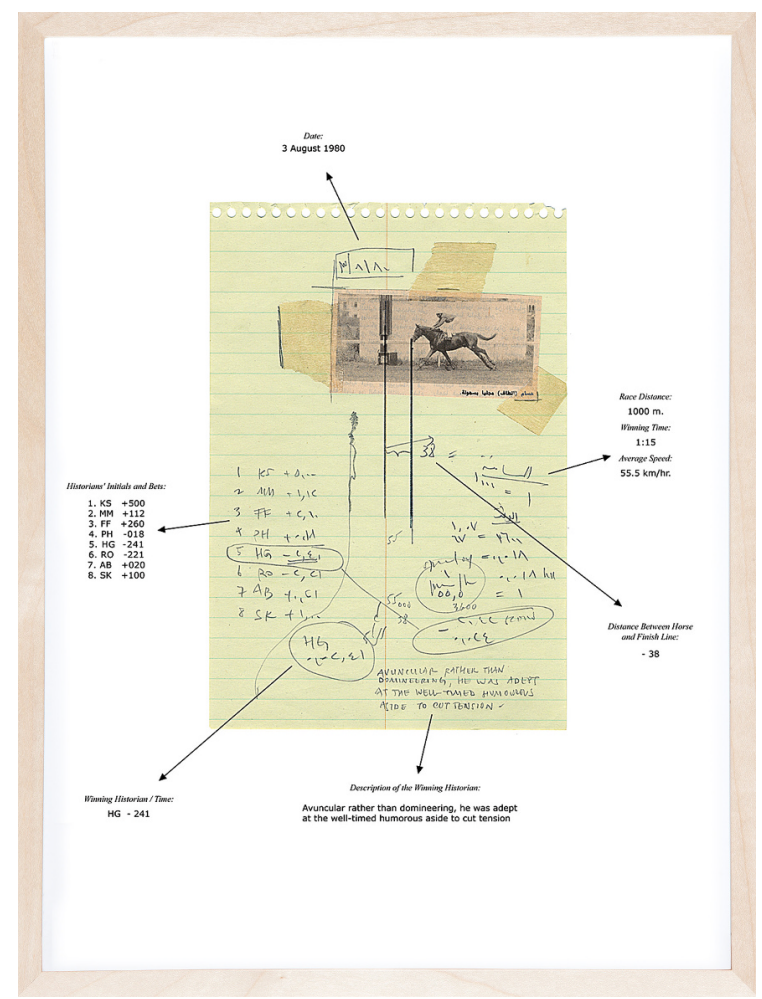

Figure 4.2 The Atlas Group/Walid Raad, Missing Lebanese Wars (Notebook Volume 72), p. 145, 1996-2002, Inkjet print on paper, $33.2 \times 24.2 \mathrm{~cm}$. Courtesy the artist and Archivo Fotográfico Museo Nacional Centro de Arte Reina Sofía. (†) the artist

The text indicates that the notebook is stored at the Arab Image Foundation, an actually existing organisation dedicated to collecting photographs from the Arab world; it was published under two pseudonyms assigned to employees of the Arab Image Foundation. In fact, however, this is a narrative written by Raad that accompanies the pictorial reproduction of ten collages allegedly taken from an eyewitness's notebook. A newspaper clipping with a photograph of a horse crossing the finish line is stuck on each page, surrounded by the aforementioned data, some calculations, and notes in Arabic and English. Some of the narrative's more absurd points, such as the arbitrary assignment of different racetracks to members of different political groups, allude to peculiarities of the Lebanese political system ${ }^{7}$ and to the population's political fragmentation; the suggestion of bribing the press photographer may refer to media manipulation during the civil war. The historians do not actually bet on the outcome of the races but rather wager on the time lag between the crossing of the finish line and the resulting photographic documentation. An exercise, therefore, in predicting the distance between events and their documentation, and in assessing the accuracy of eyewitness accounts.

As the collages make clear, the historians did not even have to be present on site once the photographer was persuaded/bribed to take only one photograph. It remains unclear whether distortions due to the different perspectives from which the photographs were taken were ever taken into account. These photo gambles, therefore, were decided exclusively on the basis of published newspaper reports on the outcome of the races-retrospectively, not according to onsite observations. The historians, therefore, 
fully relied on the published photographs despite their potential inaccuracies. Thus, the photographers-and not, pointedly, the horses or the historians-are the decisive historical actors. The camera generates the actual (media) event: the winning photo that, in the collages, is presented as evidence of the best bet. This approach to events "ex post" is remarkable. From a psychoanalytic (and cultural-theoretical) point of view, it describes a perspective of "retrospectiveness" or "afterwardsness" (Nachträglichkeit is the Freudian term) that leads to a permanent reassessment of history from the perspective of the present, and thus to a temporal deferral that arises from the distance between events and the processing of them. ${ }^{8}$ This deferral is visually evidenced in the winning photos: none of the photographers ever succeeded in capturing the actual moment when a horse crosses the finish line; or, conversely, the horse "is never on time":

It is important to note that Dr. Fadl Fakhouri's Notebook Volume 72, titled "Missing Lebanese Wars," raised for us troubling questions about the possibilities and limits of writing any history of the recent wars in Lebanon. The notebook recounts the story of some Lebanese historians who bet on photo-finish horse-race photographs as they were published in the Lebanese daily Annahar. Apart from the historians' bets and some calculations of averages, the notebook's pages include cutouts of the photo-finish photographs as they appeared in Annahar. What is fascinating about these images is that the horse is always captured either just before or beyond, but never exactly at, the finish line-the horse is never on time. This inability to be present at the passing of the present raised for us numerous questions about how to write, and more particularly about how to write the history of events that involve forms of extreme physical and psychological violence. The notebook forced us to consider whether some of the events of the past three decades in Lebanon were actually experienced by those who lived them. ${ }^{9}$

The distance between the crossing of the finish line and its photographic documentation, which is so interesting to the gambling historians, clearly also refers here to the manipulability of documentation (and historiography).

Instead of providing reliable historical data and experiences of history, the collages create a detour via materials and notes that are partly based on methodologies from the social sciences (combining data, facts, and calculations) and partly present purely speculative biographical and psychological approaches. One of the winners of the photo gambles (his initials are SK) is characterised as follows in a note in the collage: "He undeniably drank to excess, and as far as women goes, he is essentially very shy. One feels that he is sexually terribly inhibited. He is obsessively clean and tidy." Some of the character sketches are randomly taken from (actual) newspaper reports and describe other persons like RO: "a potent shadow, a legend that has grown into an officially sanctioned cult" is his description, borrowed from a New York Times article on Mustafa Kemal Ataturk. ${ }^{10}$ "Avuncular rather than domineering, he was adept at the well-timed humorous aside to cut tension" (the characterisation of HG) is from an obituary for Labour politician George Thomas published in the same newspaper on the same day, which also included an article about South Korean politician Kim Dae Jung, described among other things as: "A somber man with a thickening middle but a full head of jet black hair, a fiery orator one moment and a patient statesman the next," a description assigned to $\mathrm{PH}$ in the collages. ${ }^{11}$ These short biographies of political celebrities are at obvious odds with historical veracity. And even if one tries to make sense of the collages, the abbreviations may prove unreliable, with contradictory descriptions referring to the same person 
(for example, when KS is described alternately as a man and as a woman). Raad assigned a slightly modified characterisation of Walter Benjamin by Hannah Arendt to that variously described, ambiguously gendered, and often victorious historian KS: "What mattered to her most was to avoid anything that might be reminiscent of empathy." ${ }^{12}$ As he himself never won any bets, Fadl Fakhouri never had to describe himself.

Obviously, Raad did not use sources from the Lebanese civil wars but rather from 1990s newspaper clippings available in New York City, where he lived when he created The Atlas Group. Taking them seriously as documents leads to amusing but, in relation to the promised goal of documenting a civil war, banal questions: Which historian can be assumed to be betting on the fact that the finish would be recorded too early or too late? Who is likely to predict that the documentation will happen on time or miss the event by a large margin? Are particular psychological patterns or adherences to specific historical schools congruent with particularly frequent successes at betting? Which personalities and which ideologies are hidden behind the two historians with the initials MM and FF (Fadl Fakhouri), who always bet wrong?

All these absurdities, mistakes, and imponderables make not only possible answers questionable but also the material itself coming from, after all, "the foremost historian of the civil war in Lebanon." For all its alleged precision (photo documents, notes, calculations), it remains opaque and compromised by numerous distraction manoeuvres (irrelevant data or speculative details). There are neither eyewitness accounts nor reliable sources. This lack is filled by miscellaneous instruments and methods to measure and record reality, both highly trivial (the objects of attention are winning photographs of horse races and biographical details) and corrupt (as evidenced by hints of bribery and unreliable photographic evidence). ${ }^{13}$ This is not simply a mixture of "fact" and "fiction," as the archive of The Atlas Group is often interpreted, but touches upon fundamental questions on how the fictitious characters experienced Lebanese history:

The historians who gathered every Sunday at the track seem to have been well aware of the difficult epistemic project they faced: the difficulty of thinking about and representing the various experiences that are constituted by and that constitute the Lebanese civil war. This difficulty derives not simply from the "plurality" of experience [...]; more fundamentally, it remains difficult to describe specifically what we mean when we speak of "the experience of" the civil war. [...] How do we represent traumatic events of collective historical dimensions when the very notion of experience is itself in question? [...] How does one witness the passing of an extremely violent present? What particular conceptions of experience, of modes of assimilating the data of the world, can we presuppose when we speak of the physical and psychic violence of the civil war? What conception of time, evidence, testimony, history, and writing do we invoke? ${ }^{14}$

The scepticism brought forward regarding the reconstruction and examination of the civil war along the lines of historical experience impressively characterises the situation in Lebanon in the postwar era. The general amnesty issued in 1991 was followed by years of amnesia and a virtually complete absence of public discussions of the civil war. Instead, the violent past was manifest in widespread psychological symptoms. In fact, art, especially literature and film, repeatedly stepped in at this historical point to initiate engagements with history. ${ }^{15}$

The impossibility of directly observing and coming to terms with the "missing" Lebanese wars leads only to detours, to narratives that proliferate around actual events without actually directly touching upon them. In the accompanying text, "Ziad Abdallah" 
and "Farah Awada" (actually Walid Raad himself) call on readers to read the surviving records as "hysterical symptoms [...] based not on any one person's actual memories but on cultural fantasies erected from the material of collective memories. We also treat these as theoretical musings on the temporal dimensions of the writing of history." 16 The hysterical "symbolic acts" documented in the notebooks provide insights into a collective field of imagination that obscures actual testimonies from the civil war. In a social climate of amnesia, the historical apparatus runs empty: it is tested regularly and seems to work perfectly, but there is "nothing" to record except faulty (manipulated) documentation. The used "scientific" instruments of documentation collapse before the eyes of the viewers. Dr. Fakhouri does not fulfil the task of examining Lebanese history; metaphorically, there is not a single recording of a horse actually crossing the finish line. Instead, this historiographical blank is filled with an erratic jumble of pseudo-data, pointing to the fact that an archive on Lebanese contemporary history simply does not exist. The fictional documentation of the "Missing Lebanese Wars," as faulty as it is, takes the place of a real one, thus touching upon fundamental political, historiographical. and epistemological questions. "'You have seen nothing in Hiroshima.' Does this entail that one should not record? No. One should record this 'nothing,' which only after the resurrection can be available." 17

Historical depiction, according to Raad, is caught in a vicious circle of double aporia: it is supposed to represent what eludes representation and is therefore obliged to reconstruct, but this act of reconstruction works against what is actually decisive, namely the silencing of history. Instead of an aesthetic display of spectacular or spectacularised documents of war and violence, The Atlas Group brings to the fore the socially dominant forces of forgetting, of not dealing with history, and of the psychological consequences that follow. Furthermore, as the evident lack of winning photos that are actually "on time" demonstrates, historical analysis is always either too early or too late. There is a gap between events and their narrative that this artwork will not close for us. It points instead to an understanding of history that is rooted not in experience, but in an interweaving of remembering and not remembering, knowing and not knowing, all of which is contained in trauma. These found and fictionally created documents have no concrete points of reference in the past; there is no direct correspondence between their abundance, density, and intensity and that of history. Some documents may be regarded as "higher" in the specific truth politics of media, jurisdiction, or politics; some events are not or are insufficiently documented while other comparatively irrelevant ones may be documented excessively. The Atlas Group sheds light on these imbalances and is closely related in this respect to the Fondation arabe pour l'image that shares some of its authors and is dedicated to building a "real" archive of Arab photography. ${ }^{18}$ Dealing with the unresolved collective trauma of the Lebanese civil war will not happen by working through direct experience or its reconstruction, but leads to symbolic acts-even to the creation of a symbolic archive that may approach the past but also offers space for the blanks, fantasies, and fictionalisations arising out of it. ${ }^{19}$

\section{The Archive in Excess: Matthew Buckingham}

Matthew Buckingham is a central protagonist of artistic historiography. Not only is the majority of his extensive oeuvre-more than fifty works in photography, film, and installation created since the early 1990s-dedicated to political history but also the US artist often explicitly examines historiographical methods and instruments. The following section discusses several of his works that probe the structuring principles of the archive of historiography from different perspectives than do those of Walid Raad. 


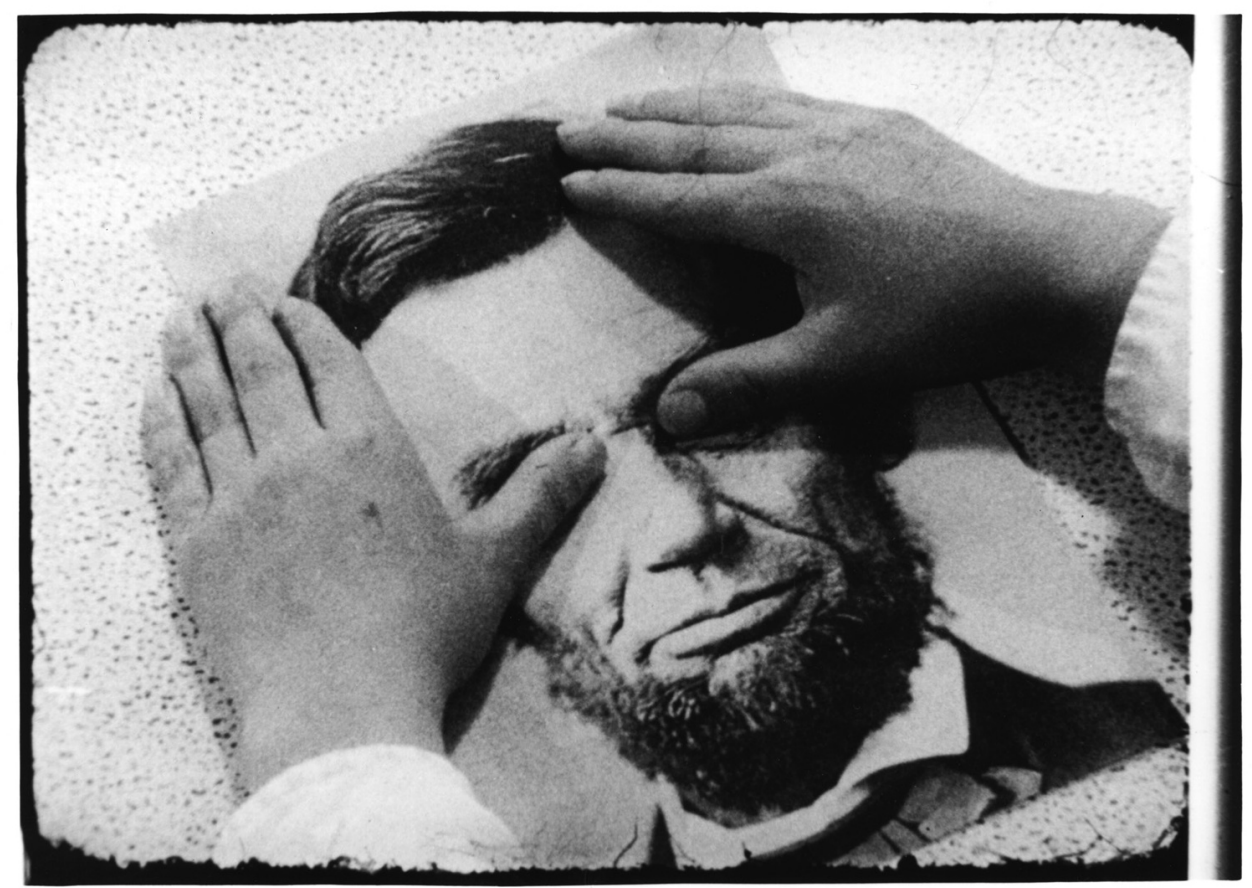

Figure 4.3 Matthew Buckingham, The Truth About Abraham Lincoln, 1992. Still image, 16mm, black and white, sound, 20 mins. Courtesy the artist

In Buckingham's first film, The Truth About Abraham Lincoln $(1992,16 \mathrm{~mm}, \mathrm{~b} / \mathrm{w}$, sound, 20 mins., Figure 4.3), bio- and hagiographical statements about the US president's life are subjected to a "True" or "False" fact check in a format akin to a quiz show. Most of them concern anecdotal details; some of them touch upon Lincoln's political views. For instance: “Before he was elected president, Abraham Lincoln had plans to found an integrated college of law with the abolitionist John Brown." In between each statement, which is either confirmed or disclaimed by large black-andwhite letters ("T" for true and "F" for false), images of a young woman are shown. Dressed in a nineteenth-century-style suit, wearing a glued-on beard, and using various other props, this female character reenacts scenes from Lincoln's life. The performances are indebted more to modern imagination than to historical reality, as becomes evident when a series of over seventy historical portraits of Lincoln files across the screen. Since, in most of them, he is shown without his characteristic beard, he is virtually unrecognisable to our eyes. And, via the quiz, even historically educated viewers sometimes have to choose answers that are historically implausible as surprising turns or trivial details suddenly become relevant. Even a false statement can retrospectively acquire historical significance, as the answer to the last quiz question shows:

After resigning the presidency, Nixon quoted Lincoln as saying, "Some actions which under normal circumstances are illegal become legal if the President orders them because of the security of the country."- "T"-Did Lincoln actually say this?-No. ${ }^{20}$ 
As Buckingham's second film, Amos Fortune Road (1996, 16mm, b/w, 20 mins.), demonstrates, well-intentioned historical research can easily get caught in the thicket of fictionalisation. This short film takes up the journey of a young teacher and her student who research the life story of former slave Amos Fortune, whose name they encounter on a road sign they regularly pass. After viewing some scattered documents and visiting his grave, it becomes clear that all their gathered information is ultimately based upon two fictionalised biographies that were integrated into public archives and public memory. Fortune remains entirely intangible as a historical personage though the road, as a map from 1795 proves, existed during his lifetime. The two women may have travelled the same roads as did Fortune, but the road sign is the sole reliable link to the past-a silent witness of it that is unable to bridge its distance from the present.

Buckingham's artistic explorations of the contingency and opacity of historical material, as well as the significance of narrative emplotment, is conducted via an explicit examination of the central authors of historiography, especially Hayden White and Reinhart Koselleck. This becomes particularly clear in Situation Leading To a Story (1999, 16mm, colour, sound, 21 mins., Figure 4.4), a film installation shown in two adjacent darkened rooms. In the first, we see a $16 \mathrm{~mm}$ film projector facing away from us; it projects film images through a small hole in the separating wall into the second room. We do not yet see the films; instead, on an audio track, the artist tells of his discovery of four amateur films from the 1920 s and explores possible

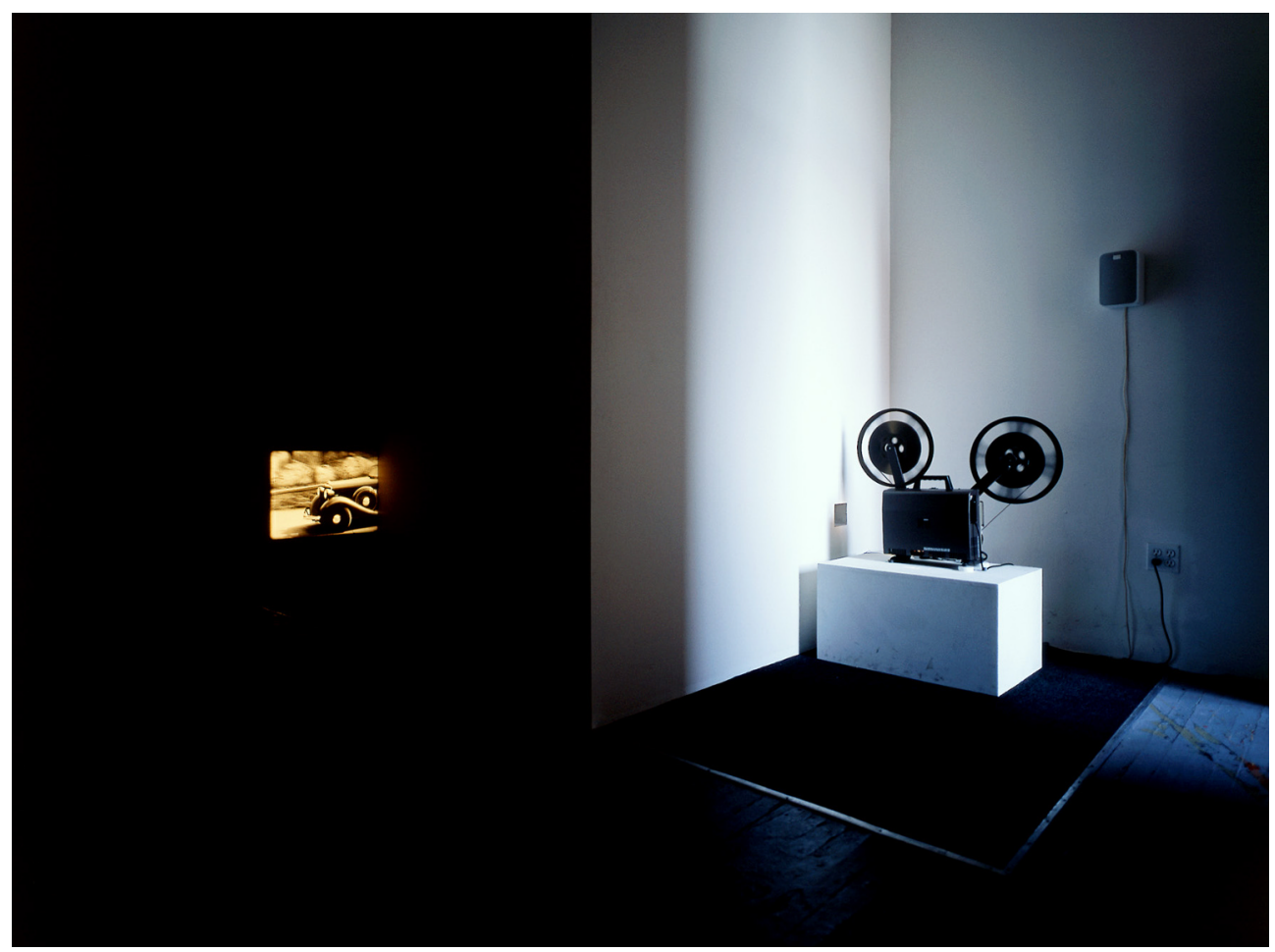

Figure 4.4 Matthew Buckingham, Situation Leading To A Story, 1999, 16mm, colour, sound, 21 mins. Installation view, Greater New York, Museum of Modern Art PS1, New York, 2000 Courtesy the artist 
connections between the private images recorded on them (which portray a wealthy New York family) and the exploitation of South American raw materials by US companies. Buckingham speaks this text himself, offering various narrative modes: anecdotal (the account of his discovery and his futile efforts to locate the makers or former owners of the films), factual (about copper mining and the early amateur film industry), and poetic (associations with the images on film). In the second room, we now view the four found films which, in their turn, bring their own stories, materiality, and details, offering an immensely rich "primary material" that cannot be linked conclusively to any one historical narrative. Just as these filmic documents and the artist's narratives that result from their viewing are spatially separated in the installation, they are two distinct "stories." The information offered about the early film industry and about copper mining in Peru is not directly reflected in the films, even if they instigated the artist's research. Buckingham's openness regarding how his narration reflects his own personal engagement with the found material rather than what the films actually show is among the strongest points of the work. It pointedly differs from documentary approaches that seamlessly interweave presentations of found footage with narratives providing background information, filling in historiographical blanks, and producing a suggestive but misleading network of plausibilities and causalities. Buckingham's False Future (2007, 16mm, colour, 10 mins.) examines the rhetorical tricks of historical narrations that aim at filling such blanks. This short film traces a possible course of development in the history of cinema that technically could have occurred as early as 1890 , five years before it actually did. The question as to which films could have been made between 1890 and 1895 is pursued by that omniscient narrator often used in historical documentaries who, with the certainty of what in French is termed faux future, provides "information" on highly speculative questions.

In light of the opacity of historical material that is often made painfully evident in Buckingham's work, how justifiable is the desire to examine "original" documents, long considered the origin point of proper historical research? What surplus value actually arises out of an insistence on examining historical sources, especially for an untrained eye? These questions are explored in a dialogue written by the artist in 2011 for an exhibition of Tacita Dean's work: "Excerpt from an Unpublished Interview with Ralph Pendrel." This is how the conversation begins:

RALPH PENDREL: Given the chance and the choice, which would you rather look at: the original Magna Carta document; a faithful facsimile of the Magna Carta; or a published typeset copy of the text of the Magna Carta?

MATTHEW BUCKINGHAM: The original.

RP: Do you mean the Magna Carta from the year 1215, 1216, 1225 or 1297 ?

MB: 1215.

RP: But the Magna Carta of 1215 has no original. Numerous exemplifications were made by scribes and sent to the Royal Archives, to the Barons of the Cinque Ports, and to the Counties of England.

MB: I would like to look at those.

RP: Only four have survived.

MB: Then it wouldn't take long to look at them.

RP: And one was burnt in a fire in 1731 .

MB: Isn't that the only copy that still has the seal of King John attached to it?

RP: Yes, but the seal is just a formless blob of wax now ... 
Tell me, do you read medieval Latin?

MB: No.

RP: Is this just a fixation then? What would you hope to gain by travelling to Lincoln and Salisbury cathedrals and to the British Library to look at the copies of the 1215 Magna Carta? ${ }^{21}$

Step by step, the question of the significance of historical materials is relativised, deferred, refuted. There is, strictly speaking, not one Magna Carta, and the artist is not schooled in reading or understanding the extant original documents now known by that name. As Tacita Dean has pointed out in an essay on Buckingham, his historiographical approach pursues less investigative than methodological interests: "Rather than looking to the past to understand the present, he prefers to look for history in the contemporary, the now, following his subjects a few paces behind, unnoticed." 22 Responding to Pendrel's question as to what he expects from looking at the originals, the artist initially describes his desire as "not entirely rational," but then provides an answer: it is about excessive information handed down by chance that may inspire reflection on its relation to the present, on the author's possible backgrounds, and on possible addressees of the documents. Buckingham openly admits that, ultimately, he would not be in a position to decipher any of these clues. But this is not quite the point of his research. Precisely because of their tendency to be opaque-because of the surplus of meaning inherent in the material that cannot be translated into information ${ }^{23}$ - the original documents are capable of stimulating new narratives and new meanings. This argument clearly does not promise to discover any evidence of truth or veracity arising from the documents' contents or their structure, since the originals reveal nothing more than new-possibly misleadingreadings and perspectives.

Finally, Buckingham returns the question: "So which version of the Magna Carta would you want to look at?" This is an interesting, highly speculative question for the interviewer, who is identified at the end of the interview as the author of an "Essay in Aid of the Reading of History." Ralph Pendrel is the protagonist of Henry James's last unfinished novel, in which the character is introduced as the author of the same essay. Ralph, as is made clear at the beginning of the novel, has an extremely delicate "sense of history," a "backward vision": "The sense of the past is your sense," the novel's heroine Aurora Coyne tells him..$^{24}$ Much of the novel is dedicated to his endeavour to pursue this sense and to find himself in the process. The story gradually becomes a ghost story, as Ralph swaps roles with an eponymous early-nineteenth-century ancestor, who is portrayed in a remarkable portrait showing him with his back to the viewer-another variation of that "backward vision" we already know from Rahel Varnhagen. The resulting journey through time, the search for himself, and the question of whether his sense of history will enable him to win Aurora is the subject of the rest of the novel, which is only preserved in two text fragments.

Buckingham has also worked with James's novel as part of an artistic research project. In a short description, the artist refers to Frankfurt School concepts of historiography - to the fact that a critical examination of history should engender agency to change society-and asks what role the visual arts can play in this process. ${ }^{25}$ Here, too, the archive as a structuring device of historical thought is important: What is the right way to deal with documents? Is historical knowledge exhausted by working with data, information, and materials? What kind of knowledge can be gained from them? Which emplotments engender which meanings? In dealing with these central questions 
of historiography, Buckingham presents various encounters with historical characters and materials. His approach to basic premises and instruments of historical scholarship leads to their questioning and deconstruction but is not directed "against" them. Instead, his work attests to a longstanding, genuine interest in historical methodology from an artistic point of view: examining its instruments and objectives; testing its truth values and potential for creating narratives; and often reconnecting them to poetic heritage that is now, after two centuries of academic history, sometimes forgotten.

\section{At the Bottom of History: Dierk Schmidt, SIEV-X-On a Case of Intensified Refugee Politics (2001-2005)}

Kein Seestück/Not a Seascape: Four fragile, small-format paintings with this title are painted on translucent foil and show objects floating in gently undulating ocean waves. The objects are not clearly identifiable, some of them contoured by omissions or breakouts within the impressionistic handling of the paint. Some of them may be documents or small utensils. In one case (Not a Seascape (I), 2002, Figure 4.5), the outlines of one object look like the shape of a boat. These works are part of Dierk Schmidt's painting, research, and publication project SIEV-X-On a Case of Intensified Refugee Politics (2001-2005). Its title refers to one of the greatest refugee tragedies at a global moment hardly poor of such disasters: a shipwreck in Australian territorial waters in the Pacific Ocean in October 2001. The title Not a Seascape heralds a break with the conventions

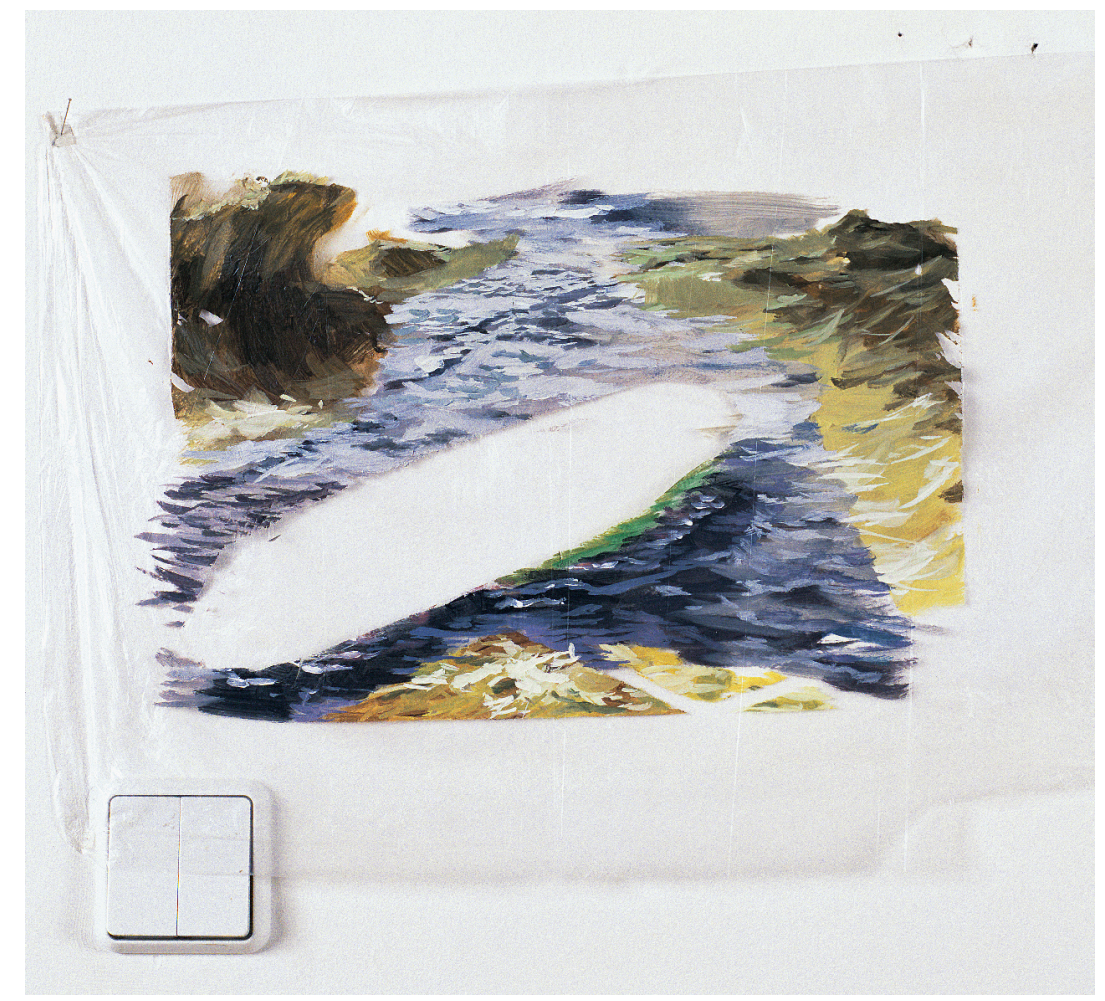

Figure 4.5 Dierk Schmidt, Not A Seascape (I), 2002. Oil on PE foil, $38 \times 62.7 \mathrm{~cm}$. Courtesy the artist and Städel Museum, Frankfurt am Main. (C) VG Bild-Kunst, Bonn 2021 
of maritime painting: Schmidt's non-seascapes do not show romantic or tourist sites, nor sublime nature as a symbol of human existence. In his paintings, the sea appears as a precisely mapped territory, sensitive in terms of national security and therefore closely monitored. Thus Schmidt does not resort to landscape painting as a genre but to another central modern mode of representation: history painting.

The painting cycle SIEV-X-On a Case of Intensified Refugee Politics comprises several versions, that trace different stages of a year-long examination of the October 2001 refugee tragedy. The cycle began small, when three paintings were shown as a triptych in the exhibition Die Gewalt ist der Rand aller Dinge (Violence is at the Margin of All Things) at the Vienna Generali Foundation in 2002 (Figure 4.6, Xenophobe-Shipwreck Scene, Dedicated to the 353 Drowned Asylum Seekers Died on the Indian Ocean, on the Morning of October 19, 2001, 2001/2002; Untitled, 2001/2002; Freedom, 2001/2002). Later that same year, the project title SIEV-X was added, an administrative term that had not been used publicly in the debate on the tragedy at the time the triptych was first shown. In this specific case, the term refers to the nameless boat that capsised on its way from Indonesia to Australia in the Australian Military Surveillance Zone. Three hundred and fifty-three men, women, and children drowned; only forty-four people survived. The acronym "SIEV" is short for Suspected Illegal Entry Vessel; "X" indicates that the vessel was not registered in the Operation Relex surveillance system of the Australian authorities. The term has now become a

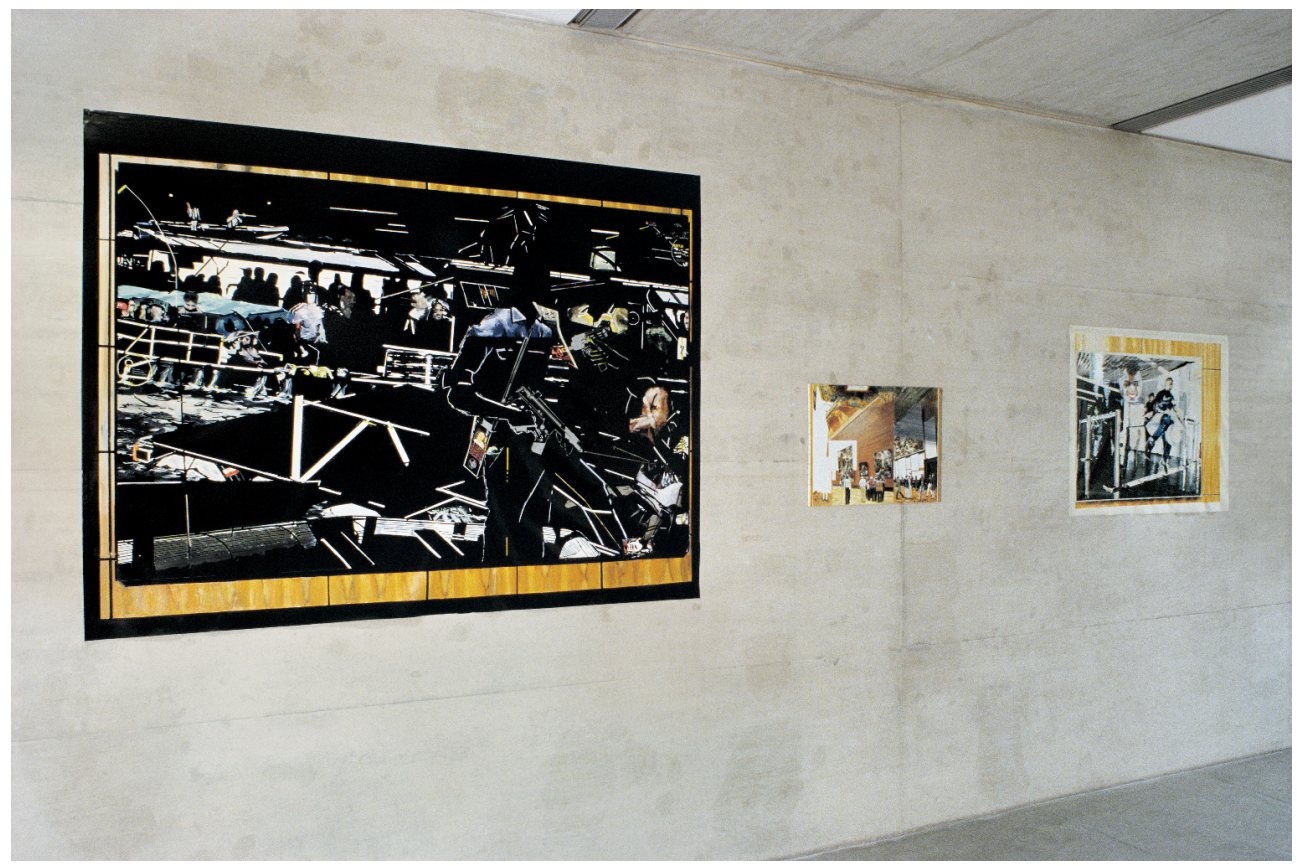

Figure 4.6 Dierk Schmidt (left to right), Xenophobe-Shipwreck Scene, Dedicated to the 353 Drowned Asylum Seekers Died on the Indian Ocean, on the Morning of October 19, 2001, 2001/2002. Oil on acrylic, PVC film, $140 \times 213 \mathrm{~cm}$; Untitled, 2001/2002. Oil on canvas, $50 \times 70 \mathrm{~cm}$; Freedom, 2001/2002. Oil on PVC film, $77 \times 97 \mathrm{~cm}$. Installation view, Die Gewalt ist der Rand aller Dinge, Generali Foundation, Vienna, 2002. Courtesy the artist and Städel Museum, Frankfurt am Main. (C) VG Bild-Kunst, Bonn 2021. Photo Werner Kaligofsky 
commonly used shorthand for the catastrophe of 2001 and the journalistic and political investigations that followed.

As Schmidt describes in a conversation held in October 2001with then Australian Labour politician Tony Kevin, ${ }^{26}$ apart from isolated newspaper reports, hardly any information about the actual course of events of the tragedy was available, despite repeated enquiries of the United Nations High Commission on Refugees (UNHCR). Schmidt himself became aware of the catastrophe via a brief note in the Berlin weekly Jungle World. When he continued his research in May 2002, Australian activist Marg Hutton had created a website collecting information documenting the event. ${ }^{27}$ Kevin had initiated a senate committee inquiry in the Australian Parliament that led to widespread public debate on the case. In 2005, Schmidt published the results of all these efforts, as well as of his own research in a volume that would conclude his project. ${ }^{28}$ The book presents 16 other paintings created between 2002 and $2003^{29}$ as well as detailed information on the boat accident that had not been available at the time of the first presentation at Generali Foundation.

Schmidt's volume reflects the overall picture that has emerged from the parliamentary inquiry: the disaster happened under the political pressure of upcoming parliamentary elections at a time when Australian authorities were trying by all means to stop the flow of refugees from Indonesia and to force its government to take a stronger stand against human trafficking. Although SIEV-X sank in an area monitored by Australian authorities, no rescue operations are recorded. To date, only one trafficker has been convicted $^{30}$ but the real responsibility for the disaster goes much deeper. According to current information, the deaths of these 353 people was tacitly accepted, presumably provoked, and possibly even caused by undercover investigators working with the Australian police in order to deter further boats and to enforce even tougher measures to repel refugees. To date, a full list of the victims' names has not been published. In 2007, activists erected a memorial consisting of 353 unmarked wooden steles in Canberra, receiving nationwide attention. ${ }^{31}$ John Howard's government was reelected in November 2001 and voted out six years later. Twenty years on, Australia's extremely restrictive refugee policy still openly works with measures of deterrence.

A nameless boat; a high number of victims whose names are not officially recorded; guilt that can only be described in abstract terms. When asked by Schmidt how this tragedy came to be systematically emptied of its narration until hardly any date, site, or persons can be ascribed to it, Kevin answered:

I think the system was constructed for what we call "plausible deniability." I don't think Australian ministers said, kill asylum seekers, drown them, to send a message. I think the language, which goes down from the top, is bureaucratic language, it's a language that says: we have to step up the disruption program, we have to increase the pressure. [...] I still believe that they are criminally accountable because they are accountable for having set up their systems. ${ }^{32}$

Schmidt's project is among several that research refugee tragedies to inquire into the brutal handling of global migration since the late twentieth century. As much as the topic has been dominating mass media and politics from the mid-2010s onwards, attention in Europe was sparse in the early millennium. Almost at the same time as SIEV-X-On a Case of Intensified Refugee Politics, the project Solid Sea 01: The Ghost Ship (2002) by Italian research collective Multiplicity was produced and shown at documenta 11. Presented as an installation with several video monitors, Solid Sea 01: The 
Ghost Ship reworked a shipwreck in December 1996 that had been successfully downplayed by the Italian authorities until 2001 though it saw 283 refugees from Southeast Asia perishing in the sea off the coast of Sicily. The Italian project highlights the gaps in information-the refusals to cooperate and officials' lack of willingness to look into the matter-thus sketching a picture of global migration as going hand in hand with the dehumanisation of all those involved: a political, administrative, and legal devaluation of migrants; an ethical dehumanisation of those responsible. Contrary to Multiplicity's investigative approach (for Solid Sea 01: The Ghost Ship, the project team consisted of artists, architects, theorists, and political activists Stefano Boeri, Maddalena Bregani, Francisca Insulza, Francesco Jodice, Giovanni La Varra, Armin Linke, and John Palmesino), SIEV-X-On a Case of Intensified Refugee Politics highlights information gaps. With one exception, the paintings are not painted on canvas but on light plastic foils of various format, transparency, thickness, and surface structure: black pond liner, cover foils, a projection foil, a sheet protector, all with different properties and used in different ways. ${ }^{33}$

From the project's start-the creation of the central triptych-the most important question was how to depict an event for which no pictures nor localisable site exist; whose victims' names are withheld; and whose course is not entirely clear. The material accessible to the artist consisted of scattered pieces of information and witness statements that were often made public against the wishes of the authorities involved. Schmidt presented his material as a discussion within two visual concepts- "history image" and "history painting"-in order to ask: How can contemporary painting devote itself to the representation of a political event? To what extent may the tradition of European history painting serve as a (renewable) model? The artist pursued these questions via a discussion of two nineteenth-century French history paintings hung in the Louvre in close proximity to each other: Théodore Géricault's 1819 The Raft of the Medusa and Eugène Délacroix's 1830 Liberty Leading the People. Both are discussed in Peter Weiss's Aesthetics of Resistance as examples of opposing artistic-political concepts, a study that had caught Schmidt's interest shortly before the shipwreck became known. His research into painting history resulted in the triptych shown at Generali Foundation in 2002. At its centre is Untitled, the only painting created on canvas-in fact, a split canvas showing two scenes (Figure 4.7): on the left, the current display of Délacroix's and Géricault's paintings in the Louvre; on the right, evoking a retrospective within the image itself, the first presentation of The Raft of Medusa at the 1819 Paris Salon exhibition (also in the Louvre) as described by Weiss, with Géricault himself in the crowd. With a side length of $70 \mathrm{~cm}$, this is the smallest painting of the triptych. The canvas was prepared on a classic stretcher frame with hand-forged nails, materially underlining the reference to nineteenth-century history painting. The other two paintings (one created on black pond liner, the other on translucent glossy foil) represent two opposite aesthetic modes: "idealistic" and "operative" procedure.

The "black" painting, Xenophobe-Shipwreck Scene, Dedicated to the 353 Drowned Asylum Seekers Died on the Indian Ocean, on the Morning of October 19, 2001 (Figure 4.6 left) introduces operative representation. Measuring $213 \mathrm{~cm}$ in length, it is by far the largest picture of the whole project cycle. The picture background is threefold: a wooden panel is painted on black foil; this in turn frames a second black foil on which painted and blank parts of the picture result in a scene that is only partly elaborated in detail. The wooden panel shows an interior in the Australian Department of Immigration, thus referring to the intended addressee of the painting, the political-administrative apparatus. ${ }^{34}$ The picture's twofold black background illustrates the lack of 


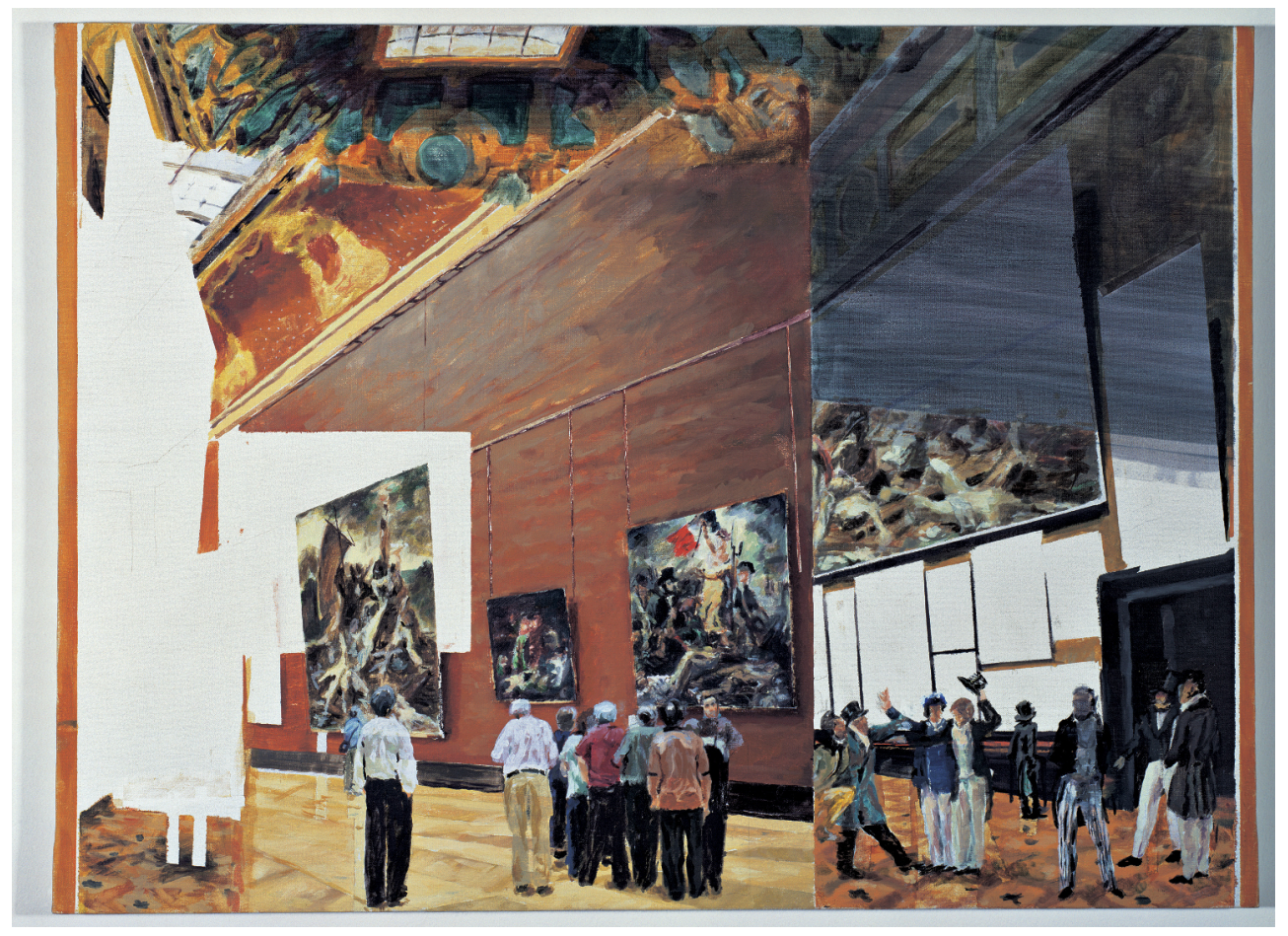

Figure 4.7 Dierk Schmidt, Untitled, 2001/2002. Oil on canvas, 50 x $70 \mathrm{~cm}$ Courtesy the artist and Städel Museum, Frankfurt am Main. (C) VG Bild-Kunst, Bonn 2021

information and visual material on the event-the emptiness at the bottom of the story, so to speak. ${ }^{35}$ The visual structure of the painting consists of a construction of white lines serving as a framework for the depiction of those few, sparse details that could be established in the course of Schmidt's research. Paint was only applied to those limited areas within the overall picture that allowed reproducing details that could be safely established through witness statements or media images: a leak in the boat, threats of violence made to immigrants when boarding the boat, portraits of individual survivors. Schmidt has refrained from completing the painting and thus bringing it to a conventional closure in the traditional history painting mode. In contrast to the translucent, delicate masking foils he used in the other paintings, this time the paint was applied onto a thicker, heavier, black background. This holds the fragile scene together and formally reinforces the political and ethical claim to the successful reconstruction of history upon a solid base, as it were.

On the right, a smaller-format picture painted on semi-transparent projection foil stands for idealistic representation. It illustrates a scene from a Nike advertising clip for the 1998 FIFA World Cup, showing the Brazilian soccer team playfully passing through several security gates and border controls at the airport. Serving as a contrast to an essentially deadly border control programme, as depicted in the "black" painting, this is a light-hearted imaginary scene where borders, under the spell of soccer (and Nike), are becoming permeable. This is staged upon a pictorial ground that also materially plays with aligning painting and moving image. Schmidt describes the opposing concepts of operative and idealistic representation underlying these two paintings as follows: 
In the [...] triptych I show three ways of painting. The Nike picture is closer to a photograph, because it's related to the Nike advertisement. But on the black painting it was important for me that it looked obviously constructed. Every kind of photograph with its closed surface would traditionally imply a documentary verification of the case, if it shows the vessel.

[...] But I wanted to reconstruct the situation in a conceptual and visibly constructed way: as a proposal, as trial, if you like. As the representation of a gap, a lack, resulting in the lethal refugee politics of the Australian government. As a situation that resisted reconstruction. And not as representation that covers that lack. ${ }^{36}$

Schmidt's depiction of the shipwreck scene in the "black" image follows the "operational" image prefigured in Géricault's The Raft of the Medusa in terms of content and structure, especially considering the painter's critical-explorative working method as described by Weiss: two years of research, including contacting the survivors and reconstructing the raft in his studio. This resulted in the reversal of representational structure to a scene in which those usually condemned to passivity in classical history paintings- "the governed"- are transformed into the painting's primary subjects. Ultimately, therefore, the painting suggests the first sketchy outlines of a new social and political concept. In the 1819 exhibition, Géricault's painting was presented under the general title Scène d'un naufrage (Shipwreck Scene). The title of Schmidt's painting (Xenophobe-Shipwreck Scene, Dedicated to the 353 Drowned Asylum Seekers Died on the Indian Ocean, on the Morning of October 19, 2001), working in the same mode of representation, starts with a nonspecific title (like the one used by Géricault) but then names the actual event.

Géricault's working method for The Raft of the Medusa contrasts with Délacroix's exuberant allegory of freedom that is neither hindered nor stopped by any visible opponent. Both politically and artistically, it was already outdated by the time of its first public presentation. The difference between idealistic and operative aesthetics is close to the distinction between utopian and realistic modes, in which images intervene in reality in different ways: in the first, by transforming reality into a visually constructed imaginary creation; in the second, by depicting reality truthfully, hopefully provoking dismay and a will to make change.

The 16 small-format paintings that Schmidt created between the first presentation of the central triptych and his 2005 publication focus on his research. Conversations with Tony Kevin, with an unnamed UNHCR staff member at Geneva, with political scientist Paolo Cuttitta, and with philosopher and author Carolin Emcke complete the documentation from different perspectives. Placed adjacent to each other on a wall like brief notes, the 16 paintings supplement, comment on, and contextualise the triptych. They contain further portraits, partly taken from media reports; descriptions of sites; and written reflections. All of them are painted on plastic foils of differing thickness, solidity, and surface structure, as if to make it clear that, from the outset, they cannot count upon a steady ground or any predetermined entitlement. Where information is lacking, blanks reveal the wall behind the paintings. In this sense, the pictures are "groundless" (Roger Buergel), expressing "a certain ontological contingency of representation itself, according to which no form of representation today can claim preferentiality or superiority over another." ${ }^{37}$ Children Overboat Affair (2002) shows a portrait of prime minister John Howard and was created in the context of his false statement that the asylum seekers had threatened to throw their children overboard in order to force the Australian state to save them. Next to it is a painted reproduction of 
a newspaper clipping with the corresponding Reuters news article disseminating this allegation worldwide. The newspaper clipping is in a transparent cover of the kind used in file folders. It becomes clear that no reliable, firm painting ground exists: the brushstrokes are set on a material that is extremely precarious as regards conservation; they create a scenario of what happened without a formally secure basis, resulting in a kind of "insubstantial" painting.

This is even more evident in the case of the small-format paintings on plastic film (such as the series entitled Kein Seestück/Not a Seascape), which have substantial losses of paint layer due to the lightweight material's flimsiness and to the resulting poor adhesion of the paint. ${ }^{38}$ Schmidt describes the use of this unstable groundthe fact of "having a picture, but actually no support" - as a "de-monumentalized relationship" characterised by a "certain openness" in contrast to the "unity of a canvas on a stretcher." ${ }^{39}$ His visual language purposefully refers to the precarious documentation of the event. Every stroke of paint references a piece of information hard gained and fought over; each stands for a trace of an elusive history difficult to reconstruct. This leads to divergent results: in the case of Xenophobe, where the brushstrokes become recognisable as individual pieces of information, the result is a painting that is perhaps "concrete" or "figurative" but definitely not "abstract," in the sense of the abstraction of structural violence emanating from the administrative apparatus. In the case of Ruddock Overboard (a Fantasy) I, presented on a transparent cover, the approach leads to a fictionalised depiction of history. This painting shows former minister for immigration and "architect" of the Australian border protection programme, Philip Ruddock, floating in the water-though by no means helplessly_as a sovereign portrait head absurdly dominating the waters surrounding him. Operation Relex ... Acting without Perpetrators I is also an imaginary scene: a collage of portraits of Howard and Ruddock that were sourced from a variety of press photographs. The principle of montage pervades the paintings, making evident that they, too, need to rely upon specific media images. As Clemens Krümmel points out, Schmidt's painting is:

not concerned with a naive and direct communication of information that can always be known, but at all times focuses on the respective fragmentary character of pieces of information as particles of an information politics-and subsequently on an analysis of the possibilities that painting possesses, as opposed to the other image media. ${ }^{40}$

But how to interpret the surprising juxtaposition of precise pieces of information on the one hand and fictionalisation on the other? In a detailed essay on the paintings, Veronica Tello has presented an interesting deviation from those interpretations that consider SIEV-X-On a Case of Intensified Refugee Politics primarily as a visualisation of research results. ${ }^{41}$ In contrast, Tello writes, Schmidt's research-e.g., his contacts with the UNHCR-yielded "no new information"; his account contains contradictory quotations and incongruities. Tello writes:

While the rise of 'history painting' in contemporary art may well be aligned with a resistance toward government control of information, it is important to emphasize that artists such as Schmidt do not intend to provide informational correctives to government misconduct. ${ }^{42}$ 
This leads her to associate Schmidt's strategy with the category of "parafiction" proposed by Carrie Lambert-Beatty. ${ }^{43}$ This term was coined to describe how heterochronous layers of time are proposed as possible forms of reality, challenging standard ways of representation. Although I agree with Tello that Schmidt's painting cycle cannot be primarily grasped as presenting research results, the concept of parafiction, in my view, is equally unhelpful. SIEV-X-On a Case of Intensified Refugee Politics focuses not on alternative historical concepts but on the question of how an event can be represented if no visual documentation-and hardly any reliable information-exists.

Fundamental elements of historiography are examined by Schmidt's work: the historian's tasks comprise, first, the collection and examination of sources; and, second, their preparation for historical presentation-this last is more than a simple compilation of found data, entailing their narrative shaping into various modes (poetic, fictional, biographical, documentary, and so on). In the case of Xenophobe-Shipwreck Scene, Dedicated to the 353 Drowned Asylum Seekers Died on the Indian Ocean, on the Morning of October 19, 2001, the mode of representation underlines the sparseness and meagreness of the scattered bits of information by setting them as isolated spots onto the black background of the picture. This visual strategy highlights the difficulties of reconstructing the exact course of events. It is important to realise that these difficulties do not simply comprise individual puzzle pieces that viewers could easily complete in their own imagination but are rather constitutive. As underlined by the pictorial ground(-lessness), the gaps and incongruities of the source material define the painting and prevent it from closure as a pictorial space. In some paintings, the blanks and gaps in information are openly exposed; in others, Schmidt presents fictional imaginations to experimentally link the sources. This suggests that both approaches are equally valid; that both are anchored firmly on the spectrum of historiography. They involve the translation of existing data and data gaps, facts and omissions into representation: a fundamental task in historiography made visible precisely by paralleling fact-oriented research and imagination. If one considers the more superficial equations as well as oppositions of art and research in recent debates on artistic research, this is an essential point. For historiography, as has been stressed already, not only becomes poetic through the use of artistic instruments such as painting or drawing; conversely, research is not always comparable across the arts and sciences. But the operational mode of SIEV-XOn a Case of Intensified Refugee Politics presents an artistic approach that is close to historiography, exemplifying the concept of apodeixis described in Droysen's theory of history: representation comprising research and reflection.

As evident in the quotation above, Schmidt has claimed this researching, reflective historiography as a privilege of contemporary painting (as opposed to other image media). He pursued and tested this approach in his subsequent project The Division of the Earth, presented for the first time at documenta 12 in 2007. The Division of the Earth uses diagrammatic abstraction to depict a historical event that was marked by structural violence in a similar way as was SIEV-X. The painting tableaux of The Division of the Earth are related to the Berlin Africa Conference of 1884/85 and the subsequent division of the African continent among the European colonial powers and the US, which led to the expulsion of the Herero tribe (today settling mostly in Namibia) and to a genocide initiated by the German colonial power. Schmidt traces the political, economic, and legal consequences of the German presence in Africa through the example of reparation claims formally declared by the Herero, which led to an emotional public apology by the German minister for economic cooperation 


\section{8}

and development in 2004, immediately followed by a declaration that no legal claim could be derived from it.

In an examination of Schmidt's use of the diagrammatic mode, Susanne Leeb asks if "images that remain in the language of functional abstraction [are] not in fact accomplices of the processes that they treat, considering that statistical diagrams seem to confirm smooth rationality and objective facticity?" 44 look at the further development of social science and its use within modern government techniques shows that often only a small step separates the "masses" from the "administrative masses." 45 Schmidt's use of diagrammatic abstraction (expressed, for instance, in footprints as symbols) confronts statistical quantification with individualising forms of historical depiction. Jacques Rancière has argued against the merging of the historical sciences with numbers, data, and facts, ${ }^{46}$ as did Benjamin: "To write history means giving dates their physiognomy." ${ }^{47}$ In Benjamin's concepts of history, the political moment of salvation was oriented towards individuals; indeed, history interlocked with and unfolded alongside the victims of history and historiography.

The historiography created by Dierk Schmidt in SIEV-X-On a Case of Intensified Refugee Politics and The Division of the Earth, which places the responsibility of individual actors as much in the foreground as it places individual subjects behind numbers of victims, statistics, and acronyms, undertakes a rehumanisation that is as technically outmoded as it is politically urgently needed. Data and statistics are central to the description of events. The SIEV-X shipwreck claimed more victims than any previously known accidents in the Indian Ocean caused by deterrence measures of refugee politics; precisely because of public disinterest in its investigation the exact reconstruction of figures, data, and facts is indispensable. But these only account for part of what it means to understand and to come to terms with history: where hard details can only be reconstructed incompletely, it must still be possible to represent and remember history. To depict this situation, therefore, (visual) languages are needed that expresses structural violence but are not limited to the representational logic of the administrative apparatus.

It is important to remember, for example, that the "namelessness" of the victims of SIEV-X was not an actual one: their names are known but have not been made public. Those who perished in the shipwreck are not anonymous but have been anonymised; because of their abstraction they have become nonsubjects barred from historiography. Considering this political situation, Schmidt's choice of history painting is decisive, as it comes with an inherent claim to represent history as consisting of events, places, and actors; and, at the same time, to create a kind of representation that will do justice to the political situation-the deprivation of rights and of victims' humanity; the denial and minimisation of catastrophe; the retreat of those responsible into "plausible deniability." Schmidt has designed history painting that intertwines "names" and "events" (in Rancière's sense), ${ }^{48}$ leaving omissions where gaps cannot be filled.

The choice of history painting (as a type of "emplotment") therefore goes beyond an interest to actualise a historical genre. In a conversation with Carolin Emcke, Schmidt shows an interest in the historical context of nineteenth-century Realism, viewing Géricault's working method as an alternative to imitation: not as a depiction of reality but as its production, uniting representation and reflection as mutually dependent components. ${ }^{49} \mathrm{He}$ takes up Géricault's Realist working method as an alternative to imitation: not as a depiction of reality but as its production, uniting representation and reflection as mutually dependent components. Schmidt's reconception of Géricault's realism is similar to Craig Owens's concept of the "allegorical”-which, like realism, chooses a 
form of examination in which mode and material of representation are displayed in equal measure. ${ }^{50}$ With respect to the artistic process, this means taking into account the representational contexts of narration; the inclusion of its political and ethical dimensions; and the claim of making reality accessible to a new kind of representation that neither stops at depiction nor seeks to evade its ethical-political responsibility. ${ }^{51}$ An apodeictic concept of representation, then. But while Owens ascribes the allegorical to pictorial media privileged in postmodernism—such as photography, film, and videoSchmidt works with paint. Thus, SIEV-X-On a Case of Intensified Refugee Politics opens up a complex debate about history painting and its aptitude for an "allegorical" reworking of Géricault's visual language. This includes an examination of how to work with and how to emplot unreliable, scattered, and contradictory sources. Painting may be a more suitable medium for this process than photography or film, as it is able to performatively select from and reassemble existing views and images, and to accentuate unevennesses and gaps in representation. The legacy of Realist history painting is employed as a medium that, like Géricault's The Raft of the Medusa, lays claim to an apodeictic representation of history in order to represent and revalue an event denied historical value in current political discourse.

\section{Notes}

1 Enwezor, "Documentary/Vérité."

2 Derrida, "Archive Fever," 34. Foucault, The Archaeology of Knowledge.

3 Raad, The Atlas Group, project website, http://www.theatlasgroup.org. For a long time, the artist varied the supposed dates of the founding of The Atlas Group: "In different places and at different times I have called the Atlas Group an imaginary foundation, a foundation I established in 1976, and a foundation established in 1976 by Maha Traboulsi. In Lebanon in 1999, I stated, 'The Atlas Group is a nonprofit foundation established in Beirut in 1967.' In New York in 2000 and in Beirut in 2002, I stated, 'The Atlas Group is an imaginary foundation that I established in 1999.' I say different things at different times and in different places according to personal, historical, cultural, and political considerations with regard to the geographical location and my personal and professional relation with the audience and how much they know about the political, economic, and cultural histories of Lebanon, the wars in Lebanon, the Middle East, and contemporary art." Alan Gilbert, "Interview With Walid Ra'ad." The earliest suggested date, 1967, is that of Raad's birth year. See The Atlas Group, Traboulsi, and Raad, "Sweet Talk," 43.

4 Osborne, Anywhere or Not at All, 28-35.

5 Again, the project's history was long obscured by the artist's continuous redatings and by the work's presentation in diverse media and constellations. The first "release" of Missing Lebanese Wars was a 6-minute video work (1996), presented as "documentation" of the travels of Zainab Fakhouri, Fadl Fakhouri's wife, between 1947 and 1971.

6 Raad, "Missing Lebanese Wars." Versions of this text accompany presentations of the same work in exhibitions, publications, and on The Atlas Group website.

7 Rogers, "Forging History, Performing Memory," 72.

8 On the concept as sketched in Sigmund Freud's early writings, see, among others, De Lauretis, Freud's Drive, 118.

9 Gilbert, "Interview with Walid Ra'ad."

10 Kinzer, "Bodrum Journal."

11 Hoge, "Viscount Tonypandy"; Kristof, "Seoul Journal."

12 Arendt, "Introduction," 48.

13 Around the same time as Missing Lebanese Wars. Notebook Volume 72, Raad also produced two publications referring to these aspects: "The Beirut Al-Hadath Archive" and Sweet Talk.

14 Raad, "Missing Lebanese Wars."

15 Haugbolle, "Public and Private Memory of the Lebanese Civil War."

16 Raad, "Missing Lebanese Wars."

17 The Atlas Group, Traboulsi, and Raad, "Sweet Talk," 44. 


\section{Archiving, Recording}

18 Cotter, "The Documentary Turn."

19 Caruth, Unclaimed Experience.

20 Buckingham, "The Truth about Abraham Lincoln," 201-2.

21 Buckingham, "Excerpt from an Unpublished Interview with Ralph Pendrel."

22 Dean, "Historical Fiction," 146.

23 "Every document is also a record of its own making, even if it doesn't want to be read. What else can the quality or 'voice' of that medium say? What is the content of that form?" Buckingham, "Excerpt from an Unpublished Interview with Ralph Pendrel."

24 James, The Sense of the Past, 33.

25 Buckingham, "The Sense of the Past."

26 Kevin, A Certain Maritime Incident: The Sinking of SIEV-X.

27 http://www.sievx.com.

28 Schmidt, SIEV-X.

29 As the painting cycle was presented at two concurrent exhibitions, two versions exist. In this chapter, I refer to the nineteen-part cycle held at the Städel Museum since 2008, which comprises both versions. This, however, is not identical to the paintings as documented in the 2005 publication (which, itself, is part of the project), since individual paintings had already been sold at the time of the Städel purchase. See Bühl, "Die Bewahrung bemalter PE- und PVC-Folien," esp. 22-25, 158-60, and 206.

30 An Egyptian citizen, Abu Quassey, was sentenced to several years in prison for human trafficking in 2003.

31 This monument is documented on https://www.sievxmemorial.com.

32 Schmidt, "One cannot maintain this sort of policy while continuing to be a democracy. Telephone conversation with Tony Kevin," 25.

33 For details of the materials used, see Bühl, "Die Bewahrung bemalter PE- und PVC-Folien." Schmidt used eight different plastic foils.

34 Over the course of the project, Schmidt discussed with the UNHCR the possibility of permanently presenting the painting cycle in their Geneva building. Dierk Schmidt, conversation with author, 25 May 2018.

35 Schmidt, "Conversation with Carolin Emcke," 55.

36 Moss and Stakemeier, "Q \& A with Dierk Schmidt," 57.

37 Quoted in Höller, "Image Leaks," 124.

38 Bühl, "Die Bewahrung bemalter PE- und PVC-Folien," 1.

39 Ibid., 31.

40 Krümmel, “The Raft of the Historical Image," 83.

41 Tello, "Counter-Memory, Heterochronia"; Tello mentions, among others, texts by Hilde Van Gelder, Angela Lampe, and Lars Bang Larsen.

42 Ibid., 27.

43 Lambert-Beatty, "Make-Believe."

44 Leeb, "The World was Becoming Numerical," 313.

45 Ibid., 316.

46 On Rancière's conviction of the "incompatibility of statistics and historical science" (Ibid., 313), see Rancière, Names of History.

47 Benjamin, The Arcades Project, 476 (N 11,2).

48 Rancière, Names of History, 7.

49 Schmidt, "Conversation with Carolin Emcke," 45.

50 The term "allegorical" here does not refer to classical allegory, as in Délacroix's Liberty Leading the People, but to the postmodernist term. Owens, "The Allegorical Impulse."

51 Richter, Ästhetik des Ereignisses, 16. 


\section{Showing, Telling, Picturing}

The previous chapter considers the precariousness and opacity of documents as well as the structuring policies of historical knowledge and representation. In this chapter we turn to the methodological aspect of showing, narrating, and displaying historical materials, beginning with the significance of testimonies. Situated at history's origin-atzero, witness accounts emerge directly from viewers of an event yet sometimes prove as impenetrable as other raw or unprocessed historical sources. As pieces of evidence, testimonies can be used in court proceedings in a manner similar to how material traces are employed. I start, therefore, with the question of how opaque linguistic testimonies and silent objects can be used to establish narratives beyond their integration into documentary procedures.

\section{Gathering Evidence: Amar Kanwar, The Lightning Testimonies (2007)}

In The Lightning Testimonies, Indian artist Amar Kanwar examines the legal, psychological, and social significance of eyewitness statements in a particularly insistent and touching way. Participating in countless international exhibitions, including four in the documenta series (2002-17), he is among the most internationally successful artists of the Indian subcontinent. Kanwar initially studied history in Delhi but, because of the impression upon him left by the political incidents of 1984 (the riots following the assassination of Indira Gandhi and the Bhopal disaster), decided to study film at the then newly founded Mass Communication Research Centre of Jamia Millia Islamia University. Many politically committed documentary filmmakers have emerged from this school, including Jeebesh Bagchi, Monica Narula, and Shuddhabrata Sengupta, who founded Raqs Media Collective in $1992 .{ }^{1}$ After some years as a documentary filmmaker, Kanwar presented his first video installation, A Night of Prophecy (2002), at documenta 11, which was curated by Okwui Enwezor. This was followed at documenta 12 by The Lightning Testimonies (2007), an extensive and complex multichannel video work. The Lightning Testimonies deals with the history of sexual violence-often publicly perpetrated, but marginalised and tabooed-against girls and women on the Indian subcontinent over the six decades since the partition of India and Pakistan in 1947, linking the history of this violence to the foundation of the Indian Republic.

The installation, comprising eight projections, condenses extensive information and narrations into rhythmically interlinked image-and-sound sequences that give the audience the freedom to engage with them for individually chosen lengths of time and intensity. Kanwar has also edited a single channel version (113 mins.) that can be shown in cinemas, on television, or in schools. ${ }^{2}$ In keeping with the activist ethos of his training, he (like other Indian filmmakers) regularly shows his work in screenings, travelling 


\section{Showing, Telling, Picturing}

exhibitions, and workshops in rural areas, seeking to engage with populations that would otherwise have little access to his work. ${ }^{3}$ These efforts to communicate political and historical information were honoured in 2014 with the Leonore Annenberg Prize for Art and Social Change.

The title of this 2007 work evokes the image of testimonies that light up in a flash and illuminate the darkness. ${ }^{4}$ The installation brings together deeply personal, often-traumatic memories, making tangible the extent to which sexual violence is used systematically as a political instrument. It demonstrates all the qualities of the politically committed, communicative documentary, including critical examination of the genre. An important topic developed over and over again in the installation is how, in the face of unspeakable humiliation and violence, limits of representability and of communication are transgressed: it is difficult to tell these stories; it is hardly bearable to listen to them. Even so, The Lightning Testimonies focusses on highlighting how existentially important and precious these hard-won accounts are.

The installation comprises eight individual narrations from different regions in India and its neighbouring countries Pakistan and Bangladesh, from different historical moments, from different perspectives, and in different narrative modes. It is usually shown on eight individual monitors or projections ${ }^{5}$ mounted in a circle or onto the walls of the exhibition space (Figure 5.1). Visitors can turn to individual narratives but experience the installation as audio-visually coherent. For although the individual films tell different stories, they are closely connected with each other via a shared opening sequence lasting several minutes, which synchronises them approximately at each halfhour, and by the audio track, which only occasionally works with speech sequences, primarily producing an overall rhythm of sound, music, and atmosphere. The Lightning Testimonies is an extremely beautiful but emotionally demanding artwork. The single channels interplay with each other in a highly sophisticated and complex way.

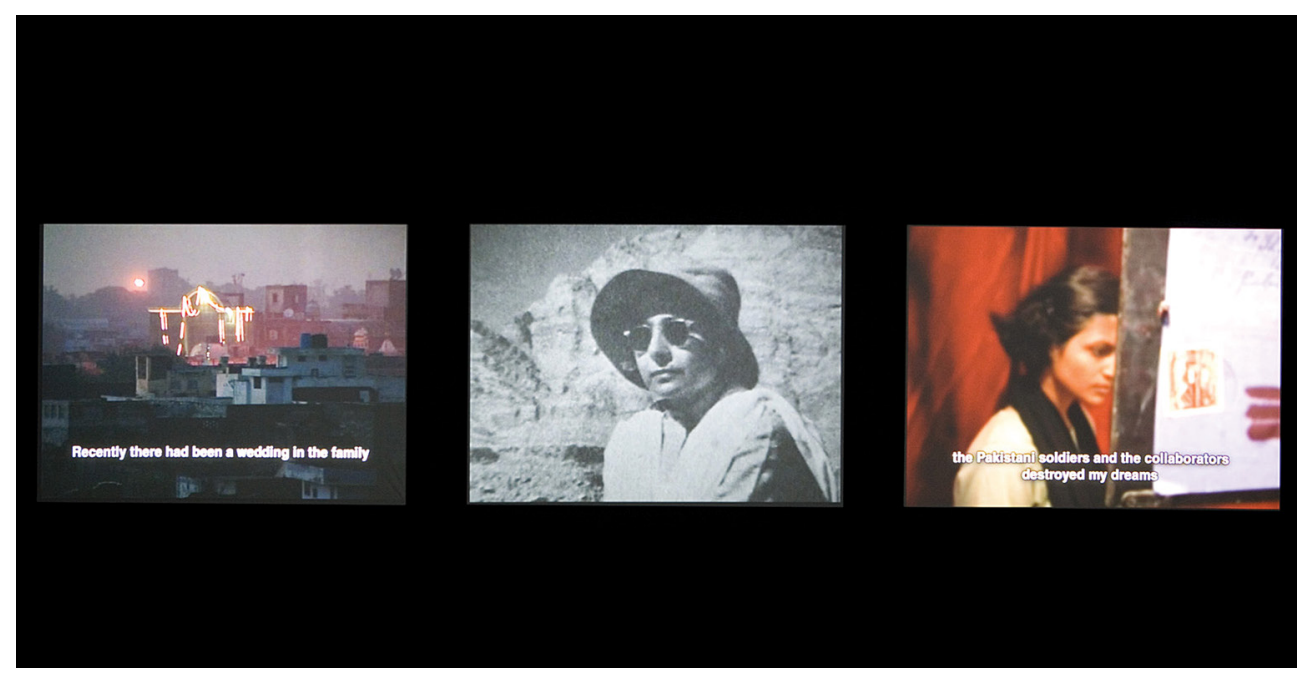

Figure 5.1 Amar Kanwar, The Lightning Testimonies, 2007. Eight-channel video installation, black and white and colour, sound, 32 mins. 31 secs. Coproduced by ThyssenBornemisza Art Contemporary and Public Press, New Delhi, Thyssen-Bornemisza Art Contemporary Collection. Installation view, Amar Kanwar, Marian Goodman Gallery, Paris, 2008. Courtesy the artist and Marian Goodman Gallery, Paris and New York. Photo Katrin Guntershausen 
One complete viewing takes about one and a half hours, comparable to the length of the cinema version. Projections 1-7 comprise a runtime of 8 to 22 mins. Only projection 8 lasts the total length of 31 mins. and 32 secs., continuing to run alone when all the others are already mute and dark, and thus always concluding the narration. ${ }^{6}$ Formally, all the individual channels are connected by the shared opening sequence, which, after the synchronous insertion of the title of the installation, repeats motifs from individual narrative strands: the image of a weaving woman (from projection 1); historical photographs of a family circle and an orange tree (from projection 2); views from the city of Amritsar and a railway wagon overcrowded with refugees (from projection 3); and so on. In this shared opening sequence, the individual stories are woven together audio-visually, with the clatter of the weaving loom, for example, leading into the sound of the moving railway. The different runtimes of the individual narrations in projections 1-7 are, to some extent, balanced by slight variations in the opening sequence and also by showing them twice in a row where necessary. The installation invites us to view the individual channels or stories together. ${ }^{7}$ Still, each projection tells its own story and demands independent attention. All information is provided by English text inserts; the soundtrack consists of atmospheric recordings, music, and sound effects. ${ }^{8}$ The interplay of the individual audio tracks is impressive: viewed individually, each film has its own, by no means sparse, soundtrack; together they form a suspenseful whole.

After the aforementioned opening sequence, projection 1 (22 mins. 6 secs.) begins with footage of the town of Ngainga in Manipur (East India), scene of a nationally known case of sexual violence. An insert addresses a request to an older woman briefly visible in the picture: "Mother, will you tell/the story of your little girl/and how she was woven/into the textures/of your dress?" 9 The woman is introduced as M. Lungshimia; her daughter is Luingamla. While their story is being told via inserts underlined by music, the clatter of a loom, and nature sounds, images show the mother, seated and dressed in red; the interior of her simple hut; a stool, a cup, other family members; a view of the village. The inserts tell of the fatal shooting in 1986 of Luingamla, who resisted her rape by an Indian military officer known by name. In memory of her daughter, the mother had a scarf woven by textile artist Zamthingla, who presents it in the film. ${ }^{10}$ She describes her concept in designing the textile, which was intended to express the character, feelings, and death of the murdered daughter. Efforts to legally process the case were also incorporated into the design.

The second video (14 mins. 22 secs.) reports on two historical events in the East Indian state of Nagaland that took place during a decade-long, violently suppressed struggle for independence that had been going on since the beginning of the state's political integration into Indian territory in 1947. Two places and historical dates are mentioned-Ungma Village, February 24, 1957; Yangkeli Village, July 1, 1971—and documented by contemporary video recordings, with information about the events provided via inserts. The video centres on the testimonies of two women who suffered public rapes under the Indian military presence. Mangyangkokla, who died in 1998, was publicly displayed naked, was abducted for three days, and was repeatedly raped in 1957. The narrative focuses on the historical importance of her public testimony, which not only helped her overcome her own trauma but also memorialises the fate of numerous other rape victims who did not-or do no longer-have the opportunity to speak out. Her son recounts: "She described all these horrid details that I didn't want to write but she asked me to//she said-'for all these years I have/carried this in my mind hounded by it/seeing it again and again in my dreams/now today you have taken it away from me/I can die in peace'//tell it my son, she said/tell it on behalf of all who 


\section{Showing, Telling, Picturing}

have not yet spoken." In the film, Mangyangkokla's photographs of her family and of scenes in the village are shown. Her story is followed by footage of another woman, Mrs. Nzano, who lost her unborn child in 1971 after being raped. She is one of several girls and women who had extensive sexual violence enacted upon them as revenge by the Indian military against Yangkeli, which had supported Nagaland's independence efforts. One of the "witnesses" of these horrific acts of violence was an orange tree: "This orange tree is as old as the village//the tree says that the army stayed for 6 days// but the villagers say it felt like 6 years." As in the first narrative, Kanwar highlights the importance of encouraging testimonies as they connect diverse but shared experiences, and also as they connect abstract notions of violence with concrete locations, names, and faces, thus restoring the dignity of the women concerned.

The third film ( 8 mins. 44 secs.) traces these histories of violence back to the 1947 Partition of British India into Pakistan and India, which was accompanied by systematic sexual violence. ${ }^{11}$ Seventy-five thousand young girls and women were kidnapped, forced into marriages, or raped. Many of them were driven to suicide or were murdered by their own family members. Text inserts that overlay the film's images tell of a failed attempt at one such murder by a young woman's husband and her brother, as well as of a young woman who gathered with her friends in festive dress in a gesture of protest anticipating the outbreak of violence. The underlying images create an atmospherically dense audio-visual matrix: urban shots of Amritsar, a city that was particularly affected by outbreaks of violence during Partition; archival recordings of a railway crowded with refugees; slowed images of thunderstorms with lightning; someone warming their hands by a fire. These compressed slowdowns are helpful in making the emotionally extremely demanding testimonies bearable at all. They vividly describe specific incidents of disturbing cruelty that are nevertheless only examples of a larger systematic history of violence.

Film 4 (12 mins.) is the only one to begin with a white image upon which the title of the installation is set in black (all other films work with white on black). It starts with a question spoken by Kanwar himself: "How to remember? What remains, and what becomes submerged?" This is the only spoken sentence in the audio track of the entire installation, which is otherwise composed exclusively of atmospheric and musical recordings. The film is about politician and activist Mridula Sarabhai who-after the mass abductions described in film 3-was charged with implementing the Abducted Persons Recovery and Restoration Act passed between India and Pakistan in 1949, and with reversing both abductions and forced marriages. Within a few years, several thousand abducted women were returned to their families. As the film makes clear, these repatriations brought new conflicts: the programme was organised without consulting the women involved, who often did not want to or could not return to their families: "One woman wanted to be saved/brought back home//another couldn't [bear] to return to the family/that tried to kill her before the rape//another accepted her abductor's home/and wanted to stay there and start again//another was in love with a man from another/religion and stayed willingly//but now she was defined as an/abducted woman and so had to be recovered//another couldn't [bear] to return to her parents/for they had traded her for the family's safety//another said she was happy for months but/ changed overnight after she met her mother//yet another screamed and abused you/ as you sent her back home." Historical footage of Sarabhai and the reception camps for the women that were set up on both sides of the new border in the course of these repatriations is screened along with audio of children, rain, and women working on spinning wheels. The latter, traditionally a symbol of Gandhi's boycott of British textile imports and thus of the Indian independence movement, dominates the soundtrack. 
After one such recording, a carpet of words visually condenses the power complex to which repatriated women were subjected: "nation," "religion," "family," "attacker," "father," "husband." Sarabhai's commitment is depicted as ambivalent in its outcome, as the wishes and needs of the women concerned remained ignored: "How does one remember you, Mridula?"

Film 5 (10 mins. 32 secs.) is also dedicated to the public political treatment of sexual violence. After a short opening sequence, it begins with an oblique view of a film projected in the dark, alternating between black-and-white and colour images of a photograph of a young girl. The insert names the place where the narrative is situated: "1971/Bangladesh." The photograph becomes recognisable as an exhibit from a history museum bearing the following inscription: "In our Liberation War the Women were the worst victims of Pakistan Army atrocities. [...] Over 250,000 women were tortured and raped by the barbarian Pakistani soldiers. This 13-year-old girl was kept for months in a military camp to satisfy the Pakistani soldiers' lust." We find ourselves in the Liberation War Museum of Dhaka, Bangladesh, where we are shown another photograph of a young woman with a museum label reading "Photograph taken on 17 July at a place 9 miles north of Jessore. The young lady was a member of a refugee group fleeing to India. She was caught by the Pakistan Army, then raped and killed. She is just one of the millions such victim." One insert elaborates on the historical background of the mass murders and rapes during the Bangladesh War of Independence, the camera panning over other photographs and exhibits while the question from the audio is repeated, this time written out: "How does one remember/and how does one tell//which image can represent the ever-changing words of a testimony?" One such testimony follows, with all the minor uncertainties, random remembered details, and interjections of personal consternation that often characterise these accounts: "It was night or maybe it was afternoon. [...] My child, my head still reels when/I talk about this." The account reports the rape of two young married women by Pakistani army personnel as well as the abuse and then murder of members of their families. A young woman then reads a letter to the prime minister of Bangladesh from the father of an abducted and raped woman that is among the museum exhibits. He asks for the recognition of his daughter as "Veeranagana"-a war heroine, according to the language established by the new Bangladeshi government in 1971-and thus for her "rehabilitation": the public and thus official restoration of her honour. By presenting this well-known history as documented in a museum, with its implications for the roles ascribed to sexual violence in national historiography and the public treatment of its victims, the work addresses aspects of collective political memory. The film ends with a fade into landscape shots of Kashmir that lead into the eighth projection.

The date visible at the beginning of the sixth projection (11 mins. 25 secs.), February 28,2002 , indicates the historical context of the Gujarat pogrom, which was recent history at the time of the installation's creation. Accompanied by a bass tone, an insert addresses the viewers directly: "You left your mother's house where you had gone for/ Eid celebrations. Your name, Bilkees Yakub Rasool. /You left with 16 members of your family. The group/moved quietly by foot, travelling a few hours at a/time. The first night was spent hiding in a village, the/men took refuge in the mosque. You helped your/ cousin Shamim deliver her baby in the house of a/midwife that night. /The next morning all of you moved on. 1st and 2nd of/March were spent hiding in another village in the home of an adivasi [Indigenous] family.” After a panning shot over the landscape, the narrative begins again: pregnant Bilkees travels in a group with her three-year-old 


\section{Showing, Telling, Picturing}

daughter. Soldiers raid the Muslim family, kill the men and the little girl, rape and kill the women, and leave the pregnant Bilkees behind, believing her dead. Bilkees hides in the dark overnight, looks for water in the morning, and gets help and clothes from an Adivasi woman. She reports the murders and rapes to the local police and gives the names of the perpetrators. But these are not included in the report and no medical examination is ordered. This lack of documentation would later make legal prosecution of the case considerably more difficult.

Bilkees' second daughter is born four months later. One year after the attack, following a request by the police, the case is closed with reference to incongruities in her testimony: "You were young, poor,//a woman, a Muslim, a minority//and now a liar." Twenty months after the attack, she succeeded in having the case reopened. The dates of the ensuing legal prosecution are traced visually along a chain of hills: "December 2003, February 2004, April 2004, February 2005, 22 February 2005," then the current date "2007" (when the film was made) and, in a new image, once again the date of the attack: March 3, 2002. The sequence of dates fades. The Indian public is familiar with Bilkees' name, as she is the first woman (despite being a member of an oppressed minority) to have her rape prosecuted after the Gujarat pogroms. " $[\mathrm{H}]$ ow did you come this far, Bilkees?" asks the next insert, questioning how she survived the five years the legal prosecution took and whether she wondered if the attackers would feel safe from prosecution. Photographs show the dry landscape of the state of Gujarat, repeatedly marked by surahis: clay pots serving as monuments that memorialise the mass rapes (Figure 5.2, left). ${ }^{12}$ The narrative joins the images: "Maybe you will never go back to

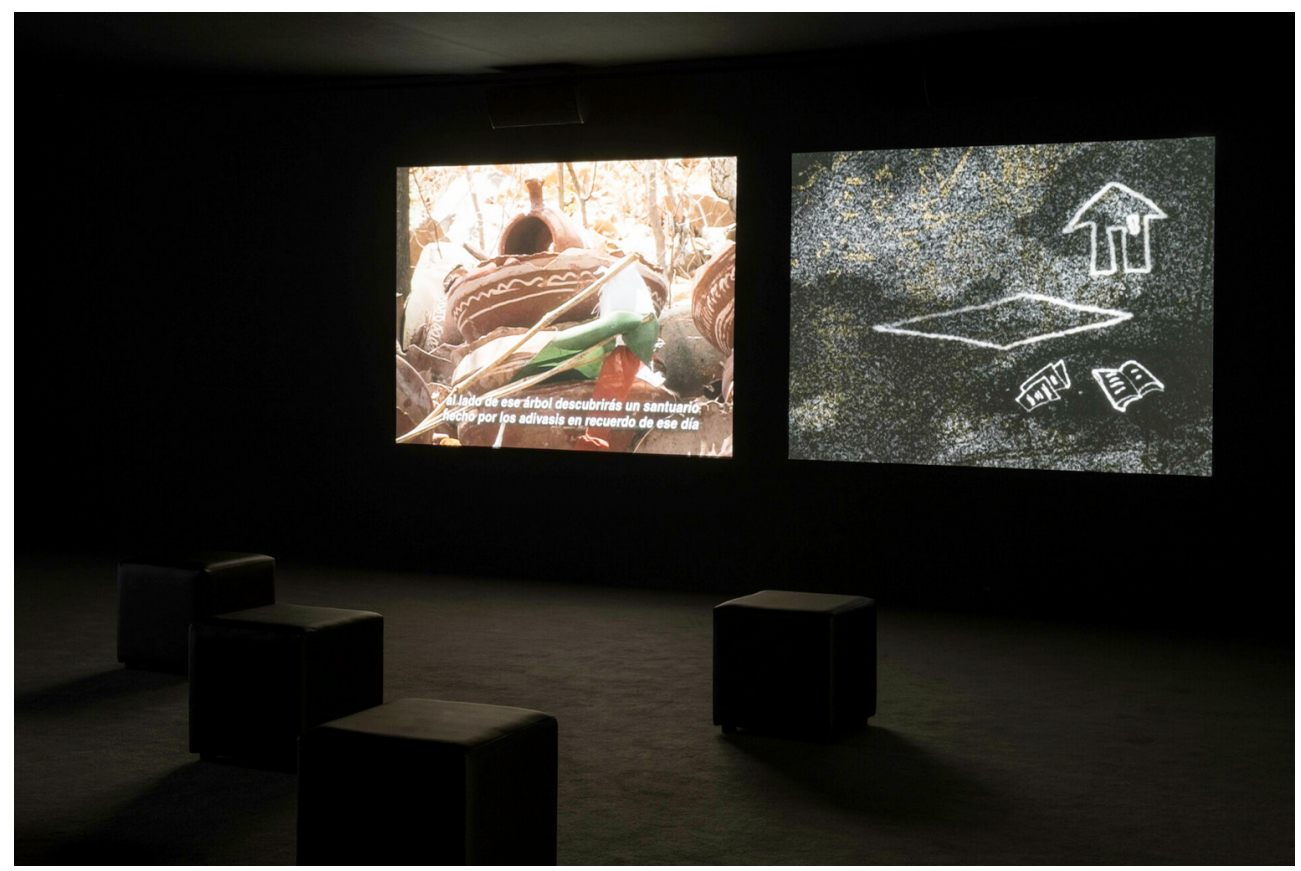

Figure 5.2 Amar Kanwar, The Lightning Testimonies, 2007. Eight-channel video installation, black and white and colour, sound, 32 mins. 31 secs. Co-produced by ThyssenBornemisza Art Contemporary and Public Press, New Delhi. Installation view, Amar Kanwar, Museo Nacional Thyssen-Bornemisza, Madrid, 2019. Courtesy ThyssenBornemisza Art Contemporary Collection. Photo Roberto Ruiz I TBA21 
that path//but Bilkees, if you ever do//you will find next to that tree a shrine/built by the adivasis in memory of that day//for every time they walk past to their village/they too cannot forget."

The seventh film (16 mins. 4 secs.) begins, after a brief opening sequence, with a blurred shot of a sand- or gold-coloured surface on which the contours of naked female nudes in dorsal pose then of a female face are being drawn. ${ }^{13}$ In between these, a crime scene photograph shows a blood-covered body in a little brook. The soundtrack contains sounds that are difficult to identify, then music. Slowly, inserts fade into a blurred background: "KHAIRLANJI/Four members of a Dalit family were murdered/by upper caste farmers over a land dispute/in Khairlanji, Maharashtra on 29 September 2006/ The two women Surekha Bhotmange and her/daughter Priyanka were paraded naked, raped and/killed. Bhaiyalal Bhotmange is the only survivor of/the family. His sons Roshan and Sudhir were also/sexually assaulted and beaten to death." A photograph of the survivor is shown, then the crime scene is sketched with simple chalk drawings on a dark background (Figure 5.2, right). This is followed by photographs of the scene (the inside of the house, a blood-smeared sickle), and an insert of the date, in the recent past: "29 September 2006." Video recordings of views around the house (the moon, a landscape with trees, the sun in the sky, water) alternate with simple drawings of the same motifs: they have become evidence of reality, testimonies. One insert describes the brutal course of the crime: "Surekha, Priyanka, Sudhir and Roshan were/dragged out of the hut to the centre of the village//Surekha and Priyanka were beaten and raped/they pushed sticks into their vaginas//Sudhir and Roshan were beaten, stabbed/their faces and penises were disfigured//Everyone in the village watched//and so did the trees." This is followed by a documentary photograph of the brook in which their bodies were found, as well as photographs of the scene. Then the insert: "The post-mortem report stated that/Surekha and Priyanka were not raped."

The chalk drawings then sketch the city of Nagpur, not far from Khairlanji. There, as the insert indicates, a stupa reminds us of the conversion of lawyer and social reformer Ambedkar to Buddhism in 1956. The murder of the Bhotmange family attests to the social discrimination against the Dalit in the Hindu caste system that Ambedkar fought against. After further photographs and portrait drawings of the two women appear, cases of the humiliating ritual of "parading naked," which regularly proceeded brutal rape and murder, are enumerated: "Paraded Naked/A Scheduled Caste woman, Yerramma was/paraded naked at Vanenur village in Bellary, /Karnatake on Sunday// Paraded Naked/A Dalit woman was stripped and paraded/naked in Talegaon village, Solapur district/Maharashtra on Tuesday by members of/the liquor lobby. They also beat up her son//Paraded Naked/Ten people were arrested on Friday for/disrobing a young adivasi woman publicly/and parading her naked in Koida village/Ratlam, Madhya Pradesh." The series continues, with changing perpetrators, victims, locations, days. Then a series of the motives for the crime: because they refused to leave their land, because they took water belonging to higher castes, because they refused to withdraw a police report, because they collected wood in the forest, because they protested against the alcohol lobby, because the husband refused to wash the feet of a groom who belonged to a higher caste, because a cricket ball fell on their ground, because her morals were doubted and she was branded a witch.

The eighth and longest projection starts by repeating the questions posed by Kanwar: "How to remember? What remains, and what becomes submerged?" After the opening sequence, the film begins with a small frame showing black-and-white shots of a house in a landscape, far away, as if from historical distance. As the camera zooms 


\section{Showing, Telling, Picturing}

out, the house recedes even farther into the distance, with the surrounding landscape slowly becoming visible. Then we see the same landscape in a colour photograph that situates it in the present, while an insert names its location in Kashmir, another region marked by violent conflicts of independence (in this respect, film 8 can also be read as a continuation of film 5). After a pan through the landscape in front of breathtaking mountain backdrops and fields of flowers, further inserts follow in rapid succession in front of a blurred dark landscape: "Hafeeza//Sara//Hajria//unknown//Naseema// minor//unknown//unknown//unknown//Haleema" and so on: a series of female names or placeholders where these remain undocumented. This is followed by shots of farm workers, an individual soldier, city life, a woman, the interior of a house. Inserts follow: "How does one remember?//Does the truth need a memorial image?//What is the value of truth/if it is powerless in the public realm?//over sixty thousand people have been killed//more than a million people have been displaced//and several thousand are missing//sexual attacks on women and girls continue//and as always everyone knows//that the Indian army attacked the Muslim women//that the militants attacked the Hindu women//that the man with the gun attacked both//now there is a never ending war//to decide who will control//the future of Kashmir." The recordings fade back to the beginning sequence: oblique shots of a canvas on which the field workers' shots (already shown in colour) appear in black and white from a distanced and distorted perspective: through this transformation we are witnessing how the Kashmir conflict turns into history; how it will become just another instance, within decades, of violence in Indian society; how it will become more and more difficult to read. The insert continues (and finally also captures the projected video image, which is only obliquely visible): "If the Indian army has impunity//and the militant cannot be questioned//and if the attacker disappears//and the family withdraws support//and the judge is a puppet//and the medical report is unavailable//and the witness is gagged//and the survivor falls silent//then how can the location present itself in court?//and if so, then which court can it be?" Scenes of violence are mentioned, starting with Ahmedabad, Gujarat, where 70 civilians were killed, and women and children were sexually abused in February 2002. "In a sexual attack, who is the target? Why do all the witnesses disappear?" On one line after another, more and more dates, locations, names, and numbers of victims are given, growing into a seemingly endless roll.

Shortly after 00: 14:30, the camera takes us to a transhistorical narrative connecting mythology and present politics that summarises and concludes the entire installation. The narrative focuses on the appropriation of a mythical character for protests against sexual violence in India. ${ }^{14}$ First, actress Heisnam Sabitri enters the stage in a theatrical adaptation of the short story "Draupadi" by Bengali writer Mahasweta Devi. The plot is set in 1971, with Adivasi woman Dopdi/Draupadi, a member of the armed Naxalite rebellion in West Bengal against the Indian army, as its protagonist. Her double name indicates an identity split across time: the local spelling of her name is Dopdi, while the Sanskrit Draupadi ${ }^{15}$ is the name of a princess from the ancient Indian epic Mahabharata. In Devi's short story, Dopdi/Draupadi is a social revolutionary who, after her rape by several members of the police, refuses to dress again. Naked, she confronts the police officer who ordered her rape, presenting her wounded, blood-smeared body. In the short story, this is the key moment when Dopdi becomes Draupadi, a woman who cannot be dishonoured. In the Mahabharata, the princess Draupadi is lost in a dice game by one of her five husbands (she is married to the five sons of an impotent king). As a result, she becomes the possession of the enemies of her powerless husband who order her to be stripped as a sign of her polyandry: having been married several 
times, she is not considered chaste and thus is to be exposed nakedly in public. But all attempts to undress her fail when Draupadi asks Krishna for help: the god makes her clothes become infinite so that she can never be completely undressed/dishonoured.

Devi's naked Dopdi/Draupadi is a counter-character to the mythical Draupadi, as she is without the protection of any god. Unlike the untouchable Draupadi, Dopdi is raped by several men, making the key moment of her story not the attempt to undress her but the attempt to force her to dress herself again and conceal the violence done to her. Dopdi proudly refuses to accept and conceal her rape or to take on the further burden of being silenced. She becomes Draupadi, a woman who cannot be dishonoured by violence but instead uses its aftereffects against her perpetrators.

Through Devi's short story, its theatrical adaptation, and its translation into English by Gayatri Chakravorty Spivak, Dopdi/Draupadi has become a well-known character. As an emblem of resistance, she provides the final touchpoint of the installation. Together with Heisnam Sabitri's performance, which continues throughout the film (Figure 5.3), Kanwar shows archive footage of a demonstration by women at the paramilitary Indian Assam Rifles base in Imphal, Manipur in 2004. Naked or half-naked, the women protest against the murder of a young woman, committed a few days earlier by the Assam Rifles. The protesters carry banners with the inscription "Indian Army take our Flesh.” The film ends with a longer sequence showing Sabitri sitting

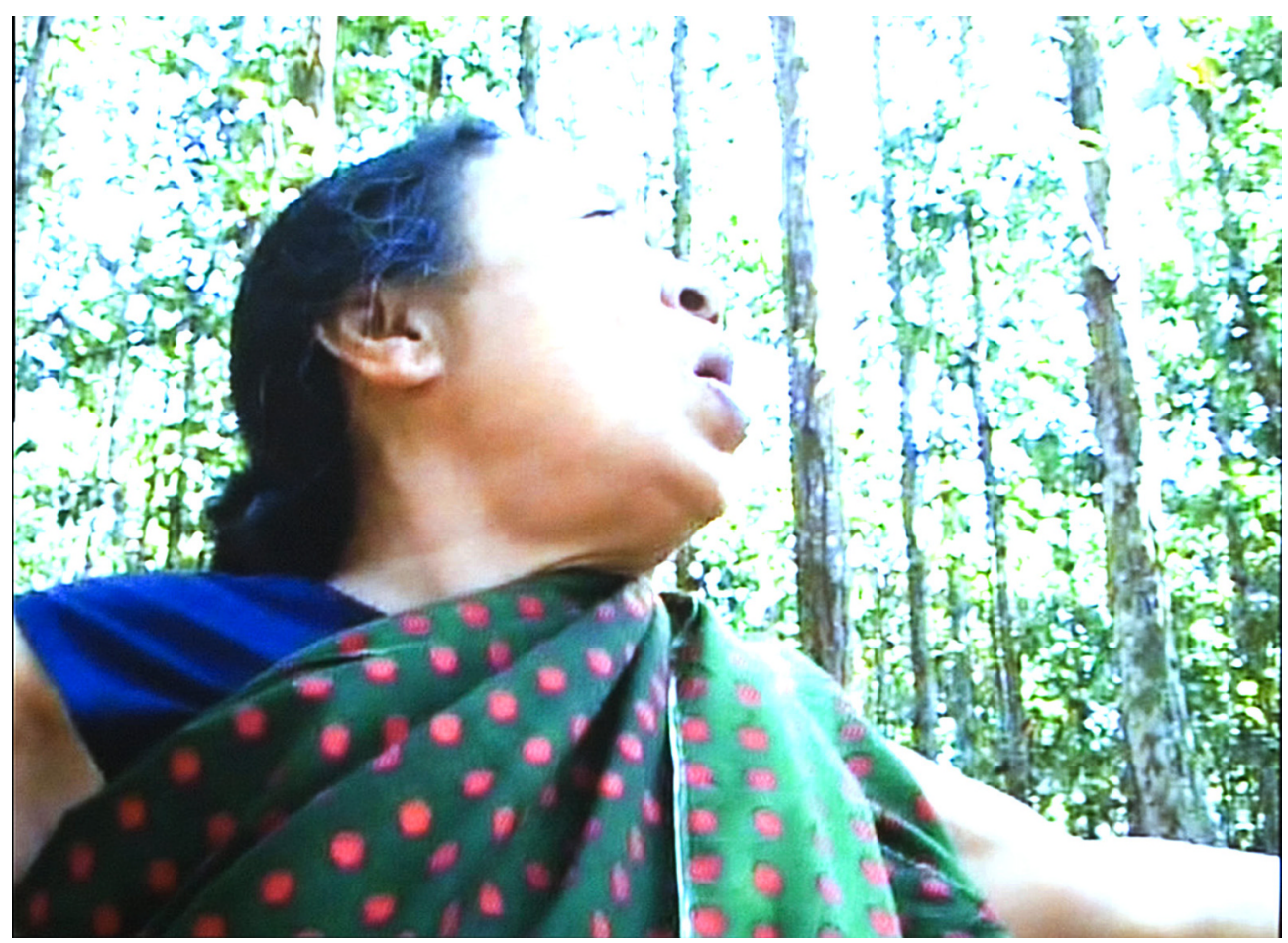

Figure 5.3 Amar Kanwar, The Lightning Testimonies, 2007. Eight-channel video installation, black and white and colour, sound, 32 mins. 31 secs. Coproduced by ThyssenBornemisza Art Contemporary and Public Press, New Delhi, Thyssen-Bornemisza Art Contemporary Collection. Courtesy the artist and Marian Goodman Gallery, Paris and New York. Photo Katrin Guntershausen 
at a campfire. Finally, the surahis from film 6 (dedicated to the victims of the Gujarat pogrom) reappear with audio recordings of a burning fire. While the stories of decades of sexual violence gradually fade away, the powerful gestures of female political protest remain. This conclusion paves a way out of the cycle of this both marginalised and public violence, tying contemporary forms of feminist resistance back to an ancient Indian epic. This is decisive for the installation's agential concept of history, since decades of sexual violence are countered by an even longer historical tradition. Partition, land grab, religious conflicts, caste hierarchies, female oppression, Indigenous rights deprivations are described as the political causes of systematic violence, but in this projection-which outlasts all the others-they are countered by powerful, transhistorical protest going back to the Mahabharata. The female protesters are as much a part of this countering as are Devi's political short stories and Kanwar's films.

The film focuses on the contextualisation of two high-profile cases of collective violence: the caste-motivated Khairlanji massacre of 2006 and the Gujarat pogroms of 2002. The question of why sexual violence is such an integral part of political conflict in the Indian subcontinent is a frequent subject of historical research and social debate. In her highly acclaimed book Hindu Wife, Hindu Nation, Tanika Sarkar historically contextualises sexual violence in Hindu culture by describing how the female body is culturally conceived as a symbol of national sovereignty. This development goes back to late nineteenth-century Hindu nationalism, when the exclusion of family matters from legal regulation was de facto accepted by British colonial authorities. The female body became a substitute territory under male Indian control, which had been curtailed by colonialism:

The home, then, had to substitute for the world outside [...]: “Just as the King reigns over his dominion, so the head of the household (karta) rules over his household"-began a mid-nineteenth-century tract on domestic management. [...] The karta, therefore, becomes within the home what he can never aspire to be outside it-a ruler, an administrator, a legislator or a chief justice, a general marshalling his troops. ${ }^{16}$

Sarkar firmly anchors the mass rapes committed (as in the Gujarat pogroms) in the political and religious symbolism of the right-wing nationalist Hindu Sangh ideology. In this context, the subjugating, life-destroying use of male sexual power becomes a political and religious duty, proclaiming the ideal of aggressive, warlike masculinity aimed at the extinction of those of different faith. ${ }^{17}$

Knowledge of this historical context is helpful when viewing The Lightning Testimonies (and the installation encourages viewers to seek it out). But lacking context does not detract from the affective impact of realising, when viewing the installation, the extent of the interconnection of sexual violence with the history of the Indian subcontinent. The installation focuses less on analysis and contextualisation than on attesting to the testimonies of those affected by violence. For instance, the long sequence of "reasons" for the public exposure of stripped and raped women ("parading naked") in film 8 does not explain anything. No analysis of social or political contexts can justify or even fully contextualise these excesses of cruelty.

However, the synchronisation of all these individual narratives and their integration into an audio-visual whole connects viewers in the exhibition space and formally counterbalances the horrors described. The sparse but explicit details of violence stand out as incomprehensible, as irreconcilable with the living world pictured in the installation and its polyphonic, atmospheric overall design. The individual narratives do not 
connect to a stream of horrors but always remain tied to the fundamental possibility of an intact and viable community. Aseem Shrivastana describes how

successfully resists the temptation of inviting anger. We all know of numerous instances in which anger, even when it is understandable and justified, clouds deeper emotions. By avoiding such a path the film opens the doors to emotions of empathy and compassion, which would otherwise remain obscured in a welter of fury. ${ }^{18}$

This describes a thoroughly humanistic address that may run counter to that analytical "discourse of sobriety" 19 that has long been dominant in art and art criticism. For instance, the installation's affective impact has been criticised by Peter Osborne as an instrument of authentication: "The work is [...] highly constructed, but in such a way as to appear as if its truth and affect (force) derives from the factual content of the subjective knowledges of the testimonies themselves." ${ }^{20}$ The crux here lies in the "as if": the effectiveness of the work, in Osborne's view, does not result from the gathered testimonies themselves but from the formal standardisation and disregard of the affected individuals, who remain subaltern outsiders. ${ }^{21}$ Indeed, the way the individual stories are formally harmonised in the installation makes each of them appear as exemplary or symbolic of a larger whole. But the installation aims not at aesthetically concealing the fragmentary, uncertain character of the individual statements but rather at emphasising it. The testimonies are reinforced and are liberated from social dishonour and marginalisation through their integration into the installative collective and through historical contextualisation. In fact, the degradation and devaluation of the victims' testimonies is an effect of the same collective violence that made the rapes and murders possible in the first place. To become marginalised, silenced, and in this sense "subaltern" is a direct effect of sexual violence. The Lightning Testimonies formally creates a collective, polyphonic sovereign subject confronting the institutions and bodies that have perpetrated and are still perpetrating violence. The installation brings together statements by women who-often from enormously difficult positions-have fought against their victimisation and who have taken legal action against all social odds. This self-empowerment culminates in the character of Dopdi/Draupadi, who reveals that the female body is a public arena of violent political conflict but refuses the role of victim.

Although created from the perspective of a most pressing and urgent political crisis, Kanwar's The Lightning Testimonies turns away from the precepts of sobriety and clarity formulated in 1970 s political film (and certainly central to his training as a documentary filmmaker). As the artist points out, his installations rather aim at answering to the diversity and heterogeneity of its audiences, presentation contexts, and performance venues:

I don't think that dealing with multiplicity and putting forth your point of view are contradictory. Further, I think in the global political situation, any activist would know that the audience he is trying to reach out to is of many kinds, with many rationales and many histories. Even if you want to make just a convincing kind of argument film you will find that you don't end up convincing at all. ${ }^{22}$

The Lightning Testimonies experiments with the formal principles of documentary in order to address heterogeneous audiences. The multichannel installation responds to different levels of willingness, ability, knowledge, and emotion viewers might bring into the gallery in order to convey an enormously complex and psychologically demanding topic in a subtle and cautious way. The formal structure of multichannel installation, 
which Kanwar first used for The Lightning Testimonies, serves to reinforce this multidimensional address:

The moment you accept that, you have to realize that when you communicate, you are not talking to any one single point. Even if you are speaking to one single person, that person is put together of so many different layers. [...] If you're able to see the complex inner diversity and heterogeneity within individuals and, therefore, in audiences, then you're able to see the many dimensions of communication itself. Film is an unbelievable medium-you can do what you want with sound, music, ambiance, image, and color. You find that when you start putting these together, it is possible to create a constellation of experiences that have the capability to relate with the multiplicity of life and audiences and eventually the multiplicity of the maker as well. ${ }^{23}$

The relatively long historical period of six decades discussed in the installation is adapted to individual biographical experiences of time and of collective political memory, thus also serving to unfold the narrative into several "layers of experience." An older audience member may be able to remember the year 1947, at least from close accounts; many others will directly remember 1971; the events of 2002 and 2006 were still fresh in the collective consciousness at the time the installation was created. This deliberate departure from documentary formats that Kanwar describes as "conventional"-designed to make clear statements; to serve to convey information-suggests questioning the title The Lightning Testimonies. For even if-as Kanwar himself shows-his work potentially conjures up the scene of a public tribunal in front of which testimonies are being collected, their presentation does not follow conventional legal rhetoric. The collected voices are often not only logically convincing but also affectively persuasive, following principles of creation "that tug at many hearts"; ${ }^{24}$ they harbour images and symbols open enough to reach different people in different ways. In this respect, the work is indeed vulnerable to criticism: The Lightning Testimonies shows not only actual sites or persons, but also those "open symbols" which, if they do not touch the heart, remain empty: a full moon, an empty corridor, a little boy, a sleeping toddler. These pictures may carry memories, as Kanwar describes with the example of a blue-glazed window (Figure 5.4):

It could be anywhere, even in the wooden kitchen window from where Mother pointed out-Look! That's from where we saw the soldiers take Aunty down the street. 57 years ago. So the child remembers of course but Aunty resides in the wooden window for eternity. That wooden window is the container of that morning 57 years ago and of every single day in time since then. ${ }^{25}$

Without this information-which is not included in the installation-the window may be perceived as merely a picturesque detail. The idea that individual objects, plants, or animals can also become witnesses of history is hinted at in the individual films (such as the orange tree in film 2); the films also suggest that textiles or drawings can become evidence (as in films 1 and 7). Arguably, these images may not simply be "filled in" by new individual emotional reactions - are not open to free personal projections or interpretation-but are firmly anchored in religious, spiritual, and poetic traditions that in part or in whole elude the international audience: Torunn Liven refers to the traditional Indian aesthetic theory of "rasa" with regard to the formal structure of the installation. The term describes a state of mind created by the affective power of artworks (theatre, music, or literature) that transcends individual experience and affectively opens the 


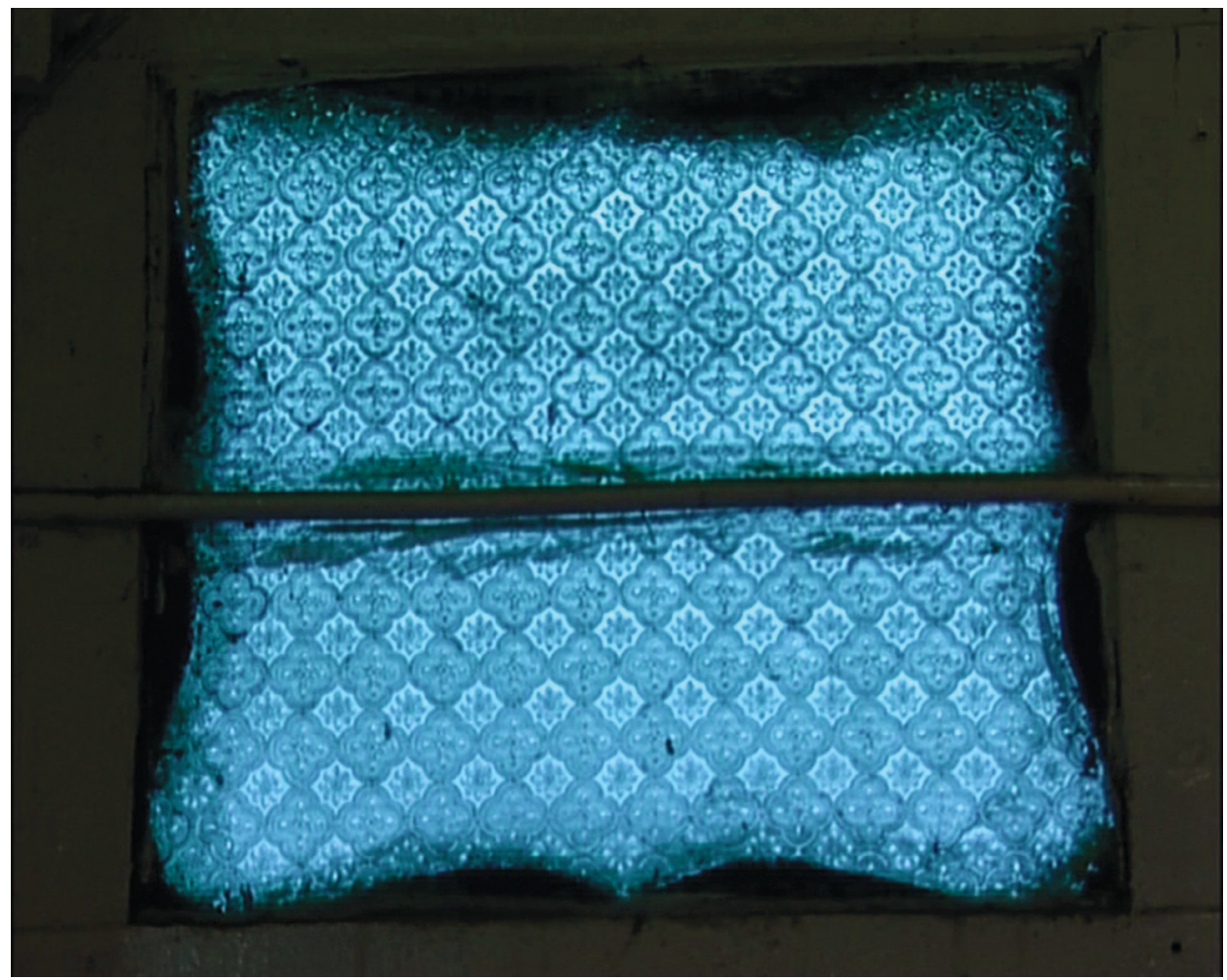

Figure 5.4 Amar Kanwar, The Lightning Testimonies, 2007. Still image, eight-channel video installation, black and white and colour, sound, 32 mins. 31 secs. Co-produced by Thyssen-Bornemisza Art Contemporary and Public Press, New Delhi. Courtesy the artist and Thyssen-Bornemisza Art Contemporary Collection

mind to become receptive to spiritual or moral reflection. ${ }^{26}$ This corresponds to an understanding of self-transgression similar to that multidimensionality described by Kanwar as decisive in the creation of his artworks. Furthermore, addressing the audience as a multidimensional entity is important as it is the basis for the public, politically valid presentation of these historical testimonies. Kanwar makes this claim precisely through the poetic, affective qualities of his work.

This way of understanding and addressing the audience as a multidimensional entity responds to a heterogeneity of experiences. For this reason, Kanwar's polyphonic narratives do not need to be welded together to create identity or to authenticate each other. The public presentation of these testimonies alone gives the documentary its political importance; is itself a political statement. And Kanwar makes this claim precisely through the poetic, affective qualities of his work.

Kanwar is deeply interested in the question of whether art may be applied as a legal instrument-a query he has pursued, among other occasions, in his artist's book Evidence: "Imagine the formal presentation of poetry as evidence in a future war crimes tribunal." 27 Among examples of art one might think of as "inadmissible evidence," according to today's legal standards, are Luingamla's woven sarong (film 1); the drawings depicting the violence against Surekha, Priyanka, Sudhir, and Roshan (film 7); Mahasweta Devi's short story; and, finally, The Lightning Testimonies themselves by virtue of their poetic, nondocumentary quality. The adaption of the Draupadi myth in 
current feminist protest, too, emerges as a transhistorical alliance of protest movements created via the interweaving of various media and drawing on the traditions of political literature, poetry, and film. "It is here that we seamlessly move between something deeply personal into something that is hugely political and back. [...] Here lies the inadmissible evidence, not yet defined by the legislations of our time." ${ }^{28}$ The Lightning Testimonies makes an emphatic claim to public impact, as illustrated by its production of a quasi-tribunal (see also Chapter 8). Unlike trials, tribunals do not need to result in final verdicts; they are open legal and ethical proceedings that focus on collecting data, information, and testimonies as well as on clarifying and visualising events. The audience is their addressee; its opinion is decisive. If no one pays attention to it, a tribunal becomes meaningless. ${ }^{29}$ With its primacy of showing and telling, Kanwar's The Lightning Testimonies may indeed work as a tribunal, as it seeks a form of justice based less on pronouncing sentences and punishing crimes than on making injustice visible and on having oppressed and disenfranchised voices heard and recognised. Thus, The Lightning Testimonies uses art as a means to put forward a collective indictment out of the most diverse historical materials, witness statements, and memories.

\section{Will Always Be Here: Zarina Bhimji's Out of Blue (2002) and Yellow Patch (2011)}

Working in photography, film, and installation, British artist Zarina Bhimji has been exhibiting since the late $1980 \mathrm{~s}^{30}$ She received major international attention after the presentation of her film installation Out of Blue (2002) at documenta 11; since then, her impressively beautiful films-including Waiting (2007), Yellow Patch (2011), and Jangbar (2015)-have been shown worldwide, often together with her photographic, textile, and graphic works. The contextual frame of reference of Bhimji's work is large, with regular references to colonial and decolonial history and to the history of medicine.

The following pages examine two of the three films based on the artist's family history: Out of Blue (24 mins. 25 secs., Super 16mm) and Yellow Patch (29 mins. 43 secs., $35 \mathrm{~mm}$ ); the third (discussed only cursorily here) is Jangbar (26 mins. 37 secs., $35 \mathrm{~mm}$ ). Linked by a similar visual language, their common point of reference is a period of political history connecting the Indian Subcontinent, Central Africa, and Europe ${ }^{31}$ beginning - in the chronology of the films, not that of events-with the violent expulsion of the Asian-born population of Uganda in 1972 following Idi Amin's plans for Ugandan "Africanization." Amin's order to expel all people considered "non-African" was broadcast on radio; it mainly affected people brought to Uganda from India and Pakistan in the course of the British colonisation who had been living in East Africa for decades, some for generations. They were given three months to leave the country. ${ }^{32}$ Among the most immediate consequences were outbreaks of violence, expropriations of goods as well as property, and disenfranchisement of those to be expelled. Bhimji's family was directly affected by the events, as the artist's father had come to rural Uganda from Gujarat as a foreign worker. Despite being illegalised, the family continued to live in Uganda in hiding until 1974, when they emigrated to Great Britain. Eleven years old at the time, the artist returned to Uganda only in 1998, creating her first film Out of Blue from this visit. But while the film was shot on site and uses audio recordings made during the trip, it does not directly reflect the artist's memories or her family history. Rather, it is based upon extensive research into historical documents on Amin's policies, on the way these were reported internationally, and on the architecture of Uganda.

Out of Blue (Super 16mm colour film, HD transfer, 24 mins. 25 secs., Figure 5.5) begins with a title insert in Gujarati and English in white letters on a black background. 


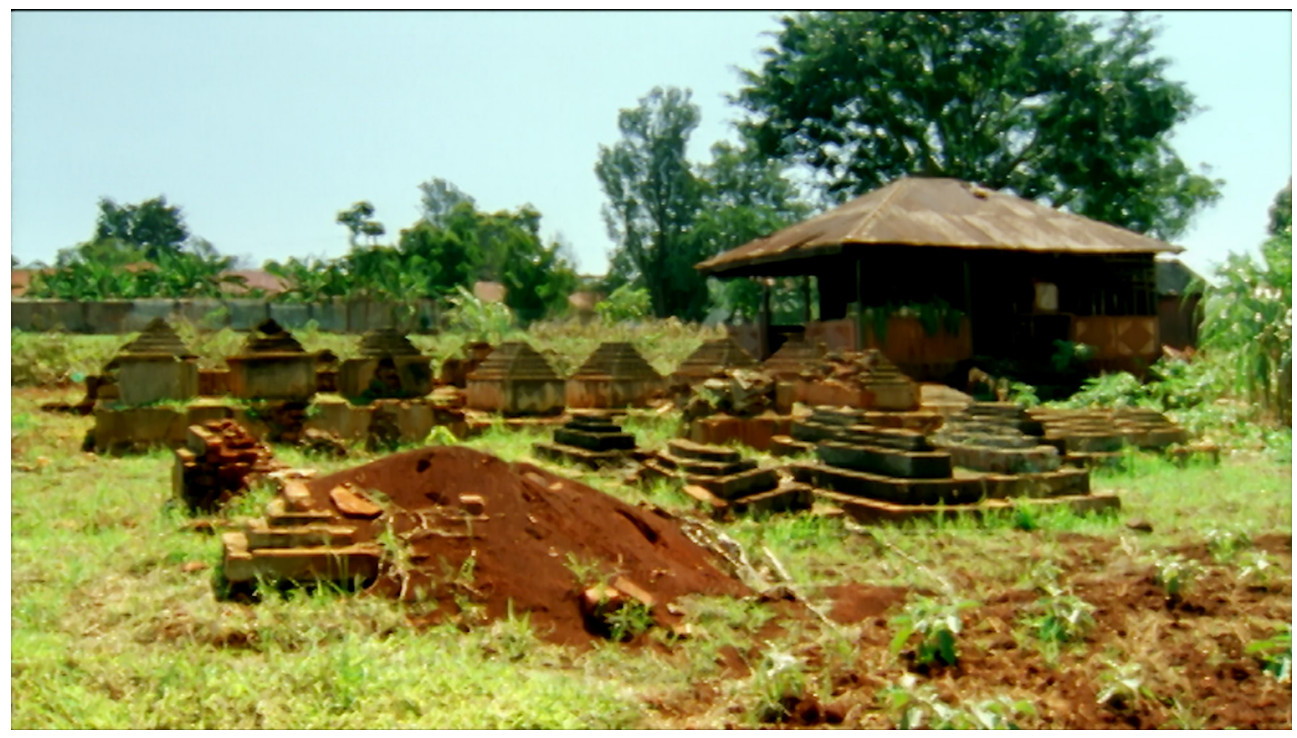

Figure 5.5 Zarina Bhimji, Out of Blue, 2002. Still image, Super 16mm colour film, HD transfer, single screen installation, 24 mins. 25 secs. (C) Zarina Bhimji. All rights reserved, DACS/Artimage 2021

Then sound and images appear: an idyllic forest landscape in Uganda emerges before the rising sun, visually and conceptually evoking the tradition of European Romantic landscape painting with its potential to symbolise feelings, memory, and identity—and a kind of affective ownership. But the actual relationship of these images to feelings, as we will see, is not easy to trace; neither do they have a direct connection to the artist's memory. Bhimji has repeatedly mentioned her admiration for Caspar David Friedrich and William Turner as well as her interest in depicting African landscapes using the visual means of Romantic European landscape painting. ${ }^{33}$ This tableau is accompanied by an atmospheric jumble of birdsong, cicada sounds, and singing that is increasingly permeated by a threatening bass tone. With slow horizontal pans and zooms at eye level, the camera leads us first through the landscape and then through urban space. The idyll is interrupted by a pan to the left that shows an open, spreading fire. Idi Amin's expulsion order came "out of the blue," chasing thousands of people into diaspora; thus, suddenly, human sounds, language, and politics break into the images of peaceful nature: recordings of the dictator's radio announcement, wailing sounds, and gun salvos; the picture now shows army barrack dormitories, colourful dishes, and rifles stacked in a row-in front of these a shadow procession of soldiers is cast. In fast motion, a cloudy sky appears over what may be a prison yard; human sounds fade away. Rows of houses follow; a colourful bird darts away; then, accompanied by singing and the sounds of children, we see a view from behind window grilles onto a rainy courtyard. Glimpsing a kitchen and another room with puddles of water, we hear frightened female breathing sounds that become silent after several shots. These are replaced by forest and animal sounds. Again, the threatening bass tone returns, while the images remain ambivalent: views of a cemetery and a single gravestone are followed by images of earth being moved with a spade, which may be read as preparing a burial or as agricultural work in the neighbouring field. These images are accompanied by radio recordings with only some words, such as "members of the Asian community," clearly audible. Finally, we see images from Entebbe airport accompanied by rapid, restless string instruments, 
conversations, and gunshots, until the camera once again roams over the airport and the landscape. The last sequence of the film is a look backwards from an airplane as it accelerates up the runway, interrupted by the peaceful landscape images we saw at the beginning, now no more than a memory.

Although no human action is directly shown, the film suggests a clear narrative structure: we witness a day from the beginning of a new morning to a departure from Uganda. The images were shot in private homes, in police stations and prisons, but the only concrete reference to a location and a history is given by the "Entebbe" sign at the end, as most of the displaced persons were forced to leave Uganda via this airport of its former capital. However, if the visuals reveal little tangible information, they still create strongly suggestive moments—as does the soundtrack. As Bhimji states, the Romantic aesthetics of the landscape images were meant to convey longing for a lost home, functioning as "an antidote to brutality." ${ }^{34}$ It is clear that we witness the breaking of a devastating catastrophe onto a peaceful landscape; that dangerous and confusing events follow; that finally we leave this landscape behind, giving viewers an impression of Bhimji's own experience of events. In an interview at her first solo exhibition at Ikon Gallery, Birmingham, in 1992, which included an installation piece titled I Will Always Be Here, Bhimji cites T. S. Eliot: "We had the experience but missed the meaning." 35 This missing of meaning is shared by the audience if its members watch the film without recourse to background information. Viewers are directly transported to locations without being able to understand immediately the historical context, about which they may only pursue information later, if at all.

The films are as rich in content as they are enigmatic, creating affective impacts that are quite detached from their historical and geographical context. They are often labelled "post-documentary," even "anti-documentary." ${ }^{36}$ In a detailed review of Yellow Patch (2011), T. J. Demos has described the film as producing a "cinema of affect" 37 that aims less at telling stories or conveying information than at triggering powerful, physically tangible emotions and reactions. As I will show, however, affects triggered in this way are both highly ambivalent and unreliable. In his essay, Demos quotes the artist's treatment for Yellow Patch: "It's not about describing a house or making it picturesque. It is to go beyond the description. It is to reveal attachment, to explore subtle shadings of our attachment. To build up emotional intensity, empty/full, communal/ solitary, rational/irrational with sound." ${ }^{38}$ Fullness and emptiness, reconstruction and loss are equally contained in these films, evoking the title of Bhimji's early exhibition piece I Will Always Be Here, which promises an unredeemable form of presence that must inevitably be accompanied or followed by loss.

The artist's two more recent films-Yellow Patch (2011) and Jangbar (2015)—were created along a similar structure that combines moving but elusive images with strongly affective soundscapes. In the case of Yellow Patch $(35 \mathrm{~mm}$ colour film, HD transfer, sound, 29 mins. 43 secs.), the overarching narrative is also a farewell; this film, too, starts with the title in Gujarati and in English in white against a black background..$^{39} \mathrm{~A}$ musical fanfare sounds as a prelude. This is followed by the sounds of a bustling street scene as the camera glides through an abandoned, dusty ticket counter (at Princess Dock in Mumbai, a port facility built by the British in 1885, though we do not know any of this when watching the film). Sounds of footprints and typewriters evoke a busy past. Accompanied by music, the camera travels through abandoned offices, stacks of paper bound with strings, and endless rows of shelves with old documents. From a historical radio recording only short fragments can be understood: "in a world," "civilization," "strikes are terrible." The soundtrack changes to a cloudburst. Pictures of slowly 
rotating fans in the office building are now accompanied by longer bits from the radio address: "Tomorrow, two sovereign states"; "We are part of history"; "There is no time to look back; there is time only to look forward." This is followed by outdoor shots of a deteriorating country estate in Kachchh, Gujarat, accompanied by recordings of what may be local sounds intermixed with Big Ben's characteristic chime.

Then we see the only image of a human presence in all three films: a woman with light, almost white hair in traditional Indian dress is seen from the back as she gently sways back and forth, accompanied by peacock cries and the melodic whistling and singing of birds. A dramatic bass tone sounds as the camera approaches the entrance gate of the estate house and sedately moves along rows of windows bricked up with stones. A peacock strides across sandy ground; we hear it cry and then hear other animal sounds. Another frontally filmed row of windows with partially open yellow shutters looks like a painting composition, evoking the film's title. The camera now explores the abandoned interior of the once magnificent estate: a row of faded animal skulls, a worn armchair, elaborately carved furniture, remains of wall paintings—all coated with a thick layer of dust. The porcelain of a chandelier clinks in the wind, followed by a sudden dynamic camera movement along the row of windows that finally slows and then hesitantly, comes to a halt. Immediately afterwards the camera approaches fissures in the wall with equally excited zooms to great cinematographic effect; they end just as indecisively. All this creates a strong but completely open-ended effect on the viewer: one is repeatedly placed in suspense, but its resolution remains hanging, neither fulfilled nor dissipated. The tracking shots test possible narrative scenarios but do not settle on any one: they may trigger melancholy, admiration, horror, or curiosity.

The house is surrounded by the salt desert of Kachchh, which seems dusted by the same whitish layer so that each plant fades into the same pale colour as the abandoned furniture or the animal skulls seen before (Figure 5.6). Once again, the atmospheric staging of light, wind, and movement_accelerating and decelerating-gives the

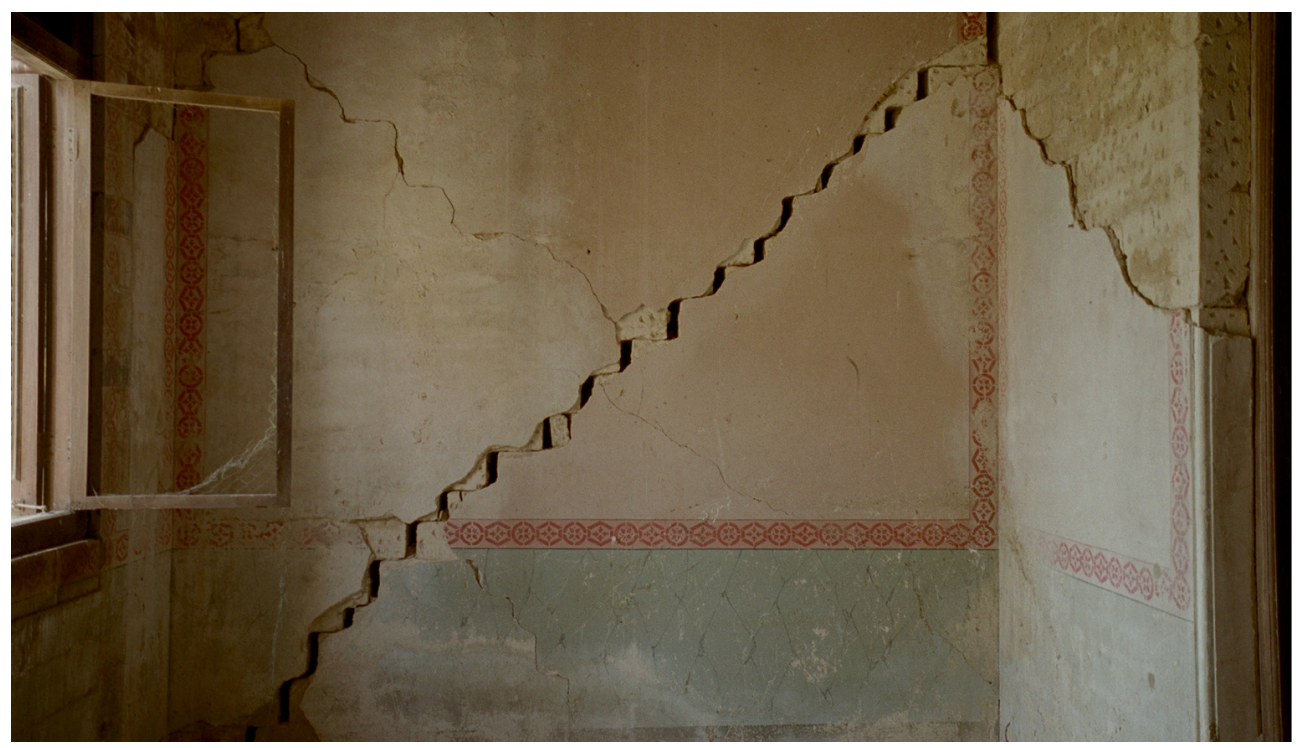

Figure 5.6 Zarina Bhimji, Yellow Patch, 2011. Single-screen installation, 35mm colour film, HD transfer with Dolby 5.1 surround sound, 29 mins. 43 secs. (C) Zarina Bhimji. All rights reserved, DACS/Artimage 2021. Photo Nina Kellgren 


\section{8}

impression that the camera is on the trail of or hunting for something, an urgency followed by calmer images that invite one to linger. The sound of rain-most welcome in the dry landscape-seems to set in, but it turns out to be only wind. This is followed by singing (the artist uses recordings of the Pakistani singer Abidi Parveen), ${ }^{40}$ then, once more, we hear booming bass tones while the camera first dramatically approaches specific locations within the house (a small, closed door, a staircase, rows of windows) but then leaves off, strangely unresolved once more.

The images convey a grandiose ruin aesthetic that plays with faded splendour and long-lost resplendence, floating cobwebs and layers of dust only enhancing a timeless elegance. However, there are some references to a specific historical background: the camera circles a marble sculpture of Queen Victoria; ${ }^{41}$ radio recordings (speeches, riots, demonstrations; then beating noises that could be from a cricket match, applause) permeate the soundtrack. The final images show a port (Mandvi Port in Gujarat): two ropes float in shallow water; shipwrecks are abandoned on a pier. To the sounds of sea and wind, the camera shows the crew cabin of a sunken boat, stray dogs; it glances into the shipyard and finally turns out to sea.

As this detailed description makes clear, sound is used expertly, with all its affective potential: "The soundtrack is as central as the images in the film. It powerfully and physically inhabits the film." ${ }^{42}$ If one were pressed to decide within which genre to classify these three of Bhimji's films, an illustrated sound piece rather than a film might well come to mind-despite the stunning visual aesthetics. Indeed, the soundtrack was created independently from the visuals and was added to them-or, rather, the images to the sound-only afterwards, producing a strongly affective interplay that is not frictionless. At times, the camera seems to fathom various possible pictorial languages and it is only the soundtrack that leads the images into specific directions. All implicit knowledge of their historical significance is condensed acoustically: the pictures, though atmospheric and beautiful, hardly reveal anything.

Research for Yellow Patch was as thorough as for Out of Blue: the radio recordings are clips from various sources held in the British Sound Archive ${ }^{43}$ that refer to Partition. The voice recordings are from Gandhi and Nehru; from anti-British resistance fighter and first Governor General of Pakistan Muhammad Ali Jinnah; and from Lord Mountbatten, the last British viceroy of the Indian colony and the first Governor General of India after Partition. For Yellow Patch, the artist took one step farther back in history, tracing her father's journey from India to East Africa, a little-known moment in the history of global migration: "This story is the lived experience of many East African Asians." ${ }^{44}$ The missing link in this global journey-between arrivals on the East African coast and in Uganda-is filled by Jangbar (2015), which was shot along the trade and migration routes of India and Africa in Kenya and Zanzibar. This third film has the most easily comprehensible spatial-geographical narrative, tracing a journey along the "Kenya Railway" built between 1885 and 1905 with the help of workers of Indian descent that leads from the Kenyan east coast (Mombasa) far inland to Kisumu on Lake Victoria.

When Out of Blue was first shown at documenta 11, it was presented without further references to its historical context. Information was only available from a short text in the exhibition guide. In subsequent presentations, the artist decided to add research material. ${ }^{45}$ In 2012, at Whitechapel Art Gallery, Yellow Patch was shown together with 12 works from Bhimji's photographic series Love (1989-2007), some of which originated from the same research trip for Out of Blue. Her exhibition Lead White (Tate Britain, 2018-19) consisted of graphic, photographic, and textile works exploring the 
textures rather than the contents of archival documents. It is important to note that neither laying out her research nor presenting additional artworks is intended to "explain" the films. These "extras" rather support the films' aesthetic condensation as material that cannot be classified as it does not serve the purpose of classification. The images created at the historical locations remain, as Demos has noted, opaque. ${ }^{46}$ Consequently, the research material presented by Bhimji may reproduce authentic archival documents but may also contain fictionalisations if they serve the empathetic reenactment of events:

For example, I was thinking what it may have been like for an Indian man, or African man, such as my father, to be barred from lots of places by the British on the basis of his skin colour. I pictured myself as a little girl standing next to him. This episode, by the way, is fictional, not personal; I fictionalise to make sense of things, this is part of my research. I like to create characters like my father, or my son, or my daughter. ${ }^{47}$

Bhimji also uses reenactment while working on photographic and film projects: "What I am doing is trying to make sense of my own history. To do this I need to project back into the feelings I had as a child, when I was eight, when I first came to England, the clothes I wore, the food I ate with my parents." 48 Or, in relation to Waiting (2007): "I wanted to engage with what it could be like to be a young African boy in a colonial situation." ${ }^{49}$ It is tempting to associate these procedures with Walter Benjamin's concept of a "stage of memory"-his conviction that "memory is not an instrument for surveying the past, but its theatre." ${ }^{50}$ Similarly, Bhimji's cinematographic works stage grandiose, affective scenes of memory that, however, mobilise highly ambiguous emotions. The resulting atmospheric audio-visual complexes are of high intensity but elude verbalisation, even interpretation. They arise from experiences that result in trauma, pain, and a destabilisation of identity. ${ }^{51}$ This leaves the viewer with evocative but strangely (given the important role of sound in her films) "mute" images that may serve as a projection matrix for aesthetic pleasure-images "of nothing, going nowhere." 52

In this way, Bhimji stages the intangible nature of past experience instead of evoking concrete memories as reliable traces of a past self witnessing past events. At first glance, her films seem to be an impressive example of Laura Marks's "haptic cinema." Marks links this concept directly to intercultural cinema, which she sees as forced by the discontinuation of traditional historiography to work not only on the basis of facts, information, and documents but also to counter this loss with a turn to the haptic, or sensory, aspects of filmmaking. ${ }^{53}$ This concentration on memory and imagination is also true for Bhimji's work, as is her departure from oculocentric filmmaking, which neglects many triggers of memory: smells, sounds, touches; the atmospheric, the intangible. Her approach to history, moreover, decidedly counters Eurocentric perspectives. But the analogy reaches its limits when it comes to aligning or drawing analogies between these haptic images and personal memories, which is central to Marks's concept. ${ }^{54}$ This is precisely what does not happen in Bhimji's films-and this in itself is moving. The evoked images and emotions are grandiose but they fade away, remaining elusive prostheses of memory. They may help to evoke experiencing an event without understanding it but not the past per se. Quite contrary to the wonderfully real and delectable madeleine in Marcel Proust's À la recherche du temps perdu-which invites us into an immediate, sensual incorporation of the past-Bhimij evokes another image: "You get hold of a bar of soap and then it slips away." 55 The "I" who has experienced 
the past, who "will always be here" is just as intangible as the experiences and emotions she has lived through.

In her films, Bhimji stages a cinematographic dramaturgy in which the past is indeed lost but the ambivalent memories, longings, and affects directed at it can find a place. Working with sound and image, her works provide a home to those elusive, visceral aspects of memory that do not yield information and elude immediate interpretation but perfectly reflect the immediacy of lived experience.

\section{Trapped in Narration: Omer Fast, Nostalgia (2009)}

At first glance, Omer Fast's artworks appear pointedly to undermine the value of testimonies. In his films and video installations, the Berlin-based artist demonstrates a highly infectious and often amusing interest in distorting and alienating memory emplotments. He shows how narratives migrate and adapt to a wide variety of new historical and cultural contexts - always carrying with them the promise of a true essence that indeed may still be there but is often transformed beyond recognition. However, considering Fast's work in light of our examination of Bhimji's films-which impressively demonstrate the irrecoverability of escaped or lost experiences and feelings-may help us to perceive his oeuvre in a new way: as an indispensable contribution to the critical appraisal of the authenticity of narration, especially in the context of current media policies and attention economies, which include the art world.

The video installation Nostalgia (2009), which won the German National Gallery Prize in the same year, consists of three individual films of increasing length, scope, and technical complexity shown separately in three consecutive rooms. Visitors first encounter a small-format single-channel video (Nostalgia I) of four and a half minutes in length (Figure 5.7). It begins with an initially hesitant autobiographical account of a young man who introduces himself as Peter, a former child soldier who had grown

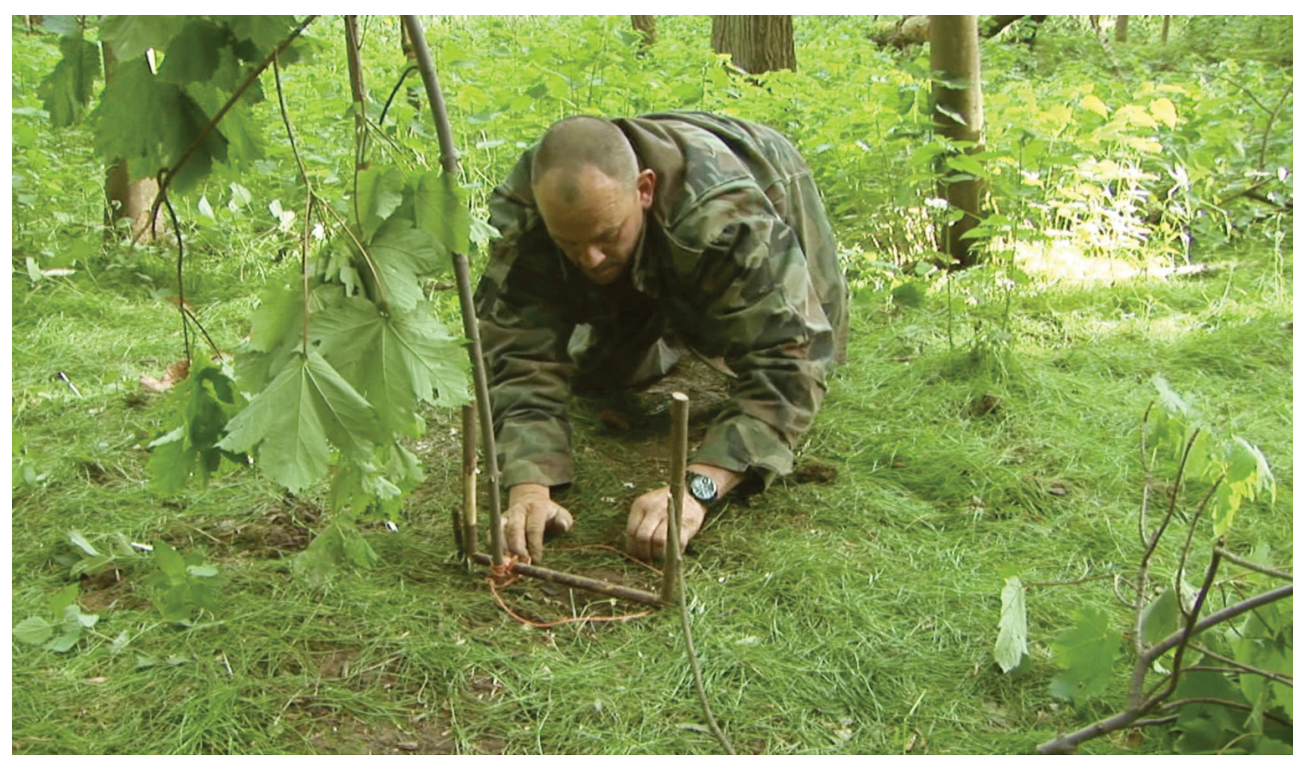

Figure 5.7 Omer Fast, Nostalgia I, 2009. Single-channel video, 4 mins. 30 secs., Production photo. Courtesy the artist 


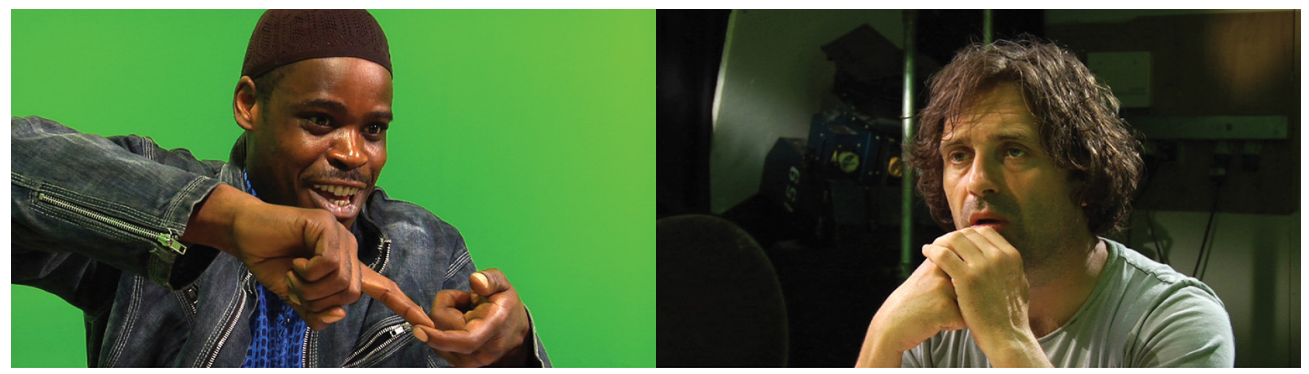

Figure 5.8 Omer Fast, Nostalgia II, 2009. Double video still, two-channel video, 10 mins. Courtesy the artist

up in the Niger Delta. He describes his friendship with one of his captors, an elderly soldier, who taught him how to build an animal trap from twigs to catch partridges. We hear Peter's story in an audio recording that is difficult to understand; we do not see him. The soundtrack is accompanied by video recordings of a skilled White trapper setting such a trap in a (presumably European) forest. Towards the end, the video suddenly shows an interior space; the trap is set upon a table. Peter, who now seems to enter the picture (the sound recording continues without interruption), shows how it snaps shut and comments on this with the casual final words: "People die like that." A press release from Fast's former gallery, gb agency, states that the audio track is a recording of a conversation between the artist and a Nigerian asylum seeker in London; ${ }^{56}$ that is, prime documentary material. The images were filmed later to accompany them.

The second film, an almost ten-minute two-channel video (Nostalgia II, Figure 5.8), represents a kind of failed reenactment of the original conversation. The dialogue is shown on two separate monitors. On one side, a young Black asylum seeker who introduces himself as William sits before a black-box-generated green background, isolated from any tangible context. His counterpart is a White American of demonstratively casual professionalism - a role in which one can easily imagine the artist parodying himself. This Omer, placed in an office environment, talks about a planned film project on migration ("a sci-fi film with props and actors"), one part of which is to include conversations with asylum seekers ("people like you," as he puts it with smug paternalism). In the following dialogue, it becomes clear that the artist is looking for a suitable motif for such a film and hopes for inspiration and apposite material from his conversation partner. Initially, William readily responds to all requests to give his account the right narrative form, the right reality bites, the right bit of colour. His narrative repeats autobiographical elements from the first part of the installation. William, too, remembers a past as a child soldier and tells the story of how to build a trap, which he describes in detail. But despite all parallels to the first conversation, we witness it gradually coming apart at the seams. The gap between the interlocutors grows wider and wider. While William strives to please and entertain, the artist's uncertainty and discomfort increase in the face of the grotesquely humorous details that emerge, playing with indecipherable hints of violence: William suggests that people were caught in the trap, only to change his narrative immediately to claim that monkeys were caught to be eventually eaten-or sold? The (fictional) Omer grows more and more disconcerted, unable to verify or contextualise the narrative of his elusive interlocutor whom he has only known briefly: To what extent may this refugee's account be trusted? What may plausibly have happened to a child soldier in Central Africa? 


\section{Showing, Telling, Picturing}

The narrative-which seemed so authentic in the fragility of the unprocessed sound recording in the first film-is now recounted by an unpredictable young man about whose credibility doubts grow for a variety of reasons. William openly seeks to impress and entertain his counterpart, offering him ever-changing narratives and identities. When the artist tells him about his planned film project, William is convinced he can take a role in it right away:

W: I want to be in the movie.

O: You what?

W: I want to be in the movie.

O: Can you act?

W: Sure, man. That's all I do since I come here.

The last, highly provocative sentence is exemplary of a looming fear that the artist shares with the audience: not only are the authenticity and usefulness of the precious material entailed in his supposed memories jeopardised by William's dishonesty (while it is obvious that William is not considered an equal partner in this dialogue but is required to deliver an engaging story), but so is the credibility of asylum seekers more generally. The conversation between William and Omer increasingly resembles an interrogation-one that is certainly supposed to produce maximum transparency and honesty but results instead in considering only very select narratives as plausible and successful. William has to convince his counterpart of his attractiveness and authenticity, as he has had to do with immigration authorities; the artist is in search of a catchy motif that must be authentic, convincing, and touching yet not violate the sense of decency of a Western art public with grotesque or tasteless details. Artistic dramaturgy may require different narratives than an interrogation in an immigration office, but in both cases there are certain conventions to which to conform.

The dialogue's results, therefore, are ambivalent. Over the course of the conversation, William slowly gains the upper hand, as he is more agile and more amusing than his perplexed counterpart. Nevertheless, the majority of a Western art public will probably feel with "Omer's" insecurity and scepticism-even if the poorly prepared, paternalistic Omer emerges, on the whole, as an rather average ignoramus who primarily follows his own professional interests and is not willing or able to seriously engage with his interlocutor.

The third and final part of the video installation (Nostalgia III, 32 mins. in loop) seems to be the promised film project described in the second part: "A sci-fi film with props and actors." This vision of the future, shot on Super $16 \mathrm{~mm}$ and staged in the style of a feature film, is moved back in history: from the push-button telephone to the clothing and a film excerpt from Chris Marker's Sans soleil (1983), everything is reminiscent of the early 1980s. The heyday of cinematographic science fiction with its technological utopias has long passed; instead, the film shows a dystopian scenario. White Europeans try to reach an unspecified African country. Scenes from a refugee tunnel alternating with shots of everyday situations are held together by the migrating motif of the trap. Depending on where in the video loop one starts viewing, different narratives emerge. One possible starting point is the scene of an interrogation of a White European man by a Black African female officer. The balance of power between the two characters is ambivalent: the woman conducts the interrogation and seems to be in control of the fate of her physically injured interviewee. On the other hand, gender and race-specific hierarchies are not adapted to the new situation. The female officer speaks English with a strong accent 


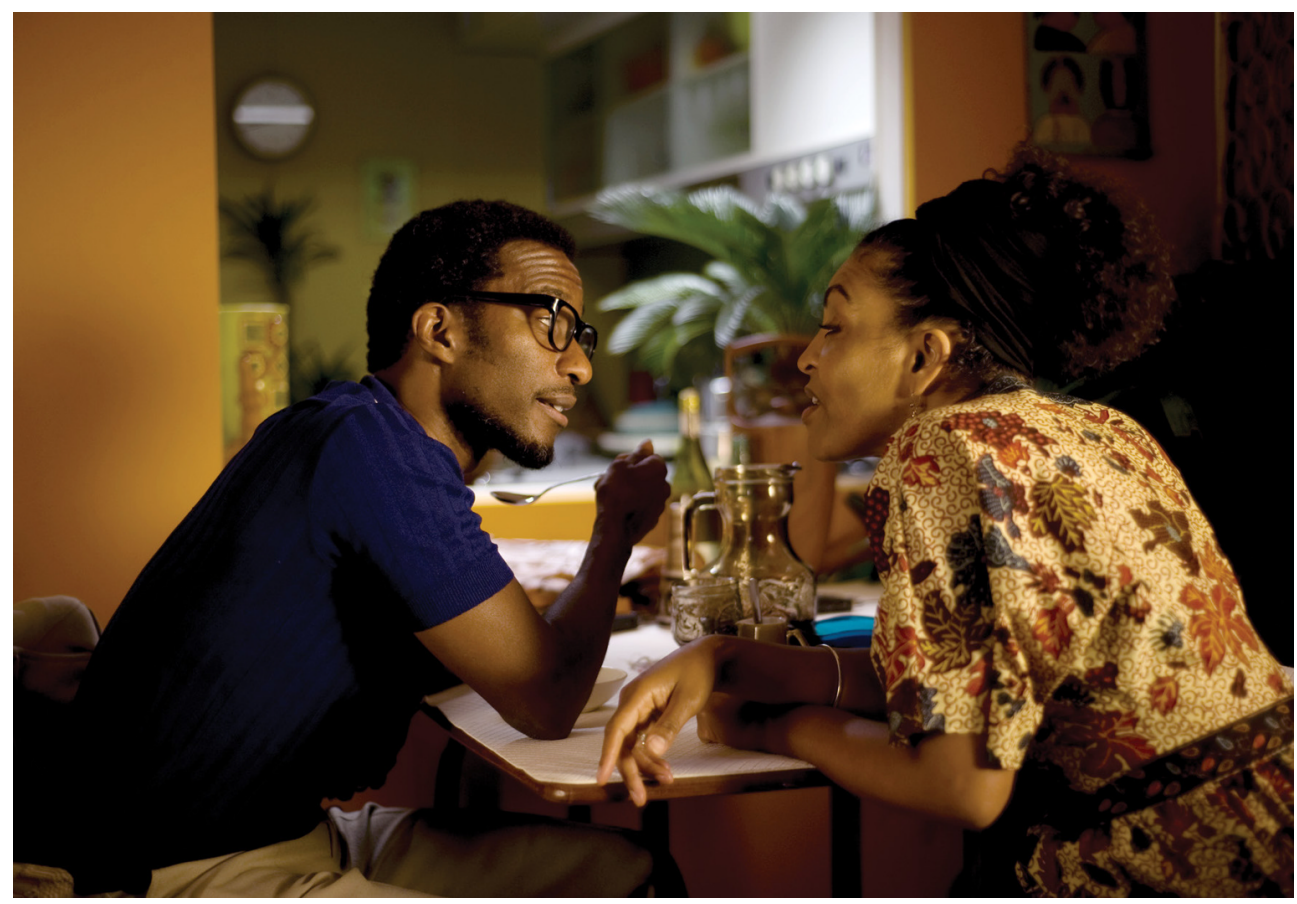

Figure 5.9 Omer Fast, Nostalgia III, 2009. Super $16 \mathrm{~mm}$ film transferred to HD video, 32 mins. 48 secs. Production photo. Courtesy the artist. Photo Thierry Bal

and is corrected by the man. As the "underdog," he may well emerge as a hero, perhaps especially for a White audience. During their exchange, the story of the trap reemerges: the White refugee tells how it was rediscovered in Europe during the crisis. Later, the female officer tells her partner about the interrogation (Figure 5.9); this man mourns a lost child while a girl listens in; the White refugee, now possibly working as the school caretaker, listens to this girl as she recounts the story about how to build a trap; and so on. The individual storylines do not develop into an overarching narrative but are linked in a circular fashion by the motif of the trap, which is passed on by hearsay.

Between these shots, we see scenes of a tunnel in which White refugees are hiding. Black police officers take up the hunt; the series ends with the arrest and death of a young White woman. Images of danger, grief, and violence are intertwined, with ambivalent feelings generated by the reversal of roles between Africa and Europe. One powerful example is Black policemen leading German shepherds, a scene that reverses historical and cultural clichés as well as current power relations in equal proportion. Their "victim," the young White woman, collapses, her vomit turning into a carpet of flowers. By this point, if not before, the film is offering itself in service, as it were, of White victimhood complexes. With its strong aesthetic stylisation, forceful genre conventions, political dichotomies, and reversal of racial identities, the film has a powerful but highly ambivalent effect: as a logical consequence of the pitfalls described in the second film, the story seems to have gotten completely out of hand in terms of narrative and political plausibility.

Erika Balsom views the death scene of the young woman as an antithesis to the only "authentic" found-footage scene in Nostalgia III: the scene from Chris Marker's Sans soleil that a man views projected in the refugee tunnel. The clip shows the death of a 


\section{Showing, Telling, Picturing}

giraffe by hunters: blood jumps like a fountain from the bullet wound on the neck of the wounded giraffe; the animal staggers and collapses. In this (real) death scene the interruption of the narrative coincides with the interruption of fiction. But how corrupted is the cliché-laden image of the dying White woman in the refugee tunnel, which suffocates all remnants of authenticity into a hypostasis of genre kitsch? As Balsom rightly points out, this image leaves plausibility and probability completely behind. ${ }^{57}$ Under the pressure of producing a confession that is both gripping and authentic, the motif of the trap from the original story has been enhanced continuously, only to collapse into a clichéd image. The film plays with the cinematographic imagination of viewers who are actively involved in dramatising the pieces presented by the artist based on their own knowledge and experience. A wall text by the artist, provided at the first exhibition of Nostalgia at South London Gallery, summarises this third part thus:

Judgment Day struck in 1980 and the world has been mired in a second Dark Ages since. Northern Europe is a wasteland and Britain has become a barren backwater where nomadic tribes roam across the dunes and raid one another for depleted resources. The only steady export from this once fabled island are migrants, who desperately stream across the European mainland in hope of a more peaceful and prosperous future in Africa. ${ }^{58}$

One of the pivotal points within this cinematographic dramaturgy is the trap itself, a motif of violence as well as a metaphor for successful narration. The trap is the punctum of the first documentary film, out of which the story is developed in different directions within films two and three. This motif wanders through all three films-documentary, reenactment, and fictionalisation-as does the audience, which follows the stories step by step farther into the installation. Even its spatial arrangement, which gradually draws viewers deeper and deeper into the narrative and offers no exit at the end, evokes the metaphor of the trap. Nostalgia follows, in the words of Bert Rebhandl, the migration of a mytheme. ${ }^{59}$ In Peter's narrative, the trap is the "interesting detail" that the artist seeks (and obviously has found) for his work, unlike in William's account, which only provides unusable grotesques. And it is not only the artist's attention and empathy that they seek, but also that of the public and the asylum authorities, who have to find Peter's and William's accounts credible.

Fast has also pursued the transformation of narratives in Talk Show, which he created at about the same time for Performa 09 in New York. For three consecutive days, guests reported traumatic experiences in a fictional talk show; these were then recounted and repeated by actors in a game of "Simon says" until they had completely lost their original context. In Nostalgia, this simultaneously disturbing and amusing process transforms Peter's account. Under the pressure of narrativisation, fragments of memory develop a fetishised life of their own. The trap, for example-an intangible placeholder for a blank space that he cannot or does not want to talk about, that perhaps cannot be translated into narrative at all-is processed into ever new motifs and figurations. Fast draws parallels between the migration-induced loss of homeland and that of memory:

The work allegorizes the loss of homeland as a kind of loss of memory. One person's failing (or reluctance) to provide details from his past opens the door for a lot of productive re-imaginings. These re-imaginings hit a ceiling at some point, however, and begin to crumble as they succumb to a kind of genre-kitsch. ${ }^{60}$ 
The title Nostalgia underlines this connection: loss of home as a loss of memory, which is replaced by the creation of new images through which the past is to be conveyed and processed. From the perspective of Marxist cultural critique, nostalgia is an inauthentic, superficial, and uncritical engagement with the past, a negative counterpart to historical experience: " $[\mathrm{A}]$ history lesson is the best cure for nostalgic pathos." ${ }^{61}$ Similar views can be found among most postmodernist authors. Susan Stewart describes nostalgia as a "social disease" that only encounters what is familiar, nonauthentic. ${ }^{62}$ Charles Maier briefly states that nostalgia is to memory what kitsch is to art. ${ }^{63}$ Some theorists have emphasised the proximity of nostalgia to utopia in order to contribute to its rehabilitation as a cultural instrument, ${ }^{64}$ but in any case (e.g., as Linda Hutcheon argues), in order to use nostalgia's affective potential for transformation it needs to be balanced by irony or other distancing tools. ${ }^{65}$

The term "nostalgia" is a Greek neologism coined by Swiss physician Johannes Hofer in the seventeenth century to describe the so-called "Swiss disease": homesickness, an illness associated with various physical and mental symptoms. ${ }^{66}$ Nostalgia afflicts the subject with a deep longing (algia) for a return to a distant home (nostos), a longing that indeed retrospectively creates its supposedly lost object. It is a deeply ambivalent disease that is difficult to cure, as the nostalgic person actually either cannot or does not want to remember the past, rather mourning a lost experience of the present. ${ }^{67}$ In the cases of William and Peter, this may be caused by trauma or by an existentially necessary pragmatism in dealing with the past. In this context, Fast refers to the concept of "reflexive nostalgia" by cultural theorist Svetlana Boym. While "restorative nostalgia" focuses on nostos-on the return to one's home, filling blanks in memory and producing individually processable pasts via their purported restoration- "reflexive nostalgia" rests within algia, longing. It is unproductive, melancholic, and situated in the present. The critical component of this nostalgia is to be sought in the melancholic consciousness of the inescapability of the present-of the afterwardsness of historical experience-and it is particularly valid when no memory (of the past) or no return (to the homeland) are possible. ${ }^{68}$ This concept of nostalgia responds to the experience of diaspora and migration that has shaped Peter's life as well as Boym's.

With the forced abandonment of home-the leaving behind of familiar places and persons as well as the loss of identity-temporal and spatial moments of nostalgia intersect. But in a certain sense, Fast's Nostalgia becomes a black comedy of homelessness: Peter's or William's attempts to reconstruct their pasts-an existential problem in the context of migration and communication with immigration authorities-produces the motif of the trap, the "vivid detail" that becomes the pivotal point of "Omer's" film project. This necessity to transform, narratively, traumatising experiences (traumaturned-drama) is not only part of the artistic process:

immediately after the tragic event, its survivors, its witnesses, and even its perpetrators start mutating into dramatic personae, into authors and actors, tasked with making sense of their own experience for themselves and for others. [...] What was once individual and private becomes public. And what's part of the public domain can be mythified. It can be denied. It can be instrumentalized. ${ }^{69}$

This description refers to the memories of war veterans and their political claims but it also applies to all those migrants who, in the political minefield of global migration, are repeatedly measured against social and political expectations. 


\section{Showing, Telling, Picturing}

The political importance of Fast's interest in examining how personal experiences become raw material for public discussions has sometimes been obscured by the artist's-or his alter ego's-supposed rejection of political issues. At the end of a conversation with a veteran Iraqi in his video work The Casting (2007), Fast, playing himself or his "dopey doppelganger," 70 says:

I'm not so much looking for a political angle. I'm more interested in how experience is turned into memory and the way memories become stories, the way memories become mediated, recorded, broadcast.

In this way, as Tom Holert writes, Fast questions "a consensus that tends to take the political in the aesthetics of the documentary mode for granted." ${ }^{71}$ Not all works that deal with political content are explicitly political, nor do documentary formats inevitably lead to social or political critique. Fast's rejection of political readings makes it possible to bring the fictional character of his self-portrayals to light and to examine the question of the political nature of his works. Yet despite the fact that the artist must have been known at the time of The Casting to work often with ambivalent doppelgangers, the passage from The Casting quoted above has sometimes been taken up as a revelatory artist's statement. It is true that Fast's work does not directly represent political topics-this is important to know in view of an oeuvre that has addressed the Shoa, the Iraq war, the US mission in Afghanistan, Palestinian suicide bombings in Israel, and migration. ${ }^{72}$ Yet memory and trauma, reflections on narration and media images come with political dimensions, as Ines Kleesattel has rightly emphasised. ${ }^{73}$ Indeed, Fast often works with political contexts that are widely discussed in public and, under the pressure of spectacularisation, have developed a kind of life of their own to which the actual victims (survivors, perpetrators, witnesses) need to relate:

In these cases the original events have been so emphatically embalmed that they can only be considered destroyed. They hardly bear any resemblance to the real experience. In the retelling, it is perceived as false. ${ }^{74}$

Fast looks at the specific economies of attention that are set in motion when individual experiences become the subject of public (political, legal, media, and artistic) debate. Under the enormous pressure of media coverage and the demands of political controversy, statements are spectacularly overloaded and reduced to vivid details, gripping individual motifs, and affective clichés. Experiences are transformed into narratives; memory becomes completely inaccessible under the pressure of trauma and the spectacularisation of individual experience.

It is an undeniable quality of his works that Fast includes his role as an artist deeply involved in the cycle of attention economies. His analysis of how meaning is being constructed is close to contemporary conceptions of a realism as described, among others, by Fredric Jameson:

So if there is such a thing as "realism" after all, it should be a realism that springs from the shock of realizing that reality can no longer be grasped "immediately" and that we must slowly become aware of a new and unique historical situation in which we are condemned to seek history only in our own popular images and simulacra, since "history itself" is lost forever. ${ }^{75}$ 
Thus, Nostalgia presents different narrative genres in the course of transforming memory into an artwork: documentarism, reenactment, and fictionalisation; comedy and tragedy; reversals, paradoxes, ironies. Instead of subtle hints on how to read or understand the narrative, it is oversaturated with content, details, and metaphors that obscure meaning rather than guide the audience. The trap turns out to be a changeable, little reliable signpost.

Nostalgia is caught in several narrative loops that explore and increase the tensions of contradictions and misunderstandings. Neither the artist nor the viewers are exempt from them. It becomes clear that "understanding"—or just "communicating"—-the past in light of its repeated spectacularisations is only possible through an agreement to conceal incomprehension, perplexity, even betrayal of one another in order to enable the flow of exchange. The result is a science fiction dystopia in which nothing is true anymore but a White audience can hopefully feel empathy for the situation of a refugee. Finally, Nostalgia exposes the price of reconstructing and communicating history under the conditions of homelessness and migration. Driving self-reflexive procedures to their extremes, ${ }^{76}$ Fast amusingly and provocatively explodes the seemingly clear-cut foundations of history and of art.

\section{Notes}

1 On Kanwar's biography and education, see Liven, "Image vs. Text."

2 The Hindi film version premiered at a women's university in Allahabad in 2008, after which it toured the Indian subcontinent. Singh, "Amar Kanwar," 128.

3 Geeta Kapur ("Secular Artist, Citizen Artist”) names Amar Kanwar as an exemplary "citizen artist."

4 In Sanskrit, "vajdra" denotes a form of enlightenment by lightning or a night vigil with candles. See Kayser, “Making Sense of the Works of Amar Kanwar," 15.

5 For the sake of simplicity, I will refer to the single channels as films or projections, even though the work is also sometimes shown on monitors.

6 The individual projections are not visibly numbered in the exhibition but are projected next to each other in this order.

7 This is also suggested by Kanwar's presentation of the installation in his artist's book Evidence, which combines images and text excerpts from all the films. See Stahel and Janser, Amar Kanwar: Evidence.

8 As in many of Kanwar's works, Sameera Jain worked as sound editor.

9 In my quotations from the inserts, single slashes indicate the end of a line, double slashes a cut.

10 Zamthingla Ruivah is both a weaver and a nationally renowned poet. The scarf named after Luingamla ("Luingamla Kashan") was designed in 1990 and is still worn today by women of the region in her memory and in protest against military violence. See Thounaojam, "The Loneliness of Manipur's Non-Combatants."

11 Kanwar comes from a Hindu family that fled Pakistan in 1947.

12 Shrivastava, "Lightning Rarely Leaves a Trace," 348.

13 The drawings were made by artist Sherna Dastur. Liven, "Image vs. Text," 67.

14 On the adaptation of the Mahabharata to naked female protest in India see Misri, "Are You a Man?"

15 Devi first published "Draupadi" in Bengali in the volume Agnigarbha (1978). The story became internationally known through the translation into English by Gayatri Chakravorty Spivak, first published in Critical Inquiry and reprinted in In Other Worlds and in South as a State of Mind.

16 Sarkar, Hindu Wife, Hindu Nation, esp. 38; Sarkar, "Semiotics of Terror.” Sarkar's interpretation is followed by Nussbaum, "Bodies of the Nation."

17 Sarkar, Hindu Wife, Hindu Nation; Sarkar, "Semiotics of Terror," 2875: "In Gujarat, mobs who raped, sometimes came dressed in khaki shorts or in saffron underwear, rape being obviously seen as a religious duty, a Sangh duty. In times of violence, Hindu male sexual organs 


\section{Showing, Telling, Picturing}

must function as instruments of torture.” The saffron or khaki clothing refers to Hindu ideology, so this clothing made a distinct and recognisable symbolic reference.

18 Shrivastava, "Lightning Rarely Leaves a Trace," 353-54.

19 Nichols, Representing Reality, 3-4.

20 Osborne, Anywhere or Not at All, 197.

21 Osborne describes Indian artist Navjot Altaf's video installation Lacuna in Testimony (20032006), which also addresses the pogrom in Gujarat, as a counterexample to The Lightning Testimonies. He praises its highlighting of the fragility of the collected testimonies; I attribute this merit to The Lightning Testimonies as well.

22 Rutherford, "Not Firing Arrows," 123. On Kanwar's reworking of politically engaged art, see Kapur, "Why the Personal Is Still Political"; Mothes, Offenes Erzählen, 101.

23 Rutherford, Not Firing Arrows, 118.

24 Ibid., 120.

25 Kanwar, "When You Step Inside," 191-92.

26 Liven, "Image vs. Text," 61-62. On Bharata Muni’s "rasa” concept, see Barlingay, A Modern Introduction to Indian Aesthetic Theory.

27 Stahel and Janser, Amar Kanwar: Evidence. See also Bauer and Rujoiu, "On 'The Sovereign Forest.'"

28 Kanwar, "When You Step Inside," 196-97.

29 Vismann, Medien der Rechtsprechung, 151.

30 She participated in the exhibition The Essential Black Art (London, Chisenhale Gallery, 1988), curated by Rasheed Araeen.

31 The films do not constitute a fixed trilogy. Bhimji had initially conceived Waiting (2007), Yellow Patch (2011), and Jangbar (2015) as a series dedicated to colonial history in South Asia and East Africa.

32 After the expulsion of all Israeli citizens, that of the Asian-born population-at first extending only to those holding a British passport-could be superficially considered a gesture of nationalist decolonisation. It followed Gaddafi's example of the expulsion of all Italian-born and then of Israeli citizens from Libya. See Epstein, "Idi Amin's Israeli Connection."

33 Okeke-Agulu, "Conversation with Zarina Bhimji," 67; "From Politics to Poetry: Zarina Bhimji in Conversation with Achim Borchardt-Hume and Kathleen Bühler." In an "outline" of the film, written before its production, Bhimji describes its beginning as follows: "Scene I: Landscape $=$ peacefulness, pleasure with the light. [...] A sublime landscape that turns into malignant wilderness. It would be filmed early in the morning at 5.30 a.m. as the sun rises, misty cold fish eye lens, vast open distance. I would like it to be still like an English landscape painting. Slowly the sunlight starts. The lenses used will be important; telephoto lens as this can transform the physical into psychological. A telescopic lens-intense heat on light waves traveling across landscape can exist as a reflection on the inner walls of the mind. A deep fire would start at 3.45 p.m. when Amin announced on Radio Uganda that all Asians were to leave. A loud roaring sound will fill the space." Bhimji, "Outline of a Film," 74.

34 Okeke-Agulu, "Conversation with Zarina Bhimji," 68.

35 Boyce, "Interview with Zarina Bhimji."

36 Dewan, "Tender Metaphor," 136.

37 Demos, "Ghostly Affect," 72, with references to Sara Ahmed, Brian Massumi, and Steven Shaviro.

38 Ibid., 73n1.

39 According to the artist, the title refers to a lecture by Doris Lessing. Ibid., 73-74.

40 Sufi singer Abida Parveen often performs in the regional dialect of Kachchh, a language the artist is familiar with from early childhood. Ibid., 94 .

$41 \mathrm{My}$ interpretation departs from that of Chika Okeke-Agulu, who primarily perceives the filmed locations as decrepit and desolate. Okeke-Agulu, "Conversation with Zarina Bhimji," 69.

42 Ibid., 68.

43 Demos, "Ghostly Affect," 75n2.

44 Zarina Bhimji, press release for Yellow Patch, cited in Demos, "Ghostly Affect," 75.

45 Okeke-Agulu, "Conversation with Zarina Bhimji," 70.

46 Demos ("Ghostly Affect," 76) refers to this as an "aesthetics of opacity."

47 "From Politics to Poetry," 34. 
48 Boyce, "Interview with Zarina Bhimji," n.p.

49 "From Politics to Poetry," 41.

50 Benjamin, "Excavation and Memory," 576.

51 In this context, Bhimji's reference to Elaine Scarry's The Body in Pain is important for describing experiences that cannot be put into language or be adequately represented. Demos, "Ghostly Affect," 87.

52 Bucher, “Television (an Address)," 11.

53 Marks, The Skin of the Film.

54 Ibid., esp. 55-71.

55 "From Politics to Poetry," 43.

56 Press release, Omer Fast, Nostalgia. The interview was arranged by the NGO Refugee Council in Brixton (information from Omer Fast, October 17, 2018).

57 Balsom, Exhibiting Cinema in Contemporary Art, 177.

58 Nostalgia was produced for an exhibition at South London Gallery. The wall text "in the parlance of trashy film-trailer language" was written by Omer Fast (email to author, October 5, 2018). It is cited in Haq, "Foresight into the New African Century," 27. Haq's description of the plot differs widely from mine, which underlines the power of Fast's cinematographic dramaturgy to stimulate the production of (subjective) narratives.

59 Rebhandl, "Anschauliches Detail."

60 Fast, cited in Rittenbach, "Dramatic Witness."

61 Jameson, "Utopianism after the End of Utopia," 156.

62 Stewart, On Longing, 23.

63 Cited in Boym, The Future of Nostalgia, xiv.

64 Huyssen, "Memories of Utopia." For a recent contribution to the discussion, see Magagnoli, Documents of Utopia.

65 Hutcheon, "Irony, Nostalgia, and the Postmodern," 207.

66 Hofer, "Medical Dissertation on Nostalgia"; on the cultural history of nostalgia, see Bernet, "Heimweh und Nostalgie"; Starobinski, "Le concept de nostalgie”; Jankélévitch, L'irréversible et la nostalgie; Radstone, The Sexual Politics of Time, 116-30.

67 Ibid., 114.

68 Boym, The Future of Nostalgia.

69 Fiduccia, "Omer Fast," 158.

70 Wilson-Goldie, "War Stories," 119.

71 Holert, "Attention Span," 153nxii.

72 Muhle, "Omer Fast."

73 Kleesattel, "Omer Fast."

74 Lewis-Kraus, "Infinite Now," 50.

75 Jameson, "The Cultural Logic of Late Capitalism," 24.

76 Holert, "Attention Span," 133ni. 


\section{Performing}

The introduction of this volume discusses the historiographical method of performing history primarily in view of how immersion into historical characters and reenactments has been recommended by some historians as useful scholarly practices. I have also mentioned reenactments as a critical practice of performing history in contemporary art. However, performative history is an aspect of many other artistic approaches as wellespecially those that encompass performative, cinematic, spatial, and activist components. It is evident in Erika Tan's works, for instance, where a historical personage is examined via performative formats. Additional examples pepper subsequent chapters, especially in the works of Yael Bartana, Andrea Geyer, and Hiwa K. This chapter addresses the works of two artists, Wendelien van Oldenborgh and Apichatpong Weerasethakul, who expand film to explore performative history via methods of embodiment and reincarnation.

\section{History on Stage: Wendelien van Oldenborgh's Maurits Script (2006), Instruction (2009), and Cinema Olanda (2017)}

Dutch artist Wendelien van Oldenborgh has developed a unique working method of "polyphonic" historiography based upon a performative conception of film. This section examines Maurits Script (2006), Instruction (2009), and Cinema Olanda (2017)— three projects that resulted in digital film works that are usually presented within spatial installations in exhibitions.

Maurits Script (2006, 38 mins.) is usually shown as a double projection on two opposite walls. The first shots are of preparations for filming in the so-called Mauritshuis in Den Haag, a well-known tourist destination that boasts an excellent art collection and a baroque period interior. This magnificent building was erected for Johan Maurits van Nassau (John Maurice of Nassau) in the years 1637-44, stone-built testimony of his tenure as governor of the Dutch lands in Brazil. This short phase of the Dutch colonial period in Brazil is usually characterised in positive terms: Maurits brought numerous researchers and artists, for instance Albert Eckhout, into the "new" countries; promoted scientific research into the culture of the Indigenous population as well as of Brazil's flora and fauna; and is still considered an enlightened humanist today. The extensive sources that Oldenborgh has compiled on the historical context of Dutch colonial activities in Brazil, however, paint a more complex picture. As a polyphonic text collage, they form Maurits Script-the script of the film and a performative event that took place in the Mauritshuis in the process of filming.

The texts researched by Oldenborgh were written by Maurits and some of his contemporaries. In her work, they are recited and performed in Dutch by a cast of eight people. These are not professional actors but researchers or activists who have personal

DOI: 10.4324/9781003166412-7 
connections to the colonial history of Brazil and the Netherlands-some for biographical and some for professional reasons. The texts they read are personally assigned to them, but each reads from two different sources and each source is assigned to two readers. This undermines any lasting identification of speakers with their historical roles, both from their own perspectives and from that of the audience. Filming was done during open hours in the historic Golden Room of the Mauritshuis, the main attraction of the museum. This results in the documentation less of a distinct performance than of a situation in which filming takes place. Two professional camera teams are at work on two sets; the film includes shots of the interior space, the technical equipment, the "film performances" happening on each side of the room, and spectators and groups of visitors passing through the rooms of the Mauritshuis. The cast members get made up, rehearse their roles, and perform for the cameras in full view of the film crew and the audience, which is sometimes drawn into the discussion of texts or performances.

Thus, the artwork itself is not the film but is rather the situation "when we are working" (Figure 6.1). This situation is determined by the presence of cameras, both in terms of its temporality (the inherent deferral to a second life of the event in its audiovisual recording) and also in terms of addressing a wider public. Watching the film, we watch a rehearsal, connecting life and film in performance. ${ }^{2}$ This rehearsal is directed at a different audience than the one that was present in the Golden Room-namely, the future audience that will watch the film in exhibitions. While, on one side of the Golden Room, the performances are filmed, on the other side the cast members come together in between takes. ${ }^{3}$ They discuss historical material on the Dutch colonial settlement in Brazil (such as Albert Eckhout's portraits of Indigenous Tapuya), including their own autobiographical, professional, or activist viewpoints.

These conversations about historical texts and images are part of Oldenborgh's polyphonic approach to history, in which different economic, political, and scientific perspectives find room. They bear witness to Brazil's early modern ethnic and social diversity:

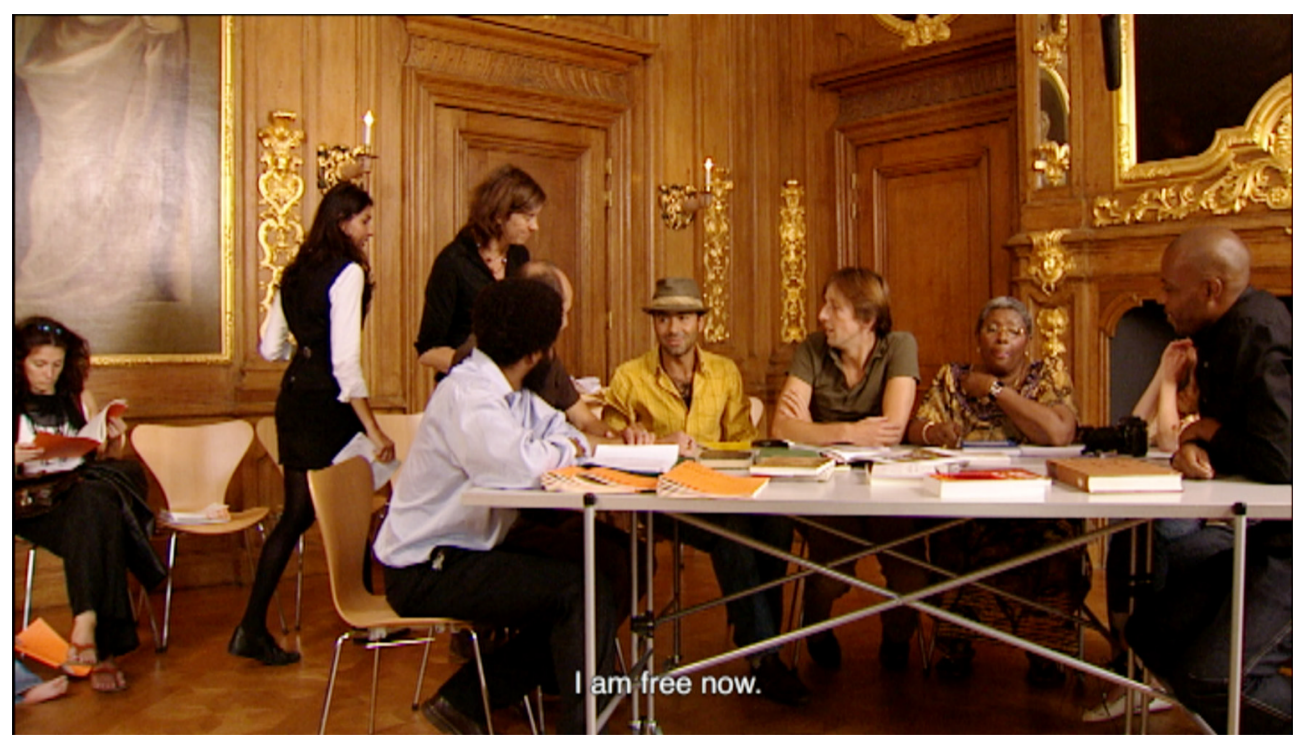

Figure 6.1 Wendelien van Oldenborgh, Maurits Script, 2006. Still image, two-channel video installation with architectural setting, 38 mins. Courtesy the artist 
Indigenous tribes; African slaves; European migrants from various phases of Portuguese, Spanish, and Dutch colonialism; missionaries; researchers; artists; merchants and mercenaries of the West India Company. Among the textual sources are Zacharias Wagener's Thierbuch, written by a man close to Maurits's social circle, which contains zoological, botanical, and ethnological notes on the Indigenous peoples of Brazil; an early history of Brazil by poet-monk Manuel Calado; letters from the Protestant missionary Vincent Soler (father of one of Maurits's mistresses); and notes by Gaspar Dias Ferreiras, a Luso-Brazilian contact of Maurits and a fascinating, if shadowy character who was later found guilty of high treason for working for both the Spanish and Portuguese sides that were competing over Brazilian settlement. ${ }^{4}$ The performers offer ambivalent insights into historical sources as well as into the characters and relationships of a historical dramatis personae: the enlightened colonial administrator, the bureaucrat committed to his native country, the shrewd businessman, the traveller faithfully reporting miracles, the narrow-minded missionary.

The artwork's informational booklet, in fact, presents all the historical authors of the text sources as "characters"; at the beginning of the film, the opening credits also introduce the cast in their roles as historical characters. Each personage deals differently with the historical situation and makes, approves, legitimises, or condemns different decisions and situations. While we repeatedly hear about the inhumanity of the Portuguese and about their brutality towards Indigenous people and slaves, Wagener casually reports in his Thierbuch:

Our people, like the Portuguese, recently decided that it would be a good idea to put certain signs or marks on men, women and children, by using a hot iron on the chest or on the neck. If they run away from their masters (which frequently happens), the field captains in charge of finding them are able to recognize them as soon as they lay their hands on them. They tie their hands behind their backs and hand them over to their owners in return for a fixed reward. They are welcomed back with many a sound beating. ${ }^{5}$

Maurits himself, who in his own texts appears less enlightened humanist than liberal economist, cites the different market values of the slaves as a further reason for branding: to ensure that "our deceitful people will not exchange the worse ones for the better ones". ${ }^{6}$ The drama of the colonial situation unfolds not only along specific events described in the textual sources but also along their poetic components: their narrative surplus, their obscurity, their incongruence, their differing perspectives. The speakers immerse themselves in their historical roles, making it difficult to distinguish between inside and outside, yesterday and today, subjects and events. Just like the historical "characters" they portray, the performers have different opinions on the Dutch colonisation of Brazil. They slip in and out of their roles, speaking, in turn, as and about historical characters as the performers switch sides in the room. In this regard, Emily Pethick aptly refers to Irit Rogoff's concept of "embodied criticality"-a form of critique that emerges from perspectivisation and involvement. ${ }^{7}$

The artist regularly uses joint readings and discussions as a basic instrument of her works, as demonstrated in No False Echoes (2008), Bete \& Deise (2012), and Cinema Olanda (2017). She creates a kind of political stage on which historical persons and texts are subjected to multiperspective polyphonic negotiation. As Binna Choi points out in relation to No False Echoes, ${ }^{8}$ Oldenborgh creates a kind of (ideal) parliament: "actor-participants" gather at a (historically, politically, symbolically) significant site to which they have personal connections. In Bete of Deise, this is a building site in a 
backyard in São Paulo; in No False Echoes and Cinema Olanda, modernist architectures offer open stages for a larger number of actors. In Maurits Script, the Golden Room of the Mauritshuis becomes the site of an ideal deliberative democracy in which historical documents are presented and discussed. No confrontational dissent arises from the debates among the experts, who are thoroughly knowledgeable in relation to the subject matter. Their goal is neither to judge nor to distribute power but rather to seek an exchange of perspectives. The inclusion of bystanders in this ideal democratic parliament is thus structural: they represent an ever-widening audience, the ends of the stage fraying as ideas pass from person to person across an even broader public. In the classical pictorial tradition, this was the function of supporting characters:

The audience becomes part of the performance, and the performers, viewers and listeners as well as actors. [...] Their willingness and interest to engage in reading the given roles and in the act of conversation [give] life and directness to the event. ${ }^{9}$

In exhibitions, the way the film is installed enables a further opening up of the material discussed, allowing visitors to switch between the two halves of the film during its viewing. Sven Lütticken has considered Oldenborgh's working method as within the genealogy of "expanded film." ${ }^{10}$ Her approach is also related to historical theatre-such as Bertolt Brecht's epic theatre and Augusto Boal's forum theatre-as well as to practices from performance, film, and theatre working with amateur actors-such as the films of Peter Watkins and Jean Rouch or contemporary documentary theatre. ${ }^{11}$ Certainly, concepts of Brazilian modernism are important inspirations as well. Maurits Script is the third project in Oldenborgh's series A Certain Brazilianness ( A C_C__), which includes an examination of: the legacy of the Antropofagía movement (also in contemporary writings, such as those of Suely Rolnik); the works of Ricardo Basbaum; ${ }^{12}$ the archi- $^{-}$ tecture of Lina Bo Bardi with its experimental approach to the roles of audiences and performers in urban, theatre, and exhibition spaces (such as her Teatro Oficina in São Paulo) $;{ }^{13}$ and, generally, the rich heritage of socially committed art in Brazil. ${ }^{14}$

In Oldenborgh's work, stage settings are designed in many ways: in the choice of locations for the performance/filming situations, which often function as protagonists in their own right; in how the cast comes together; in the film sets with cameras and microphones; and in the strongly spatial installations of her films when presented in exhibitions. ${ }^{15}$ In the Golden Room in the Mauritshuis, the idealised democratic stage is presented in a small space-in the sense of Rancière's understanding of how politics needs a "scene of revelation", ${ }^{16}$ which, in fact, remakes theatrical settings as possible sites of political emancipation. Putting oneself in other positions and the associated emancipation from established norms and identities serves to negotiate social truths, judgements, and decisions.

This transhistorical scene is where not only the historical "characters" appear but also our contemporaries, the speakers. We learn about their autobiographical and professional connections to the Dutch colonial past and about their own migration experiences. It soon becomes clear that the Dutch population today is just as diverse socially, ethnically, and in terms of citizenship status as that of early modern Brazil, everything depending on respective countries of origin, skin colour, migration background, and moment of entry into Europe. Oldenborgh regularly collaborates with some of her performers, who not only appear in several projects but also assist in their conception and preparation. The artist gives the actors great scope in terms of content. They contribute to the design, bring their expertise, raise new topics, and lead discussions in undefined directions. This is why she has chosen the analogy to polyphony: 
In general, I started working the way I do because of an interest in the voices of others and using them to make compositions. So, I invite people to join me at a film shoot, which can be a public occasion and may or may not be a live event. However, it always has a "live" aspect to it. I invite these people to speak as themselves in various ways and through that I create what I call the "script." This script develops during the shoot, which I consider to be the productive moment. This productive moment emerges collectively-you could think of them as "collective moments." ${ }^{17}$

For the film Instruction (2009, 31 mins. 52 secs., Figure 6.2), the artist worked with a group of people in situations similar to those of their historical counterparts. She asked cadets from the Dutch Military Academy to present and discuss documents from the Indonesian independence movement between 1945 and $1949 .{ }^{18}$ Viewers also learn about the artist's own personal involvement, as the young soldiers read letters from her mother that were written during a trip to Indonesia in 1981. This film was not created as a public performance. When shown in exhibitions, the presentation includes three photographs of her father from the same trip. The narration starts with a visit to her mother's former home in Indonesia; she would later, after the fall of the Dutch colonial power, be interned in a Japanese prison camp between 1941 and 1945. From the letters, we learn about parts of buildings she recognises; about ruins and about the completely changed garden; about a man now living there (but unknown to her) who does not (or does not want to) know anything about "tempo dahulu"-the past. A recurring motif in the film is a whiteboard in a classroom of the Military Academy that is continuously filled by dates that appear as the text sources are read out and presented: 1981, 1970, 1945-50, 1969.

1945 marks the period of the withdrawal of the Japanese occupation, which gave a boost to the Indonesian independence movement. The Netherlands reacted, in its role as colonial power, by sending more than 100,000 soldiers to contain the situationviolently. Most of those sent were young and inexperienced members of the Dutch military (the Royal Netherlands Army) rather than soldiers in the Royal Netherlands

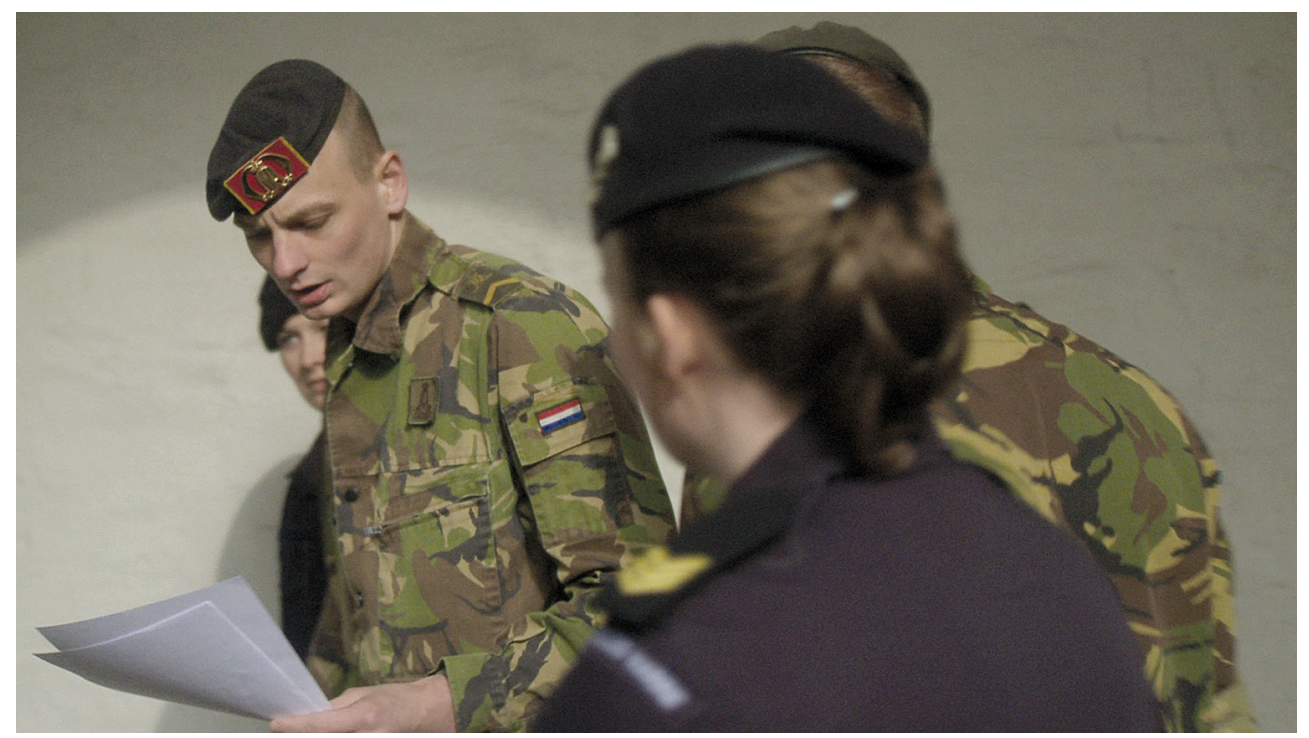

Figure 6.2 Wendelien van Oldenborgh, Instruction, 2009. Still image, video, 31 mins. 52 secs. Courtesy the artist 
Indian Army that was actually stationed in the colonies and, at that time, consisted largely of Indonesians. The official term for this military intervention, which quickly lost international political support, was "police action," intended to give the impression of a domestic affair. 1969 refers to the year when veteran Joop Hueting came to public attention with statements about the atrocities committed by himself and other military personnel in Indonesia, thus breaking ground for public discussion. Text transcriptions of television programmes in which Hueting appeared provide the material for an investigation of his actions and historical position as well as that of other military leaders. The discussion among the cadets focuses on questions around how individual military personnel might act in similar cases; the moral resilience of soldiers; and personal responsibility in times of war. For the cadets in whose classrooms Instruction was filmed, these are not theoretical but deeply personal issues. Here, too, location determines the structure of the film: choosing classrooms to stage critical discussion of a teaching example from a historical situation enables the artist to propose a kind of role play that is comparable to other didactic formats the cadets may encounter in their real-world course of training. The staged situation makes it easier for them to identify with the historical characters they are performing.

"The Past is not dead. It's not even past." This sentence by William Faulkner, which introduces Instruction, is characteristic of Oldenborgh's work and has often been referred to in writings on her work. The artist deploys this present-day approach in a complex way, opening up the past through reenactments and discussions by persons who personally relate to history and who comment on it from subjective personal and/or professional positions. This filmic-performative dispositif brings together partial perspectives and "situated knowledges." ${ }^{19}$ As in her other works, the film credits list the participants together with the artist as responsible for the script. This specific procedure-an artist inviting amateurs for a "delegated performance"-follows well-known precepts of participatory art. ${ }^{20}$ But this is no socially engaged art project, nor is it a reenactment of history inviting amateur actors for the purpose of authentication. Instruction is the result of a multifaceted formal structure in which everyday life and performative stage, personal and political perspectives, past and present, presentations and discussions of documents are closely interwoven and in which artistic authorship is thus subject to a clear division of labour.

In 2017, Oldenborgh created the installation Cinema Olanda for the Dutch pavilion at the Venice Biennale of the same year (Figure 6.3). Again, location and space were central: the artist focused on the raison d'être of the pavilion, the representation of national identity. However, the Dutch pavilion had been conceived as a break with conventions of national representation. Its architect, Gerrit Rietveld, had emphasised that the "Dutch-ness" of his celebrated pavilion was to be found in the transcendence of national into international modernism. ${ }^{21}$ As its reception shows, in its clarity, simplicity, colourfulness, and transparency the pavilion's formal design was in keeping with prevalent (self-)attributions of Dutch national identity. Today, these seem threatened by a present marked by political conflicts, identity crises, xenophobia, and racism. ${ }^{22}$

The lettering on the pavilion, "Olanda," was complemented with "Cinema": the pavilion offers "Cinema Olanda," or Dutch cinema. The geometrically contoured structure of the walk-in De Stijl building was accentuated, but also partly disturbed, by the addition of coloured panels on narrow steel frames. Some views were blocked and thus transparency reduced. Within this setting, Oldenborgh showed two thematically linked film installations, Prologue: Squat/Anti-Squat (2016, two parts, 16 mins. each) and Cinema Olanda Film (2017, 17 mins. 30 secs.), as well as a series of lenticular prints titled Footnotes to Cinema Olanda (2017). 


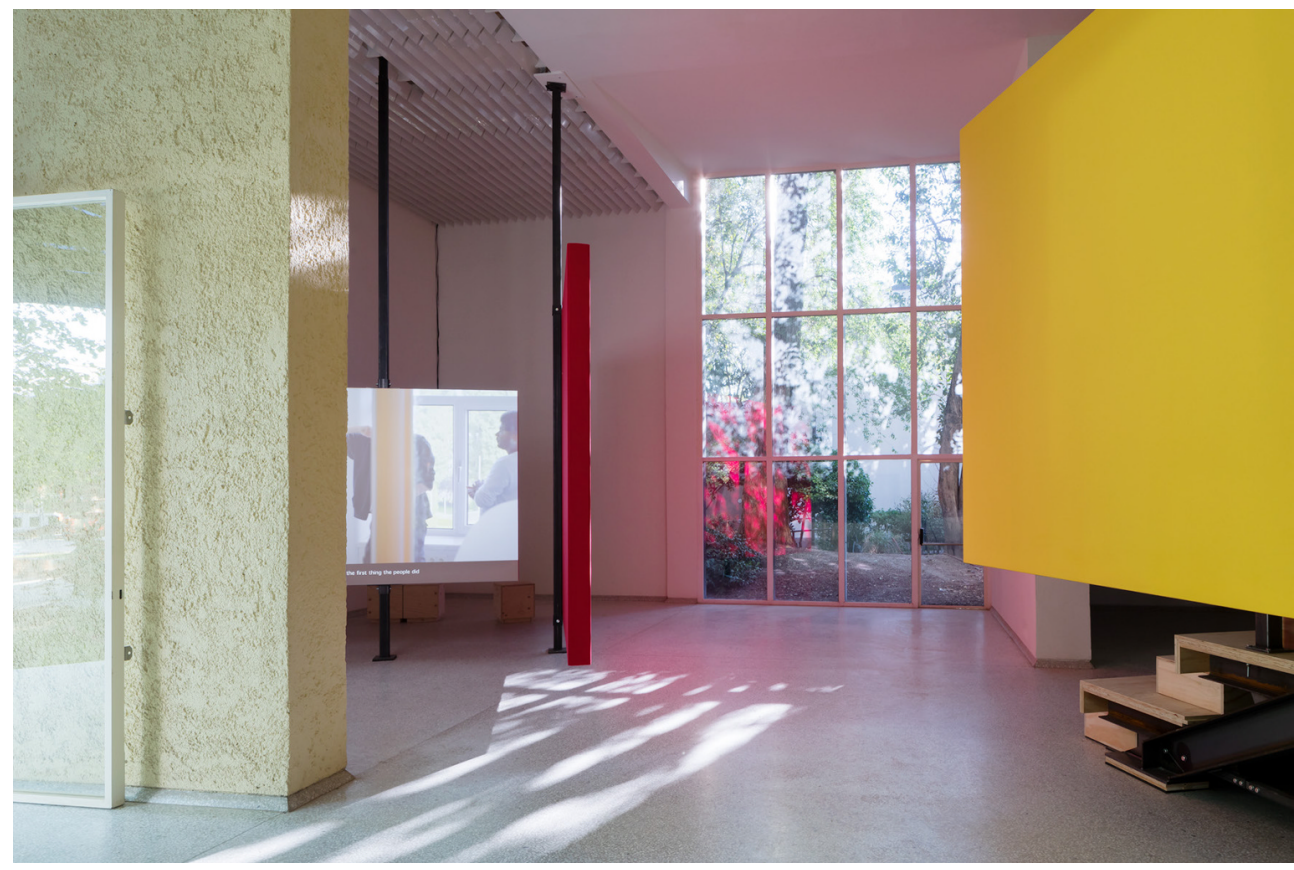

Figure 6.3 Wendelien van Oldenborgh, Cinema Olanda, 2017. Installation view, Dutch Pavilion, 57th Venice Bienniale, 2017. Photo Daria Scagliola

The two films formally diverge, displaying the range of Oldenborgh's artistic choreography within the principles already described. Prologue: Squat/Anti-Squat was filmed in the Tripolis office building in Amsterdam that was designed by Aldo van Eyck and had recently become prominent in the news as the scene of an occupation-a "squatting"-by the refugee movement We Are Here. The film considers Dutch squatting movements since the 1970s in the context of postcolonial spatial policy. In particular, it refers to the activities of a group of Surinamese immigrants in the Bijlmer, a run-down residential area in Amsterdam, thus expanding the popular conception of squatting that focused on the activities of White left-wing alternative groups. ${ }^{23}$ Prologue: Squat/ Anti-Squat, shown on two projections opposite each other, brings together more than a dozen architects, researchers, and activists from different generations-some as contemporary witnesses-integrated with historical film material on Amsterdam's housing policy. The film thus fans out across different temporal levels in terms of both source material and content.

In contrast, Cinema Olanda Film was conceived much more strictly formally, centred as it is on principles of linearity and continuity-although here too different temporal levels are linked. Filmed in a single, continuous camera shot, the action starts in front of and then inside St. Bavo Church, a modernist building in Rotterdam located in a postwar reconstruction area planned by the Bauhaus architect Lotte Stam-Beese. StamBeese, who emigrated to the Soviet Union in the 1930s to work on housing projects, had a strong influence on the Rotterdam cityscape after the Second World War. The film centres on her biography and those of Otto Huiswoud, the Surinam-born cofounder of the Communist Party USA and later protagonist of the Surinamese independence movement, as well as of his equally politically active wife Hermine. Their lives' transnational scope and impact was informed by international communism, which contributed 
to the decision to undertake a modernist (instead of historical) reconstruction of Den Haag that Stam-Beese helped to shape, providing a link to international decolonisation movements. Stam-Beese and the Huiswouds all came to the Netherlands after the Second World War, but did not know each other personally. All of them left their communist activities mostly unmentioned in the political climate of the postwar period but remained artistically and politically active. Den Haag, therefore, has been shaped considerably by international communism, yet to date this has largely been suppressed in the collective Dutch memory.

At the beginning of the film, Mitchell Esajas-head of the New Urban Collective, which houses the estate of Otto and Hermine Huiswoud-reads their biographies as he descends from the church's modernist bell tower. At ground level, he meets three women who are familiar with the political history of the Netherlands as scholars, artists, and activists. After a pan to a group of young people, we enter the church, following the camera, while cultural anthropologist Lizzy van Leeuwen recites an endless number of expressions used to describe violent acts (beating, battering, etc.) in the colonial language of the Dutch-Indonesian population. Inside the church, along with further information on the life of the Huiswouds, the group views material from their estate and performs a reading of Democracy by Langston Hughes, whom they met in New York. A discussion ensues about the wounds of the Dutch colonial past, which are still noticeable today, and current Dutch politics, which are marked by right-wing extremism. The conversations are interrupted with a song by an Indo Rock band (a style of music brought to the Netherlands by Indonesian immigrants), which passes into another musical performance by a young band that develops into a catchy political pop song. The final credits introduce all participants, while conversations continue to the fade out.

Cinema Olanda Film is more strictly choreographed and tightly timed than Oldenborgh's earlier films. This is mainly due to the use of the sequence shot, which binds together the various themes, characters, and actors. The individual sequences-plots, narratives, conversations, pieces of music, presentations of discussions of historical material-sometimes merge into and sometimes interrupt each other. The result is not harmonious but is rather a succession and juxtaposition of different information and opinions; echoes and aftereffects; recordings and revivals; appropriations and continuations of a national history that is characterised by ruptures and tensions much more than by homogeneity. This way, the price of the project of unification as a fundamental principle of order in nation-state thinking finds impressive formal expression. We literally feel the cost of continuity. This is all the more palpable as the control of visuality is a recurring theme within the installation, evident in the architectural interventions in the pavilion and in the lenticular prints. The sequence shot used in Cinema Olanda Film takes into account the task of comprehensive, universal representation underlying national representation and historiography as well as its cost-and its failure. ${ }^{24}$ Representing a continuous whole means having to do without cuts, caesurae, interruptions, details-failure is already inscribed in its claims. The lenticular prints, in contrast, change again and again as visitors move through the space, shifting with every new position (Figure 6.4). This results in a performative mode of representation that is a counterpart to spatially and epistemologically fixed units, highlighting the artist's diverse approaches to representation in the installation.

Oldenborgh's performative history entails much more than just a contemporary updating of narration. It includes physical embodiments of the past, allowing empathy as well as criticism; the use of the stage as a political "scene of revelation"; and a polyphonic engagement with history through the interweaving of information, data, 


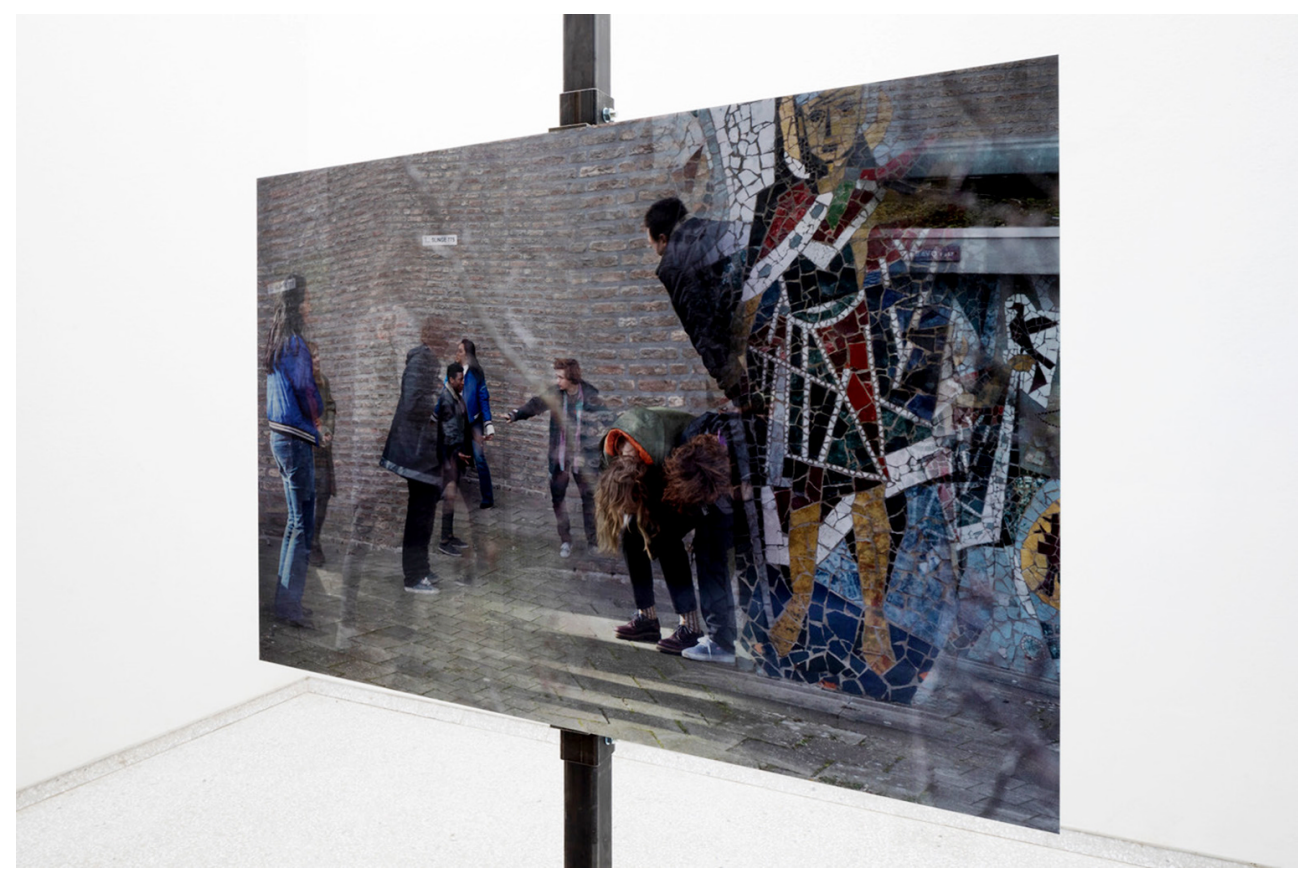

Figure 6.4 Wendelien van Oldenborgh, Footnotes to Cinema Olanda, 2017. Lenticular print. Installation view, Dutch Pavilion, 57th Venice Bienniale, 2017. Photo Daria Scagliola

and facts with diversified partial perspectives that expand the possibilities of history writing. Here, too, we encounter an apodeictic practice that wields the representation and performance of history as a specific contribution to its research, actualisation, and politicisation.

\section{The Medium Film: Apichatpong Weerasethakul, Primitive (2009)}

The multipart video installation Primitive (2009) by Thai artist and filmmaker Apichatpong Weerasethakul adopts strategies of reenactment to integrate local traditions of (re)performing history. Through theatre, roleplay, ghost stories, and reincarnation, his artworks reveal how the latent past can be awakened and reactivated at any time.

Apichatpong is among the most internationally well-known Asian film directors, working in an art scene that is particularly active and innovative regarding examinations of the past. Wang Bing's films-for instance, Dead Souls (2018), a collection of testimonies from a forced labour camp in the Gobi Desert-and Lav Diaz's ongoing examinations of Philippine history are among the most impressive works of artistic historiography in contemporary film. As these directors regularly produce films of considerable duration-eight, nine, twelve, or more hours-they are not only established in cinema but also in art. This also applies to Apichatpong, who was trained at the School of the Art Institute of Chicago and has been creating equally in art and cinema, often for the same project series, since his early works.

Apichatpong's film installation Primitive deals with the buried political past of the rural region Isan in northern Thailand, where the filmmaker grew up. Preparations for filming were similar to those for a reenactment. The film crew arrived on location and travelled in the area; researched witnesses, places, and memories; and worked with 
the local population, especially with a group of young men from the village who were to slip into historical costumes and roles. It soon became clear to Apichatpong's team that there remained hardly any traces of the region's brutal political history to encounter first-hand. Instead, the past was passed on selectively, through scattered memories, songs, and ghost stories; Apichatpong took up these elements to create the installation.

Ghosts are an integral part of Southeast Asian popular culture: in a text written for Apichatpong, Thai artist Rirkrit Tiravanija recalls the horror movies and ghost stories in TV melodramas from his childhood and how they frightened him (despite the ghosts' conventional release, in the end, with the help of a powerful monk's prayers). ${ }^{25} \mathrm{He}$ shares these memories with the director as indeed part of Thailand's collective memory. ${ }^{26}$ The cult of spirits leads a comfortable existence in popular culture alongside and connected to Buddhism, to which most Thais adhere. As such, the cult is an important instrument of social control, especially in combination with Buddhist faith. ${ }^{27}$ "Ghosts—-the unknown, invisible powers in society-are utilized as a device to set and control moral standards. This ultimate, hidden institution evokes fear and, at the same time, provides comfort." ${ }^{28}$ Thus, in Apichatpong's works, ghosts appear as invisible powers in society, controlling social behaviour and defending moral standards. They can act as helpful and comforting guardian spirits (Uncle Boonmee Who Can Recall His Past Lives, 2010) or become dangerous ghouls (Mekong Hotel, 2012).

In Primitive, ghosts are used as a metaphor for unresolved, latent history, but (in contrast to the feature Uncle Boonmee Who Can Recall His Past Lives, which belongs to the same project) they do not appear as concrete characters. The film installation is dedicated to the village of Nabua in the northeastern Thai province of Nakhon Phanom not far from the Mekong River. The village, like other cities in the region, was under military occupation from the 1960s to the 1980s; to this day, Nabua is home to a Thai Air Force base that was used by US forces during the Vietnam War. This repression served to reinforce centralised state power in Bangkok vis-à-vis the poorer northeast, which had been repeatedly marked by regionally organised resistance. ${ }^{29}$ Thai forces cooperated with the US to suppress communism, which had found growing approval in rural regions, in exchange for extensive economic investments and financial aid. This would form the basis for Thai economic growth during the "American Era." 30

After clashes between Communist units and the Thai army in August 1965, the military began to terrorise the entire region with torture, murder, and rape. Political martyrs like the communist teacher Krong Jundawong, who was executed in 1965-he is briefly mentioned in the Primitive installation-became widely known in the region. ${ }^{31}$ The male population fled to the surrounding forests. In the district of Renu Nakhon, an old legend of a widow ghost who, in revenge for violence against women, kidnaps all men who enter her kingdom, was resuscitated. Thus, the disappearance of the men of Nabua-in fact caused by political persecution-was passed on in mythical disguise.

Apichatpong takes up the repressed political past of his country to show how the current political tensions in Thailand are not a new, exceptional phenomenon, but a logical continuation of unresolved and repressed conflicts. Primitive was created after the director's journey to his home region in northeastern Thailand in search of a man named Boonmee Srigulwong, whom Apichatpong had learned about in a book manuscript written by a Buddhist monk in the early 1980s. According to these records, Boonmee is said to have spent several of his former lives in the region-which has suffered high rates of unemployment, rural exodus, and decades of centralist political control-and to have remembered these former lives through meditation. 
Apichatpong visited Nabua over several months, starting in autumn 2008. He found numerous memories of the past, especially of August 7,1965 (the day of the "exploding guns," sian puen tak), but no visible traces of the region's violent history:

Everywhere we went there were stories. Helicopters shot down here, friends shot there, beheadings happened here. Gradually, just standing in this quiet land became an intense experience for me. Perhaps too intense, for I doubted I was in the right place. $^{32}$

Memories of the occupation were kept alive purely via oral history. There were no signs, no monuments, no other indications of any official recognition of the past.

The seven-part film installation Primitive developed after this journey. In 2009 it was shown at the Munich Haus der Kunst, the Musée d'Art Moderne de la Ville de Paris, FACT Liverpool, and the New York New Museum of Contemporary Art; in the years following it travelled to the Yokohama Triennial, the Museo Universitario de Arte Contemporáneo in Mexico City, and the Jim Thompson Art Center in Bangkok. Each presentation was installed differently. In the Haus der Kunst, it was shown in one large room; in other galleries it was distributed over several rooms, sometimes with additional elements. The larger Primitive complex includes several photographs, an artist's book, ${ }^{33}$ two more short films produced by the English platform Animate Projects (Phantoms of Nabua, 2009, and A Letter to Uncle Boonmee, 2009), ${ }^{34}$ and the feature film Uncle Boonmee Who Can Recall His Past Lives, which was produced for international cinema. Below, I refer to the presentation of Primitive as it was shown in spring 2009 at the Haus der Kunst.

The entrance to the exhibition room was indicated by a metre-high curtain (the monumental ceiling of the Haus der Kunst's ground floor is nearly $6 \mathrm{~m} \mathrm{high}$ ). Above the heads of the audience, a music video for the song I'm Still Breathing by the Bangkok band Modern Dog was mounted on a monitor. Filmed with several handheld cameras,

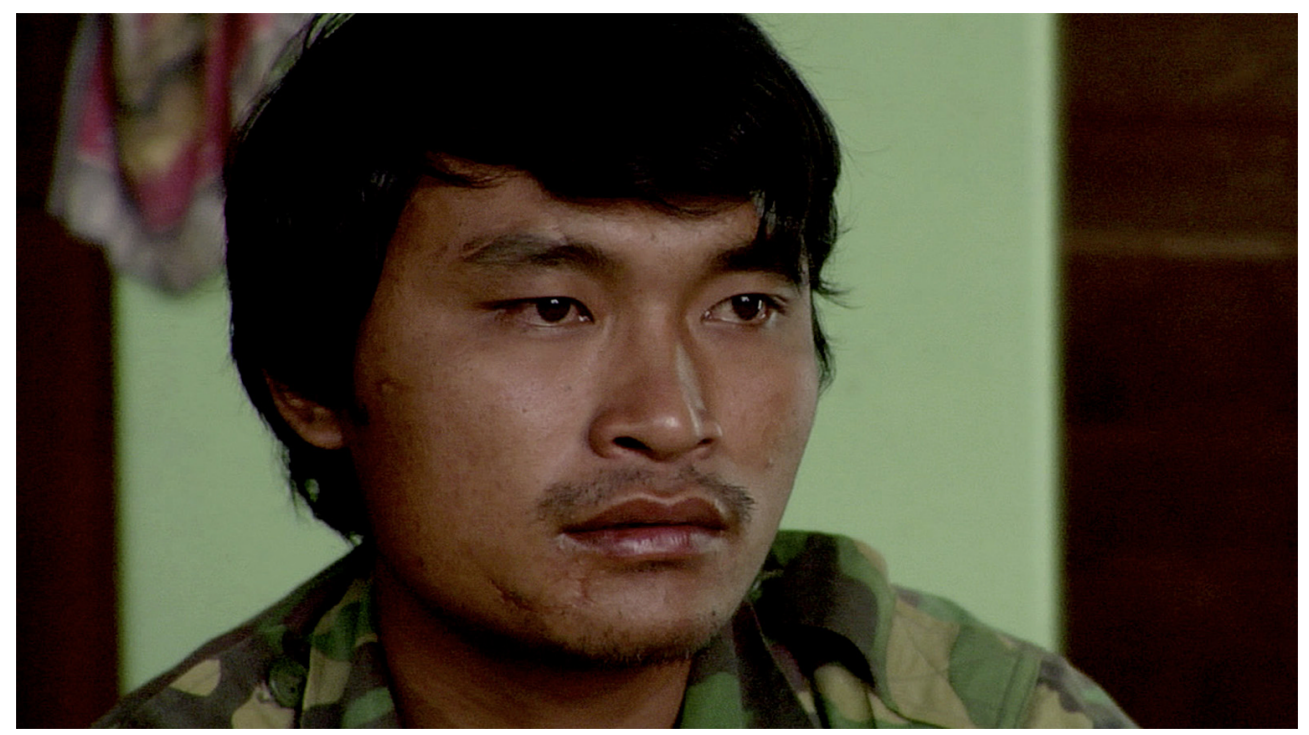

Figure 6.5 Apichatpong Weerasethakul, Nabua Song, 2009. Still image. Courtesy Kick the Machine Films. Cinematographer Sayombhu Mukdeeprom 
it shows several young men from Nabua running and playing with a smoking paper. Styled like Thai or Korean pop idols, the village youth are transported into a pop-cultural place to be; ritualised actions from the political protests in Bangkok ("running and throwing things" ${ }^{35}$ ) are translated into music video format. Once the audience entered the exhibition space, six additional short films and video installations of various sizes, technical formats, and soundscapes were on view. The video Nabua Song, shown on monitor, gives the clearest indication of the political history of the village. A young man (called Petch in a wall text) recites a simple hymn he had composed in memory of the clash between communist farmers and the Thai military in August 1965 (Figure 6.5). We also see his friend Kumgieng, whose grandfather was killed by anti-communist units. Both I'm Still Breathing and Nabua Song are described as music videos, ${ }^{36}$ but they present completely different interpretations of the same theme. The first takes up urban forms of political protest and is shown on a high-hanging monitor with ambient sound, as though one were seeing it on a barroom TV. The second portrays the young village singer-songwriter and is heard through headphones-a much more intimate environment for listening. Music and politics, rural and urban culture connect the buried history of Nabua with the current political situation in Thailand.

The main space was dominated by the two-channel installation Primitive in large-format projections screened vertically one above the other and flanked on both sides by the four remaining films A Dedicated Machine and An Evening Shoot (left) as well as Nabua and Making of the Spaceship (right). The way individual audience members chose to view the installation was guided by the different lengths, soundtracks, and technical presentations of the films. Primitive has a soundtrack subtitled in English that is accompanied by the atmospheric soundtrack of Nabua. In the latter, the village is staged by means of special effects as a (widow) ghost village reminiscent of Thai horror film: torches, lights, and artificial lightning flicker through the darkness and illuminate the rice fields as bright as day. The film plays upon the topic of Nabua's invisible past, which appears only in numerous scattered memories. Just as one does not believe in

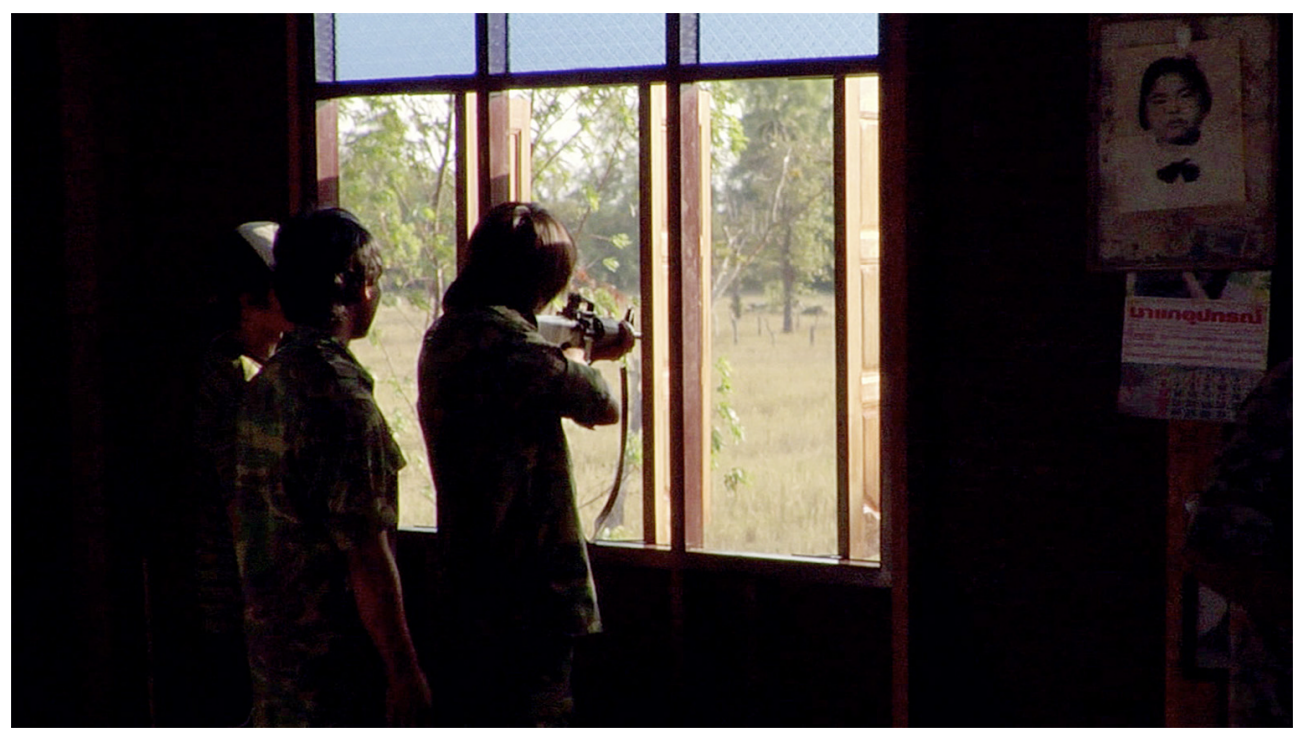

Figure 6.6 Apichatpong Weerasethakul, An Evening Shoot, 2009. Still image. Courtesy Kick the Machine Films. Cinematographer Sayombhu Mukdeeprom 


\section{Performing}

ghosts in the daytime, it is difficult to believe in the region's cruel, violent history, which has left hardly any visible traces.

The other three films are directly related to Apichatpong's month-long visits to Nabua. An Evening Shoot (Figure 6.6) shows scenes from "shooting an unknown film" 37 in the middle of rice fields. Young people wear soldiers' uniforms and slip into the role of the 1960s Thai military, just like in a play ${ }^{38}$ or public performance. The video Making of the Spaceship, lasting almost half an hour, shows the construction of a prop-a huge "spaceship" made of metal struts and fabric or plastic film. A Dedicated Machine, the shortest film of the installation at only one and a half minutes, displays attempts to send this lightweight oval object up into the air. According to the director, the crew succeeded in having it float at about four metres off the ground.

The two-channel video Primitive dominated the gallery space. It shows young men, again in soldiers' uniforms, in the red illuminated "spaceship" (safely on the ground, Figure 6.7). The images are accompanied by a sound recording in which a story unfolds about the object's use as a time machine. A male voice-over recounts wanderings through different times, souls, and lives. He describes how, as a young man, he would follow lights in the jungle through which he could "read" thoughts—even whole life stories. "The adults thought I was crazy or possessed. But they didn't bother to take me to a doctor, or to a shaman." He meets demons, spirits, and animals, although he cannot always understand them. As an adolescent he loses interest, but then this supernatural gift returns in the form of dream encounters, enabling him to travel into the past and the future: "I also dreamt about the future. I arrived there from the past in a vehicle, a sort of time machine." 39

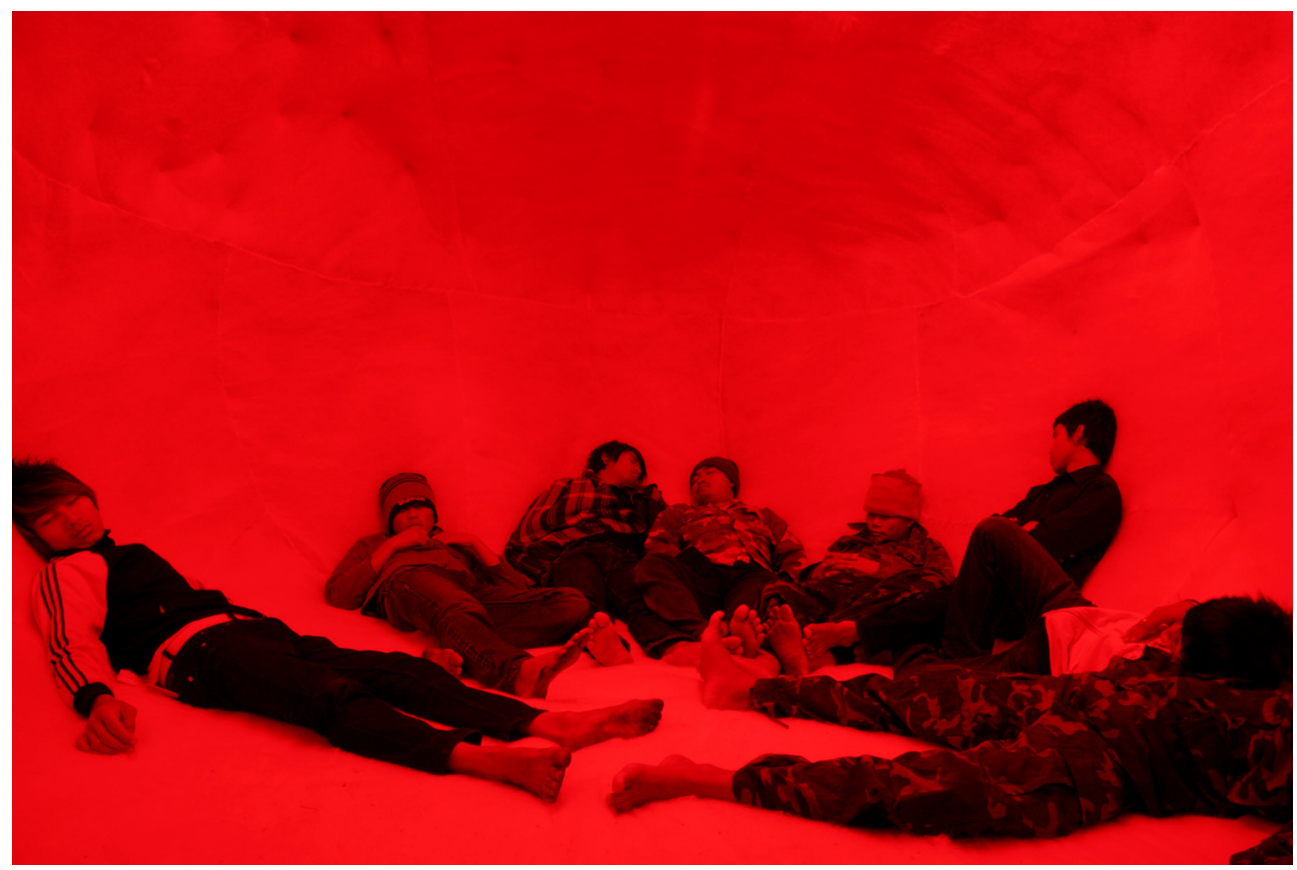

Figure 6.7 Apichatpong Weerasethakul, Primitive, 2009. Still image. Courtesy Kick the Machine Films. Photo Chaisiri Jiwarangsan 
As the young man works in Malaysia as a migrant labourer, he arrives at a mysterious place where past lives and memories of time travel are projected as film images until they disappear. This fragmentary narrative alternates between monologue and dialogue and is interspersed with questions and military interjections. Visually, the two-channel work picks up on various themes of the installation: the medium of film, as the soundtrack so impressively conveys, enables transmigrations of souls as well as time travel, mediating across different levels of reality and time, past and present, documentary and fiction.

In the installation, visitors are free to choose which films they want to watch for how long, whether simultaneously or consecutively.

I want to give the audience the freedom to fly or to float, to just let their mind go here and there, to drift, like when we sit in a train, listen to a Walkman, and look at the landscape. ${ }^{40}$

This decision corresponds to the usual conventions of audiovisual installations in the exhibition space, but in the case of Apichatpong's works it includes a specific innovation. Primitive brings together different experiences of audiovisual reception through the use of a wide variety of presentation formats that are connected to specific visual conventions from everyday life: exhibitions, cinema, video, television, and the internet. ${ }^{41}$ The vertically superimposed two-channel projections, small-format projections on transparent screens, and monitor screenings mean that intimate and collective viewing situations take turns (Figure 6.8).

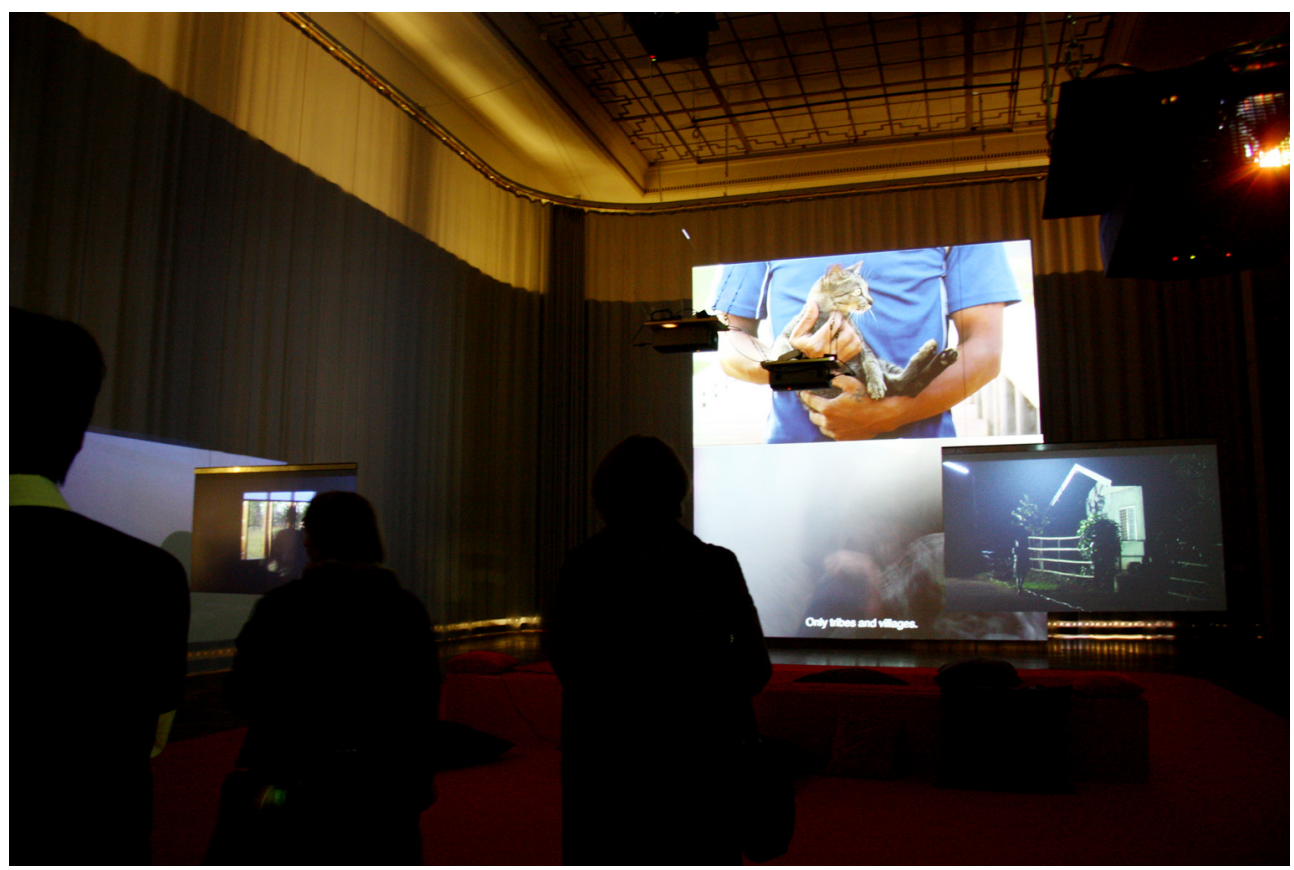

Figure 6.8 Apichatpong Weerasethakul, Primitive, 2009. Installation view, Haus der Kunst, Munich, 2009. Courtesy Kick the Machine Films. Photograph by Haus der Kunst 


\section{Performing}

Apichatpong has further probed this approach in his exhibition The Serenity of Madness (2016), which comprises audio-visual works that are not so much connected in terms of content as by a formal postcinematographic aesthetic. The artist again showed film and video installations as well as short films from different contexts using various presentation techniques. ${ }^{42}$ The exhibition circuit began with two short films projected directly onto the wall from palm-sized video projectors on filigree light stands next to each other (Velocity, 2016). Another private video recording his brother had made of Apichatpong's father's dialysis treatment in hospital (Father, 2003) was presented similarly, but with the display apparatus disappearing in the darkened surroundings. The exhibition continued with a projection on a holographic screen that reflected onto the back wall, revealing images wandering through space, distorted in perspective (Fireworks [Archives], 2015), with staged close-ups of Apichatpong's sleeping partner filmed on a mobile phone but grandly magnified in an immersive, Warholesque presentation (Teem, 2007); videos tinted red in postproduction (The Palace, 2007) and footage filmed with a red-light camera (Haiku, 2009, showing footage from Nabua). A time-lapse video shot on LomoKino (Ashes, 2012) was also shown. Other works were presented on a grey painted surface (Windows, 1999), on a canvas hung in front of the wall (Sakda [Rousseau], 2012), and on a framed flat screen (Firegarden, 2010). The exhibition space was dotted with "screens" of diverse materialities, intensities, and dimensions, as in optimistic response to Kate Mondloch's assertion that the display of audio-visual works in the exhibition space triggers forms of reception geared to short attention spans that are hardly discernible from the way the mass media pervade everyday life. ${ }^{43}$ The audience witnesses the medium of film across diverse production and reception devices, accompanied by photographs, scripts, and drawings relating to film.

\section{A Transmedial and Transnational "Cinema of Passages"}

Apichatpong works within the shared transnational institutional framework of art and film, extended by web platforms, theatre, and festival contexts. ${ }^{44}$ His films are for the most part produced internationally (financed by the Hubert Baals Fund, New Crowned Hope, Anna Sanders Film, SØRFOND, the Berlin Biennale's World Cinema Fund, and other public and private sponsors). ${ }^{45}$ As an artist he is represented, as of 2020, by several galleries worldwide. He himself presents his artistic career as a secondary activity facilitated by personal contacts that serves to prepare, contextualise, and potentially also cofinance his films. ${ }^{46}$

In the installation Primitive, the history of the city of Nabua gradually unfolds as a meandering of audio-visual images through different social contexts and technical formats. Concrete historical details can only be gathered from the artist's book Primitive (which was not yet available at the Munich exhibition) and from scattered statements and texts accompanying the project. The artist's book contains, among other things, the memories of female communist fighter Nittaya, who was sent to the nearby Laotian capital Vientiane for training at the age of about 20. Around this time a ghost woman began to visit Nittaya regularly in her dreams, enabling her to foresee the future. When she wishes to return to Thailand, a fortune teller informs Nittaya that her ghost would only be able to cross the border by means of a ritual (a kind of spiritual visa). Nittaya decides to leave her ghost behind. ${ }^{47}$ Next to this story is a conversation between Apichatpong's crew and Nittaya's mother, Mrs. Damnuan, that includes detailed memories of violent oppression, murder, exile, and rape. ${ }^{48}$ These are partly corrected and commented upon; they are less documents than stories that lead finally to the legend of the 
murderous ghost widow plaguing the region's men. Memories, myths, and documentary truths complement each other. In his text "The Memory of Nabua: A Note of the Primitive Project," Apichatpong mentions a conversation with the father of actress Jenjira Pongpas, with whom the director often works, at her hometown near the Laotian border. A former government official in the 1960s, this man used to show anti-communist $16 \mathrm{~mm}$ propaganda films in the region's villages. The director also recalls the story of his parents who worked in a hospital in Khon Kaen, where he himself grew up: another demonstration of Bangkok's presence in the rural northeast. Thus the director's and the actress's lives are revealed as deeply integrated with the forgotten past of Thailand. ${ }^{49}$

As mentioned above, Primitive extends to two short films produced for the English web platform Animate Projects that take up numerous motifs from the installation; ${ }^{50}$ the feature film Uncle Boonmee Who Can Recall His Past Lives, which was created shortly after Primitive, also contains references to the installation. When the terminally ill Boonmee is left to die in a cave towards the end of the film, images from the installation are shown as fade-ins. These visual references illustrate the interlocking nature of the director's film and art projects. They refract as much as succeed each other, each one representing, so to speak, the afterlife and the survival of the others. Apichatpong's cinema is an "art of passages" (Christa Blümlinger) traversed by storylines, characters, locations, actors, and autobiographical references-which, like ghosts or wandering souls, are brought back to life again and again. ${ }^{51}$ These thematic and formal repetitions and entanglements ${ }^{52}$ are comparable to a chain of cinematic reincarnation; ${ }^{53}$ or, to take the analogy to biological reproduction further, to "surrogacy reincarnation." 54 May Adadol Ingawanij and David Teh have considered this phenomenon in relation to Primitive:

In this body of work, the past is neither dug up, nor reconstituted; rather, it floats to the surface in storytelling and role-play; through the cracks and fissures of the everyday rural environment, as the gestures of the dead are channelled "through their offspring." 55

This description can be extended to the relationship between documentary and fiction film in Primitive: the young actors try out historical roles and situations, familiarising themselves with the historical past of the former inhabitants of Nabua in artistic reincarnations enabled by the medium of film.

Apichatpong's films, especially his work with amateur actors, evoke many of the characteristics of "expressive, ethnographic realism" (Margrit Tröhler) that even via film characters brings scenes of everyday life into transnational circulation. ${ }^{56}$ This is particularly true of Primitive: shooting on location was a central component of the project, and the actors were given freedom of action in these scenes. The whole project was not conceived as didactic. When asked whether his presence in Nabua changed the relationship of the local inhabitants to their past, Apichatpong replied: "I don't think so. I hope not. The idea was not to change." ${ }^{57}$ But their embodiment of past events produced "borrowed" presences of history, often with the help of myths and spirits. Open to diverse readings and contextualisations, the films carefully balance political references and thus may avoid direct confrontation and censorship. In an unusually explicit public statement accompanying his installation Unknown Forces (2007), ${ }^{58}$ which was created in direct reaction to the political protests surrounding the overthrow of Prime Minister Thaksin, the artist addressed fears that any open critical political stance would be countered by threats and repression. ${ }^{59}$ 


\section{Performing}

Apichatpong's films are often praised as paradigmatic examples of contemporary global cinema because of their formal unconventionality and their casual depictions of everyday rural life in Thailand. At Cannes alone, he has won three highly prestigious awards (Prix Un Certain Regard for Blissfully Yours, 2002; Jury Prize for Tropical Malady, 2004; Golden Palm for Uncle Boonmee Who Can Recall His Past Lives, 2010). With appearances at documenta 13 and numerous other shows, Apichatpong is also well established on the global art circuit, though still firmly anchored in Southeast Asia with regards to his cultural references. In particular, Primitive and Uncle Boonmee Who Can Recall His Past Lives are dedicated to a portrayal of Thai rural culture. ${ }^{60}$ However, politicians in Thailand often not only deny the "Thainess" of Apichatpong's internationally produced and financed films but also play down his significance as a director. ${ }^{61}$

Kong Rithdee and the late Benedict Anderson have examined the reasons for this lack of official and public recognition. ${ }^{62}$ According to Apichatpong, his internationally acclaimed Tropical Malady was on view for only three weeks in one single cinema in Thailand. ${ }^{63}$ Many researchers have taken up the question of how Apichatpong's films are positioned within the complex cultural identity of Thailand and in relation to a transnational audience. ${ }^{64}$ International audiences are often fascinated by the lyrical beauty of his films but ignore their political and social aspects, while audiences in Bangkok, well aware of the political and sociocritical implications, tend to ignore the films' formal qualities. This often leads international viewers to believe that they understand his films better-but at what a price: "The auteur and his work are immediately sucked into a transnational zone of appreciation, bypassing their potential to create friction and to provoke his national bourgeoisie." 65

In 2004, film critic Alongkot Maiduang (also known as Kanlaphraphruek) created a documentary entitled Room Kat Sat Pralaat (Ganging Up on Sat Pralaat), which mainly consisted of showing Tropical Malady to rural audiences in Thailand. This feature's first half depicts the romance of a gay couple; its second half is dedicated to recounting a mysterious story about a man-tiger, the images becoming more or less completely submerged in the black of a night jungle. Both formally and in terms of content, the film, it would seem, makes considerable demands on its viewers. But the rural audiences shown in Kanlaphraphruek's documentary have a good time and afterwards describe their reactions to the film in short interviews. ${ }^{66}$ Accusations that Tropical Malady might be too "Western" or "highbrow" for Thailand illustrate, in Anderson's view, a conflict among different political conceptions of what constitutes Thai culture. ${ }^{67}$ Apichatpong's films treat a rural, "provincial” culture considered marginal from Bangkok's perspective. Because of their strong connection to the Isan region, they are not compatible with cultural conceptions of the dominant bourgeois-metropolitan classes in Bangkok. ${ }^{68}$ According to Anderson, this creates a superficially paradoxical constellation that is helpful for the international funding and production of Apichatpong's projects-but not for their distribution in Thailand. Official conceptions of an internationally marketable Thai national identity have little to do with the actual ethnically and culturally diverse structure of the Thai population. ${ }^{69}$ Apichatpong turns conventions of how to portray Thailand on their head, presenting controversial themes in experimental form without recourse to "internationality" in the sense of a blockbuster aesthetic and instead articulating a new "vernacular modernism" $" 70$ of high acclaim within the limited reach of art house cinema.

Apichatpong's feature-length Cemetery of Splendour (2015) can be read as a comment on this debate. Kong Rithdee has worked out numerous references to the political situation in Thailand, which can be found in subtle, sometimes melancholic and sometimes 
humorous allusions: A school is transformed into a hospital for narcoleptic soldiers and thus into a place of collective oblivion and twilight sleep, permeated with images and symbols of Thailand's triadic power complex (nation, religion, and monarchy). These soldiers' souls are forced to fight an invisible, centuries-old war during their sleep, their lives becoming literally absorbed by the past-not their own personal but the political past. In the film, actress Jenjira Pongpas tells her (real) US husband: "You're a foreigner, you won't get it, honey." This is a literal reference to a standard reproach by the Thai military junta against international criticism: foreign media do not understand the country, which makes Thai politics unassailable behind a bastion of national identity. ${ }^{71}$

In the context of Apichatpong's "transnationality" 72 and his opposition to cultural politics, his interest in ghosts appears less as a means of asserting cultural authenticity than of connecting the past with the present, traditional with popular culture. At the same time, he introduces a new conceptual frame for history that negotiates between local traditions and secularised Enlightenment concepts. This often produces uneasy translations, especially into the Western or Northern exhibition circuit. For instance, his short film Phantoms of Nabua was shown in Europe in 2012 in the exhibition Animism and, in a completely different contextual framework, at the group exhibition Phantoms of Asia: Contemporary Awakens the Past (Asian Art Museum, San Francisco) in the same year. In San Francisco, the reference to ghosts was not understood as a cultural-spiritual end in itself but as a motive to dig up the past, as is the case with most publications, debates, and exhibitions on ghosts in Southeast Asia. ${ }^{73}$ Primitive was also published as a contribution by Apichatpong to the catalogue of the group exhibition Ghosts, Spies, and Grandmothers: Modernities Against Modernity at the SeMA Biennial Mediacity Seoul 2014, which focused on artistic examinations of gwisin (ghosts or souls of the deceased) as an extended metaphor for the return of unfinished histories. But even within Southeast Asian reception, the situation is complex. Park Chan-kyong describes an "internalized Orientalism" widespread in Asian countries, ${ }^{74}$ adapting an exoticised self-image that preventively excludes local traditions. He views gwisin as a means to address local Asian myths, religions, and histories, helping to reposition cultural identity between (Western-oriented) modernism and traditionalism. Indeed, gwisin are largely disseminated via popular transnational Asian Gothic, and yet they are closely connected with different local faiths and cultural customs.

Within this extremely intricate and conflict-laden cultural terrain, Primitive exposes the past as inaccessible to reconstruction. The documentary elements of the installation are limited to the "making of" a feature film, to a single hymn, to location shots that reveals nothing of its past. But the past is still present, indirectly, via role play, costumes, and local ghost stories. The ghosts serve as mediators between local (theatrical) traditions and Southeast Asian popular culture. This entails a cultural and political commitment to local cultures that breaks away from restrictions within Thai cultural politics and, in some respects, from Western art criticism. The director's commitment to rural culture of the rural population is clearly political: it is directed at those individuals who not only carry on the memory of the communist persecutions of the 1960s but are also active in the current political protests. With his use of film as a time machine enabling "reincarnations" of the past, Apichatpong performatively anchors history in the present.

\section{Notes}

1 Oldenborgh, "Voice - Script - Public," 153.

2 Buchmann, Lafer, and Ruhm, Putting Rehearsals to the Test. 


\section{8}

\section{Performing}

3 Since Maurits Script is shown as a double projection, the two different situations of dealing with history can be installed in a manner spatially similar to that of the performance on the day of filming.

4 A booklet available on the day of the filming at the Mauritshuis provides the full script and historical background of Maurits's involvement in the Dutch colonisation of Brazil. Oldenborgh, "Maurits Script."

5 Zacharias Wagener, Thierbuch (Mauricia/Dresden, 1640-48). English translation in Oldenborgh, "Maurits Script," 14.

6 Johan Maurits, "Political Testament of 1644." English translation in Oldenborgh, "Maurits Script," 14.

7 Rogoff, "Smuggling: An Embodied Criticality," cited in Pethick, "Wendelien van Oldenborgh," 60.

8 Choi, "When We Assemble."

9 Oldenborgh, "Retouching Some Real with Some Real," 70.

10 Lütticken, "Production Notes."

11 Bangma, "The Polyphonic Work of Wendelien van Oldenborgh."

12 See the revealing exchange between Oldenborgh and Basbaum in Basbaum, "Conversations 2004-15."

13 Oldenborgh, A Certain Brazilianness, introduction to the project website.

14 For Lina Bo Bardi: The Didactic Room at the Van Abbemuseum, Eindhoven, Oldenborgh took up Renato Rosaldo's concept of “cultural citizenship." See Rosaldo, "Cultural Citizenship and Educational Democracy."

15 Oldenborgh in Basbaum, "Conversations 2004-15," 105.

16 Rancière, Disagreement: Politics and Philosophy, 25.

17 Oldenborgh, "Voice - Script - Public," 151.

18 For excerpts from the resulting readings and dialogues, see Choi and Oldenborgh, Wendelien van Oldenborgh: A Well Respected Man, 101-25.

19 Haraway, "Situated Knowledges."

20 Bishop, "Delegated Performance: Outsourcing Authenticity."

21 Colomina, "Bioscope Architecture," 58.

22 Cotter, "Cinema Olanda: Projecting the Netherlands," 11-13.

23 Martina, "(Ware)Housing Black People."

24 Pethick, "Cinema Olanda," 138.

25 Tiravanija, "Ghosts in the Projector," 32. Ghost motifs are still very popular in contemporary Thai horror, as attested by box office hits such as Nang Nak (1999, Nonzee Nimibutr), Bangkok Dangerous (2000, Oxide Pang Chun, Danny Pang), and The Child's Eye (2010, Oxide Pang Chun, Danny Pang Phat).

26 Weerasethakul, cited in Hruska, "The Architecture of Apichatpong."

27 Weerasethakul, "Ghosts in the Darkness."

28 Weerasethakul, "Influence: Today and Tomorrow," 269.

29 Phatharathananunth, Civil Society and Democratization. On the term "America Era," see Anderson, In the Mirror, 9-87.

30 Hyun, "Indigenizing the Cold War."

31 Chanrochanakit, "Deforming Thai Politics," 427.

32 Weerasethakul, "The Memory of Nabua," 198.

33 Weerasethakul and Field, Primitive.

34 The films are available at https://www.animateprojects.org.

35 Quandt, Apichatpong Weerasethakul, 246.

36 Weerasethakul, "The Memory of Nabua," 200.

37 Weerasethakul, "An Evening Shoot."

38 Böhler, "Fiction, Interrupted."

39 This strand of narration is closely linked to a dream of the protagonist in Uncle Boonmee Who Can Recall His Past Lives.

40 Quandt, "Exquisite Corpus," 231.

41 Jihoon Kim connects the formal unconventionality of Apichatpong's films to the conventions of exhibition display. Kim, "Between Auditorium and Gallery"; Joo, "Present Again."

42 I am referring to the presentation of The Serenity of Madness at Parasite in Hong Kong, September 18- November 27, 2016. The show was first conceived by Gridthiya Gaweewong for MAIIAM Contemporary Art Museum in Chiang Mai. 
43 Mondloch reminds us that art exhibitions "may serve to reinforce an extremely conventional viewing subject," as viewers stroll through the exhibition space and react to the attraction of the images presented. Mondloch, Screens, 57, with reference to Païni, "Le retour du flâneur / The Return of the Flâneur."

44 Weerasethakul's website, http://www.kickthemachine.com, lists 19 installations, 25 shorts, 8 feature films, and 1 performance.

45 The complex structure of this "arthouse economy" (Simon Rothöhler) works like art funding. See Elsaesser, "Film Festival Networks"; Falicov, "The Festival Film."

46 Baumgärtel, "'I make films for myself,”" 184.

47 Weerasethakul and Field, Primitive, entry on 24 August 2008.

48 On the political background of Uncle Boonmee/Primitive and Unknown Forces, see Joo, "Present Again."

49 Weerasethakul, "The Memory of Nabua," 195.

50 These are Phantoms of Nabua and A Letter to Uncle Boonmee, see Addison and Thomas, Animate Projects.

51 Blümlinger, "La mémoire, moteur des images"; Blümlinger, "Film as the Art of Passages."

52 Rithdee, "Cemetery of Splendour by Apichatpong Weerasethakul," 17.

53 Derieux, "Apichatpong Weerasethakul," 93.

54 Rayns, "The Roving Eye."

55 Ingawanij and Teh, "Only Light and Memory," 24.

56 Tröhler, "Multiple Protagonist Films," 464.

57 Carrion-Murayari, "Interview with Apichatpong Weerasethakul," 12.

58 Weerasethakul, "Statement on Unknown Forces," in Quandt, Apichatpong Weerasethakul, 238. Apichatpong's 2006 film Syndromes and a Century was affected by Thai censorship. See Weerasethakul, "The Folly and Future of Thai Cinema"; Chanrochanakit, "Deforming Thai Politics."

59 Weerasethakul, cited in Joo, "Present Again."

60 Weerasethakul in conversation with Alexander Horvath at the Film Museum, Vienna, September 11, 2017.

61 Ladda Tangsupachai, former director of the censorship authorities of the Thai Ministry of Culture, justified censorship of Syndromes and a Century claiming that the Thai population was too uneducated for such films (and therefore urgently in need of censorship). Montlake, "Making the Cut"; Anderson, "The Strange Story of a Strange Beast," esp. 172-77.

62 In a review of Cemetery of Splendour, Thai critic Kong Rithdee mentions that he often had to rely on the English subtitles when viewing the film, as it was shot in a local dialect in the northeast. Rithdee, "Cinema of Reincarnations."

63 Anderson, "The Strange Story of a Strange Beast," 158n5.

64 Ingawanij and MacDonald, "Blissfully Whose?”; Böhler, "Globalized Haunting”; Teh, "Itinerant Cinema".

65 Ingawanij and MacDonald, "Blissfully Whose?" 133

66 See also Araya Rasdjarmrearnsook's The Two Planet Series (2008), which records reactions of Thai rural audiences to well-known Western artworks, such as Manet's Dejeuner sur l'herbe. See Chanrochanakit, "Deforming Thai Politics," 423-24.

67 Anderson, "The Strange Story of a Strange Beast"; Gaweewong, "On Thai Artists."

68 Ingavanij, "Hyperbolic Heritage," 27-36. Ingawanij describes in detail the concept of the thai sakon, internationally recognised Thainess (kwampenthai) that fits perfectly into the country's tourist image.

69 Herzfeld, "Conceptual Allure of the West."

70 Hansen, "Mass Production of the Senses."

71 Ridthee, "Cemetery of Splendour."

72 Anderson, "The Strange Story of a Strange Beast"; O'Hara, "Mysterious Objects of Desire"; Böhler, "Globalized Haunting"; Farmer, "Apichatpong Weerasethakul, Transnational Poet."

73 Bräunlein and Lauser, Ghost Movies in Southeast Asia, esp. Bräunlein's introduction, 1-39, with a detailed examination of comparable cultural marginalisations of "irrationality" in Western thought.

74 Park, "The Collaboration among Ghosts," 12. 


\section{Counterfactual History, Parafiction, and the Critical Ends of Utopia}

This chapter discusses artworks engaging with counterfactual historiography: narrations of a past that never happened leading to a present that is different from the one we know. The potentialities and aporias of counterfactual history also bring us, productively, towards an analysis of its better-known counterpart: utopia.

Counterfactual historiography emerged as a scholarly instrument to highlight contingencies, probabilities, and coincidences within history; to facilitate judgements about key historical situations and processes; and to fill the space between what we can imagine and what has actually happened. ${ }^{1}$ This approach opens up the course of the past-which is inaccessible in its factuality and closure-to conceptual examination but requires two conflicting criteria: On the one hand, counterfactual historiography must recognisably differ from reality. On the other, it cannot be invented freely but must at least be plausible in light of its mirror image, the actual past. It is thus often used to explore the "sense of possibility" 2 that encircles historical objects, events, and characters like an aura.

To mobilise historical events counterfactually is an anachronistic operation. Counterfactual history has the potential to set off processes of disidentification: freeing historical actors and events from the roles, places, and positions ascribed to them as well as enabling new political subjectivities. ${ }^{3}$ None of this can work, however, if counterfactual history remains within the bounds of anachronistic equation of what has not happened with what is not possible, perpetuating the very "regime of probability" that anachronies are trying to overcome. ${ }^{4}$ Michael Blum's A Tribute to Safiye Behar (2005) illustrates how the resulting subjection of possible but counterfactual events as mere fiction-as never having happened and as therefore impossible-can be avoided.

\section{Sensing Possibility, Sensing Probability: Michael Blum's A Tribute to Safiye Behar (2005)}

Montreal-based artist Michael Blum created the fictional historical character Safiye Behar (1890-1965) as part of a project for the 2005 Istanbul Biennial (Figure 7.1). Behar, a Jewish-Turkish woman of humble origins, was supposed to have gained access to education and the women's liberation movement with the support of her parents. As a teacher, translator, and feminist activist as well as through a secret longstanding love affair, she was imagined as having had considerable influence on reforms by former Turkish president Mustafa Kemal Atatürk on women's policy. After Kemal's death in 1938, the fictional Behar followed her husband to Chicago, where she moved in left-wing activist circles. The artist's "long overdue" installation of a memorial room for her at the Istanbul Biennial was, again supposedly, owing to the support of her

DOI: $10.4324 / 9781003166412-8$ 


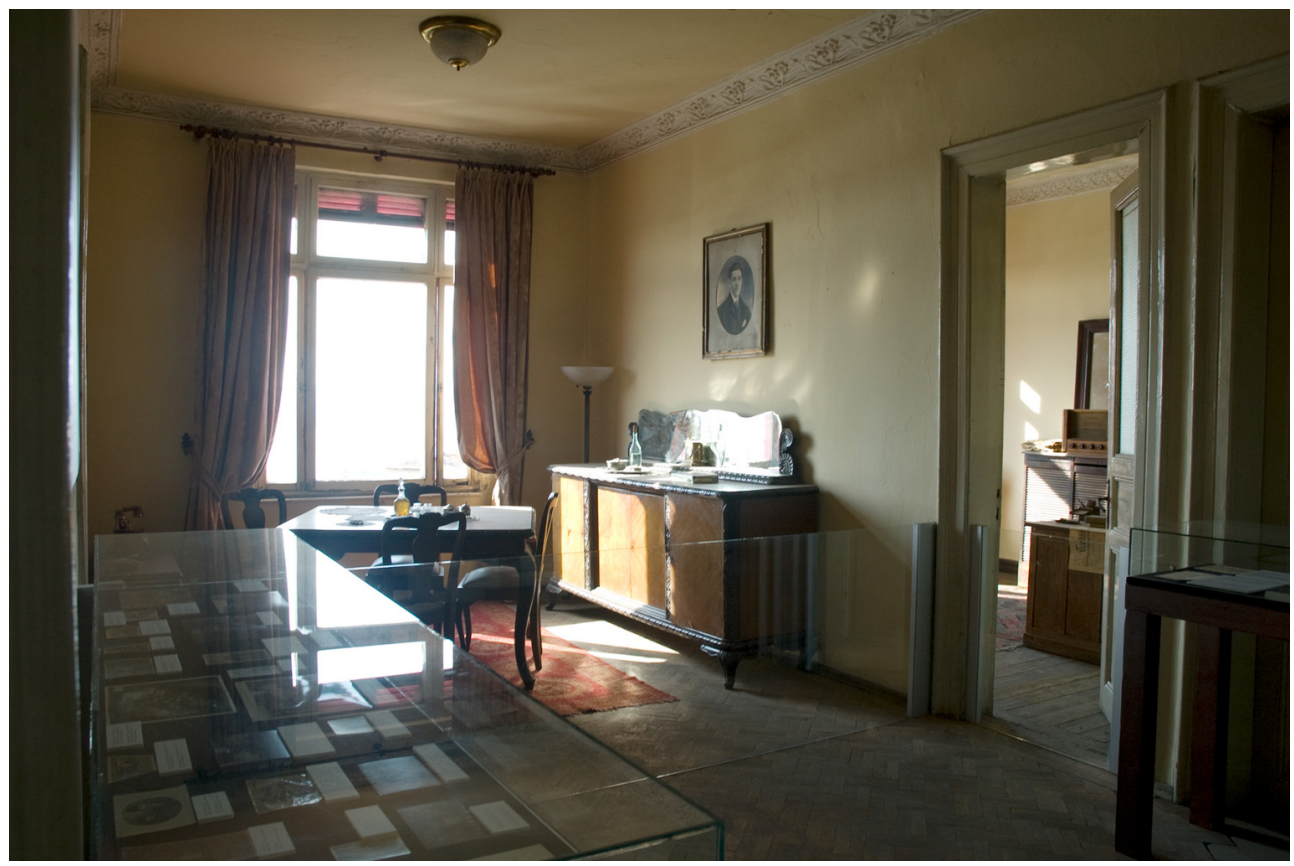

Figure 7.1 Michael Blum, A Tribute to Safiye Behar, 2005. Mixed-media. Installation view, 9th Istanbul Biennial, 2005. Courtesy the artist

grandson Melik Tutuncu, an architect from Chicago who had contributed the installation's series of photographs, letters, books, and furnishings that had been once in her possession. His memories of his grandmother were documented on video in the exhibition; her personal belongings and documents were presented in a Plexiglass showcase. In the political climate of the early millennium, when the integration of Turkey into the European Union was discussed, updating the country's political image by remembering a secularised, emancipated, and internationally politically active woman plausibly fit more optimistic expectations of the future of the Turkish republic. Even if she in fact did not, Behar should have existed, and so she was an attractive exceptional character to discover. As his practice is regularly devoted to historical research, it seemed not unlikely that Blum was the one to discover her.

Examining Blum's interest in intermingling fiction and documentary, Carrie Lambert-Beatty has developed the term "parafictional"-mentioned above in the discussion of Dierk Schmidt's works ${ }^{5}$ - to describe the inscription of fictional characters in historical reality. Blum invented a character who is deeply enmeshed in reality and plausibility; who is historically possible and politically opportune at the moment of her creation. And so, the artist, the curatorial team, and the exhibition setting deliberately left open the question of whether Behar had actually existed; only a critical, close look at the historical "documents" assembled in her "museum" provided hints of her fictionality.

This artistic use of counterfactual historiography touches upon a fundamental question of politically engaged art: should it, in accordance with the documentary ethos, be committed to a truthful representation of reality, risking prescribing reality by describing it, or at least committed to always reiterating its limitations? Or should art rather give us a glimpse of alternatives, of what reality could be like, pointing to the untapped potentials of reality? There is no conclusive answer to this question when mapping the fields of the 


\section{2}

real and the fictional in art projects. Lambert-Beatty explores these debates with reference to Brian Holmes' essay "Liar's Poker," which criticises what he observes to be a recurring, double game of fictionality and unmasking in art projects: in the inevitable moment of their exposure as "mere" art, their political content is lost. Creative freedom pays the price of political ineffectiveness. ${ }^{6}$ With art's increasing use as an asset within a globally operating speculative sector; the distance of its audience from the majority of the population; and yet growing expectations that it can change the world, it seems that the "failure" of art must be inevitable. Holmes confronts the pitfalls of presenting art as playground for "safely"-but in the end ineffectively—expressing political impulses. This criticism has lost none of its weight and, if tracked through to its logical ends, must also apply to uses of utopia in art. Political utopias in art easily become vehicles of hope, as their realisation is postponed further and further into the future because they are "just" art. Additionally, not only has the emancipatory potential of utopian thought become questionable in view of the normativity of positive thought in neoliberalism, but also thinking the "impossible" has become conventional in business and political rhetorics. T. J. Clark has pointed out that the continual renewal of utopias may obscure useful insights into social and political failure, all the more so because artistically staged utopias permanently shift the moment of this failure into the sphere of art, as if it were art and not politics that stands in the way of their realisation. "Utopias reassure modernity as to its infinite potential. But why? It should learn-be taught- to look failure in the face."

If conceived as far removed from present reality, utopias risk contributing to the growing gap between the "space of experience" and "horizon of expectation" of which Paul Ricœur, referring to Reinhart Koselleck, has warned.

The idea of progress which still bound the past to a better future $[\ldots]$ tends to give way to the idea of utopia as soon as the hopes of humanity lose their anchorage in acquired experience and are projected into an unprecedented future. With such utopias, the tension [between experience and expectation] becomes a schism. ${ }^{8}$

From this historical-philosophical and political paralysis Ricœur derives two imperatives:

[On the one hand, to] resist the seduction of purely utopian expectations. They can only make us despair of all action, for, lacking an anchorage in experience, they are incapable of formulating a practical path directed to the ideals that they situate "elsewhere." Our expectations must be determined, hence finite and relatively modest, if they are to be able to give rise to responsible commitments. We have to keep our horizon of expectations from running away from us. [...]

On the other hand, we must also resist any narrowing of the space of experience. To do this, we must struggle against the tendency to consider the past only from the angle of what is done, unchangeable, and past. We have to reopen the past, to revivify its unaccomplished, cut-off-even slaughtered—possibilities. In short, [...] we have to make our expectations more determinate and our experience less so. [...]

The present is wholly a crisis when expectation takes refuge in utopia and when tradition becomes only a dead deposit of the past. Faced with this threat of the historical present exploding, we have the task anticipated above: to prevent the tension between the two poles of thinking about history from turning into a schism. ${ }^{9}$

It is precisely at this common endpoint of future and past that the potential of anachronistic thought becomes evident once again-a potential that is connected with 
counterfactual historiography as well as with utopia. Utopia has recently been complemented by the concept of "preenactment," ${ }^{10}$ a short-term performative realisation of future concepts (in utopian or dystopian form). By making the future concrete, embodied, and at least temporarily real, it comes closer to the present. Utopias can thus be tried out, tested, corrected, and possibly also discarded.

Of course, the creation of counterfactual and utopian imaginations is inherent in all artistic creation, regardless of genre, convention, or medium. ${ }^{11}$ Nor is it necessarily linked to a particular attitude-emancipatory or affirmative, traditionalist or innovative. Artistic imaginations may be representative, informative, escapist, political, or interventionist. Thus, counterfactual and utopian potentials may be employed with varying intensity and quality. The question of how far politically committed art projects can go to think about and contextualise their own "unmasking"-how deeply they are able to entrap their viewers in "impossible" histories-is just as decisive in the context of counterfactual historiography as it is in utopian concepts. Behar, who so plausibly fits into both past and present, teaches us less about what history "should have been" than she encourages us to reflect on our own expectations. This is possible because Blum takes seriously the "sense of possibility" in its proximity to present reality and because he never "unmasks" his protagonist. The project focusses, therefore, less on Turkish history than on an analysis of what we believe and what we can imagine Turkish history to be: our current understanding of anachronism and its transgressions in art.

\section{History in Reverse: Yael Bartana's ... And Europe Will Be Stunned (2007-11)}

Yael Bartana's ... And Europe Will Be Stunned (2007-11) radically expands concepts of artistic and political utopia. This comprehensive art project by the Berlin-based, Israel-born artist uses counterfactual historiography as a highly effective and contentious instrument for confronting any "sense of possibility." Bartana's project revolves around the fictitious "Jewish Renaissance Movement in Poland" (JRMiP), which seeks the return to Poland of those 3.3 million Jews that were displaced and murdered during the Shoah. This connects an unrealisable political project with the equally unrealisable reparation of a historical trauma. Political utopia and counterfactual history are linked to rewrite Europe's political past and present as well as the instruments of politically committed art.

The project consists of three short films; a social media-supported website with extensive textual, visual, and film material; several movement "congresses" in the form of participatory performances in theatres and art institutions; and a large number of public presentations by the artist and her project partners at workshops, panel discussions, and other events. The first of the three short films, Mary Koszmary (Nightmares, Super $16 \mathrm{~mm}$ on video, 10 mins. 30 secs., Figure 7.2), was created in $2007 .{ }^{12}$ It begins with the sound of the Polish national anthem accompanying the entrance of a young man into a sports stadium. He proclaims an urgent plea, amplified in the empty stadium via speakers, to the absent Jews who lived in Poland before the Shoah whom he begs to return, not as "shadows of the past" but in the hope of a shared, better, more diverse Polish future:

We want three million Jews to return to Poland, we want you to live with us again. We need you! [...] With one language, we cannot speak. With one religion, we cannot listen. With one colour, we cannot see. With one culture, we cannot feel. Without you, we cannot even remember. Without you, we will remain locked away in the past, with you, a future will be open for us. ${ }^{13}$ 


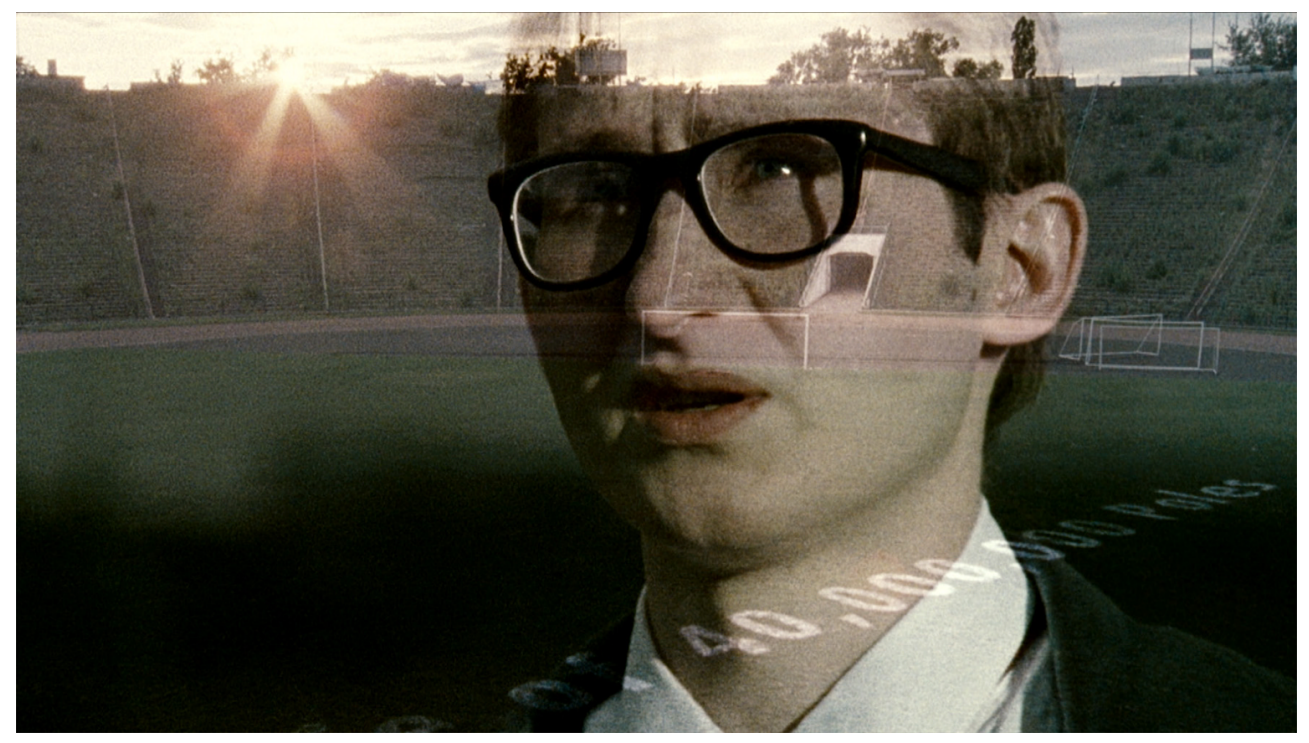

Figure 7.2 Yael Bartana, Mary Koszmary (Nightmares), 2007. Still image, Super 16mm on video, 10 mins. 30 secs. Courtesy Annet Gelink Gallery, Amsterdam, and Foksal Gallery Foundation, Warsaw

This lonely speaker's only audience is a group of children in Boy Scout uniforms who carry Polish flags and write the speech's motto into the grass of the empty soccer field: "3,300,000 Jews can change the life of 40,000,000 Poles." The sports stadium setting, the speaker's entrance from a dark tunnel into the light, his haunting rhetoric, the closeups filmed from below, the wide pans over the stadium, the flags, the attentive group of children-all this suggests the mode of a propaganda film. But its aesthetic is crumbling - as is the ruinous stadium, deserted and overgrown with green plants: this is Warsaw's Stadium of the 10th Anniversary, built in the 1950s and now abandoned, a former venue for party rallies as well as the home base of the Polish national soccer team. In the background a few stalls are visible, indicating the use of the area as a (black) market after the collapse of Communism.

The text of the speech was written by its performer, Polish activist and critic Sławomir Sierakowski, together with writer Kinga Dunin. It is presented authentically and faithfully because the speaker believes in it. The presence of children, his only audience, attests to the fact that the speech is directed towards the future. As Sierakowski says, his plea is not intended to wake the ghosts of Polish history but to initiate a new beginning. And yet he reiterates the exact number of Jews living in Poland before the Second World War, by whose expulsion and murder Poland was to be "freed" of its Jewish citizens and heritage. This horrifying figure painfully ties the utopian, future-oriented speech back to reality, to the past, to the millions of individuals murdered and exiled. Bartana's plea to rewrite history does not offer itself as a free political utopia but is concretely linked to an attempt to make amends for the past, to heal a historical trauma.

The second part of the trilogy, Mur $i$ Wieza (Wall and Tower, HD video, 15 mins. 56 secs., Figure 7.3), followed in 2009. Again, the film was shot publicly. It shows a group of young Jewish "settlers" dressed as Zionist pioneers who seem to have followed Sierakowski's call and gather at the site of the former Warsaw Ghetto, right opposite the monument dedicated to the 1943 uprising of the Jewish resistance against 


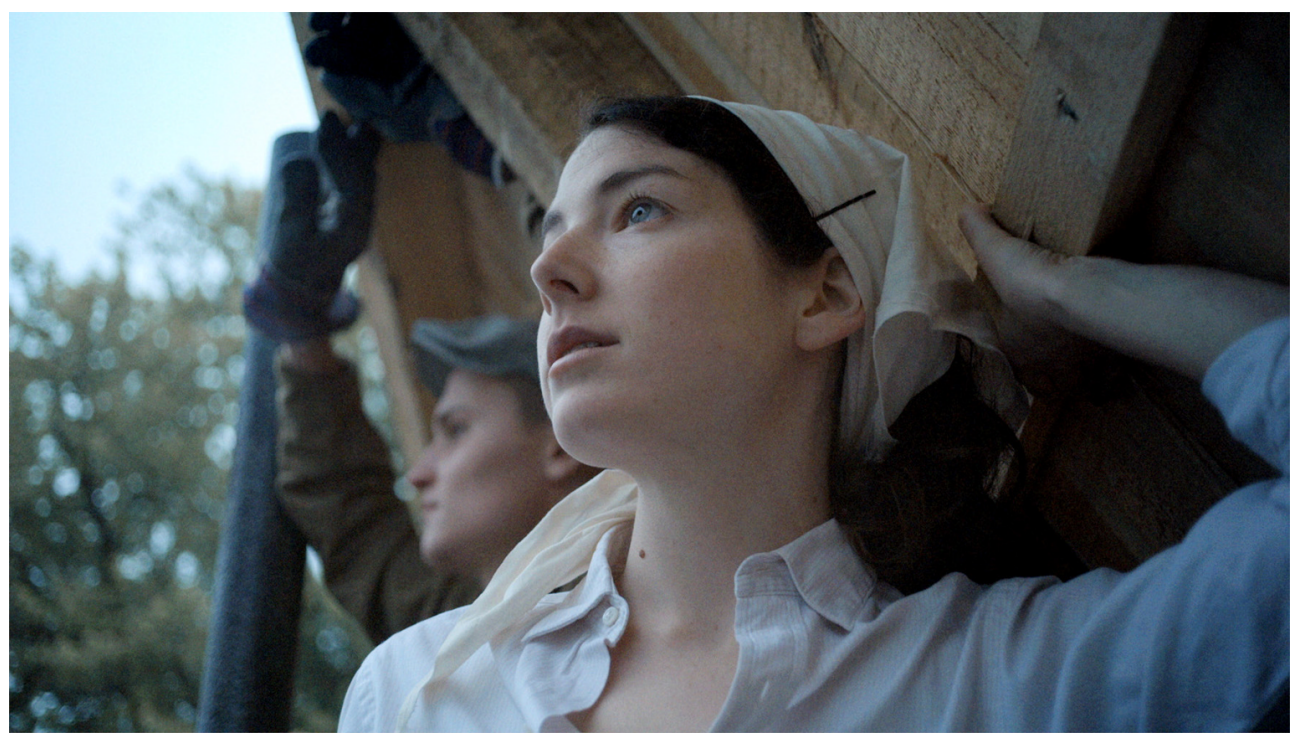

Figure 7.3 Yael Bartana, Mur i wieża (Wall and Tower), 2009. Still image, HD video, 15 mins. 56 secs. Courtesy Annet Gelink Gallery, Amsterdam, and Sommer Contemporary Art, Tel Aviv

the transportation of the Ghetto population to the death camps. The newcomers are instructed by a construction foreman how to build the basic structure of a kibbutz in the manner of the historical model of a Zionist "wall and tower" configuration. This symbol and, with it, the kibbutz movement has become a highly ambivalent myth, given the aggressive and internationally criticised Israeli settlement policy in the West Bank and Golan Heights areas. The performers are taught their first Polish words in language courses, watched by passers-by in the background who probably perceive the scenes as public film sets.

The conclusion of the film trilogy, Zamach (Assassination, video, 35 mins.), was also shot in Warsaw, this time at the Stalinist Pałac Kultury i Nauki and at Piłsudski Square in 2011. The movement's leader-again Sierakowski-has been assassinated. His friends and followers gather at his funeral, which is celebrated ceremoniously with choirs, marches, and speeches. His fictional death helps weaken the trilogy's serial narrative: without a leader, the fictitious movement may now be implemented into reality as a political force. Most speakers at the funeral are, indeed, politically active in real life.

... And Europe Will Be Stunned (which is often referred to as the "Polish Trilogy") was first shown in the Polish Pavilion at the 2011 Venice Biennale and, later, at numerous international exhibitions and festivals. The presentation was accompanied by a Cookbook for Political Imagination, with numerous artistic and theoretical contributions revolving around the topic of political utopia. In addition, Bartana published the movement's manifesto on the project website, which formed the basis for numerous talks and discussions that were soon extended thematically to the conflict in the Middle East, EU migration policy, and the current surge in anti-Semitic, nationalist, and xenophobic tendencies. The range of discussions accompanying the films was enormous, and the commitment of those active in the project-above all Yael Bartana, Sławomir Sierakowski, and Galit Eilat-remarkable. At the 2012 Berlin Biennale, curated by artist Artur Żmijewski, the Hebbel-Theater am Ufer (HAU), which had already shown 
the first two short films in 2010, hosted a JRMiP congress (Figure 7.4). Events like the Berlin congress united aspects of public event and performance, making it difficult to distinguish presentations of the project from its commentary and criticism.

Finally, a "farewell letter" by Sierakowski was published in several publications accompanying the project, with five demands on Polish politicians: to grant Polish citizenship to all migrants; to introduce a reintegration tax to finance the costs that would arise from the relocation of 3.3 million Jews to Poland; to introduce Hebrew as a second official language; to cancel the Concordat with the Vatican as a prerequisite to granting equal rights to all religious institutions; and to dissolve the Senate in favour of a minority house in the Polish parliament. ${ }^{14}$ This letter was presented as a starting point for discussions at the Berlin congress, where farther-reaching political issues as well as the relationship between art and politics were discussed. ${ }^{15}$ Right at the outset, one delegate demanded that the JRMiP "criticize the instrumentalization of politics for the sake of art" - a demand that, as Juli Carson believes, was probably due to "fatigue over the participatory agitprop activities that characterized the concurrent 7 th Berlin Biennale" and thus fundamentally called the project into question. ${ }^{16}$ The so-called "delegates" were active participants in a discussion recorded on video on the HAU stage. The audience of the Berlin Biennial was also invited to participate actively (which, according to Carson, happened at times). The political goals of the JRMiP-which, within the narrative logic of the film trilogy, had failed-were debated at various events in galleries and theatre venues. ${ }^{17}$ Thus, the film trilogy was once more transformed into a participatory art project, inviting debates on the loss of Jewish culture in Poland and, from there, on current political issues.

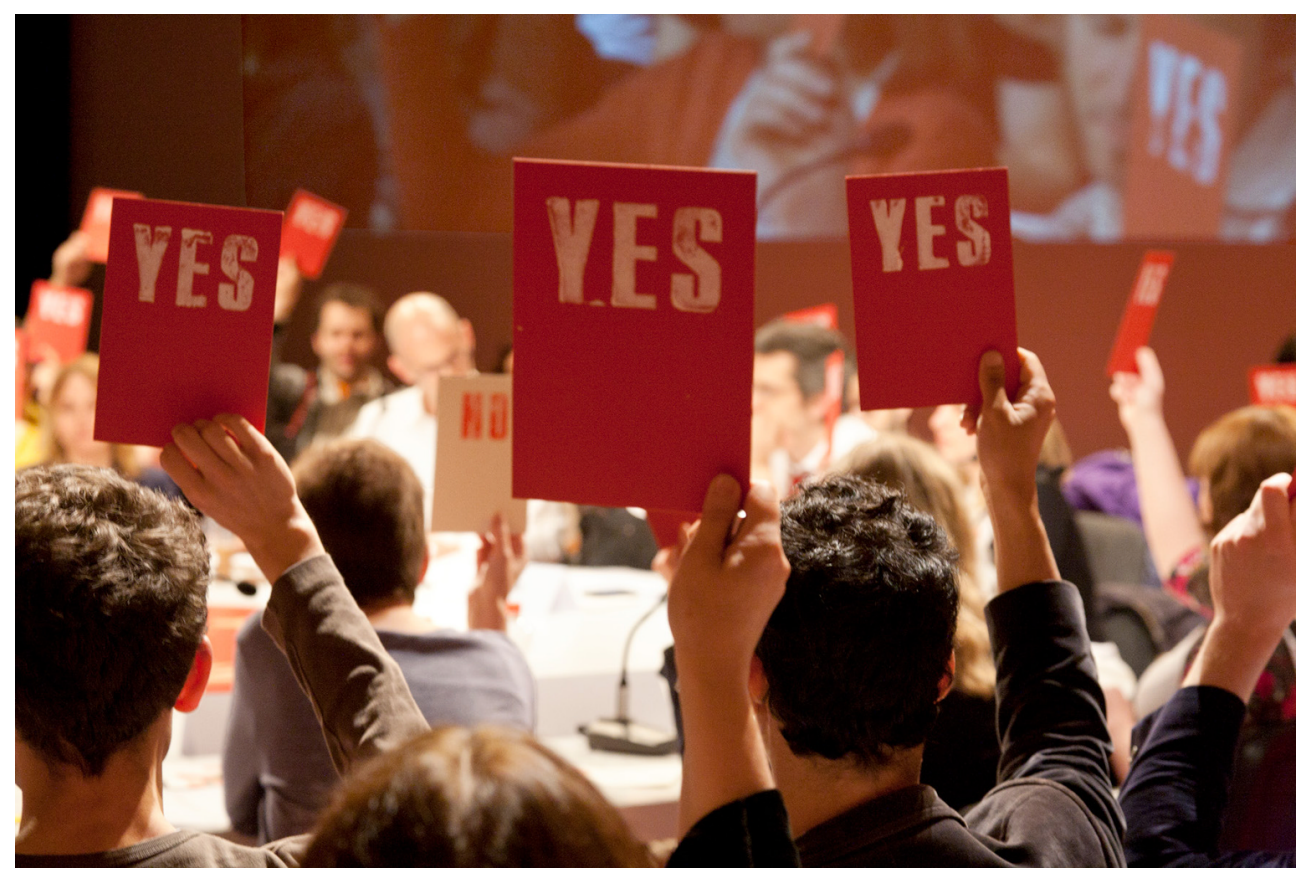

Figure 7.4 Yael Bartana, JRMIP Congress, Hebbel am Ufer Theatre, Berlin, 2012. Photo Ilya Rabinovich 
Bartana's Polish trilogy uses art as a historiographic instrument: by telling history in "reverse," as she puts it, she developed a utopian vision of turning back the wheel of history. ${ }^{18}$ It is the declared aim of the fictitious JRMiP to become reality and to "write history," supported by a whole range of artistic tools that can engage with politics: processions, manifestos, appeals, speeches, and propaganda films. The project thus demonstrates concrete practices of staging political imagination with aesthetics; it does so with recourse to art history-and especially modernist utopia-with its appropriation of propaganda film format and the concept of an aesthetic fiction demanding to become political reality.

Bartana drew on a variety of artistic and political concepts to create the project. She researched the Zionist movement, especially Theodor Herzl's utopian novel Altneuland (1902), with its description of an independent Jewish state. ${ }^{19}$ Borrowings from Zionist films are explicit in the construction of the kibbutz building in Mur $i$ Wie $z a$, which led Jewish pioneer work of the 1930s in the "wrong" direction (away from Israel). Historicisation of Zionism is a core element of the Polish trilogy, as "turning back the wheel of history" entails abandoning Israel's exclusive role as the safe haven of the Jewish diaspora. Embedding the objectives of the JRiMP into Israel's current politics instead raises several controversial issues. In his speech in Zamach, Israeli journalist Yaron London describes European Jewish culture as lost forever and the return of Polish Jews to Europe as a nightmare (thus taking up the title of the first part of the trilogy). Only the existence of the Israeli state with its powerful army provided security from a new holocaust, in his view. "The diaspora", he reminds his listeners, "ended in Auschwitz." 20

Since 2006, Bartana has repeatedly confronted Zionist aesthetics with the current political situation in Israel. Her best-known work before the Polish trilogy-the film installation Summer Camp (2006) shown at documenta 12 (2007), among other locations-documented the reconstruction of a Palestinian house destroyed by Israeli forces, visually appropriating Helmar Lerski’s film Avodah (1936). Bartana projected Avodah on the back of her own work's projection and used Lerski's soundtrack to establish a direct connection between both films. In a political reversal of Avodah, however, her film showed not Jewish settlers but antisettlement activists. ${ }^{21}$ In this confrontation between Zionist (and socialist) aesthetics and the political present, the former may function as an ethical norm for the latter.

The first two parts of ... And Europe Will Be Stunned work similarly to bring about a confrontation between the expulsion of the European Jews and Jewish settlement policy in Palestine. The visual language of modernist propaganda films as found in Zionist, socialist, and fascist modernist movements is used as a strong aesthetic dispositif; indeed, Bartana has repeatedly expressed her interest in the shared origins of modernist propaganda:

In general, I want to show how Bolshevik propaganda influenced the fascist films of the 1930s and how it particularly influenced the Zionist movement. One finds the same aesthetics in completely different, if not contradictory contexts. Communists, fascists, Zionists, they all used very similar methods, very similar images, many close-ups, attitudes creating strong heroes and glorifying narratives. By reusing precisely this language, by appropriating it, I refer to imaginary events that may be read as part of history in the future. I am often told that today there is no longer any justification for using this cinematographic aesthetic, that it is outdated. But this is exactly what its purpose is for me, that is why I use this aesthetic. It evokes emotional reactions because it transports people to another time when these films were really ideological and influential. ${ }^{22}$ 
Borrowings from modernist propaganda films are clearly recognisable in ... And Europe Will Be Stunned; Bartana, according to her own statement, "never gave up on" even Leni Riefenstahl's work as an aesthetic model..$^{23}$ I would object that, despite their common roots, the heroisation formulae are formally distinct in socialism and fascism, respectively, and that their appropriation in Bartana's work is highly selective. Compared to the aesthetics of Sieg des Glaubens (The Victory of Faith, 1933) and the Triumph des Willens (Triumph of the Will, 1935), her films do not include the powerful strategy of acoustically staging the masses, and her visual aesthetics are also quite different from those of Nazi propaganda. In Mary Koszmary, the stadium remains empty; the appeal remains largely unheard so that the void to which the film attests - and that, on another level, is also indicated by the fact that such an appeal was never actually made in any postwar European country-is given aesthetic prominence. Instead of serving as a direct model, Riefenstahl's fascist aesthetic is like a caricature against whose background the fragile imperfection of Bartana's paradoxical propagandist aesthetic becomes especially prominent. Consider the loneliness of the speaker, the small group of children as his only audience, the overgrown, half-ruined stadium. Yet all this does not weaken the film's propagandistic impact. On the contrary, this fragmentary, broken aesthetic is the ideal way to make Bartana's film effective, true to the movement's slogan: "We shall be strong in our weakness." Only in this way can the film's propagandistic effect take hold, expressing a belated, melancholy longing for healing and completeness as well as grief over the loss of the Jewish population of Europe.

Bartana's statement therefore seems to call for reflection on the shared roots of the political projects of modernism rather than actually testing their aesthetics. The three short films do not directly borrow from Nazi aesthetics; thus, her appropriation of Zionist and socialist aesthetics has interested commentators much more ${ }^{24}$ and results in a far more nuanced interweaving of historical propaganda aesthetics and current Israeli and EU politics than would have been a direct appropriation of a Riefenstahl film. Building upon aesthetic obsolescence, Bartana eclectically appropriates this heritage for a propaganda film suited to today's viewers. The outdated modernist imagery ${ }^{25}$ transports the audience to times when these propagandistic visual languages were still formidable. This entails a reversal of the political content of her historical aesthetics: Bartana deliberately stages political imagination via counterfactual history. Healing the "shared" Polish-Jewish trauma is promised by the utopia of a reversal of history that simultaneously represents a geographical reversal-a return home. This topos is profoundly antimodern; it is instead revisionist and ignores the historical reality of the twentieth and twenty-first centuries, which are marked by ongoing and irreversible migration and diaspora. And yet assurance of a return to the Promised Land still underlies the ideological concept of (historical and current) Israeli settlement policy.

... And Europe Will Be Stunned takes us, therefore, out of time. Historical material is removed from its contexts and history is rewritten counterfactually in a direct, linear reversal. Bartana's work has been said to reveal a desperate sense of humour, ${ }^{26}$ and perhaps this best captures the boldness of her appeal to Jews to return to Poland, considering current politics (in 2011 as much as today). This is a particularly provocative, unrealistic plea, as not only is Poland-as the main site of the mass murder of European Jews-a tragic antithesis to the Promised Land of Israel but also the relationship between these two national histories-which position their populations as both chosen and oppressed peoples-is characterised by a sense of rivalry. The fact that Sierakowski so clearly addresses the uniformity of the Polish population directly alludes the political 
supremacy of Catholicism, to which $95 \%$ of Poles adhere (as opposed to only $66 \%$ before 1939). He also mentions anti-Semitic assaults and speeches after the Second World War, commenting on a conflict that came to a head in Poland during the years before Bartana's trilogy as a result of discussion surrounding the publication Neighbors (2001) by US historian Jan T. Gross. With his book about the pogrom in Jedwabne of 1941, which saw between 300 and 400 Polish Jews murdered by their Polish fellow citizens under the supervision of the German Ordnungspolizei, Gross triggered a fierce debate about Polish collaboration during the Shoah. This first led to the public confession of Polish complicity by President Kwaśniewski in the same year. Then, in 2006, after power shifted to the right-wing conservative alliance Law and Justice, the Polish parliament passed a "Lex Gross," banning public statements on the Polish participation or responsibility for Communist or Nazi crimes. This law was withdrawn as unconstitutional a year and a half later. Gross responded with Fear (2006) and Golden Harvest (2011), two more publications on Polish anti-Semitism after the end of the Second World War and on the profits made by non-Jewish Poles from the Shoah. These books have triggered ongoing, fierce debates that highlight the continuing crisis in Poland's efforts to address its past.

Bartana's historiographical project is thus also situated in the context of the current debate on the complicity and contribution of non-Jewish Poles to the near extinction of Poland's Jewish population. Largely ignored during Communist rule, the process of recognising and dealing with this history only began in $1989 .{ }^{27}$ Recently, the "absence" of Jewish culture in Poland has received growing attention, if not in official politics, then at least in the cultural sector, attesting to deepening engagement with the more problematic aspects of national history and manifesting in events and festivals on Jewish culture. However, Karen Underhill has commented critically on this phenomenon and on the question of how the near extinction of Jewish culture in Poland (and Ukraine) is being addressed:

Of particular interest here is the centrality of Jewish absence in this dynamic of Polish [...] myth-creation. I propose that the profound absence or void opened up in the wake of the Holocaust - a void magnified by the silence surrounding Jewish matters and Jewish history in post-WWII Communist-controlled Polandhas become also a kind of pregnant space of possibility, and mythic/imaginative potentiality, into which can be projected a new conception of Polishness [...] -or more accurately, a new self-conception that transcends these ethnic and national identifications and seeks to escape them. ${ }^{28}$

Underhill also analyses Sierakowski's speech in the first film of Bartana's trilogy, underlining that it evokes nostalgic longing for Jewish culture in Poland: the speech plays with the mythical-imaginary (im)possibility of a return of the Jewish population. Bartana is committed to the affective use of nostalgia, not "in the sense of a passive feeling, but as a method to enable a different way of thinking." ${ }^{29}$ Step by step, the trilogy creates a series of "what if" situations that follow each other, growing in scale. What if a public call for the return of the Jews to Poland were possible — as an act of conceding a loss, a desire? What if a movement for the return of the Jewish population really did emerge, and they, like Zionist settlers in Palestine, settled in Warsaw? Would an optimistic departure for a new Jewish community in Poland be possible? What would this mean for Poland's conflicted relationship to its national history? What about for its current migration politics? 
According to an article in Bartana's Cookbook for Political Imagination, reactions to the proposal to return the Jewish population to Poland were mixed. Journalist Anka Grupińska, who circulated the manifesto via email without further comment, documented her Polish friends' and colleagues' mostly negative reactions, no matter whether they were non-Jewish or Jewish Poles; Israeli, Polish, or non-Polish Jews. Some simply thought it was a provocation or a joke. ${ }^{30}$ There were also frightened reactions, such as fears that it might be taken to justify new pogroms. In one response, the idea of returning Jewish culture to Poland was described as theoretically worthy of support but unlikely and risky, with the manifesto in fact counteracting any attempt to implement it. Its message was perceived as confused, unclear, even somewhat insulting: “Above all, I'm repulsed by this Manifesto's ideological layer: the intense ideologization, glaring artificiality, completely unconvincing founding myths ('settlers'), etc. [...] I'd be surprised if a movement announced by such a manifesto was favourably received." 31 The project, therefore, would only make sense as an "artistic provocation."

The question of whether the return of the Jews is indeed desirable was discussed at numerous events held as part of the project. The topos of return, like all nostalgic projects, collapses when tested. Only supposedly traditionalist or past-oriented, return is rooted in an imaginary origin that is actually firmly anchored in the present, not in the restoration of a specific historical moment. In the case of Israel, if the case for a nostalgic return home were stretched, it would entail discussing a "right of return" for the Palestinian population, raising the question of how far the Israeli state would be prepared to actually turn back time. Connecting the Jewish diaspora with the European migration crisis was also heavily criticised. And, finally, what in Bartana's view may appear as an important contribution to critically questioning Zionism may just as easily advocate for anti-Semitic rhetorics. The proposal that Europe should admit Jews in order to finally make the Middle East free for the Arab-Muslim population, for instance, was made several times by radically anti-Semitic former Iranian President Mahmoud Ahmadinejad, who was in office at the time of the creation and presentation of the Polish trilogy.

The formula of return, staged by Bartana as part of a progressive political imagination, is not only a component of Zionist thought but also a playground for revisionists. This became particularly clear when the project was presented at the 7 th Berlin Biennial. ${ }^{32}$ The collective Rosa Perutz included it in a biting critique of the exhibition as primarily aiming at an indiscriminate spectacularisation of politics. The fact that Bartana's fictitious JRMiP was shown alongside the revisionist German Federation of Expellees-which had long tried to equate the fate of Germans displaced after the Second World War with the persecution of the European Jews-was viewed as relativist and as ignoring not only "subjective interests, fears and historical contexts, but also the anti-Semitic, reactionary and misanthropic resentments of the individuals who are welded together to form a victim collective." 33

In the context of the Berlin Biennial, Bartana's affective blending of distinct historical agendas developed an effect that today, in view of the rise of nationalism and right-wing extremism in Europe, has become even more problematic than she may have anticipated a decade ago. While some of her audiences may consider the political or ethical connections she implicitly draws between the persecution of European Jews and current Israeli settlement policy in a nuanced way, her proposal to address the "shared" political trauma of Jews and Poles evokes a series of revisionist tropes that are being reiterated time and again in current discussions on Middle East conflict and on Europe's political past. Her appropriation of Zionist, fascist, and socialist propaganda, moreover, only stimulates reflection within audiences ready to reflect critically upon their historical and contemporary contexts-preaching, as it were, only to the converted. 
As one of the speakers at the funeral depicted in the third film, Yaron London states: "One man's dream is another man's nightmare." This, finally, is probably the strongest point made by Bartana's project: as the title of the first short film Mary Koszmary demonstrates, it is announced as a nightmare right from the start, thus addressing the ambivalence of the historical utopias it evokes. ${ }^{34}$... And Europe Will Be Stunned does not promise an innocent political utopia; rather, it sketches a future scenario that may not only have questionable political consequences but is in itself highly questionable. The project asks not only whether a return of the Jewish population to Poland can but whether it should be realised. And so the "nightmare" refers both to the unresolved Polish trauma-which Sierakowski addresses in his speech and which has as much blame as loss to bear-and, much more fundamentally, to the desire for a return of the Jewish population to Poland. That this is a nightmare shared by Zionist and Polish nationals in equal measure today is an irony of history. The return of Jewish culture, therefore, is part only of a politically liberal imagination, evoking a cultural fantasy that cannot be translated into reality in light of the social and ethnic diversity of the globally dispersed Jewish population today, over 80 years later.

Do Poles desire the return of the country's pre-war Jewish population-or perhaps only religious ones with peyes? Would they be equally pleased by an influx of Moroccan or Ethiopian or Russian Jewish emigres? [...] Jews seem to belong exclusively to a narrowly imagined past. ${ }^{35}$

Bartana's "propaganda film" is, of course, far removed from reality in this respect: the young, attractive people dedicated to building the new kibbutz may promise diversity, but they are far removed from the actual social, ethnic, and cultural mix of global migration. But despite its ambivalences, Bartana does not allow a formal collapse of the visual language of propaganda. Although her project poses the question of whether political concerns that can be pressed into the affective format of a propaganda film are not in themselves questionable-and although the trilogy may be viewed as a critique of both the goal of the return of the Polish Jews and the propagandistic formats of modernism-the mode of her address remains caught between advertisement and propaganda. While her project is an exegesis of the power of political imagination and the radical mass movements it may set in motion, it does not fundamentally question artistic formats that work to proliferate affective identity politics.

Bartana's appropriation of utopia comes with a recourse to history that is based upon a specific understanding of the relationship between art and politics. The questions of how artistic projects can intervene in current political debates, of which historical formats are meaningful in this context, and of which historical responsibilities may arise from them, ultimately remains unresolved, while the utopia of an art that can change society directly, through manipulation, stands unimpaired. "Which is the history we want to be governed by?" ${ }^{6} 6$ This question is indispensable in view of the return of modernist constructs and identity politics as demonstrated in Bartana's project. But this entails another question just as important: Which connection between aesthetics and politics do we-and does art-want to be governed by?

\section{Notes}

1 Hawthorne, Plausible Worlds; Tetlock and Belkin, Counterfactual Thought Experiments in World Politics.

2 Robert Musil, The Man Without Qualities. 


\section{Counterfactual History, Parafiction, and the Critical Ends of Utopia}

3 Rancière, Disagreement: Politics and Philosophy.

4 Ibid.; Rancière, "The Concept of Anachronism."

5 Lambert-Beatty, "Make-Believe."

6 Holmes, "Liar's Poker."

7 Clark, "For a Left With No Future," 69. See also Traverso, Left-Wing Melancholia.

8 Ricœur, Narrated Time, 207.

9 Ibid., 215, 216, 235.

10 Czirak et al., Performance zwischen den Zeiten; see Yael Bartana's take on preenactment in Inferno (2013), studio website, http://yaelbartana.com.

11 On the demarcation of utopia from art's basic potential for imagination, see Richard Noble's introduction to Utopias, 15-16.

12 "Mary" is Polish for "spirits" or "dreams"; "Koszmary" is an adaptation of the French cauchemar (nightmare). The title also evokes the Polish expression "Czary Mary" for "magic" or "hocus-pocus."

13 The speech is delivered in Polish with English subtitles. For an English transcription, see Lingwood, Yael Bartana, 120.

14 Sławomir Sierakowski, fictional letter to his followers, in Pacher and Bartana, Yael Bartana: If You Will It, It Is Not a Dream, 5.

15 Questions discussed were, among others, on day 1: "How should the EU change in order to welcome the Other?" moderated by Boris Buden; on day 2: "How should Poland change within a reimagined EU?" moderated by Marc Siegel; on day 3: "How should Israel change to become part of the Middle East?" moderated by Charles Esche.

16 Carson, “Art of the Impossible," 29.

17 This aspect, among others, is discussed in Pantenburg, "Loudspeaker and Flag," 56-57, 60.

18 Bartana et al., "Geschichte und Fiktion."

19 The project was presented in Vienna with a focus on Theodor Herzl: Yael Bartana: If You Will It, It Is Not a Dream, Vienna Secession, December 7, 2012-February 10, 2013.

20 Lingwood, Yael Bartana, 124.

21 The film was shot at the fourth meeting ("Summer Camp") of the Israeli Committee against House Demolitions (ICAHD), which brings together Palestinian, Israeli, and international activists to reconstruct destroyed Palestinian settlements.

22 Bartana et al., "Geschichte und Fiktion," 54-55.

23 "A Conversation between Yael Bartana, Galit Eilat and Charles Esche," 95.

24 See Groys, "Answering a Call."

25 Simon, "Spaces of Appearance," 142.

26 Knott, "Die Geister sind noch da."

27 For contextualisation of the JRMiP in public, political, and artistic engagement with Polish history after 1989, see Lehrer and Waligórska, "Cur(at)ing History." On the historical loss of Jewish culture in Eastern Europe, see Underhill, "Next Year in Drohobych."

28 Underhill, "Next Year in Drohobych," 582-83.

29 Bartana et al., "Geschichte und Fiktion," 66, paraphrasing Boym, The Future of Nostalgia.

30 Grupińska, "Dear Founding Mothers."

31 Ibid., 164.

32 In an interview, Artur Żmijewski considers the social and political dimension of art by wondering whether "artists [could] acquire the same manipulative skills as politicians?" Unpublished English version of an interview of Artur Żmijewski by Joanna Warsza, email from Joanna Warsza to author, 24 June 2020.

33 Perutz, "Immun gegen die Freiheit."

34 Rose, "History is a Nightmare."

35 Lehrer and Waligórska, Cur(at)ing History, 14.

36 Leeb, "Flucht nach nicht ganz vorn," 29. 


\section{Testing Truth \\ Tribunal, Script, Trial}

Over the past few decades, a remarkable proliferation of artistic appropriations of legal procedures, such as trials and tribunals, has taken place. In part, this reflects the more and more frequent positioning of ethical and social issues under the logic of legal and judicial appraisal: public apologies, attempts at reconciliation, plans for reparations, and debates over compensation in the media support legally founded negotiations around what constitutes justice. Artworks frequently take up trials or tribunals in order to investigate our ethical responsibilities for the events of history and to reach verdicts on historical truth: in 2002, documenta 11 initiated the platform Experiments with Truth in reference to truth and reconciliation commissions. ${ }^{1}$ The theatre and film group IIPM, directed by Milo Rau, has been working regularly with staged trials and tribunals such as The Moscow Trials (2013) and The Congo Tribunal (2015). We have already encountered Amar Kanwar's exploration of the possibilities of admitting poetic evidence to legal proceedings, as well as Kader Attia's concept of historical "repair," which directly refers to historical reparation. The 2017 Contour Biennale 8 in Mechelen was dedicated to the theme of Polyphonic Worlds: Justice as Medium, ${ }^{2}$ which has led Jacinto Lageira to develop the concept of an artistic historiography through which history can be held "legally accountable" 3 - that is, through which individuals and corporations are held responsible for historical injustices.

These contemporary artistic approaches evoke a long tradition in European history. Idealistic views of the historian as judge, or of "world history" as a "world's court of judgement" (borrowed from Friedrich Schiller, "Die Weltgeschichte ist das Weltgericht”), are classic motifs, especially when it comes to defending timeless objectivity and impartiality. ${ }^{4}$ As justice is not inherent in the course of history; it must be claimed by historians and by history writing. ${ }^{5}$ The analogy between judge and historian is therefore most often taken up when history and justice diverge. ${ }^{6}$ Judging history and condemning injustice is necessary to set ethical standards for the present. ${ }^{7}$

In addition to establishing judgements, viewing history from a judicial perspective includes foregrounding the investigation of historical evidence. Marc Bloch has viewed the historian less as judge than as detective, or rather examining magistrate-a juge d'instruction who leads the investigation, gathers the evidence, and defines the extent of the accusation. ${ }^{8}$ History is, in this case, the judge, but the historian can create the basis for the most accurate judgement possible by correctly and fully assembling the facts. Such a magisterial historian is less moral authority than precise methodologist; however, the common origins of establishing and judging facts are difficult to separate. Paul Ricœur has emphasised, along with Ginzburg, "that the word historia stems at one and the same time from medical language, from the rhetorical argumentation of the juridical setting, and from the art of persuasion practiced before the court." ${ }^{9}$ Objective representation 
and argumentation cannot entirely be separated, since the process involves a "ceremony of language" that produces a performative adaptation of reality to legal logic and regulation. ${ }^{10}$ This entails a fundamental reworking of history: a reduction to events; a separation and categorisation of facts in relation to the extent of the case tried; the narrowing of these facts to specific aspects (such as the question of guilt); and, finally, a conclusive adjudication-a verdict. This transformation is also conditioned by the media of jurisprudence as outlined by Cornelia Vismann: on the one hand, there is the theatrical, performative dispositif, derived from the origin of trials as assemblies; on the other hand, the agonal dispositif, derived from its origin in competition. ${ }^{11}$

\section{History as Trial: Andrea Geyer, Criminal Case 40/61: Reverb (2009)}

Andrea Geyer's Criminal Case 40/61: Reverb (2009, 6-channel video installation, colour, sound, 42 mins., Figure 8.1) has pursued this double sense of theatricality and competition in a work that does not only track but also critically questions judicial and ethical examinations of history. The 42-mins. video installation is based on historical files and documents from the trial of Adolf Eichmann before the Jerusalem District Court in spring 1961 (internally referred to as "Criminal Case 40/61"). The project's starting point, therefore, is a trial that was simultaneously a court case, moral example, and worldwide media event-and that indeed galvanised the faltering prosecution of Nazi crimes.

Criminal Case 40/61: Reverb is based upon a staged reading of documents and materials from the trial for the camera. It is often categorised as a reenactment. In the six-channel video installation, transgender artist and performer Wu Tsang simultaneously takes on six different roles: those of defendant, judge, prosecutor, reporter, accused, and audience. With the exception of the latter, which merges several historical characters and reactions documented in the courtroom, each of these roles can be assigned to one identifiable historical actor, who nevertheless remains unnamed in the installation: the defendant is Adolf Eichmann; the defence attorney Robert Servatius; the presiding judge Moshe Landau; the chief prosecutor Gideon Hausner. Hannah Arendt, whose book Eichmann in Jerusalem (1963) is probably still the best-known analysis of the trial, appears as the reporter; indeed, she actually followed the court proceedings in this function for The New Yorker, contributing a five-part article on the trial.

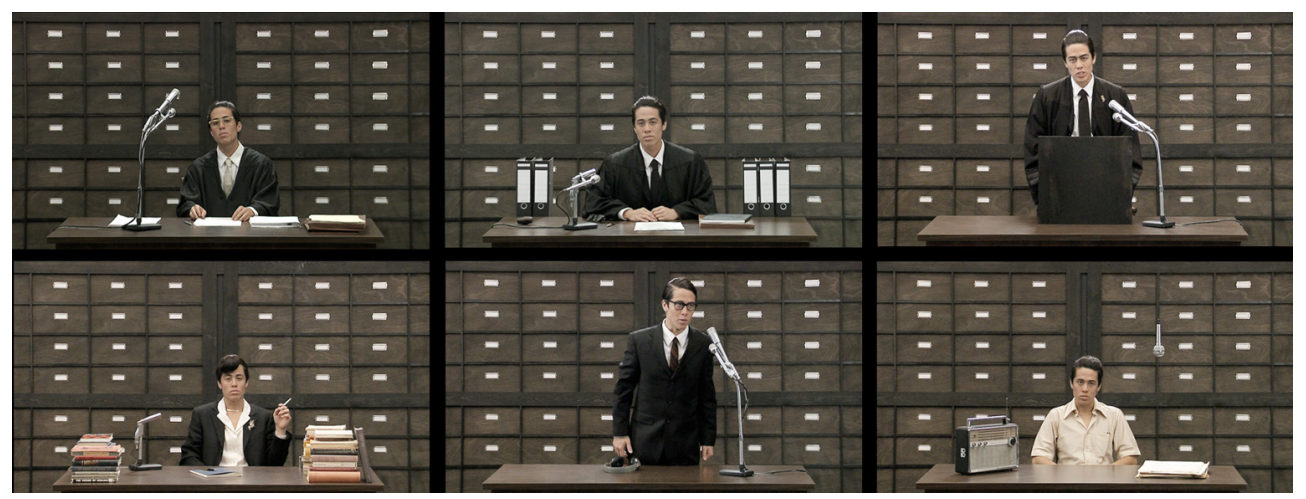

Figure 8.1 Andrea Geyer, Criminal Case 40/61: Reverb, 2009. Compilation of six video stills from six-channel video installation, colour, sound, 42 mins. Courtesy the artist 
The courtroom hearings were simultaneously translated into English and French and broadcast in Hebrew on radio, as there was no public television in Israel at that time. However, the documentation of the trial was state of the art: 350 hrs. of footage from four cameras was made available to international television agencies and broadcast, among other countries, in the US. ${ }^{12}$

In Geyer's installation, Tsang simultaneously embodies the six different roles in slightly modified costumes in front of a highly abstract, frontally arranged film setting that consists, on all six screens, of a desk with filing cabinets in the background and stacks of documents on both sides. On the judge's desk are files; on the reporter's desk stacked books. The accused uses a microphone and the audience a radio, both devices referring to the highly mediated character of the trial. The strictly controlled setting illustrates that Geyer's work is based upon specific, identifiable documents: the court records, the radio broadcast of the trial (which Tsang listens to at one point), Hannah Arendt's publications-particularly Eichmann in Jerusalem and her correspondence with Gershom Scholem, which culminated in a heated discussion of her report-sources from contemporary magazines, and other documents. When Tsang, in her role as the accused, reads Eichmann's actual statement from a historical newspaper, these documents also become part of the assembled historical voices, true to the title of the work, which focuses on the "reverb" - reverberations or echoes-of the trial. In its gestures and facial expressions, Tsang's performance is recognisably based on the well-known historical film footage. The six screens are synchronised so that they relate to and comment upon each other, physically and/or verbally. While Tsang performs in historical costumes and uses historical equipment, which may evoke the character of a reenactment, the setting Geyer produced is entirely new and fictitious. Seated at the centre of the multiscreen installation, the audience finds itself at the centre of a novel and expanded trial: an artistically staged multiperspective debate about law and ethics, institutional responsibility, and personal guilt. Geyer accentuates Hannah Arendt's character in particular, so that-together with Eichmann's guilt and the correctness of the legal proceedings-her moral judgement is also open to debate: quotes from her writing form the prelude and some intermediate commentary, and it is her final verdict on the trial (taken from the epilogue of Eichmann in Jerusalem) that concludes Tsang's performance. The montage allows for a differentiation of those speaking "inside" and "outside" the picture, and thus reinforces the spoken word as the main instrument of the trial, while the formal arrangement of the video installation enhances the event's publicity.

The installation starts with the paraphrase of a quotation from Arendt, spoken by the audience: "Nothing and nobody exists in this world without a spectator. What we call consciousness, that I am aware of myself, and therefore can appear to myself anytime, anywhere, is never enough to guarantee reality." ${ }^{13}$ This becomes the starting point of the debate and explains the arrangement of the installation: we can approach a historical situation only via media documents (a first sense of "reverb") that epistemologically and ethically unfold in the way they are perceived by others-a second sense of "reverb," that is, their resonance in a community.

By restricting the representation of the trial (which certainly could have been more "accurately" or "fully" represented given its fulsome documentation) to isolated single roles, the staged character of the setting is emphasised. Historical individuals and their roles diverge- - a central point that the trial sought to clarify as, after all, the defendant's guilt was largely beyond question: his responsibility was well documented and he had publicly, even boastfully and repeatedly, admitted to it. Tsang reads files from the trial 
beginning with an excerpt from the 95th session, in which the core question of the defendant's personal responsibility is discussed. This he refused to acknowledge (in the trial, not in earlier statements), making an argument that he had been nothing more than the recipient of orders that had to be followed.

PROSECUTION: When it says "I order," it does not mean that you were complicit with these possibilities for killing people that are discussed in the document?

EICHMANN: It is the bureaucratical language. That has nothing to do with my person. $[\ldots]$ These were not private documents. (00:31:01-00:31:24)

EICHMANN: It was a time in which crime had, within the state, become a legal action. And this is why it was the responsibility of the state itself. (00:36:30-00:36:42)

This reduction of the act of killing to the purely formal argumentation of administrative logic prompted Arendt to develop her well-known concept of the "banality of evil," which was severely criticised at the time. In Geyer's installation, this observation is presented in detail. The condemned had had no other motives than to further his personal advancement; he had been "not Iago and not Macbeth"14 (00:38:15-00:38:33). Arendt criticised the court for having, from its position in Israel, given too little consideration to the fact that the genocide of European Jews had neither politically nor legally derived directly from anti-Semitism and the earlier persecution of Jews but rather represented a novel crime against humanity due to its technocratic nature. She consequently touched upon the highly controversial question of the singularity of the Shoah. ${ }^{15}$ In the installation, a debate unfolds about her analysis not only of the trial but also of the political agendas of the state of Israel entailed in it, conducted in dialogue with the audience in the role of Gershom Scholem (00:38:35-00:41:43). These text passages are based upon the highly confrontational correspondence between both scholars that was published in yet another "reverb" - that of Arendt's report. ${ }^{16}$ It becomes clear that the trial, if staged as a play, allows for further changes of roles and positions as well as further confrontations. The reporter (Arendt) reiterates her stance in a postscript after the judgement is pronounced:

He was not stupid. I have become convinced, after months of watching, that it was sheer thoughtlessness, something by no means identical with stupidity, that predisposed him to become one of the greatest criminals. And if I have called this "banal" and even funny, it is because even with the best will in the world, one was not able to exact any diabolical or demonic profundity from the accused. Yet that is far from calling the accused, his actions and the evil inherent in them commonplace. That such remoteness from the reality in front of him and such thoughtlessness can wreak more havoc than all the evil instincts taken together which perhaps are inherent in men, this was in fact the lesson one could learn in this trial. [...] The accused supported and carried out a policy of not wanting to share the earth with the people who fell victim to his crimes. We find that no-one, that is, no member of the human race, can be expected to want to share the earth with him. This is the reason, and the only reason, he must hang. [...] The concept of human rights can only be meaningful if they are redefined as a right to the human condition itself, which depends upon belonging to some human community, the right never to be dependent on some inborn human dignity, which de facto, aside from its guarantee by fellow-men, not only does not exist, but is the last and most arrogant myth we have invented in all our long history. $(00: 48: 33-00: 52: 14)^{17}$ 
This conclusion-expressing a judgement not only on Eichmann but also on this new kind of trial, on its legitimacy, and on the legal concepts emerging from the catastrophe of the Shoah-forming the basis upon which judgements will have to be pronounced in the future-is significant in relation to the overall concept of the installation: "reverb" as echo. The origin of the concept of justice articulated in Arendt's conclusion is adherence to the human community as a prerequisite for the right to have rights. This was violated by Eichmann when he decided to "follow orders." As the installation has viewers positioned centrally, it suggestively grants them a key role: that of making an ethically responsible judgement.

The austere artificiality - a simple repeated setting-of the installation points to the notion of trial as staged performance. Tsang, in the role of reporter, reads an observation made by Arendt at the beginning of her report from Jerusalem that explicitly compares the trial to a stage play. ${ }^{18}$ They are both highly formalised procedures with distributed roles, a clearly regulated structure, and a defined objective: making a public judgement. However, according to Arendt, this formality was disrupted by the witnesses' testimonies that, in the installation, can only be heard in Hebrew on the radio:

REPORTER: It was precisely the play aspect of the trial that collapsed under the weight of testimony. A trial resembles a play and they both begin and end with the accused, the doer, and not the victims. At the center of the trial can only be this one, who did it, like a hero in a play. If he suffers, he suffers for what he has done, not for what he has caused others to suffer. ${ }^{19}(00: 20: 37-00: 20: 58)$

The moment the witnesses gave their testimonies, however, the immense historical scope of the Shoah overshadowed the question of Eichmann's personal guilt. This is the point where a key aspect of Criminal Case Reverb 40/61 unfolds, as it did in Arendt's Eichmann in Jerusalem: the difference between the spheres of historical and judicial justice. Arendt criticised Ben Gurion's statement that “anti-Semitism throughout history" was on trial, ${ }^{20}$ observing that if this were true, the criminal proceedings would run the risk of going beyond a verdict of Eichmann's personal guilt. In her report, she cast in a positive light the role of presiding judge Moshe Landau, who-in contrast to the prosecutor's "love of showmanship," and to the stage-like setting of the courtroomtried to keep the hearings from becoming a show trial. ${ }^{21}$ This was in open contrast to contemporary intellectuals who not only were unconcerned about the idea of Israel conducting a "symbolic" trial but even welcomed this approach as a new, appropriate, and satisfying form of historical justice. ${ }^{22}$ Today, adaptations of trials and tribunals in art and theatre are often set up to investigate globally entangled responsibilities and thus explicitly aim at surpassing judicial limitations.

Geyer's Criminal Case Reverb 40/61 approaches this in a more nuanced tone, problematising the division between history and law without betraying the artwork's own ethical standards. The installation illustrates how the trial is anchored in theatrical and agonal settings, thus presenting a complex problematisation of its own tools, settings, and structures. Geyer not only confronts her audience with the pitfalls of moral and historical responsibility but also questions the way history is reworked and processed according to aesthetic as well as legal regulations. The explicit elaboration of the medial, technical, rhetorical, and aesthetic prerequisites of trials does not allow for distanced judgement but rather shows how individual historical actors-as well as, within the video installation, the artist and her audience-are entangled in the logics of history, law, and aesthetics. 


\section{History as Script: Philippe Parreno and Liam Gillick, The Trial of Pol Pot (1998)}

In his 1998 essay "Should the Future help the Past?",23 Liam Gillick distinguishes between societies that base their progress on "planning and action" and those that do so on the basis of "scenarios": continuous rewritings of the future responding to constantly changing expectations and calculations of risk and profit. Acting is thus positioned as the opposite of action, shaping the future against speculating on its various outcomes. Gillick attributes the second path to capitalist societies and their flexible political leaders; the first one represents that of socialist countries as well as biopolitical policies as introduced in twentieth-century European welfare states. Thinking in scenarios requires the ability to think history as taking ever new courses with ever new meanings for one's own position and actions: to perceive the historical "sense of possibility" as having permanent potential for improvement. Flexible and modifiable, scenarios are susceptible to spontaneous rewritings.

Gillick connects the proliferation of scenarios to that of film and video (while referring to earlier traditions in literature and theatre), thus picking up on a line of development that we have already encountered as "readiness for history" (chapter 2). During the 1990s, he created several scripts for cinematic stagings of history: McNamara Papers (1992-1995), Erasmus and Ibuka! Realisations (1994-1996), and The What If? Scenarios (1996), among others. ${ }^{24}$ The resulting scripts, trailers, posters, and texts describe short features ready to be realised as live-action or animated films. They contain possible and impossible encounters of historical characters as well as fictitious or documented events; they explore the blending of parallel temporalities and failed opportunities in social or economic history, such as the history of the working class or the emergence of capitalist structures. Thus, Gillick presents history as script: through the interweaving of diverse times, actors, and historical ideas, everything becomes possible and at the same time eludes realisation, implementation, and consolidation as a factual, actual course of action.

It should be noted that this approach is related to that of conceptual art more generally, as realisation is only inherent in it as a potentiality. Quite in line with the requirements of (artistic) production in late performative capitalism, What If? Scenarios creates props for the rehearsal of ideas, situations, and actions. ${ }^{25}$ This "testing" of possible constellations therefore concerns artistic as well as nonartistic processes.

In the installation The Trial of Pol Pot (1998), developed in collaboration with Philippe Parreno, Gillick combined this "script" configuration with the problem of truthful representation. History was put to test via the exploration of trials in the extended sense of experimental arrangements investigating specific forms of representation and narration:

I don't only mean trial in a judicial [...] sense, but the ongoing testing of something institutionally. You question, you investigate, and you reach out to people who do not necessarily have vested interests in art but specialize in certain areas. ${ }^{26}$

The Trial of Pol Pot refers to a concrete historical event taking place at the time: the People's Tribunal conducted by the Khmer Rouge from July 1997 against its former leader Pol Pot. The tribunal received harsh criticism from the Cambodian government. The only observers not directly involved were two US journalists, who had probably been invited to ensure its international dissemination. Pol Pot's death in April 1998 put an end to the proceedings after only a few months. 
The exhibition The Trial of Pol Pot, which opened in November of the same year in the Grenoble exhibition space Le Magasin, illuminated the failed trial as a legal, ethical, and epistemological field of debris. From the beginning, the juridical examination of one of the most murderous tyrannies of the twentieth century had been intended to be broadcast as a global media event. In its inextricable interweaving of visibility and impenetrability, the image politics of the Cambodian trial are similar to those of the Romanian Revolution (discussed in chapter two). As Gillick and Parreno noted in a discussion paper written in July 1998, the questionable-and indeed internationally highly questioned-tribunal recalled show trials, as it seemed more committed to the effect on its audience than to exercising justice. ${ }^{27}$

Gillick and Parreno's installation countered the way the trial's audio-visual documentation had been set up as a means of authentication (and, eventually, legitimation) by highlighting how images as well as written and spoken text can be equally dubious sources of information. The exhibition space was dominated by text fragments applied directly to the walls. In addition to this installative use of language, the exhibition included other types of texts. The artists had called in 14 "supervisors," who were asked to evaluate the progress of the exhibition and were regularly informed about its development. Initially, 12 such supervisors had been considered, ${ }^{28}$ alluding to the 12 jurors usual in (Anglo-American) trials, well-known from pop cultural references. Their ideas and suggestions were collected on posters, which were available as free giveaways near the entrance. ${ }^{29} \mathrm{~A}$ manuscript for a puppet theatre play written by the two artists, which was to be performed once a week, described the involvement of this "jury" as ensuring a high degree of reflection and transparency in the process of artistic creation. However, the actual cooperation of the jury, and the actual possibilities for implementing its suggestions varied greatly:

Every time Liam and Philippe made a decision about the design of the walls or the kind of texts they were interested in, they sent everything to the supervisors. Sometimes the supervisors just approved everything, some supervisors just asked a lot of complicated questions, and remained sceptical about the whole process. ${ }^{30}$

The design of the posters formally captured the tension between transparency and opacity as a central motif of the exhibition: the jury's proposals were printed on top of each other, creating a barely legible word picture (Figure 8.2). The artists' manuscript, which was to serve as the script for the puppet theatre, names one obvious possible objection to this design: "But I can't read it." Their answer is simple:

That's because all the ideas from all the supervisors were layered on top of each other. After all, Liam and Philippe did ask for lots of single solutions, so it would be silly to leave them all separate. They wanted to make a picture in words of what it might look like if you really did apply one idea and then another and then another and then another. ${ }^{31}$

A semi-transparent blue screen stretched across the entire width of the main gallery, picking up this tension between legibility and illegibility. Two pictorial elements in black and white on blue, which could be read as simplified representations of a landscape (a forest, a full moon) or as a mixture of signs (canvas, headlights, a typographical forest of signs) performed an interweaving of image and text, transparency and opacity (Figure 8.3). The 29 wall texts were written in continuous sans serif type 


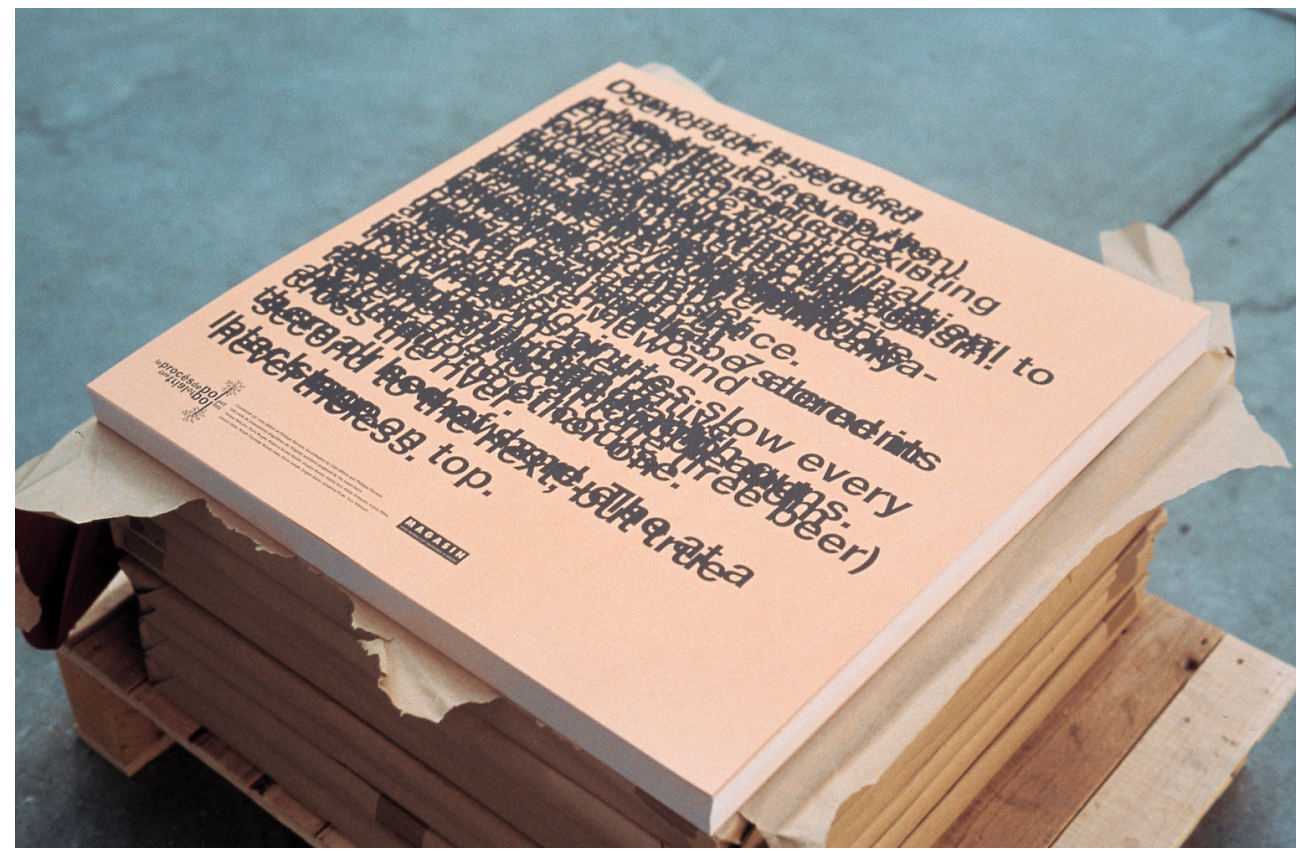

Figure 8.2 Liam Gillick and Philippe Parreno, The Trial of Pol Pot, 1998. Poster stack. Le Magasin, Grenoble, 1998. Courtesy the artists

(Helvetica Medium). Rows of numbers and words ran around the wall, black on white, in an endless mimicry of unmistakable, institutionally certified pieces of information and proofs. Some were related to the historical context of the project (such as "Khmer Rouge," "1979 19791979 1979," and "question n³5668”); some seemed to begin a story. One of the wall texts reads: "Lamps fading as the character // slumps forward his face // dripping with more spit." This text fragment may describe a scene of torture or interrogation, merging historical narrative with filmic or theatrical dramaturgy. Spotlights bathed the gallery in different colours and levels of brightness, thus transforming it into a kind of film set or TV studio. But the forest of signs and symbols unfolding on this stage was hardly decipherable.

Setting the exhibition space as a stage, a book, or a dispositif for the communication of information all touches upon the fundamental question of whether and how art can represent and communicate (historical) facts at all. In a sense, presenting the installation as a kind of negotiation provided a testing ground for references to and correspondences with reality; for judgements on the use of artistic, judicial, and scientific instruments of authentication and documentation. These spheres were all the more interconnected as the "trial" of Pol Pot was staged as a public tribunal (an aspect that contributed to its being widely). Unlike trials, which are cases of state jurisdiction, tribunals can be held without a neutral judge, without impartiality with regard to hearing the concerned parties, and ultimately without a binding judgement. ${ }^{32}$ In the art context, this more informal format is taken up more frequently than is trial format, as the former offers more scope for performatively establishing truth and justice. Unlike trials, tribunals focus on making statements, documents, and information visible-and are thus closer to the way these may be explored in art. ${ }^{33}$ In The Trial of Pol Pot, the instruments of this visualisation were themselves under scrutiny. The formal openness 


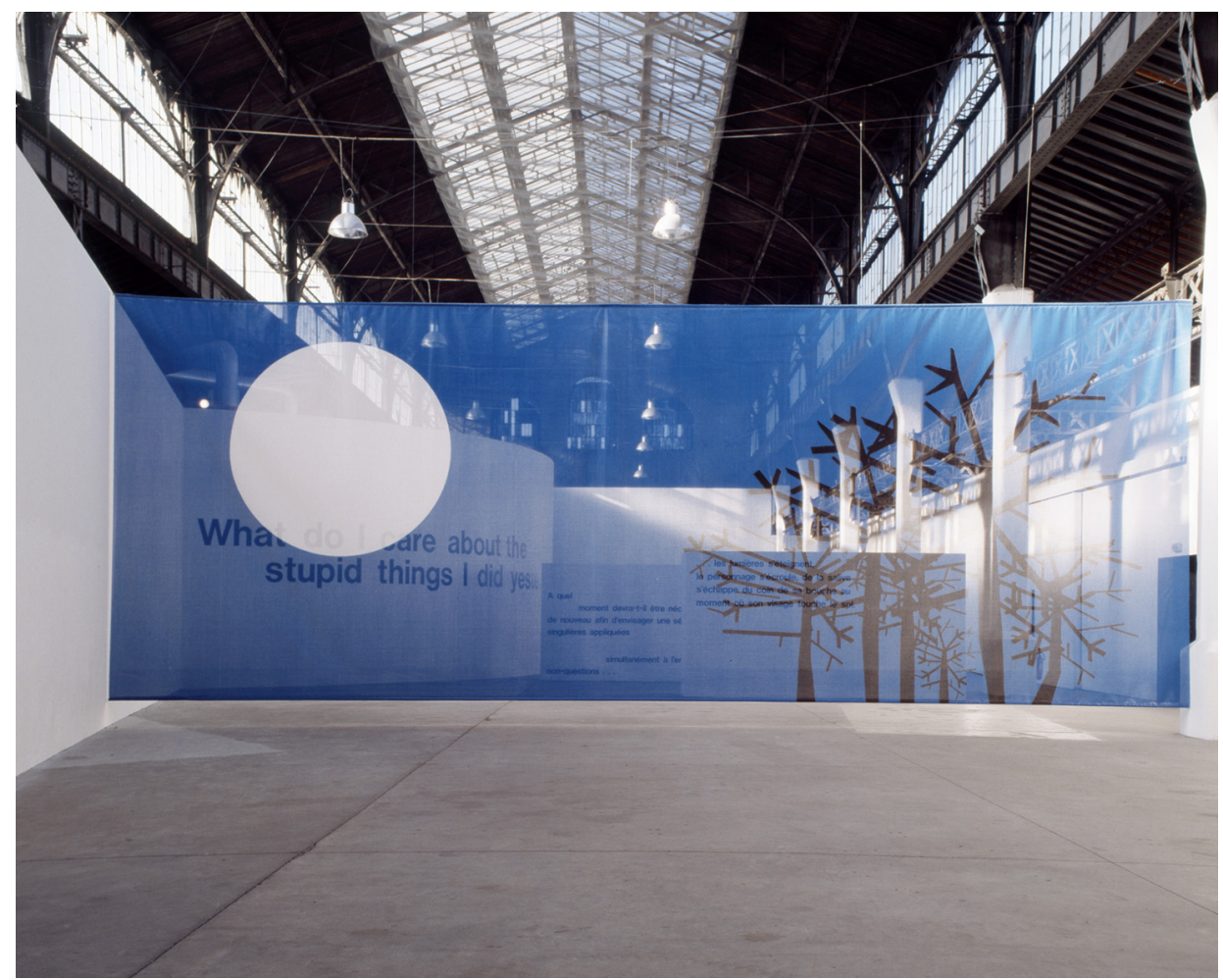

Figure 8.3 Liam Gillick and Philippe Parreno, The Trial of Pol Pot, 1998. Installation view, Le Magasin, Grenoble, 1998. Courtesy the artists

of the installation (drifting off repeatedly into illegibility, opacity, and inconclusiveness), as well as the integration of different authors and presentation arrangements, allowed a constant testing of the rules and mechanisms of art. In the artistic show tribunal of the Trial of Pol Pot, then, not only history but also art was, once again, put on trial. Art, historiography, and law came together to collectively transform reality along their respective institutional logics, leaving behind an inscrutable thicket of data and information, of approaches to narrativisation and representation, testing the audience's aesthetic as well as ethical judgements.

\section{Truth Distorted in Perspective: Hiwa K, View from Above (2017)}

This examination of trials and tribunals provides background for another, more recent aspect of the legalisation of history and its exploration through art: the adjustment of historical experience to the institutional requirements of police and legal bureaucracy. This section focuses on pressures to adapt the depiction or narration of reality to police procedures, especially with regard to the fluctuating and arbitrary regulations of European migration policy. Personal experiences are thus scripted along the lines of the rhetoric of specific administrative apparatuses in a very similar way as is required for the procedures of trial and tribunal.

Exploring the archaeopolitics (Yannis Hamilakis) ${ }^{34}$ of European identity, documenta 14 in 2017 attempted to counter colonial and postcolonial "aphasia" through artistic, curatorial, poetic, and scientific articulations. ${ }^{35}$ The exhibition portrayed Europe as profoundly marked by cultural infringements and internal conflicts, with several artworks 


\section{Testing Truth}

specifically referring to the European migrant crisis that had occupied the south of the continent for more than two decades. At one of documenta's exhibition sites, the city museum of Kassel, the Kurdish-German artist Hiwa K showed the single-channel video installation View from Above (2017, 12 mins. 27 secs.). Screened on a large monitor, the work presents a model of the ruined city of Kassel after a devastating Allied Forces bombing in October 1943, one of the museum's best-known displays illustrating the destruction of the city exhibited in the adjacent room. Taking up the model as a form of presentation in both form and structure, Hiwa K combined an autobiographical examination of his own experience of war and migration with an exploration of the altered, abstract view of a once-familiar urban space.

The artist, whose public persona remains explicitly nonidentified by leaving his surname a mere initial, entered Europe, after several failed attempts by land and sea, as a Kurdish-Iraqi refugee in the late 1990s via Iran, Turkey, Greece, Italy, and France. In 2001 he arrived in Germany. An accomplished autodidact in music and arts, he began studying at the art academy in Mainz after his arrival in Germany, slowly building a new artistic identity. As Juan A. Gaitán has suggested, his initial, analogous to Franz Kafka's "K," may stand for the interweaving of institution and subject. Like Kafka's character, " $\mathrm{K}$ " appears as a scattered subject that has lost its identity and remains a mere product of the system. ${ }^{36}$ As A View from Above suggests, Hiwa K shares this with others affected by flight and migration.

Visually, the video consists of a slow tracking shot through the city model of bombed Kassel from a close-up, ground-level perspective (Figure 8.4). The resulting images of the urban space that documenta visitors have already been perusing for hours or days guide a visit through a ghost town that is both familiar and unknown. Most of the houses are in ruins, covered by a thick layer of dust, with pale colouring staining the ruins. Only a few prominent places, such as Königsplatz or the arms of the Karlaue river, are more easily recognised once the camera allows for a little overview.

This unreal city walk is accompanied by an anecdote spoken by Hiwa K himself. It is about a deserter from the Iraqi army, introduced with the initial "M.” M's asylum application to an unnamed European Schengen country is rejected. The reason given is that he has arrived from a "safe zone" in Iraq (this is true as well for the Kurdish areas of Iraq from which Hiwa $\mathrm{K}$ hails) and therefore has no right to protection in Europe. Threatened by the prospect of the death penalty in the event of a "repatriation" to Iraq, $\mathrm{M}$ flees to another Schengen country and from there submits another asylum application, this time with a different, fictitious background. He contacts people who come from a city in the "non-safe" zone that is unknown to him, mapping the cityscape that has been handed down to him second-hand. Finally, he receives a positive asylum decision:

When $M$ finally had his refugee interview, the official was quite surprised, even impressed. He asked M questions about the geography of the town, and compared M's answers to a map. M's answers demonstrated knowledge of $\mathrm{J}$ as it was seen from above.

It took only twenty minutes for the official to grant $M$ refugee status. Meanwhile, thousands of people who were actually from J and other cities in the unsafe zone waited as long as ten to fifteen years for the same thing, because their answers only demonstrated knowledge of their towns from the ground. ${ }^{37}$

M's success is due to a fundamental change in perspective: while many people who have actually lived in the city, even for years, find it difficult to convey their familiarity with the cityscape in a credible manner, $M$ takes on the abstract perspective of the authorities 
via a cartographic appropriation of a city that is unknown to him: a view from above, completely impersonal but correct on paper, notwithstanding its distance from personal experiences or from the state in which its former inhabitants last saw it. Ultimately, this mentally appropriated space is an administrative fiction-like Hiwa K's former hometown. As he puts it: "A safe zone is a fictitious place," existing only to reject asylum applications and legitimise deportations.

This fictional "view from above" recurs in the performance Mirror (2010), in which the artist traces his original escape route via Turkey, Greece, and Italy, with a multipart mirror device made of motorcycle rear-view mirrors attached to a pole that he balances on his nose. Again, a new, objectifying perspective is introduced. The recording of the escape route from a bird's-eye view evokes associations with a surveillance camera that constantly follows him. The artist's gaze, directed upwards, is thus itself largely shielded from sensomotoric means of orientation.

The anecdote Hiwa K recounts in View from Above-which, like most good stories, is both authentic and of symbolic value-is a wonderful parable presenting one of the pitfalls of established asylum procedures: under the pressure of having to comply with a thicket of measures and regulations, memory and fiction become interchangeable to the point where the acceptance of a foreign identity may be necessary in order to be recognised as a refugee. In the popular imagination, such a split identity has often been left to science fiction, as for example the enigmatic replicant Rachel's "prosthetic memory" 38 in Ridley Scott's Blade Runner (1982), an identity constructed from "fake" memories. As Rachel herself is unaware of this, however, her identity is authentic, leaving the audience wondering how to establish with certainty their own human identity. In A View from Above this scifi-style figure has found a wretched real-world successor: the refugee forced to give up memories in order to appropriate a false identity that will legally legitimise his or her existence. This, piled on top of the harrowing experience of flight and migration, may lead to a complete destabilisation of subjectivity. Let's listen to the opening sequence of Hiwa K's narrative:

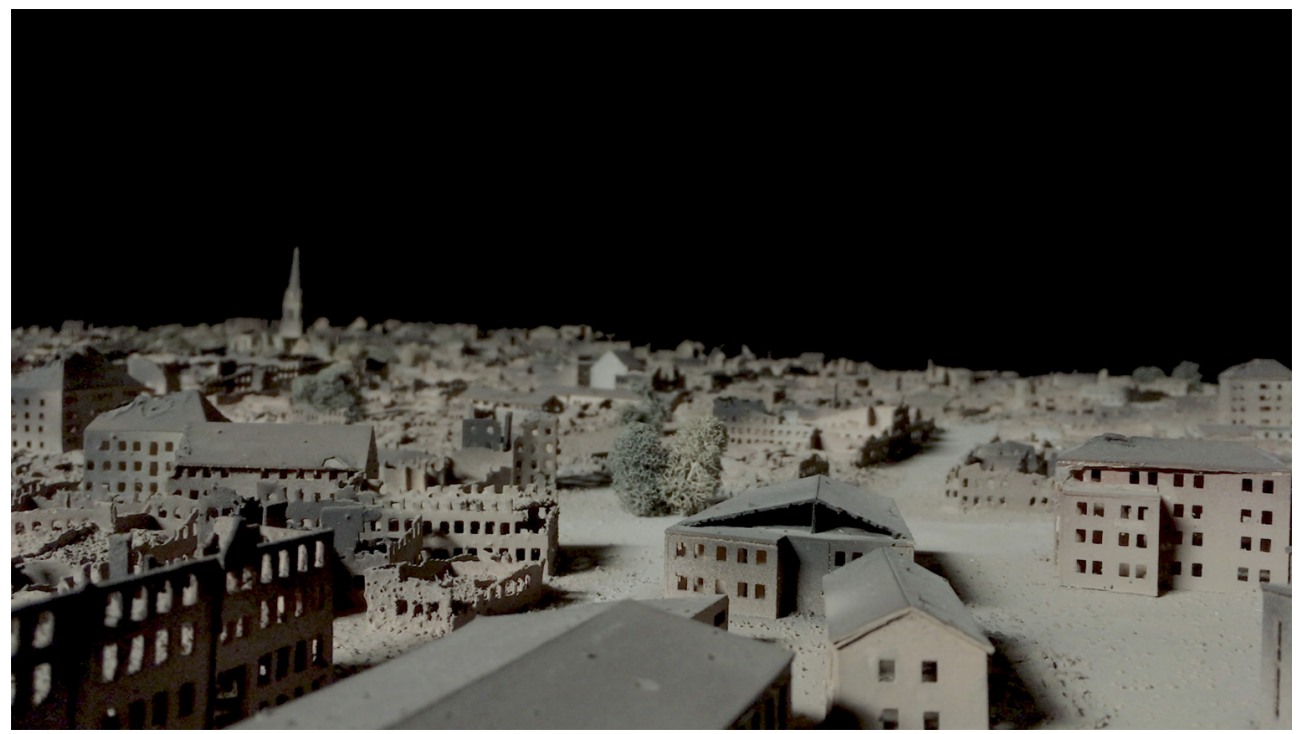

Figure 8.4 Hiwa K, View From Above, 2017. Single-channel HD video, 16:9, colour, sound, 12 mins. 27 secs. Courtesy the artist and KOW, Berlin 
The last time I saw $\mathrm{M}$ was one year ago. It was to be our last exchange after living together for 15 years. He asked me, "Do you ever feel like you forgot the city where you come from?" The irony in this question went unnoticed as it was I who taught him where he came from. I even gave him his name, $M$, on the day we first met. When I pointed this out to him, he retorted, "Who are you to teach me where I come from?" I replied, "Because I am the only one who knows that you have actually never been there. You still have the map I drew for you?" He remained silent, but his vacant gaze was articulate enough. He has lost almost all of his memory from those days. I think he forgot his own story because we didn't need it anymore to exist. To check whether he lost his memory for certain I asked, "Have we met before?" "Four seconds ago," he said. It was in fact 15 years ago when I helped M to learn the map of the city of $\mathrm{K}$.

The original individual identity is no longer needed and withers away; a new, legally compliant identity based on the appropriation of foreign memories is the first step towards the right of residence and thus to legal existence in Europe. Loss of identity and amnesia are the results-and possibly also a split identity. For the fact that the speaking "I" (i.e., "(Hiwa) K") appears so confidently sovereign makes another reading possible: $\mathrm{K}$ may have replaced $\mathrm{M}$, with whom he, according to his own statement, lived together for 15 years: "It was I who taught him where he came from. I even gave him his name, $\mathrm{M}$, on the day we first met." $\mathrm{M}$ may be an acquaintance, but it is just as possible to think of this scene as describing a process of self-extinction leading to a split subject, in which $\mathrm{M}$ has been replaced by his new identity $\mathrm{K}$.

Regardless of how the relationship between these two identities is determined, a blending of memory and fiction permeates Hiwa K's art and public artistic persona in equal measure. This is where the great importance of narration in his work steps in: entire collections of anecdotes can be found on his website and in his exhibition catalogues; most of his artworks are closely linked to, or have directly emerged from, them. Their close interweaving with the artist's identity may evoke Danh Võ's paratextual biography, which entwines his works in an authenticating way: an economisation of the biopolitical that is deeply rooted in the mechanisms of artistic production. ${ }^{39}$ In the case of Hiwa K, the blending of fiction and reality-and the integration of autobiographical elements-in his art go much deeper, as they affect his right to exist legally: the right to bear a name, to be entitled to living and working in a safe place-even if this requires self-extinction and reinvention. In this sense, anecdotes are important far beyond mere fictionalisation. They lend individuality and authenticity not only to the artist's works but also to his existence, and thus affect his identities as both artist and refugee. They do not need to be "plausible" in the way narrative fiction usually does, credibly mimicking reality. Instead, they need to mimic and correspond to the requirements of veracity established by the police and immigration bureaucracy.

\section{Notes}

1 Enwezor et al., Experiments with Truth.

2 See Ginwala, Hearings: A Reader.

3 Lageira, "Repairing, Resisting," 43; See also Lageira, L'art comme histoire.

4 See Koselleck, "History, Law, and Justice"; Ginzburg, The Judge and the Historian; Frei, Laak, and Stolleis, Geschichte vor Gericht; Ricœur, "The Historian and the Judge."

5 Koselleck, "History, Law and Justice."

6 Ginzburg, The Judge and the Historian, exposes a miscarriage of justice; Frei, Laak, and Stolleis, Geschichte vor Gericht, addresses miscarriages of justice from the Nazi era. 
7 See, among others, Koselleck, Futures Past; Löwith, Meaning in History.

8 This is a position not found in the adversarial law systems of Great Britain or the United States, but is important in countries of civil law jurisdictions such as France, where the prosecutor impartially leads the investigation. Bloch appropriated this analogy from Kant, who had described the scientist as a judge in his Critique of Pure Reason. See Bloch, Histoire et Historiens.

9 Ricœur, Memory, History, Forgetting, 317.

10 Ibid., 319.

11 Vismann, Medien der Rechtsprechung.

12 Wenzel, M., "Eichmann, Arendt and the Theater in Jerusalem.” In 2011, Yad Vashem published the entire archive on YouTube.

13 Paraphrase of Arendt, The Life of the Mind, 1:19.

14 Arendt, Eichmann in Jerusalem, 287.

15 Continuing discussion about Arendt's report shows how controversial her position is still today. See Golsan and Misemer, The Trial That Never Ends.

16 Gershom Scholem to Hannah Arendt, June 23, 1963. Letter 32 in Arendt and Scholem, The Correspondence of Hannah Arendt and Gershom Scholem, 201-5.

17 Geyer here uses paraphrases of Arendt, Eichmann in Jerusalem, 279, 287-88; "The concept of human rights [...] in all our long history" is taken from the conclusion of the first edition of The Origins of Totalitarianism (1951), replaced in later editions by another, more "sober" version: Arendt, The Origins of Totalitarianism, 631.

18 See Sontag, "Reflections on The Deputy."

19 Arendt, Eichmann in Jerusalem, 9. However, as in the Nuremberg Trials, the witnesses in the Eichmann Trial were actually selected by chief prosecutor Hausner on the basis of statements already documented in writing. They were to come from different European countries in order to be geographically and culturally "representative" of the Nazi crimes, and they were to be able to testify in a media-friendly manner-in a way, one might say they were selected as would occur for a casting. Wieviorka, "Die Entstehung des Zeugen,” 144-45.

20 Arendt, Eichmann in Jerusalem, 19.

21 Ibid., 4.

22 Sontag, "Reflections on The Deputy."

23 Gillick, "Should the Future Help the Past?"

24 For all three projects, see Troncy, Liam Gillick.

25 See Buchmann, Lafer, and Ruhm, Putting Rehearsals to the Test.

26 Gillick, "Selected Transcription from Talk at UN Plaza," 42. See Inkster, "Liam Gillick and Philippe Parreno, The Trial of Pol Pot (1998)," 21n3.

27 Gillick and Parreno, "The Trial of Pol Pot Discussion Document" (provided to author by Liam Gillick, January 2018).

28 Inkster, "Liam Gillick and Philippe Parreno, The Trial of Pol Pot (1998)," 25: Thomas Mulcaire, Pierre Huyghe, Rebecca Gordon-Nesbitt, Douglas Gordon, Gabriel Kuri, Jeremy Millar, Josephine Pryde, Carsten Höller, Rirkrit Tiravanija, Roland Jones, Pierre Joseph, Zeigam Azizov, Adrian Schiesser, Terry Atkinson.

29 It was suggested to visitors either to take one of the posters with all the ideas and feedback of the jury or to buy a ticket and view the show (email from Liam Gillick to author, October 7, 2020).

30 Gillick and Parreno, "Le Procès de Pol Pot."

31 Ibid.

32 Vismann, Medien der Rechtsprechung, 165.

33 Ibid., chapter 5, and passim.

34 Hamilakis, "Some Debts Can Never Be Repaid," 227-64.

35 Hopkins, "The Gilded Gaze,” 237. Hopkins refers to Ann Laura Stoler's term "colonial aphasia" as a "dissociation so profound that colonial history becomes unspeakable." Stoler, "Colonial Aphasia."

36 See the foreword to Downey, Don't Shrink Me to the Size of a Bullet, by Krist Gruijthuijsen and Heike Cathera Mertens, 5, with reference to Juan A. Gaitán's opening speech at the artist's exhibition at Wattis Institute for Contemporary Arts, Los Angeles, 2012.

37 This part of the anecdote is published on Hiwa K's website, http://www.hiwak.net, with slightly differing punctuation.

38 Landsberg, "Prosthetic Memory."

39 Danh Võ's work is discussed briefly in the introduction to the present volume. 


\section{Anachronism and Anachrony}

Many of the artworks discussed in this book employ anachronic concepts as a means to critically explore and activate history. This chapter takes a closer look at artworks that address the historiographical "scandalon" of anachronism so that we might consider anachrony and anachronism, and their relationship to each other.

\section{Real and Existing Anachronism: Deimantas Narkevičius's His-story (1998), Once in the XX Century (2004), The Head (2007), and Into the Unknown (2009)}

I begin with a discussion of four short films by Lithuanian artist Deimantas Narkevičius that present different forms of anachronism, each linked to specific statements about historical or sociopolitical agendas. These works can be associated productively with Jacques Rancière's concepts of anachronism and anachrony as well as to a related theory by Paolo Virno. As Narkevičius himself does not explicitly refer to these theoretical concepts, his works are more often interpreted as working with repetition rather than with anachrony or anachronism. ${ }^{1}$ However, rather than revisiting narratological, autobiographical, and psychoanalytical perspectives on repetition, this section pursues the multifaceted potential of anachronism to reverse, shut down, or devalue history that is made evident in several of his works through the biopolitical inscription of individuals in history.

In his works, Narkevičius himself becomes tangible as one of these individuals: the historical references of the short films discussed here-His-story (1998), Once in the XX Century (2004), The Head (2007), and Into the Unknown (2009)-revolve around a reappraisal and reconceptualisation of perceptions of the fall of communism in 1989, a year of revolutions that abruptly left behind the "grand narratives" of modernism, leaving the present open to musings on a capitalist posthistoire. Narkevičius's film and video works represent an ongoing examination of the historical span marking his own lifetime: born in 1964, in the midst of the blossoming of the Soviet dream, he experienced-at a young age-the collapse of the Soviet Union and the first decades of post-communist Lithuania. The political and cultural identity of the new nation-states emerging in Eastern Europe was formed decisively by new approaches to coming to terms with twentieth-century history, specifically with the Shoah, Stalinism, Socialism, and the Cold War.

Narkevičius was trained as a sculptor but uses film as a medium to investigate history, interweaving his own biography with perspectives on the political past of Eastern Europe. Film history thus becomes, here, a part of this (auto)biographically shaped space of experience. ${ }^{2}$ One of his earliest film installations, His-story $(1998,35 \mathrm{~mm}$ and 
$16 \mathrm{~mm}$, double projection, 7 mins. 30 secs.), opens with a family photograph from the late 1960s showing him as a child with his parents on the beach $(16 \mathrm{~mm}$ film, b/w, silent, 30 secs. in loop). This photograph constitutes the point of departure for a narrative in which the artist and his siblings trace their family history. The film on the second screen ( $35 \mathrm{~mm}, \mathrm{~b} / \mathrm{w}$, sound, $7 \mathrm{mins}$.) begins with a walk on (presumably) the same beach where the now adult Narkevičius starts a conversation with his wife that they continue on a train ride: its subject is the largely covert story of his father's dissidence that led to the loss of his job and temporary compulsory psychiatric treatment. Speculations about actual events and their causes, fragmentary memories, and uncertainty about the parents' intentions characterise the conversation. After a cut, the camera switches to the artist's brother, who recounts a dream about the sudden disappearance of his deceased mother. A camera pan across a forest landscape accompanies the final scene, in which the artist and his sister remember their father's early departure from the Soviet Union (Figure 9.1). ${ }^{3}$

In its formal design and through the use of Russian film material from the 1960s, this black-and-white short film is based on Soviet realism. His-story creates a direct correspondence between the narrative-which is oriented towards autobiographical realism-and its formal vessel, entirely in keeping with the modernist aesthetic criteria of quality. And yet this interweaving remains an anachronism: regardless of its formal mode, a film in Soviet times that was committed to social and political veracity-and was thus in this sense "realistic"-would have been impossible to make for social and political reasons, ${ }^{4}$ making a direct correspondence between history and its form of artistic expression impossible.

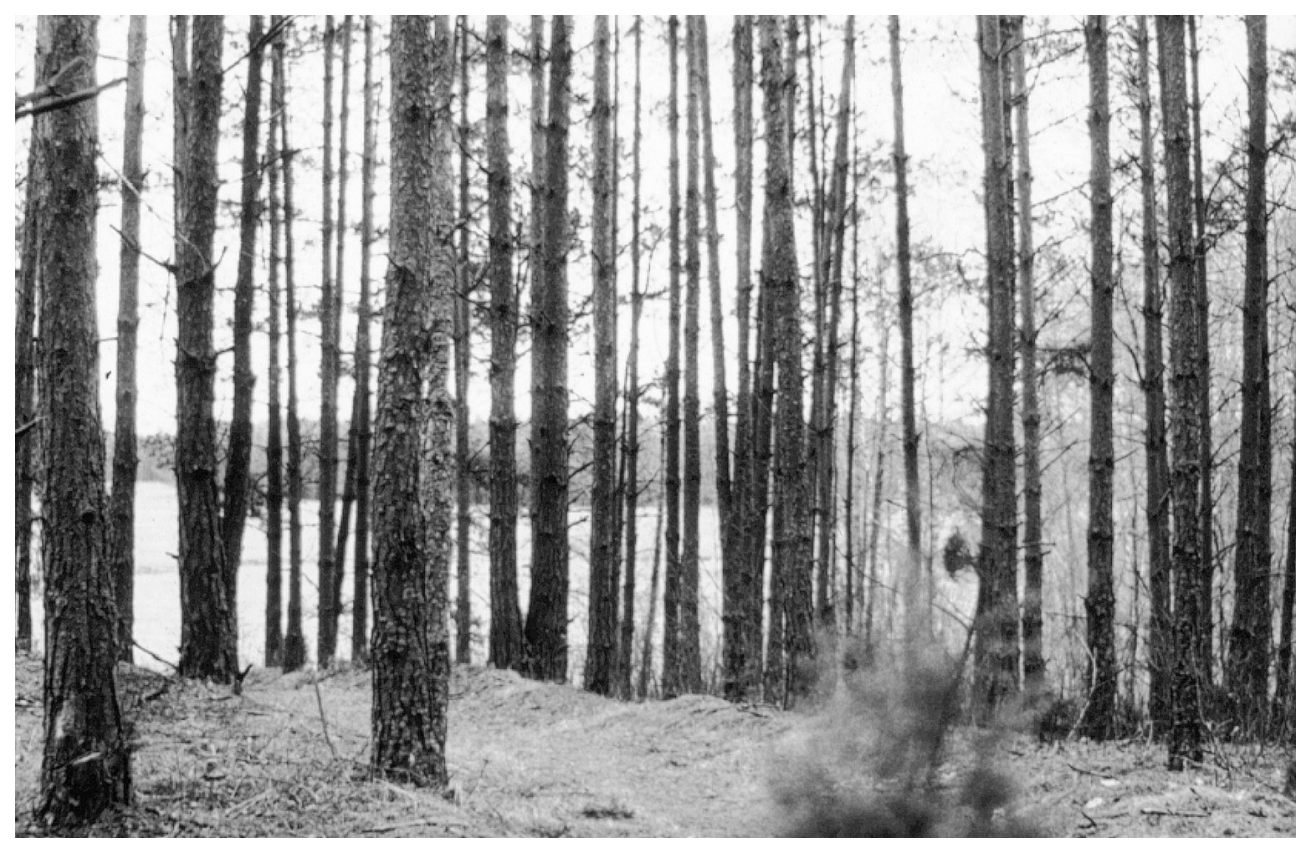

Figure 9.1 Deimantas Narkevičius, His-story, 1998. Still image, double projection: $16 \mathrm{~mm}$ film, black and white, silent, 30 secs. in loop and $35 \mathrm{~mm}$, black and white, sound, 7 mins. Courtesy the artist 


\section{8}

Anachronism and Anachrony

Even though Narkevičius appears in person, together with his siblings, in this film, his autobiographical narrative does not engender a personal approach to history. Instead, the artist presents himself and his parents as representatives of two generations living within a socialist life plan whose transformation deeply marks the family's history. Every personal colouring, every individual action bears the traces of the larger political context. In His-story, just as the aesthetic promise of Soviet realism can only be fulfilled after decades of delay, the long-gone socialist concept of a complete penetration of state and subject is only realised belatedly, and artistically.

Narkevičius examines this penetration most explicitly in relation to the topic of childhood, ${ }^{5}$ a phase of life that occupies a key functional position in the socialist life plan. The staging of children as embodying the future of the Communist state was a core motif of Soviet propaganda (and is shared by other political ideologies as well). Presented as an immediately affective metaphor for the intertwining of present and future, and as malleable material for socialist education, children are an ideologically effective historical frame of reference. This is demonstrated in a particularly impressive way in Narkevičius's short film The Head $(2007,35 \mathrm{~mm}$ transferred to video, colour and b/w, sound, 12 mins.), edited from found footage of the historical GDR - specifically, a propaganda film on the creation of a colossal head of Karl Marx for the city of Chemnitz by Russian sculptor Lev Efimovich Kerbel (Figure 9.2). At the time, this was the world's second-largest monumental bust. ${ }^{6}$ The Head was commissioned by the sculpture festival Skulptur Projekte Münster in 2007, after Narkevičius's original idea to have the bust

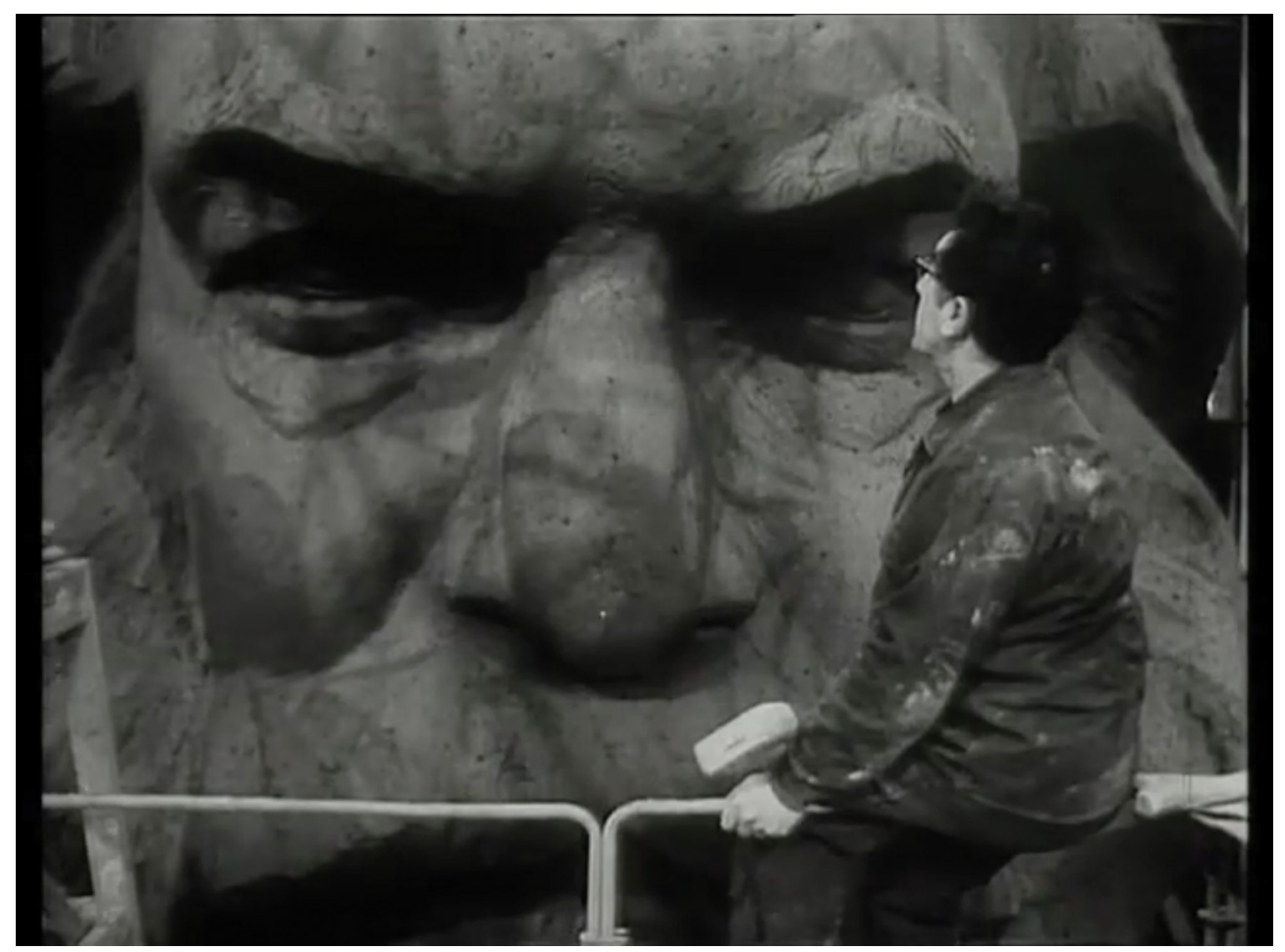

Figure 9.2 Deimantas Narkevičius, The Head, 2007. Still image, $35 \mathrm{~mm}$ film (found footage) transferred to video, colour and black and white, sound, 12 mins. Courtesy the artist 
temporarily relocated from Chemnitz to Münster had failed. Despite the consent of the artist's widow, he was not even allowed to have a copy made for Münster-which seems rather a misconception of public monumental art that makes sense neither in socialism nor in postsocialism. ${ }^{7}$ Considered by the city of Chemnitz to be part of its irreplaceable cultural heritage, the bust is among the few surviving works by Kerbel, who, as the creator of countless Lenin statues placed in innumerable sites from Smolensk to Havana, lived to witness the demolition of many of his sculptures. ${ }^{8}$ Instead of showing the bust itself in Münster, the film The Head presented found footage from historical GDR film material, describing the historical context of the creation of the statue until its erection on October 9, 1971 on a public square specifically designed for it in Chemnitz.

The film's prelude, opening with a series of short recordings of children, is of particular interest in the context of our question regarding how subjects are embedded in political history. One after another, the young people describe their career aspirations and personal role models in Russian translated in a voice-over. Among the role models are pilot Valery Ckalov, cosmonaut Valentina Tereškova, partisan Kosmodemyanskaya, and Aleksandr Matrosov, a soldier of the Red Army-all public figures bearing the honorary title "Heroes of the Soviet Union." One girl names her mother, a boy his brother as their role models. Socialist utopias are sketched on the bodies of these children: the boys dream of becoming pilots, engineers, sailors, chauffeurs, and inventors; the girls wish to become doctors and researchers. The children's statements refer to the history of the Soviet Union as well as to the (historical) plan for its future that they share with that envisioned by the state for the artist himself: Narkevičius had received an art education that-in an ideal socialist scenario-would have brought him directly onto Kerbel's path. This staging of the children not only offers a striking view of their instrumentalisation by socialist ideology-their social education is compared over and over again with the way clay is shaped by an artist-but also of how life plans diverge from the expected course of lived experience. "These kids will stand at the threshold of the year 2000. Dreams for them are not just uncertain ambitions," the film later states, the turn of the millennium still in the distant future. It is obvious today that the actual developments of history have proved less predictable than socialist propaganda would have had it: not only the Soviet Union but also the institutions of the socialist welfare state that brought forth these life dreams and promised their feasibility, have crumbled. ${ }^{9}$

These children, therefore, grow up in fundamentally different scenarios than the ones predicted-and possibly expected-for and by them when they were young. Had this horizon of expectations actually been fulfilled, what kind of life plans would those have been, as exemplified by the heroes of the Soviet Union? The concept of a future in which socialism invested offers no potential for development, only fulfilment; ironically, in this it hardly differs from the stagnant perspectives of late capitalist prognostics. Kerbel fits perfectly into this narrative. In a GDR propaganda film that is part of the material of The Head, the sculptor, born on the day of the storming of the Winter Palace, begins an account on the artwork he is currently working on-a statue of Lenin-with an autobiographical memory of the day Lenin died: he performs the biopolitical ideal of a model Soviet artist fully inscribing his own experiences into Soviet history.

In 2004, Narkevičius examined the symbolic function of the demolition of a public monument that could easily have been created by Kerbel: Once in the XX Century (2004, 8 mins.) is a montage of archive footage from Lithuanian television and private footage from the 1990s that show the dismantling of a Lenin statue-a historical moment the artist witnessed himself (inscribed, like Kerbel, into history). At first glance, the film corresponds entirely to the conventions of political iconography. A crowd has 
gathered around the base of a monument, waving flags of the young Lithuanian Republic. Young men climb the monument to pose with the statue for the cameras. But it soon becomes clear that Narkevičius has reversed the familiar sequence of images: instead of being toppled and then transported away, the gigantic statue suddenly flies through the air (in an fantastical gesture reminiscent of the opening sequence of Fellini's La dolce vita) to land firmly on its pedestal-installed, before our eyes, for eternity.

It is easy to see that these images are "fake," and it was easy to fake them. Narkevičius did not even need to tap the technical possibilities of image processing available to an international artist in 2004, rather simply resorting to those propagandistic film montage techniques that had been in use at the time the statue was erected: ${ }^{10}$ he played the footage in reverse to visualise the public erection of the Lenin statue instead of its removal. The fact that such a decisive visual reinterpretation of the event and a reversal of time are possible using such simple means-that this "inverted world" also "works" when itself inverted-underlines the precisely choreographed character of both the construction and demolition of public monuments, as well as the highly formalised visual imagery of revolutions. For just as the delegations gathered in rank and file in front of Kerbel's Marx statue at the aforementioned celebration of the Free German Youth in autumn 1971, the removal of statues produces certain gestures, codes, and symbols that can be transformed into their exact opposite if played backward. Yet even if we perceive that what is shown is not what should have happened-that history turns into an animated farce before our eyes-the film celebrates, for several minutes, the imagined return of the (Marxist-Leninist) revolution, thus making clear precisely how far the utopia of a revolutionary new beginning has shifted away from our historical perspective. At the same time, the visual evocation of a subjunctive past (what should have happened) is an apt commentary on the limited historical scope opening up for Eastern Europe after 1989, in line with expectations that these nations would now quickly reconnect with Western history. ${ }^{11}$

Once in the XX Century demonstrates, once again, the draining of history by means of a simple reversal, thus performing a series of anachronisms that are to be read on more than the level of content-in this instance, the erection of a public statue as a political act. Instead of showing, according to the title Once in the XX Century, an event in its historical significance, we see an inverted déjà-vu. If events have already occurred before they can possibly take place, then we are not dealing with history in its true sense, in its actuality and potentiality. An already completed future-a "future perfect," in other words-is a stolen future, nothing but a memory of what is happening or will happen that can best be described as akin to the illusion of déjà vu: a feeling of “'inevitability,' a feeling that no power on earth could stop the words and acts, about to come, from coming." ${ }^{12}$ In the illusionary reliving of an experience that has already been experienced, a process of depersonalisation sets in: "He becomes a stranger to himself, ready to be his double, present as a simple spectator at what he is saying and doing." 13 Paolo Virno describes this state of people "watching themselves live" as "real anachronism": "This means apathy, fatalism, and indifference to a future that seems prescribed even down to the last detail. [...] It is impossible to change something that has taken on the appearances of memory." 14

"Watching themselves live" is a lucid description of how an orchestrated event that only happens "once in the twentieth century"-and yet is already known to everyone-is "lived through"; of how historical time is simulated and the future is completed before it has even begun. This is where we find a specific mode of repetition in Narkevičius's films: individuals mirror, or merge with, society; history "fulfils" itself 
by running according to a socialist plan. Such an emptying out of historical scope for action is also evident in the state-controlled concept of socialist utopia as a concept of the future; it also asks fundamentally for fulfilment according to plan, rejecting all deviations as aberrations.

Personal and political history are described as closely linked in His-story; Narkevičius's other works present history as just as deeply rooted in the biopolitics of the twentieth and twenty-first centuries, shaping, controlling, and limiting human life; subjecting communities to political consensus. In socialism, as historian Martin Sabrow has shown, these depended upon "the successful creation of a quasi-prepolitical framework of perception and evaluation" that was never or hardly ever questioned individually and that allowed the ruling ideology to develop most effectively. ${ }^{15}$ Narkevicius has succinctly portrayed the shared prepolitical experience of this ideology, which is permeated by disciplining biopolitical structures, in his film Into the Unknown $(2009,35 \mathrm{~mm}$ found footage transferred to video, colour and b/w, sound, 19 mins. 45 secs.). The images shown in the film are mostly DEFA (the state-owned film company of the GDR) footage from the 1970s and 1980s, stored in the British Film Institute's Socialist propaganda film E-TV archive. ${ }^{16}$ The GDR was a "consensus dictatorship" whose "most effective instrument [...] was not repression, but rather-suggested, staged, forced or voluntary-consent." It permanently "mobilized the masses in order to legitimize itself out of an asserted identity of people and leadership." ${ }^{17}$ Exemplarily suited to reflections on anachronism, the example of the GDR can also serve to consider, more generally, structures of enforced harmonisation and conformity.

The film opens with a short sound clip that presents creative ability as a fundamental characteristic of human nature. After the film title fades in, an elegiac landscape view, probably from the late 1970s, appears to the sound of Beethoven's Moonlight Sonata. A fishing scene at a pond is accompanied by the first verse, read in English translation, of a poem by GDR poet Louis Fürnberg:

I want to grow old as an ancient tree, with annual circles far too numerous to count, with bark that peels year after year around, with roots so deep no spade can ever reach them. In these times, when everything is beginning anew, and seeds of old dreams begin to ripen, let him who can comprehend the meaning of death, for I cannot. ${ }^{18}$

This peaceful beginning is interrupted by sound and image recordings of a shipyard, followed by bustling factory and street scenes (Figure 9.3). Nature, productivity, and the social community: all have been presented as intact so far. But when the camera returns to the factory interior, a woman's voice suddenly can be heard-in a mode counteracting and subverting the images we have seen to this point. She talks about her private fears and feelings of social isolation:

It often happens to me that, very politely, I greet someone and yet I simply cannot imagine what I would do if that person started talking to me. I'm almost afraid of the conversation, and I do my best not to draw attention to myself. ${ }^{19}$

After images of several GDR landmarks in Berlin-including the Television Tower and the Palace of the Republic-and of public festivities, families, and lovers, the female voice furtively returns: "I want to be as simple as water ... in order to resemble water." We then see books presented for sale in a bookstore, including more ambitious and 


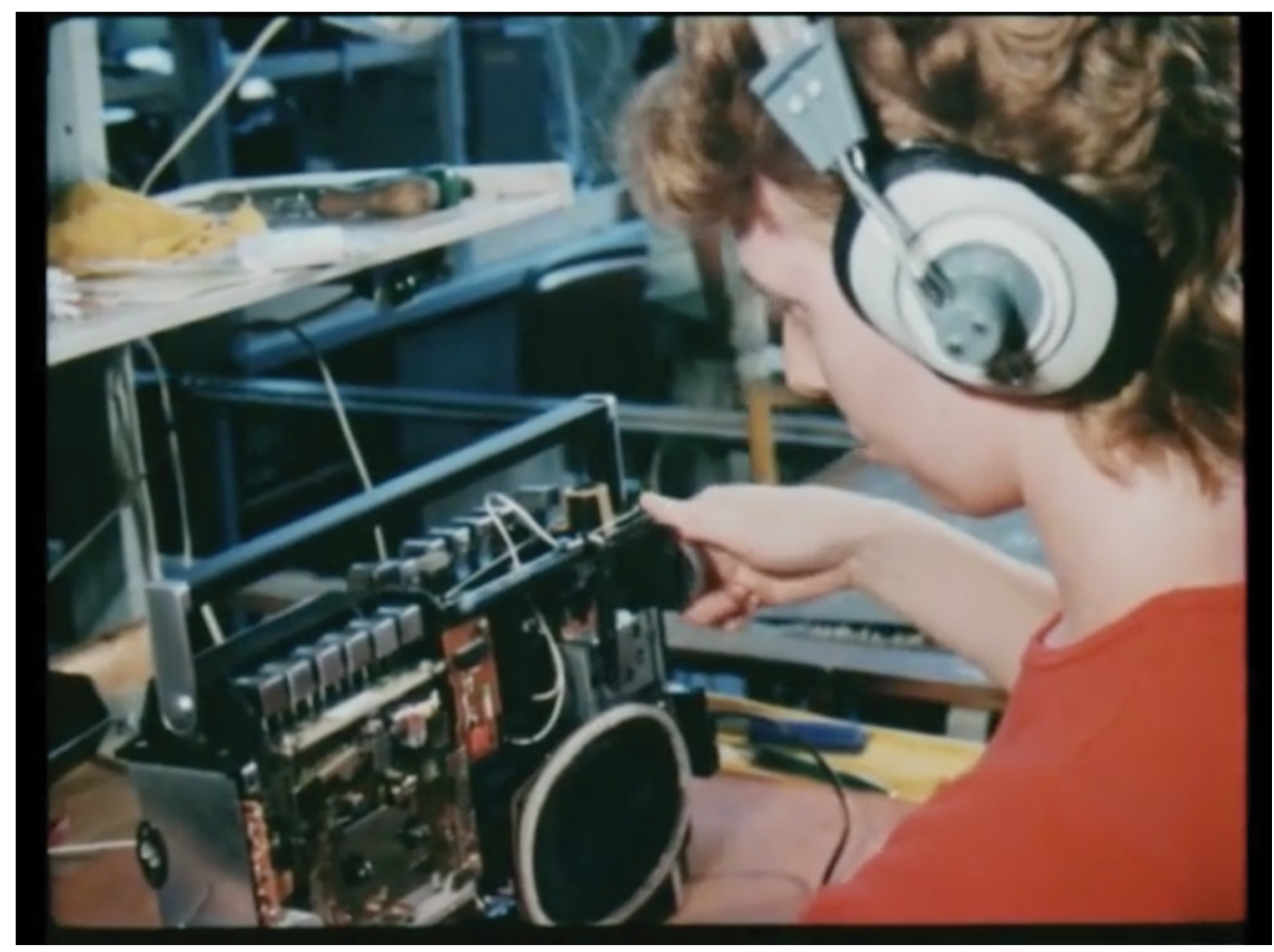

Figure 9.3 Deimantas Narkevičius, Into the Unknown, 2009. Still image, 35mm transferred to video, colour and black and white, sound, 19 mins. 45 secs. Courtesy the artist

critical literature from the GDR such as Ruth Werner's Sonjas Rapport (1977), Christa Wolf's Kindheitsmuster (1976), a record with Peter Duhr's "Lied der Stummen" (Song of the Silent) from his report from a concentration camp (Inferno, 1956), Bruno Apitz's novel about the rescue of a three-year-old boy from Buchenwald (Nackt unter Wölfen, 1958-trans. Naked Among Wolves, 1960), and Peter Engel's Die Bilder des Zeugen Schattmann (Images of Witness Schattmann, 1969). A book table with international political literature, all in German editions, displays works ranging from those of Russian, Swedish, Finnish, Polish, and Slovak authors to John Oliver Killen's And Then We Heard the Thunder, 1971. Then the camera approaches an apartment building and shows interiors with street noise only slightly audible. We return, next, to the country: the face of an old man on a horse-drawn cart; meadows and fields; dramatic thunderstorm skies; and, accompanied by the sonata, the second verse of Fürnberg's poem:

I want to grow old as an ancient tree, where wanderers drowse on sunny summer days. Let them find rest and shelter on their ways in these times when all begins anew. I want to grow from legendary days, days full of suffering and nightmare 'twas, into a time of which mankind will say: 'How wonderful. It's good to be alive.'

A cut leads into a residence for senior citizens, where an elderly gentleman accompanies a group of ladies singing "Sah ein Knab' ein Röslein stehn” (a Goethe poem set to music by Franz Schubert) with the charm of a professional entertainer. Dance music 
follows, then an outdoor party and more images from different regions of the GDR: a truck ride through the country and the Zentrale Poliklinik der Bauarbeiter (Central Polyclinic for Construction Workers) with shots from various wards, laboratories, and an archive with personnel files. The female voice returns stealthily: "A door had banged shut behind me. I do not know when I am going to see you again with my healthy eyes. [...] I saw this body alive and I said, 'Step out of the frame." An employee opens a "work and social security" card that was commonly used in the GDR, then we hear a stammering call for help. After further images from the hospital showing professional work and care routines, we return to the streets of Berlin with their then-new housing tracts. This vision of urban modernism is followed by recordings of a bell foundry where sounds are finely tuned, and then, concluding, we hear Bach's Ave Maria as a carillon that accompanies images of a church and the village surrounding it. The GDR is presented as a welfare state utopia taking care of work, health, and old age while cultivating classical German art, music, and literature, translated into the Biedermeier reality of real socialism-including censorship, fear, and paranoia.

Only when the credits are over does the sound become electronic and an atmosphere unfold that reminds us of the constant surveillance that lies underneath these harmonious images. The excerpts depict an orderly social life "without a single hiccup." ${ }^{20}$ Work or leisure, rural or urban, indoors or outdoors, private or public: all aspects of life are well ordered, without any direct traces of control and surveillance. Indeed, they are seemingly free from politics - and yet they are very much its direct product. Accordingly, Fürnberg's poem connects images of nature (tree, seed, wanderer) with the creation of a new state, a new society-this too, contrary to its elegiac-romantic title, is a vision of life that is thoroughly steeped in politics. Fürnberg's collection Wanderer in den Morgen, which includes this poem, ends with the infamous "Song of the Party" ("Lied der Partei," 1950) with its chorus "The Party, the Party, is always right." Fürnberg unreservedly allowed himself to be absorbed by GDR propaganda and its anachronistic thinking, a fact attested to by a "Statement on Hungary" he published in 1956 that coupled derisive polemics against Western solidarity with the Hungarian Uprising: "Only fools and adventurers believe they can stop socialism with coup attempts. Socialism is unstoppable." ${ }^{21}$

The conjuring of elegiac landscapes is thus only one step away from the fantasies of power and violence rooted in a totalitarian concept of history. In Into the Unknown, only image and sound separate utopia from dystopia. The disquieting female offscreen voice is taken from footage of banned cultural production from the same era, an underworld of socialism invisible in the film's images. The main audio source is the Czechoslovak film Call into Silence (Výzva do Ticha, 1965, directed by Dušan Hanák), which was banned during the Communist era for its dedication to giving schizophrenic patients a voice. Hanák's interest in who would not or could not be integrated into the official structure of socialism regularly led to censorship or outright bans of his work. In Into the Unknown, these outsiders are both invisible and omnipresent, as the restless female voice suggests that her inner monologue is potentially shared by all members of the harmoniously staged community visible on film. As Narkevičius believes, the permanent mutual surveillance, disciplining, and (self-)censorship usual in Socialist countries was apt to spark "milder forms of schizophrenia" in the population. ${ }^{22}$ Only the title Into the Unknown counteracts the pictured utopia of a total fulfilment of the individual in history; the total biopolitical embrace by a political regime that infiltrates the psyche. In the official imagery of the GDR, the strictly regulated life staged in the film-without deviation from the plan-was presented as the ideal in propaganda films and was staged as a living image in marches and celebrations. 
In a way, Narkevičius's films urge a critical review of the oft-unquestioned use of utopia in art, with its fabrication of very specific and concrete "horizons of expectation." It becomes apparent that political potential rather requires a future brought into being by openness and with a scope of action in the present-it needs the "unknown," not a normative, paralyzing prospect of history as fulfilment. We have already encountered Paul Ricœur's reservations about utopia. Brian Massumi stands out amidst a generally positive assessment of utopian thinking in art theory, as radically associating it with hopelessness and the extinction of individual agency:

There's always a sort of vagueness surrounding the situation, an uncertainty about where you might be able to go and what you might be able to do once you exit that particular context. This uncertainty can actually be empowering-once you realise that it gives you a margin of manoeuvrability and you focus on that, rather than on projecting success or failure. [...] This brings a sense of potential to the situation. [...] You may not reach the end of the trail but at least there's a next step. The question of which next step to take is a lot less intimidating than how to reach a far-off goal in a distant future where all our problems will finally be solved. It's utopian thinking, for me, that's "hopeless." 23

The hope that emerges from an ability to shape the present is directed not at improving the world but rather, for the time being, at "simply the bope that it continue"- "a desire for more life, or for more to life." ${ }^{24}$ It is decisive, however, that only individual immersion into lived, present reality makes participation in the present, and in the community, possible. Massumi's perspective, which is based upon a affective approach to agency and potentiality, reveals the intimate intertwining of concepts of history and society, and, at the same time, of totalitarian (utopian or anachronistic) organisation of time and of community: the way history is structured has a direct effect on social relations. The uncanny silence in politics - that whirring noise that is found in the doubling of society and psyche, of surveillance and (self-)censorship-vividly depicts the anachronistic draining of history as an existential disaster that is psychologically and physically devastating.

\section{Kader Attia, The Repair from Occident to Extra-Occidental Cultures (2012)}

Since about 2010, French artist Kader Attia has been working on a comprehensive project entitled The Repair, which was presented in numerous exhibitions over the course of several years. Born to Algerian parents in Paris, Attia studied in Barcelona, spent his compulsory ten-month military service in Brazzaville, and now lives in Berlin. Comprising various media, variations, and formats, the project focuses on the question of the "repair" of history-a deeply anachronistic concept that proceeds from the idea of repairing history in a way that leaves scars and damage as visible traces for the future.

I refer mainly to the installation The Repair from Occident to Extra-Occidental Cultures (2012) as shown at documenta 13 in the Fridericianum in Kassel. ${ }^{25}$ The windowless room was divided into three areas by the individual elements of the installation. On a wall near the entrance were two large antique wooden display cases suggesting a former use in ethnological museums, with disparate objects presented together. Some of these were "trench art"-i.e., objects made in the trenches during the First World War from cartridge cases or artillery ammunition and used as souvenirs, talismans, or religious symbols. There were also "mestizo objects"—non-Western objects integrating elements from Western cultures-in this case, mainly from central and west Africa. ${ }^{26}$ 
Most of the space at the back of the room was taken up by high metal shelving reminiscent of museum storage vaults. The shelves contained wooden and marble sculptures as well as antique photographs, magazines, and books that mostly pointed to art and medicine in European modernism. These, some in stacks, were mounted onto the shelves with large screws (Figure 9.4). The art-historical reproductions contained in the books refer to avant-garde art and world art history publications from circa 1900 to 1920. Permeated with primitivisms, exoticisms, and universalisms, these volumes were strongly influenced by the reception of art and culture from the colonies without, however, recognising them as equal partners-a relationship of "inclusive exclusion." 27

Placed among these book and magazine objects, groups of sculptures made of marble and wood-differing in terms of not only their material but also their aesthetic models-were arranged. The black marble busts were made according to traditional techniques by sculptors in Carrara and portrayed (mostly Congolese) tribesmen in traditional garb with body scarification and modification. These sculptures track the logic of a specific material iconography: in European art, white marble was traditionally reserved for the representation of idealised White bodies; while in this installation, black marble was used for the representation of idealised Black bodies. There were also wooden busts that Attia had carved in Dakar after historical photographs of injured soldiers from the First World War, the rough carving technique enhancing the drastic facial injuries of those disabled by war. Their overall design was at first glance reminiscent of African and Polynesian masks, which were fundamental for the primitivist

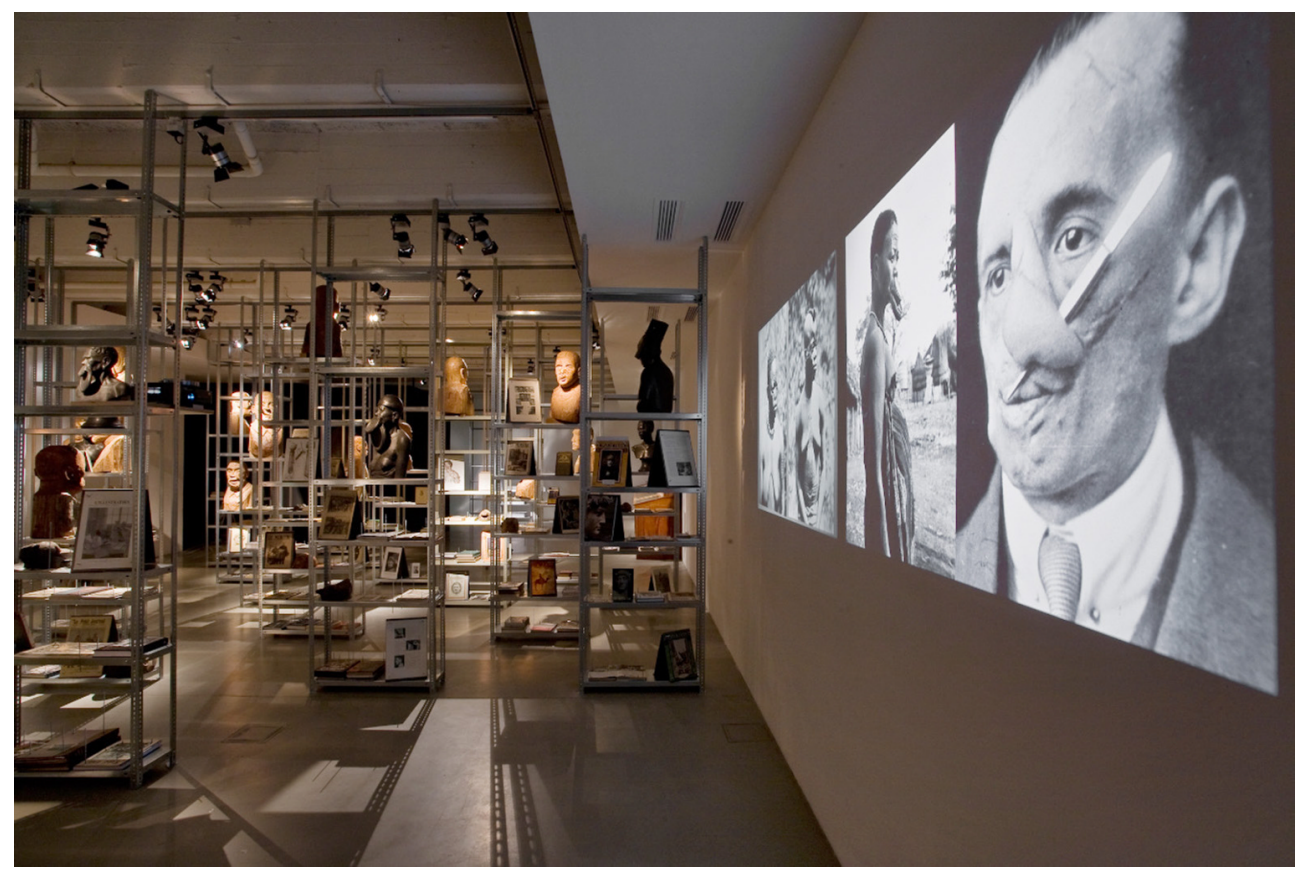

Figure 9.4 Kader Attia, The Repair from Occident to Extra-Occidental Cultures, 2012. Mixed media installation. Installation view, documenta 13, Fridericianum, Kassel. Commissioned and produced by documenta 13 with the support and courtesy of the artist, Galleria Continua; Galerie Nagel Draxler; and Galerie Krinzinger. Further support by Fondation nationale des arts graphiques et plastiques, France. Photo Roman März 
appropriation of non-European art by European modernism. Next to the sculptures, historical books, and photographs, a slide projector was installed, showing a cycle of images adding yet more historical layers to the presentation. Various historical photographs, graphic works, and reproductions of historical objects were compiled in the slideshow, divided into chapters such as "Modernity," "Repairs," "Extra-Occidental Repairs," and "Universalities": ${ }^{28}$ medical illustrations, repaired artefacts, and images of grievously injured soldiers from the First World War with badly disfigured faces. These shocking portraits of faces "restored" via what were then novel procedures illustrate progress in cosmetic surgery ("chirurgie reparatrice," in French) and prosthesis technology. Before the twentieth century, soldiers usually did not survive such severe injuries. Their survival, however, came at the price of a creation of new faces and bodies that simultaneously testified to the vulnerability of the human body and the inability of medical technology to restore its vital functions. In the slide projection, these "repaired bodies" were placed next to photographs of "repaired objects": small artefacts with seams, putty, braces, buttons, or rivets that served as ornaments as well as means for prolonging their functional lives-just as the life span of the injured soldiers was extended by medical intervention. Some of these objects were collected by Attia over the years, others were from museum storage. An example: a fetish from the Congo had one of its two "eyes" replaced with a nail from an upholstered piece of furniture (Figure 9.5, left). Here we see that processes of repair, correction, and decoration-both anthropomorphic and mechanical-are intertwined. A second, approximately six-minute digital slide projection was shown on the back wall of the Kassel installation. It illustrated the shared historical and geopolitical space of colonialism and primitivism, opening with the title page "Introduction to the Repair" and announcing a "History of Repair: Cultural Anthrophagy." The series of images that followed consisted of historical photographs and prints showing the participation of soldiers from French colonial countries in the First World War and then artefacts and objects created in this historical context.

The installation unfolds across two conceptual ranges-people and objects; breaking/ disfiguring and mending/embellishing - within the context of a precise history, showing portraits of war-disabled soldiers from the First World War next to visual documents of ritual incisions and body modifications on people from Central Africa. The faces

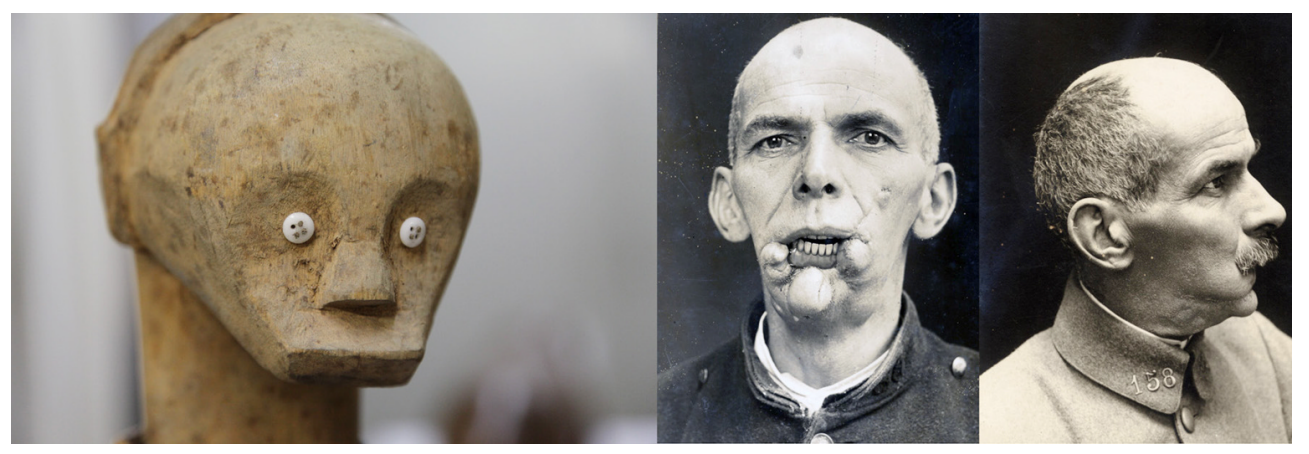

Figure 9.5 Kader Attia, The Repair (detail), from The Repair from Occident to Extra-Occidental Cultures, 2012. Diptych of slide projections. Courtesy the artist; Collection Marguliés, USA; Centre Georges Pompidou, Paris; private collection, and Galleria Continua. Photo Musée du Service de Santé des Armées, Paris; Martin Monestier; Royal Museum for Central Africa, Tervuren 
disfigured by grenades and heavy ammunition, only crudely stitched together surgically, are placed in visual analogy to images of bodies strengthened and beautified by ritual markings. Both very different types of physical markings, the analogy suggests, bear witness to honour, courage, and invulnerability. While it is doubtful that soldiers who were certainly classified as "handicapped" and were even dehumanised would have perceived themselves as "invulnerable," especially after experiencing this first horrific industrialised war, the installation is certainly a powerful anachronistic reframing of the victimised "gueules cassées" (broken faces).

The cultural history of prosthetic bodies is an ambivalent conglomerate of rejection and fetishisation, of a fascination emanating from the possibility of surpassing the vulnerable human body through technical improvement and repair-at the price of its dehumanisation. Coarsely disfigured and reconfigured bodies and faces were deeply unsettling to humanist and idealist equations of health with "natural" beauty and moral integrity. ${ }^{29}$ The injured soldiers could be read as survivors in a prophetic sense: bodies that had experienced the double violence of military and surgical technologies; that had been tested, improved, and optimised for the engineered world of the future. Destruction and repair are intertwined in this double face of technology, as attested by the innovative power of technical progress that brought about weapons of unimagined destructive power as well as the medical means of physical reconstruction-and the slow infiltration of the military apparatus into civil environments, all this heralded by a biopolitical transition into the age of technical superiority. Alongside these surgically repaired prosthetic bodies-which miserably attest to the inferiority of the human physique to technologically advanced warfare- the artistically but just as painfully modified bodies of Congolese men and women also test the boundaries of what constitutes natural beauty and what was, from the point of view of Europe, considered "human."

Thus, in the installation, humans, dehumanised physiques and objects, scarification, repair, and disfiguration conjoin. These contrasts-but also their hybridisation-characterise Attia's artistic approach to history: contexts "falsely" connected with each other stand next to plausible historical analogies. The (book) sculptures and busts shown in the "storage" section play with cultural ideals of beauty (from newly made and intact "antique" female busts to primitivist masks and African body modifications) and open up art-historical constellations wherein, for example, the aesthetic promise of Cubism is brought to life, in a shocking manner, as the disfigured face of an injured soldier. Thus is the primitivist fascination with the "exoticism of the monstrous" ${ }^{30}$ turned back upon European culture. Within the concept of "repair," yet another contradictory pair meets: on the one hand, we see how human interventions into nature-stretching, scarring, and other physical manipulations-are perceived as beautiful. On the other hand, we see how mended objects should, ideally, appear unspoilt and bear no trace of intervention at all—an ideal actively subverted by many of Attia's "repaired" objects, which bear the marks of mending as decoration or improvement, similar to the Japanese practice of kintsugi.

Attia's compilation creates aesthetic and historical entanglements that savour formal similarities and productively neglect context and chronology: an anachronistic fall from historical grace. The bodies and objects presented in the installation share traces of cultural hybridity-foreign and native, occidental and non-occidental materials. The appropriation of found objects in trench art may turn out to be similar to practices of assemblage and collage in European avant-gardes and in African tribal art. And all these practices may even share authorship, as soldiers from African colonial countries fought side by side with Europeans in the First World War. The bodies and objects presented in the installation also share 
the historical context of European nationalism and imperialism, which led first to colonial expansion and a (re)mapping of large parts of the African continent, then to the First World War and the political remapping of Europe. The context of colonialism is also evoked by the antique display case that might have presented "exotic" artefacts in an ethnological museum (emerging at the same time, at the beginning of the twentieth century) but now displays Western artefacts. Attia's installation illustrates the unequal but joint history of Western and non-Western, Northern and Southern cultures, intertwining on several levels. This hybridised, entangled history was carefully worked around in most variants of primitivism in modernism, with its categorical differentiations between the exotic artefacts and the artworks they inspired, qua White creativity. In The Repair from Occident to Extra-Occidental Cultures, occidental and extra-occidental practices and materials are subjected to the same ethnographic gaze. Appropriation and reappropriation (derived from Oswald de Andrade's cultural anthropophagy and from anarchist writer Pierre-Joseph Proudhon, as Attia states) ${ }^{31}$ are revealed as vital to the shared histories of Africa and Europe.

As indicated above, Attia's historical montage repeats practices of appropriating found materials presented in the installation: here, too, objects are taken from history and used to creating new historical analogies, constellations, and contexts. Serge Gruzinski establishes this connection in a text on the installation that, presented as a poster, was made available at the entrance to the installation in Kassel. In this text, "repair" is understood as a not only mechanical intervention but also an epistemological concept:

To repair is therefore also to connect-times, people, things ... —and that's why any global history of humanity must pay a profound attention to this gesture [...] which often consists in inventing a way to insert one world into another [...].

This interpretation is derived directly from Attia's practice: to create

encounters between Western and Outer Western worlds, at emblematic times, cruel or glorious, of their history. But beyond these juxtapositions, this work seeks to present a reading of existence through 'universalities,' more than a bipolar confrontation between West and Outer Western world. ${ }^{32}$

The "repair" of history in the sense of the word used by Attia is also explained etymologically by ethnographer Thomas Reinhardt: "restoration, remedy, renewal, compensation, returning, pairing." ${ }^{33}$

This "universalism" arranges transcultural appropriations and migrations of form not in harmonious coexistence but as shocking juxtapositions. At no point is it possible to ignore the historical contexts of racism, colonialism, war, and destruction; the fact that contact and exchange mostly happened through violence; and that this violence continues to shape the shared histories of Africa and Europe. Though the visual montages leave historical differentiations aside, aesthetically and logically "wrong" and anachronistic comparisons emerge. These are the bodies, for instance, that are brought together in the installation:

"les gueules cassées" [...] of World War One, the traumatized bodies, the bodies for exhibitions, the repaired bodies, the fetishized bodies, the aestheticized bodies, objectified bodies, bodies of people, white bodies, black bodies, bodies of Africans, bodies of Europeans, bodies carved in wood, bodies stitched in clothes, masked bodies, tattooed bodies, hollowed bodies, protruding bodies, and bodies locked up in boxes like stereotypes. ${ }^{34}$ 
Injured, disfigured, fetishised, tabooed, exposed, and masked bodies are presented side by side on an equal footing by virtue of formal comparison. The equations thus created may appear historically wrong, politically inappropriate, and/or morally offensive. They are the result of a brutality; of disarranging orders and categories; of visibly scarring history. This is an aesthetic quite different from that measuring the "success" of surgical interventions by their inconspicuousness or similarity to nature, closer to the soldiers' maimed faces. Attia's visual montages of this scarred history may evoke art history lectures, neatly trying to derive historiographical connections from formal analogies, but indeed they rather work by the Surrealist tactics of subverting them (think of the disquieting compilations of images in Georges Bataille's and Georges-Henri Rivière's Documents). Indeed, in the installation, the historical context of "ethnographic surrealism" ${ }^{35}$ is referenced by a publication by Surrealist writer and ethnographer Michel Leiris on one of the shelves in the "storage" section.

Attia's questioning of concepts of beauty and value is closely related to Surrealist aesthetics and similarly based on the intertwined history of European and non-European cultures. Supported by the stacked books in the "storage" section, the installation "repairs" European primitivism by means of a recourse to Surrealism. Western and non-Western artefacts were first exhibited together in Dada and Surrealist exhibitionsfor example, in the 1936 Exposition surrealiste d'objets-a practice still uncommon today. Thus, the White ideal of what constitutes beauty came under major attack, and the ideals of purity of European primitivism-which sought authenticity and "untouchedness" in non-European cultures, even at the height of colonialism-were thwarted. Surrealism also provides the art-historical precursors to Attia's concept of appropriation. For instance, Marcel Griaule considered African interest in modern weaponry, alcohol, and petrol to be equal and reciprocal to European interest in tribal artefacts. ${ }^{36}$ The (auto) ethnographic gaze of Surrealism suspended the distinctions between everyday objects, folk art, and "high" art that are still apparent in European galleries and museums:

Neither the repair nor the hybrid have their place in traditional museums. If we keep them instead of getting rid of them, objects thus listed end up most often confined to storerooms, out of the general public's sight, who is ever more asking for purity and integrality. ${ }^{37}$

Attia's “mixed objects," testimonies of mixed cultures and mixed times, together create a new category of objects that integrates diverse but coexisting and entangled cultural and historical relations, ${ }^{38}$ and that visibly breaks up conventional systems of classification and display (storage, showcase, slideshow, documentary photograph, illustrated art history publication). At this point, the concept of repair discloses not only its transcultural scope but also its potential for a renewal of historiographical categories: interventions, appropriations, exchanges, transformations, and the interactions resulting thereby conceptualise a history operating with anachronisms that cannot be integrated into the categories of "art," "culture," "influence," "epoch," and "style." In this way, the intertwining of cultures is also expressed as an intertwining of temporal concepts. For instance, the shocking juxtapositions of maimed faces and beautified bodies overcomes not only cultural-geographical distances but also the temporal gap of allochrony ${ }^{39}$ that had transferred non-Western cultures into the eternal prehistory of the "primitive."

The Repair from Occident to Extra-Occidental Cultures thus not only unites the histories of European and non-European cultures but also creates its own history of plural temporalities, as Alexander Nagel and Christopher Wood outline in their book 
Anachronic Renaissance, mentioned at the beginning of this study. Nagel and Wood take up different approaches to the status of the material originality and integrity of objects. Their prelude opens with the tail of the ship of Theseus, which was kept in Athens for centuries, whereby it became necessary from time to time to replace old planks with new ones until hardly any one piece of the "original" remained. Out of time, it evoked a philosophical discussion with regard to the question of whether an object in need of constant repair for its survival in fact remained the same, identical. Indeed, the ship of Theseus eludes historical anchoring and is therefore anachronistic in the sense pursued by the authors. "Anachronism" is, as we have seen, the property (or potential) of artworks to unite several contradictory temporalities and thus to disorder (art-) historical categories.

Attia's provocative, shock-inducing montages are even more wilful, producing plausible constellations as well as "false" comparisons that confuse separations of people and objects, art and culture, technology and aesthetics, defacement and embellishment, preservation and destruction, and so forth. These artworks bring together phenomena that may have appeared simultaneously but—at least in disciplinary registers—are, in fact, not comparable. As the stacked and bolted books and magazines demonstrate, Attia's forced analogies result from a violent, scarred history and operate via anachronistic, often disturbing conjunctions that demonstrate the limitations of historical categories and trace a path of anachronistic thought that, with all its disfigurations and mendings, may shed new light on the historical relations between Africa and Europe.

\section{Notes}

1 See, for instance, Scotini and Caffoni, Deimantas Narkevičius.

2 See Lind, "Giving Body, Giving Voice."

3 All dialogues appear in Scotini and Caffoni, Deimantas Narkevičius, 41-43.

4 See Narkevičius's artist statement in ibid., 35.

5 For another perspective on the topic of childhood in Narkevičius's works, see Scotini, "Da Capo: Deimantas Narkevičius's 'once more."”

6 Dević, "The Head," 165.

7 "Karl-Marx-Plastik."

8 Raunig, "Becoming Lenin," 15.

9 Buden, "In Memory of Utopia," 84.

10 Rehm, "Suspended Vocation," 4.

11 See Jürgen Habermas's term "catching-up revolution": Habermas, Die nachholende Revolution.

12 Bergson, "Memory of the Present and False Recognition," 135.

13 Ibid., 134-35.

14 Virno, Déjà Vu and the End of History, 8, 20-22, 26-28.

15 Ibid., 91.

16 Narkevičius, "Into the Unknown," 185.

17 Sabrow, "Der Konkurs der Konsensdiktatur," 90.

18 The poem "Alt möchte ich werden" was published in the poetry collection Wanderer in den Morgen. Fürnberg, Gesammelte Werke, 1: n.p.

19 Scotini and Caffoni, Deimantas Narkevicius, 193-95. My own transcription, made during a viewing of the film, differs slightly.

20 Mytkowska, "Into the Unknown," 189.

21 Fürnberg, Gesammelte Werke, 5:480.

22 Narkevičius, "Into the Unknown," 187.

23 See the interview with Massumi in Zournazi, "Navigating Movements," 211-12.

24 Ibid., 242.

25 The exhibition folder, the documenta archive website, and other publications refer to the elements of the exhibition — an installation of shelves, a showcase, two projections-individually, 
each with its own title. According to Kader Attia's studio (email to author, November 6, 2017), however, the artist tends to use the overall installation title, and in fact the separation of the various elements of the installation in space was neither marked nor perceptible in my viewing. I therefore treat the exhibition as an overall installation.

26 The term "mestizo" is a reference to Edouard Glissant's "métissage."

27 Leeb, Die Kunst der Anderen, 10.

28 In an interview with Kitty Scott, Attia underscores that the way the objects are classified and categorised in photography and science is countered by their "re-appropriation" through repair. See "In Conversation: Kitty Scott and Kader Attia discuss the concept of Repair," in Attia, The Repair, 165-66.

29 Harrasser, Prothesen.

30 Leeb, "Zeitgenössische Kunst und Weltkultur."

31 Amado, "Kader Attia talks about 'Repair. In Five Acts."”

32 Gruzinski, "From Holy Land to Open Your Eyes."

33 Reinhardt, "The Cannibalization of the Other," 57.

34 Diawara, "Kader Attia."

35 Clifford, "On Ethnographic Surrealism."

36 Griaule, "Un coup de fusil," 46. See Clifford, “On Ethnographic Surrealism," 117-51.

37 Gruzinski, "From Holy Land to Open your Eyes." For a more recent exploration into the potential of destabilising these categories, see Azoulay, Potential History.

38 Lageira, "Repairing, Resisting," 43-57.

39 Fabian, Time and the Other, 25-35. 


\section{No End of History Art and History in the Anthropocene}

The preceding chapters have foregrounded different artistic approaches to history that explore the archive; the historian's role and tasks; concepts and practices of representation; historical narratives; and the complexities of temporal experience and temporal conceptions-especially the anachronic. A final look at the present moment indicates that, in the face of the immediate urgency of environmental politics, the need to explore the categories of history is undiminished. Our historical present has become part of a new historiographical chapter, the Anthropocene: that epoch in which humans have been recognised as the decisive force initiating atmospheric, biological, and geological planetary changes. The immediate impact of conceptualising our present as part of the Anthropocene, however, has led to a revival of posthumanism and posthistoire concepts, which sometimes strikingly recall postmodernist theories of stagnation. But let us start first with exploring the potential of the Anthropocene as a concept:

In the 1930s Henri Cartier-Bresson remarked indignantly, "The world is going to pieces and people like [Ansel] Adams and [Edward] Weston are photographing rocks!" With his condemnation of the inorganic as an unworthy subject for photography, we understand Cartier-Bresson to be arguing for a more socially engaged art practice. ${ }^{1}$

This anecdote appears at the beginning of the volume Art in the Anthropocene, edited by Heather Davis and Etienne Turpin. The artists and theorists presented therein advocate for an increased attention of critical art to rocks and, more generally, to geological, geophysical, and ecological issues. It is easy to agree that the anthropocentric understanding of socially engaged or political art expressed by Cartier-Bresson in this quotation is limited. Distinctions between human and natural history become invalid in view of the insight that humans not only make "their" history but also that of nature-indeed that of the entire planet. On the one hand, this has led to the recognition of a shift in the scale of human activity: for centuries, artists have turned to the aesthetics of the ruin to demonstrate the supposed futility of human efforts to leave lasting, monumental traces upon history. But now the power imbalance is reversed: human history inscribes itself, in a highly destructive way-on a geospatial scale-into the "big time" 2 of the Anthropocene. On the other hand, however, the traditional focus on the human subject as an agent of history is increasingly questioned by the realisation that our planet may well (and would, probably, much better) exist without us and that the Anthropocene, therefore, is only one geological epoch among many. The structuralist conviction that man is not the only measure of history is returning in theories of accelerationism, in a rescaling of history towards cliodynamics, and in the reappearance of concepts such as Gaia, the personified goddess Earth. ${ }^{3}$

DOI: $10.4324 / 9781003166412-11$ 
But let us not overlook the fact that in the quotation above, the two editors plead for an abandonment of the oppositionality of nature and (human) culture/politics/history, not for a simple reversal of classifications. Paradoxically, the shift in scale from individual human action to the conception of humans as a geospatial force often makes the consequences of human actions seem intangible and inconceivable-just at a historical moment when the effects of human actions threaten our very existence. For centuries, natural history has been the conceptual antithesis to man-made history, since in the latter the "natural" has no place: nothing is unchangeable; everything is contingent. ${ }^{4}$ But in view of the fatalistic, teleological temporalities of the seductively eschatological Apocalypse, it seems easier to imagine the end of mankind-or the end of historythan a change in the world order of our present. ${ }^{5}$ We may well recall Walter Benjamin's insight that our most serious threat, our actual catastrophe, might just turn out to be not an unforeseen event but rather the sombre verity that things "just go on" as they do now.

In 2009, Dipesh Chakrabarty developed four theses intended to place historical thought in the Anthropocene on a new footing. ${ }^{6}$ He begins by emphasising that the consequences of human actions are not relativised by the longue durée of geological ages but, on the contrary, have become more significant. But now modernity (the age of industrialisation, capitalism, and progress) marks the beginning no longer of a glorious age but rather of human (self-)extinction. The global history of capitalism needs to be fundamentally connected to human history in order to take into account that ecological threats increase social inequalities and affect disadvantaged regions and populations to a much greater extent. In light of these observations, Chakrabarty struggles for a conception of humanity that would allow for a rescaling of human agency on a global level but avoid universalistic concepts. He concludes with the speculative conception of a negative universal history that would take into account heterogeneity and disjunctiveness.

This, indeed, is an essential point: how to grasp our transnational, global present without falling back upon universalistic concepts of humanity at a time when both agency and political responsibilities for our global crisis are so unevenly distributed? In art as well as cultural theory, we need a thorough critical reexamination of what remains of Enlightenment categories of history and politics-especially concepts of subjectivity, of agency, of time-in our decolonial, neocolonial present. ${ }^{7}$ With respect to contemporary art, we can build upon Peter Osborne's postulation of its potential to speculatively unite disjunctive temporalities and communities, which seems like a parallel plea to Chakrabarty's. The ways in which Walid Raad, Erika Tan, Wendelien van Oldenborgh, Bouchra Khalili, Amar Kanwar, Apichatpong Weerasethakul, and Kader Attia, for example, create new transcultural and transhistorical spaces can indicate approaches for shared but not equal concepts of experience and action. As I have shown, these artists' works have both taken up and questioned Enlightenment concepts of history and their epistemological, social, and political categories by critically examining not just academic but also artistic approaches to history. These artists' works expose and explore its forms and methods; premises of representation and visualisation; and, finally, the whole regulatory structure of aesthetic education. ${ }^{8}$

The project of artistic historiography is challenged by the Anthropocene even as artists and theorists often have joined in criticism of the concept. ${ }^{9}$ T. J. Demos has warned pointedly against using the conceptual universe of the Anthropocene ${ }^{10}$ as it risks coadopting or developing an aesthetics that tends visually to naturalise and sublimate the effects of industrial expansion into nature. Against the term "Anthropocene" 
he brings the term "Capitalocene" into play, naming more concretely the actual actor of current environmental destruction. ${ }^{11}$ This criticism voiced in art and art theory is shared by historians:

Caught in the storm of Gaia, major sociologists and philosophers have decided to jettison from "Spaceship Earth" the whole analytic, explanatory and critical arsenal of the human and social sciences. [...] Whole books can now be written on the ecological crisis, on the politics of nature, on the Anthropocene and the situation of Gaia without so much as mentioning Capitalism. ${ }^{12}$

The shockwave of the Anthropocene has transformed not only humanity as such but also, as Christophe Bonneuil and Jean-Baptiste Fressoz argue, the whole apparatus of the humanities with it. Both historians note an alarmingly exclusive prioritisation of scientific methods of quantification ("big data") even where global political processes are researched. They urge a differentiation, historical contextualisation, and repoliticisation of the discourse- a renewed appreciation for the humanities. ${ }^{13}$ These arguments may also be valuable for conceptualising the role of art in approaching the representation of the Anthropocene. In 1974, looking back on the beginning of space travel, Marshall McLuhan stated: "Ecological thinking became inevitable as soon as the planet moved up into the status of a work of art." ${ }^{14}$ But if art is not capable of adding more to this discourse than any another (today mostly dystopian) variety of aesthetically sublimating the planet (and thus refashioning aesthetic historicism), then it becomes meaningless. By voluntarily submerging itself in eschatological teleologies, art becomes anaesthetics, ${ }^{15}$ contributing to that "deep historicism" 16 which (paradoxically, in an age when human actions are so decisive) renders human history inactive-not because humans as agents were actually extinguished but because of the quantification of history as big data, a simple shift in scale. One result of this translocation of the human subject into ever more gigantic dimensions is the anachronistic "explosion of the now," in which the reality of having to live different, incompatible temporalities contemporaneously has become an omnipresent experience. ${ }^{17}$ Here, too, art can offer a more critical approach.

Matthew Buckingham's installation The Six Grandfathers, Paha Sapa, in the Year 502,002 C.E. (2002, Figure 10.1) sketches the history of the mountain range known to the Sioux as Paha Sapa (Black Mountains) across a time stream extending over almost 67 million years. This era spans the geological origins of the mountains and the political history of the last four centuries: the violent colonisation and conquest of the land accompanied by only partially legalised violent and nonviolent transactions (purchase, resale, surrender, robbery, reparation claims). Most "events" in a traditional historical sense are summed up within this relatively short historical period, beginning with the purchase of the French possessions of North America by Thomas Jefferson and the allocation of the territory as "permanent Indian land" to the Indigenous population. This was followed by a violent land grab by the US government when mineral resources were discovered in the area, followed by the symbolic marking of the mountains as "Mount Rushmore" by the famous carving of four presidents' portraits into the rock. This monumental project was undertaken by sculptor Gutzon Borglum between 1927 and 1941, who joined the Ku Klux Klan during these years.

The timeline progresses to the year 2000, with a recapitulation of the legal disputes of several Sioux groups against the US government that have been ongoing since the 1980s. Although the land grab has now been recognised as illegal, the restitution of the Paha Sapa is considered "practically impossible" and reparation payments have been 


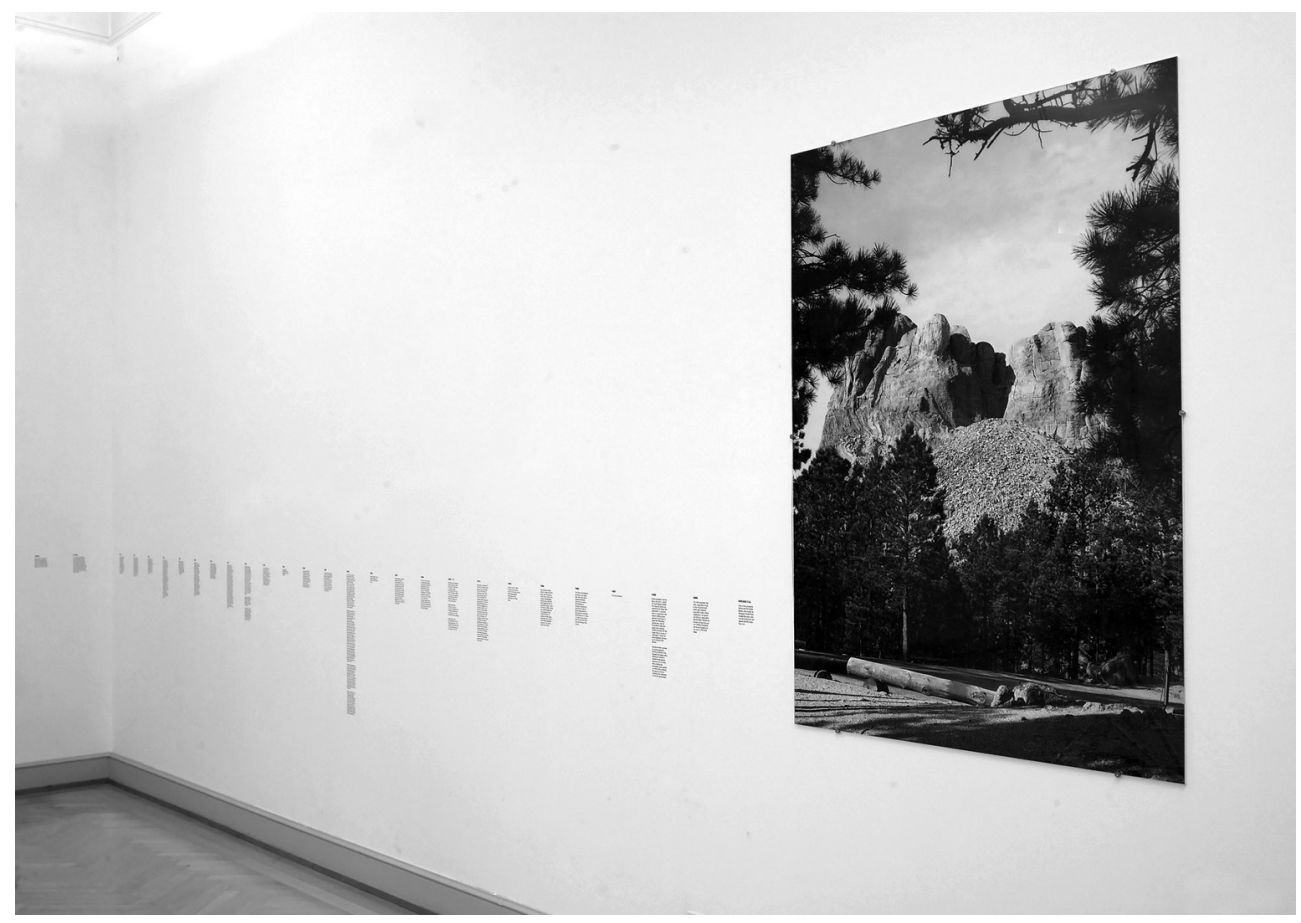

Figure 10.1 Matthew Buckingham, The Six Grandfathers, Paha Sapa, in the Year 502,002 C.E., 2002. Installation view, Time Lines, Kunstmuseum St. Gallen, 2005. Courtesy the artist

rejected by representatives of the Sioux. From this moment, the timeline jumps forward by half a million years to the year 502,002. This is where we find the only visual document of the installation: a digital rendering of the rocks in the far future, the presidents' portraits having long since disappeared. A range of distinct temporal velocities and conceptualisations of history are brought together unevenly in this work: natural geological weathering alongside the faded monumentality of the carved portraits, once postulating a claim to eternity by turning nature into art; a short, violent political history, concluding with a verdict justifying the irreversibility of the land grab with the argument that the "progress of time" makes any restitution impossible. Buckingham's work was conceived before the concept of the Anthropocene had become prevalent but, using two visual instruments of "big history" - the timeline and a digital rendering of an event far in the future, it convincingly shows how strongly our experience of the present is shaped by the coexistence of different dimensions and concepts of time. A mere inscription of human actions into big-time historiographies cannot fully grasp our current reality, nor can an exclusive concentration on small-scale events. It is necessary to overcome the opposition generated by the juxtaposition of political and natural history by fostering a new, materialistic historiography that includes not only rocks but also sediments and raw materials; the history of carbon ${ }^{18}$ as well as that of the oceans; that of human activity alongside that of living beings in the Earth's biosphere. A historiography as conceived, for example, in Ursula Biemann's video work Deep Weather (2013) or in Laura Gustafsson and Terike Haapoja's exhibition and book project History According to Cattle (2013-15), both projects that try to broaden the documentary's exclusive approach to representing human history. 
A further urgent task of artistic historiography is an examination of the rhetorical instruments and discursive formations of the Anthropocene-which, in addition to historiographical concepts, also include specific visual representations.

Climate change is global-scale violence against places and species, as well as against human beings. Once we call it by name, we can start having a real conversation about our priorities and values. Because the revolt against brutality begins with a revolt against the language that hides that brutality. ${ }^{19}$

Just as resistance against brutality begins with resistance against the language that conceals and disguises it, crucial aspects of this resistance is Nicholas Mirzoeff and T. J. Demos's demand for a critical examination of the visual "aesthetics of the Anthropocene." ${ }^{20}$ This refers to the artistic (and nonartistic) aestheticisation of human interventions into nature, especially those numerous dazzling, sublime visualisations of industrialisation, land grabs, and pollution that are, at first glance, intended to represent what eludes immediate perception. But aesthetics also tends to naturalise what it sets out to represent. Our task, as Demos illustrates, is to resist and counteract the sublime contemporary doomsday aesthetics. Foregrounding the impact of human agency in the Anthropocene, he underlines the critical responsibility of artworks by means of an example from the politically informed documentary tradition, namely Ursula Biemann's and Paulo Tavares's Forest Law (2014).

This video work documents the immense environmental destruction caused by the US oil company Texaco (now Chevron) in Ecuador, which has been countered by legal action initiated by the Indigenous population. In her contribution on contemporary geopolitics in Art in the Anthropocene, Biemann argues that oil-and water-should be perceived not as natural substances but rather as contested resources, thus politicising "natural" as a category in a novel way. ${ }^{21}$ This includes an intertwining of economy and ecology that, conversely, will lead to radically extending the concept of politics to include nonhuman factors. Just as we need to continue the deconstruction of concepts such as nation, state, population-and, thus, develop new conceptions of who might be or might become subjects of history-we also have to continue to question the rhetoric and logic of the documentary; the primacy of representation; and, generally, art's power to transmit information, knowledge, and scope for action.

Indeed, the history of the Anthropocene risks resuscitating not only now-discounted historical concepts but also actors. Nicholas Mirzoeff reminds us of Thomas Carlyle's insistence that it is "the mark of the 'great man,' or hero" always to be able to "visualize history as it happened": the great actors of history are, therefore, also great visualisers. ${ }^{22}$ And while this heroic image has been thoroughly critiqued and transformed, it still lives on in Enlightenment concepts: are we not all striving to oversee, to comprehensively grasp history-its directions, its actors, its causes, its effects-in order to do the right thing? The Anthropocene brings us to a tipping point in terms of how to visualise this bewildering, overbearing situation that surpasses human scale and to conceive of visualisations that are not immediately directed at grasping, conceptualising, or understanding history.

If the aesthetics of the Anthropocene limits itself to visualising the world catastrophe, this leads to a new aesthetic historicism of a most menacing variety: history at a standstill; fatalism; a conception of change or progress this is only ever horizontal, that just disseminates the status quo indefinitely. Let us recall Heinz and Hannelore Schlaffer's description of nineteenth-century aesthetic historicism, in which "the temporal structure 
of the relationship between the present and the past is turned into a spatial structure" wherein historical thought and historical sense find an "aesthetic answer" sense the way the past is visualised in the mind is perceived as analogous to viewing pictures. ${ }^{23}$ Such an aestheticising paralysis of historical consciousness also characterises the most problematic aspects of our global present, which seems to have lost hold of either past and future. Fortunately, however, we have more tactics with which to counter this situation than a concept of art aimed primarily at the sublimating transformation of reality into aesthetics. Instead of foregrounding the role of art in illustrating that which eludes immediate perception we should also ask what this "illustration" entails.

"Art teaches us to see things. It is Anschauungsunterricht-training in observation." This is a sentence from a joint contribution of artist Emily Jacir and philosopher Susan Buck-Morss to the documenta 13 series 100 Notes-100 Thoughts. ${ }^{24}$ This leap from "training in observation" to "visual instruction" is remarkable- the first term denoting a form of teaching directed towards an active understanding and analysis of visual material (i.e., not only the viewing of artworks); the second describing learning through images. Within the dialectics of these two possibilities for combining learning and visuality ("learning to see" on the one hand, "learning by seeing" on the other), the whole richness of what makes up artistic and academic history unfolds.

By the nineteenth century, Anschaulichkeit ("illustrativeness" or providing clarity) was a central concept of historical science as it competed with the empiricism of the natural sciences. ${ }^{25}$ The ideal stems from rhetoric, in the sense of producing evidence, including deceptive evidence-if sources were not well verified or if artists or historians did not sufficiently make clear their own creative contribution to their representation of the "facts." Droysen, who was critical of the principle that would be furthered in Ranke's school, explicitly warned that even a "complete" compilation of available historical material would not produce a picture of the whole, a "photographically correct image of the time," but only files and documents. ${ }^{26}$ Therefore, the Anschaulichkeit of historical evidence is always in tension with another important step in historiographical methodology: criticism. This tension has accompanied us throughout this entire investigation of artistic approaches to history. During the Anthropocene, however, the necessity of fundamentally questioning means of providing clarity-of making the effects of environmental degradation tangible and comprehensible-has become much more urgent.

According to Mark Godfrey, academic and artistic approaches to history differ significantly, though both share a double focus on representing historical events and reflecting upon the methods of historiography. In contrast to academic history, Godfrey suggest, artistic approaches are freer in their use of methodology; also, they tend to focus on reconstructing rather than on deconstructing history. ${ }^{27}$ In the course of this book, I have rather argued that artistic and academic history share not only concerns but also methods and instruments. However, they do not necessarily use these for the same ends. Scholarly methods may be employed independently in art, may acquire an intrinsic value, and may be productively used "wrongly" - thereby leading to completely different results. I would therefore make a different distinction than has Godfrey. At the methodological centre of historical scholarship as developed in nineteenth-century humanities, we find hermeneutics, striving for the exact and systematic approach of the social sciences, and flanked - and often questioned-by ethnography, philosophical superstructures, and historical materialism. For all the diversity that results from this productively unstable scientific basis of history, it also produces objectives that artistic approaches will not necessarily share. These do not need to focus on comprehending 
or understanding history. Rather, they endeavour to enable audiences to situate themselves in relation to history by reconstructing or deconstructing history, perhaps via the production or visualisation of new conceptions of time and history. As the previous chapters demonstrate, art very often critically questions conventional concepts of representation that focus on merely "illustrating" knowledge. Instead, and increasingly, art will contribute to research-oriented and conceptually nuanced approaches to representation that provide actual visual instruction in its dual sense-apodeixis, in short. I foreground conceptuality here because, as Mirzoeff-who has focused on how (not) to visualise the Anthropocene artistically-has observed, the "countervisuality" that is needed now is not restricted to visual categories. "Rather, the project is to create a mental space for action that can link the visible and the sayable." 28

Thus artistic historiography is not limited to making events visible or understandable but rather makes the significance of not understanding understandable; it sets forth how problematic, changeable, and manipulative are the tools of what understanding supposedly entails-narrative and pictorial structures, explanations, interpretations, etc.- - laying bare the pitfalls and limitations of such a claim. Critical artistic historiography will not be restricted to telling specific, "relevant" stories—or to processing them according to affective parameters-but will rather seek to identify the nonnatural, unnecessary, contingent aspects of our present, as this is the task of historical and political thought. Art will be able to contribute to organising past, future, and present; to formulate experimental and performative conceptions of history. Especially in the Anthropocene-this disjunctive, anachronic global present-an ethically binding and politically open understanding of history is necessary to regain the future as a category of thought and action. Then history will not only provide for art a rich source of attractive topics and motifs but also a means of establishing a vibrant connection to the world through which the rhetorics of standstill and doom can be shattered.

\section{Notes}

1 Davis and Turpin, “Art \& Death,” 3.

2 See Christian, Maps of Time.

3 Latour, Facing Gaia.

4 Foucault, "Nietzsche, Genealogy, History."

5 "We seem collectively unable to think outside of the box, as it were, of Western modernity with its progressive concept of history and its teleological philosophies of history." Karlholm, "Is History to Be Closed, Saved, or Restarted?," 13.

6 Chakrabarty, "The Climate of History: Four Theses."

7 Lowe and Lloyd, The Politics of Culture in the Shadow of Capital.

8 Lloyd, Under Representation.

9 See esp. the comprehensive Anthropocene Project, Haus der Kulturen der Welt, 2012-14; Mirzoeff, "Visualizing the Anthropocene"; Davis and Turpin, Art in the Anthropocene; Mackert and Petritsch, Mensch macht Natur; Demos, Against the Anthropocene.

10 Demos, Against the Anthropocene.

11 See Moore, Anthropocene or Capitalocene?

12 Bonneuil and Fressoz, The Shock of the Anthropocene, 68.

13 Ibid., 60.

14 Ibid., 141.

15 Ibid., 220.

16 Tung, "Baddest Modernism," 516.

17 Ibid., 518.

18 Wark, Molecular Red.

19 Solnit, "Climate Change is Violence," cited in Demos, Against the Anthropocene, 59, 81. 
20 Demos, Against the Anthropocene; Mirzoeff, "Visualizing the Anthropocene." Cf. also Caroline Jones' and Peter Galison's project "How Images Obscure the Anthropocene, or How Not to See" (MPIWG Berlin, 2018).

21 Biemann, "Geochemistry \& Other Planetary Perspectives."

22 Mirzoeff, "Visualizing the Anthropocene," 216.

23 Schlaffer and Schlaffer, Studien zum ästhetischen Historismus, 13.

24 Sauerländer, Emily Jacir and Susan Buck-Morss, 27.

25 Christöphler, Geschichte als Anschauung.

26 Droysen, Historik, 1:11.

27 See Godfrey, "The Artist as Historian."

28 Mirzoeff, "Visualizing the Anthropocene," 226. 


\section{Bibliography}

(all online sources last accessed on March 24, 2021)

Adorno, Theodor W. Aesthetic Theory. Edited by Gretel Adorno and Rolf Tiedemann. Newly translated and edited by Robert Hullot-Kentor. London: Continuum, 2004.

Agamben, Giorgio. "Time and History: Critique of the Instant and the Continuum.” In Infancy and History: The Destruction of Experience, translated by Liz Heron, 89-105. London: Verso 1993.

"Marginal Notes on Commentaries on the Society of the Spectacle." In Means without End: Notes on Politics, translated by Vincenzo Binetti and Cesare Casarino, 73-89. Minneapolis: University of Minnesota Press, 2000.

. "What Is the Contemporary?" In What is an Apparatus? And Other Essays, translated by

David Kishik and Stefan Pedatella, 39-54. Stanford: Stanford University Press, 2009.

Agnew, Vanessa. “Introduction: What Is Reenactment?” Criticism 46, no. 3 (2004): 327-39.

- "History's Affective Turn: Historical Reenactment and Its Work in the Present." Rethinking History 11, no. 3 (2007): 299-312.

Ahmed, Sara. The Cultural Politics of Emotion. Edinburgh: Edinburgh University Press, 2000.

Allen, Jennifer. “Clues, Shadows and Faces: An Interview with Matthew Buckingham.” In Kreuger, Messages from the Unseen, 24.

Amado, Miguel. "Kader Attia talks about Repair. In Five Acts." Artforum (online), August 23, 2013, https://www.artforum.com/interviews/kader-attia-talks-about-repair-in-five-acts42670.

Ameline, Jean-Paul, and Harry Bellet, eds. Face à l'histoire: L'artiste moderne devant l'événement historique. Paris: Editions du Centre Pompidou/Flammarion, 1996.

Amelunxen, Hubertus von, and Andrei Ujica, eds. Television/Revolution: Das Ultimatum des Bildes. Rumänien im Dezember 1989. Marburg: Jonas, 1990. $11-24$.

Anderson, Benedict R. In the Mirror: Literature and Politics in Siam in the American Era. Bangkok: Southeast Asia Program Publications, 1985.

- "The Strange Story of a Strange Beast. Receptions in Thailand of Apichatpong Weerasethakul's Sat Pralaat," in Quandt, Apichatpong Weerasethakul, 158-177.

Andresen, Sabine. Sozialistische Kindheitskonzepte: Politische Einflüsse auf die Erziehung. Munich: Reinhardt, 2006.

Ankersmit, Frank R. "Historical Representation.” History and Theory 27, no. 3 (1988): 205-28.

_. "Wahrheit in Literatur und Geschichte." In Geschichtsdiskurs. Vol. 5, Globale Konflikte, Erinnerungsarbeit und Neuorientierungen seit 1945, edited by Wolfgang Küttler, Jorn Rüsen, and Ernst Schulin, 337-59. Frankfurt am Main: Fischer, 1999.

- "Trauma and Suffering: a Forgotten Source of Western Historical Consciousness." In Rüsen, Western Historical Thinking, 72-85.

—. "Truth in History and Literature." Narrative 18, no. 1 (January 2010): 29-50.

Appadurai, Arjun. Modernity at Large: The Cultural Dimensions of Globalization. Minneapolis: University of Minnesota Press, 1997. 
Arendt, Hannah. The Life of the Mind. Edited by Mary McCarthy. 2 vols. New York: Mariner Books, 1981.

- The Origins of Totalitarianism. Edited by Samantha Power. New York: Schocken Books, 2004.

-Eichmann in Jerusalem: A Report on the Banality of Evil. With a New Introduction by Amos Elon. New York: Penguin, 2006.

-. "Introduction.” In Benjamin, Illuminations, 1-55.

Arendt, Hannah, and Gershom Scholem. The Correspondence of Hannah Arendt and Gershom Scholem. Edited by Marie Luise Knott. Translated by Anthony David. Chicago: University of Chicago Press, 2017.

Aristotle. Poetics. Edited and translated by Anthony Kenny. Oxford: Oxford University Press, 2013.

Armstrong, Carol. Scenes in a Library: Reading the Photograph in the Book, 1843-1875. Cambridge, MA: MIT Press, 1998.

Arns, Inke, Igor Čubarov, and Sylvia Sasse, eds. Nikolaj Evreinov \& andere: "Sturm auf den Winterpalast”. Zurich: Diaphanes, 2017.

Arns, Inke, and Gabriele Horn, eds. History Will Repeat Itself: Strategien des Reenactment in der zeitgenössischen (Medien-)Kunst und Performance. Frankfurt am Main: Revolver, 2007.

Arns, Inke, and Kurt Wettengl, eds. Mit allem rechnen: Medienkunst aus Estland, Lettland und Litauen. Frankfurt am Main: Revolver, 2006.

Assmann, Aleida. Cultural Memory and Western Civilization: Functions, Media, Archives. New York: Cambridge University Press, 2011.

Shadows of Trauma: Memory and the Politics of Postwar Identity. Translated by Sarah Clift. New York: Fordham University Press, 2015.

- Is Time out of Joint? On the Rise and Fall of the Modern Time Regime. Translated by Sarah Clift. New York: Cornell University Press, 2020.

Assmann, Jan. Cultural Memory and Early Civilization: Writing, Remembrance, and Political Imagination. Cambridge: Cambridge University Press, 2011.

Attia, Kader. The Repair: From Occident to Extra-Occidental Cultures. Berlin: Green Box, 2014.

Augé, Marc. An Anthropology of Contemporaneous Worlds. Stanford: Stanford University Press, 1999.

- The Future. London: Verso, 2014.

Aurich, Rolf, and Ulrich Kriest, eds. Der Ärger mit den Bildern: Die Filme von Harun Farocki. Konstanz: UVK Medien, 1998.

Auslander, Philip. Liveness: Performance in a Mediatized Culture. New York: Routledge, 1999.

Baier, Simon. "Danh Võ: Where The Lions Are.” Spike Art Quarterly, 21, September 2009: 142-43.

Baker, George. “Artist Questionnaire: 21 Responses.” In Krauss and Baker, "Obsolescence,” 26.

Balsom, Erika. "A Cinema in the Gallery, A Cinema in Ruins.” Screen 50, no. 4 (Winter 2009): 411-27.

- Exhibiting Cinema in Contemporary Art. Amsterdam: Amsterdam University Press, 2013.

Balsom, Erika, and Hila Peleg, eds. Documentary Across Disciplines, Berlin: MIT Press, 2016.

Bangma, Anke. “The Polyphonic Work of Wendelien van Oldenborgh.” Metropolis M 4 (2008), https://wilfriedlentz.com/wp-content/uploads/2017/12/W_v_O_MM_Eng.pdf.

Bangma, Anke, Steve Rushton, and Florian Wüst, eds. Experience, Memory, Re-enactment. Frankfurt am Main: Revolver, 2005.

Bann, Stephen. The Inventions of History: Essays on the Representation of the Past. Manchester: Manchester University Press, 1990.

- Romanticism and the Rise of History. New York: Twayne, 1995.

—. "Face-to-Face with History." New Literary History 29, no. 2 (1998): 235-46. 


\section{Bibliography}

Barlingay, Surendra Sheodas. A Modern Introduction to Indian Aesthetic Theory: The Development from Bharata to Jagannātha. New Delhi: DKPrintworld, 2007.

Barnouw, Dagmar. Critical Realism: History, Photography, and the Work of Siegfried Kracauer. Baltimore: The Johns Hopkins University Press, 1994.

Barrows, Adam. Time, Literature, and Cartography after the Spatial Turn: The Chronometric Imaginary. London: Palgrave Macmillan, 2016.

Bartana, Yael, Maryam Jafri, Romuald Karmakar, Clemens von Wedemeyer and Kathrin Peters. "Geschichte und Fiktion. Ein Roundtablegespräch über die (Re-)Konstruktion von Geschichte in Kunst und Film mit Yael Bartana, Maryam Jafri, Romuald Karmakar und Clemens von Wedemeyer, moderiert von Kathrin Peters.” Texte zur Kunst 76 (December 2009): 53-68.

Barthes, Roland. Camera Lucida: Reflections on Photography. Translated by Richard Howard. London: Cape, 1982.

- "The Discourse of History." In The Rustle of Language, translated by Richard Howard, 127-40. Berkeley: University of California Press, 1986.

Basbaum, Ricardo. “Conversations 2004-15.” In Van Oldenborg, Morris, and Pethick, Wendelien van Oldenborgh: Amateur, 101-29.

Baucom, Ian. "History $4^{\circ}$ : Postcolonial Method and Anthropocene Time." Cambridge Journal of Postcolonial Literary Inquiry 1, no. 1 (March 2014): 123-42.

Baudrillard, Jean. "The Timisoara Syndrome: The Télécratie and the Revolution.” Columbia Documents of Architecture and Theory 2 (1993): 61-71.

- "Pataphysics of the Year 2000." In The Illusion of the End, translated by Chris Turner, 1-9. Cambridge: Polity Press, 1994.

- "The Timisoara Massacre." In The Illusion of the End, 54-61.

. Symbolic Exchange and Death. Translated by Iain Hamilton Grant. London: Sage, 2017.

Bauer, Ute Meta, and Anca Rujoiu. “On 'The Sovereign Forest.' Ute Meta Bauer and Anca Rujoiu in conversation with Amar Kanwar.” Afterall, 49 (Spring/Summer 2020), https://www.afterall. org/journal/issue.49/on-the-sovereign-forest.

Baumann, Stephanie. “'Here goes B. wrong': Siegfried Kracauers Anmerkungen zu Benjamins 'Über den Begriff der Geschichte.” Benjamin-Studien 3 (2014a): 31-44.

-Im Vorraum der Geschichte: Siegfried Kracauers "History: The last things before the last”. Konstanz: Konstanz University Press, 2014b.

Baumgärtel, Tilman. Southeast Asian Independent Cinema: Essays, Documents, Interviews. Hong Kong: Hong Kong University Press, 2012.

—. "'I make films for myself.' Interview with Apichatpong Weerasethakul.” In Southeast Asian Independent Cinema, 179-290.

Baumgartner, Hans Michael, and Jörn Rüsen, eds. Historische Objektivität: Aufsätze zur Geschichtstheorie. Göttingen: Vandenhoeck \& Ruprecht, 1975.

Beckmann, Anne Marie, et al. “Making History.” In Horvay, Making History, 10-19.

Beckstette, Sven. "Das Historienbild im 20. Jahrhundert: Künstlerische Strategien zur Darstellung von Geschichte in der Malerei nach dem Ende der klassischen Bildgattungen." PhD diss., Freie Universität Berlin, 2010. http://www.diss.fu-berlin.de/diss/receive/FUDISS_ thesis_000000018889.

Benjamin, Walter. “Central Park.” New German Critique 34 (Winter, 1985), 50.

- "Rigorous Study of Art. On the First Volume of the Kunstwissenschaftliche Forschungen." Translated by Thomas Y. Levin. October 47 (Winter 1988): 84-90.

- Gesammelte Schriften. Edited by Rolf Tiedemann and Hermann Schweppenhäuser, Frankfurt am Main: Suhrkamp, 1991.

- Selected Writings. 4 vols. Edited by Michael W. Jennings. Cambridge, MA: Harvard University Press, 1996-2003.

- "The Philosophy of History of the Late Romantics and the Historical School." In Selected Writings. Vol. 1, 1913-1926, 284-285.

—. "The Author as Producer." In Selected Writings. Vol. 2, 1931-1934, 762-782.

_. "The Crisis of the Novel." In Selected Writings. Vol. 2, 1931-1934, 299-304. 
—_. "Excavation and Memory." In Selected Writings. Vol. 2, 1931-1934, 576.

260-285.

- "On the Concept of History." In Selected Writings. Vol. 4, 1938-1940, 389-400.

- The Arcades Project. Translated by Howard Eiland and Kevin McLaughlin. Cambridge, MA: Harvard University Press, 1999.

- Illuminations. Translated by Harry Zohn, edited by Hannah Arendt. New York: Schocken Books, 2007

—. "Theses on the Philosophy of History." In Illuminations, 253-64.

- Origin of the German Trauerspiel. Translated by Howard Eiland, Cambridge, MA: Harvard University Press, 2019.

Bentley, Michael, ed. Companion to Historiography, London: Routledge, 1997.

Berardi, Franco. After the Future. Edited by Gary Genosko and Nicholas Thoburn. Edinburgh: AK Press, 2011.

Bergson, Henri. "Memory of the Present and False Recognition.” In Mind-Energy. Lectures and Essays, edited by Herbert Wildon Carr, 134-85. New York: H. Holt, 1920.

Bernet, Rudolf. "Heimweh und Nostalgie." In "Pathos": Konturen eines kulturwissenschaftlichen Grundbegriffs, edited by Kathrin Busch and Iris Därmann, 103-18. Bielefeld: transcript, 2007. Bernheim, Ernst. Lehrbuch der historischen Methode. Leipzig: Duncker und Humblot, 1889.

Berrebi, Sophie. “'The Story of Muriel cannot be told': Alain Resnais, Wendelien van Oldenborgh and How to Decolonise the Document." Simulacrum - Beyond the Horizon 18, no. 2-3 (2010): 98-101, https://sophieberrebi.net/filter/2010/The-Story-of-Muriel-cannot-be-toldAlain-Resnais-Wendelien-van.

- The Shape of Evidence: Contemporary Art and the Document. Amsterdam: Valiz, 2014.

Bertaux, Françoise, ed. Les inquiets: Yael Bartana, Omer Fast, Rabih Mroué, Ablam Shibli, Akram Zaatari, cinq artistes sous la pression de la guerre. Paris: Editions du Centre Pompidou, 2008.

Beshty, Walead, ed. Ethics. London: Whitechapel Gallery, 2015.

Bhimji, Zarina. Zarina Bhimji: Jangbar. Nottingham: New Art Exchange, 2015.

—. "Outline of a Film.” In Okeke-Agulu, “Conversation with Zarina Bhimji,” 74.

Biemann, Ursula. "Geochemistry \& Other Planetary Perspectives.” In Davis and Turpin, Art in the Anthropocene, 117-30.

Bilger, Burkhard. “The Possibilian.” The New Yorker, April 18, 2011, https://www.newyorker. com/magazine/2011/04/25/the-possibilian.

Bing, Gertrud. “A. M. Warburg.” Journal of the Warburg and Courtauld Institutes 28 (1965): 299-313.

Birnbaum, Daniel. Chronology. New York: Lukas \& Sternberg, 2005.

Bishop, Claire. "Delegated Performance: Outsourcing Authenticity." In Artificial Hells: Participatory Art and the Politics of Spectatorship, 219-39. London: Verso, 2012.

Blackson, Robert. "Once More ... With Feeling: Reenactment in Contemporary Art and Culture." Art Journal 66, no. 1 (Spring 2007): 28-40.

Bloch, Marc. The Historian's Craft. Translated by Peter Putnam. Manchester: Manchester University Press, 1967.

—: Histoire et Historiens, edited by Etienne Bloch, Paris: Armand Colin, 1995.

Blocker, Jane. Becoming Past: History in Contemporary Art, Minneapolis: University of Minnesota Press, 2015.

Blumenstein, Ellen, ed. Kader Attia: Transformations. Leipzig: Spector Books, 2014.

Blümlinger, Christa. Kino aus zweiter Hand: Zur Ästhetik materieller Aneignung im Film und in der Medienkunst. Berlin: Vorwerk 8, 2009.

- "La mémoire, moteur des images: Les variations d'Oncle Boonmee chez Apichatpong Weerasethakul." Traffic 76 (Winter 2010): 12-21.

"Film as the art of passages. Apichatpong's Weerasethakul Variations on 'Boonmee." In Kernbauer, Kunstgeschichtlichkeit, 199-215. 


\section{Bibliography}

Böhler, Natalie. "Fiction, Interrupted. Discontinuous Illusion and Regional Performance Traditions in Contemporary Thai Independent Film.” In Baumgärtel, Southeast Asian Independent Cinema, 59-67.

- "Globalized Haunting: The Transnational Spectral in Apichatpong's Syndromes and a Century and its Reception." In Bräunlein and Lauser, Ghost Movies in Southeast Asia and Beyond, 221-36.

Bolle, Willi. “Geschichte.” In Opitz and Wizisla, Benjamins Begriffe, 399-442.

Bonneuil, Christophe, and Jean-Baptiste Fressoz, eds. The Shock of the Anthropocene: The Earth, History and Us. Translated by David Fernbach. London: Verso, 2016.

Borchardt-Hume, Achim, Kathleen Bühler, and Doro Globus, eds. Zarina Bhimji. London: Ridinghouse, 2012.

Bossé, Laurence, ed. Dominique Gonzalez-Foerster, Pierre Huyghe, Philippe Parreno. Paris: Edition of the Réunion des musées nationaux, 1998.

Bourdon, Jérôme. "Live Television Is Still Alive: On Television As an Unfulfilled Promise." Media, Culture \& Society 22, no. 5 (2000): 531-56.

Boyce, Sonia. "Interview with Zarina Bhimji." In McGregor, Zarina Bhimii: I Will Always be Here, n. p.

Boyd, Kelly, ed. Encyclopedia of Historians and Historical Writing. 2 vols. London: Fitzroy Dearborn Publishers, 1999.

Boym, Svetlana. The Future of Nostalgia. New York: Basic Books, 2001.

Bradley, Will, and Charles Esche, eds. Art and Social Change: A Critical Reader. London: Tate Publishing, 2007.

Brauner, Christian. Risikolandschaft der Zukunft. Zurich: Schweizerische RückversicherungsGesellschaft，2004. http://www.pharma.gally.ch/UserFiles/File/Risikolandschaft $\% 20 \mathrm{der} \% 20$ Zukunft \%20Swissre.pdf.

Bräunlein, Peter J., and Andrea Lauser, eds. Ghost Movies in Southeast Asia and Beyond: Narratives, Cultural Contexts, Audiences. Leiden: Brill, 2016.

Breitwieser, Sabine, ed. Kunst/Geschichten: Art/Histories. Munich: Hirmer, 2014.

Breton, André. L'amour fou. Paris: Gallimard, 1937.

Briefel, Aviva. "On the 1886 Colonial and Indian Exhibition." In Branch: Britain, Representation and Nineteenth-Century History, http://www.branchcollective. org/?ps_articles=aviva-briefel-on-the-1886-colonial-and-indian-exhibition.

British Empire Exhibition 1924, Wembley, London, April-October 1924, Handbook of general information. London, Glasgow, and Manchester, 1924.

Brown, Wendy. "Resisting Left Melancholy." boundary 2, vol. 26, no. 3 (Fall 1999): 19-27.

Bucher, François. “Television (an address)." Journal of Visual Culture 4, no. 1 (2005): 5-15.

Buchmann, Sabeth. "Putting History to the Test." Parkett 93 (2013): 163-67.

Buchmann, Sabeth, Ilse Lafer, and Constanze Ruhm, eds. Putting Rehearsals to the Test: Practices of Rehearsal in Fine Arts, Film, Theater, Theory, and Politics. Berlin: Sternberg Press, 2016.

Buck-Morss, Susan. The Dialectics of Seeing: Walter Benjamin and the Arcades-Project. Cambridge, MA: MIT Press, 1989.

-Dreamworld and Catastrophe: The Passing of Mass Utopia in East and West. Cambridge, MA: MIT Press, 2002.

Buckingham, Matthew. "The Truth about Abraham Lincoln." In Kreuger, Messages from the Unseen, 196-205.

—. "Excerpt from an unpublished Interview with Ralph Pendrel." In Cullinan, Tacita Dean: Film, 57.

—_. "Muhheakantuck—Everything Has a Name.” In Maria Hlavajova, Jill Winder, and Binna Choi, On Knowledge Production: A Critical Reader in Contemporary Art, 16-37. Utrecht: BAK, Basis voor Actuele Kunst, 2008.

Buden, Boris. "The Revolution of 1989: The Past of Yet Another Illusion.” In The Manifesta Decade: Debates on Contemporary Art Exhibitions and Biennials in Postwall Europe, edited by Barbara Vanderlinden and Elena Filipovic, 113-21. Cambridge, MA: MIT Press, 2005. 
" "In Memory of Utopia or In the Utopia of Memory. An art that interpellates subjects as individuals." In Martínez, Deimantas Narkevičius: The Unanimous Life, 81-88.

Bühl, Lena. "Die Bewahrung bemalter PE- und PVC-Folien. Fragile Gemälde im Bildzyklus 'SIEV-X. Zu einem Fall von verschärfter Flüchtlingspolitik' von Dierk Schmidt.” Diploma thesis, Staatliche Akademie der Bildenden Künste Stuttgart, 2013.

Butler, Maeve, ed. For Tomorrow for Tonight: Apichatpong Weerasethakul. Dublin: Irish Museum of Modern Art, 2011.

Caldecott, Andrew. Report on the Malaya Pavilion, British Empire Exhibition (with Appendix). Singapore: Government Printing Office, 1926.

Caldwell, John T. Televisuality: Style, Crisis, and Authority in American Television. New Brunswick: Rutgers University Press, 1995.

- "Live Slippages: Performing and Programming Televisual Liveness." In Live is Life: Mediale Inszenierungen des Authentischen, edited by Gerd Hallenberger and Helmut Schanze, 21-46. Baden-Baden: Nomos, 2000.

—. "New Media/Old Augmentations: Television, the Internet, and Interactivity." In Realism and "Reality" in Film and Media, edited by Anne Jerslev, 253-74. Copenhagen: Museum Tusculanum Press, 2002.

Carrion-Murayari, Gary, and Massimiliano Gioni, eds. Apichatpong Weerasethakul. New York: New Museum, 2011.

—_. "Interview with Apichatpong Weerasethakul." In Carrion-Murayari and Gioni, Apichatpong Weerasethakul, 10-14.

Carson, Juli. “Art of the Impossible. The Jewish Renaissance Movement in Poland (JRMiP).” In Pacher and Bartana, Wenn Ihr wollt, ist es kein Traum: Yael Bartana, 29-37.

Caruth, Cathy. Unclaimed Experience: Trauma, Narrative, and History. Baltimore: Johns Hopkins University Press, 1996.

Carvajal, Rina, ed. Tacita Dean: Film Works. Milan: Edizioni Charta, 2007.

Chakrabarty, Dipesh. Provincializing Europe: Postcolonial Thought and Historical Difference. Princeton: Princeton University Press, 2008.

—. "The Climate of History: Four Theses." Critical Inquiry 35, no. 2 (2009): 197-222.

Chanrochanakit, Pandit. "Deforming Thai Politics." Third Text 25, no. 4 (2011): 419-29.

Choi, Binna. "When We Assemble." In Oldenborgh, Morris, and Pethick, Wendelien van Oldenborgh: Amateur, 185-203.

Choi, Binna, and Wendelien van Oldenborgh, eds. Wendelien van Oldenborgh: A Well Respected Man, or Book of Echoes. Utrecht: Casco, 2010.

Chris, Cynthia, ed. Andrea Geyer, Sharon Hayes: History is Ours. Heidelberg: Kehrer, 2009.

Christian, David. Maps of Time: An Introduction to Big History, Berkeley: University of California Press, 2004.

Christöphler, Jörg. Geschichte als Anschauung: Geschichtstheoretische Reflexionen über Historiographie von der Aufklärung bis zum Historismus. Kamen: Hartmut Spenner, 2015.

Cichocki, Sebastian, and Galit Eilat, eds. A Cookbook for Political Imagination. Warsaw: Sternberg Press, 2011.

Clark, T. J. "For a Left With No Future.” New Left Review 74 (March-April 2012): 53-75.

Clendinning, Anne. “On The British Empire Exhibition, 1924-25.” In Branch: Britain, Representation and Nineteenth-Century History, http://www.branchcollective.org/?ps_articles=anne-clendinningon-the-british-empire-exhibition-1924-25.

Clifford, James. “On Ethnographic Surrealism.” In The Predicament of Culture: Twentieth-Century Ethnography, Literature, and Art, 117-51. Cambridge, MA: Harvard University Press, 1988.

Collingwood, Robin G. The Idea of History. Oxford: Oxford University Press, 1994.

Colomina, Beatriz. "Bioscope Architecture." In Cotter, Wendelien van Oldenborgh: Cinema Olanda, 51-59.

“A Conversation between Yael Bartana, Galit Eilat and Charles Esche.” In Ljungberg and Nilsson, Och Europa kommer att häpna, 42-169.

Correia, Alice. “Zarina Bhimji: Light, Time and Dislocation.” Third Text 26, no. 3 (2012): 359-63. 


\section{Bibliography}

. "Diasporic Returns." Third Text 31, no. 2-3 (2017): 321-40.

Cotter, Lucy, ed. Wendelien van Oldenborgh: Cinema Olanda. Berlin: Hatje Cantz, 2017.

- "Cinema Olanda. Projecting the Netherlands." In Wendelien van Oldenborgh, 11-21.

Cotter, Suzanne. "The Documentary Turn: Surpassing Tradition in the Work of Walid Raad and Akram Zaatari.” In Contemporary Art in the Middle East, edited by Paul Sloman, 50-57. London: Black Dog Publishing, 2009.

Couldry, Nick. "Liveness, 'Reality' and the Mediated Habitus From Television to the Mobile Phone." Communication Review 7, no. 4 (2004): 353-61.

Cowie, Elizabeth. “The Spectacle of Actuality." In Collecting Visible Evidence, edited by Jane M. Gaines and Michael Renov, 19-45. Minneapolis: University of Minnesota Press, 1999.

Croce, Benedetto. Die Geschichte auf den allgemeinen Begriff der Kunst gebracht. Hamburg: Meiner, 1984.

- La storia ridotta sotto il concetto generale dell'arte. Edited by Giuseppe Galasso. Milan: Adelphi 2017.

Cullinan, Nicholas, ed. Tacita Dean: Film. London: Tate Publishing, 2011.

Cundall, Frank, ed. Reminiscences of the Colonial and Indian Exhibition. London: Published with the sanction of the Royal Commission by William Clowes \& Sons, 1886.

Czirak, Adam, Sophie Nikoleit, Friederike Oberkrome, Verena Straub, Robert Walter-Jochum and Michael Wetzels, eds. Performance zwischen den Zeiten: Reenactments und Preenactments in Kunst und Wissenschaft. Bielefeld: transcript, 2019.

Dahl, Øyvind. "When the Future Comes from Behind: Malagasy and Other Time Concepts and Some Consequences for Communication." International Journal of Intercultural Relations 19, no. 2 (Spring 1995): 197-209.

Dainton, Barry. "Temporality, Philosophical Perspectives." In The Oxford Companion to Consciousness, edited by Tim Bayne, Axel Cleeremans, and Patrick Wilken, 625-28. Oxford: Oxford University Press, 2010.

Damisch, Hubert. Le jugement de Pâris. Paris: Flammarion, 1992.

Daney, Serge. "Montage Obligatory: The War, the Gulf and the Small Screen.” Rouge Magazine Archive, 2006. Translated by Laurent Kretzschmar and Rouge, http://www.rouge.com.au/8/ montage.html.

—. "Nicolae und Elena vermachen ihre Leichen dem Fernsehen." In Sei, Von der Bürokratie zur Telekratie, 86-93.

Daniel, Noel, and Doug Aitken, eds. Broken Screen: 26 Conversations with Doug Aitken; Expanding the Image, Breaking the Narrative. New York: Distributed Art Publishers, 2006.

Dann, Otto, Norbert Oellers, and Ernst Osterkamp, eds. Schiller als Historiker. Stuttgart: Metzler, 1995.

Daston, Lorraine, and Peter Galison. "The Image of Objectivity." Representations 40 (1992): 81-128.

- Objectivity. New York: Zone Books, 2007.

Davis, Heather, and Etienne Turpin, eds. Art in the Anthropocene: Encounters Among Aesthetics, Politics, Environments and Epistemologies. London: Open Humanities Press, 2015.

— "Art \& Death: Lives Between the Fifth Assessment \& the Sixth Extinction." In Art in the Anthropocene, 3-29.

Dayan, Daniel. Media Events: The Live Broadcasting of History. Cambridge, MA: Harvard University Press, 1992.

Dean, Tacita. Seven Books. Vol. 1, Selected Writings. Paris and Göttingen: ARC, Musée d'Art moderne de la Ville de Paris, and Steidl, 2003.

-. "Pie." In Selected Writings, [n. p].

—. "Historical Fiction." Artforum 42, no. 7 (March 2004): 146-51.

- "Analogue." In Vischer and Friedli, Tacita Dean: Analogue: Drawings 1991-2006, 8-9.

De Bolla, Peter. “Disfiguring History.” Diacritics 16, no. 4 (Winter 1986): 48-58.

De Certeau, Michel. "Histoire et structure: Débat entre Michel de Certeau, Pierre Nora et Raoul Girardet.” Recherches et débats 68 (1970): 165-95. 
. The Writing of History. Translated by Tom Conley.New York: Columbia University
Press, 1992a.
. The Mystic Fable. Vol. 1, The Sixteenth and Seventeenth Centuries. Translated by Michael
B. Smith. Chicago: University of Chicago Press, 1992b.
De Grazia, Margreta. "Anachronism." In Cultural Reformations: Medieval and Renaissance in
Literary History, edited by Brian Cummings and James Simpson, 13-32. Oxford: Oxford
University Press, 2010.
De Groot, Jerome. Consuming History: Historians and Heritage in Contemporary Popular
Culture. London: Routledge, 2009 .

De la Fuente, JuanMa, Julio Santiago, Antonio Román, Cristina Dumitrache and Daniel Casasanto. "When You Think About It, Your Past Is in Front of You: How Culture Shapes Spatial Conceptions of Time.” Psychological Science 25, no. 9 (2014): 1682-90.

De Lauretis, Teresa. Freud's Drive: Psychoanalysis, Literature and Film. Basingstoke: Palgrave Macmillan, 2008.

Deleuze, Gilles. Cinema 1: The Movement-Image. Translated by Hugh Tomlinson and Barbara Habberjam. Minneapolis: University of Minnesota Press, 1986.

- Cinema 2: The Time-Image. Translated by Hugh Tomlinson and Robert Galeta. Minneapolis: University of Minnesota Press, 1989.

Deller, Jeremy. The English Civil War Part II: Personal Accounts of the 1984-85 Miners' Strike. London: Artangel, 2001.

Delorme, Stéphane, and Jean-Philippe Tessé. "Differentes réalités: Entretien avec Apichatpong Weerasethakul.” Cahiers du cinema 657 (June 2010): 10-12.

Demos, T. J. Return to the Postcolony: Specters of Colonialism in Contemporary Art. Berlin: Sternberg Press, 2013a.

—. "Ghostly Affect: Zarina Bhimji's Yellow Patch." In Return to the Postcolony, 72.

- The Migrant Image: The Art and Politics of Documentary During Global Crisis. Durham: Duke University Press, 2013b.

- Against the Anthropocene: Visual Culture and Environment Today. Berlin: Sternberg Press, 2017.

Derieux, Florence. “Apichatpong Weerasethakul: In-Between State.” Flash Art International 274 (October 2010): 92-95.

Derrida, Jacques. "Archive Fever: A Freudian Impression." Translated by Eric Prenowitz. Diacritics 25, no. 2 (Summer 1995): 9-63.

- Specters of Marx: The State of Guilt, the Work of Mourning and the New International. Translated by Peggy Kamuf. London: Verso, 2008.

Devi, Mahasweta. Breast Stories. Translated and with an introduction by Gayatri Chakravorty Spivak. Calcutta: Seagull Books 2014.

Dević, Ana. “The Head” In Scotini and Caffoni, Deimantas Narkevičius, 164-71.

Dewan, Deepali. “Tender Metaphor. The Art of Zarina Bhimji.” In Tawadros, Fault Lines, 13137. London: Institute of International Visual Arts, 2003.

- "Draupadi." Translated by Gayatri Chakravorty Spivak. South as a State of Mind 7, documenta 14, no. 2 (2016): 201-12, https://www.documenta14.de/en/south/468_draupadi.

Diawara, Manthia. “Kader Attia: A Poetics of Re-Appropriation.” In Attia, The Repair, 5-13.

Didi-Huberman, Georges. Devant le temps: Histoire de l'art et anachronisme des images. Paris: Les Éditions de Minuit, 2000.

- "Before the Image, Before Time: The Sovereignty of Anachronism." In Compelling Visuality: The Work of Art in and out of History, edited by Claire Farago and Robert Zwijnenberg, 31-44. Minneapolis: University of Minnesota Press, 2003.

- Images in Spite of All: Four Photographs from Auschwitz. Translated by Shane B. Lillis. Chicago: University of Chicago Press, 2008.

—. "How to Open Your Eyes." In Ehmann, Harun Farocki, 38-50.

- The Surviving Image: Phantoms of Time and Time of Phantoms. Translated by Harvey

Mendelsohn. University Park: The Pennsylvania State University Press, 2017. 


\section{Bibliography}

Dilthey, Wilhelm. Der Aufbau der geschichtlichen Welt in den Geisteswissenschaften. Edited by Manfred Riedel. Frankfurt am Main: Suhrkamp 1981.

- Selected Works. Vol. 1, Introduction to the Human Sciences, edited by Rudolf A. Makkreel and Frithjof Rodi. Princeton: Princeton University Press, 1989.

- Selected Works. Vol. 3, The Formation of the Historical World in the Human Sciences, edited by Rudolf A. Makkreel and Frithjof Rodi. Princeton: Princeton University Press, 2002.

— Briefwechsel. Vol. 2, 1882-1895, edited by Gudrun Kühne-Bertram and Hans-Ulrich Lessing. Göttingen: Vandenhoeck \& Ruprecht, 2015.

Dirks, NicholasB. "History as a Sign of the Modern." Public Culture 2, no. 2 (Spring 1990): 25-32.

Doane, Mary Ann. “Information, Crisis, Catastrophe.” In Logics of Television: Essays in Cultural Criticism, edited by Patricia Mellencamp, 222-39. Bloomington: University of Indiana Press, 1990.

- The Emergence of Cinematic Time: Modernity, Contingency, the Archive. Cambridge, MA: Harvard University Press, 2002.

Donnelly, Mark and Claire Norton. Doing History. London: Routledge, 2011.

Douglas, Ann. The Feminization of American Culture. New York: Knopf, 1977.

Douglas, Stan, and Christopher Eamon, eds. Art of Projection. Ostfildern: Hatje Cantz, 2009.

Downey, Anthony, ed. Don't Shrink Me to the Size of a Bullet: The Works of Hiwa K. Cologne: König, 2017.

Draxler, Helmut. "Was tun? Was lassen? Passivität und Geschichte.” In Theorien der Passivität, edited by Helmut Draxler and Katrin Busch, 196-215. Munich: Fink, 2013.

Dray, William H. History as Re-Enactment: R. G. Collingwood's Idea of History. Oxford: Oxford University Press, 2001.

Droysen, Johann Gustav. Outlines of the Principles of History. Translated by E. Benjamin Andrews. Boston: Ginn \& Company, 1897.

- Texte zur Geschichtstheorie mit ungedruckten Materialien zur "Historik." Edited by Günter Birtsch and Jörn Rüsen. Göttingen: Vandenhoeck \& Ruprecht, 1972.

- Historik. Vol. 1, Rekonstruktion der ersten vollständigen Fassung der Vorlesungen (1857); Grundriß der Historik in der ersten handschriftlichen (1857/1858) und in der letzten gedruckten Fassung (1882), edited by Peter Leyh. Stuttgart-Bad Cannstatt: FrommannHolzboog, 1977.

- Historik. Vol. 2, Texte im Umkreis der Historik, edited by Horst Walter Blanke. StuttgartBad Cannstatt: Frommann-Holzboog, 2007.

. "Die Droysen zuzuschreibenden Beiträge zu dem von A. Schöll und ihm verfaßten Bericht über die Berliner Kunst-Ausstellung (1834).” In Texte im Umkreis der Historik, 47-79.

Dziewior, Yilmaz. "Keine Atempause: Geschichte wird gemacht, es geht voran." In Dziewior and Oetker, Wessen Geschichte, 8-13.

Dziewior, Yilmaz, and Brigitte Oetker, eds. Wessen Geschichte: Vergangenheit in der Kunst der Gegenwart; Jahresring 56 - Jahrbuch für moderne Kunst. Cologne: König, 2009.

Eagleman, David M. "Human Time Perception and its Illusions." Current Opinion in Neurobiology 18, no. 2 (April 2008): 131-36.

- "Temporality, Scientific Perspectives." In The Oxford Companion to Consciousness, edited by Tim Bayne, Axel Cleeremans, and Patrick Wilken, 628-30. Oxford: Oxford University Press, 2010.

Eagleman, David M. and Alex O. Holcombe. "Causality and the Perception of Time." Trends in Cognitive Sciences 6, 8 (2002): 323-25.

Ehmann, Antje, ed. Harun Farocki: Against What? Against Whom? London: König Books, 2009.

Elsaesser, Thomas. Harun Farocki: Working on the Sightlines. Amsterdam: Amsterdam University Press, 2004.

- "Harun Farocki: Filmmaker, Artist, Media Theorist." In Harun Farocki: Working on the Sightlines, 11-40.

- "Film Festival Networks: The New Topographies of Cinemas in Europe." In European Cinema: Face to Face with Hollywood, 82-107. Amsterdam: Amsterdam University Press, 2005. 
Enwezor, Okwui, “Archive Fever: Photography Between History and the Monument.” In Archive Fever: Uses of the Document in Contemporary Art, 11-51. Göttingen: Steidl, 2008.

. "The Postcolonial Constellation: Contemporary Art in a State of Permanent Transition." In Smith, Enwezor, and Condee, Antinomies of Art and Culture, 207-29.

- "Documentary/Vérité. Bio-Politics, Human Rights and the Figure of 'Truth' in Contemporary Art.” In Lind and Steyerl, The Greenroom, 62-102.

Enwezor, Okwui, Carlos Basualdo, Ute Meta Bauer, Susanne Ghez, Sarat Maharaj, Mark Nash, and Octavio Zaya, eds. Experiments with Truth: Transitional Justice and the Processes of Truth and Reconciliation; Documenta11_Platform2. Ostfildern-Ruit: Hatje Cantz, 2002.

Epstein, Helen. “Idi Amin's Israeli Connection.” The New Yorker, June 27, 2016, https://www. newyorker.com/news/news-desk/idi-amins-israeli-connection.

Ernst, Wolfgang, and Harun Farocki. “Towards an Archive for Visual Concepts.” In Elsaesser, Harun Farocki: Working on the Sightlines, 261-83.

Eugenides, Jeffrey. “Tacita Dean.” Bomb Magazine, 95, April 1, 2006, https://bombmagazine.org/ articles/tacita-dean/.

Fabian, Johannes. Time and the Other: How Anthropology Makes Its Object. New York: Columbia University Press, 2002.

Falicov, Tamara L. “'The Festival Film': Film Festivals Funds as Cultural Intermediaries.” In Film Festivals: History, Theory, Method, Practice, edited by Marijke de Valck, Brendan Kredell, and Skadi Loist, 227-47. London: Routledge 2016.

Farmer, Brett. "Apichatpong Weerasethakul, Transnational Poet of the New Thai Cinema: Blissfully Yours/Sud Sanaeha.” Senses of Cinema, 38 (January-March 2006), http://sensesofcinema.com/2006/cteq/blissfully_yours/.

Farocki, Harun. Bilderschatz: 3rd International Flusser Lecture. Cologne: König, 2001a.

—. Nachdruck/Imprint, Texte/Writings. Edited by Susanne Gaensheimer. Berlin: Vorwerk 8, 2001b.

—. "Substandard." In Nachdruck/Imprint, Texte/Writings, 248-66.

_. "Written Trailers." In Ehmann, Harun Farocki, 220-42.

Farr, Ian, ed. Memory. Cambridge, MA: MIT Press, 2012.

Fer, Briony. “A Natural History of Chance.” In Carvajal, Tacita Dean: Film Works, 6-41.

Ferguson, Russell, ed. Art and Film since 1945: Hall of Mirrors. New York: Monacelli Press, 1996.

Feuer, Jane. "The Concept of Live Television: Ontology as Ideology.” In Regarding Television: Critical Approaches - An Anthology, edited by E. Ann Kaplan, 12-21. Frederick: University Publications of America, 1983.

Fiduccia, Joanna. “Omer Fast: A Multiple 'I'” UOVO 17 (2008): 156-76.

Fisher, Mark. Capitalist Realism: Is There No Alternative? Winchester: Zero Books, 2009.

. Ghosts of My Life: Writings on Depression, Hauntology and Lost Futures. Winchester: Zero Books, 2014.

Focillon, Henri. Vie des formes. First published 1934. Paris: Presses Universitaires France, 2010.

- The Life of Forms in Art. Translated by Charles Beecher Hogan and George Kubler. New Haven: Yale University Press, 1942.

- The Year 1000. N.p: F. Ungar, 1969.

Folkerts, Hendrik. "Twenty-Two Hours: Bouchra Khalili and Hendrik Folkerts in Conversation.” Mousse Magazine 64 (Summer 2018): 240-47.

Foster, Hal. "The Artist as Ethnographer." In The Return of the Real: The Avant-Garde at the End of the Century, 171-204. Cambridge, MA: MIT Press, 1996.

—. "An Archival Impulse." October 110 (Fall 2004a): 3-22.

- "Vision Quest: The Cinema of Harun Farocki." Artforum 43, no. 3 (November 2004b): 156-61.

Foucault, Michel. "Nietzsche, Genealogy, History." In Language, Counter-Memory, Practice. Selected Essays and Interviews, edited by Donald F. Bouchard, 139-64. Ithaca: Cornell University Press, 1980. 


\section{Bibliography}

. The Archaeology of Knowledge. Translated by A. M. Sheridan Smith. London: Routledge, 1989.

Freeman, Elizabeth. Time Binds: Queer Temporalities, Queer Histories. Durham: Duke University Press, 2010.

Frei, Norbert, Dirk van Laak, and Michael Stolleis, eds. Geschichte vor Gericht: Historiker, Richter und die Suche nach Gerechtigkeit. Munich: Beck, 2000.

Fritzsche, Peter. "Specters of History: On Nostalgia, Exile, and Modernity." The American Historical Review 106, no. 5 (December 2001): 1587-1618.

Frohne, Ursula, Mona Schieren, and Jean-François Guiton, eds. Present Continuous Past(s): Media Art; Strategies of Presentation, Mediation and Dissemination. Vienna: Springer, 2005.

Frohne, Ursula, and Lilian Haberer, eds. Kinematographische Räume: Installationsästhetik in Film und Kunst. Munich: Fink, 2012.

"From Politics to Poetry: Zarina Bhimji in Conversation with Achim Borchardt-Hume and Kathleen Bühler.” In Borchardt-Hume, Bühler, and Globus, Zarina Bhimji, 33-43.

Fulda, Daniel. Wissenschaft aus Kunst: Die Entstehung der modernen deutschen Geschichtsschreibung 1760-1860. Berlin: de Gruyter, 1996.

Fürnberg, Louis. Gesammelte Werke in sechs Bänden. Vol. 1, Gedichte: 1927-46, edited by Lotte Fürnberg. Berlin: Aufbau, 1964.

- Gesammelte Werke in sechs Bänden. Vol. 5, Reden, Aufsätze, edited by Lotte Fürnberg. Berlin: Aufbau, 1971.

Gabanyi, Anneli Ute. Die unvollendete Revolution: Rumänien zwischen Diktatur und Demokratie. Munich: Piper, 1990.

- "Die rumänische Revolution von 1989." In Zwischen Diktatur und Demokratie: Erfahrungen in Mittelost- und Südosteuropa, edited by Michael Gehler and Imke Scharlemann, 241-59. Hildesheim: Olms, 2013.

Gadamer, Hans-Georg. "Diltheys Verstrickung in die Aporien des Historismus.” In Rodi and Lessing, Materialien zur Philosophie Wilhelm Diltheys, 286-315.

Gaensheimer, Susanne, ed. Raqs Media Collective: Everything Else Is Ordinary. Bielefeld: Kerber, 2018.

Gamper, Michael, and Helmut Hühn. Was sind ästhetische Eigenzeiten? Hannover: Wehrhahn, 2014.

Gaweewong, Gridthiya. “On Thai Artists and an Issue of Cultural Identity.” ApexArt, August 15, 2001, http://www.apexart.org/conference/gaweewong.htm.

Gaweewong, Gridthiya, ed. Apichatpong Weerasethakul: Primitive. Bangkok: The James H. W. Thompson Foundation, 2011.

Gb agency. “Omer Fast, Nostalgia.” Press release, Autumn 2010, http://www.gbagency.fr/en/330/ Omer-Fast-Nostalgia-/\#!/Press-release/site_textes/379.

Geimer, Peter. Ordnungen der Sichtbarkeit: Fotografie in Wissenschaft, Kunst und Technologie. Frankfurt am Main: Suhrkamp, 2002.

— . "Wer regiert den Autor? Über 'Regieren im Bildraum' von Tom Holert.” Texte zur Kunst 76 (December 2009): 152-55.

Gervinus, Georg. Grundzüge der Historik. Leipzig: Wilhelm Engelmann, 1837.

Geyer, Andrea. "Criminal Case 40/61 Reverb.” In Chris, Andrea Geyer, Sharon Hayes, 33-39.

Gibbons, Joan. Contemporary Art and Memory: Images of Recollection and Remembrance. London: I. B. Tauris, 2007.

Gierstberg, Frits. Documentary Now! Contemporary Strategies in Photography, Film and the Visual Arts. Rotterdam: NAi Publishers, 2005.

—. "The Big History Quiz." In Van der Stok, Gierstberg, and Bool, Questioning History, 44-57.

Gilbert, Alan. "Interview with Walid Ra'ad." Bomb Magazine, 81, October 1, 2002, https:// bombmagazine.org/articles/walid-raad.

Gili, Marta, ed. Bouchra Khalili: Blackboard. Paris: Les presses du reel, 2018.

. "A Populated Opacity: Conversation between Bouchra Khalili and Omar Berrada." In Bouchra Khalili: Blackboard, 163-69. 
Gillick, Liam. “Should the Future Help the Past?” In Bossé, Dominique Gonzalez-Foerster, Pierre Huyghe, Philippe Parreno, 8-17, http://www.liamgillick.info/home/texts/prevision.

- "Should the Future Help the Past? (Prevision: The Short Version)." Afterall 0 (1998/99): 104-9.

- "Selected Transcription from Talk at UN Plaza, Berlin.” Printed Project 6 (2006): 41-47.

Ginwala, Natasha, ed. Hearings: A Reader. Berlin: Sternberg Press, 2017, http://hearings.contour8.be/hearings.

Ginzburg, Carlo. The Judge and the Historian: Marginal Notes on a Late-Twentieth-Century Miscarriage of Justicer. Translated by Antony Shugaa, London: Verso, 1999.

Gludovatz, Karin. ed. Auf den Spuren des Realen: Kunst und Dokumentarismus. Vienna: Museum Moderner Kunst Stiftung Ludwig Wien, 2004.

Godfrey, Mark. “The Artist as Historian.” October 120 (Spring 2007): 140-72.

Godfrey Mark, T. J. Demos, Eyal Weizman, and Ayesha Hameed. "Rights of Passage.” Tate Etc. 19 (Summer 2010), http://www.tate.org.uk/context-comment/articles/rights-passage.

Golsan, Richard J., and Sarah M. Misemer, eds. The Trial That Never Ends. Hannah Arendt's Eichmann in Jerusalem in Retrospect, Toronto: University of Toronto Press, 2017.

Goodman, Jordan. "History and Anthropology." In Bentley, Companion to Historiography, 783-804.

Graeber, David. “Of Flying Cars and the Declining Rate of Profit.” The Baffler 19 (March 2012), http://thebaffler.com/salvos/of-flying-cars-and-the-declining-rate-of-profit.

Grafton, Anthony, and Daniel Rosenberg. Cartographies of Time: A History of the Timeline. New York: Princeton Architectural Press, 2010.

Green, David, and Peter Seddon, eds. History Painting Reassessed: The Representation of History in Contemporary Art. Manchester: Manchester University Press, 2000.

Greenhalgh, Paul. Ephemeral Vistas: The Expositions Universelles, Great Exhibitions and World's Fairs, 1851-1939, Manchester: Manchester University Press, 1988.

Greiert, Andreas. Erlösung der Geschichte vom Darstellenden: Grundlagen des Geschichtsdenkens bei Walter Benjamin 1915-1925. Munich: Fink 2011.

Griaule, Marcel. "Un coup de fusil.” Documents 1 (1930): 46.

Gronlund, Melissa. "Story Telling.” frieze 106 (April 2007): 120-25.

Groys, Boris. Under Suspicion: A Phenomenology of Media. Translated by Carsten Strathausen. New York: Columbia University Press, 2012.

—. "Answering a Call.” In Lingwood, Yael Bartana: And Europe Will Be Stunned, 134-39.

Gruijthuijsen, Krist, and November Paynter, eds. We All Laughed at Christopher Columbus. Frankfurt am Main: Revolver, 2007.

Grupińska, Anka. "Dear Founding Mothers and Founding Fathers of the Jewish Renaissance Movement in Poland!" in Cichocki and Eilat, A Cookbook for Political Imagination, 161-70.

Gruzinski, Serge. "From Holy Land to Open Your Eyes.” Translated by Hoda Fourcade Zeid. Paris: BlackJack éditions, 2012.

Gumbrecht, Hans Ulrich. After 1945: Latency as Origin of the Present. Stanford: Stanford University Press, 2013.

- Our Broad Present. Time and Contemporary Culture. New York: Columbia University Press, 2014.

Gunning, Tom. “Moving Away from the Index: Cinema and the Impression of Reality.” Differences 18 , no. 1 (2007): $29-52$.

Habermas, Jürgen. “Modernity vs. Postmodernity.” New German Critique 22 (1981): 3-14.

—. Die nachbolende Revolution. Frankfurt am Main: Suhrkamp, 1990.

" "Modernity: An Incomplete Project." Translated by Seyla Ben-Habib. In The AntiAesthetic: Essays on Postmodern Culture, edited by Hal Foster, 3-15. Port Townsend, WA: Bay Press, 1983.

Hadouchi, Olivier. “'African culture will be revolutionary or will not be': William Klein's Film of the First Pan-African Festival of Algiers (1969).” Third Text 25, no. 1 (2001): 117-28.

Hahn, Daniela, ed. Beyond Evidence: Das Dokument in den Künsten. Paderborn: Fink, 2016. 


\section{Bibliography}

Hall, Stuart. The Hard Road to Renewal: Thatcherism and the Crisis of the Left. London: Verso, 1988.

Hamilakis, Yannis. "Some Debts Can Never Be Repaid: The Archaeo-politics of the Crisis." Journal of Modern Greek Studies 34, no. 2 (October 2016): 227-64.

Hansen, Miriam Bratu. "The Mass Production of the Senses: Classical Cinema as Vernacular Modernism.” Modernism/Modernity 6, no. 2 (1999): 59-77.

- Cinema and Experience: Siegfried Kracauer, Walter Benjamin, and Theodor W. Adorno. Berkeley: University of California Press, 2012.

Haq, Nav. "Foresight into the New African Century." Kaleidoscope Magazine 5 (FebruaryMarch 2010): 26-29.

Haraway, Donna. "Situated Knowledges. The Science Question in Feminism and the Privilege of Partial Perspective.” Feminist Studies 14, no. 3 (Autumn 1988): 575-99.

Harrasser, Karin. Prothesen: Figuren einer lädierten Moderne. Berlin: Vorwerk 8, 2016.

Harrison, Rachel V., and Peter A. Jackson, eds. The Ambiguous Allure of the West: Traces of the Colonial in Thailand. Hong Kong: Hong Kong University Press, 2010.

Hartman, Saidiya. "Venus in Two Acts." Small Axe 12, no. 2 (2008): 1-14.

Hartog, François. Regimes of Historicity. Presentism and Experiences of Time. Translated by Saskia Brown. New York: Columbia University Press, 2015.

Haugbolle, Sune. "Public and Private Memory of the Lebanese Civil War." Comparative Studies of South Asia, Africa and the Middle East 25, no. 1 (2005): 191-203.

Hawthorne, Geoffrey. Plausible Worlds: Possibility and Understanding in History and the Social Sciences. Cambridge: Cambridge University Press, 1991.

Hegel, Georg Wilhelm Friedrich. Lectures on the Philosophy of World History: Introduction; Reason in History. Translated by H.B. Nisbet. Cambridge: Cambridge University Press, 1975.

- Lectures on the Philosophy of World History. Vol. 1, Manuscripts of the Introduction and the Lectures of 1822-23, edited and translated by Robert F. Brown and Peter C. Hodgson. Oxford: Clarendon Press, 2011.

Heidegger, Martin. Being and Time. Translated by Joan Stambaugh. Albany: State University of New York Press, 1996.

Hentschel, Linda, ed. Bilderpolitik in Zeiten von Krieg und Terror: Medien, Macht und Geschlechterverhältnisse. Berlin: b_books, 2008.

Herzfeld, Michael. "The Conceptual Allure of the West: Dilemmas and Ambiguities of CryptoColonialism in Thailand." In Harrison and Jackson, The Ambiguous Allure of the West, 173-86.

Hirsch, Marianne. The Generation of Postmemory: Writing and Visual Culture After the Holocaust. New York: Columbia University Press, 2012.

Hochdörfer, Achim, ed. Tacita Dean: Seven Books Grey. 7 vols. Göttingen: Steidl, 2011.

Höller, Christian. "Image Leaks: Dierk Schmidt's Critical Opening of a Permeable Medium." Afterall 29 (Spring 2012): 123-30.

Hofer, Johannes. "Medical Dissertation on Nostalgia by Johannes Hofer, 1688." Translated by Carolyn Kiser Anspach. The Bulletin of the Institute of the History of Medicine 6 (August 1934): 376-91.

Hoffmann, Jens, eds. A Little Bit of History Repeated. Paris: Edition Valerio, 2001.

Hofmann, Michael, Jörn Rüsen, and Mirjam Springer, eds. Schiller und die Geschichte. Munich: Fink, 2006.

Hoge, Warren. "Viscount Tonypandy, 88, Ex-Speaker of Commons, Dies." The New York Times, September 24, 1997, https://www.nytimes.com/1997/09/24/world/viscount-tonypandy-88-exspeaker-of-commons-dies.html.

Hohenberger, Eva, and Judith Keilbach, eds. Die Gegenwart der Vergangenheit: Dokumentarfilm, Fernsehen und Geschichte. Berlin: Vorwerk 8, 2003.

Holert, Tom. Imagineering: Visuelle Kultur und Politik der Sichtbarkeit. Cologne: Octagon, 2000.

- "The Apparition of the Documentary." In Gierstberg, Documentary Now!, 150-70.

- Regieren im Bildraum. Berlin: b_books, 2008. 
—. “Attention Span.” In Schaschl, Omer Fast: In Memory, 131-71.

. "Für eine meta-ethische Wende: Anmerkungen zur neueren Verantwortungsästhetik." Zeitschrift für Kunstgeschichte 4 (2018): 538-54.

Holmes, Brian. "Liar's Poker: Representation of Politics / Politics of Representation.” Springerin 1 (2003), https://www.springerin.at/en/2003/1/liars-poker.

Hopkins, "The Gilded Gaze: Wealth and Economies on the Colonial Frontier." In Latimer and Szymczyk, The documenta 14 Reader, 222-48.

Horn, Eva. The Future of Catastrophe: Imagining Disaster in the Modern Age. Translated by Valentine Pakis. New York: Columbia University Press, 2018.

Horvay, Andrea, ed. Making History. Ostfildern: Hatje Cantz, 2012.

Hruska, Jordan. "The Architecture of Apichatpong." Art in America online, September 28, 2010, https://www.artnews.com/art-in-america/interviews/apichatpong-joe-weerasethakul-56152.

Humboldt, Wilhelm von. "On the Historian's Task." History and Theory 6, no. 1 (1967): 57-71. Husserl, Edmund. On the Phenomenology of the Consciousness of Internal Time. Translated by James S. Churchill. The Hague: Martinus Nijhoff, 1964.

Hutcheon, Linda. The Politics of Postmodernism. London: Routledge, 1989.

- "Irony, Nostalgia, and the Postmodern." In Methods for the Study of Literature as Cultural Memory, edited by Raymond Vervliet and Annemarie Estor, 189-207. Amsterdam/ Atlanta: Editions Rodopi, 2000.

- A Poetics of Postmodernism: History, Theory, Fiction. New York: Routledge, 2005.

Huyssen, Andreas. “Mass Culture as Woman: Modernism's Other.” In Studies in Entertainment: Critical Approaches to Mass Culture, edited by Tania Modleski, 188-207. Bloomington: Indiana University Press, 1986.

- Twilight Memories: Marking Time in a Culture of Amnesia. New York: Routledge, 1995. . "Memories of Utopia." In Twilight Memories, 85-101.

Hyun, Sinae. "Indigenizing the Cold War: Nation-Building by the Border Patrol Police of Thailand, 1945-1980.” PhD diss., University of Wisconsin-Madison 2014, https://depot. library.wisc.edu/repository/fedora/1711.dl:JKW6YYIA5ESL28Y/datastreams/REF/content.

Iggers, Georg G. The German Conception of History: The National Tradition of Historical Thought from Herder to the Present. Middletown: Wesleyan University Press, 1968.

Illustrated Guide to British Malaya. [Kuala Lumpur?]: Malayan Governments, 1924.

Ingawanij, May Adadol. "Hyperbolic Heritage: Bourgeois Spectatorship and Contemporary Thai Cinema.” PhD diss., London, University of London, 2007.

_. "Playing for Real." Brochure for the exhibition Apichatpong Weerasethakul, Fiction, Future Perfect, Singapore, 18 January-24 February 2013.

_. "The Unruly Life of Tradition: Versioning, Cinematic Apparatus and Artistic Labour in Thailand." In Tradition (Un)Realized, edited by Hyunjin Kim, David Teh and Younggyu Jang, 90-93. Seoul: Arko Art Center, 2014.

Ingawanij, May Adadol, and Richard Lowell MacDonald. "The Value of an Impoverished Aesthetic: The Iron Ladies and Its Audiences.” In "Screening South East Asia," edited by Sophia Siddique Harvey. Special issue, Spectator 24, no. 2 (2004): 73-81.

_ . "Blissfully Whose? Jungle Pleasures, Ultra-modernist Cinema and the Cosmopolitan Thai Auteur." In Harrison and Jackson, The Ambiguous Allure of the West, 119-34.

Ingawanij, May Adadol, and Benjamin McKay. Glimpses of Freedom: Independent Cinema in Southeast Asia. Ithaca: Southeast Asia Program Publishing, 2012.

Ingawanij, May Adadol, and David Teh, "Only Light and Memory: The Permeable Cinema of Apichatpong Weerasethakul.” In Gaweewong, Apichatpong Weerasethakul: Primitive, 17-25.

Inkster, Dean. "Liam Gillick and Philippe Parreno, The Trial of Pol Pot, 1998." In "The Artist as Curator 2.” Special issue, Mousse Magazine 43 (2014): 21-33.

Iversen, Margaret. “Analogue: On Zoe Leonard and Tacita Dean.” Critical Inquiry 38, no. 4 (2012): 796-818.

Jablonskiené, Lolita, and Nicolaus Schafhausen, eds. Changing Society: Lithuania. New York: Lukas \& Sternberg, 2002. 


\section{Bibliography}

James, Henry. The Sense of the Past. London: Collins, 1917.

Jameson, Fredric. Postmodernism, or, The Cultural Logic of Late Capitalism. London: Verso, 1991.

_. "The Cultural Logic of Late Capitalism." In Postmodernism, 1-54.

_. "Utopianism after the End of Utopia." InPostmodernism, 154-80.

—. "The Aesthetics of Singularity." New Left Review 92 (March-April 2015): 101-32, https://newleftreview.org/issues/II92/articles/fredric-jameson-the-aesthetics-of-singularity.

Jankélévitch, Vladimir. L'irréversible et la nostalgie. Paris: Flammarion, 1983.

Jauß, Hans Robert. Die nicht mehr schönen Künste: Grenzphänomene des Ästhetischen. Munich:

Fink, 1968.

_ "Geschichte der Kunst und Historie.” In Koselleck and Stempel, Geschichte: Ereignis und Erzäblung, 175-209.

—. "Epilog auf die Forschungsgruppe 'Poetik und Hermeneutik' (1996).” In Kontingenz

(Poetik und Hermeneutik XVII), edited by Gerhart von Graevenitz and Odo Marquard, 525-

33. Munich: Fink, 1998.

Jay, Martin. “The Extraterritorial Life of Siegfried Kracauer.” Salmagundi 31-32, no. 6 (Fall 1975-Winter 1976): 49-106.

- "The Uncanny Nineties." In Cultural Semantics: Keywords of our Time, 157-64. London:

Athlone Press, 1998.

Jenkins, Keith. Re-thinking History. London: Routledge, 1991.

- Why History? Ethics and Postmodernity, London: Routledge, 1999.

-., ed. The Postmodern History Reader. London: Routledge, 1997.

Jones, Caroline A. “Doubt Fear.” Art Papers 29, no. 1 (Jan-Feb 2005): 24-35.

Joo, Eungie. "Present Again.” In Butler, For Tomorrow for Tonight, n.p.

Jordanova, Ludmilla. History in Practice. London: Bloomsbury, 2000.

Jussen, Bernhard, ed. Von der künstlerischen Produktion der Geschichte. Göttingen: Wallstein, 1997-2004.

Kammerer, Dietmar. Bilder der Überwachung. Frankfurt am Main: Suhrkamp, 2008.

Kanwar, Amar. The Torn First Pages. Cologne and New Delhi: König and Public Press, 2008.

_. "When You Step Inside You See That It Is Filled with Seeds." In Stahel and Janser, Amar Kanwar: Evidence, 188-97.

Kapur, Geeta. "Secular Artist, Citizen Artist." In Bradley and Esche, Art and Social Change, 422-39.

Kapur, Jyotsna. "Why the Personal Is Still Political: Some Lessons from Contemporary Indian Documentary.” Jump Cut. A Review of Contemporary Media 46 (2003), http://www.ejumpcut. org/archive/jc46.2003/indiandocs.kapur/.

Karlholm, Dan. "Is History to Be Closed, Saved, or Restarted? Considering Efficient Art History." In Karlholm and Moxey, Time in the History of Art, 14-16.

Karlholm, Dan, and Keith Moxey, eds. Time in the History of Art: Temporality, Chronology and Anachrony. London: Routledge, 2018.

"Karl-Marx-Plastik: Münster darf den Nischel nicht kopieren.” Mitteldeutsche Zeitung, April 24, 2007, https://www.mz-web.de/kultur/karl-marx-plastik-muenster-darf-den-nischel-nichtkopieren-8889758.

Kayser, Christine Vial. "Making Sense of the Works of Amar Kanwar: A Phenomenological Perspective." Open Library of Humanities 2, no. 2 (2016): 1-29, http://olh.openlibhums.org/ articles/10.16995/olh.65/.

Kernbauer, Eva. "Once upon a time: On Apichatpong Weerasethakul's Primitive." Texte zur Kunst 75 (September 2009): 171-76.

- "Establishing Belief: Harun Farocki and Andrei Ujica, Videograms of a Revolution." Grey Room 41 (Fall 2010): 72-87.

. "Close Encounters: Intersections of Film and Photography in the Work of Hannes Böck." In Spörr, Hannes Böck, 81-87.

- "Anschauungsunterricht: Geschichtsarbeit in der Gegenwartskunst." In Breitwieser, Kunst/Geschichten: Art/Histories, 22-41. 
. "With your Back to the Future: on Right Senses and Left Melancholia." Springerin 2 (2017a): 45-49, https://www.springerin.at/en/2017/2/mit-dem-rucken-zur-zukunft.

- "Anachronic concepts, art historical containers and historiographical practices in contemporary art.” Journal of Art Historiography, June 16, 2017b, https://arthistoriography.files. wordpress.com/2017/05/kernbauer.pdf.

- ed. Kunstgeschichtlichkeit: Historizität und Anachronie in der Gegenwartskunst. Paderborn: Fink, 2015.

Kevin, Tony. A Certain Maritime Incident: The Sinking of SIEV X. Melbourne: Scribe Publications, 2004.

Khatib, Sami. "No Future: The Space of Capital and the Time of Dying." In Former West: Art and the Contemporary after 1989, edited by Maria Hlavajova and Simon Sheikh, 639-52. Cambridge, MA: MIT Press, 2017.

Khatib, Sami R. “Teleologie ohne Endzweck”: Walter Benjamins Ent-stellung des Messianischen. Marburg: Tectum, 2013.

Khalili, Bouchra. "Blackboard.” In Gili, Bouchra Khalili: Blackboard, 40-49.

Kim, Jihoon. "Between Auditorium and Gallery: Perception in Apichatpong Weerasethakul's Films and Installations." In Global Art Cinema: New Theories and Histories, edited by Rosalind Galt and Karl Schoonover, 125-41. Oxford: Oxford University Press, 2010.

Kinzer, Stephen. "Bodrum Journal; Ataturk the Icon Is About to Take a Bit of a Hit.” The New York Times, October 3, 1997, https://www.nytimes.com/1997/10/03/world/bodrum-journalataturk-the-icon-is-about-to-take-a-bit-of-a-hit.html.

Kirkham, Richard L. Theories of Truth: A Critical Introduction. Cambridge, MA: Cambridge University Press, 1992.

Kleesattel, Ines. “Omer Fast. Exhibition Review, Kölnischer Kunstverein, October 22 to December 18, 2011.” Springerin 1 (2012): 65-66.

Klein, Kerwin Lee. "On the Emergence of Memory in Historical Discourse.” Representations 69 (Winter 2000): 127-50.

- From History to Theory. Berkeley: University of California Press, 2011.

Klingan, Katrin, Ashkan Sepahvand, Christoph Rosol, and Bernd M. Scherer, eds. Textures of the Anthropocene: Grain Vapor Ray. Cambridge, MA: MIT Press, 2014.

Knaller, Susanne, ed. Realitätskonstruktionen in der zeitgenössischen Kultur. Vienna: Böhlau, 2008.

Knörer, Ekkehard and Simon Rothöhler. "ArtCinema: Apichatpong Weerasethakul im Gespräch.” Cargo 1 (March 31, 2009), https://www.cargo-film.de/gespraech/video/ apichatpong-weerasethakul-im-gesprach.

Knott, Marie Luise. “Die Geister sind noch da.” Perlentaucher (2011), https://www.perlentaucher. de/post-aus-venedig/die-geister-sind-noch-da.html\#.

Koch, Gertrud. Siegfried Kracauer: An Introduction. Translated by Jeremy Gaines. Princeton: Princeton University Press, 2000.

Koch, Gertrud, and Christiane Voss, eds. "Es ist, als ob": Fiktionalität in Philosophie, Film- und Medienwissenschaft. Munich: Fink, 2009.

Korte, Barbara, and Sylvia Paletschek, eds. History Goes Pop: Zur Repräsentation von Geschichte in populären Medien und Genres. Bielefeld: transcript, 2009.

Koselleck, Reinhart. “Geschichte, Historie.” In Deutschland. Vol. 2, Geschichtliche Grundbegriffe: Historisches Lexikon zur politisch-sozialen Sprache, edited by Otto Brunner, 593-717. Stuttgart: Klett-Cotta, 1998.

—. "Über die Theoriebedürftigkeit der Geschichtswissenschaften.” In Zeitschichten. Studien zur Historik, 298-316. Frankfurt am Main: Suhrkamp 2000a.

—. "Erfahrungswandel und Methodenwechsel: Eine historisch-anthropologische Skizze," In Zeitschichten. Studien zur Historik, 27-77. Frankfurt am Main: Suhrkamp 2000b.

. The Practice of Conceptual History: Timing History, Spacing Concepts. Translated by Todd Samuel Presner, Kerstin Behnke, and Jobst Welge. Foreword by Hayden White. Stanford: Stanford University Press, 2002. 


\section{Bibliography}

. Futures Past: On the Semantics of Historical Time. Translated by Keith Tribe. New York: Columbia University Press, 2004.

"On the Disposability of History." In Futures Past, 192-204.

- Sediments of Time: On Possible Histories. Translated and edited by Sean Franzel and Stefan-Ludwig Hoffmann. Stanford: Stanford University Press, 2018.

- "History, Law, and Justice." In Sediments of Time, 117-36.

Koselleck, Reinhart, and Wolf-Dieter Stempel, eds. Geschichte: Ereignis und Erzählung. Munich: Fink, 1973.

Koselleck, Reinhart, Heinrich Lutz, and Jörn Rüsen, eds. Formen der Geschichtsschreibung.

Munich: Deutscher Taschenbuch Verlag, 1982.

Kracauer, Siegfried. History: The Last Things Before the Last. Edited and completed by Paul

Oskar Kristeller. Princeton: Markus Wiener Publishers, 1994.

Kracauer, Siegfried, and Erwin Panofsky. Siegfried Kracauer/Erwin Panofsky: Briefwechsel 19411966. Edited by Volker Breidecker. Berlin: Akademie Verlag, 1996.

Krauss, Rosalind, and George Baker, eds. "Obsolescence.” Special issue, October 100 (Spring 2002).

Kreuger, Anders, ed. Messages from the Unseen: Matthew Buckingham. Rotterdam: Veenman Publishers, 2006.

Kristof, Nicholas D. "Seoul Journal; Ex-Enemy of the State Sees His Chance to Lead It.” The New York Times, September 24, 1997, http://www.nytimes.com/1997/09/24/world/seoul-journalex-enemy-of-the-state-sees-his-chance-to-lead-it.html.

Krümmel, Clemens “The Raft of the Historical Image: Dierk Schmidt's Painting against Painting.” In Schmidt, SIEV-X, 82-89.

LaCapra, Dominick. History and Criticism. Ithaca: Cornell University Press, 1985.

Laclau, Ernesto. “The Time Is Out of Joint.” Diacritics 25, no. 2 (1995): 86-96.

-. Emancipation(s). London: Verso, 1996.

Lageira, Jacinto. L'art comme histoire. Un entrelacement de poétiques. Paris: Édition Mimesis, 2016.

—. "Repairing, Resisting.” In Attia, The Repair, 43-57.

Lambert-Beatty, Carrie. "Make-Believe: Parafiction and Plausibility." October 129 (Summer 2009): 51-84.

Landsberg, Alison. "Prosthetic Memory: Total Recall and Blade Runner." In Cyberspace, Cyberbodies, Cyberpunk. Cultures of Technological Embodiment, edited by Mike Featherstone, 175-89. London: Sage, 1995.

Larsen, Lars Bang. "Dierk Schmidt: Packing the Hard Potatoes.” Afterall 29 (Spring 2012): 114-21.

Latimer, Quinn, and Adam Szymczyk, eds. The documenta 14 Reader. London: Prestel, 2017.

Latour, Bruno. Politics of Nature: How to Bring the Sciences into Democracy. Translated by Catherine Porter. Cambridge, MA: Harvard University Press, 2004.

- On the Modern Cult of the Factish Gods. Translated by Heather MacLean and Catherine Porter. Durham: Duke University Press, 2010.

- Facing Gaia: Eight Lectures on the New Climatic Regime. Translated by Catherine Porter. Cambridge: Polity Press, 2017.

Lawrence, George Clarke. Official Guide: The British Empire Exhibition 1924. London: Fleetway Press, 1924.

Lax, Thomas J., and Katell Jaffrès, eds. Bouchra Khalili: Foreign Office. Paris: SAM Art Projects, 2015.

- "The Translation of a Translation. A Conversation between Bouchra Khalili and Thomas J. Lax.” In Bouchra Khalili, 71-75.

Lazzarato, Maurizio. Videophilosophy: The Perception of Time in Post-Fordism. Edited and translated by Jay Hetrick. New York: Columbia University Press, 2019.

Lebovici, Elisabeth. “From Homer to Omer Fast.” Afterall 20 (Spring 2009): 28-35.

Lee, Pamela M. Forgetting the Art World, Cambridge, MA: MIT Press, 2012. 
- New Games: Postmodernism After Contemporary Art. New York: Routledge, 2013.

Leeb, Susanne. "Flucht nach nicht ganz vorn: Geschichte in der Kunst der Gegenwart.” Texte zur Kunst 76 (December 2009): 29-45.

—. "“...The World was Becoming Numerical...' Informational graphics and art Dierk Schmidt's 'Die Teilung der Erde'.” In The Division of the Earth: Tableaux on the Legal Synopses of the Berlin Africa Conference, edited by Lotte Arndt et al., 112-21. Cologne: König, 2010.

—. "Zeitgenössische Kunst und Weltkultur: Umordnung der Museen.” Lecture in the series Permanent Migration, University of Applied Arts Vienna, 14 June 2013.

- Die Kunst der Anderen: "Weltkunst" und die anthropologische Konfiguration der Moderne. Berlin: b_books, 2015.

Lefort, Claude. Les formes de l'histoire: Essais d'anthropologie politique. Paris: Gallimard, 2000.

Le Goff, Jacques. History and Memory. Translated by Steven Rendall and Elizabeth Claman. New York: Columbia University Press, 1992.

Lehrer, Erica, and Magdalena Waligórska. “Cur(at)ing History: New Genre Art Interventions and the Polish-Jewish Past." East European Politics and Societies: and Cultures 27, no. 3 (2013): $1-35$.

Leighton, Tanya, ed., In The Poem About Love You Don't Write The Word Love. New York: Sternberg Press, 2006.

Lepenies, Wolf. "History and Anthropology: A Historical Appraisal of the Current Contact Between the Disciplines.” Social Science Information 15, no. 2-3 (1976): 287-306.

Lessing, Theodor. Geschichte als Sinngebung des Sinnlosen. Munich: Matthes \& Seitz, 1983.

Lévi-Strauss, Claude. The Savage Mind. London: Weidenfeld \& Nicolson, 1962.

Lewis-Kraus, Gideon. “Infinite Now.” In Schaschl, Omer Fast: In Memory, 26-83.

Lind, Maria. "Giving Body, Giving Voice: On the Work of Deimantas Narkevičius, Mindaugas Simkus, and Peter Watkins (2002)." In Selected Maria Lind Writing, edited by Brian Kuan Wood, 259-73. Berlin: Sternberg Press, 2010.

Lind, Maria, and Hito Steyerl, eds. Reconsidering the Documentary and Contemporary Art. Vol. 1, The Greenroom. Berlin: Sternberg Press, 2008.

Lingwood, James, ed. Yael Bartana: And Europe Will Be Stunned; The Polish Trilogy. London: Artangel, 2012.

Liven, Torunn. "Image vs. Text: Aesthetical Operations and Ethical-Political Spectatorial Production in Amar Kanwar's A Season Outside (1997) and The Lightning Testimonies (2007)." Master's thesis, University of Oslo, 2012.

Ljungberg, Joa, and Andreas Nilsson, eds. Yael Bartana: ... Och Europa kommer att häpna / ... And Europe will be stunned. Berlin: Revolver, 2010.

Lloyd, David. Under Representation. The Racial Regime of Aesthetics. New York: Fordham University Press, 2018.

Löffelholz, Claudia. "Omer Fast: A Nice Breaded Schnitzel: On Narrative and Conceptualism, Truth and Construction." Arte e Critica 15, no. 58 (2009): 52-55.

Love, Heather. Feeling Backward: Loss and the Politics of Queer History. Cambridge, MA: Harvard University Press, 2009.

Lowe, Lisa. The Intimacies of Four Continents. Durham: Duke University Press, 2015.

Lowe, Lisa, and David Loyd, eds. The Politics of Culture in the Shadow of Capital. Durham: Duke University Press, 1997.

Löwith, Karl. Meaning in History: The Theological Implications of the Philosophy of History. Chicago: Chicago University Press, 1949.

Lugon, Olivier. "Documentary: Authority and ambiguities." In Lind and Steyerl, The Greenroom 28-37.

Lütticken, Sven. Secret Publicity: Essays on Contemporary Art. Rotterdam: NAI Publishers, 2005a. - Life, Once More: Forms of Reenactment in Contemporary Art. Rotterdam: Witte de With, 2005b.

$47-56$. 


\section{Bibliography}

. History in Motion: Time in the Age of the Moving Image. Berlin: Sternberg Press, 2013. . "Production Notes: On Wendelien van Oldenborgh's Unframed Films.” In Van Oldenborg, Morris, and Pethick, Wendelien van Oldenborgh: Amateur, 9-25.

Macel, Christine, ed. Promises of the Past: A Discontinuous History of Art in Former Eastern Europe. Zürich: JRP Ringier, 2010.

Macgregor, Elizabeth, ed. Zarina Bhimii: I Will Always Be Here. Birmingham: Ikon Gallery, 1992.

Mackert, Gabriele, and Paul Petritsch, eds. Mensch macht Natur / Humans Make Nature: Landschaft im Anthropozän / Landscapes of the Anthropocene. Berlin: de Gruyter, 2016.

Magagnoli, Paolo. Documents of Utopia: The Politics of Experimental Documentary. London: Wallflower Press, 2015.

Makkreel, Rudolf A. Dilthey: Philosoph der Geisteswissenschaften. Frankfurt am Main: Suhrkamp, 1991.

Malabou, Catherine. "The Brain of History, or, the Mentality of the Anthropocene." South Atlantic Quarterly 116, no. 1 (2017): 39-53.

Markopoulos, Leigh. “Nostalgia/Matrix 230.” Art Practical, 1, no. 4, September 1, 2009, http:// www.artpractical.com/review/nostalgia_matrix_230.

Marks, Laura U. The Skin of the Film: Intercultural Cinema, Embodiment, and the Senses. Durham: Duke University Press, 2000.

Martina, Egbert Alejandro. “(Ware)Housing Black People: Livability and the Black Squat Movement.” In Cotter, Wendelien van Oldenborgh: Cinema Olanda, 89-97.

Martínez, Chus, ed. Deimantas Narkevičius: The Unanimous Life. Madrid: Museo Nacional Centro de Arte Reina Sofia, 2008.

Massumi, Brian. Ontopower: War, Powers, and the State of Perception. Durham: Duke University Press, 2015.

Masters, H. G. "Agrarian Reincarnations of Cinema." Art Asia Pacific 70 (September-October 2010): 134-41.

Mattl, Siegfried. "Foto, Film, Geschichte. Das Bild der Vergangenheit bei Siegfried Kracauer.” In Robnik, Kerikes, and Teller, Film als Loch in der Wand, 116-27.

Mathur, Saloni. "Living Ethnological Exhibits: The Case of 1886." Cultural Anthropology 15, no. 4 (2000): 492-524.

- ed. An Indian Encounter: Portraits for Queen Victoria. London: National Gallery, 2002.

Meier, Christian, and Jörn Rüsen, eds. Beiträge zur Historik. Vol. 5, Historische Methode. Munich: Deutscher Taschenbuch Verlag, 1988.

Melville, Stephen W., ed. The Lure of the Object. New Haven: Yale University Press, 2005.

Mengoni, Angela, ed. Carte Semiotiche. Vol. 1, Anacronie: La temporalità plurale delle immagini. Florence: La Casa Usher, 2013.

Michelet, Jules. Histoire de France. Vol. 2. Paris: 1835.

Mirzoeff, Nicholas. "Visualizing the Anthropocene." Public Culture 26, no. 2 (Spring 2014): 213-32.

Misri, Deepti. “'Are You a Man?’: Performing Naked Protest in India.” Signs 36, no. 3 (2011): 603-25.

Mondloch, Kate. Screens: Viewing Media Installation Art. Minneapolis: University of Minnesota Press, 2010.

Montlake, Simon. "Making the Cut.” Time Magazine, October 11, 2007.

Möntmann, Nina, ed. Scandalous: A Reader on Art and Ethics. Berlin: Sternberg Press, 2013.

Moore, Jason W., ed. Anthropocene or Capitalocene? Nature, History, and the Crisis of Capitalism. Oakland: PM, 2016.

Moss, Avigail, and Kerstin Stakemeier, eds. Painting: The Implicit Horizon. Maastricht: Jan van Eyck Academie, 2012.

- "Q \& A with Dierk Schmidt.” In Painting: The Implicit Horizon, 55-58.

Mothes, Ulrike. Offenes Erzählen: Experimente im zeitgenössischen indischen Dokumentarfilm.

Bielefeld: transcript, 2017. 
Muhlack, “Theorie und Praxis der Geschichtsschreibung.” In Koselleck, Lutz, and Rüsen, Formen der Geschichtsschreibung, 607-20.

Muhle, Maria. “Omer Fast: When Images Lie ... About the Fictionality of Documents.” Afterall 20 (Spring 2009): 37-44.

—. "History Will Repeat Itself. Für eine (Medien-)Philosophie des Reenactment." In Körper des Denkens: Neue Positionen der Medienphilosophie, edited by Lorenz Engell, Frank Hartmann, and Christiane Voss, 113-34. Paderborn: Fink, 2013.

Mülder-Bach, Inka. "'Mancherlei Fremde': Paris, Berlin und die Extraterritorialität Siegfried Kracauers.” Juni: Magazin für Kultur und Politik 3, no. 1 (1989): 61-72.

Mytkowska, Joanna. “The Return of the Stranger." In Lingwood, Yael Bartana: And Europe Will Be Stunned, 130-33.

—. "Into the Unknown.” In Scotini and Caffoni, Deimantas Narkevičius, 189-92.

Nagel, Alexander, and Christopher S. Wood. "Interventions: A New Model of Renaissance Anachronism.” Art Bulletin 87, no. 3 (September 2005): 403-15.

- Anachronic Renaissance. New York: Zone Books, 2010.

Nash, Mark, ed. Experiments with Truth. Philadelphia: Fabric Workshop and Museum, 2005.

Neubauer, Susanne, ed. Documentary Creations. Frankfurt am Main: Revolver, 2005.

Nichols, Bill. Representing Reality: Issues and Concepts in Documentary. Bloomington: Indiana University Press, 1991.

-Blurred Boundaries: Questions of Meaning in Contemporary Culture. Bloomington: Indiana University Press, 1994.

- Speaking Truths with Film: Evidence, Ethics, Politics in Documentary. Oakland: University of California Press, 2016.

- "The Question of Evidence: The Power of Rhetoric and the Documentary.” In Speaking Truths with Film, 99-110.

Niethammer, Lutz. Posthistoire: Has History Come to an End?. Translated by Patrick Camiller. London: Verso, 1992.

Nietzsche, Friedrich. "On the Uses and Disadvantages of History for Life." In Untimely Meditations, edited by Daniel Breazeale, translated by R. J. Hollingdale, 59-123. Cambridge: Cambridge University Press, 1997.

Nippel, Wilfried. Johann Gustav Droysen: Ein Leben zwischen Wissenschaft und Politik. Munich: Beck, 2008.

- "Das forschende Verstehen, die Objektivität des Historikers und die Funktion der Archive. Zum Kontext von Droysens Geschichtstheorie.” In Rebenich and Wiemer, Johann Gustav Droysen, 337-91.

Noble, Richard, ed. Utopias. London and Cambridge, MA: Whitechapel Gallery and MIT Press, 2009.

Noord, Gerrie van, ed. Off Limits: 40 Artangel Projects. London: Merrell, 2002.

Nora, Pierre. "Between Memory and History: Les Lieux de Mémoire." Representations 26 (Spring 1989): 7-24.

Nowotny, Helga. Time: The Modern and Postmodern Experience. Translated by Neville Plaice. Cambridge: Polity Press, 1994.

—. Life in the Digital Time Machine. The Wittrock Lecture Book Series No. 2, Lecture at the Swedish Collegium for Advanced Study (SCAS), Uppsala, February 25, 2020.

Nussbaum, Martha C. "Body of the Nation: Why Women Were Mutilated in Gujarat.” Boston Review, June 1, 2004, http://bostonreview.net/martha-nussbaum-women-mutilated-gujarat.

Obrist, Hans Ulrich. The Conversation Series. Vol. 28, Tacita Dean. Cologne: König, 2012.

Ogle, Vanessa. The Global Transformation of Time: 1870-1950. Cambridge, MA: Harvard University Press, 2015.

O'Hara, Angela. "Mysterious Objects of Desire: The Haunted Cinema of Apichatpong Weerasethakul." In Transnational Asian Identities in Pan-Pacific Cinemas: The Reel Asian Exchange, edited by Philippa Gates and Lisa Funnell, 177-90. New York: Routledge 2010.

Okeke-Agulu, Chika. "Conversation with Zarina Bhimji." Art Journal 69, no. 4 (2010): 66-75. 


\section{Bibliography}

Oldenborgh, Wendelien van. "Maurits Script (English Version), booklet on the performance at the Mauritshuis, The Hague.” 2006, https://wilfriedlentz.com/wp-content/uploads/2017/12/ Mauritsscript-english.pdf.

—. "Voice - Script - Public (In Public, The Public) - Collective - Cultural Production." In Scotini and Galasso, Politics of Memory, 151-61.

Oldenborgh, Wendelien Van, David Morris, and Emily Pethick, eds. Wendelien van Oldenborgh: Amateur.Berlin: Sternberg Press, 2015.

Opitz, Michael, and Erdmut Wizisla, eds. Benjamins Begriffe. Frankfurt am Main: Suhrkamp, 2011.

Organization of African Unity. "Pan-African Cultural Manifesto." Africa Today 17, no. 1 (January-February 1970): 25-28.

Osborne, Peter. The Politics of Time: Modernity and Avant-Garde. London: Verso, 1995.

_. "The Truth Will be Known When the Last Witness is Dead': History, not Memory." In After the Event: New Perspectives on Art History, edited by Charles Merewether and John Potts, 202-17. Manchester: Manchester University Press, 2010.

- Anywhere or Not at All: Philosophy of Contemporary Art. London: Verso, 2013.

Owens, Craig. "The Allegorical Impulse: Toward a Theory of Postmodernism.” October 12 (Spring 1980): 67-86.

Pacher, Jeanette, and Yael Bartana, eds. Wenn Ihr wollt, ist es kein Traum: Yael Bartana. Vienna: Revolver, 2013.

Païni, Dominique. "Le retour du flâneur / The Return of the Flâneur." Art Press 255 (March 2000): 33-41.

Pandel, Hans-Jürgen. Mimesis and Apodeixis. Hagen: Rottmann, 1990.

Pantenburg, Volker. "Visibilities: Harun Farocki between Image and Text.” In Farocki, Nachdruck/ Imprint, 12-40.

- "Loudspeaker and Flag: Yael Bartana, from Documentation to Conjuration." Afterall 30 (Spring 2012): 48-61.

-Farocki/Godard: Film as Theory. Amsterdam: Amsterdam University Press, 2015.

Park, Chan-kyong, ed. Ghosts, Spies, and Grandmothers: Modernities against Modernity. Seoul: Hyunsil Books, 2014.

— . "The Collaboration among Ghosts, Spies, Grandmothers, and Artists." In Ghosts, Spies, and Grandmothers, 9-27.

Pasolini, Pier Paolo. "Comments on free indirect discourse." In Heretical Empiricism, edited by Louise K. Barnett, translated by Ben Lawton and Louise K. Barnett, 79-101. Bloomington: Indiana University Press, 1988.

Peleg, Hila, ed. Berlin Documentary Forum Magazine. Vol. 2, New Practices Across Disciplines. Berlin: Haus der Kulturen der Welt, 2012.

Perutz, Rosa. "Immun gegen die Freiheit." Jungle World, April 26, 2012, https://jungle.world/ index.php/artikel/2012/17/immun-gegen-die-freiheit.

Pethick, Emily. "Wendelien van Oldenborgh: 'The past is never dead. It's not even past'.” Afterall 29 (Spring 2012): 57-68.

_. "Cinema Olanda: An Interview with Wendelien van Oldenborgh," In Cotter, Wendelien van Oldenborgh Cinema: Olanda, 133-40.

Pettifor, Steven. "Video Art in Thailand." In Video: An Art, A History, 1965-2010; a selection from the Centre Pompidou and Singapore Art Museum collections, 55-63. Singapore: SAM 2011.

Phatharathananunth, Somchai. Civil Society and Democratization: Social Movements in Northeast Thailand. Kopenhagen: NIAS, 2006.

Pichler, Wolfram. "Horizon and Line of Fate (with Tacita Dean and Leo Steinberg)." In Hochdörfer, Tacita Dean, 1:5-15.

Pinto, Ana Teixeira, ed. The Reluctant Narrator. Berlin: Sternberg Press, 2015.

Poivert, Michel, ed. L'événement: Les images comme acteurs de l'histoire. Paris: Jeu de Paume, 2007. 
Polan, Dana. "A Brechtian Cinema? Towards a Politics of Self-Reflexive Film.” In Movies and Methods: An Anthology. Vol. 2, edited by Bill Nichols, 662-72. Berkeley: University of California Press, 1985.

Pomian, Krzysztof. L'ordre du temps. Paris: Gallimard, 1984.

Preuße, Detlev. Umbruch von unten: Die Selbstbefreiung Mittel- und Osteuropas und das Ende der Sowjetunion. Wiesbaden: Springer, 2014.

Puleo, Risa. "Bouchra Khalili Maps Algiers's 'Foreign Offices' at the Palais de Toyko.” Modern Painters, April 12, 2015, http://www.bouchrakhalili.com/wp-content/uploads/2015/05/ KHALILI_PDT_MODERN-PAINTERS_APRIL-2015-RD-ENC.pdf.

Quandt, James. "Exquisite Corpus: Interview with Apichatpong Weerasethakul.” Artforum 43, no. 9 (May 2005): 226-32.

, ed. Apichatpong Weerasethakul. Vienna: Synema Society for Film and Media, 2009.

Qureshi, Sadiah. Peoples on Parade: Exhibitions, Empire, and Anthropology in NineteenthCentury Britain. Chicago: University of Chicago Press, 2011.

Raad, Walid. "The Beirut Al-Hadath Archive.” Rethinking Marxism 11, no. 1 (Spring 1999a): 15-29.

- Scratching on Things I Could Disavow: Some Essays from the Atlas Group Project. Cologne: Walther König, 2007.

—_ (as "Ziad Abdallah” and "Farah Awada”). "Missing Lebanese Wars.” Public Culture 11, no. 2 (Spring 1999b): i-xiv.

Radstone, Susannah. The Sexual Politics of Time: Confession, Nostalgia, Memory. London: Routledge, 2007.

Rajchman, John. "Deleuze's Time, or How the Cinematic Changes our Idea of Art.” In Leighton, Art and the Moving Image, 307-27.

- "The Contemporary: A New Idea?" In Aesthetics and Contemporary Art, edited by Armen Avanessian and Luke Skrebowski, 125-44. Berlin: Sternberg Press, 2011.

Ramonet, Ignacio. “Necrophiliac Television.” Le monde diplomatique (March 1990): 3.

Ramos-Martínez, Manuel. "The Oxidation of the Documentary: The Politics of Rust in Wang Bings Tie Xi Qu: West of the Tracks.” Third Text 29, no. 1-2 (January 2015): 1-13.

Rancière, Jacques. Names of History: On the Poetics of Knowledge. Translated by Hassan Melehy. Minneapolis: University of Minnesota Press, 1994.

—. "Le concept d'anacronisme et la verité de l'historien.” L'inactuel 6 (Autumn 1996): 53-68.

- Disagreement: Politics and Philosophy. Translated by Julie Rose. Minneapolis: University of Minnesota Press, 1998.

. Film Fables. Oxford: Berg, 2006a.

. "Documentary Fiction. Marker and the Fiction of Memory." In Film Fables, 157-68.

. "The Ethical Turn of Aesthetics and Politics." Critical Horizons 7, no. 1 (2006b): 1-20.

. Figures of History. Translated by Julie Rose. Cambridge: Polity Press, 2014.

. "The Concept of Anachronism and the Historian's Truth." Edited by Tim Stott and Noel Fitzpatrick. InPrint 3, no. 1 (June 2015): Article 3.

Ranke, Leopold Von. The Theory and Practice of History. Translated by Wilma A. Iggers and Konrad von Moltke. Indianapolis: The Bobbs-Merrill-Company, 1973.

—. "On the Relation of and Distinction between History and Politics." In The Theory and Practice of History, 75-82.

- "On the Character of Historical Science (A Manuscript of the 1830s)." In The Theory and Practice of History, 33-46.

—. "Fragment einer Vorlesungseinleitung von 1840.” In Vorlesungseinleitungen, edited by Volker Dotterweich and Walther Peter Fuchs. München: Oldenbourg, 1975, 140-41.

Raqs Media Collective, Ravi Sundaram, and Daniela Zyman. "Has the Moment of the Contemporary Come and Gone?," https://aaa.org.hk/en/ideas/ideas/has-the-moment-of-thecontemporary-come-and-gone.

Rau, Milo, and Jens Dietrich. Die letzten Tage der Ceausescus: Materialien, Dokumente, Theorie. Berlin: Verbrecher Verlag, 2010. 


\section{Bibliography}

Raunig, Gerald. “Becoming Lenin.” In Martínez, Deimantas Narkevičius: The Unanimous Life, $15-23$.

Rayns, Tony. “The Roving Eye.” In Butler, For Tomorrow for Tonight, n.p.

Rebenich, Stefan, and Hans-Ulrich Wiemer, eds. Johann Gustav Droysen: Philosophie und Politik - Historie und Philologie. Frankfurt am Main: Campus, 2012.

Rebentisch, Juliane. Theorien der Gegenwartskunst: Zur Einführung. Hamburg: Junius 2013. . "The Contemporaneity of Contemporary Art." New German Critique 124, vol. 42, no. 1 (February 2015): 223-37.

Rebhandl, Bert. "Ghost World.” Frieze Online, November 2, 2006, https://frieze.com/article/ ghost-world.

_. "Anschauliches Detail: Omer Fasts Filminstallation 'Nostalgia." Cargo (Webmagazine), September 10, 2009, http://www.cargo-film.de/anderes-kino/videoinstallation/anschaulichesdetail/.

Regnier, Isabelle. “Jenjira Pongpas, actrice: Je lui raconte des histoires que je ne confie à personne.” Le Monde, September 1, 2015, https://www.lemonde.fr/cinema/article/2015/09/01/jenjirapongpas-actrice-je-lui-raconte-des-histoires-que-je-ne-confie-a-personne_4742139_3476.html.

Rehm, Jean-Pierre. “Suspended Vocation.” A Prior Magazine 14 (May 2007): 159-69.

Reinhardt, Thomas. "The Cannibalization of the Other: Mirror, Art, and Postcolonialism in Kader Attia's Repair. 5 Acts.” In Blumenstein, Attia: Transformations, 55-62.

Renov, Michael, ed. Theorizing Documentary. New York: Routledge, 1993.

- "Documentary Horizons: An Afterword." In Collecting Visible Evidence, edited by Jane M. Gaines and Michael Renov, 313-25. Minneapolis: University of Minnesota Press, 1999.

Respini, Eva, ed. Walid Raad. New York: Museum of Modern Art, 2015.

- "Slippery Details and Optical Mysteries: The Work of Walid Raad." In Walid Raad, $28-48$.

Richter, Gerhard. Ästhetik des Ereignisses: Sprache - Geschichte - Medium. Paderborn: Fink, 2005.

Ricœur, Paul. Time and Narrative. Vol. 3, Narrated Time. Translated by Kathleen Blamey and David Pellauer. Chicago: Chicago University Press, 1988.

- Memory, History, Forgetting. Translated by Kathleen Blamey and David Pellauer. Chicago: Chicago University Press, 2004.

- "Der Historiker und der Richter." In Memory, History, Forgetting, 488-515.

Riedel, Manfred. Verstehen oder Erklären? Zur Theorie und Geschichte der hermeneutischen Wissenschaften. Stuttgart: Klett-Cotta, 1978.

Rifkin, Adrian. “Adrian Rifkin on Face à l'histoire.” Artforum 35, no. 8 (April 1997): 86. Rithdee, Kong. "Cinema of Impermanence”. Bangkok Post, April 20, 2007.

—_. "Cinema of Reincarnations." In Quandt,Apichatpong Weerasethakul, 118-24.

. "Cemetery of Splendour by Apichatpong Weerasethakul." In The Book Whale 1, edited by Jongkwan Paik, 17-21. Gwangju: Asia Culture Center, 2015.

Rittenbach, Kari. "Dramatic Witness: The Art of Omer Fast." Art in America online, December 15, 2009, https://www.artnews.com/art-in-america/features/omer-fast-2-57880.

Robinne, Gregory, ed. Danh Võ: Go Mo Ni Ma Da. Paris: Edition Dilecta, 2014.

Robnik, Drehli. "Kino, Krieg, Gedächtnis: Affekt-Ästhetik, Nachträglichkeit und Geschichtspolitik im deutschen und amerikanischen Gegenwartskino.” PhD diss., University of Amsterdam, 2007.

Robnik, Drehli, Amália Kerikes, and Katalin Teller, eds. Film als Loch in der Wand: Kino und Geschichte bei Siegfried Kracauer. Vienna: Turia + Kant, 2013.

Robnik, Drehli, Thomas Hübel, and Siegfried Mattl, eds. Das Streit-Bild: Film, Geschichte und Politik bei Jacques Rancière. Vienna: Turia + Kant, 2010.

Rodi, Frithjof, and Hans-Ulrich Lessing, eds. Materialien zur Philosophie Wilhelm Diltheys. Frankfurt am Main: Suhrkamp, 1984.

Roelstraete, Dieter. “After the Historiographic Turn: Current Findings." e-flux Journal 6 (May 2009), https:/www.e-flux.com/journal/06/61402/after-the-historiographic-turn-current-findings. 
—. "Wessen 'Ende der Geschichte'? Eine unzeitgemäße Betrachtung zur Kunst und Historiografie.” In Dziewior and Oetker, Wessen Geschichte, 76-84.

— .After the Historiographic Turn: Current Findings (2014 Remix)." In Art in the Periphery of the Center, edited by Christoph Behnke, 186-96. Berlin: Sternberg Press, 2015.

- ed. The Way of the Shovel: On the Archaeological Imaginary in Art. Chicago: University of Chicago Press, 2013.

. "Field Notes." In The Way of the Shovel, 14-47.

Rogers, Sarah. “Forging History, Performing Memory: Walid Raad's The Atlas Project.” Parachute 108 (October 2002): 68-79.

Rogoff, Irit. "Smuggling: An Embodied Criticality." 2006, http://eipcp.net/transversal/0806/ rogoff1/en.html.

Rohbeck, Johannes. "Rehabilitating the Philosophy of History.” In The Discovery of Historicity in German Idealism and Historism, edited by Peter Koslowsky, 187-211. Berlin: Springer, 2005.

Rosaldo, Renato. "Cultural Citizenship and Educational Democracy.” Cultural Anthropology 9, no. 3 (August 1994): 402-11.

Rose, Jacqueline. "History is a Nightmare." In Lingwood, Yael Bartana: And Europe Will Be Stunned, 140-45.

Rosen, Philip: Change Mummified: Cinema, Historicity, Theory. Minneapolis: University of Minnesota Press, 2001.

- "Document and Documentary: On the Persistence of Historical Concepts." In Change Mummified, 225-64.

Rosler, Martha. "In, Around, and Afterthoughts (on Documentary Photography)." In Decoys and Disruptions: Selected Writings, 1975-2001, 151-206. Cambridge, MA: MIT Press, 2004.

Ross, Christine. The Past Is the Present: It's the Future Too; The Temporal Turn in Contemporary Art. New York: Continuum International Publishing, 2012.

Rothöhler, Simon. queDas verteilte Bild: Stream - Archiv - Ambiente. Paderborn: Fink, 2018.

Ruchel-Stockmans, Katarzyna. Images Performing History: Photography and Representations of the Past in European Art after 1989. Leuven: Leuven University Press, 2015.

Rüsen, Jörn. Ästhetik und Geschichte: Geschichtstheoretische Untersuchungen zum Begründungszusammenhang von Kunst, Gesellschaft und Wissenschaft. Stuttgart: Metzler, 1976a.

—. Für eine erneuerte Historik: Studien zur Theorie der Geschichtswissenschaft. StuttgartBad Canstatt: Frommann-Holzboog, 1976b.

- Grundzüge einer Historik. Vol. 1, Historische Vernunft: Die Grundlagen der Geschichtswissenschaft. Göttingen: Vandenhoeck \& Ruprecht, 1983.

- "Historische Methode." In Meier and Rüsen, Historische Methode, 62-81.

- Konfigurationen des Historismus: Studien zur deutschen Wissenschaftskultur. Frankfurt am Main: Suhrkamp, 1993.

- Making Sense of History, Studies in Historical Cultures. Vol. 10, Time and History: The Variety of Cultures. New York: Berghahn Books, 2007.

- ed. Western Historical Thinking: An Intercultural Debate. New York: Berghahn Books, 2002.

Rüsen, Jörn, and Jürgen Straub, eds. Die dunkle Spur der Vergangenheit: Psychoanalytische Zugänge zum Geschichtsbewusstsein. Frankfurt am Main: Suhrkamp, 1998.

Rutherford, Anne. "'Not Firing Arrows': Multiplicity, Heterogeneity and the Future of Documentary; Interview with Amar Kanwar.” Asian Cinema 16, no. 1 (Spring-Summer 2005): 117-24.

Sabrow, Martin. "Der Konkurs der Konsensdiktatur: Überlegungen zum inneren Zerfall der DDR aus kulturgeschichtlicher Perspektive.” In Weg in den Untergang: Der innere Zerfall der DDR, edited by Konrad H. Jarausch, 83-116. Göttingen: Vandenhoeck \& Ruprecht, 1999.

Sahlins, Marshall David. Islands of History. Chicago: University of Chicago Press, 1985.

Samuel, Raphael. Theatres of Memory: Past and Present in Contemporary Culture. London: Verso, 2012. 


\section{Bibliography}

Sarda, Shveta, ed. Raqs Media Collective: With an Untimely Calendar. Delhi: NGMA, 2014.

Sarkar, Tanika. "Semiotics of Terror: Muslim Children and Women in Hindu Rashtra." Economic and Political Weekly 37, no. 28 (2002): 2872-76.

- Hindu Wife, Hindu Nation: Community, Religion and Cultural Nationalism. New Delhi: Permanent Black, 2003.

Sauerländer, Katrin, ed. Emily Jacir and Susan Buck-Morss. Documenta 13: 100 Notes-100 Thoughts, no. 4. Ostfildern: Hatje Cantz, 2011.

Saupe, Achim. Der Historiker als Detektiv - der Detektiv als Historiker: Historik, Kriminalistik und der Nationalsozialismus als Kriminalroman. Berlin: transcript, 2009.

Scarry, Elaine. Resisting Representation. New York: Oxford University Press, 1994.

Schaar, Elisa. "Bouchra Khalili, Lisson Gallery.” Artforum 55, no. 8 (April 2017): 219.

Schaffer, Johanna. Ambivalenzen der Sichtbarkeit: Über die visuellen Strukturen der Anerkennung, Bielefeld 2008.

Schafhausen, Nicolaus, ed. The Future of Memory: An Exhibition on the Infinity of Present Time. Vienna: Kunsthalle Wien, 2015. https://kunsthallewien.at/application/files/5614/2799/8321/ katalog-the-future-of-memory.pdf?x35133.

Schaschl, Sabine, ed. Omer Fast: In Memory / Zur Erinnerung. Berlin: The Green Box, 2010.

Schlaffer, Hannelore, and Heinz Schlaffer. Studien zum ästhetischen Historismus. Frankfurt am Main: Suhrkamp, 1975.

Schmidt, Dierk. SIEV-X: Zu einem Fall von verschärfter Flüchtlingspolitik / On a case of intensified refugee politics. Berlin: b_books, 2005.

- "What I Am Theoretically Interested in Is the Connection between Violence, Traumatization and the Loss of Speech: Conversation with Philosopher and Journalist Carolin Emcke, Berlin, September 2004.” In Schmidt, SIEV-X, 45-60.

— "One cannot maintain this sort of policy while continuing to be a democracy. Telephone conversation with Tony Kevin, former member of the Australian government, Canberra-Berlin, June 2004.” In Schmidt, SIEV-X, 12-29.

Schmieder,Jürgen."FiktionverschmilztmitFakten.”SüddeutscheZeitung,February27,2014,https:// www.sueddeutsche.de/kultur/oscar-nominierungen-fiktion-verschmilzt-mit-fakten-1.1899035.

Scholem, Gershom, and Theodor W. Adorno, eds. The Correspondence of Walter Benjamin, 1910-1940. Chicago: University of Chicago Press, 2019.

Scotini, Marco. "Da Capo: Deimantas Narkevičius's 'once more'." In Scotini and Caffoni, Deimantas Narkevičius. 11-23.

Scotini, Marco, and Elisabetta Galasso, eds. Politics of Memory: Documentary and Archive. Berlin: Archive Books, 2015.

Scotini, Marco, and Paolo Caffoni, eds. Deimantas Narkevičius: Da Capo; Fifteen Films. Berlin: Archive Books, 2015.

Sei, Keiko, ed. Von der Bürokratie zur Telekratie: Rumänien im Fernsehen; Perspektiven der Technokultur. Berlin: Merve, 1990.

Sharma, Sarah. In the Meantime: Temporality and Cultural Politics. Durham: Duke University Press, 2014.

Shrivastava, Aseem. "Lightning Rarely Leaves a Trace.” In Stahel and Janser, Amar Kanwar: Evidence, 350-55.

Siani-Davies, Peter. The Romanian Revolution of December 1989. Ithaca: Cornell University Press, 2007.

Silverman, Kaja. "What Is a Camera? or: History in the Field of Vision." Discourse 15, no. 3 (Spring 1993): 3-56.

Simmel, Georg. The Problems of the Philosophy of History: An Epistemological Essay. Translated by Guy Oakes. New York: The Free Press, 1977.

Simon, Joshua. "Spaces of Appearance." In Ljungberg and Nilsson, Och Europa kommer att häpna, 21-147.

Singh, Devika. "Amar Kanwar: The Compass That Keeps Spinning." Art Asia Pacific 59 (JulyAugust 2008): 126-31. 
Skoller, Jeffrey. Shadows, Specters, Shards: Making History in Avant-Garde Film. Minneapolis: University of Minnesota Press, 2005.

Smith, Alison, David Blayney Brown, and Carol Jacobi, eds. Artist and Empire: Facing Britain's Imperial Past. London: Tate Publishing, 2015.

Smith, Gary, ed. Hannah Arendt Revisited: "Eichmann in Jerusalem” und die Folgen. Frankfurt am Main: Suhrkamp, 2000.

Smith, Terry, Okwui Enwezor, and Nancy Condee, eds. Antinomies of Art and Culture: Modernity, Postmodernity, Contemporaneity. Durham: Duke University Press, 2008.

Sobchack, Vivian. "The Scene of the Screen: Envisioning Photographic, Cinematic, and Electronic 'Presence'.” In Carnal Thoughts: Embodiment and Moving Image Culture, 135-62. Berkeley: University of California Press, 2004.

- ed. The Persistence of History: Cinema, Television, and the Modern Event. New York: Routledge, 1996.

Solnit, Rebecca. "Climate Change Is Violence.” Truthout, February 15, 2015, https://truthout. org/articles/climate-change-is-violence.

Sontag, Susan. "Reflections on The Deputy." In Against Interpretation, 124-31.

Spigel, Lynn. "Television in the Family Circle.” In Logics of Television: Essays in Cultural Criticism, edited by Patricia Mellencamp, 73-93. Bloomington: University of Indiana Press, 1990.

Spivak, Gayatri Chakravorty. “'Draupadi’ by Mahasveta Devi.” Critical Inquiry 8, no. 2 (1981): 381-402.

- In Other Worlds: Essays in Cultural Politics. London and New York: Routledge, 1988a. . "Can the Subaltern Speak?" In Marxism and the Interpretation of Culture, edited by Cary Nelson and Lawrence Grossberg, 66-111. Chicago: University of Illinois Press, 1988b.

Spörr, Bettina, ed. Hannes Böck: Fünf Skulpturen aus den ägyptischen Heiligtümern im Museo del Sannio, Benevento: n. 252 Hockender Pavian, Diorit; n. 253 Falke, Amphibolit; n. 255 Falke, Gabbro; n. 256 Hockender Pavian, Diorit; n. 280 Apis-Stier, Diorit. Vienna: Revolver, 2013.

Stahel, Urs, and Daniela Janser, eds. Amar Kanwar: Evidence. Göttingen: Steidl, 2012.

Stalder, Felix. The Digital Condition. Translated by Valentine A. Pakis. Cambridge: Polity, 2018.

Stanard, Matthew G. "Interwar Pro-Empire Propaganda and European Colonial Culture: Toward a Comparative Research Agenda." Journal of Contemporary History 44, no. 1 (2009): 27-48. Starobinski, Jean. “Le concept de nostalgie.” Diogene 54, (1966): 92-115.

Stewart, Susan. On Longing: Narratives of the Miniature, the Gigantic, the Souvenir, the Collection. Durham: Duke University Press, 1996.

Steyerl, Hito. "Documentarism as Politics of Truth." Translated by Aileen Derieg. 2003, https:// transversal.at/transversal/1003/steyerl/en.

. "Documentary Uncertainty." A Prior Magazine 15 (2007a): 302-8. Delat Newspapers (2007b). https://chtodelat.org/b8-newspapers/12-55/the-uncertainty-ofdocumentarism.

- Die Farbe der Wahrheit: Dokumentarismen im Kunstfeld. Wien: Turia + Kant, 2008.

Stoler, Ann Laura. “Colonial Aphasia: Race and Disabled Histories in France.” Public Culture 23, no. 1 (2011): 121-56.

Sybel, Heinrich Von. Kleine historische Schriften. Vol. 1. Stuttgart: Cotta, 1880.

Tamir, Chen. "Omer Fast: New Magic Realism.” Flash Art International 41, no. 262, October 2008.

Tan, Erika, ed. Come Cannibalise Us, Why Don't You? Sila Mengakanibalkan Kami, Mabu Tak? Singapore: NUS Museum, NUS Centre for the Arts, 2014.

Tawadros, Gilane, ed. Fault Lines: Contemporary African Art and Shifting Landscapes. London: Institute of International Visual Arts, 2003.

Taylor, Nora A. "Art Without History? Southeast Asian Artists and Their Communities in the Face of Geography." Art Bulletin 70, no. 2 (Summer 2011): 6-23. 


\section{Bibliography}

Tedjasukmana, Chris. Mechanische Verlebendigung: Ästhetische Erfahrung im Kino. Paderborn: Fink, 2014.

Teh, David. "Itinerant Cinema: The Social Surrealism of Apichatpong Weerasethakul." Third Text 25, no. 5 (September 2011): 595-609.

- "Travelling Without Moving: Historicizing Thai Contemporary Art." Third Text 26, no. 5 (September 2012): 567-83.

Tiedemann, Rolff. "Dialectics at a Standstill: Approaches to the Passagen-Werk." In Benjamin, The Arcades Project, 929-45. Cambridge, MA: Harvard University Press, 1999.

Tello, Veronica. "Between Counter-Memory and Paranoia: Dierk Schmidt’s Triptych: Xenophobe, Freedom and Untitled (Louvre)." In "Shaping the Archive." Special issue, Kunstlicht32, no. 4 (2011): 16-23.

- "Counter-Memory, Heterochronia, and 'History Painting' (After Géricault): Dierk Schmidt's SIEV-X - On a Case of Intensified Refugee Politics.” Contemporaneity: Historical Presence in Visual Culture 3 (2014): 21-37.

Tessé, Jean-Philippe. "L'ecran des sommeils: Entretien avec Apichatpong Weerasethakul.” Cahiers du cinéma 659 (September 2010): 10-13.

Tetlock, Philip E., and Aaron Belkin, eds. Counterfactual Thought Experiments in World Politics. Logical, Methodological and Psychological Perspectives. Princeton: Princeton University Press, 1996.

The Atlas Group, Zeina Traboulsi, and Walid Raad. "Sweet Talk or Photographic Documents of Beirut." Camera Austria 80 (December 2002): 43-56.

Thounaojam, Swar. “The Loneliness of Manipur's Non-Combatants.” The Wire, April 9, 2016, https://thewire.in/books/the-loneliness-of-the-noncombatant-people-of-manipur.

Tiravanija, Rirkrit. "Ghosts in the Projector." In Carrion-Murayari and Gioni, Apichatpong Weerasethakul, 30-32.

Toufic, Jalal. Over-Sensitivity. Forthcoming Books, 2009.

Trainor, James. "Omer Fast: Truth Bends and Decays as it Travels." Art Asia Pacific 68, May-June 2010, http://artasiapacific.com/Magazine/68/TruthBendsDecaysAsItTravelsOmerFast.

Traverso, Enzo. Left-Wing Melancholia: Marxism, History, and Memory. New York: Columbia University Press, 2016.

Tredell, Nicolas. "Stephen Heath in Conversation." PN Review 18, no. 3 (January-February 1992): 12-20.

Troeltsch, Ernst. Kritische Gesamtausgabe. Vol. 16, Der Historismus und seine Probleme. Edited by Friedrich Wilhelm Graf. Berlin: de Gruyter, 2008.

Tröhler, Margrit. "Multiple Protagonist Films: A Transcultural Everyday Practice." In Characters in Fictional Worlds: Understanding Imaginary Beings in Literature, Film, and Other Media, edited by Jens Eder, Fotis Jannidis, and Ralph Schneider, 459-77. Berlin: De Gruyter, 2010.

Troncy, Eric, ed. Liam Gillick: McNamara Papers, Erasmus and Ibuka! Realisations, the What If? Scenarios. Hamburg and Dijon: Kunstverein and Le Consortium, 1997.

Trummer, Thomas, ed. Déjà-vu: Der Augen-Blick der Nachträglichkeit in der zeitgenössischen Kunst. Vienna: Schlebrügge, 2005.

Tung, Charles M. "Baddest Modernism: The Scales and Lines of Inhuman Time.” Modernism/ Modernity 23, no. 3 (2016): 515-38.

Turvey, Malcolm, Hal Foster, Chrissie Iles, George Baker, Matthew Buckingham, and Anthony McCall. "Round Table: The Projected Image in Contemporary Art." October 104 (Spring 2003): 71-96.

Uhl, Elke. "Gebrochene Zeit? Ungleichzeitigkeit als geschichtsphilosophisches Problem." In Geschichtsphilosophie und Kulturkritik. Historische und semantische Studien, edited by Johannes Rohbeck and Herta Nagl-Docekal, 50-74. Darmstadt: Wissenschaftliche Buchgesellschaft, 2003.

Ujica, Andrei. Short text on "Videograms of a Revolution", https://www.harunfarocki.de/de/filme/1990er/1992/videogramme-einer-revolution.html. 
Underhill, Karen C. "Next Year in Drohobych: On the Uses of Jewish Absence.” East European Politics and Societies: and Cultures 25, no. 3 (2011): 581-96.

Van der Stok, Frank, Frits Gierstberg, and Flip Bool. Questioning History: Imagining the Past in Contemporary Art. Rotterdam: NAI Publishers, 2008.

Varnhagen, Rahel Von. Briefwechsel mit August Varnhagen von Ense. Edited by Friedhelm Kemp. Munich: Kösel, 1967.

Verhagen, Marcus. "Pleasure and Pain: Omer Fast Interviewed by Marcus Verhagen." Art Monthly 330 (October 2009): n.p.

Verwoert, Jan. "Home Truths: Jan Verwoert on Deimantas Narkevičius." Frieze 72 (JanuaryFebruary 2003): 76-79.

Veyne, Paul. Writing History: Essay on Epistemology. Translated by Mina Moore-Rinvolucri. Manchester: Manchester University Press, 1984.

Vincent, Cédric. “An Interview with Bouchra Khalili.” The Chimurenga Chronic, June 9, 2015, https://chimurengachronic.co.za/entretien-boucha.

Virno, Paolo. Déjà Vu and the End of History. London: Verso, 2015.

Vischer, Theodora, and Isabel Friedli, eds. Tacita Dean: Analogue: Drawings 1991-2006. Göttingen: Steidl, 2006.

Vismann, Cornelia. Medien der Rechtsprechung. Edited by Alexandra Kemmerer and Markus Krajewski. Frankfurt am Main: Fischer, 2011.

Voss, Christiane. "Fiktionale Immersion zwischen Ästhetik und Anästhetisierung." Image: Zeitschrift für interdisziplinäre Bildwissenschaft 8 (2008): 3-15.

Wagner, Julia. "Anfangen. Zur Konstitutionsphase der Forschungsgruppe 'Poetik und Hermeneutik'." International Archive for the Social History of German Literature (IASL) 35, no. 1 (2010): 53-76.

Ward, Martha. "Art in the Age of Visual Culture: France in the 1930s." In Melville, The Lure of the Object, 86-100.

Wark, McKenzie. Molecular Red: Theory for the Anthropocene. London: Verso, 2015.

Weerasethakul, Apichatpong. "Influence: Today and Tomorrow." ArtAsiaPacific, Almanac 2008, 3 (2008): 269.

- "An Evening Shoot." Wall text in the exhibition Primitive, Haus der Kunst, Munich, 20 February-17 May 2009.

—. "Ghosts in the Darkness." In Quandt, Apichatpong Weerasethakul, 104-17.

—. "The Folly and Future of Thai Cinema under Military Dictatorship." In Quandt, Apichatpong Weerasethakul, 178-81.

- "The Memory of Nabua. A Note on the Primitive Project." In Quandt, Apichatpong Weerasethakul, 192-206.

Weerasethakul, Apichatpong, and Simon Field, eds. Cujo Series, Year II. Vol. 1, Primitive. Milan: Edizioni Zero, 2009.

Wegner, Phillip E. Imaginary Communities: Utopia, the Nation, and the Spatial Histories of Modernity. Berkeley: University of California Press, 2006.

Weiss, Peter. The Aesthetics of Resistance. Translated by Joachim Neugroschel. Durham: Duke University Press, 2005.

Welsch, Wolfgang. Unsere postmoderne Moderne. Weinheim: VCH, 1987.

Wenzel, Eike. "'Hinter der sichtbaren Oberfläche der Bilder': Harun Farockis dokumentarische Arbeit an gesellschaftlichen Umbruchsituationen. Zu Videogramme einer Revolution und Die führende Rolle." In Der Ärger mit den Bildern: The Filme von Harun Farocki, edited by Rolf Aurich and Ulrich Kriest, 269-86. Konstanz: UVK Medien, 1998.

Wenzel, Mirjam. "Eichmann, Arendt and the Theatre in Jerusalem: On the Semantics of Theatre in the Reception of the Eichmann Trial.” Hannah Arendt.net. 6, no. 1/2 (November 2011), http://www.hannaharendt.net/index.php/han/article/view/61/78.

Wettengl, Kurt, ed. Das Gedächtnis der Kunst: Geschichte und Erinnerung in der Kunst der Gegenwart. Ostfildern-Ruit: Hatje Cantz, 2000.

White, Hayden V. "The Burden of History." History and Theory 5, no. 2 (1966): 111-34. 


\section{Bibliography}

. Metahistory: The Historical Imagination in Nineteenth-Century Europe. Baltimore: Johns Hopkins University Press, 1974.

- "Review of History, by Johann Gustav Droysen." History and Theory 19, no. 1 (February 1980): 73-93.

- The Content of the Form: Narrative Discourse and Historical Representation. Baltimore: Johns Hopkins University Press, 1987.

- "The Question of Narrative in Contemporary Historical Theory," in The Content of the Form, 26-57.

- Figural Realism: Studies in the Mimesis Effect. Baltimore: Johns Hopkins University Press, 1999.

- The Fiction of Narrative: Essays on History, Literature and Theory; 1957-2007. Edited by Robert Doran. Baltimore: Johns Hopkins University Press, 2010.

Wieviorka, Annette. “Die Entstehung des Zeugen.” In Smith, Hannah Arendt Revisited, 136-59.

Wikipedia, S.V. "List of shipwrecks of the Isles of Scilly," https://en.wikipedia.org/wiki/List_of_ shipwrecks_of_the_Isles_of_Scilly\#1901.E2.80.931914.

Wilde, Oscar. The Artist as Critic: Critical Writings of Oscar Wilde. Edited by Richard Ellmann. London: Allen, 1970.

Willemsen, Paul, ed. Actors \& Extras. Brussels: Argos Centre for Art \& Media, 2009.

Williams, Linda. "Mirrors without Memories: Truth, History, and the New Documentary." Film Quarterly 46, no. 3 (Spring 1993): 9-21.

Wilson-Goldie, Kaelen. "Walid Raad and Akram Zaatari, Mapping Sitting: On Portraiture and Photography, 2002.” In “The Artist as Curator 3.” Special issue, Mousse Magazine 44 (2013): 21-34.

—. "War Stories." Parkett 99 (2017): 114-29.

Witzgall, Susanne, and Kerstin Stakemeier, eds. Die Gegenwart der Zukunft. Zurich: Diaphanes, 2016.

Wöhrer, Renate, “Die Kunst des Dokumentierens. Zur Genealogie der Kategorie 'dokumentarisch."” In Han, Beyond Evidence, 45-57.

Young, Benjamin. "On Media and Democratic Politics: Videograms of a Revolution." In Harun Farocki: Working on the Sightlines, edited by Thomas Elsaesser, 245-60. Amsterdam: Amsterdam University Press, 2004.

Zapperi, Giovanna. "Woman's Reappearance: Rethinking the Archive in Contemporary Art Feminist Perspectives." Feminist Review 105 (2013): 21-47.

Zemel, Carol. "The End(s) of Irony." Forward, July 2011, http://forward.com/culture/139457/ the-ends-of-irony.

Zuckermann, Moshe, ed. Tel Aviver Jahrbuch für deutsche Geschichte. Vol. 34, Geschichte und bildende Kunst. Göttingen: Wallstein, 2006.

Zournazi, Mary. "Navigating Movements: A Conversation with Brian Massumi.” In Hope: New Philosophies for Change, 210-42. New York: Routledge, 2002.

\section{Repositories and Project Websites}

Addison, Abigal, and Gary Thomas, directors. Animate Projects, https://www.animateprojects. org.

Bartana, Yael. Artist's website, http://yaelbartana.com.

Buckingham, Matthew. The Sense of the Past. Project Website, Malmö Art Academy, January 1, 2007-November 1, 2014, http://www.iac.lu.se/projects/the-sense-of-the-past.

Hall, Richard Andrew. The Archive of the Romanian Revolution of 1989, https://romanianrevolutionofdecember1989.com.

Hutton, Marg, ed. Web archive, Sinking of “SIEV-X”, 19 October 2001, http://www.sievx.com.

Hiwa, K. Artist's website, http://www.hiwak.net.

Oldenborgh, Wendelien van. Project website, A Certain Brazilianness (A C_B_). http://www. acertainbrazilianness.net/htmlpages/introduction.html. 
Raad, Walid. Project website, The Atlas Group, http://www.theatlasgroup.org.

SIEVX National Memorial Project, https://www.sievxmemorial.com.

Tan, Erika. Project website, The Forgotten Weaver. http://theforgottenweaver.blogspot.com.

- Artist's website, https://www.erikatan.net.

Weerasethakul, Apichatpong. Artist's website, http://www.kickthemachine.com.

\section{Unprinted Sources}

Gillick, Liam and Philippe Parreno. "Le Procès de Pol Pot: Some Questions / A Puppet Show for Children.” 1998a.

. "The Trial of Pol Pot, Discussion Document." November 1998b.

—. "The Trial of Pol Pot, Outline.” July 16, 1998c. 


\section{Index}

Page numbers in Italics indicate figures and page numbers followed by $\mathrm{n}$ indicate notes.

Abbas, Ferhat 85

Abducted Persons Recovery and Restoration Act 114

Abdullah, Halimah binti 20, 76-8, 81-3

identity 79-80

academic history 3, 18, 19, 40, 42, 207

aesthetic historicism 38, 42, 204, 206-7

Aesthetics of Resistance (1975) (Weiss) 103

Agamben, Giorgio 11, 13, 48n67, 53, 67n24

Ahmadinejad, Mahmoud 170

À la recherche du temps perdu (1913-27)

(Proust) 129

allegory $75,105,108,109,110 \mathrm{n} 50$

allochrony (Fabian) 17, 77, 199

Al-Nahar 91

Altneuland (1902) (Herzl) 167

Ambedkar, B. R. 117

Amin, Idi 124, 125, 138n33

Amos Fortune Road (1996) (Buckingham) 97

Anachronic Renaissance (2005) (Nagel \&

Wood) 199-200

anachronism 7-8, 186, 190, 199, 200

concepts of time 20

differentiation of anachrony $21,23 \mathrm{n} 41$

GDR propaganda and 193

historical events and 160

anachrony 7-8, 10, 21, 23n41, 45, 76, 186

Anderson, Benedict 156

And Europe Will Be Stunned (2007-11)

(Bartana) 163, 165, 171

Mary Koszmary (Nightmares) 163-64, 164, 168,171

Mur $i$ Wieża (Wall and Tower) 164-65, 165, 167

Zamach (Assassination) 165

Andrade, Mario Pinto de 85

Andrade, Oswald de 198

And Then We Heard the Thunder (1971)

(Killen) 192

"Angel of History" (Benjamin) 12

Angelus Novus (1920) (Klee) 12

Animism exhibition 157
Ankersmit, Frank 22n14, 30, 46n22

Anschaulichkeit 207

Anthropocene 6, 21, 204, 205

aesthetics of 206

art and history in 202-8

artistic historiography and 203, 206

visual aesthetics of 206

anthropology 17,44

"antropofagía" (Oswald de Andrade) 143

APA JIKA, The Mis-Placed Comma (2017)

(Tan) 80, 80, 82

Apitz, Bruno 192

apodeixis 3, 19, 33-5, 45, 107, 109, 148

Appadurai, Arjun 20-1

Arab Image Foundation 92

Arcades Project (Benjamin) 42-3, 49n101

archaeology 19, 87

Archipelago, The (2015) (Khalili) 83, 84, 87-8

"Archival Impulse, An" (Foster) 73

archive 6, 73, 90, 99, 114, 129

historical 6, 20

symbolic 95

Arendt, Hannah 94, 174-77, 175, 176, $185 \mathrm{n} 19$

Aristotle 34, 46n14

Arns, Inke 41

art

criticism, ethical turn in 2

history and 1-2, 8, 34, 38, 44, 79, 82, 167, 199; see also artistic historiography

Art in the Anthropocene (Davis \& Turpin) 202, 206

artistic historiography $2,13,18,21 \mathrm{n} 2,22 \mathrm{n} 5$, 71, 90, 95, 203, 208

aim of 7

Anthropocene and 203, 206

archaeological practice 19

attractiveness of 4

comprehensive reconception of 16-7

divisions 1

engagements with history 1 
historical crisis and 4-5

Artists and Empire exhibition 80

artworks 1, 13, 78, 81, 82, 173

audiovisual 18-9

historicity of 8

memory discourses in 15

Assmann, Aleida 15

Assmann, Jan 15

Atatürk, Mustafa Kemal 93, 160

Atlas Group, The (Raad) 20, 90, 91, 92, 94, 95, 109n3

Attia, Kader 2, 21, 173, 194, 195, 200n25, 203

appropriation concept 199

artistic approach to history 197

forced analogies 200

historical montage 198

"mixed objects," testimonies 199

questioning concepts of beauty 199

visual montages 199; see also Repair from

Occident to Extra-Occidental Cultures,

The (Attia)

aura (Benjamin) 75, 76, 160

authorship 20, 87, 90, 145, 197

Ave Maria (1852) (Bach/Gounod) 193

Avodah (1936) (Lerski) 167

Bagchi, Jeebesh (Raqs Media Collective) 111

Bakhtin, Mikhail 65

Balik Kampung: Return by Proxy (Tan) 82

Balsom, Erika 13, 88n1, 133-34

Bardi, Lina Bo 143

Barnouw, Dagmar 45, 49n125

Bartana, Yael 2, 21, 140, 163, 165

Cookbook for Political Imagination 165, 170

historical agendas 170

historiographical project 169

modernist propaganda and 167-68

Polish trilogy 167, 169

propaganda film 171

Summer Camp 167

use of nostalgia 169; see also And Europe

Will Be Stunned

Barthes, Roland 30, 46n23, 59

Basbaum, Ricardo 143

Bataille, Georges 199

Battle of Orgreave, The (2001) (Deller) 40-1, 41

Baudrillard, Jean 5, 54, 63

Beautiful Sheffield (2001) (Dean) 73, 73

Beckstette, Sven 26n116

Benjamin, Walter 3, 8, 11, 19, 75, 78, 94, 203

"Angel of History" 12

Arcades Project 42-3

"On the Concept of History" 42

empathy 37-8

montage 43,44 philosophy of history $6,15,27,38,42,43$, 45, 108

Bergson, Henri 200n12

Berlin Africa Conference (1884/85) 107

Berlin Art Exhibition (1834) 33

Berlin Biennial 39, 166, 170

Bete \& Deise (2012) (Oldenborgh) 142-43

Bhimji, Zarina 2, 20, 124, 126, 138n33

cinematographic works 129-30

I Will Always Be Here 126

Jangbar 124, 126, 128

Lead White 128-29

Love 128

Out of Blue 124-26, 125, 128

Ugandan "Africanization" 124-25

use of reenactment 129

Yellow Patch 124, 126-28, 127

Bhopal disaster (1984) 111

Biemann, Ursula 205, 206

Blade Runner (1982) (Scott) 183

Bloch, Marc 173, 185n8

Blümlinger, Christa 59, 155

Blum, Michael 2, 21, 160, 161, 161, 163

"B movie" 72

Boal, Augusto 143

Bo Bardi, Lina 143

Böck, Hannes 10, 10

Bonneuil, Christophe 204

Borglum, Gutzon 204

Bouchra, Khalili 2, 20, 83, 203

Foreign Office 83-8

historiographical writing 86

Mapping Journey 86-7

Bowie, David 74

Boym, Svetlana 135

Brecht, Bertolt 143

Breton, André 88n9

British Empire Exhibition, London (1924) 76-7, 79, 81, 82

Brown, John 96

Bucharest 52, 55, 60

Bucher, François 139n52

Buckingham, Matthew 2, 4, 20, 27, 100, 204, 205

Amos Fortune Road 97

artistic historiography 95

False Future 98

James's novel and 99

narration 98

Situation Leading To a Story 97, 97-8

Truth About Abraham Lincoln, The 96

Buck-Morss, Susan 15, 207

Buergel, Roger 105

Burckhardt, Jacob 38

Cabral, Amílcar 85

Calado, Manuel 142 
Call into Silence (Výzva do Ticha 1965)

(Hanák) 193

"Capitalocene" 204

Carlyle, Thomas 206

Carmichael, Stokely 83

Carson, Juli 166

Cartier-Bresson, Henri 202

Casting, The (2007) (Fast) 136

Castoriadis, Cornelius 21

Ceauşescu, Elena 53, 56, 57, 61-3

Ceauşescu, Nicolae 52, 53, 56, 57, 58, 61, 63

Cemetery of Splendour (2015) (Apichatpong) 156-57

Centre for Contemporary Art Singapore 79

Certain Brazilianness, A (A C_C_ ) (20042008) (Oldenborgh) 143

Certeau, Michel de 46n6, 86-7

Chakrabarty, Dipesh 17, 18, 203

Children Overboat Affair (2002) (Schmidt) 105-6

Choi, Binna 142

Cinema Olanda (2017) (Oldenborgh) 140, 142, 143, 146, 148

Dutch pavilion 145

linearity and continuity principles 146

sequence shot in 147

Ciocârlie, Livius $68 \mathrm{n} 48$

Clark, T. J. 162

Cleaver, Eldridge 83, 85, 89n44

Cleaver, Kathleen 83

collective memory $5,6,14-5$

Collingwood, George 39, 48n82

Colonial and Indian Exhibition, London (1886) 77

“colonial aphasia" (Stoler) 181, 185n35

colonialism 77, 107, 120, 124, 181, 198

Dutch 140-42, 144, 147

geopolitical space of 196

communism 146-47, 157, 164, 167, 169, 186

Thai army and 149, 151

Congo Tribunal, The (2015) (Rau) 173

contemporaneity 13-4

definition 14

shared 17-21

contemporary art 2, 19

historical task of 14

historicity of 3

historiographic turn in 13-7

philosophical concept for 14

theoretical conceptions of 13

Contour Biennale 8, 2017173

Cookbook for Political Imagination (Bartana)

165,170

Copernican revolution 38

counterfactual history 20, 27, 40, 160, 168

artistic use of 161

Tribute to Safiye Behar, A (Blum) 160-63, 161 utopias and 162,163; see also Bartana, Yael
Criminal Case 40/61: Reverb (2009) (Geyer) $174,174-6$

Crimp, Douglas 23n24

critical art 12-3, 16, 17

Croce, Benedetto 34-5

Cuttitta, Paolo 105

Damisch, Hubert 9

Daney, Serge 53, 54, 58, 62, 63

Danto, Arthur 30

Dăscălescu, Constantin 56

David, Catherine 50

Davis, Heather 202

Dead Souls (2018) (Wang) 148

Dean, Tacita 2, 19, 71, 88n1, 98

Beautiful Sheffield 73, 73

Girl Stowaway 74-5

Pie 71, 72

understanding of obsolescence 75-6

works 71

decoloniality 124, 203

Dedicated Machine, A (2009) (Apichatpong) 151, 152

Deep Weather (2013) (Biemann) 205

DEFA company 191

Délacroix, Eugène 103, 105

Deleuze, Gilles 11

Deller, Jeremy 27, 40, 41, 49n92-n94

Demos, T. J. 126, 129, 203, 206

Den Haag 140

Derrida, Jacques 6, 7, 90

Devi, Mahasweta 118-19, 118-20, 123, $137 \mathrm{n} 15$

diaspora 125, 135, 167, 168, 170

Diaspora Pavilion (Venice Biennale 2017) 82,83

Diawara, Manthia 201n34

Diaz, Lav 148

Didi-Huberman, Georges 8, 23n41

Die Bilder des Zeugen Schattmann (1969) (Engel) 192

Die Gewalt ist der Rand aller Dinge

(Violence Is at the Margin of All Things)

exhibition 101

"Die Weltgeschichte ist das Weltgericht" (Schiller) 173

Dilthey, Wilhelm 36-8, 48n64, 48n66, 48n81

historical thinking 38

human sciences 37

"productive nexus" 36

Dirks, Nicholas B. 22n20

Disappearance at Sea (1996) (Tan) 71

Disappearance at Sea II (1997) (Tan) 71

Division of the Earth, The (2007) (Schmidt) 107, 108

documenta 11 exhibition 21n3, 50, 90, 111, $124,128,173$ 
documenta 12 exhibition $21 \mathrm{n} 3,111,167$

documenta 13 exhibition $21 \mathrm{n} 3,111,156$, 194, 207

documenta 14 exhibition 21n3, 111, 181

documentarism 19, 40, 59, 61, 67n2, 111, $136,137,155,205-6$

documentary gesture 51,52

documentary practices 50

evidence 62

film 51-2; see also Videograms of a

Revolution (Farocki \& Ujica)

documenta $X$ exhibition 50

Douglas, Stan 67n6

"Draupadi” (Devi) 118-19, 121, 137n15

Draxler, Helmut 22n19, 46n9

Droysen, Johann Gustav 3, 8, 28-36, 207

apodeixis concept $34,35,45$

"Encyclopedia and Methodology of

History" 30

"exploratory understanding" 35, 36

historical methodology 30, 34-4

historical scholarship 32

historical works 30

History of Prussian Politics (1855-86) 30

"Lecture upon the Encyclopedia and

Methodology of History" 28

own concept of art 33

representation concept 33-5

theory of history 107

Duhr, Peter 192

Dunin, Kinga 164

Eagleman, David M. 11

Eckhout, Albert 140

Eichmann, Adolf 174, 177

Eichmann in Jerusalem (1963) (Arendt) 174, 175,177

18 October 1977 (1988) (Richter) 27

Eilat, Galit 165

Eisenstein, Sergei 39

Eliot, T. S. 126

"embodied criticality" (Rogoff) 142

Emcke, Carolin 105, 108

emplotment 8, 30, 72, 73, 99, 108

Engel, Peter 192

Enlightenment 3-4, 12, 21, 27, 157, 203

Enwezor, Okwui 50, 65, 111

Erasmus and Ibuka! Realisations (19941996) (Gillick) 178

Esajas, Mitchell 147

ethnographer 17, 18, 20, 50, 77, 87, 198, 199

ethnology 17, 77, 25n108, 142, 194, 198

Eugenides, Jeffrey 74

Evening Shoot, An (2009) (Apichatpong) 151, 151,152

Evreinov, Nikolai 39
"Excerpt from an Unpublished Interview with

Ralph Pendrel” (Buckingham) 98-9

EX PARTE exhibition (2015) 79

Exposition surrealiste d'objets exhibition, Paris (1936) 199

Eyck, Aldo van 146

Fabian, Johannes 17, 18

fall of communism in Eastern Europe (1989)

$53,186,190$

False Future (2007) (Buckingham) 98

Fanon, Frantz 85

Farocki, Harun 2, 19, 51, 52, 55, 57, 59, 62,66

fascism 15, 167, 168, 170

Fast, Omer 2, 20, 130, 135

artworks 130

Nostalgia 131, 132, 133

rejection of political readings 136

Talk Show 134

Faulkner, William 145

Fear (2006) (Gross) 169

Felix in Exile (1989-99) (Kentridge) 27

Ferreiras, Gaspar Dias 142

FIFA World Cup 104

Figgis, Mike 41

Flusser, Vilém 54

Focillon, Henri 44

Fondation arabe pour l'image 95

Footnotes to Cinema Olanda (2017)

(Oldenborgh) 146

Foreign Office (2015) (Khalili) 20, 83-6, 85

Forest Law (2014) (Biemann \& Tavares) 206

Formation of the Historical World in the

Human Sciences, The (1910) (Dilthey)

36,37

Foster, Hal 73, 78

Foucault, Michel 109n2, 208n4

"free indirect discourse" concept (Pasolini) 87

French Revolution (1789) 53, 55

Fressoz, Jean-Baptiste 204

Freud, Sigmund 109n8

Friedrich, Caspar David 125

Frohne, Ursula 19

Fürnberg, Louis 191, 192, 193

future $6-7,12,16,161-64,188-91$

Gaia concept 202, 204

Gaitán, Juan A. 182

Gandhi (Mahatma) 114, 128

Gandhi, Indira 111

GDR 188, 189, 191-93

Geimer, Peter 62

Generali Foundation, Vienna 101, 103

Géricault, Théodore 103, 105, 108, 109

German Federation of Expellees 170 
Geschichte (1979) (Schmit) 32

Geyer, Andrea 2, 21, 140, 174, 175

Ghosts, Spies, and Grandmothers exhibition 157

Gillick, Liam 2, 19, 21, 178, 179, 180, 181

Ginzburg, Carlo 173

Girl Stowaway (1994) (Dean) 71, 74-5

Glissant, Edouard 83

Godard, Jean-Luc 59, 87

Godfrey, Mark 27, 207

Golden Harvest (2011) (Gross) 169

Gorin, Jean-Pierre 87

Greiert, Andreas 38

Griaule, Marcel 199

Gross, Jan T. 169

Groys, Boris 58, 59

Grupinśka, Anka 170

Gruzinski, Serge 198

Gujarat pogrom (2002) 115, 116, 120

Gumbrecht, Hans Ulrich 6

Gurion, Ben 177

Gustafsson, Laura 205

Haapoja, Terike 205

Habermas, Jürgen 42

Halbwachs, Maurice 14

Halimah-The-Empire-Exhibition-Weaverwho-Died-Whilst-Demonstrating-Her-Craft (2015) (Tan) 79

Hamilakis, Yannis 181

Hanák, Dušan 193

"haptic cinema" (Marks) 129

Hartog, François 6

Hausner, Gideon 174

Head, The (2007) (Narkevičius) 188, 188-89

Hegel, Georg Wilhelm Friedrich 28, 29, 33

Herodotus 33

Herzl, Theodor 167

heterochrony 14

heuristics 19, 30, 33, 34

Hindu Wife, Hindu Nation (Sarkar) 120, $137 \mathrm{n} 17$

His-story (1998) (Narkevičius) 186-88, 187, 191

Histoire(s) du cinema (1988-98)

(Godard) 87

historicism 3, 22n11, 38, 42, 45, 204, 206

historicity $7,8,13,18,37$

historiés apódeixis (Herodotus) 33

Historik (Outlines of the Principles of

History) (1897) (Droysen) 8, 29, 30, 33, 35, 46n17, 47n26, 47n28

historiography $1,21 \mathrm{n} 2,30-1,43-5,61-2$

artistic character of 29

contemporary art and 13-7

elements of $107-8$

methodological writings on 3

polyphonic 140 time and 11-2; see also artistic

historiography; counterfactual history

history

artistic explorations of 27

creating $42-5$

depicting 28-35

Enlightenment concept of 3

fictions of 4,5

historical materialism 38, 207

historical scholarship 8, 16, 19, 30, 32, 35

historical science 3, 8, 39, 108, 207

human 202, 203, 205

judging 173

modernist concept of 8

performing 39-42

relationship between art and 1-2, 34

relationship between imagery and 5-6

as script $178-81$

as trial $174-77$

understanding 35-9

History According to Cattle (2013-15)

(Gustafsson \& Haapoja) 205

History of Prussian Politics (Droysen) 30

history painting 22n5, 103, 104, 106, 108-9

History: The Last Things Before the Last (1969, 1971) (Kracauer) 43, 44

Hofer, Johannes 135

Holert, Tom 2, 51, 52, 58, 136

Holmes, Brian 162

"horizon of expectation"

(Erwartungshorizont) (Koselleck) 16

Howard, John 102, 105, 106

Hueting, Joop 145

Hughes, Langston 147

Huiswoud, Hermine 147

Huiswoud, Otto 146, 147

Humboldt, Wilhelm von 28-9

Hungarian Uprising (1956) 193

Hutcheon, Linda 135

Hutton, Marg 102

If You Were to Climb the Himalayas

Tomorrow (2006) (Võ) 9-10

Ikon Gallery, Birmingham 126

Imagination of the Poet: Elements for a

Poetics, The (1887) (Dilthey) 36-7

I'm Still Breathing (2009)

(Apichatpong) 150

Ingawanij, May Adadol 155

Instruction (2009) (Oldenborgh) 140, 144, 144-45

Interface (1995) (Farocki) 59, 60

Into the Unknown (2009) (Narkevičius) 186, 191, 192, 193

Introduction to the Human Sciences (1883)

(Dilthey) 36, 37

I Will Always Be Here (1992) (Bhimji) 126 
Jacir, Emily 15, 207

James, Henry 99

Jameson, Fredric 5, 6, 23n24, 136

Jangbar (2015) (Bhimji) 124, 126, 128

Jauß, Hans Robert 44

Jefferson, Thomas 204

Jenkins, Keith 22n8

Jensen, Niels Borch 72

Jinnah, Muhammad Ali 128

Jungle World 102

Jussen, Bernhard 46n4

Kafka, Franz 182

Kanlaphraphruek, see Maiduang, Alongkot

Kanwar, Amar 2, 20, 111, 121-22, 123, 137n7, 173, 203

Karlholm, Dan 8

Kentridge, William 27

Kerbel, Lev Efimovich 188, 189, 190

Kevin, Tony 102, 105

Khairlanji massacre (2006) 120

Khatib, Sami 23n37, 24n56

K, Hiwa 2, 21, 140, 181-84, 183

Killen, John Oliver 192

Kim Dae Jung 93

Kindheitsmuster (1976) (Wolf) 192

Kittler, Friedrich 54

Klee, Paul 12

Kleesattel, Ines 136

Klein, Kerwin Lee 25n91

Koselleck, Reinhart 8, 16, 18, 27, 30, 97, 162

Kracauer, Siegfried 3, 19, 27, 43, 50, 76

conception of history 43

extraterritoriality 45,76

rejection of a historiography 45

relationship between art and history 44

Krong, Jundawong 149

Krümmel, Clemens 106

Kubler, George 44

Kwaśniewski, Aleksander 169

Laclau, Ernesto 6

Lageira, Jacinto 173

Lambert-Beatty, Carrie 107, 161, 162

Landau, Moshe 174, 177

La storia ridotta sotto il concetto generale dell'arte (1893) (Croce) 34

Latour, Bruno 67n4, 208n3

Lazzarato, Maurizio 69n77, 69n80

Lebanese wars (1975-1990) 90, 93, 94, 95

Lectures on the Philosophy of World History (1837) (Hegel) 28

Leeb, Susanne 108

Lee, Pamela M. 13

Leeuwen, Lizzy van 147

Lefort, Claude 55

Leiris, Michel 199
Lerski, Helmar 167

Levi-Strauss, Claude 17, 44

Liberation War Museum, Dhaka 115

Liberty Leading the People (1830)

(Délacroix) 103

Lied der Stummen (1969) (Duhr) 192

Lightning Testimonies, The (Kanwar) 111-21, $112,119,122$

Gujarat pogrom 115, 116

historical events in Nagaland 113-14

histories of violence 111, 114

multichannel installation 111-12, 121-22

Partition of British India 114

public political treatment of sexual

violence 115

synchronisation of individual narratives

$120-21$

as tribunal 124

Lincoln, Abraham 96

Liven, Torunn 122

London, Yaron 171

Lots (2013) (Võ) 9, 9

Love (1989-2007) (Bhimji) 128

Lütticken, Sven 18, 143

MacDonald, Richard Lowell 159n64-n65

Magna Carta (1215) 99

Mahabharata 118, 120

Maiduang, Alongkot 156

Maier, Charles 135

Makeba, Miriam 83

Making of the Spaceship (2009)

(Apichatpong) 151, 152

Mapping Journey (2008-11) (Khalili) 86

Marker, Chris 86, 133, 134

Marks, Laura 129

Marquard, Odo 44

Marx, Karl 83, 188, 190

Mary Koszmary (Nightmares) (2009)

(Bartana) 163-64, 164, 168, 171

Massumi, Brian 194

Maurits Script (2006) (Oldenborgh)

140-44, 141

artwork 141, 142

genealogy of "expanded film" 143

McLuhan, Marshall 204

McNamara Papers (1992-1995) (Gillick) 178

McQueen, Steve 27

memory 25n89, 129-30, 135-37, 190

of Algeria's revolutionaries 86

collective $5,6,14-5,149$

political $27,53,115,122$

radical rejection of 16

stage of 129

migration 7, 15, 131, 132, 134-37, 170, 183

Brazilian 143

EU migration policy 165,181

European 6, 195, 196 
global 15, 102, 103, 128, 137, 171

Mirror (2010) (Hiwa K) 183

Mirzoeff, Nicholas 206, 208

Missing Lebanese Wars. Notebook Volume 72

(1996-2002) (Raad) 90-5

modernism 3, 15, 27, 34, 145, 156, 186, 193

modernity $5,37,162,203$

aesthetic 42

chronopolitics of 17

"Modernity—an Incomplete Project"

(Habermas) 42

Mofokeng, Santu 27

monde diplomatique, Le 53

Mondloch, Kate 18, 154, 159n43

montage 43, 44, 85

Moonlight Sonata (1801) (Beethoven) 191

Morse, Margaret 54

Moscow Trials, The (2013) (Rau) 173

Mountbatten, Lord 128

Muhle, Maria 40

multiplicity (collective) 87, 102-3, 121, 122

Munteanu, Aurel-Dragos 56

Mur $i$ Wieża (Wall and Tower) (2009)

(Bartana) 164-65, 165, 167

Musil, Robert 171n2

Nabua Song (2009) (Apichatpong) 150, 151

"Nachträglichkeit" (Freud) 93

Nagel, Alexander 8, 199

Narkevičius, Deimantas 2, 21, 186, 190, 191

education 189

Head, The 188, 188-89

His-story 186-88, 187, 191

Once in the XX Century 186, 190-91

short films 186

Into the Unknown 186, 191, 192, 193

use of utopia in art 194

Narula, Monica (Raqs Media Collective) 111

Nassau, Johan Maurits van 140

National Gallery Singapore 78, 80

Nehru, Jawaharlal 128

Neighbors (2001) (Gross) 169

Neto, Agostinho 85

New Yorker, The 174

Nichols, Bill 51

Nietzsche, Friedrich 17, 45

Night of Prophecy, A (2002) (Kanwar) 111

Nike 104-5

No False Echoes (2008) (Oldenborgh) 142,143

Nora, Pierre 15

nostalgia 76, 135, 169

Nostalgia (2009) (Fast) 130, 135, 137, 139 n58

as black comedy of homelessness 136

cinematographic dramaturgy 134

Nostalgia I 130, 130-31

Nostalgia II 131, 131-33
Nostalgia III 132-34, 133

title 135

video installation 130

Not a Seascape (I) (2002) (Schmidt) 100, 100

Nowotny, Helga 24n47, 25n76

nuit coloniale, La (1962) (Abbas) 85

obsolescence 75-6, 168

October (1927) (Eisenstein) 39

Oldenborgh, Wendelien van 2, 20, 140, 203

artistic choreography 146

Bete of Deise 142-43

No False Echoes 142-43

performative history 147-48

"polyphonic" historiography 140, 141

stage settings 143; see also Cinema Olanda

Oma Totem (2009) (Võ) 10

Once in the XX Century (2004) (Narkevičius) 186, 190-91

"One-World" (Tout-Monde) (Glissant) 83

"On the Concept of History" (1940)

(Benjamin) 42

"On the Historian's Task" (1821)

(Humboldt) 28

Operation Relex ... Acting without

Perpetrators I (2003) (Schmidt) 106

Osborne, Peter 14-8, 37, 39, 90, 138n21, 203

instrument of authentication 121

memory discourse 16

reconception of artistic historiography 16-7

rejection of memory 16

Out of Blue (2002) (Bhimji) 124-26, 125,128

Owens, Craig 23n24, 108-9

Pan-African Festival, Algiers (1969) 83, 84

"parafiction" (Lambert-Beatty) 107, 161

Paris Salon exhibition 103

Park, Chan-kyong 157

Parreno, Philippe 2, 19, 21, 178-81

Partition, of British India (1947) 111, 114, 128

Parveen, Abidi 128, 138n40

Pasolini, Pier Paolo 20, 87

Peleg, Hila 13

Perutz, Rosa 170

Pethick, Emily 142

Phantoms of Asia: Contemporary Awakens the Past exhibition 157

Phantoms of Nabua (2009)

(Apichatpong) 157

Pie (2003) (Dean) 71, 72

Pintilie, Stelian 56

Poetics (Aristotle) 46n14

Pol Pot 178, 180

Pongpas, Jenjira 157

pop history 5 
postcolonialism $14,15,86,146,181$

posthistoire 2, 6, 12, 21, 53, 186, 202

posthumanist $4,6,12$

postmodernism $1,2,5,6,15,109$

cultural theory $23 \mathrm{n} 24$

media theory 13

theorems 7

"preenactment" concept 90,163

Presentation by Proxy, A (2013) (Tan) 79

Primitive (2009) (Apichatpong) 148-49, 152, 153, 154, 157

audiovisual reception 153

documentary and fiction 155

film installation 148, 150

gallery space 152

ghosts in 149

Serenity of Madness exhibition 154

soundtrack 151

Thai rural culture in 153, 156

Prologue: Squat/Anti-Squat (2016)

(Oldenborgh) 146

propaganda 57,58

films 155, 164, 168, 171

GDR 188, 189, 193

modernist 167

Proudhon, Pierre-Joseph 198

Proust, Marcel 45, 129

psychoanalysis $15,93,186$

Public Culture 90

Queen Victoria 128

Quintilian 28, 29

Raad, Walid 2, 20, 90, 91, 92, 109, 203

art project 90

historical depiction 95

Missing Lebanese Wars. Notebook Volume 72 90, 91, 92; see also Atlas Group, The

Raft of the Medusa, The (1819) (Géricault) 103, 105, 109

Rancière, Jacques 7-8, 51, 108, 143, 186

Ranke, Leopold von 29, 30, 31, 38

Raqs Media Collective 14, 111

Rau, Milo 173

realism 40, 108, 136, 187, 188

Rebentisch, Juliane 13

Rebhandl, Bert 134

reenactment 55, 56, 129, 140, 145, 148

artistic 39, 40, 42

Battle of Orgreave, The 40-1, 41

Criminal Case 40/61: Reverb as 174, 175

historical 40

popular 40

as scientific method 39

"reflexive nostalgia" (Boym) 135

Reinhardt, Thomas 198

Renov, Michael 52
Repair from Occident to Extra-Occidental

Cultures, The (2012) (Attia) 194, 195, 196

art-historical reproductions 195

bodies and objects 197-98

cultural history of prosthetic bodies 197

installation 194-95

occidental and extra-occidental

practices 198

portraits of faces 196

Resnais, Alain 79

"restorative nostalgia" (Boym) 135

Richter, Gerhard 27

Ricoeur, Paul 162, 173, 194

Ridthee, Kong 159n71

Riefenstahl, Leni 168

Rietveld, Gerrit 145

Rithdee, Kong 156

Rivière, Georges-Henri 199

Roelstraete, Dieter 4, 19

Rogoff, Irit 142

Rolnik, Suely 143

Romanian Revolution (1989) 53, 65-7

image manipulations 54-5

images of 56

"telerevolution" 55

video recordings of 60; see also Videograms of a Revolution (1992)

Room Kat Sat Pralaat (Ganging Up on Sat Pralaat) (2004) (Maiduang) 156

Rouch, Jean 143

Ruddock Overboard (a Fantasy) (2002) (Schmidt) 106

Ruddock, Philip 106

Rüsen, Jörn 30-1

Russian Ending, The (2002) (Dean) 19, 72, 73, 73

Russian Revolution (1917) 55

Sabitri, Heisnam 118, 119

Sabrow, Martin 191

Sab ein Knab' ein Röslein stehn (1815)

(Schubert) 192

Said, Som 80, 81

Sala, Anri 27

Sans soleil (1983) (Marker) 132, 133

Sarabhai, Mridula 114-15

Sarkar, Tanika 120, 137n17

Savage Mind, The (1962) (Lévi-Strauss) 17

Schiller, Friedrich 28, 29, 46n10, 173

Schlaffer, Hannelore 206

Schlaffer, Heinz 38, 206

Schlegel, Friedrich von 34

Schmidt, Dierk 2, 19, 20, 100, 161

choice of history painting 108

Division of the Earth, The 107

elements of historiography 107

fictional imaginations 107

history image 103 
history painting 103

Nike advertisement 104-5

Not a Seascape (I) 100, 100

painting cycle $101,107,110 \mathrm{n} 29$

SIEV-X project $101-3$

use of diagrammatic mode 108

visual language 106

Xenophobe-Shipwreck Scene 101, 101, 103-4, 105

Schmit, Tomas 32

Scholem, Gershom 175, 176

Schubert, Franz 192

Scott, Ridley 183

Sengupta, Shuddhabrata (Raqs Media Collective) 14,111

Servatius, Robert 174

Shepp, Archie 83

Shoah 15, 163, 169, 176, 177, 186

Shrivastana, Aseem 121

Sieg des Glaubens (The Victory of Faith 1933) (Riefenstahl) 168

Sierakowski, Sławomir 164, 165, 166, 168-69, 171

SIEV-X-On a Case of Intensified Refugee Politics (2001-2005) (Schmidt) 19, 20, 100, 109

historiography created by 108

painting cycle 101

parliamentary inquiry 102

refugee tragedies $100-2$

visualisation of research 106

SIEV-X, sinking of (2001) 102, 108

Simmel, Georg 36

Situation Leading To a Story (1999)

(Buckingham) 97, 97-8

Six Grandfathers, Paha Sapa, in the Year 500,002 C.E., The (2002) (Buckingham) 204, 205

Skulptur Projekte Münster exhibition 188-89

Sobchack, Vivian 18

socialism 167-68, 186, 188, 193

propaganda 170, 189, 191, 193

utopias 189, 191

Soler, Vincent 142

Solid Sea 01: The Ghost Ship (2002)

(Multiplicity) 102-3

Solnit, Rebecca 208n19

Som Said 80, 81

Sonjas Rapport (1977) (Werner) 192

"space of experience" (Erfahrungsraum)

(Koselleck) 16

Specters of Marx (Derrida) 6

Spivak, Gayatri Chakravorty 119

Städel Museum, Frankfurt 110n29

Stalder, Felix 41-2

Stam-Beese, Lotte 146, 147

statues meurent aussi, Les (1953) (Marker) 79

Stewart, Susan 135
Steyerl, Hito 13, 56, 60

Story of Beard, The (1992) (Dean) 71

structuralism 17, 202

subaltern $17,78,83,121$

Summer Camp (2006) (Bartana) 167

Surrealism 199

Tan, Erika 2, 19-20, 76, 140, 203

APA JIKA, The Mis-Placed Comma 80, 80,82

British Empire Exhibition 76-7

"Halimah" project 76-83, 84

instrument of animation 79

representation issues 78

Weavers Lament, The $80-1,81$

Tan, Fiona 27

Tavares, Paulo 206

Teh, David 155

Teignmouth Electron (2000) (Dean) 71

"telerevolution" 55, 56, 61

Tello, Veronica 106-7

Texaco (now Chevron) 206

Thatcher, Margaret 40, 41

Thierbuch (1640-48) (Wagener) 142

Thomas, George 93

Timişoara syndrome 53, 55, 57, 63

Tiravanija, Rirkrit 149

trial $65,105,179-81$

history as 174-77

of Nicolae and Elena Ceauşescu 53, 63

Trial of Pol Pot, The (1998) (Parreno \&

Gillick) 19, 180, 181

exhibition 179-80

historical event 178

installation 180-81

tribunal 124, 173, 177-81

Tribute to Safiye Behar, A (2005) (Blum) 160-63, 161

Triumph of the Will (Triumph des Willens 1935) (Riefenstahl) 168

Tröhler, Margrit 155

Tropical Malady 156

Truth About Abraham Lincoln, The (1992)

(Buckingham) 96, 96

Tsang, Wu 174, 175, 177

Tung, Charles M. 208n16

Turner, William 125

Turpin, Etienne 202

Ujica, Andrei 2, 19, 52, 53, 55, 57, 66

Uncle Boonmee Who Can Recall His Past Lives (2010) (Apichatpong) 149, 150, 155,156

Underhill, Karen 169

United Nations High Commission on Refugees (UNHCR) 102, 106

Unknown Forces (2007) (Apichatpong) 155 
Untimely Meditations (Nietzsche) 43

utopias 7

counterfactual historiography and 162, 163

political 163, 165

socialist 189

Varnhagen, Rahel 11, 12, 99

"Velvet Revolution" of 1989 in

Czechoslovakia 53

Victoria \& Albert Museum, London 81, 82

Videograms of a Revolution (1992) (Farocki

\& Ujica) 19, 53, 55, 57, 64, 66, 69n 66

communication technology and media 64-5

cultural image practice 65

documentary evidence 62

film as seminar 55-61

film montage 59

Groys" "submedial space" and 59

live broadcast on TV 57-8

media images 58

media technologies 66

reality and its representation 52

recordings lack evidence 62

video camera use 64-5

video images 57

video recordings 55

Vie des formes (1934) (Focillon) 8-9

Vietnam War/American War (1955-1975) 149

View from Above (2017) (Hiwa K)

181-83, 183

Virilio, Paul 54

Virno, Paolo 186, 190

Vismann, Cornelia 174

Võ, Danh 9, 10, 183

von Ense, Karl August 11

Wagener, Zacharias 142

Waiting (2007) (Bhimji) 124, 129

Wang, Bing 50, 148

Warburg, Aby 8

Warhol, Andy 154

Warsaw Ghetto Uprising (1943) 164

Warsaw, Pałac Kultury i Nauki 165
Wartenburg, Paul Yorck von 37

Watkins, Peter 143

Weavers Lament, The (2016) (Tan) 80-1, 81

Weerasethakul, Apichatpong 2, 20, 140, 148,203

awards 156

Cemetery of Splendour 156-57

Dedicated Machine, A 151, 152

Evening Shoot, An 151, 151, 152

ghost in works of 149

Making of the Spaceship 151, 152

Phantoms of Nabua 157

political tensions in Thailand 149

Primitive 148-49

Serenity of Madness exhibition 154

transnationality 157

work with amateur actors 155

Weibel, Peter 54

Weiss, Peter 103

Werner, Ruth 192

West of the Tracks (2003) (Bing) 50-1

What If? Scenarios, The (1996) (Gillick) 178

Whitechapel Art Gallery, London 128

White, Hayden 8, 27, 30, 33, 72, 97

Wilde, Oscar 4

Williams, Linda 59

Wolf, Christa 192

Wood, Christopher 8, 199

Wretched of the Earth, The (1961) (Fanon) 85

Xenophobe-Shipwreck Scene (2001/02)

(Schmidt) 101, 101, 103-4, 106, 107

Yacine, Kateb 83, 86

Yellow Patch (2011) (Bhimji) 124, 126-28, 127

Yorck von Wartenburg, Paul 37

Young, Benjamin 55

Zamach (Assassination) (2011) (Bartana) 165

Zionist 164, 165, 167-71

Żmijewski, Artur 39, 165, 172n32 